\title{
REVISIÓN SISTEMÁTICA DEL GÉNERO Gephyrocharax EIGENMANN, 1912 (CHARACIFORMES: CHARACIDAE: STEVARDIINAE)
}

Tesis Doctoral

Tomo I

Biol. James Anyelo Vanegas Ríos

Facultad de Ciencias Naturales y Museo

División Zoología de Vertebrados

\section{Directores:}

Dra. María de las Mercedes Azpelicueta

Dr. Juan Marcos Mirande

\section{La Plata, Argentina}


“...Era demasiado bueno para durar, pensó.

Ahora pienso que ojalá hubiera sido un sueño y

que jamás hubiera pescado el pez y que me hallara

solo en la cama sobre los periódicos..."

\section{Ernest Hemingway}

A mis padres Elíast y Yolanda, mi hermano Renzot, mi bella Kari y a todos los que creyeron en mí 


\section{ÍNDICE}

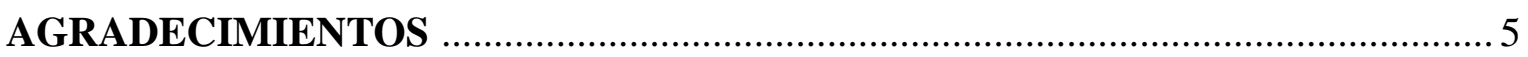

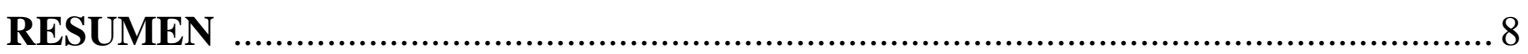

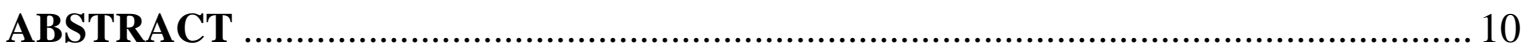

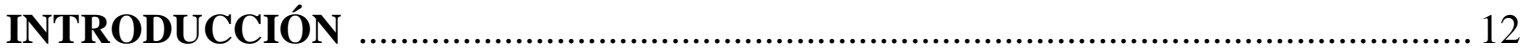

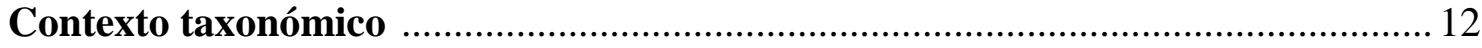

Historia sistemática del género Gephyrocharax ................................................. 22

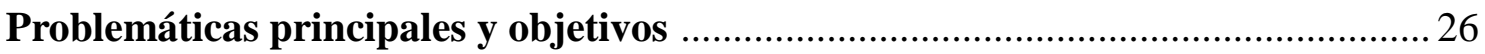

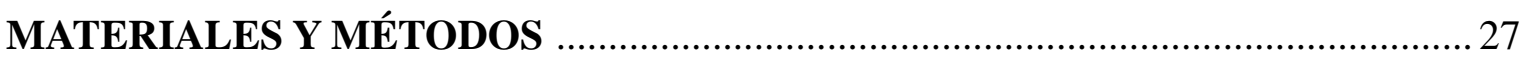

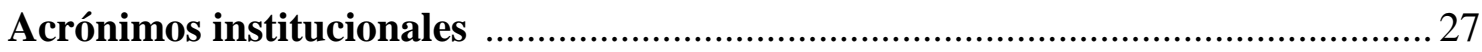

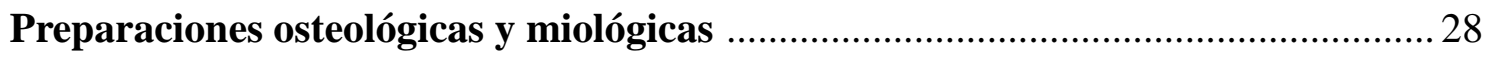

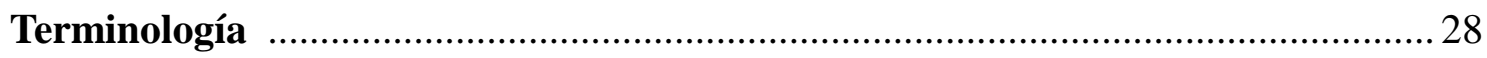

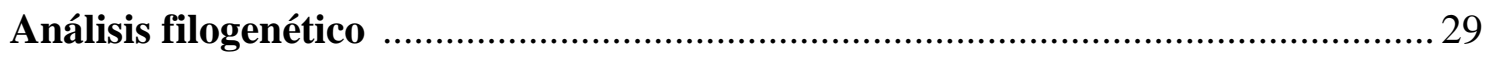

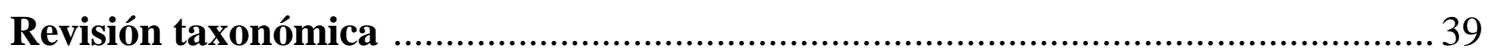

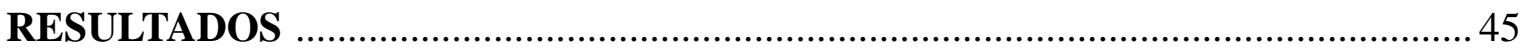

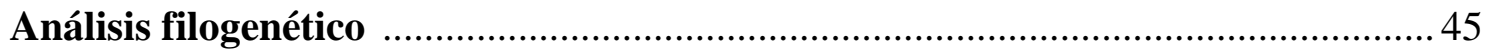

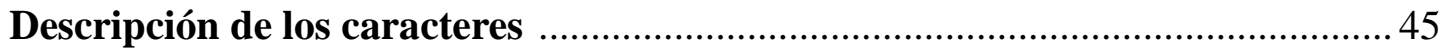

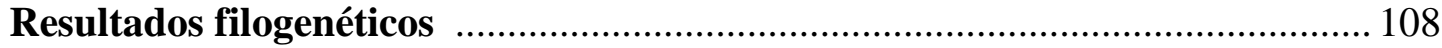

Clados principales y sinapomorfías ………................................................ 110

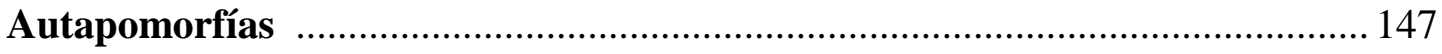

Material comparativo examinado …............................................................. 153

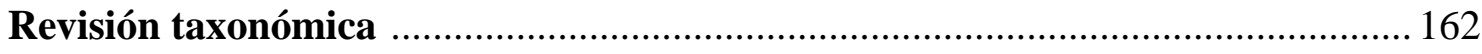

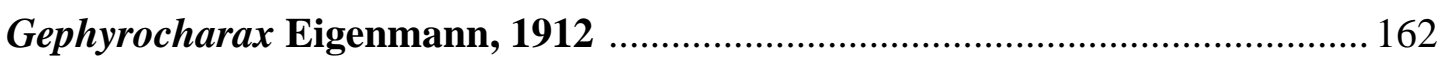

Clave taxonómica de las especies de Gephyrocharax ..................................... 167

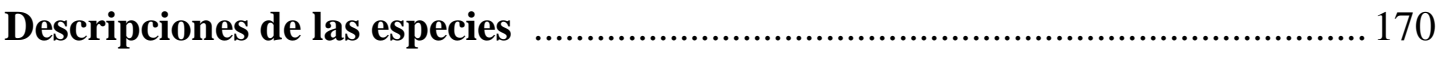

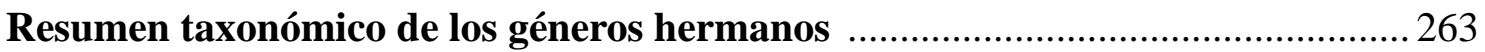




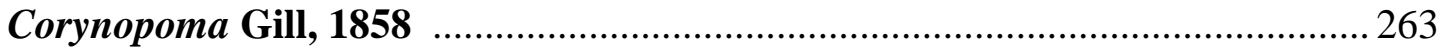

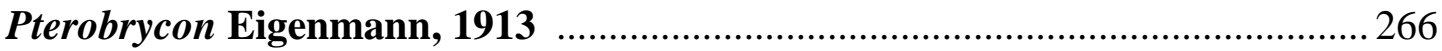

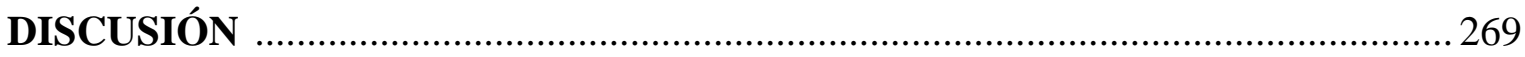

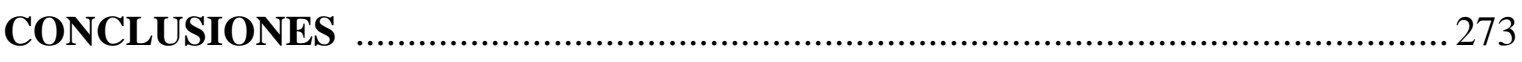

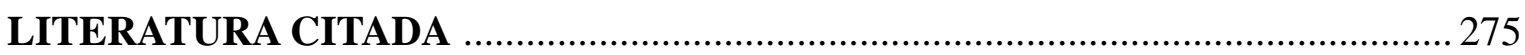




\section{AGRADECIMIENTOS}

A mi familia, especialmente a mi madre Yolanda Ríos Nossa por su entera paciencia y esfuerzo para apoyar mis estudios durante tantos años. A los miembros de la familia Montes y Manzanares por su gran amistad y apoyo personal en diversos momentos del transcurso de esta investigación. A mi amada Karina Verónica Montes por su paciencia, comprensión y apoyo durante el desarrollo de la carrera de Doctorado. A todos los amigos/as de la ciencia que hicieron más fácil las largas horas de estudio y trabajo, especialmente a Guillermo Terán, Felipe Alonso, Santiago Genta, Jhon César Neita, Catalina Suarez Gómez, Pablo Asaroff y Mariela Castro.

Al CONICET por otorgarme las becas tipo I y II que permitieron el desarrollo de los estudios de Doctorado. A César Román-Valencia y Francisco Antonio Villa-Navarro por avalar mis presentaciones a CONICET. A la Fundación para la promoción de la Investigación y la Tecnología del Banco de La Republica-COLOMBIA por la financiación de la presente investigación (Investigador Principal, Proyecto 2814). Por el apoyo parcial recibido desde los proyectos (ANPCyT-PICT 913, a María de las Mercedes Azpelicueta y FONCyT (PICT-2011-0992, J. M. Mirande). A los miembros de la Maestría en Biomatemáticas y Grupo de Investigación y Asesoría en Estadística de la Universidad del Quindío por el apoyo logístico ofrecido en diversos momentos del transcurso de esta investigación; especialmente a María D. García Gonzales, quien ha sido un gran apoyo en todos los sentidos. Al programa de Doctorado de la Facultad de Ciencias Naturales y Museo por el subsidio otorgado (Expte: 1000-007351/2011). A Richard P. Vari por su ayuda y apoyo logístico para obtener un subsidio "Fellowship program" del National Museum of Natural History (NMNH), Smithsonian Institution, Washington, D.C.

A mis directores María de las Mercedes Azpelicueta y Juan Marcos Mirande por su gran amistad, todo el tiempo, paciencia, dedicación, ayuda, orientación, las tremendas discusiones académicas acerca de peces y el material científico brindados desinteresadamente durante la carrera de Doctorado. A todos los colegas ictiólogos que de una u otra manera enriquecieron mi formación a través de estos años de estudio con discusiones y comentarios sobre peces o sistemática filogenética, especialmente Adriana Almirón, Alberto Cione, Alex Burbano-Bonilla, Ana Bonilla, Armando Ortega-Lara, Carlos A. Lucena, Dahiana K. Arcila, Dawn A. T. Phillip, Donald C. Taphorn, Fernando Jerep, Felipe Alonso, Francisco A. Villa-Navarro, Francisco Provenzano, Gastón Aguilera, Guilherme Dutra, Gian Carlo Sánchez, Gustavo A. Ballen, Guillermo Terán, Henry 
Agudelo, Hernán Ortega, Jorge Casciotta, Naercio A. Menezes, Mauricio Torres-Mejía, Ricardo Betancur, Paulo A. Buckup, Richard P. Vari, Ruth Reina, Stanley H. Weitzman, Stefan Koerber, Tiago Carvalho y Vanessa Meza-Vargas. A Stanley H. Weitzman por su amable disposición para facilitar ciertos datos, dibujos e informaciones sobre los Gephyrocharax. A Cristina Scioscia y Alex Bachman (MACN) por sus recomendaciones en la nomenclatura usada.

A Jon Fong (CAS), Andrew Williston (MCZ), Bruno Pianzola (MLP), Kevin Swagel y Chris Jones (FMNH) y Sandra Raredon (USNM) por su gran colaboración en la toma de una gran cantidad de fotografías usadas en este trabajo. A mis queridos Armando Ortega-Lara, Gian Carlo Sánchez (FUNINDES, PUJ), Jaider M. Peña Serpa (CZUT-IC) y su familia por toda su gran ayuda y apoyo logístico ofrecido durante las salidas de campo realizadas en Colombia. A Philip Willink por tomar algunos datos morfológicos de los holotipos de Gephyrocharax caucanus, G. chocoensis y G. intermedius depositados en FMNH. A Guillermo Terán por su gran ayuda con el procesamiento histológico de los esqueletos branquiales estudiados. A Juan Martín Díaz de Astarloa y Claudio Oliveira por su colaboración con las muestras de peces intercambiadas con Ricardo Britski. A Stefan Koerber por compartir algunas muestras capturadas durante sus búsquedas de peces ornamentales. A Dawn A. T. Phillip por sus recomendaciones al resumen en ingles.

A las siguientes personas e instituciones por el permiso, apoyo logístico y asistencia técnica otorgados para visitar las colecciones ictiológicas bajo su cuidado y/o por el material científico facilitado en préstamo, donación e intercambio y las fotografías y las radiografías suministradas: John Lundberg, Mark Sabaj-Perez y Kyle Luckenbill (ANSP); Barbara Brown (AMNH); Jon Armbruster y David C. Werneke (AUM), Jon Fong y Dave Catania (CAS); Juan Marcos Mirande, Gastón Aguilera, Guillermo Terán (CI-FML), Carlos Ardila-Rodríguez (CAR); Luz P. Jiménez y Henry Agudelo (CIUA); Jaider M. Peña, Francisco Villa-Navarro, Gladys Reinoso-Flórez (CZUT-IC); Mary Rogers, Leo Smith, Philip Willink, Susan Mochel, Kevin Swagel y Chris Jones (FMNH); José I. Mojica, Ofelia Mejía y Gustavo Ballen (ICNMHN); Armando Ortega, Gian Carlo Sánchez y Raúl Ríos (IMCN, INCIVA); Mike Retzer y Daniel Wylie (INHS); Rick Feeny (LACM); Francisco Provenzano (MBUCV); María de las Mercedes Azpelicueta, Jorge Casciotta, Adriana Almirón, Amalia Miquelarena, Hugo López y Diego Nadalin (MLP), Karsten Hartel y Andrew Williston (MCZ); Hernán Ortega, Max Hidalgo, Junior Chuctaya, Lisveth Valenzuela, Vanessa Meza y demás miembros del laboratorio (MUSM), Lars Lundquist (MZLU); Bodil Kajrup y Sven O. Kullander (NRM); Hernán López- 
Fernández (ROM); Ruth Reina y Eldregde Bermingham (STRI); Larry Page y Rob Robins (UF); Mauricio Torres-Mejía y Martha Ramírez-Pinilla (UIST); Mabel Maldonado (UMSS), Richard Vari, Jeff Clayton y Sandra Raredon (USNM); y Dawn P. Phillip y Mike Rutherford (UWIZM).

A las instituciones Field Museum of Natural History, The Academy of Natural Sciences of California y The National Museum of Natural History por mantener en Internet el acceso libre a material fotográfico de una gran cantidad de holotipos de miembros de la familia Characidae. 


\section{RESUMEN}

El género carácido Gephyrocharax alberga 13 especies válidas que se distribuyen en diferentes ríos y quebradas dentro de las cuencas cis y transandinas en la América neotropical. La taxonomía de Gephyrocharax no ha sido revisada en más de 50 años, y por tal motivo, las descripciones de sus especies son insuficientes, la mayoría carecen de diagnosis y otras están basadas en una muy pequeña muestra de especímenes. La hipótesis filogenética disponible más relevante sobre las relaciones intergenéricas de Gephyrocharax es la filogenia morfológica de Weitzman \& Menezes (1998), en el cual la tribu Stevardiini fue propuesta con este género como grupo hermano de un clado compuesto por Corynopoma y Pterobrycon. En la presente investigación, se estudió la taxonomía y la filogenia de las especies de Gephyrocharax basadas en un amplio número de características anatómicas dentro del contexto de la filogenia de la familia Characidae y la subfamilia Stevardiinae. Especímenes tipos y no tipos fueron examinados para la revisión sistemática y ejemplares adicionales fueron preparados para observar huesos, cartílagos y músculos. Se tomó como punto de partida la última matriz de datos publicada para Stevardiinae, con la cual se elaboró una matriz de 218 taxones terminales y 542 caracteres, en su gran mayoría morfológicos. Esta matriz fue analizada bajo pesos iguales y pesos implicados extendidos por medio de búsquedas heurísticas. Se calculó el árbol de consenso estricto de cada esquema de pesado para discutir la filogenia de Gephyrocharax y sus géneros relacionados. El árbol de consenso bajo pesos implicados extendidos, que fue obtenido de un intervalo estable con 21 concavidades $(\mathrm{K})$ exploradas, fue tomado como la hipótesis filogenética final. Los procedimientos filogenéticos fueron realizados con TNT 1.1. La revisión taxonómica está basada en caracteres de la morfología externa, coloración, datos morfométricos, merísticos, osteológicos y miológicos. Los datos morfométricos y merísticos fueron analizados a través de varios procedimientos estadísticos implementados en PAST 2.17 y SigmaPlot 10.10. Se obtuvo un árbol de consenso estricto bajo pesos implicados extendidos a partir de un intervalo estable entre las $6^{\mathrm{a}}$ y $13^{\mathrm{a}}$ concavidades $(\mathrm{K}=8,85-17,18)$. Los resultados de pesos iguales y pesos implicados extendidos mostraron grandes similitudes en la composición genérica de cuatro clados importantes: 1) el clado Stevardiinae (pesos iguales: nodo 261; pesos implicados extendidos $=$ nodo 293); 2) el clado Pterobrycon + Corynopoma + Gephyrocharax (pesos iguales: nodo 354; pesos implicados extendidos = nodo 416); 3) el clado Corynopoma + Gephyrocharax (pesos iguales: nodo 353; pesos implicados 
extendidos $=$ nodo 415); y 4) el clado Gephyrocharax (pesos iguales: nodo 377; pesos implicados extendidos = nodo 423). Se define a Gephyrocharax con base en cinco sinapomorfías: la mancha humeral presente, el contorno ventral de la aleta anal en los machos adultos es convexo desde su porción anterior hasta la mitad o tres cuartos de su longitud (los radios son un poco más largos en este intervalo que en otras regiones de la aleta), el tercer radio procurrente ventral de los machos adultos alcanza o sobrepasa la región media del primer radio procurrente ventral, los interradialis modificados en la aleta caudal de los machos adultos alcanzan posteriormente un mismo punto o son apenas más largos en el lóbulo ventral que en el dorsal y las fibras musculares de los interradialis no sobrepasan el borde posterodorsal de la escama-bolsillo de los machos adultos. Se reconocen once especies válidas en Gephyrocharax (G. atracaudatus, G. caucanus, G. chocoensis, G. intermedius, G. major, G. martae, G. melanocheir, G. sinuensis, G. torresi, G. valencia y G. venezuelae) y se presenta una clave taxonómica para identificarlas. Se designa lectotipo y paralectotipos para G. major y neotipo para G. sinuensis. Se propone que $G$. whaleri es sinónimo de G. intermedius y Corynopomops opisthopterus y $G$. chaparae son sinónimos de G. major. El estudio filogenético aquí presentado es el más extenso que se conoce para Stevardiinae en cuanto a la cantidad de caracteres y taxones terminales analizados y también constituye la primera filogenia interespecífica para otros géneros relacionados como Chrysobrycon y Diapoma. 


\section{ABSTRACT}

The characid genus Gephyrocharax has 13 valid species that are distributed in different rivers and creeks of the Cis- and Trans-Andean basins in the neotropical America. The taxonomy of Gephyrocharax has not been revised in more than 50 years, and as a consequence the descriptions of its species are insufficient; the majority of them lack a diagnosis; and others are based on a very small sample of specimens. The most relevant available hypothesis about the intergeneric relationships of Gephyrocharax is the morphological phylogeny of Weitzman \& Menezes (1998), in which the tribe Stevardiini was proposed with this genus as the sister group of a clade composed of Corynopoma and Pterobrycon. In the present research, I studied the taxonomy and phylogeny of Gephyrocharax on the basis of an extensive number of anatomical features within the context of the family Characidae and the subfamily Stevardiinae. Type and non-type specimens were examined for the systematic revision, and additional specimens were prepared to observe bones, cartilages, and muscles. The latest data matrix published for Stevardiinae was taken as a starting point to construct a matrix of 218 terminal taxa and 542 mainly morphological characters. This matrix was analyzed under equal and extended implied weights using heuristic searches. The strict consensus tree for each weighting scheme was calculated to discuss the phylogeny of Gephyrocharax and its related genera. The consensus tree under extended implied weights, which was obtained from a stable range of 21 concavities (K) explored, was taken as the final hypothesis. The phylogenetic procedures were carried out with TNT 1.1. The taxonomic review is based on characters from external morphology, coloration, morphometric and meristic data, bones, and muscles. The morphometric and meristic data were analyzed using several statistical procedures implemented in PAST 2.17 and SigmaPlot 10.10. I obtained a strict consensus tree under extended implied weights from a stable range between the $6^{\text {th }}$ and $13^{\text {th }}$ concavities $(\mathrm{K}=8.85-17.18)$. Results of equal and extended implied weights showed great similarities in the generic composition of four important clades: 1) the clade Stevardiinae (equal weights: node 261; extended implied weights $=$ node 293); 2) the clade Pterobrycon + Corynopoma + Gephyrocharax (equal weights: node 354; extended implied weights $=$ node 416$) ; 3$ ) the clade Corynopoma + Gephyrocharax (equal weights: node 353; extended implied weights $=$ node 415 ); and 4) the clade Gephyrocharax (equal weights: node 377; extended implied weights = node 423). I define Gephyrocharax on the basis of five synapomorphies: the humeral spot is present, the ventral shape of the anal fin 
of the adult males is convex from its anterior portion to one-half or three-quarters of the fin length (rays are slightly longer in this range than in other portions of the fin), the third ventral procurrent ray in adult males reaches or surpasses the central region of the first ventral procurrent ray, the interradialis modified in the caudal fin of adult males reaches posteriorly to the same point or is slightly longer in the ventral lobe than in the dorsal lobe, and the muscles fibers of interradialis do not surpass the posterodorsal border of the pouch scale in adult males. I recognize eleven valid species in Gephyrocharax ( $G$. atracaudatus, G. caucanus, G. chocoensis, G. intermedius, G. major, G. martae, G. melanocheir, G. sinuensis, G. torresi, G. valencia, and G. venezuelae) and present a taxonomic key for their identification. Lectotypes and paralectotypes are designated for $G$. major, and neotype for $G$. sinuensis. I propose that $G$. whaleri is synonymous with $G$. intermedius, and Corynopomops opisthopterus and G. chaparae are synonymous with $G$. major. The phylogenetic study presented herein is the largest known for the Stevardiinae in terms of the number of characters and terminal taxa analyzed, and this also constitutes the first interspecific phylogeny for others related genera as Chrysobrycon and Diapoma. 


\section{INTRODUCCIÓN}

\section{Contexto taxonómico}

Characiformes. Es un orden de peces (bocachicos, bogas, carácidos, dorados, pirañas, tetras, sardinas, etc.) que habita variados cuerpos de agua dulce como ríos, quebradas, caños, ciénagas, esteros, lagos y lagunas en la regiones Neártica, Neotropical y Etíope, a ambos lados de la cordillera de los Andes y con mayor cantidad de especies en América del Sur (Helfman et al., 2009). Characiformes es un orden dentro del superorden Characiphysae, sección Otophysa, subcohorte Ostariophysi, infraclase Teleostei, subclase Neopterygii y clase Actinopterygii acorde al consenso entre las clasificaciones modernas de Wiley \& Johnson (2010), quienes usaron grupos monofiléticos con sinapomorfías morfológicas testeadas y putativas, y de Betancur-R. et al. (2013) con caracteres moleculares (o secuencias de ADN). Ambas clasificaciones coinciden en que Characiformes (18 familias, 270 géneros, 1674 especies) comparte el mismo rango jerárquico con los Gonorynchiformes (4 familias, 7 géneros, 37 especies), Cypriniformes (6 familias, 321 géneros, 3268 especies), Siluriformes (35 familias, 446 géneros, 2867 especies) y Gymnotiformes (5 familias, 30 géneros, 134 especies) (cifras de Nelson, 2006). Actualmente, Characiformes cuenta con 3375 especies, en tercer lugar después de las 5771 especies de Siluriformes y 7326 especies de Cypriniformes (Eschmeyer \& Fong, 2014). Aunque la monofilia de Characiformes es aceptada, todavía existe mucho por resolver en las relaciones filogenéticas internas de sus miembros (Dahdul, 2010: revisión histórica).

Fink \& Fink (1981) reconstruyeron una hipótesis filogenética de Ostariophysi con caracteres morfológicos y obtuvieron un clado donde Characiformes es el grupo hermano de Siluriformes (Silurioidei + Gymnotoidei). Fink \& Fink (1996) mantuvieron está hipótesis, solo elevaron los gimnótidos a Gymnotiformes. Dimmick \& Larson (1996) combinaron caracteres morfológicos y moleculares (secuencias de ADN mitocondrial y nuclear) en un mismo análisis filogenético de Otophysa (solo 10 especies analizadas) y obtuvieron una hipótesis de relaciones entre los miembros de Otophysa parecida a la de Fink \& Fink (1981); cuando Dimmick \& Larson (1996) analizaron solo los datos moleculares, los resultados dieron muy diferentes: un clado Characiformes más Gymnotiformes con Siluriformes como su grupo hermano. Broughton (2010) estudió la filogenia de teleósteos (230 genomas analizados) con secuencias mitocondriales (13 genes que codifican proteínas) y encontró un esquema de relaciones filogenéticas similar al 
presentado por Dimmick \& Larson (1996) con evidencia molecular únicamente. Después, Nakatani et al. (2011: 14 genes mitocondriales y ribosomales), Betancur-R. et al. (2013: un gen mitocondrial y 20 nucleares) y Chen et al. (2013: cinco genes nucleares) obtuvieron coincidentemente un clado Characiformes y Siluriformes con Gymnotiformes como su grupo hermano.

En la historia taxonómica de Characiformes, se han presentado diferentes clasificaciones precladísticas para sus familias (e. g. Fowler, 1954), pero las más ampliamente usadas son las Greenwood et al. (1966) y Géry (1977). Greenwood et al. (1966) propusieron 16 familias en este orden: Anostomidae, Characidae, Chilodontidae, Citharinidae, Ctenoluciidae, Curimatidae, Cynodontidae, Distichodontidae, Erythrinidae, Gasteropelecidae, Hemiodontidae, Hepsetidae, Ichthyboridae, Lebiasinidae, Parodontidae y Prochilodontidae. Géry (1977) uso 14 familias, mantuvo nueve de Greenwood et al. (1966), y propuso Alestidae, Crenuchidae, Characiididae, Hemiodidae y Serrasalmidae. Estas clasificaciones han sido muy discutidas a luz de estudios cladísticos subsecuentes.

Buckup (1998) con caracteres morfológicos y Calcagnotto et al. (2005) con secuencias de ADN mitocondrial y nuclear hicieron análisis filogenéticos de Characiformes. Estos autores propusieron los subórdenes Citharinoidei (Citharinidae y Distichodontidae) y Characoidei (con las restantes familias reconocidas). Buckup (1998) organizó filogenéticamente Characoidei en: Parodontidae, Curimatidae, Prochilodontidae, Anostomidae, Chilodontidae, Crenuchidae, Hemiodontidae, Alestidae, Gasteropelecidae, Characidae, Acestrorhynchidae, Cynodontidae, Erythrinidae, Lebiasinidae, Ctenoluciidae y Hepsetidae. Este suborden fue también propuesto por Mirande (2010) en su filogenia morfológica. Actualmente, Characoidei alberga 18 familias de acuerdo al consenso entre las filogenias morfológicas y moleculares (Buckup, 1998; Berra, 2001; Calcagnotto et al., 2005; Nelson, 2006; Mirande, 2010; Oliveira et al., 2011): Acestrorhynchidae (= Acestrorhynchinae de Mirande, 2010), Alestidae, Anostomidae, Characidae, Crenuchidae, Chilodontidae, Ctenoluciidae, Curimatidae, Cynodontidae (= Cynodontinae de Mirande, 2010), Distichodontidae, Erythrinidae, Gasteropelecidae, Hemiodontidae, Hepsetidae, Lebiasinidae, Parodontidae, Prochilodontidae y Serrasalmidae. De acuerdo a la filogenia molecular de Oliveira et al. (2011), se adicionarían cuatro familias más que provienen de Characidae (las tres primeras) y Alestidae (la última): Bryconidae, Triportheidae, Iguanodectidae y Chalceidae. Más allá de la clasificación de familias usada en Characiformes, Characidae se ha destacado como la familia más compleja en términos 
sistemáticos (Nelson, 2006; Mirande, 2010, Oliveira et al., 2011; Eschmeyer \& Fong, 2014).

Characidae. De acuerdo al catálogo de peces de Eschmeyer \& Fong (2014), el cual se apoya fundamentalmente en la clasificación molecular de Oliveira et al. (2011), la familia Characidae es la cuarta familia de peces más grande del mundo, con alrededor de 1059 especies válidas, después de Cyprinidae $(\approx 2938)$, Gobiidae $(\approx 1710)$ y Cichlidae $(\approx 1663)$ y es la familia más rica en especies del orden de los Characiformes, seguida muy por debajo por Anostomidae $(\approx 145)$. Desde el punto de vista biogeográfico, la familia Characidae tiene una distribución cis y transandina en las regiones Neártica (provincia Río Grande) y Neotropical (en la Etíope solo si se aceptan miembros africanos); en América los carácidos tienen un ámbito de distribución desde el sur de Texas, a través de México y América Central, y a lo largo de los principales ríos de América del Sur (Atrato, CaucaMagdalena, Amazonas, Orinoco, la Plata, entre otros) hasta una latitud de $41^{\circ} \mathrm{S}$ en Chile y Argentina (Berra, 2001; Helfman et al., 2009).

La primera clasificación sistematizada y revisada del siglo XX para la familia Characidae (tetras, mojarras, sardinas, brinconcitas) fue propuesta en varios estudios precladísticos de Eigenmann, $(1914,1915,1917,1918,1921,1922,1927)$ y Eigenmann \& Myers (1929), en los cuales se usaron 21 subfamilias en consenso: Acestrorhamphinae, Anostomatinae, Bryconinae, Characinae, Chalcininae, Cheirodontinae, Erythrininae, Gasteropelecinae, Glandulocaudinae, Hydrocininae, Iguanodectinae, Lebiasininae, Narnostomatinae, Parodontinae, Prochilodinae, Pyrrhulininae, Rhoadsiinae, Salmininae, Stethaprioninae, Stichodontinae y Tetragonopterinae. Gregory \& Conrad (1938) revisaron los carácidos, nombrados Characinidae, y propusieron más conservadoramente nueve subfamilias: Anostomatinae, Characinae, Cheirodontinae, Citharininae, Distichodontinae, Erythrininae, Hemiodontinae, Sarcodacinae y Serrasalmoninae. Fowler (1954) propuso nueve subfamilias en Characidae: Acestrorhynchinae, Bryconinae, Characinae, Ctenoluciinae, Cynodontinae, Iguanodectinae, Pyrrhylininae, Piabucinae y Salmininae. Böhlke (1958) usó principalmente la clasificación de Eigenmann (1915; 1917, 1918, 1921, 1922, 1927) y Eigenmann \& Myers (1929) en su revisión de los peces de la familia Characidae distribuidos en Ecuador. Géry (1977) planteó nueve subfamilias de carácidos en su catálogo de peces carácidos: Agoniatinae, Aphyocharacinae, Bryconinae, Glandulocaudinae, Characinae, Cheirodontinae, Clupeacharacinae, Paragoniatinae, Stethaprioninae, Rhaphiodontinae, Rhoadsiinae y Tetragonopterinae. Reis et al. (2003) compilaron en una serie de capítulos, con diferentes autores (e. g. Lima et al., 2003), una 
nueva clasificación de Characidae (el número de especies entre paréntesis): nueve especies y 88 géneros incertae sedis, Agoniatinae (2), Aphyocharacinae (10), Bryconinae $(\approx 45)$, Characinae (70), Cheirodontinae ( $\approx 46)$, Clupeocharacinae (1), Glandulocaudinae (50), Iguanodectinae (11), Rhoadsiinae (6), Serrasalminae $(\approx 80)$, Stethaprioninae (12) y Tetragonopterinae (2). Esta clasificación se mantuvo por varios años (e. g. Nelson, 2006), pero ha sido modificada en estudios cladísticos de los últimos tiempos.

Estudios filogenéticos no publicados sobre Characidae (Uj, 1990; Lucena, 1993) sirvieron de punto de partida para análisis filogenéticos posteriores que aportaron al conocimiento sistemático sobre la familia. Ortí \& Meyer (1997) presentaron una filogenia molecular de Characiformes con base en dos genes mitocondriales (12S y 16S) que incluyó varios géneros de Characidae, y aunque no obtuvieron la monofilia de la familia, sí reportaron las subfamilias con mejor apoyo (Serrasalminae, Alestinae y Glandulocaudinae). El libro compilado por Malabarba et al. (1998) incluyó ocho estudios filogenéticos con caracteres morfológicos sobre miembros de Characiformes y Characidae (e. g. Buckup, 1998; Weitzman \& Menezes, 1998). Entre estos estudios, Buckup (1998) reportó un clado Characidae (con Alestidae por fuera) como hermano de Acestrorhynchidae más Erythrinoidea. Después, Malabarba \& Weitzman (2003) presentaron un filogenia morfológica sobre el conocimiento de la familia Characidae a la fecha. Estos autores propusieron un clado poco resuelto apoyado por la presencia de ganchos óseos en los radios de las aletas en los machos y compuesto por (en el orden de su cladograma): Roestinae, Salminus Agassiz, "Gasteropelecidae", Serrasalminae, Brycon Müller \& Troschel, Bryconops Kner, Lignobrycon Eigenmann \& Myers, Triportheus Cope, Cheirodontinae, Characinae, Stethaprioninae, Iguanodectinae, Aphyocharacinae, Rhoadsiinae, Tetragonopterinae, géneros incertae sedis y un agrupamiento llamado "clado A" que contiene los restantes géneros con cuatro dientes en la hilera interna premaxilar y ii,8 radios en la aleta dorsal. Calcagnotto et al. (2005), con caracteres moleculares, asignaron 38 especies a Characidae (incluyeron entre otros géneros a Acestrorhynchus Eigenmann \& Kennedy, Brycon, Chalceus Cuvier y Triportheus).

Pasados varias años en los que las sinapomorfías y el "clado A" de Malabarba \& Weitzman (2003) se habían usado como guía en las descripciones de nuevas especies y géneros (e. g. Weitzman et al., 2005; Menezes \& Weitzman, 2009), se publicó el estudio de Mirande (2009) que representó la filogenia morfológica con mayor número de especies analizadas de Characidae (360 caracteres y 160 taxones terminales). Este estudio fue posteriormente ampliado por Mirande (2010: 365 caracteres), donde se detalló una nueva 
definición para la familia en la siguiente propuesta clasificatoria (en orden descendente en su cladograma): Salmininae, Agoniatinae, Cynodontinae, Acestrorhynchinae, Bryconinae, Iguanodectinae, clado Bryconops, Heterocharacinae, Characinae, clado Bramocharax Gill, clado Pseudochalceus Kner, Rhoadsiinae, Tetragonopterinae, clado Hyphessobrycon luetkenii (Boulenger), clado Astyanax parís Azpelicueta, Almirón \& Casciotta, clado Astyanax Baird \& Girard, clado Bryconamericus scleroparius (Regan), Gymnocharacinae, Aphyocharacinae, Aphyoditeinae, Cheirodontinae y Stevardiinae. Mirande (2010) apoyó su definición de Characidae en nueve sinapomorfías, de las cuales solo una (la fusión de los radios procurrentes ventrales anteriores de la aleta caudal en huesos laminares mediales) no tiene alguna reversión o paralelismo. La clasificación general de Mirande (2010) ha sido usada o discutida en estudios morfológicos subsiguientes (Carvalho, 2011; Mirande et al., 2011, 2013; Malabarba et al., 2012; Weiss et al., 2012; Cione \& Azpelicueta, 2013). Sin embargo, la clasificación filogenética de Mirande (2010) no es definitiva, existen interrogantes por resolver dentro de muchas subfamilias y géneros, y puede ser vista como un comienzo para testear diversas hipótesis de interés intrafamiliar.

Javonillo et al. (2010) presentaron una filogenia molecular de Characidae, más ambiciosa que las mencionadas con caracteres moleculares, apoyada en tres genes mitocondriales (12S, 16S y Coi) y un gen nuclear (Rag2). Sin embargo, estos autores no propusieron mayores ajustes a la clasificación interna de la familia por no tener representantes de todas sus subfamilias. Javonillo et al. (2010: en orden descendiente en el cladograma) encontraron tres clados: clado B que contiene a Exodon Müller \& Troschel y miembros de Aphyocharacinae, Cheirodontinae, Tetragonopterinae y Characinae (sin Gnathocharax Fowler); un clado A (afín al clado A de Malabarba \& Weitzman, 2003) y un clado C (hermano de estos A + B) que incluye a ciertos géneros incertae sedis (sensu Lima et al., 2003) y especies de Stethaprioninae. Después, Oliveira et al. (2011) presentaron una filogenia molecular de Characidae, más completa que la anterior de Javonillo et al. (2010) en términos de número de caracteres y taxones terminales, (incluye representantes de todas las subfamilias reconocidas y 54 géneros incertae sedis acorde a Lima et al., 2003) apoyado en dos genes mitocondriales (16S y CytB) y tres nucleares (Myh6, Rag1 y 2). Estos autores, entre sus resultados, redefinieron Characidae y apoyaron su resultado molecular con la extrapolación de dos sinapomorfías putativas: ausencia de hueso supraorbital y salida de la arteria hioidea desde la región posterior del ceratohial anterior. Esta definición de Oliveira et al. (2011) incluye tres grandes clados: clado A [afín con el "clado A" de Malabarba \& Weitzman (2003), el clado A de Javonillo et al. (2010) y 
Stevardiinae de Mirande (2010)], clado B [en parte afín al clado B de Javonillo et al. (2010) con representantes de Cheirodontinae, Aphyocharacinae, Characinae y Tetragonopterinae, entre otros] y un clado C [en parte afín al clado C de Javonillo et al. (2010) con representantes de Astyanax, Hyphessobrycon Durbin, Moenkhausia Eigenmann, Oligosarcus Günther, Stethaprioninae y Rhoadsiinae, entre otros]. Además, Oliveira et al. (2011) excluyeron de Characidae a Spintherobolus Eigenmann, antes ubicado en Cheirodontinae por Malabarba (1998), y clasificaron como familias a Bryconidae (Bryconinae + Salmininae), Gasteropelecidae, Triportheidae, Acestrorhynchidae e Iguanodectidae.

Hasta la fecha, no se conocen estudios que combinen ambos tipos de caracteres (morfológicos y moleculares) para testear la monofilia de Characidae, pero se han publicado estudios que usaron ambos tipos de datos, combinados o no, para testear otras hipótesis menos inclusivas. Tagliacollo et al. (2012) combinaron caracteres moleculares y los caracteres morfológicos de la matriz de Mirande (2010) y Mirande et al. (2011) para testear la monofilia de Aphyocharacinae y sustentar sus clados internos. Netto-Ferreira et al. (2013) también usaron independientemente la matriz de caracteres de Mirande (2010) y los datos moleculares de Oliveira et al. (2011) para clasificar a un nuevo género y especie, Erythrocharax altipinnis Netto-Ferreira, Birindelli, de Sousa, Mariguela, Oliveira; estos autores concluyeron que aún es necesario resolver muchas interrogantes en la clasificación interna de la familia. En términos generales, las dos clasificaciones propuestas para Characidae (Mirande, 2010; Oliveira et al., 2011) en los últimos años tienen ciertas concordancias (e. g. Stevardiinae en gran parte), pero difieren grandemente en su definición y clasificación por subfamilias y como consecuencia quedan abiertos a investigación y discusión muchos detalles de interés a este nivel jerárquico. Parte de esta problemática interna de Characidae por resolver tiene lugar en las subfamilias Glandulocaudinae y Stevardiinae (ambas incluidas en Stevardiinae por Mirande, 2010), las cuales han sido punto de interés en los últimos años (Menezes \& Weitzman, 1990, 2009, 2011; Weitzman \& Menezes, 1998; Mirande, 2010; Ferreira et al., 2011; Mirande et al. 2013).

Glandulocaudinae y Stevardiinae. La historia sistemática de los glandulocaudinos y stevardinos ha estado asociada a lo largo del tiempo. Gill (1858) fue el primero en utilizar el nombre de Stevardiinae para una subfamilia que incluyó a Stevardia Gill (= Corynopoma Gill) y Corynopoma. Günther (1864: xviii) no utilizó esta subfamilia, en vez de eso dividió su familia Characinidae en varios grupos, uno de los cuales llamó 
Erythrinina que incluyó a Corynopoma (Stevardia como su sinónimo). Eigenmann (1914: 32) fue el primero en usar la subfamilia Glandulocaudinae con los géneros Coelurichthys Miranda Ribeiro, Diapoma Cope, Gephyrocharax Eigenmann, Glandulocauda Eigenmann, Hysteronotus Eigenmann, Microbrycon Eigenmann, Pseudocorynopoma Perugia, Pterobrycon Eigenmann y Stevardia (= Corynopoma). Eigenmann (1914: 34-35) también incluyó en su clave de Glandulocaudinae a Argopleura Eigenmann, Bryconamericus Eigenmann y Landonia Eigenmann \& Henn, géneros que consideró en Tetragonopterinae. Además, Glandulocaudinae fue sustentado por Eigenmann (1914) con los siguientes caracteres en especial (parafraseados algunos de ellos): dientes premaxilares hendidos y divididos en dos hileras; dientes de la mandíbula inferior y maxila en una hilera; origen de la aleta dorsal considerablemente posterior a la mitad del cuerpo, hocico muy oblicuo; mandíbula inferior casi o localizada en el perfil dorsal, aletas pectorales largas, falcadas y extendidas más allá del origen de las aletas pélvicas o algunas veces el origen anal; dimorfismo sexual muy marcado en los machos, los cuales tienen "...the lower fulchra..." separada de los demás radios procurrentes ventrales y una escama glandular o bolsillo de escamas unificadas (= "pouch") en la aleta caudal; y algunas veces con el opérculo y escamas del cuerpo modificadas.

En su revisión de los carácidos americanos, Eigenmann \& Myers (1929) mantuvieron en términos generales la definición de Eigenmann (1914) de Glandulocaudinae, pero con los siguientes cambios: Corynopoma con Stevardia como sinónimo y Mimagoniates Regan con Coelurichthys como sinónimo. Böhlke (1958) también aceptó ocho de los géneros de Eigenmann \& Myers (1929) para Glandulocaudinae, cambió a Microbrycon como sinónimo de Pterobrycon y adicionó a Acrobrycon Eigenmann \& Pearson, Argopleura, Landonia, Phenacobrycon Eigenmann y Planaltina Böhlke. Fowler (1954) usó la familia Stevardiidae con una única subfamilia, Stevardiinae, que incluyó a Corynopoma, Diapoma, Gephyrocharax, Glandulocauda, Gnathocharax, Hysteronotus, Mimagoniates, Pseudocorynopoma, Tyttocharax Fowler y Xenurobrycon Myers \& Miranda Ribeiro. Géry (1964) describió a Glandulocauda terofali Géry (= Diapoma terofali) y la asignó a una tribu que llamó Stevardiidi (= Stevardiinae o Glandulocaudinae auct.). Géry (1966) preservó esta tribu por conveniencia en su discusión, a pesar de haberla considerado polifilética, pero para su clave usó la tribu Glandulocaudini con Acrobrycon, Argopleura, Gephyrocharax, complejo Glandulocauda, Landonia, Phenacobrycon, Planaltina y Pterobrycon. Géry (1977) reconoció sus ocho géneros anteriores (Géry, 1966) e incluyó a Corynopoma, Diapoma, el complejo 
Glandulocauda-Mimagoniates-Coelurichthys, Iotabrycon Roberts, Hysteronotus, Pseudocorynopoma, Tyttocharax y Xenurobrycon. Además del número de géneros, se han propuesto varios nombres disponibles a nivel supragenérico afines con y dentro de Glandulocaudinae: Stevardiinae, Diapominae, Pterobryconinae, Glandulocaudinae, Pseudocorynopominae, Hysteronotinae, Corynopominae y Xenurobryconini (Gill, 1858; Eigenmann, 1910, 1913, 1914, 1927; Fowler, 1954; Myers \& Böhlke, 1956; Géry, 1966). No obstante, estas propuestas taxonómicas son precladísticas y no fueron construidas para reflejar grupos naturales.

Roberts (1973) comparó osteológicamente a tres glandulocaudinos (no usó estrictamente un método cladístico): Iotabrycon praecox Roberts (descripto en ese estudio), Landonia latidens Eigenmann \& Henn y Phenacobrycon henni (Eigenmann) en un intento por encontrar caracteres compartidos que sugirieran alguna afinidad filogenética entre sí y con otros carácidos, pero falló en tal propósito. El primer estudio filogenético detallado en glandulocaudinos, es presentado por Weitzman \& Fink (1985), quienes revisaron ampliamente la morfología de estos peces con énfasis en la monofilia de la tribu Xenurobryconini. Además de sustentar la monofilia de Xenurobryconini, estos autores citaron 17 géneros en Glandulocaudinae (hasta ese momento no demostrado como grupo natural): doce de los mencionados por Géry (1977), Mimagoniates y Glandulocauda separadamente, Tyttocharax, Xenurobrycon y Scopaeocharax Weitzman \& Fink (descripto en ese estudio). Weitzman, Fink \& Menezes (en Weitzman \& Fink, 1985: 112) criticaron la monofilia de Glandulocaudinae según Nelson (1964), quien apoyó su hipótesis precladística en la extrapolación de caracteres etológicos sexualmente dimórficos, inseminación y tejido glandular en las aletas caudales de los machos. Posteriormente, Weitzman et al. (1988: fig. 10) y Menezes \& Weitzman (1990: fig. 1) propusieron la monofilia de la tribu Glandulocaudini (con Glandulocauda y Mimagoniates) sustentados en estructuras del esqueleto caudal de los machos adultos. Apoyados en la hipótesis de Weitzman \& Fink (1985), Weitzman et al. (1994) describieron un nuevo género xenurobryconino, Ptychocharax rhyacophila Weitzman, Fink, Machado-Allison \& Royero y mantuvieron la monofilia de Xenurobryconini.

Weitzman \& Menezes (1998) realizaron el primer estudio filogenético de los miembros aceptados en Glandulocaudinae basados en la morfología, especialmente aquella asociada al dimorfismo sexual de los machos adultos. Estos autores definieron 19 géneros en un grupo monofilético, llamado Glandulocaudinae, apoyado en cuatro sinapomorfías: 1) inseminación, 2) esperma localizado en un área de almacenamiento en 
el testículo, 3) espermatozoide alargado y 4) collar citoplasmático alargado ligando el flagelo al núcleo del espermatozoide. Esta subfamilia fue organizada por Weitzman \& Menezes (1998) en siete tribus (orden filogenético descendiente), Landonini (Landonia), Glandulocaudini (Glandulocauda y Mimagoniates), Diapomini (Planaltina, Acrobrycon y Diapoma), Phenacobryconini (Phenacobrycon), Hysteronotini (Hysteronotus y Pseudocorynopoma), Corynopomini (Gephyrocharax, Corynopoma y Pterobrycon) y Xenurobryconini (Chrysobrycon Weitzman \& Menezes, Argopleura, Ptychocharax Weitzman, Fink, Machado-Allison \& Royero, Iotabrycon, Xenurobrycon, Tyttocharax y Scopaeocharax). Aunque Weitzman \& Menezes (1998) presentaron diagnosis para estas tribus, las relaciones filogenéticas entre estas fue uno de los puntos menos resueltos en su hipótesis filogenética.

La hipótesis filogenética de Glandulocaudinae de Weitzman \& Menezes (1998) fue mantenida por varios años en subsiguientes investigaciones (e. g. Menezes et al., 2003: revisión de Planaltina). En una hipótesis filogenética resumida de Characidae con datos morfológicos, Malabarba \& Weitzman (2003) propusieron un "clado A", no resuelto, que contenía a los miembros de Glandulocaudinae de Weitzman \& Menezes (1998). Castro et al. (2003) describieron a Lophiobrycon weitzmani Castro, Ribeiro, Benine \& Melo como miembro de la tribu Glandulocaudini sustentados en la hipótesis filogenética de Weitzman \& Menezes (1998).

Calcagnotto et al. (2005), con datos moleculares, analizaron por primera vez primera vez dos géneros de Glandulocaudinae, Mimagoniates y Gephyrocharax, en su filogenia de Characiformes y los recuperaron en un clado relacionado con Bryconamericus, Creagrutus Günther, Hemibrycon Günther y Knodus Eigenmann. Con nueva evidencia histológica, Weitzman et al. (2005) restringieron Glandulocaudinae a la tribu Glandulocaudini, en tanto las demás tribus glandulocaudinas fueron asignadas a la subfamilia Stevardiinae. El principal argumento de esta decisión de Weitzman et al. (2005) se fundamentó en la evidencia que el tejido glandular de la aleta caudal de machos adultos en miembros de Glandulocaudini y el de las restantes tribus stevardinas tendría orígenes no homólogos. En el primer grupo el tejido está compuesto por células de alarma "club cells", mientras que en el segundo está compuesto de células mucosas "mucous cells" (extrapolado a partir de observaciones en Corynopoma riisei Gill). Mirande (2009, 2010) presentó una hipótesis filogenética de Characidae apoyada en morfología, incluyó algunos géneros glandulocaudinos y stevardinos como Acrobrycon, Diapoma, Mimagoniates y Pseudocorynopoma. Sin embargo, estos géneros formaron parte una 
nueva definición de Stevardiinae realizada por Mirande (2009, 2010), que incluyó a todas las tribus glandulocaudinas de Weitzman \& Menezes y a los miembros del "clado A" propuesto por Malabarba \& Weitzman (2003). Esta subfamilia Stevardiinae fue definida por la ausencia de rama epifisaria del canal supraorbital, ocho o menos radios ramificados y nueve pterigióforos proximales en la aleta dorsal (Mirande, 2010: 534). En oposición, Menezes \& Weitzman (2009) no aceptaron la hipótesis filogenética de Mirande (2009) y cuestionaron el concepto de Stevardiinae definido por este autor. Estos autores mantuvieron la propuesta de Glandulocaudinae y Stevardiinae dentro del "clado A" de acuerdo a lo propuesto antes (Weitzman et al., 2005).

Con datos moleculares, Javonillo et al. (2010) obtuvieron un clado Stevardiinae similar al "clado A" de Malabarba \& Weitzman (2003) y Stevardiinae de Mirande (2010). Ferreira et al. (2011) reconstruyeron una filogenia morfológica con nueva evidencia histológica del tejido glandular y los espermatozoides de especies de Stevardiinae (sensu Menezes \& Weitzman, 2009). En esta nueva hipótesis filogenética, la monofilia de estos Stevardiinae y Glandulocaudinae no es completa, el género Landonia se relaciona con Glandulocauda, como clado externo a los demás miembros de Stevardiinae. Oliveira et al. (2011), en su filogenia molecular de Characidae, demostraron la problemática de los Stevardiinae de Weitzman et al. (2005), Menezes \& Weitzman (2009) y Ferreira et al. (2011) y a su vez coincidieron con el concepto más amplio de Stevardiinae propuesto por Mirande (2010). Tagliacollo et al. (2012) hicieron un análisis combinado de morfología (agregaron ocho caracteres a la matriz de Mirande, 2010) y secuencias moleculares que coincidió bastante con la definición de Mirande (2010) y Oliveira et al. (2011) de Stevardiinae, aunque nuevamente, volvieron a demostrar la naturaleza no monofilética de Stevardiinae según Menezes \& Weitzman (2009). Recientemente, Mirande et al. (2013) reanalizaron la filogenia de Stevardiinae, mantuvieron esta definición de subfamilia, y enfocaron su atención en la monofilia de un grupo de géneros compuesto por Carlastyanax Géry, Creagrutus, Microgenys Eigenmann y Piabina Reinhardt.

Mirande (2010) incluyó en su definición de Stevardiinae a las tribus usadas por Weitzman \& Menezes (1998) y Weitzman et al. (2005) para Glandulocaudinae. Este esquema de tribus glandulocaudinas y stevardinas no se ha ajustado al esquema de las filogenias morfológicas y moleculares de los últimos años (Javonillo et al., 2010; Mirande, 2010; Ferreira et al., 2011; Oliveira et al., 2011; Tagliacollo et al., 2012). Particularmente, Diapomini y/o Glandulocaudini han resultado no monofiléticos en las hipótesis filogenéticas de Javonillo et al. (2010: fig. 6), Oliveira et al. (2011: fig. 12), 
Ferreira et al. (2011: fig. 1) y Tagliacollo et al. (2012: fig. 2); pero por ejemplo, la tribu Diapomini ha sido defendida (Menezes \& Weitzman, 2011: revisión de Diapoma). En cambio, otras tribus han permanecido menos cuestionadas en este aspecto, ya sea por el número de sinapomorfías que apoyan su monofilia (Xenurobryconini, principalmente sino incluyese Chrysobrycon) o porque no han sido investigadas posteriormente en profundidad (Corynopomini). Corynopomini fue renombrada como Stevardiini por Weitzman et al. (2005) y Weitzman (2003) incluyó en esta tribu a Corynopoma, Gephyrocharax y Pterobrycon, donde Gephyrocharax es el género más numeroso en especies.

\section{Historia sistemática del género Gephyrocharax}

Antecedentes taxonómicos. El género Gephyrocharax fue descripto originalmente para los ríos transandinos San Juan y Cauca-Magdalena en Colombia y considerado intermedio entre Paragoniates Steindachner e Hysteronotus (Eigenmann, 1912: 23). En esta descripción de Eigenmann (1912), se designó a G. chocoensis Eigenmann como la especie tipo del género y se definió a Gephyrocharax con la siguiente combinación de caracteres [traducción]: dientes premaxilares en dos series distintas, cinco dientes en la hilera interna, segundo suborbital cubriendo toda la mejilla, aleta caudal sin escamas glandulares, estructura de soporte inferior de la aleta caudal libre y formando un particular espolón en el macho, aleta adiposa presente, origen de la aleta dorsal más cercana de la aleta caudal que del ojo y considerablemente detrás de la vertical que cruza por el origen de la aleta anal y pectorales largas, solapando las ventrales.

Eigenmann (1912) acompañó la definición de Gephyrocharax con tres nuevas especies colombianas: G. caucanus Eigenmann (alto río Cauca), G. chocoensis (río San Juan) y G. melanocheir Eigenmann (río Magdalena). Este autor presentó una descripción breve acompañada del respectivo material tipo, pero no incluyó una diagnosis explícita o figuras de cada una de estas especies. Ese mismo año, Meek \& Hildebrand (1912) describieron muy brevemente a Deuterodon atracaudatus Meek \& Hildebrand (mal grafiado como "atracaudata", véase más adelante) para el río Frijoles en la zona del Canal del Panamá (basado en el holotipo), pero no presentaron diagnosis o fotografías del ejemplar tipo. Luego, esta especie fue transferida al género Gephyrocharax por Eigenmann (1914), como primer revisor, quien a su vez incluyó el género en su nueva subfamilia Glandulocaudinae y presentó la primera clave taxonómica para los géneros de esta subfamilia. Meek\& Hildebrand (1916) aceptaron esta combinación de Eigenmann 
(1914), describieron a G. intermedius Meek \& Hildebrand (río Chame, Panamá) basado en el holotipo y paratipos (no incluyeron ilustraciones del holotipo), contrastaron en un breve párrafo las diferencias de esta especie con Gephyrocharax atracaudatus y G. chocoensis y presentaron una clave para identificar las especies de Panamá. Eigenmann (1920a) describió brevemente la primera especie cisandina del género, G. valencia Eigenmann (cuenca Lago Valencia, Venezuela), y aunque citó holotipo y paratipos, no incluyó una diagnosis explícita o figuras de la especie. Pearson (1924: 46) citó a G. chocoensis para varias localidades del alto río Beni en Bolivia. Myers (en Eigenmann \& Myers, 1929) revisó el material examinado de Pearson (1924) para esta cita, lo consideró mal identificado y lo usó para describir la segunda especie cisandina del género, G. major Myers (alto río Beni). La descripción de esta especie fue resumida, incluye una comparación con G. chocoensis y no presenta ilustraciones de la especie. En ese mismo estudio, Myers hizo una revisión de todas las especies de Gephyrocharax descriptas, incluyó clave para género, actuó como primer revisor de todas las especies (excepto, $G$. chocoensis que se aclaró antes) y presentó la primera clave para identificar las especies descriptas. Myers también incluyó redescripciones resumidas de las especies e ilustraciones de G. atracaudatus, G. caucanus y G. chocoensis, pero no presentó diagnosis comparativas entre las especies (excepto su clave). Hildebrand (1938) revisó las especies de Gephyrocharax en Panamá, incluyó redescripciones amplias de las especies y describió detalladamente a G. whaleri Hildebrand (río Chame o quebradas cercanas) basado en el holotipo (incluyó figura) y los paratipos. Este autor también incluyó un cuadro comparativo de las diferencias morfológicas entre las especies de Panamá. Fowler (1940) describió la tercera especie cisandina de Gephyrocharax, G. chaparae Fowler (sistema río Chapare, Bolivia), designó cotipos (= sintipos), incluyó figuras de la especie y presentó una breve comparación con G. major (actuó como primer revisor) y G. chocoensis. Dahl (1943) describió brevemente a G. martae Dahl (río San Jorge, Colombia) como un raro carácido, basado en el holotipo (fotografiado). Schultz (1944) revisó las especies venezolanas de Gephyrocharax, incluyó una clave para llegar a género y sus especies (actuó como primer revisor de G. whaleri, pero no revisó a G. martae) y describió detalladamente a Gephyrocharax venezuelae Schultz (sistema Lago Maracaibo) en una comparación con G. valencia; Schultz designó holotipo (con figura) y una gran cantidad de paratipos. Adicionalmente, este autor observó que la fontanela frontal (o anterior) es informativa para separar las especies de Gephyrocharax solo en ejemplares adultos (utilizó este carácter en su clave). Fowler (1943) describió el género y especie, Corynopomops 
opisthopterus Fowler (río Chapare, Bolivia), basado en un único ejemplar de forma algo irregular (fig. 4). Böhlke (1958) revisó el holotipo de esta especie y lo consideró un ejemplar anormal y sinónimo de G. chaparae; este autor también presentó una clave de géneros de glandulocaudinos. La sinonimia de Böhlke (1958) ha sido aceptada hasta la fecha y seguida por otros autores (e. g. Weitzman \& Fink, 1985; Vanegas-Ríos \& Phillip, 2013; Vanegas-Ríos et al., 2013). Las últimas dos especies descriptas de Gephyrocharax fueron registradas para ríos transandinos colombianos, Gephyrocharax sinuensis Dahl y Gephyrocharax torresi Vanegas-Ríos, Azpelicueta, Mirande \& González. La primera fue descripta detalladamente por Dahl (en Dahl \& Medem, 1964), quien la consideró endémica del río Sinú; este autor también designó holotipo y paratipos e incluyó una ilustración de esta especie, pero no presentó una diagnosis respecto de los demás congéneres. La segunda fue descripta detalladamente por Vanegas-Ríos et al. (2013) para la cuenca del río Cascajales en el río Magdalena. Esta descripción, al ser más moderna que las anteriores, es más completa por incluir información de variados aspectos anatómicos.

Weitzman (2003), Vanegas-Ríos et al. (2013) y Eschmeyer (2014) listan 13 especies válidas de Gephyrocharax: G. atracaudatus, G. caucanus, G. chocoensis, G. intermedius, G. melanocheir, G. martae, G. sinuensis, G. torresi, G. valencia, $G$. venezuelae y $G$. whaleri. Una gran cantidad de registros de distribución han sido publicados para las especies de Gephyrocharax después de sus descripciones originales (mayores detalles en los resultados presentados más adelante). En términos generales (Weitzman, 2003; Vanegas-Ríos et al., 2013; Vanegas-Ríos \& Phillip, 2013), Gephyrocharax es un género de ambientes cis y transandinos en el Neotrópico americano, distribuido en los ríos costeros del Caribe y Pacífico de Panamá en el sur de América Central y a través de América del Sur en los ríos San Juan, Atrato, San Jorge-CaucaMagdalena, Sinú, drenajes del Lago de Maracaibo, ríos costeros del Caribe de Venezuela, sistema del río Orinoco, ríos costeros en la isla de Trinidad (Trinidad \& Tobago) y en el sur en diferentes drenajes de los ríos Beni y Chapare en el Amazonas Boliviano.

Antecedentes filogenéticos. La historia filogenética del género Gephyrocharax y la tribu Stevardiini están íntimamente conectadas, ya sea en las subfamilias Glandulocaudinae o Stevardiinae. Inicialmente, Eigenmann (1917: fig. 1) en su hipótesis precladística posicionó implícitamente a Gephyrocharax en su Glandulocaudinae que a su vez aparece relacionado con Cheirodontinae, Rhoadsiinae e Iguanodectinae. Estos glandulocaudinos de Eigenmann fueron considerados por mucho tiempo un grupo morfológicamente afín ( $e$. g. Eigenmann \& Myers, 1929; Nelson, 1964), hecho que no estuvo totalmente libre de 
críticas (e. g. Böhlke, 1958, Géry, 1964, 1977; Weitzman, Fink \& Menezes en Weitzman \& Fink, 1985). Weitzman \& Fink (1985) en su estudio de la tribu Xenurobryconini examinaron ejemplares de las especies de Gephyrocharax, pero no encontraron razones suficientes para incluirlo en esta tribu. Sin embargo, Weitzman \& Fink (1985) comentaron la gran afinidad morfológica del esqueleto caudal de los machos adultos en especies de Gephyrocharax, Corynopoma y Pterobrycon. Weitzman et al. (1988) y Menezes \& Weitzman (1990) reconstruyeron una hipótesis filogenética de Glandulocaudini, pero excluyeron a Gephyrocharax de esta tribu. Weitzman \& Menezes (1998) fueron los primeros en realizar un análisis filogenético morfológico de los glandulocaudinos (principalmente según Böhlke, 1958) con una matriz de 19 géneros terminales y 51 caracteres morfológicos (en su mayoría asociados a los machos adultos). En este análisis filogenético (Weitzman \& Menezes, 1998), se encontró a la tribu Stevardiini (= Corynopomini) monofilética con Gephyrocharax, Pterobrycon y Corynopoma. Weitzman \& Menezes (1998) informaron dos sinapomorfías de los machos adultos en Stevardiini: escama-bolsillo con radii hipertrofiados extendidos en todo el borde de la escama y escama-bolsillo extendida desde la región del radio caudal 12 a los radios procurrentes ventrales de la aleta caudal. Si bien, esta tribu formada como (Gephyrocharax $($ Corynopoma + Pterobrycon)) fue apoyada en sinapomorfías sin reversiones o paralelismos, Weitzman \& Menezes (1998) no discriminaron en su matriz de caracteres cuáles especies de Pterobrycon y Gephyrocharax fueron analizadas; aparentemente se extrapolaron los datos del género o se fusionaron las codificaciones de todas las especies. Weitzman \& Menezes (1998) sustentaron la hipótesis de Pterobrycon y Corynopoma como grupos hermanos basados en la presencia de una aleta anal muy expandida ventralmente en los machos adultos. Estudios moleculares posteriores, Javonillo et al. (2010) y Oliveira et al. (2011), han demostrado la estrecha relación filogenética entre Gephyrocharax y Corynopoma (no se conocen estudios moleculares que incluyan especies de Pterobrycon). En contraste, Tagliacollo et al. (2012) en su filogenia molecular encontraron a Stevardiini parafilético. De cualquier manera, poca atención se le ha dado desde Weitzman \& Menezes (1998) a retestear la monofilia de esta tribu y sus géneros (especialmente la filogenia interna de Gephyrocharax, género más diverso de la tribu). Tampoco se conoce la posición filogenética de esta tribu en las clasificaciones morfológicas de Characidae y Stevardiinae propuestas en los últimos años (Mirande, 2010, Mirande et al., 2013). Estos y otros interrogantes relacionadas con Stevardiini y 
Gephyrocharax siguen abiertos a investigación (e. g. politomía en Weitzman \& Menezes, 1998: fig. 1).

\section{Problemáticas principales y objetivos}

La mayoría de las especies de Gephyrocharax descriptas no tienen diagnosis explícitas, y más aún, la diagnosis del género (Eigenmann, 1912; Myers en Eigenmann \& Myers, 1929; Schultz, 1944) no da indicios de que sea un grupo natural e incluso contiene ciertos caracteres (e. g. número de dientes premaxilares, aleta dorsal posterior al origen de la aleta anal) presentes en Corynopoma o Pterobrycon, sus géneros hermanos. Tampoco se conoce la posición filogenética de Gephyrocharax y sus géneros hermanos en las filogenias modernas de Characidae y Stevardiinae (Mirande, 2010; Mirande et al., 2013). Además, algunos caracteres que definen a Corynopoma o Pterobrycon asociados al dimorfismo sexual de los machos, no han sido demostrados como autapomorfías (en el caso de Corynopoma por ser monotípico) o sinapomorfías (en el caso de Pterobrycon) que reflejen un comportamiento jerárquico apoyado en una filogenia y que los muestre como géneros monofiléticos. Por lo tanto, ¿pueden Corynopoma o Pterobrycon separarse de Gephyrocharax desde la filogenia? Esta pregunta no ha sido contestada. Si bien Weitzman \& Menezes (1998) abordaron parcialmente este punto, ellos no incluyeron todos los caracteres diagnósticos de estos tres géneros en su matriz de caracteres y por lo tanto no satisficieron totalmente el interrogante. Además, un punto desfavorable del estudio de Weitzman \& Menezes (1998) es que su matriz contiene, en su mayoría, caracteres sexualmente dimórficos de los machos adultos (49 de sus 51 analizados) y muy poca información de otras partes anatómicas. Entonces, es posible pensar que hay cierto peso $a$ priori indirecto sobre este tipo de caracteres sexuales en la filogenia de Stevardiini y en todas las interrelaciones tribales obtenidas por estos autores. Todas estas razones llevan a varios interrogantes: ¿es posible constituir la tribu Stevardiini con Gephyrocharax?, ¿es Gephyrocharax un grupo monofilético?, ¿pertenece Gephyrocharax a Stevardiinae según Mirande (2010) o según Weitzman et al. (2005)?, ¿son Pterobrycon y Corynopoma grupos hermanos relacionados con Gephyrocharax?, ¿cuántas especies válidas tiene Gephyrocharax? y ¿cómo son las relaciones filogenéticas entre estas especies?

En concordancia con lo expuesto previamente, el objetivo central de este estudio fue efectuar la revisión sistemática del género Gephyrocharax: la taxonomía de sus especies, el diagnóstico del género y la construcción de una hipótesis filogenética a nivel intragenérico y un análisis intergenérico y supragenérico que refleje mejor las relaciones 
filogenéticas de sus grupos afines, especialmente dentro de la subfamilia Stevardiinae según Mirande (2010) y Mirande et al. (2013).

\section{MATERIALES Y MÉTODOS}

\section{Acrónimos institucionales}

Todos los ejemplares examinados para el análisis filogenético y la revisión taxonómica del género Gephyrocharax están depositados en las siguientes instituciones (material comparativo examinado y material examinado respectivamente):

- (AMNH) American Museum of Natural History, Nueva York.

- (ANSP) Academy of Natural Sciences, Filadelfia.

- (AUM) Natural History Museum, Auburn University, Auburn.

- (CAS) California Academy of Sciences, San Francisco.

- (CAR) Colección privada Carlos Ardila-Rodríguez, Barranquilla.

- (CIUA) Colección de Ictiología, Universidad de Antioquia, Medellín.

- (CI-FML) Colección de Ictiología, Fundación Miguel Lillo, San Miguel de Tucumán.

- (CZUT-IC) Ictiología, Colección Zoológica, Universidad del Tolima, Ibagué

- (FMNH) Field Museum of Natural History, Chicago.

- (IAvH-P) Colección peces dulceacuícolas, Instituto Alexander von Humboldt, Villa de Leyva.

- (ICNMHN) Instituto de Ciencias Naturales, Museo de Historia Natural, Universidad Nacional de Colombia, Bogotá.

- (IMCN) Ictiología, INCIVA, Museo de Ciencias Naturales Federico Carlos Lehmann V., Cali.

- (INHS) Illinois Natural History Survey, Champaign.

- (IU) Indiana University Collections, Bloomington, Con frecuencia usado como I. U. M. en publicaciones de C. H. Eigenmann y colaboradores. Los especímenes ahora están depositados formalmente en la colección del CAS, con algunas muestras repartidas en otras colecciones.

- (LACM) Natural History Museum of Los Angeles County, Los Angeles.

- (MBUCV) Museo de Biología, Universidad Central de Venezuela, Caracas.

- (MCP) Museu de Ciências e Tecnologia, Pontifícia Universidade Católica do Rio Grande do Sul, Porto Alegre.

- (MCZ) Museum of Comparative Zoology, Harvard University, Cambridge.

- (MEPN) Museo de Historia Natural, Escuela Politécnica Nacional, Quito. 
- (MHNG) Muséum d'histoire naturelle, Ginebra.

- (MLP) Museo de La Plata, La Plata.

- (MPUJ) Colección de peces, Museo Javeriano de Historia Natural "Lorenzo Uribe S. J.". Bogotá.

- (MUSM) Museo de Historia Natural, Universidad Mayor de San Marcos, Lima.

- (MZLU) Museum of Zoology, Lund University, Lund.

- (NRM) Ichthyology collection, Swedish Museum of Natural History, Estocolmo.

- (ROM) Royal Ontario Museum, Toronto.

- (STRI) Smithsonian Tropical Research Institute, Balboa.

- (UF) University of Florida, Florida Museum of Natural History, Gainesville.

- (UIST) Colección Ictiológica, Escuela de Biología, Universidad Industrial de Santander, Bucaramanga.

- (UMSS) Museo de Historia Natural “Alcide D’Orbigny”, Cochabamba.

- (USNM) National Museum of Natural History, Smithsonian Institution, Washington, D.C.

- (UWIZM) Zoology Museum, University of West Indies, St. Augustine.

\section{Preparaciones osteológicas y miológicas}

Uno a 14 ejemplares fueron diafanizados y teñidos (d\&t) según la metodología propuesta por Taylor \& Van Dyke (1985) para observación de huesos y cartílagos. Entre uno a cuatro ejemplares fueron diseccionados y teñidos con una solución al 10\% de Azul de Metileno y otros ejemplares de algunas especies de Gephyrocharax y de grupos comparativos fueron doblemente teñidos para hueso y cartílago (t\&m) según la metodología de Datovo \& Bockmann (2010) y Datovo \& Castro (2012) para observación de músculos.

\section{Terminología}

La nomenclatura osteológica sigue a Weitzman (1962) con las siguientes modificaciones mencionadas por Mirande (2010): prevómer por vómer, opistótico por intercalar (Zanata \& Vari, 2005), epioccipital por epiótico (Patterson, 1975), epihial o posterohial por ceratohial posterior, ceratohial o anterohial por ceratohial anterior (Nelson, 1969) y etmoides por mesetmoides (Fink \& Fink, 1981). Las costillas pleurales fueron contadas acorde al conteo de vértebras (i. e. la costilla de la quinta vértebra corresponde a la quinta costilla) y no en el modo usado por Mirande (2010). Los radios procurrentes ventrales o dorsales fueron contados en sentido posteroanterior con un orden numérico ascendente $(e$. g. el radio más posterior corresponde al primer radio), debido a que los radios más 
anteriores varían en cantidad entre las distintas especies estudiadas, lo cual dificulta su procesamiento en términos de homologación. La nomenclatura miológica sigue a Winterbottom (1974), Datovo \& Castro (2012) y la reciente terminología de Datovo \& Vari (2013). Términos específicos sobre modificaciones de la musculatura caudal siguen a Weitzman \& Fink (1985).

Las hipótesis filogenéticas del presente estudio se limitan a la subfamilia Stevardiinae. No es el objetivo testear la monofilia de Characidae o las relaciones de otras de sus subfamilias o clados. La clasificación principal usada para Characidae y Stevardiinae es la propuesta por Mirande (2010) y Mirande et al. (2013) pero en consenso, y para discusión, con la clasificación de Oliveira et al. (2011). Aunque estos estudios difieren en varios aspectos en cuanto a la definición de Characidae, ambos tienen una definición de Stevardiinae parecida (también afín con Javonillo et al., 2010). La definiciones de Stevardiinae y Glandulocaudinae propuestas por Weitzman et al. (2005), Menezes \& Weitzman (2009) y Ferreira et al. (2011) no fueron asumidas en un sentido estricto pero sí son discutidas a lo largo de esta contribución. Además, las definiciones de estos autores en cuanto a tribus de Stevardiinae (e. g. Diapomini) son usadas por conveniencia en la metodología para propósitos de claridad de la selección de los grupos de externos y son analizadas posteriormente a la luz de los resultados de la presente investigación.

\section{Análisis filogenético}

Para reconstruir la filogenia del género Gephyrocharax se empleó un análisis que permitiese testear su posición filogenética dentro de Characidae y Stevardiinae, su grupo hermano y las relaciones filogenéticas entre sus especies en un mejor contexto de relaciones intergenéricas dentro de la subfamilia Stevardiinae. Para alcanzar tales objetivos, lo primero fue seleccionar como punto de partida la matriz de caracteres morfológicos de Mirande et al. (2013), la cual es la versión más reciente de la matriz de Mirande $(2009,2010)$ y Mirande et al. (2011) y aumenta el número de taxones terminales analizados para Stevardiinae. La matriz de caracteres final (llamada así de aquí en adelante) parte de los 366 caracteres usados por Mirande et al. (2011) y nueve caracteres adicionados por Mirande et al. (2013) y los 177 taxones terminales analizados por Mirande et al. (2013) en esa matriz. La ventajas de usar la información de la matriz de Mirande et al. (2013) son diversas: 1) se testean hipótesis de posición filogenética de Gephyrocharax dentro de la familia Characidae (en vez de extrapolar sinapomorfías); 2) 
se aprovecha toda la variación morfológica descripta para una mejor optimización de los estados de carácter; 3) se examina más información morfológica que mejora la obtención de las sinapomorfías; y 4) se brinda la posibilidad de reconstruir un mayor número de taxones terminales en un mejor escenario filogenético para testear la monofilia de Gephyrocharax, especialmente sus relaciones con otros stevardinos. Si bien es alternativo construir una nueva matriz de caracteres, esta estrategia necesitaría codificar casi toda la información morfológica usada por Mirande (2010) y el proceso podría ser en parte redundante. Además, se tiene la desventaja de perder información (taxones terminales) e interacción entre caracteres (grados de homoplasia y mejor optimización de los nodos).

Otros detalles sobre la construcción de la matriz de caracteres final son dados en el apartado "Taxones terminales muestreados" y "Descripción de los caracteres". La matriz de caracteres final fue codificada y analizada según la metodología cladística usada por Mirande (2008, 2009, 2010) y Mirande et al. (2011, 2013), la cual es descripta detalladamente abajo.

Taxones terminales muestreados. A la matriz de caracteres final que tiene los 177 taxones terminales de Mirande et al. (2013) se le adicionaron 41 taxones terminales, 11 del grupo interno bajo estudio y 30 del grupo externo, especialmente miembros de las tribus de Weitzman \& Menezes (1998). La matriz de caracteres de Mirande et al. (2013) ya incluye 40 especies de Stevardiinae, que contribuyeron como grupos externos para la optimización de los caracteres. El grupo interno codificado en este estudio fue el género Gephyrocharax (11 especies en total incluidas, véase resultados revisión taxonómica); aunque no fue el objetivo primario (sino secundario) probar la monofilia de la tribu Stevardiini, se incluyeron sus miembros y grupos externos relevantes para este grupo "interno" secundario. Los 41 taxones terminales seleccionados y agregados como grupos externos fueron elegidos con base en un criterio filogenético [con caracteres morfológicos (Weitzman \& Fink, 1985, Weitzman \& Menezes, 1998; Castro et al. 2003; Malabarba \& Weitzman, 2003; Weitzman et al., 2005; Menezes \& Weitzman, 2009; Ferreira et al. 2011; Mirande, 2010; Mirande et al., 2013) y caracteres moleculares (Calcagnotto et al., 2005; Javonillo et al., 2010; Oliveira et al., 2011)]. Mirande et al. (2013) codificaron cinco especies de las tribus o clados dentro de Stevardiinae (según Weitzman \& Menezes, 1998) más cercanos a Gephyrocharax. Para aumentar los taxones terminales de estas tribus o clados, se agregaron dieciséis especies representativas y relacionadas con Gephyrocharax [ya sea según Mirande (2010) o Weitzman et al. (2005)]: 1) Glandulocaudini, Mimagoniates inequalis (Eigenmann); 2) Landonini, Landonia latidens; 3) Diapomini, 
Diapoma terofali (Géry) y D. pyrrhopteryx Menezes \& Weitzman; 4) Phenacobryconini, Phenacobrycon henni; 5) Stevardiini (= Corynopomini, incluye a Gephyrocharax) Corynopoma riisei, Pterobrycon landoni Eigenmann y P. myrnae Bussing y 6) Xenurobryconini, Chrysobrycon eliasi Vanegas-Ríos, Azpelicueta \& Ortega, C. hesperus (Böhlke), C. myersi (Weitzman \& Thomerson), Chrysobrycon yoliae Vanegas-Ríos, Azpelicueta \& Ortega y Chrysobrycon sp. nov. A, Scopaeocharax rhinodus (Böhlke), Tyttocharax sp. y Xenurobrycon macropus Myers \& Miranda Ribeiro. También fueron adicionadas cuatro especies representativas de otros géneros putativamente clasificados en Stevardiinae (según Mirande, 2010) pero considerados por Weitzman et al. (2005) como externos a las demás tribus de su filogenia: Bryconamericus plutarcoi Román-Valencia, Vanegas-Ríos \& Ruiz-C., B. yokiae Román-Valencia, Cyanogaster noctivaga Mattox, Britz, Toledo-Piza \& Marinho y Knodus sp. Se codificaron ejemplares de un nuevo género preliminarmente clasificado en Stevardiinae. Y finalmente, fueron adicionadas cuatro especies representativas de Characidae: Genycharax tarpon Eigenmann, Odontostilbe pulchra (Gill), Markiana geayi (Pellegrin) y Nematobrycon lacortei Weitzman \& Fink. Todas las especies mencionadas no fueron analizadas por Mirande (2010) o Mirande et al. (2013). Cuatro de las especies adicionadas a la matriz de caracteres final fueron codificadas casi completamente y/o con ciertas restricciones por las limitaciones de su material examinado o fuente de información: C. noctivaga desde las descripciones osteológicas y fotografías provistas por Mattox et al. (2013); G. martae, desde el ejemplar holotipo y su radiografía; L. latidens, desde la descripción osteológica de Roberts (1973), ejemplares preservados en alcohol y el holotipo fotografiado y radiografiado; y P. landoni, a partir de seis ejemplares radiografiados y fotografiados en alta resolución y de datos morfológicos e ilustraciones presentadas en la redescripción de Bussing (1974).

Muchas de las especies analizadas por Mirande et al. (2013) no fueron codificadas en este estudio para los 176 caracteres adicionados (véase "Descripción de los caracteres") en la matriz final de caracteres. Como las relaciones de estas especies no son necesariamente relevantes para el clado Stevardiinae o sus miembros, y especialmente para la filogenia de Gephyrocharax, se utilizó una estrategia de codificación que disminuyera el número de entradas faltantes y contribuyera en la optimización de los estados de caracteres en los clados superiores de interés. La estrategia implementada fue codificar el mayor número posible de caracteres adicionados para un grupo de especies representativas y usadas por Mirande et al. (2013), ubicadas en Stevardiinae y que pertenecen a clados representativos relacionados de Characidae y/o Characiformes. Todas 
estas especies fueron codificadas con el mismo material examinado usado por Mirande (2009, 2010) y Mirande et al. $(2011,2013)$ y en algunos casos fueron usados nuevos ejemplares diafanizados y teñidos, nuevos ejemplares preservados en alcohol y en algunos casos fotografías y radiografías de alta resolución de holotipos de las especies correspondientes. Las especies codificadas acorde a esta estrategia para los 176 caracteres son (clados numerados según Mirande, 2010 y/o Mirande et al., 2011): 1) en Stevardiinae, Acrobrycon ipanquianus (Cope) (antes A. tarijae Fowler, de Mirande et al., 2013; también Diapomini), Argopleura magdalenensis (Eigenmann) (Xenurobryconini), Attonitus ephimeros Vari \& Ortega, Aulixidens eugeniae Böhlke, Bryconadenos tanaothoros Weitzman, Menezes, Evers \& Burns, Bryconamericus agna Azpelicueta \& Almirón, B. cf. iheringii (Boulenger), B. cf. rubropictus (Berg), B. emperador (Eigenmann \& Ogle), B. exodon Eigenmann, B. mennii Miquelarena, Protogino, Filiberto \& López, B. rubropictus, B. scleroparius (Regan), B. thomasi Fowler, Carlastyanax aurocaudatus (Eigenmann), Cyanocharax alburnus (Hensel), C. obi Casciotta, Almirón, Piálek \& Říčan, Creagrutus anary Fowler, C. atrisignum Myers, C. taphorni Vari \& Harold, Diapoma speculiferum Cope (Diapomini), Hemibrycon dariensis Meek \& Hildebrand, H. surinamensis Géry, Knodus breviceps (Eigenmann), K. heteresthes (Eigenmann), K. gamma, K. meridae Eigenmann, Mimagoniates rheocharis Menezes \& Weitzman, Microgenys minuta Eigenmann, Nantis indefessus Mirande, Aguilera \& Azpelicueta, Odontostoechus lethostigmus Gomes, Piabina argentea Reinhardt, Piabarchus analis (Eigenmann), Prodontocharax melanotus Pearson, Pseudocorynopoma doriae Perugia (Hysteronotini); 2) en Cheirodontinae, Cheirodon interruptus (Jenyns), Odontostilbe microcephala Eigenmann, O. paraguayensis Eigenmann \& Kennedy, O. pequira (Steindachner) y Serrapinus calliurus (Boulenger); 3) en Aphyoditeinae, Aphyocharacidium bolivianum Géry, Aphyodite grammica Eigenmann, Axelrodia lindeae Géry, Microschemobrycon casiquiare Böhlke y Parecbasis cyclolepis Eigenmann; 4) en Aphyocharacinae, Aphyocharax anisitsi Eigenmann \& Kennedy, A. dentatus Eigenmann \& Kennedy, A. nattereri (Steindachner), Inpaichthys kerri Géry \& Junk, Paragoniates alburnus (Steindachner), Phenagoniates macrolepis (Meek \& Hildebrand), Prionobrama paraguayensis (Eigenmann) y Xenagoniates bondi Myers; 5) en Gymnocharacinae, Nematobrycon palmeri Eigenmann, Grundulus cochae Román-Valencia, Gymnocharacinus bergii Steindachner; 6) clado Bryconamericus scleroparius, $B$. emperador (Eigenmann \& Ogle) y B. scleroparius; 7) clado Astyanax, A. asuncionensis Géry, A. chico Casciotta \& Almirón, A. cf. eigenmanniorum 1, A. troya Azpelicueta, 
Casciotta \& Almirón, Astyanacinus moorii (Boulenger), H. anisitsi (Eigenmann), Psellogrammus kennedyi (Eigenmann) y Markiana nigripinnis (Perugia); 8) clado Astyanax parís, A. parís Azpelicueta, Almirón \& Casciotta; 9) clado Hyphessobrycon luetkenii (Boulenger), H. bifasciatus Ellis, H. meridionalis y A. latens Mirande, Aguilera \& Azpelicueta; 10) en Tetragonopterinae, Deuterodon iguape Eigenmann, D. langei Travassos, Gymnocorymbus ternetzi (Boulenger), Hemigrammus erythrozonus Durbin, $H$. ulreyi (Boulenger), Hyphessobrycon pulchripinnis Ahl, Moenkhausia dichroura (Kner), M. cf. intermedia Eigenmann, M. sanctaefilomenae (Steindachner), Stethaprion erythrops Cope, Stichonodon insignis (Steindachner), Tetragonopterus argenteus Cuvier y Thayeria boehlkei Weitzman; 11) en clado Bramocharax, B. bransfordii Gill y Oligosarcus cf. jenynsii (Günther) у O. bolivianus (Fowler); 12) clado Pseudochalceus, Hollandichthys multifasciatus (Eigenmann \& Norris) y P. kyburzi Schultz; 13) en Rhoadsiinae, Carlana eigenmanni (Meek), Nematocharax venustus Weitzman, Menezes \& Britski y Rhoadsia altipinna Fowler; 14) en Characinae, Acestrocephalus sardina (Fowler), Bryconexodon juruenae Géry, Charax stenopterus (Cope), Exodon paradoxus Müller \& Troschel, Galeocharax humeralis (Valenciennes), Phenacogaster tegatus (Eigenmann), Roeboexodon geryi (Puyo) y Roeboides descalvadensis Fowler, 15) en Heterocharacinae, Heterocharax macrolepis Eigenmann, Hoplocharax goethei Géry y Lonchogenys ilisha Myers; 16) en clado Bryconops; B. affinis (Günther) y B. melanurus (Bloch); 17) en Iguanodectinae, Piabucus menalostomus Holmberg; 18) en Bryconinae, Brycon meeki Eigenmann \& Hildebrand y Triportheus pantanensis Malabarba; 19) en Salmininae, Salminus brasiliensis (Cuvier); 20) en Agoniatinae, Agoniates anchovia Eigenmann; 21) en Acestrorhynchinae, Acestrorhynchus pantaneiro Menezes, 22) en Cynodontidae, Rhaphiodon vulpinus Spix \& Agassiz; 23) en Characoidea, Chalceus macrolepidotus Cuvier (Alestidae) y Thoracocharax stellatus (Kner) (Gasteropelecidae); 24) en Characoidei, Apareiodon affinis (Steindachner) y Leporinus striatus Kner; y 25) en grupo externo raíz, Systomus tetrazona (Bleeker) que pertenece a Cypriniformes. Las especies fueron organizadas en material comparativo examinado, excepto aquellos ejemplares de las especies de Gephyrocharax que están organizados y presentados separadamente para cada especie dentro de los resultados de la revisión taxonómica. El material comparativo examinado fue organizado por país, colección científica y número de catálogo, especie, número de ejemplares, tallas de los ejemplares y localidad.

Fotografías, descripciones e ilustraciones de los variados estudios y revisiones fueron usados complementariamente durante el proceso de codificación (Weitzman, 1962, 
1964; Roberts, 1973; Géry, 1977; Fink \& Fink, 1981; Weitzman \& Fink, 1983; Mahnert \& Géry, 1984; Weitzman \& Fink, 1985; Uj, 1987; Vari \& Siebert, 1990; Malabarba, 1998; Weitzman \& Menezes, 1998; Vari \& Harold, 2001; Malabarba \& Weitzman, 2003; ValdezMoreno \& Contreras-Balderas, 2003; Malabarba, 2004; Weitzman et al., 2005; Ferreira, 2007; Menezes \& Weitzman, 2009, 2011; Bertaco \& Malabarba, 2010; Mirande, 2010; Zarske, 2010; Carvalho, 2011; Ferreira et al., 2011; Malabarba et al. 2012; Weiss et al., 2012; Cione \& Azpelicueta, 2013). Adicionalmente, se utilizaron los siguientes estudios para la codificación de caracteres histológicos (Burns et al., 1995; Burns \& Weitzman, 2005; Pecio et al., 2005; Javonillo et al., 2007; Pecio et al., 2007; Javonillo et al., 2009; Baicere-Silva et al., 2011a, b).

Selección de caracteres y codificación. Se trató de representar toda la variación morfológica observada. Los caracteres que no pudieron ser codificados se representan de dos maneras en la matriz: las entradas faltantes como "?", cuando el correspondiente carácter no pudo ser observado y los inaplicables como “-”, cuando dentro de la descripción del carácter, la estructura de la que se hace mención no está presente en la correspondiente especie (casos particulares se explican en el listado de caracteres). Los programas de filogenia consideran ambos signos como la unión de todos los estados definidos para ese carácter (Strong \& Lipscomb, 1999). La mayoría de los caracteres utilizados son binarios. El procesamiento de las series multiestado fue organizado con base en las recomendaciones revisadas por Brazeau (2011). Adicionalmente, se prefirió usar algunos caracteres multiestado ordenados como binarios para mantener el esquema usado por Mirande (2009) y Mirande (2010). Esta recodificación binaria es totalmente equivalente a incluir al carácter como aditivo, en las búsquedas más comúnmente realizadas, y es ejecutada internamente por el programa TNT. Además, se tuvieron en cuenta varios criterios para los caracteres que agrupan conteos discretos de estructuras: 1) buscar los valores máximo y mínimo dentro de los taxones analizados para el respectivo conteo; 2) detectar los vacíos en la distribución de los conteos para evitar crear estados artificiales que no tengan ninguna especie a codificar con dicho estado; 3) agrupar intervalos que mostraran cierta señal filogenética; 4) usar intervalos que disminuyan al máximo posible los polimorfismos. Las autapomorfías no fueron descartadas del análisis porque pueden ser consideradas útiles para futuros análisis y para su uso en las diagnosis de las especies de Gephyrocharax y géneros relacionados.

Bases cladísticas y esquemas de pesado de caracteres: Las hipótesis filogenéticas fueron construidas siguiendo la metodología cladística propuesta por Hennig $(1950,1966)$ 
y desarrollada por otros autores (e. g. Farris, 1969, 1970, 1983; Goloboff, 1993, 1995, 1997, 1997, 1999; Goloboff \& Farris, 2001) bajo el criterio de parsimonia. Los análisis fueron enraizados usando el criterio de grupo externo "outgroup" (Nixon \& Carpenter, 1993). Debido al tamaño de la matriz, una búsqueda exacta es impracticable, por lo que los análisis fueron realizados mediante búsquedas heurísticas utilizando el programa TNT v. 1.1 (Goloboff et al., 2008a). Se hicieron búsquedas mediante dos esquemas de pesado de caracteres: pesos implicados ("Implied weighting"; Goloboff, 1993) y pesos iguales. Este último esquema fue implementado solo con la intención de contrastar la hipótesis filogenética final bajo pesos implicados para Gephyrocharax y algunos géneros muy relacionados con éste. El esquema de pesado para seleccionar la hipótesis filogenética final, las búsquedas filogenéticas y las medidas de apoyo siguen a Mirande (2008, 2009, 2010) y Mirande et al. (2011, 2013). La estrategia metodológica detallada en Mirande (2009) logra un punto intermedio entre robustez y poder de información de las hipótesis filogenéticas. También es posible discutir, bajo las mismas condiciones de análisis, los resultados obtenidos con aquellos presentados en estos trabajos (e. g. Mirande et al., 2013). Los resultados de esta metodología dieron un avance en la filogenia de Characidae que ha sido útil para otros estudios filogenéticos con morfología (e. g. Malabarba, 1998; Malabarba \& Weitzman, 2003; Malabarba et al., 2012; Mattox \& Toledo-Piza, 2012; Weiss et al., 2012), con moléculas (Oliveira et al., 2011) y con ambos tipos de caracteres (e. g. Netto-Ferreira et al., 2013: Tagliacollo et al., 2012). Mirande (2010) demostró que la morfología con señal filogenética para Characidae es relativamente homoplásica y pocos caracteres proveen de sinapomorfías "perfectas". Ante esta homoplasia relativa en la morfología de Characidae, resulta útil usar un esquema de pesado que trate la homoplasia implícitamente a la hora de las búsquedas filogenéticas (pesos implicados), en vez de aplicar un esquema donde este punto es tratado por igual (pesos iguales).

El método de pesos implicados (Goloboff, 1993) trata la congruencia entre cada carácter y el resto de los datos durante la búsqueda de árboles de máxima parsimonia, para dar mayor peso a los caracteres menos homoplásicos. La idea de este método, al igual que en pesos sucesivos "Successive weighting"; (Farris, 1969), es que los caracteres con menos homoplasia entre las especies observadas son más predictivos ante la incorporación de nueva evidencia al análisis. Este criterio para el pesado de caracteres ha sido justificado repetidamente en la literatura (Farris, 1969; Goloboff, 1993, 1995, 1997; Ramírez, 2003; Aguilera \& Mirande, 2005; Goloboff et al., 2008b; Mirande, 2008; 2009; Mirande, 2010; Mirande et al. 2011; Goloboff, 2013; Mirande et al., 2013). En pesos implicados, 
Goloboff (1993) propuso que la proporción con la que disminuye el peso de los caracteres, según su grado de homoplasia, esté determinada por una curva de concavidad producida por una fórmula que incluye una constante de concavidad/convexidad (K). Más detalles metodológicos sobre pesos son explicados en estudios como Arias \& Miranda-Esquivel (2004), Goloboff (1993, 1995, 1997), Goloboff et al. (2008b) y Mirande (2008, 2009).

Para los análisis bajo pesos implicados, el usuario debe elegir un valor de K. La estrategia utilizada para las búsquedas consistió en definir un intervalo amplio de valores de K (en este caso 21), analizar la matriz de caracteres final con esos valores y comparar la estabilidad de las hipótesis obtenidas bajo diferentes condiciones de análisis a través de un procedimiento similar a un análisis de sensibilidad ("Sensitivity analysis"; Wheeler et al., 1995; Whiting et al., 1997; Prendini, 2000; Giribet, 2003; Mirande, 2008, 2009; 2010; Mirande et al. 2011, 2013). Debido a la forma cóncava de las funciones de pesado empleadas (Goloboff, 1993, 1997), la comparación entre los árboles más parsimoniosos obtenidos en intervalos regulares de K no tiene sentido. La razón de esto es que las fuerzas de pesado y las hipótesis filogenéticas serán más parecidas en tanto mayores sean los valores de K (Goloboff, 1993). Por tal motivo, se dividió en intervalos regulares a la distorsión (D) o al ajuste (F) (donde $\mathrm{F}=1-\mathrm{D}$ ) de los árboles más parsimoniosos correspondientes, en vez de los valores de K; acorde a la estrategia propuesta por Mirande (2008, 2009). En general, para el análisis bajo pesos implicados se utilizaron las concavidades que un carácter tenga con un número promedio de pasos entre el $50 \%$ y el $90 \%$ del ajuste ("fit" de un carácter sin homoplasia y este intervalo fue dividido en 21 intervalos regulares. Los valores de $\mathrm{K}$ resultantes fueron expresados con dos decimales en el texto, pero los números utilizados tienen cinco decimales.

Búsquedas filogenéticas. Para pesos implicados se siguen las especificaciones para las búsquedas de árboles realizadas por Mirande (2009, 2010) y Mirande et al. (2013). Los métodos de búsqueda y parámetros usados fueron calculados mediante el uso de diferentes macros "aaa" y "aab" (Mirande et al., 2013). Se usaron la permutación de ramas con SPR y TBR ("subtree pruning regrafting" y "tree bisection reconnection", respectivamente: Swofford \& Olsen, 1990), utilizando las técnicas de piñón de parsimonia ("parsimony ratchet”: Nixon, 1999), deriva de árboles, fusión de árboles y búsquedas sectoriales ("tree dritfing", "tree fusing" y "sectorial searches": Goloboff, 1999), implementados en TNT (Goloboff et al., 2008a) bajo "new technology searches". El script "aaa" fue corrido con "xmult= hits3 level7 drift10". Estas búsquedas parten de 11 árboles de Wagner con diferentes secuencias de adición (Farris, 1970), realizando 10 ciclos de piñón de 
parsimonia, 18 de deriva de arboles, 7 ciclos de fusión de fusión de árboles y búsquedas sectoriales aleatorias ("random sectorial searches"); en cada tipo de búsqueda se utilizaron los parámetros definidos por defecto. El script "aaa" incluye búsqueda con pesos implicados extendidos (Goloboff, 2013: “xpiwe"), recientemente implementado en TNT. Para el uso de este método, es necesario convertir las entradas inaplicables “-”en entradas polimórficas “*” (equivalente en términos algorítmicos) en la matriz de datos. Este método (que es una modificación a pesos implicados) previene que los caracteres con muchas entradas faltantes tengan artificialmente pesos altos. Para el caso de este estudio que tiene una gran cantidad de entradas faltantes por las razones explicadas arriba, esta modificación es muy positiva porque trata de contrarrestar el posible efecto adverso de las entradas faltantes a lo largo de las búsquedas filogenéticas. Las búsquedas de los árboles más parsimoniosos bajo pesos iguales fueron calculadas con los comandos "xmult= hits3 level7 rat10 drift10 keepall" más "bbreak = tbr".

Reconstrucción de la hipótesis final. Como se mencionó y justificó antes, el cladograma final obtenido bajo pesos iguales es presentado con el propósito de comparar los resultados de Gephyrocharax y algunos géneros relacionados con éste en la hipótesis final bajo pesos implicados, lo cual es provechoso para fines argumentativos de la discusión. Se calculó un consenso estricto de todos los árboles igualmente parsimoniosos bajo pesos iguales. En el caso de pesos implicados, se usó un consenso estricto entre los árboles obtenidos a través de varios criterios según los parámetros explorados. Esta estrategia usa un punto intermedio entre un consenso estricto entre todos los árboles obtenidos y la selección de un árbol en particular, para equilibrar la robustez de la hipótesis obtenida con su poder informativo. Esto sigue la propuesta metodológica de Mirande (2008, 2009, 2010) y Mirande et al. (2011, 2013), que evalúa la robustez (sensu Giribet, 2003) de cada una de las hipótesis obtenidas, a través de un esquema similar al análisis de sensibilidad (Wheeler et al., 1995; Whiting et al., 1997). En términos generales, la idea de esta propuesta es que el árbol cuyos nodos sean más estables en conjunto, tendrá una topología similar al resto de los árboles-fuente. Para llevar esto a cabo, Mirande (2009) usó la comparación entre árboles a partir de dos medidas topológicas: 1) el coeficiente de Similitud (Farris, 1989), con un valor máximo de $1=$ mayor similitud, que mide la semejanza entre dos árboles con base en los índices de retención de la matriz de representación de cada uno en el otro; y 2) la distancia de SPR, que calcula el número mínimo de movimientos de SPR necesarios para transformar un árbol en otro que sirva de referencia comparativa, y muestra que los árboles más parecidos requerirán menor número 
de movimientos de SPR para volverse idénticos (el valor mínimo posible es 0). Los cálculos de los coeficientes de similitud (“tcomp”) y las distancias SPR (“sprdiff”) están implementados en el script "aab" usado durante las búsquedas. Si bien, estas medidas comparan aspectos diferentes de los árboles-fuente, es evidente que una convergencia entre ambas proporcionaría una buena medida sobre la similitud entre los árboles comparados (Mirande, 2009). Puede darse la situación en la que estas medidas topológicas muestren que un solo árbol es globalmente más estable con respecto a los demás y sería una posibilidad consecuente usar este resultado para seleccionar la hipótesis final. Sin embargo, Mirande $(2008,2009,2010)$ discutió que esta idea no es acertada porque tiene un elevado grado de subjetividad; por eso propuso que estas medidas sean usadas parcialmente como un metacriterio para identificar el o los árboles de mayor estabilidad global entre los árboles-fuente y así establecer el intervalo (que incluya a ese árbol) más amplio de hipótesis cuyo consenso estricto sea lo más resuelto posible. La delimitación de este intervalo de árboles puede ser algo subjetiva, pero es la mejor estrategia para obtener un equilibrio entre robustez y poder informativo de la hipótesis en cuestión (Mirande, 2009). De acuerdo a esto, la hipótesis final de este estudio (pesos implicados) es el consenso estricto de los árboles-fuente obtenidos en ese intervalo restringido de parámetros. Por último y para propósitos comparativos, la distancia SPR (100 replicaciones y 10 niveles de estratificación) fue calculada entre la hipótesis final bajo pesos implicados y el consenso estricto bajo pesos iguales.

Medidas de estabilidad. Para cada nodo de la hipótesis final (pesos implicados) se calculó una medida de estabilidad: los valores de GC (grupos presentes/contradichos o diferencias de frecuencias por grupos) que están implementados en TNT (Goloboff et al., 2003) a través de la opción "do group frecuencies" o el comando "majority". Se utilizó como árboles-fuente los consensos estrictos de cada una de las hipótesis obtenidas bajo los diferentes parámetros analizados. El valor de GC se calcula para cada nodo como el número de árboles en que este nodo está presente, menos el número de árboles en que está presente la hipótesis alternativa más frecuente. Un valor positivo de GC significa que un nodo está presente más veces de lo que está contradicho por su hipótesis alternativa más frecuente, mientras que un valor negativo significa que los nodos están presentes menos veces en los árboles-fuente que su hipótesis alternativa más frecuente (Goloboff et al., 2003). El valor de GC es usado para calcular el apoyo de ramas, a partir de los árbolesfuente obtenidos durante los análisis de matrices reducidas bajo un conjunto de parámetros determinado (Goloboff et al., 2003). En este estudio, se usó esta medida como un 
indicador de estabilidad en vez de un indicador de apoyo de nodos para este caso (más detalles en Mirande, 2009).

Medidas de apoyo. El apoyo de un nodo bajo ciertas condiciones de análisis probablemente está correlacionado con su estabilidad, pero esto no ocurre siempre (Giribet, 2003). Por esta razón, se realizaron mediciones del apoyo de ramas para ciertas condiciones de análisis que siguen las especificaciones metodológicas llevadas a cabo por Mirande (2008, 2009). Las estimaciones de apoyo de ramas fueron realizadas con el decimo valor K bajo pesos implicados. Para evaluar el apoyo en los análisis bajo pesos implicados se utilizo remuestreo simétrico ("symmetric resampling") expresado como frecuencias absolutas de grupos y valores de GC (Goloboff et al., 2003) a partir de 200 matrices replicadas a través de búsquedas sectoriales, fusión de árboles, parsimonia ratchet y deriva de árboles hasta alcanzar dos veces el o los árboles óptimos. En este caso los valores de GC miden apoyo y no estabilidad como se mencionó arriba.

Índices de consistencia y retención. Para cada carácter se calcularon los índices de consistencia (ci) (Kluge \& Farris, 1969) y retención (ri) (Farris, 1989). Los cálculos de los índices globales (CI o RI) para la matriz de datos no son comparables entre diferentes análisis, porque están influenciados por el tamaño y complejidad de la matriz (Mirande, 2008). A medida que la matriz de datos es mayor y/o más compleja, el valor de CI tiende a disminuir y el de RI tiende a aumentar. Consecuentemente, el cálculo de estos índices para la matriz completa carece de sentido práctico, por la que su implementación no ha sido continuada en TNT. Sin embargo, los valores de estos índices para cada carácter pueden ser útiles para comparar su congruencia con los demás caracteres (los índices se presentan en el apéndice I).

\section{Revisión taxonómica}

Las medidas morfométricas y los conteos siguieron el esquema general de Fink \& Weitzman (1974), con las adiciones de Menezes \& Weitzman (2009) y Vanegas-Ríos et al. (2013). Aunque se observó que el radio más proximal (o el último) de las aleta pectoral o aleta pélvica es con frecuencia simple, en ambos casos fue contado como ramificado acorde a Böhlke (1958). Se tomaron veintiséis medidas: longitud estándar, altura del cuerpo al origen de la aleta dorsal, distancia hocico-origen aleta dorsal, distancia hocicoorigen aleta pectoral, distancia hocico-origen aleta pélvica, distancia hocico-origen aleta anal, distancia aleta dorsal-aleta pectoral, distancia aleta dorsal-aleta adiposa, distancia aleta dorsal-complejo hipural, distancia ojo-origen aleta dorsal (parte del extremo más 
posterior del ojo), distancia aleta pectoral-aleta pélvica, distancia aleta pélvica-aleta anal, longitud aleta dorsal, longitud base aleta dorsal, longitud aleta pectoral, longitud aleta pélvica, longitud aleta anal, longitud base aleta anal, altura del pedúnculo caudal, longitud del pedúnculo caudal (desde la porción posterior de la base del radio más posterior de la aleta anal hasta un punto medio entre el complejo hipural y la base de los radios caudales), longitud cabeza, longitud hocico, diámetro del ojo (distancia horizontal entre sus extremos anterior y posterior), longitud postorbital de la cabeza, ancho mínimo interorbital y longitud mandíbula superior (desde el extremo posterior de la maxila hasta el hocico). Las distancias entre aletas fueron tomadas desde y hacia el respectivo origen de cada una. La longitud base aleta dorsal o anal fueron tomadas desde el origen hasta el extremo posterior de la base de el radio más posterior. La longitud cabeza y postorbital fueron tomadas hasta la porción ósea más posterior del opérculo. Las longitudes de las aletas fueron tomadas desde su origen hasta el extremo distal de su primer radio (o el simple lateral). Las medidas fueron tomadas punto a punto con un calibrador digital bajo estereomicroscopio y se expresan como porcentajes de la longitudes estándar (LE) y de la cabeza (LC).

En los conteos se tomó: el número de radios en la aletas dorsal, anal (se incluyó la cantidad de pterigióforos proximales en los ejemplares d\&t y radiografiados), pectoral, pélvica y caudal; el número de dientes premaxilares, maxilares y dentarios; el número de escamas con poros en la línea lateral, escamas predorsales, hileras de escamas entre la aleta dorsal y la línea lateral, hileras de escamas entre la línea lateral y la aleta anal, hileras de escamas entre la línea lateral y la aleta pélvica, escamas circumpedunculares, escamas dispuestas a lo largo de la base de la aleta anal; el número de vértebras; el número de rastrillos branquiales del primer arco branquial; y el número de filamentos branquiales que forman la glándula branquial de los machos adultos (si corresponde). Se excluyeron de los conteos de escamas entre la aleta dorsal y la línea lateral las escamas de la hilera media dorsal y la escama pequeña ventral que a veces se ubica ventral a la inserción de la aleta dorsal o dorsal a la hilera transversa de escamas. En los conteos primero se da la frecuencia de cada carácter entre paréntesis, con el valor del holotipo (o tipo nomenclatural que lo reemplaza) indicado por un asterisco. Solo cuando una especie incluye más de un tipo en su material examinado y los conteos de estos difieren entre sí, los valores respectivos de tales ejemplares se indican en el orden descendiente de la lista de sinonimias por uno, dos o tres asteriscos respectivamente y separados por una barra según corresponda (los valores de los tipos llevan un solo asterisco cuando son iguales entre sí). El número total de vértebras fue determinado en ejemplares diafanizados y 
teñidos $(\mathrm{d} \& \mathrm{t})$ o radiografiados $(\mathrm{R})$ e incluye el primer centro pleural más el primer centro ural (PU1+U1) como un elemento y las cuatro vértebras del aparato de Weber. También se describieron aspectos usados por Vanegas-Ríos et al. (2013) para la morfología externa, coloración en alcohol y/o en vida, osteológicos y diferencias morfológicas entre machos y hembras. Las diagnosis de cada especie fueron complementadas con autapomorfías obtenidas en el análisis filogenético; para el caso de género, este fue redefinido con base en las sinapomorfías obtenidas.

El material examinado de cada especie del género Gephyrocharax fue organizado de la siguiente manera: país, colección científica y número de catálogo, número de ejemplares, talla de los ejemplares en longitud estándar (LE), datos de localidad en orden descendiente por cuencas hidrográficas o división política, coordenadas geográficas y altitud en $\mathrm{m}$ sobre el nivel del mar (s.n.m.), fecha y colectores. Para facilitar el ordenamiento y evitar la repetición de datos en el material examinado, el país y/o departamento fueron usados como criterios de agrupamiento. Cuando las coordenadas geográficas y/o altitud no acompañaban la información original del lote, estas fueron estimadas con base en los datos de localidad disponibles; para indicar tales casos se usó el término "aproximadamente". En este proceso, sobre todo se utilizaron los sistemas de posicionamiento geográfico de cartografía digital de Google Earth 6.1.7601.1 (Windows), del Instituto Geográfico Agustín Codazzi en Colombia (http://www.igac.gov.co/geoportal), el gacetero de localidades del STRI, Panamá (http://mapserver.stri.si.edu/gazeteer/search/) y mapas o atlas geográficos de cada cuenca hidrográfica. A partir de los datos georeferenciados de cada una de las especies de Gephyrocharax, se construyeron mapas de distribución geográfica con el programa QGIS Valmiera 2.2.0. Los ejemplares diafanizados y teñidos (d\&t) y/o radiografiados $(\mathrm{R})$ aparecen, cuando corresponde, antes del dato de localidad. Información complementaria sobre la localidad de cada lote, ya sea un holotipo (o ejemplar afín por nomenclatura) y/o un paratipo, fue agregada entre corchetes. Lotes de ejemplares que aparecen marcados con un asterisco $\left(^{*}\right)$ indican que sus datos morfométricos y merísticos fueron tomados a partir de imágenes y/o radiografías digitales de alta resolución. Se utilizó el programa tpsDig 2.17 (Rohlf, 2005, Windows) para la toma de los datos morfométricos de estos lotes; cada medida fue tomada tres veces en cada ejemplar (su imagen digitalizada) y se le asignó el valor promedio correspondiente.

Se usaron los esqueletos branquiales de tres machos maduros de $G$. intermedius (36,0 mm LE, STRI 1200; 38,1 mm LE, ANSP 104434; y 33,3 mm LE, ANSP 99856) 
para procesar histológicamente y reconfirmar observaciones preliminares sobre la glándula branquial. Las muestras procesadas ya estaban fijadas en formaldehido al $10 \%$ y conservadas en alcohol etílico al $70 \%$. Se extrajo el arco branquial de cada macho y se utilizó solo la mitad izquierda para efectuar los cortes histológicos. Cada arco fue descalcificado con ácido fórmico al $10 \%$ durante una semana, incluido en paraplast y seccionado en sentido paralelo al ceratohial con cortes cada 6 a 7 micrómetros. Los preparados fueron teñidos con hematoxilina-eosina para su observación en el microscopio óptico.

Se recolectó material del género Gephyrocharax en diferentes drenajes fluyendo en aguas de cuenca alta del río Cauca, de la cuenca baja del río San Juan y de la cuenca media-baja del río San Jorge. Las artes de pesca utilizadas fueron las convencionales para captura de peces de tallas pequeñas y medianas, con redes de malla fina (entre $5 \mathrm{~mm}$ a 1 $\mathrm{cm}$ ), nasa acuática, y equipo de pesca eléctrica (en todos los casos el trabajo de pesca se hizo entre 3 a 4 personas). El equipo de pesca eléctrica es de fabricación personal (Armando Ortega-Lara, comun. pers.) y tiene una corriente eléctrica entre los 150-600 voltios, proveniente de un generador de 0,5 a $1,5 \mathrm{kws}$ y regulada por un transformador de 2 a 6 amperios. Tal equipo consta de dos polos, uno positivo o ánodo y otro negativo o cátodo; el ánodo fue conectado mediante un cable a una red tipo nasa, la cual fue introducida al agua al iniciar las capturas, mientras el cátodo fue conectado a un cable corto, cuyo extremo estaba conectado a una parrilla metálica que se introdujo al agua. Al aplicar la electricidad, los peces situados en un diámetro de 1-5 m (dependiendo de la calidad del agua y voltaje aplicado) son adormecidos y atraídos a la nasa introducida al agua. El material capturado fue fijado en una solución de formol al $10 \%$ y preservado en una solución de alcohol etílico al $70 \%$. Se tomaron tejidos de aletas y se preservados en alcohol etílico al 95\%, para futuros análisis con ADN. Los individuos y tejidos preservados fueron depositados en la colección de peces del IMCN y/o CZUT-IC.

Se llevaron a cabo diferentes métodos y/o pruebas estadísticas bivariadas y multivariadas en los programas estadísticos PAST 2.17 (Hammer et al., 2001) y SigmaPlot 10.10 (2006, Systat Software, Inc.) bajo Windows. Se usó el análisis de componentes principales $(\mathrm{ACP})$ para testear hipótesis de sinonimias y/o variación poblacional a partir de los datos morfométricos. Es conocido que la primera componente (CP1) tiende a estar influenciada por el efecto del "tamaño" (Klingenberg, 1996; Strauss, 2010), el cual sesga la interpretación de las demás componentes y distorsiona la discriminación de los grupos en cuestión aportada por la “forma”. En resultados preliminares del ACP, se encontró para 
todos los casos (véase comentarios G. chocoensis, G. intermedius, G. major y G. valencia) que las medidas analizadas estaban altamente correlacionadas con la CP1 ( $\mathrm{r} \geq 0,8)$, la cual explicaba más del $80 \%$ de la varianza total. Esto sugirió un posible efecto de un factor latente ("tamaño") en la CP1. Para los objetivos aquí buscados con el ACP este factor latente no es informativo. Por estas razones, se utilizó una corrección del "tamaño" sobre los ACP que permitiese maximizar la discriminación por "forma". La corrección aplicada fue el ACP cizallado ("sheared") que fue descripto detalladamente por Humphries et al. (1981). La idea central de este ajuste es calcular una combinación lineal de variables que cuantifican diferencias por forma independientes del tamaño entre grupos. Esta corrección utiliza la combinación lineal $\mathrm{H}=\mathrm{PCII}-\alpha\left(\beta_{1} \mathrm{PCI}+\beta_{2} \mathrm{PCII}\right)$, donde $\mathrm{H}$ corresponde a la segunda componente principal (CP2) cizallada o "sheared", pero puede generalizarse a otras componentes de interés. Para calcular H se siguió paso a paso el método presentado por Humphries et al. (1981: 300); las regresiones implícitas usadas en cada paso fueron ejecutadas por mínimos cuadrados. Basado en los esquemas de Humphries et al. (1981), los gráficos del ACP utilizados son dados en función de la componente $\mathrm{S}$ que equivale a la primera componente (CP1) obtenida a partir de la matriz de covarianza de los datos ajustados a media cero para cada grupo particular. Para realizar la corrección de Humphries et al. (1981: 300) los datos morfométricos fueron transformados a logaritmo (base 10, disminuye el efecto alométrico y tiende a normalizar los datos) y cada ACP fue ejecutado a partir de la matriz de covarianza. La estadística descriptiva de cada medida (valores mínimos y máximos, media y desviación estándar) fue el principal criterio usado para considerar una medida como informativa en una diagnosis de especie o para considerar superposición de datos entre hipótesis de sinonimias o grupos poblacionales (independientemente de que el ACP aporte un resultado coincidente). Aquellas medidas con tendencias sexualmente dimórficas (e. g. superposiciones mínimas de los valores mínimos y máximos) fueron descriptas en mayor detalle de acuerdo con el comportamiento de los estadísticos descriptivos por sexo de las especies de Gephyrocharax y los hallazgos de Vanegas-Ríos et al. (2013). Se construyeron varios gráficos de regresión en función de la variable del tamaño correspondiente para detectar un patrón generalizado para el género, en vez de gráficos individuales para cada una de las especies. Esto se hizo porque las tendencias morfométricas asociadas al dimorfismo sexual tuvieron escasa importancia discriminatoria en las comparaciones efectuadas entre las especies de Gephyrocharax. Además, se elaboraron gráficos de cajas de Tukey 
comparativos entre especies para describir tendencias informativas en los conteos más útiles en las diagnosis o con menor superposición entre especies. 


\section{RESULTADOS}

\section{Análisis filogenético}

\section{Descripción de los caracteres}

El listado de caracteres analizado está compuesto por 542 caracteres principalmente morfológicos (únicamente cinco caracteres cromosómicos), los cuales fueron representados en una matriz de datos (Tabla 1). Se listan los estudios taxonómicos y filogenéticos utilizados con sus abreviaturas correspondientes, para que los caracteres se puedan relacionar al estudio original consultado (separado por dos puntos después de la respectiva abreviatura): EI12 (Eigenmann, 1912); WF85 (Weitzman \& Fink, 1985); WM98 (Weitzman \& Menezes, 1998); VH01 (Vari \& Harold, 2001); MW03 (Malabarba \& Weitzman, 2003); FE07 (Ferreira, 2007); BE08 (Bertaco, 2008); MW09 (Menezes \& Weitzman, 2009); MI10 (Mirande, 2010); CA11 (Carvalho, 2011); FE11 (Ferreira et al., 2011); ME11 (Mirande et al., 2011); MT12 (Mattox \& Toledo-Piza, 2012); ME13 (Mirande et al., 2013). El término "modificado" (= m), que precede las abreviaturas mencionadas, significa que el carácter listado difiere de su descripción original o que su serie de transformación fue reorganizada. Todos los caracteres usados por primera vez en este estudio o no citados en los estudios relacionados, se indican con una letra " $n$ " entre paréntesis (= nuevos). Se hicieron comentarios descriptivos o informativos en un párrafo debajo de los correspondientes caracteres, cuando fue necesario, con el propósito de mejorar el contexto o aclarar algún dato importante para la codificación. Los caracteres de Mirande (2010) y Mirande et al. $(2011,2013)$ ya fueron explicados, por lo que solo se presentan comentarios donde se señala alguna modificación o aspecto relevante para este estudio. Se incluyen ilustraciones de los estados de caracteres informativos, novedosos o complejos, debido a que una parte de los caracteres aquí presentados fueron ampliamente ilustrados por Weitzman \& Fink (1985), Weitzman \& Menezes (1998), Menezes \& Weitzman (2009), Mirande (2010) y Mirande et al. (2011, 2013). Todos los caracteres fueron ordenados anatómicamente, excepto los caracteres sexuales dimórficos en los machos adultos, que por su gran cantidad (> 100) y relevancia para este estudio, fueron ordenados en un apartado separado para mejorar su comprensión.

\section{Neurocráneo}

- Barra epifisaria:

1. Expansión ósea posterior a la barra epifisaria (MI10: 1): (0) ausente; (1) presente.

- Basioccipital 
2. Crestas ventrales longitudinales del basioccipital (MI10: 2): no alcanzan en el borde posterior del basioccipital; (1) alcanzan el borde posterior del cráneo.

3. Proyección ventral de las cápsulas lagenares (MI10: 3): (0) poco desarrolladas, no proyectadas ventralmente a la línea de articulación entre el basioccipital y parasfenoides; (1) desarrolladas ventralmente a esta articulación.

- Epiótico y fosas relacionadas:

4. Puente epioccipital sobre la fosa postemporal (MI10: 4): (0) ausente; (1) presente.

5. Forma del puente epioccipital (MI10: 5): (0) cilíndrico o expandido verticalmente; (1) muy deprimido en su región media.

6. Articulación anterior del puente epioccipital (MI10: 6): (0) con el parietal y el pterótico; (1) sólo con el parietal.

7. Espina del epioccipital dirigida posteriormente (MI10: 7): (0) presente; (1) ausente.

8. Abertura ventromedial de la fosa postemporal (MI10: 8): (0) ausente; (1) presente.

9. Ubicación de la abertura ventromedial de la fosa postemporal (MI10: 9): (0) entre el exoccipital y el epioccipital; (1) ubicada enteramente en el epioccipital.

- Esfenótico:

10. Longitud de la espina esfenótica (MI10: 10): (0) no extendida ventralmente sobre la articulación entre el esfenótico y el hiomadibular; (1) extendida ventralmente sobre la articulación entre el esfenótico y el hiomandibular.

11. Posición de la espina esfenótica en relación al hiomandibular (MI10: 11): (0) alineada con el borde anterior del hiomandibular; (1) desplazada anteriormente con respecto al borde anterior del hiomandibular.

12. Posición de la espina esfenótica en relación a la órbita (MI10: 12): (0) bordea posteriormente la órbita y está alineada al borde anterior del cuarto y quinto infraorbitales; (1) claramente posterior al borde de la órbita.

13. Forma del extremo distal de la espina esfenótica (ME11: 366): (0) fina o poco expandida; (1) con una escotadura, limitada anterior y posterodorsalmente por el levator arcus palatini.

14. Fosa temporal (MI10: 13): (0) bien desarrollada. (1) ausente o reducida.

- Etmoides lateral:

15. Forma del proceso anterior del etmoides lateral (MI10: 14): (0) ancho en vista ventral, contacta con la zona proximal del vómer en toda su longitud; (1) fino, separado del vómer. 
16. Abertura lateral entre las láminas ventrales divergentes del mesetmoides y el proceso anterior del etmoides lateral (MI10: 15): (0) amplia; (1) estrecha, oval y en parte ocluida por las láminas divergentes del mesetmoides y el proceso anterior del etmoides lateral.

17. Borde dorsal de los etmoides laterales (MI10: 16): (0) alineados; (1) dirigidos en sentido oblicuo en vista dorsal, convergen en un ángulo orientado anteriormente.

18. Articulación entre la zona medial del etmoides lateral y el frontal o el mesetmoides (MI10: 17): (0) ausente, el etmoides lateral articula principalmente con las láminas ventrales divergentes del mesetmoides; (1) extensa articulación de todo el borde dorsal del etmoides lateral.

- Intercalar y Exoccipital:

19. Intercalar (n): (0) presente; (1) ausente.

La pérdida del intercalar es frecuente entre las especies con procesos de miniaturización (Weitzman \& Vari, 1988). Algunas de estas pérdidas son denominadas como caracteres "reductivos", los cuales no fueron incluidos formalmente en la matriz de Mirande (2010) y por eso son codificados en el presente estudio. Hay cierta correlación entre la pérdida del intercalar con la pérdida o reducción del proceso anteroventral del postemporal, pero esta correlación no es exacta, por lo que ambos caracteres fueron codificados separadamente (véase carácter 298).

20. Fosa subtemporal (MI10: 18): (0) extendida medialmente a la región media del exoccipital; (1) restringida al pterótico y proótico.

Como el intercalar delimita en parte la fosa subtemporal, aquellas especies sin este hueso fueron codificadas inaplicables para este carácter.

21. Proceso ascendente en el ángulo posterodorsal del exoccipital dirigido hacia el complejo neural del aparato de Weber (MI10: 19): (0) ausente; (1) presente.

- Frontal:

22. Extensión anterior del frontal (MI10: 20): (0) alcanza el borde posterior de las narinas; (1) extendida entre los nasales y alcanza la mitad de la longitud de las narinas.

23. Fontanela anterior o frontal (MI10: 22): (0) presente; (1) totalmente cerrada por los frontales.

24. Zona anterior de la fontanela anterior en ejemplares adultos (m, VH01: 37; FE07: 24; BE08: 31; MI10: 21): (0) delimitada por el mesetmoides; (1) delimitada por el contacto anterior entre los frontales. 
En estos dos caracteres (23 y 24), se observó que la fontanela anterior presenta un grado de desarrollo intermedio en algunas especies. Sin embargo, esta variación no fue considerada en otro estado de la serie de transformación u otro carácter por su gran complejidad intraespecífica. Casos con fontanela anterior reducida o muy pequeña fueron codificados como polimórficos. Además, algunas especies de Gephyrocharax (e. g. G. torresi) tienen esta fontanela asociada al tamaño, es decir, está presente en juveniles y ausente en ejemplares con tallas mayores. Por eso se codificó en los caracteres los ejemplares adultos de mayor talla para evitar en lo posible el sesgo ontogenético.

25. Tamaño relativo de las fontanelas frontal y parietal (MI10: 23): (0) la fontanela frontal tiene hasta $2 / 3$ de la longitud de la fontanela parietal; (1) la fontanela frontal tiene $3 / 4 \mathrm{O}$ más de la longitud de la fontanela parietal.

26. Fosa del dilatator operculi (MI10: 24): (0) ausente; (1) presente.

- Mesetmoides:

27. Extremo anterior del mesetmoides (MI10: 25): (0) trifurcado, con procesos insertados en depresiones sobre las premaxilas; (1) no trifurcado, con una espina anterior y procesos articulares reducidos o ausentes.

28. Proyección ventral de la espina del mesetmoides en forma de tabique vertical entre las premaxilas (MI10: 26): (0) ausente; (1) presente.

29. Forma de la espina del mesetmoides (MI10: 27): (0) larga, extendida entre las premaxilas; (1) relativamente corta, con las premaxilas articulando entre sí anterior al mesetmoides.

30. Región posterior de la espina del mesetmoides (MI10: 28): (0) relativamente fina; (1) tan ancha como los procesos laterales del mesetmoides.

31. Procesos laterales del mesetmoides (MI10: 29): (0) presentes; (1) ausentes.

32. Láminas ventrales divergentes del mesetmoides (MI10: 30): (0) ausentes; (1) presentes.

33. Confluencia de las láminas ventrales divergentes del mesetmoides con el septo nasal del mesetmoides (MI10: 31): (0) ausente o confluyen cerca de la articulación terminal del septo nasal del mesetmoides; (1) confluyen en la terminación posterior del septo nasal.

34. Septo nasal del mesetmoides (MI10: 32): (0) con una lámina longitudinal. (1) con dos láminas paralelas aparentemente formadas, en parte por las láminas ventrales divergentes. 
- Nasal:

35. Hueso nasal (MI10: 33): (0) presente; (1) ausente.

36. Láminas óseas que bordean el canal sensorial del nasal (MI10: 34): (0) ausentes o más finas que la región tubular; (1) tan anchas como la región tubular.

37. Extensión anterior del nasal (m, FE07: 18; BE08: 29; FE11: 96): (0) no alcanza el proceso lateral del mesetmoides; (1) alcanza el proceso lateral del mesetmoides.

38. Extensión anterior del nasal (m, FE07: 18; FE11: 96): (0) no cubre casi todo el proceso lateral del mesetmoides; (1) cubre casi todo el proceso lateral del mesetmoides.

39. Extensión anterior del nasal (m, FE07: 18; FE11: 96): (0) no se extiende anterior al proceso lateral del mesetmoides; (1) se extiende anteriormente, más allá del proceso lateral del mesetmoides en una distancia mayor a su ancho.

Ferreira (2007) y Ferreira et al. (2011) usaron estos últimos tres caracteres en una serie de transformación multiestado, la cual fue convertida en una serie de transformación de dos estados en los caracteres 37 al 39 que describen la longitud relativa del nasal.

40. Longitud del nasal (n, Fig. 1: estado 1): (0) mayor que la del antorbital; (1) tan larga o más corta que la altura del antorbital.

41. Nasal en vista dorsal (n): (0) recto a lo largo de toda su longitud o apenas cóncavo, arqueado en un ángulo mayor a $135^{\circ}$; (1) en forma de media luna, muy cóncavo, arqueado en un ángulo igual o menor a $135^{\circ}$.

- Orbitosfenoides:

42. Articulación sincondral entre el etmoides lateral y el borde anterodorsal del orbitosfenoides (MI10: 35): (0) presente; (1) ausente, orbitosfenoides distante del etmoides lateral.

43. Cobertura lateral ósea del nervio olfatorio (MI10: 36): (0) ausente; (1) cubierto por una expansión posterior del etmoides lateral; (2) cubierto por una proyección tubular del orbitosfenoides; (3) cubierto lateral y ventralmente por el orbitosfenoides y etmoides lateral, los cuales no forman un canal.

44. Forma del orbitosfenoides (MI10: 37): (0) fino, relativamente pequeño y alejado del parasfenoides; (1) grande, casi alcanza el parasfenoides ventralmente.

45. Distancia entre el borde posterodorsal del cartílago etmoidal y el etmoides lateral (MI10: 38): (0) contacta o casi contacta el etmoides lateral; (1) alejado del etmoides lateral.

46. Abertura entre el orbitosfenoides y pterosfenoides (MI10: 39): (0) presente, redondeada u ovoide; usualmente bordeada por el frontal dorsalmente; (1) ausente. 


\section{- Parasfenoides:}

47. Proyecciones pareadas anteriores del parasfenoides (MI10: 40): (0) ausentes; (1) presentes.

- Parietal:

48. Fontanela posterior o parietal (MI10: 41): (0) presente en adultos; (1) ausente o reducida en adultos.

En el carácter 48 (estado 1), Mirande (2010) codificó la pérdida de la fontanela posterior, causada por el contacto total entre los frontales y los parietales en el estado 1. En este estado, se incluyó un grupo de especies, no analizado por Mirande (2010), donde la fontanela posterior está reducida por el contacto de los frontales en tres cuartos o más de su longitud. Mirande (2010) reportó una asociación del desarrollo de esta fontanela con el crecimiento y por tal motivo en este carácter siempre fueron tomados en cuenta los ejemplares adultos de mayor talla disponibles.

49. Longitud del borde lateral del hueso parietal (n): (0) tan larga o más corta que la longitud de su borde medial; (1) más larga que la longitud de su borde medial.

Los frontales por lo general cubren posteriormente a la región anterior de los parietales. El borde medial del parietal por lo general se extiende entre los frontales y el supraoccipital, mientras que el borde lateral se extiende principalmente entre el pterótico y el supraoccipital. En este carácter (Fig. 2), se consideraron los bordes limítrofes del parietal para asignar los estados definidos y no la línea yuxtapuesta con los frontales.

\section{- Proótico:}

50. Foramen trigéminofacialis, en la cara anterior del proótico (MI10: 42): (0) amplio, bordeado dorsalmente por el esfenótico; (1) estrecho, como una hendidura limitada casi totalmente por el proótico y pterosfenoides.

\section{- Pterosfenoides:}

51. Foramen en el centro del pterosfenoides (MI10: 43): (0) ausente; (1) presente, muy desarrollado.

52. Pequeño foramen cerca del borde posterior del pterosfenoides (MI10: 44): (0) ausente, o no atravesado por nervios; (1) presente, atravesado por una rama del nervio supraorbital.

- Pterótico: 
53. Proceso dorsal del pterótico donde ancla el tendón de la musculatura epaxialis (MI10: 45): (0) ausente; (1) presente, proyectado dorsalmente desde el tubo al canal semicircular.

54. Longitud relativa de la espina del pterótico (MI10: 46): (0) extendida posteriormente más allá de la zona de anclaje del ligamento procedente del hiomandibular; (1) restringida a la zona de anclaje del ligamento hiomandibular.

- Rinosfenoides:

55. Rinosfenoides (MI10: 47): (0) ausente; (1) presente.

56. Expansión dorsal del rinosfenoides (MI10: 48): (0) ausente; (1) presente, esta forma un tabique óseo entre los nervios olfatorios.

57. Extensión posterior del cartílago del rinosfenoides (MI10: 49): (0) extendido hasta cerca de la longitud media horizontal del orbitosfenoides; (1) extendido hasta la línea vertical que pasa por la articulación entre el orbitosfenoides y el pterosfenoides.

58. Borde ventral del rinosfenoides (MI10: 50): (0) alejado del parasfenoides; (1) casi contacta al parasfenoides.

\section{- Supraoccipital:}

59. Borde anterior del supraoccipital (MI10: 51): (0) ubicado totalmente por detrás de la línea vertical que pasa por el borde posterior de la órbita; (1) ubicado por delante de la línea vertical que pasa por el borde posterior de la órbita.

60. Longitud de la espina supraoccipital (MI10: 52): (0) extendida dorsalmente sobre todo el complejo neural del aparato de Weber; (1) extendida dorsalmente sobre la mitad de la longitud del complejo neural.

61. Longitud de la espina supraoccipital (MI10: 53): (0) extendida posteriormente hasta, al menos, la longitud media del complejo neural del aparato de Weber; (1) extendida solo hasta el límite anterior del complejo neural.

62. Lámina posterior del supraoccipital, debajo de la espina (n, Fig. 1a: estado 1): (0) sin una fenestra; (1) con una fenestra.

Las especies con esta lámina reducida o incompleta fueron codificadas inaplicables (Fig. 1b). Se codificó polimórfico o intermedio a aquellos casos en los que la lámina se encontró perforada por uno o varios forámenes.

- Vómer:

63. Procesos dorsolaterales del vómer (MI10: 54): (0) ausentes; (1) presentes.

\section{Región orbital}

- Antorbital: 
64. Antorbital (MI10: 55): (0) presente; (1) ausente o fusionado al primer infraorbital.

65. Posición del antorbital en relación al etmoides lateral en vista lateral (MI10: 56): (0) el antorbital está completamente anterior al etmoides lateral; (1) el antorbital está superpuesto con el etmoides lateral.

66. Posición relativa del borde anterior del antorbital y el primer infraorbital (MI10: 57): (0) borde anterior del antorbital alineado o anterior al primer infraorbital; (1) borde anterior del antorbital posterior al primer infraorbital.

- Infraorbitales:

67. Lámina ósea que bordea el canal laterosensorial del primer infraorbital (MI10: 58): (0) presente; (1) ausente.

68. Longitud de la expansión lateral del primer infraorbital sobre la maxila (MI10: 59): (0) cubre menos de la mitad de la longitud de la maxila; (1) cubre más de la mitad de la maxila.

69. Solapamiento lateral del primer infraorbital por el borde anterior del segundo infraorbital (MI10: 60): (0) ausente; (1) presente.

70. Solapamiento del segundo infraorbital en la maxila (MI10: 61): (0) ausente; (1) presente.

71. Articulación entre el primer y segundo infraorbitales (MI10: 62): (0) vertical; (1) inclinada en sentido anteroventral; (2) inclinada en sentido posteroventral.

72. Zona anterior del tercer infraorbital (MI10: 63): (0) no muy expandida respecto a la zona posterior del segundo infraorbital; (1) más expandida ventralmente que la zona posterior del segundo infraorbital.

73. Desarrollo ventral del tercer infraorbital (MI10: 64): (0) alcanza la rama horizontal del preopérculo; (1) no alcanza la rama horizontal del preopérculo.

74. Extensión posterior del tercer infraorbital (MI10: 65): (0) cubre todo el ángulo del preopérculo; (1) relativamente reducida, el cuarto infraorbital cubre en parte el ángulo del preopérculo.

75. Cuarto infraorbital (MI10: 66): (0) presente, desarrollado; (1) ausente o reducido, limitado posteriormente por el tercer y quinto infraorbitales.

76. Forma del cuarto infraorbital (MI10: 67): (0) más desarrollado longitudinalmente que dorsoventralmente o aproximadamente cuadrado; (1) más desarrollado dorsoventralmente que longitudinalmente.

77. Expansión posterior dorsoventral del cuarto infraorbital (MI10: 68): (0) ausente; (1) presente. 
78. Cobertura de la fosa del dilatator operculi por parte del sexto infraorbital (MI10: 69): (0) casi total, cubre al menos todo el borde ventral de la fosa; (1) deja un área conspicua y desnuda en la zona anterior de la fosa del dilatator.

- Supraorbital:

79. Supraorbital (MI10: 70): (0) presente; (1) ausente.

80. Contacto entre el supraorbital y el sexto infraorbital (MI10: 71): (0) ausente; (1) presente.

- Esqueleto esclerótico:

81. Huesos escleróticos (MI10: 350): (0) un hueso abierto anteroventralmente; (1) dos huesos separados por cartílagos.

El anillo esclerótico se encontró completamente óseo en Nematobrycon lacortei y se codificó con el estado 0 en el mismo sentido que Coptobrycon bilineatus (Ellis) según Mirande (2010). En Xenurobrycon macropus, se encontró que toda el área que rodea el ojo es cartilaginosa y se codifico inaplicable para esta especie.

\section{Sistema laterosensorial de la línea lateral}

- Rama infraorbitaria:

82. Tubo laterosensorial en el antorbital (MI10: 72). (0) ausente. (1) presente.

83. Tubo laterosensorial del primer infraorbital (MI10: 73): (0) sobresale dorsalmente de la lámina del hueso; (1) ausente o no sobresale dorsalmente.

84. Ramificación en el tubo del sistema laterosensorial en el cuarto o quinto infraorbitales (MI10: 74) (0) ausente; (1) presente.

85. Dirección de la rama posterior del tubo laterosensorial del cuarto y quinto infraorbitales (MI10: 75): (0) hacia un poro en el preopérculo cerca del cóndilo del hiomandibular; (1) hacia un poro conspicuamente ventral en relación al cóndilo hiomandibular.

86. Tubo laterosensorial del sexto infraorbital (MI10: 76): (0) no ramificado; (1) ramificado.

87. Posición de la abertura del neurocráneo que comunica con el tubo laterosensorial del sexto infraorbital (MI10: 77): (0) entre el frontal y el pterótico; (1) en el frontal.

88. Posición de la abertura del neurocráneo que comunica con el tubo laterosensorial del sexto infraorbital (MI10: 78): (0) lateral o ligeramente anterior al tubo del canal semicircular vertical del esfenótico; (1) muy anterior al tubo del canal semicircular vertical del esfenótico. 
89. Longitud del tubo laterosensorial del dentario (MI10: 79): (0) atraviesa casi todo el dentario; (1) reducido o ausente.

90. Poros del sistema laterosensorial de la mandíbula inferior (MI10: 80): (0) seis o menos; (1) siete o más.

91. Superficie lateral del tubo vertical del preopérculo (MI10: 81): (0) no cubierto y ubicado posterior a la musculatura mandibular y los infraorbitales; (1) cubierto por la musculatura mandibular y/o los infraorbitales.

92. Extremo dorsal del tubo sensorial del preopérculo y suprapreopérculo (MI10: 82): (0) no solapa el proceso anterodorsal del opérculo; (1) solapa el proceso anterodorsal del opérculo.

- Rama frontoparietal:

93. Zona anterior del tubo laterosensorial del frontal (MI10: 83): (0) contenido completamente en el frontal; (1) abre hacia una cámara limitada dorsalmente por el frontal y ventralmente por el etmoides lateral.

94. Rama posteromedial o parietal del canal sensorial supraorbital en el frontal (m, WF85: 13; WM98: 21: VH01: 39; ME13: 386) (Fig. 1): (0) presente; (1) ausente.

95. Longitud de la rama posteromedial del canal sensorial supraorbital (m, WF85: 13; WM98: 21; VH01: 39; ME13: 386) (Fig. 1): (0) larga, esta rama alcanza el hueso parietal; (1) corta, esta rama no alcanza el hueso parietal.

En este carácter, el estado 0 corresponde a las especies en las que la rama de canal abre lateralmente en la superficie del parietal. En cambio, en el estado 1 se codificaron todos los casos en los que la rama abre en el frontal. Las especies en las que el poro de esta rama abre justo entre el límite entre el frontal y el parietal fueran codificados como casos intermedios.

96. Rama epifisaria del tubo supraorbital (MI10: 84): (0) presente; (1) ausente.

Varias especies de Stevardiinae (Corynopoma riisei, Chrysobrycon spp., Pterobrycon myrnae, Gephyrocharax spp., entre otras) tienen el canal supraorbital muy complejo medialmente, con variados túbulos diminutos que abren hacia las fontanelas frontal o parietal, incluso dirigidos hacia la barra epifisaria. Sin embargo, ninguno de estos túbulos pudo ser considerado homólogo a la rama epifisaria y por tal motivo todos estos casos fueron considerados con el estado 1. Mirande (2010) codificó ausente la barra epifisaria en Cyanocharax alburnus, pero en un ejemplar examinado se observó la rama epifisaria muy fina y con un diminuto poro que abre dorsal a la barra, por tal motivo se recodificó como polimórfico. 
97. Rama epifisaria de cada tubo laterosensorial del supraborbital (MI10: 85): (0) ambos alineados con la barra epifisaria; (1) ambos dirigidos oblicuamente, desembocan posteriormente a la barra epifisaria.

98. Desembocadura de las ramas epifisarias del sistema laterosensorial (MI10: 86): (0) abren a lo largo del borde de la fontanela craneana; (1) continúan dorsomedialmente en tejido blando y abren en la fontanela craneana o justo lateral a ella.

99. Poro frontoetmoidal del tubo sensorial supraorbital (n): (0) localizado aproximadamente a media distancia entre la articulación del frontal con el etmoides lateral y la barra epifisaria; (1) localizado más cerca de la articulación del frontal con el etmoides lateral que de la distancia media entre esta articulación y la barra epifisaria.

100. Poro supraorbitario localizado sobre la base de la barra epifisaria, cercano a ésta o en punto entre ésta y el poro frontoetmoidal (n): (0) ausente; (1) presente.

En los carácidos examinados, el canal laterosensorial supraorbital tiene cuatro poros principales. El primero, aquí llamado frontoetmoidal, abre por lo general en posición dorsal al punto medio longitudinal de la órbita (Fig. 1b: carácter 99, estado 0) o anterior a este punto, cerca o sobre la región del etmoides lateral que articula con el frontal (Figs. 1a y 2: carácter 99, estado 1). El segundo, aquí nombrado supraorbitario, se localiza más medial y posterior al frontoetmoidal (Figs. 1a y 2: carácter 100, estado 1). El tercero, aquí nombrado epifisario, se ubica en el extremo medial de la rama epifisaria cuando está presente. Aunque en los carácidos examinados el segundo poro está presente solo cuando no está el tercer poro y ambos podrían ser interpretados como el mismo en cierto punto, hay ciertas excepciones a esta condición (e. g. Piabina argentea, cuyos ejemplares examinados presentan el segundo y tercer poro simultaneamente). Por esta razón y para ser cautelosos, se prefirió codificar el segundo poro por separado, al menos hasta tener un entendimiento más generalizado del número de veces que los poros supraorbitario y epifisario aparecen simultáneamente en las especies de Characidae. Además, la posición del poro supraorbitario es variable y distante del poro epifisario, lo que también puede ser otro criterio para considerarlos diferentes. El cuarto, aquí nombrado poro orbitario, es posterior a estos dos y está cerca de la zona posterodorsal de la órbita y/o de la fosa del dilatator operculi (Fig. 2). La posición del poro orbitario es poco variable respecto de la de los otros dos poros en las especies stevardinas examinadas y su posible variación no es considerada en este estudio. Los casos intermedios entre los estados del carácter 99 fueron codificados como polimórficos. Los caracteres 99 y 100 son inaplicables para las especies con 
complejos sistemas de poros en el canal supraorbital, los cuales no permiten discriminar entre estos poros (e. g. Diapoma terofali).

101. Posición del poro supraorbitario (n, Figs. 1 y 2): (0) localizado sobre la base de la barra epifisaria o en punto inmediatamente anterior a ésta; (1) distante de la base de la barra epifisaria, en un punto cercano al poro frontoetmoidal o central entre éste y la barra epifisaria.

Este carácter es inaplicable para las especies codificadas con el estado 0 del carácter anterior.

102. Tubo laterosensorial del esfenótico (MI10: 87) (0) ausente; (1) presente.

- $\underline{\text { Rama postemporal: }}$

103. Tubo laterosensorial del hueso postemporal (WF85: 14; WM98: 22): (0) ausente; (1) presente.

104. Ramificación posterior del tubo laterosensorial del postemporal (MI10: 88): (0) presente; (1) ausente.

- Línea lateral

105. Forma de la línea lateral (MI10: 89): (0) aproximadamente recta; (1) curvada ventralmente en la zona abdominal.

106. Grado de curvatura ventral de la línea lateral (MI10: 90): (0) recta o levemente curvada, con su porción posterior alineada con los radios medios de la aleta caudal; (1) muy curvada y posicionada ventralmente, con su porción posterior en la mitad ventral del pedúnculo caudal y alineada con el lóbulo ventral de la aleta caudal.

107. Continuidad de la línea lateral (MI10: 91): (0) completa; (1) interrumpida.

108. Tubo terminal de la línea lateral sobre las membranas de la aleta caudal (MI10: 92): (0) ausente; (1) presente.

109. Extensión posterior del tubo de la línea lateral sobre la aleta caudal (MI10: 93): (0) alcanza solo la mitad de la aleta caudal; (1) casi alcanza el borde posterior de la aleta caudal.

\section{Mandíbula superior}

- Maxila:

110. Flexión de la maxila en el punto de anclaje con la premaxila (VH01: 6; ME13: 372): ausente o poco pronunciada, maxila bastante recta; (1) flexión pronunciada.

111. Extremo anterior del proceso ascendente de la maxila (MI10: 94): (0) con una escotadura o muesca conspicua; (1) con su extremo puntiagudo o redondeado. 
112. Borde ventral de la zona dentada de la maxila (MI10: 95): (0) aproximadamente recto; (1) fuertemente cóncavo.

113. Bordes dorsal y ventral de la zona dentada de la maxila (MI10: 96): (0) aproximadamente paralelos; (1) divergentes dorsalmente.

114. Expansión de la porción laminar de la maxila justo posterior a la zona dentada (MI10: 97): (0) ausente o muy suave; (1) conspicua y abrupta.

115. Túbulos para el paso de vasos sanguíneos sobre la porción laminar de la maxila (MI10: 98): (0) un túbulo simple, paralelo al borde dorsal de la maxila; (1) túbulo con una rama anterior que corre paralela al borde anterior de la maxila y alcanza un tercio de su longitud; (2) túbulos anastomosados.

116. Longitud posterior de la maxila (MI10: 99): (0) no alcanza al segundo infraorbital; (1) alcanza al segundo infraorbital.

117. Longitud de la maxila relativa al dentario (MI10: 100): (0) la maxila alcanza posteriormente el borde posterior del cartílago de Meckel; (1) la maxila no alcanza al borde posterior del cartílago de Meckel.

118. Alargamiento ontogenético de la maxila (MI10: 101): (0) ausente; (1) presente.

119. Proyección dorsal de la maxila (MI10: 102): (0) no solapa lateralmente al segundo infraorbital; (1) solapa lateralmente al segundo infraorbital.

- Premaxila:

120. Extremo anterior de la premaxila (n): (0) al nivel de la mitad inferior de la órbita o justo sobre su línea media; (1) al nivel de la mitad superior de la órbita.

En este carácter, se describe el grado de inclinación relativo del hocico en función de la posición anterior de la premaxila. Es decir, por lo general aquellas especies con hocico superior tienen el estado 1 (Fig. 1a), mientras que aquellas especies con hocico terminal o subterminal presentan el estado 0 (Fig. 1b).

121. Interdigitaciones entre las premaxilas (MI10: 103): (0) presentes; (1) ausentes.

122. Longitud de la rama ascendente de la premaxila (MI10: 104): (0) llega hasta 1/3 de los nasales; (1) alcanza solo el extremo anterior de los nasales.

123. Alineamiento de la rama ascendente de la premaxila (MI10: 105): (0) alineada con el borde medial de los nasales; (1) desplazada medialmente respecto a los nasales.

124. Forma de la porción posterolateral de la premaxila (MI10: 106): (0) con una escotadura; (1) con un pedicelo expandido lateralmente hacia la maxila.

\section{Mandíbula inferior}

- Ánguloarticular: 
125. Cresta lateral del ánguloarticular (MI10: 107): (0) ausente; (1) presente.

126. Proceso laminar dorsolateral del hueso ánguloarticular (WF85: 26): (0) presente; (0) ausente o reducido.

127. Proceso horizontal del ánguloarticular (MI10: 108): (0) cubierto lateralmente por el dentario solo en su porción anterior; (1) ampliamente cubierto por el dentario, que alcanza el borde posterior del cartílago de Meckel.

128. Borde ventral del proceso horizontal del ánguloarticular (MI10: 109): (0) angulado en sentido posteroventral con respecto al tubo laterosensorial del dentario, en vista medial; (1) perpendicular al tubo laterosensorial del dentario, en vista medial.

129. Yuxtaposición posterior entre el ánguloarticular y la zona posterodorsal del dentario (n, Fig. 3): (0) simple, la porción posterodorsal del dentario está ubicada medial al proceso dorsolateral del ánguloarticular; (1) compleja, la porción posterodorsal del dentario está ubicada parcial o completamente entre los procesos dorsolateral y horizontal del ánguloarticular.

En la yuxtaposición compleja (Fig. 3b: estado 1) el borde dorsal de los procesos dorsolateral y horizontal del ánguloarticular dejan una hendidura poco profunda en la cual se aloja el borde posterior del dentario. Mientras que en la yuxtaposición simple (Fig. 3a: estado 0), esta hendidura está ausente y el borde posterior del dentario está ubicado completamente medial al proceso dorsolateral del ánguloarticular. En Oligosarcus jenynsii, se observó una condición intermedia entre ambos estados y se codificó consecuentemente como polimórfico; este criterio se aplicó en casos similares. En Microschemobrycon casiquiare, la yuxtaposición se codificó compleja (aunque la hendidura es muy reducida), debido a que en los dos ejemplares examinados los bordes de los procesos dorsolateral y horizontal están claramente interrumpidos sagitalmente.

130. Altura del proceso dorsolateral del ánguloarticular (n, Fig. 3b: estado 0): (0) mayor a la altura de la región posterior del proceso horizontal; (1) casi igual a la altura de la región posterior del proceso horizontal.

Este carácter es solo aplicable para aquellas especies con un proceso dorsolateral bien desarrollado y con una yuxtaposición compleja entre el dentario y el ánguloarticular. Las especies en los que el proceso horizontal está muy poco desarrollado posteriormente (e. g. Knodus heteresthes) y tengan un mínimo solapamiento con el dentario y el proceso dorsolateral del ánguloarticular fueron codificados inaplicables (Fig. 3a).

- Coronomeckeliano: 
131. Ubicación del coronomeckeliano (MI10: 110): (0) principalmente lateral al cartílago de Meckel; (1) principalmente dorsal al cartílago de Meckel.

- Dentario:

132. Interdigitaciones entre los dentarios (MI10: 111): (0) ausentes; (1) presentes.

133. Forma de las interdigitaciones entre los dentarios (MI10: 112): (0) láminas óseas simples; (1) láminas onduladas.

134. Forma y dentición de la zona anterior del dentario (MI10: 113): (0) dentado y no deprimido anteriormente; (1) edentado y muy deprimido anteriormente.

135. Escotadura medial y anteroventral en el dentario (MI10: 114): (0) ausente o poco desarrollada; (1) presente.

136. Proceso medial del dentario que bordea al cartílago de Meckel dorsal y medialmente (MI10: 115): (0) ausente; (1) presente.

137. Lámina ósea que cubre el foramen dentario (MI10: 116): (0) ausente; (1) presente.

138. Cresta longitudinal que cubre los poros laterosensoriales del dentario (MI10: 117):

(0) ausente; (1) presente.

\section{Dentición}

- Generalidades:

139. Morfología de la premaxila, maxila y dentario (MI10: 118): (0) todos los dientes cónicos, caniniformes o mamiliformes; (1) con dientes multicúspidados o molariformes.

140. Dientes en la premaxila, maxila y dentario (MI10: 119): (0) no pedunculados o si pedunculados, solo en algunos de esos huesos; (1) todos pedunculados y con similar número de cúspides.

- Premaxila:

141. Dientes mamiliformes ubicados por fuera de la boca (MI10: 120): (0) ausentes; (1) presentes.

142. Un par de dientes caninos en la premaxila (MI10: 121): (0) ausentes; (1) presentes.

143. Dentición premaxilar (ME13: 368): (0) una o más series de dientes similares; (1) una triada de grandes dientes con base redondeada.

144. Número de hileras de dientes premaxilares (MI10: 122): (0) una; (1) dos o tres.

145. Número de hileras de dientes premaxilares (MI10: 123): (0) una o dos; (1) tres.

- Hilera externa de dientes premaxilares:

146. Tamaño de los dientes de la hilera externa de la premaxila (FE07: 38; FE11: 128): (0) más pequeños que los de la hilera interna; (1) más largos que los de la hilera interna. 
En este carácter, los criterios de homología de los estados propuestos siguen a esos usados por Mirande (2010) para la morfología dentaria premaxilar.

147. Alineamiento de los dientes de la primera hilera premaxilar (MI10: 124): (0) alineados; (1) no alineados, con uno o dos dientes ubicados anteriormente a los restantes.

148. Cúspides de los dientes premaxilares de la hilera externa (MI10: 125): (0) una a tres cúspides; (1) con cinco o más cúspides.

- Hilera interna de dientes premaxilares:

149. Número máximo de cúspides de la hilera interna de dientes de la premaxila (m, MW03; FE07: 40; FE11: 130): (0); tres o menos; (1) cuatro o más.

150. Número máximo de cúspides de la hilera interna de dientes de la premaxila (m, MW03; FE07: 40; FE11: 130): (0) cuatro o menos; (1) cinco o más.

151. Número máximo de cúspides de la hilera interna de la premaxila (m, MW03; FE07: 40; FE11: 130): (0) seis o menos; (1) siete o más.

152. Dientes en la hilera interna de la premaxila (MI10: 126): (0) molariformes; (1) con cúspides alineadas en series rectas o en un patrón anteriormente cóncavo; (2) con un patrón anteriormente cóncavo más unas cúspides anteriores.

153. Alineamiento de las cúspides en los dientes de la hilera interna de la premaxila (MI10: 127): (0) forman un semicírculo anteriormente cóncavo en vista ventral; (1) forman un arco suave o están alineadas en series rectas en vista ventral.

154. Forma de los dientes de la hilera interna de la premaxila (MI10: 128): (0) con cúspides que forman un arco anteriormente cóncavo; (1) con cúspides alineadas, en series rectas y sin concavidad anterior.

155. Número de dientes en la hilera interna de la premaxila (MW03; MI10: 129): (0) cuatro o menos; (1) cinco o más.

156. Número de dientes de la hilera interna de la premaxila (CA11: 367; FE11: 127): (0) cinco o menos; (1) seis o más.

157. Número de dientes de la hilera interna de la premaxila (m, FE11: 127): (0) seis o menos; (1) siete o más.

Los caracteres 156 y 157 fueron agregados para completar la serie de caracteres usados por Mirande (2010) y que describen el número de dientes en la hilera interna premaxilar. Aunque hay especies con conteos polimórficos de estos dientes, también hay muchas especies con conteos estables que pueden ser útiles como sinapomorfías a diferentes niveles. 
158. Número de dientes en la segunda hilera premaxilar (MI10: 130): (0) siete o menos; (1) ocho o más.

159. Polimorfismo de los dientes de la hilera interna de la premaxila (MI10: 131): (0) ausente; (1) presente, con los dos dientes mediales mayores y generalmente con un diastema marcado respecto de los demás.

160. Número de hileras de dientes premaxilares de recambio (MI10: 132): (0) una; (1) dos o más.

161. Fosa para los dientes de recambio de la hilera interna premaxilar (MI10: 133): (0) ausente; (1) presente.

- Dientes maxilares:

162. Dientes maxilares (MI10: 134): (0) ausentes; (1) presentes.

163. Número de dientes maxilares (MI10: 135): (0) cero o solo uno; (1) dos o más.

164. Número de dientes maxilares (MI10: 136): (0) hasta tres; (1) cuatro o más.

165. Extensión de la implantación dentaria a lo largo de la maxila (MI10: 137): (0) no alcanza la longitud media de la lámina maxilar; (1) extendida sobre casi toda la lámina maxilar.

166. Número de cúspides de los dientes maxilares anteriores (MI10: 138): (0) una, dientes cónicos; (1) tres o más.

167. Número de cúspides de los dientes maxilares anteriores (MI10: 139): (0) hasta tres; (1) con cinco o más.

168. Aparición ontogenética de dientes cónicos en la maxila (MI10: 140): (0) ausente; (1) presente.

- Dientes del dentario:

169. Orientación de los dientes anteriores del dentario (MI10: 141): (0) dirigidos en sentido dorsal o anterodorsal; (1) dirigidos en sentido anterior, casi paralelos al cuerpo del dentario.

170. Tamaño y número de los dientes anteriores del dentario (MI10: 142): (0) cuatro o cinco dientes relativamente anchos al frente del dentario; (1) ocho o más dientes pequeños y de base angosta al frente del dentario.

171. Hilera interna de dientes en el dentario (MI10: 143): (0) presente; (1) ausente.

172. Dientes dentarios sinfisiales (MI10: 144): (0) ausentes; (1) presentes.

173. Articulación entre los dientes del dentario (MI10: 145): (0) ausente. (1) presente, con fosetas y procesos asociados. 
174. Posición de los dientes anteriores del dentario (MI10: 146): (0) ubicados a lo largo del borde del dentario; (1) ubicados internamente, con el dentario formando un reborde anterior.

175. Número máximo de cúspides de los primeros cuatro dientes del dentario (m, VH01: 18; FE07: 55; FE11: 145; ME13: 380): (0) cinco o menos; (1) seis o más.

Este carácter sigue los estados propuestos por Ferreira et al. (2011). Los estudios de Vari \& Harold (2001) y Mirande et al. (2013) se citan para referenciar un carácter afín pero con otros intervalos usados en los estados.

176. Longitud del segundo diente del dentario (n): (0) su cúspide central alcanza o sobrepasa la punta dorsal del primer y tercer diente o al menos la del primero; (1) su cúspide central no alcanza la punta dorsal del primer y tercer diente o al menos la de este último.

Los criterios de homología para los estados de este carácter siguen a esos definidos por Mirande (2010) para la morfología de los dientes dentarios. El estado 1 es común entre las especies de Gephyrocharax. Por ejemplo, especies con complejas series de dientes en el dentario, como Tyttocharax sp., fueron codificadas inaplicables para el carácter.

177. Separación entre los dientes posteriores del dentario (MI10: 147): (0) menor al ancho de estos dientes; (1) mayor al ancho de estos dientes.

178. Abrupta disminución del tamaño de los dientes dentarios (MI10: 148): (0) ausente; (1) presente.

\section{Suspensorio y aparato opercular}

- Cuadrado:

179. Foramen sobre el cóndilo del cuadrado (MI10: 149): (0) ausente; (1) presente.

180. Forma del cuadrado (MI10: 150): (0) con la porción ventral más larga que la porción anterodorsal; (1) con la porción anterodorsal igual o más larga que la porción horizontal.

181. Extensión posterior del proceso ventral del cuadrado (MI10: 151): (0) alcanza la línea vertical que pasa por el borde posterior del simpléctico; (1) no alcanza dicha línea.

182. Cresta longitudinal en el cuadrado, que limita ventral y, en parte, lateralmente al adductor mandibulae (MI10: 152): (0) ausente; (1) presente.

183. Articulación entre el cuadrado y el ánguloarticular (MI10: 153): (0) anterior o en la línea vertical que pasa por el etmoides lateral; (1) posterior al etmoides lateral. 
184. Articulación entre el cuadrado y el ánguloarticular (MI10: 154): (0) anterior o coincidente con la línea vertical que pasa por el centro del ojo; (1) posterior a la mitad del ojo.

185. Articulación entre el borde ventral del metapterigoides y el borde posterodorsal del cuadrado (MI10: 155): (0) ausente; (1) presente.

- Ectopterigoides:

186. Forma del ectopterigoides (MI10: 156): (0) alargado; (1) triangular, muy ensanchado anteriormente; (2) casi cuadrado.

187. Forma de la porción anterior del ectopterigoides (MI10: 157): (0) ancho, articulando extensamente con el palatino y unido al neurocráneo por ligamentos; (1) fino, articulando solo en el borde lateral del palatino y sin ligamentos dirigidos hacia el neurocráneo.

188. Proceso dorsal en el ectopterigoides dirigido al etmoides lateral (MI10: 158): (0) ausente; (1) presente.

189. Hilera de dientes en el ectopterigoides (MI10: 159): (0) ausente; (1) presente.

190. Parche de dientes ectopterigoideos (MI10: 160): (0) ausente; (1) presente.

191. Posición del cartílago longitudinal dorsal al ectopterigoides (MI10: 161): (0) bordeado medialmente por el mesopterigoides; (1) desplazado lateralmente, separado del borde del mesopterigoides.

192. Contacto entre el ectopterigoides y la porción anterodorsal del cuadrado (MI10: 162):

(0) presente; (1) ausente.

- Interopérculo:

193. Extensión anterior del interopérculo (MI10: 163): (0) extendido más allá de la punta anterior de la rama horizontal del preopérculo; (1) no extendido más allá del extremo anterior de la rama horizontal del preopérculo.

194. Expansión posterior abrupta en el interopérculo (MI10: 164): (0) ausente; (1) presente.

- Mesopterigoides:

195. Dientes en el mesopterigoides (MI10: 165): (0) ausentes; (1) presentes.

\section{- Metapterigoides:}

196. Lóbulo en el metapterigoides dirigido anterodorsalmente hacia el mesopterigoides (MI10: 166): (0) ausente, o poco desarrollado y dirigido en sentido dorsal; (1) presente, conspicuo y dirigido en sentido anterior. 
197. Forma de la fenestra cuadradometapterigoidea (MI10: 167): (0) aproximadamente redondeada u oval, limitada anteriormente por la porción anterodorsal del cuadrado; (1) cerrada total o parcialmente por la convergencia del metapterigoides y la porción ventral del cuadrado.

198. Foramen en la zona posterior del metapterigoides (MI10: 168): (0) ausente; (1) presente, delimitada por el metapterigoides o cartílago; (2) en forma de un arco incompleto, limitado posteriormente por el hiomandibular.

- Simpléctico:

199. Porción anterior, cartilaginosa, del simpléctico (n): (0) no alcanza el borde anterior de la fenestra metapterigoidea; (1) alcanza o sobrepasa el borde anterior de la fenestra metapterigoidea.

- Opérculo:

200. Estrías radiales dirigidas posteriormente desde la zona articular del opérculo (MI10: 169): (0) ausentes; (1) presentes.

201. Longitud de la cresta ósea medial del opérculo (MI10: 170): (0) 60 \% o más larga que el ancho del opérculo; (1) menor al 50\% del ancho del opérculo.

202. Opérculo y subopérculo (n): (0) no modificados o extendidos posteriormente; (1) modificados, forman una extensión posterior de aspecto lobulado.

Esta modificación del opérculo y subopérculo fue descripta e ilustrada por Menezes \& Weitzman (2011: fig. 11 vs. fig. 28) para Diapoma speculiferum and D. pyrrhopteryx. Dicha morfología del opérculo y subopérculo es poco común en Characidae y está ausente en las especies de Gephyrocharax. En Corynopoma riisei, los machos adultos presentan una modificación del opérculo, subopérculo y radio branquiostego más posterior (carácter 426) que contribuye durante el cortejo sexual. Esta condición es considerada diferente a la observada en las especies de Diapoma donde el opérculo y subopérculo están expandidos posteriormente en ambos sexos. Además, la modificación presente en $C$. riisei es claramente más compleja y desarrollada que aquella encontrada en las especies de Diapoma.

- Palatino:

203. Cartílago etmopalatino (MI10: 171): (0) ausente o poco desarrollado; (1) presente y autógeno.

204. Longitud relativa del palatino (MI10: 172): (0) casi la mitad o menos de la longitud del ectopterigoides; (1) distintamente mayor que la mitad de la longitud del ectopterigoides. 
205. Foramen palatino (MI10: 173): (0) ausente o reducido; (1) presente y conspicuo.

\section{- Preopérculo}

206. Forma de la esquina posteroventral del preopérculo (MI10: 174): (0) aguda; (1) redondeada.

- Suprapreopérculo:

207. Suprapreopérculo (MI10: 175): (0) fusionado al preopérculo; (1) autógeno, claramente separado del preopérculo.

208. Láminas óseas que bordean el tubo laterosensorial del suprapreopérculo (MI10: 176): (0) ausentes; (1) presentes

\section{Esqueleto branquial e hioideo}

- Ceratohial anterior:

209. Proyección anterior del ceratohial anterior que articula lateralmente con los hipohiales (MI10: 177): (0) ausente o muy reducida; (1) presente, alcanza la mitad de la longitud de los hipohiales.

210. Arteria hioidea (MI10: 178): (0) contenida completamente dentro del ceratohial anterior en el paso desde el ceratohial posterior al hipohial; (1) emerge desde el ceratohial anterior cerca de su articulación con el ceratohial posterior.

211. Borde ventral del ceratohial anterior (MI10: 179): (0) liso, sin escotaduras; (1) con escotaduras en las que articulan los radios branquiostegos.

212. Número de escotaduras en el borde ventral del ceratohial anterior (MI10: 180): (0) cero o dos; (1) tres.

213. Articulación entre los ceratohiales anterior y posterior (MI10: 181): (0) sincondral, sin interdigitaciones óseas; (1) con interdigitaciones óseas.

- Basibranquiales:

214. Primer basibranquial (MI10: 182): (0) ausente o muy reducido, sin articulación anterior con el basihial; (1) bien desarrollado, con articulación anterior con el basihial.

215. Lámina ósea entre el primer y segundo basibranquiales (n): (0) ausente, (1) presente.

216. Contacto entre la lámina sobre la porción anterior del primer basibranquial con lámina sobre la porción posterior del segundo basibranquial (MI10: 183): (0) ausente; (1) presente.

217. Lámina ósea entre el segundo y tercer basibranquiales (MI10: 184): (0) ausente; (1) presente.

218. Lámina dorsal ósea sobre el cuarto basibranquial (MI10: 185): (0) presente; (1) ausente. 
219. Porción principal del cuarto basibranquial (MI10: 186): (0) completamente cartilaginosa; (1) osificada.

220. Dientes sobre la lámina dorsal del cuarto basibranquial (MI10: 187): (0) ausentes. (1) presentes.

- Basihial:

221. Cartílagos anteriores al basihial (MI10: 188): (0) uno o dos bloques de cartílago, pero el anterior muy reducido; (1) dos bloques bien desarrollados.

222. Lámina edentada del basihial (MI10: 189): (0) ausente; (1) presente.

223. Desarrollo anterior del basihial (MI10: 190): (0) sobrepasa ampliamente el borde anterior de los hipohiales; (1) apenas sobrepasa el borde anterior de los hipohiales.

224. Forma de la expansión anterior del basihial (MI10: 191): (0) fina, con el borde anterior menor a dos tercios de su longitud; (1) expandida, el borde anterior tiene dos tercios de su longitud.

- Rastrillos branquiales:

225. Hileras de rastrillos branquiales en el primer ceratobranquial (MI10: 192): (0) uno; (1) dos.

226. Hileras de rastrillos branquiales en el segundo ceratobranquial (MI10: 193): (0) uno; (1) dos.

227. Hileras de rastrillos branquiales en el tercer y cuarto ceratobranquiales (MI10: 194): (0) uno; (1) dos.

228. Número de rastrillos branquiales en el primer hipobranquial y ceratobranquial (MI10: 195): (0) 16 o más; (1) 15 o menos.

229. Número de rastrillos branquiales en el primer hipobranquial y ceratobranquial (MI10: 196): (0) 11 o más. (1) 10 o menos.

230. Forma de los rastrillos branquiales del primer ceratobranquial (MI10: 197): (0) puntiagudos, no muy comprimidos anteroposteriormente; (1) laminares y muy comprimidos, perpendiculares al ceratobranquial; (2) cortos, anchos y espinosos.

231. Forma de los rastrillos branquiales anteriores del primer ceratobranquial (MI10: 198): (0) no fusionados; (1) fusionados en sus bases, formando placas anchas ampliamente articuladas con el ceratobranquial.

232. Base lateral de los rastrillos branquiales del primer ceratobranquial (MI10: 199): (0) fina; (1) ancha y laminar, al menos, en los rastrillos branquiales más anteriores. 
233. Forma y grado de osificación de los rastrillos branquiales del primer ceratobranquial (MI10: 200): (0) laminares dorsalmente, no osificados en su porción distal; (1) de apariencia robusta, totalmente osificados en su región distal.

234. Dentículos en los rastrillos branquiales (MI10: 201): (0) presentes; (1) ausentes.

235. Distribución de dentículos en los rastrillos branquiales (MI10: 202): (0) restringidos a los bordes o ausentes; (1) a lo largo de toda la superficie de los rastrillos branquiales.

236. Número de hileras de rastrillos branquiales en el primer epibranquial (MI10: 203): (0) una; (1) dos.

- Ceratobranquiales:

237. Forma de la placa dentífera del quinto ceratobranquial (MI10: 204): (0) redondeada, con una escotadura posterior; (1) alargada, sin una escotadura posterior.

238. Dientes en el quinto ceratobranquial (MI10: 205): (0) presentes; (1) ausentes.

- Faringobranquiales:

239. Dientes en el tercer faringobranquial (MI10: 206): (0) presentes; (1) ausentes.

240. Dientes en el cuarto faringobranquial (MI10: 207): (0) presentes; (1) ausentes.

241. Dientes en el quinto faringobranquial (MI10: 208): (0) presentes; (1) ausentes.

242. Contacto entre las placas dentíferas del cuarto y quinto faringobranquiales (MI10: 209): (0) ausente; (1) presente.

- Interhial:

243. Interhial (MI10: 210): (0) presente; (1) ausente.

244. Longitud del interhial (MI10: 211): (0) corto, menor a un tercio de la longitud del simpléctico; (1) igual o mayor a la mitad de la longitud del simpléctico.

- $\underline{\text { Radios branquiostegos: }}$

245. Número de radios branquiostegos (MI10: 212): (0) tres; (1) cuatro o cinco.

246. Número de radios branquiostegos (MI10: 213): (0) tres o cuatro; (1) cinco.

247. Porciones anteriores de los radios branquiostegos (MI10: 214): (0) ensanchadas cerca de su punto de articulación con los ceratohiales; (1) finas cerca de su articulación con los ceratohiales.

248. Zona de anclaje del primer radio branquiostego (MI10: 215): (0) sobre la porción proximal de la longitud media del ceratohial anterior o anterior a este punto: (1) posterior a la longitud media del ceratohial anterior.

249. Distancia entre los sitios de anclaje del primer y segundo radios branquiostegos (MI10: 216): (0) igual o menor a la distancia entre el segundo y tercer radios; (1) mayor a la distancia entre el segundo y tercer radios branquiostegos. 
250. Número de radios branquiostegos articulados con el ceratohial posterior (MI10: 217):

(0) uno; (1) dos.

\section{Vértebras y aparato de Weber}

- Aparato de Weber:

251. Forma y articulación del pedicelo neural de la tercera vértebra (MI10: 218): (0) pedicelo bien desarrollado, articula de manera sincondral con el complejo neural; (1) pedicelo muy reducido, sin una superficie articular con el complejo neural.

252. Desarrollo del proceso transverso del arco neural de la tercera vértebra (MI10: 219): (0) no alcanza al borde anterior del tripus; (1) muy desarrollado, supera anteriormente al borde anterior del tripus.

253. Proceso ascendente en el pedicelo neural de la tercera vértebra (MI10: 220): (0) ausente; (1) presente.

254. Desarrollo dorsal del proceso dorsal del pedicelo neural de la tercera vértebra (MI10: 221): (0) no solapa ampliamente al complejo neural; (1) solapa ampliamente al complejo neural.

255. Arco neural y centro vertebral de la cuarta vértebra (MI10: 222): (0) no fusionados y con el arco neural autógeno; (1) fusionados.

- Costillas:

256. Espina dirigida anteromedialmente en la base de la quinta (primera) costilla (MI10: 223): (0) ausente; (1) presente.

257. Crestas laminares sobre los bordes dorsales de las costillas abdominales (MI10: 224): (0) ausentes; (1) presentes.

258. Costillas abdominales en las vértebras caudales anteriores (MI10: 225): (0) ausentes; (1) presentes, asociadas a la primera y ocasionalmente a la segunda vértebra caudal.

- Vértebras:

259. Número relativo de vértebras precaudales (MI10: 226): (0) excede en dos o más elementos a las vértebras caudales; (1) igual o menos que las vértebras caudales.

260. Número total de vértebras (MI10: 227): (0) 40 o menos; (1) 41 o más.

261. Número total de vértebras de transición (MI10: 228): (0) cuatro o más; (1) tres o menos.

262. Vértebras transicionales con canal hemal (MI10: 229): (0) presentes; (1) ausentes.

263. Número de vértebras transicionales con canal hemal (FE07: 103; FE11: 76): (0) una; (1) dos o más. 
264. Número de vértebras anteriores al pterigióforo más anterior de la aleta dorsal (m, FE07: 102; FE11: 75): (0) 10 o menos; (1) 11 o más.

265. Número de vértebras anteriores al pterigióforo más anterior de la aleta dorsal (m, FE07: 102; FE11: 75): (0) 13 o menos; (1) 14 o más.

266. Número de vértebras anteriores al pterigióforo más anterior de la aleta dorsal (m, FE07: 102; FE11: 75): (0) 17 o menos; (1) 18 o más.

\section{Cintura pectoral}

- Aletas pectorales:

267. Borde del primer radio pectoral en ejemplares adultos (MI10: 230): (0) no aserrado; (1) aserrado conspicuamente.

268. Base del segundo radio pectoral (MI10: 231): (0) ensanchado y solapando en parte la base del primer radio pectoral, en vista lateral; (1) similar en forma y tamaño a las bases de los radios posteriores.

- Cleitro:

269. Borde anterior del cleitro (MI10: 232): (0) levemente sinuoso; (1) con una proyección anterior puntiaguda.

270. Forma del borde posterior del cleitro (MI10: 233): (0) convexo o ligeramente sinuoso, justo dorsal a la inserción de las aletas pectorales; (1) con una escotadura justo anterior a la inserción de las aletas pectorales.

271. Borde posterior del cleitro (MI10: 234): (0) sin una concavidad ventral al primer postcleitro; (1) con una concavidad ventral al primer postcleitro.

272. Borde posterior del cleitro (MI10: 235): (0) con una concavidad poco pronunciada o ausente; (1) con una marcada concavidad que casi forma un ángulo recto.

273. Expansión laminar media en el extremo dorsal del cleitro (MI10: 236): (0) ausente; (1) presente.

274. Desarrollo dorsal del cleitro (MI10: 237): (0) muy extendido dorsalmente al mesocoracoides; (1) termina en una posición justo dorsal a la punta del mesocoracoides.

275. Porción anterior del cleitro (n, Fig. 1): (0) no alcanza el borde posterior del metapterigoides; (1) alcanza el borde posterior del metapterigoides.

276. Porción anterior del cleitro (n, Fig. 1: estado 1): (0) no alcanza la base del tubo vertical del canal laterosensorial del preopérculo; (1) alcanza la base del tubo vertical del canal laterosensorial del preopérculo. 
277. Porción anterior del cleitro (n, Fig. 1: estado 1): (0) no alcanza el borde posterior del preopérculo; (1) alcanza el borde posterior del preopérculo.

- Coracoides:

278. Porción posterior del coracoides (n, Fig. 4): (0) no alcanza el borde posterior del cleitro; (1) alcanza o sobrepasa el borde posterior del cleitro.

279. Desarrollo de la lámina medial del coracoides (MI10: 238): (0) no expandida; (1) expandida en forma de una quilla.

280. Cresta lateral ósea del coracoides ubicada entre la base del mesocoracoides y el borde ventral del espacio interóseo (MI10: 239): (0) ausente; (1) presente.

281. Extensión anterior de la lámina ventral del coracoides (MI10: 240): (0) alcanza al cleitro; (1) no alcanza al cleitro.

282. Extensión ventral de la lámina del coracoides (MI10: 241): (0) alcanza al borde ventral del cleitro; (1) no alcanza al borde ventral del cleitro.

283. Límite anterior del espacio interóseo (MI10: 242): (0) formado por el borde dorsal de la lámina medial del coracoides y el borde dorsal del cleitro; (1) formado por el borde dorsal de la lámina medial del coracoides y una cresta ósea oblicua ubicada justo ventralmente al borde dorsal del cleitro.

284. Foramen coracoideo (MI10: 243): (0) ausente o reducido a un poro poco conspicuo; (1) muy desarrollado.

- Escápula:

285. Proceso anterior de la escápula que forma el borde anterior del foramen escapular (MI10: 244): (0) presente; (1) ausente.

- Mesocoracoides:

286. Articulación entre el proceso ventral del mesocoracoides y el borde dorsal de la escápula (MI10: 245): (0) ausente o corta; (1) presente y extensa.

287. Articulación ventral del mesocoracoides (MI10: 246): (0) anteriormente con el coracoides y posteriormente con la escápula; (1) solo con el coracoides.

- Postcleitros:

288. Primer postcleitro (MI10: 247): (0) presente; (1) ausente.

289. Segundo postcleitro (MI10: 248): (0) presente. (1) ausente.

290. Tercer postcleitro (MI10: 249): (0) presente; (1) ausente.

291. Distancia entre el primer y segundo postcleitros (n): (0) contactándose o separados por una distancia igual o menor a un tercio de la longitud del tercer postcleitro; (1) mayor a un tercio de la longitud del tercer postcleitro. 
292. Distancia entre el primer y segundo postcleitros (n): (0) mayor a tres cuartos de la longitud del tercer postcleitro; (1) menor a tres cuartos de la longitud del tercer postcleitro.

En los caracteres 291 y 292 se muestra la posición relativa del primer postcleitro respecto de la del segundo. En el primer carácter (291: estado 0) se incluye la variación donde ambos postcleitros están en contacto (e. g. Brycon meeki, Weitzman, 1962: fig. 18-19) o muy cercanos entre sí. En el estado 1 de los caracteres 291 y 292 (Fig. 4), se describen los casos donde hay una separación considerable entre estos postcleitros, la cual se organizó en proporción a la longitud del tercer postcleitro.

293. Tamaño del segundo postcleitro (n): (0) grande, ligeramente solapado por el cleitro; (1) pequeño, casi completamente solapado por el cleitro.

En este carácter, se describe el tamaño del segundo postcleitro teniendo en cuenta el grado de superposición con la zona posterior del cleitro. En el estado 0 (Fig. 4a), el cleitro solapa al segundo postcleitro en menos de tres cuartos de su longitud, mientras que en el estado 1 (Fig. 4b), el cleitro lo solapa completamente o usualmente en más de tres cuartos de su longitud. Condiciones intermedias entre ambos estados fueron codificadas como polimórficas.

294. Posición del tercer postcleitro (n, Fig. 4: estado 1): (0) no alcanza la mitad ventral del segundo postcleitro; (1) alcanza o sobrepasa la mitad ventral del segundo postcleitro.

La reducción de tamaño del segundo postcleitro descripta en el carácter anterior (293) no se encontró completamente asociada con la posición del tercer postcleitro (294). Por tal motivo ambos caracteres fueron codificados separadamente.

295. Forma del tercer postcleitro (MI10: 250): (0) fino, sin láminas asociadas; (1) con una lámina posterior.

296. Desarrollo dorsal del tercer postcleitro (MI10: 251): (0) proyectado dorsalmente sobre a la zona posterior de la escápula; (1) no proyectado dorsalmente sobre la zona posterior de la escápula.

- Extraescápula:

297. Extraescapula (n, Fig. 4): (0) bien desarrollada y atravesada por rama del canal laterosensorial del parietal; (1) ausente o reducida a una rama del canal laterosensorial que usualmente comunica con el pterótico.

La reducción o pérdida de la extraescapula puede ser una característica relacionada con la miniaturización (Weitzman \& Vari, 1988), pero no ha sido considerada en un análisis filogenético como tal. 


\section{- Postemporal:}

298. Proceso anteroventral del postemporal (m, WF85: 15; WM98: 23) (Fig. 4): (0) presente, osificado y bien desarrollado; (1) reducido, no osificado o ausente.

En especies como Knodus heteresthes y Nantis indefessus y, el proceso anteroventral y el canal laterosensorial no se desarrollan sobre el postemporal. Sin embargo, no se observó una asociación perfecta entre esta doble pérdida y por tal motivo ambos estados de carácter fueron codificados separadamente (caracteres 103 y 298).

299. Posición del borde ventral del postemporal (MI10: 252): (0) anterior al borde lateral de epioccipital; (1) lateral o posterior al borde lateral del epioccipital.

300. Posición del extremo ventral del postemporal (MI10: 253): (0) lateral o anterior al borde lateral del epioccipital; (1) posterior al borde lateral al epioccipital.

\section{- Supracleitro:}

301. Salida ventral del tubo laterosensorial del supracleitro (MI10: 254): (0) sale medialmente y está cubierta por la lámina posterior del supracleitro; (1) sale sobre el borde posterior del supracleitro y está ubicada ventral a lámina de este hueso.

302. Fusión entre el postemporal y el supracleitro (MI10: 255): (0) ausente; (1) presente.

\section{Cintura pélvica}

- Aleta pélvica:

303. Primer radio pélvico (MI10: 256): (0) no ramificado; (1) ramificado.

304. Número de radios pélvicos ramificados (MI10: 258): (0) seis o menos; (1) siete o más.

305. Número de radios pélvicos ramificados (MI10: 259): (0); siete o menos; (1) ocho o más.

- Hueso pélvico:

306. Hueso pélvico (MI10: 260): (0) no bifurcado anteriormente; (1) bifurcado, con una escotadura conspicua.

307. Articulación entre los huesos pélvicos (MI10: 261): (0) a través de ligamentos; (1) con interdigitaciones entre los procesos isquiáticos.

308. Extensión anterior del eje principal del hueso pélvico (MI10: 262): (0) no proyectado anterior a las láminas medial y lateral; (1) proyectado anterior a las láminas medial y lateral del hueso pélvico.

309. Extremo anterior del hueso pélvico (MI10: 263): (0) redondeado y bordeado anteriormente por un pequeño cartílago; (1) puntiagudo y sin cartílago asociado, con frecuencia proyectado hacia el exterior del cuerpo. 
310. Cresta dorsal longitudinal en la lámina medial del hueso pélvico (MI10: 264): (0) presente; (1) ausente.

311. Posición del extremo anterior del hueso pélvico (m, WF85: 41; WM98: 20, 37, 38; BE08: 84; FE11: 41) (Fig. 1b: estado 0): (0) anterior a la quinta costilla; (1) posterior a la quinta costilla.

312. Posición del extremo anterior del hueso pélvico (m, WF85: 12, 42: WM98: 20, 37, 38; BE08: 73; FE11: 41) (Fig. 1b: estado 0): (0) anterior a la sexta costilla; (1) posterior a la sexta costilla.

313. Posición del extremo anterior del hueso pélvico (m, WM98: 20, 37, 38; BE08: 73; FE11: 41): (0) anterior a la séptima costilla; (1) posterior a la séptima costilla.

314. Posición del extremo anterior del hueso pélvico (m, WM98: 20, 37, 38; BE08: 73; FE11: 41): (0) anterior a la octava costilla; (1) posterior a la octava costilla.

315. Posición del extremo anterior del hueso pélvico (m, WM98: 20, 37, 38; BE08: 73; FE11: 41): (0) anterior a la novena costilla; (1) posterior a la novena costilla.

Los caracteres 311 a 315 fueron organizados en dos caracteres binarios y restringidos a machos adultos por Weitzman \& Fink (1985). Ambos caracteres, por otro lado, fueron organizados por Weitzman \& Menezes (1998) y Ferreira et al., (2011) en una serie de transformación multiestado con otros estados adicionales. En Ferreira et al., (2011), no se aclaró si se codificó el carácter para ambos sexos o solamente para los machos adultos. Bertaco (2008) también uso este carácter en una serie multiestado, siguiendo a Weitzman \& Menezes (1998), pero tampoco aclaró si la variación era solo para machos adultos o para ambos sexos. En este estudio, la variación de la posición del extremo anterior del hueso pélvico con respecto a la posición de las costillas pleurales se organizó en cinco caracteres binarios y ésta se codificó para ambos sexos (caracteres 311-315). En cambio, la variación descripta por Weitzman \& Menezes (1998) en la posición del hueso pélvico asociada al dimorfismo sexual fue codificada en otro carácter (430) dentro del apartado respectivo del presente listado. Esto se hizo con el objetivo de codificar separadamente ambos tipos de variabilidad y no perder la información encontrada por Weitzman \& Menezes (1998) en los machos de algunos miembros de Xenurobryconini, a pesar que pueda ser polimórfica en algunas especies.

Epineurales, supraneurales, pterigióforos y aleta dorsal

- Aleta dorsal: 
316. Posición relativa de la inserción anterior de la aleta dorsal (MI10: 265): (0) anterior o en la línea vertical que pasa por el origen de las aletas pélvicas; (1) posterior a la línea vertical que pasa por el origen de las aletas pélvicas.

317. Número de radios articulados con el primer pterigióforo dorsal (MI10: 266): (0) dos; (1) tres o cuatro.

318. Espina anteriormente formada por el primer radio dorsal (MI10: 267): (0) ausente; (1) presente.

319. Número de radios ramificados de la aleta dorsal (m, FE07: 91; FE11: 43): (0) siete o menos; (1) ocho o más.

Este carácter se adicionó para complementar el carácter 270 (listado abajo) de Mirande (2010).

320. Número de radios ramificados en la aleta dorsal (WM03; MI10: 270): (0) ocho o menos; (1) nueve o más.

En varias especies de Stevardiinae, y particularmente en algunas especies de Gephyrocharax, se observó un gran polimorfismo (7 a 9 radios ramificados) en el conteo de estos radios de la aleta dorsal.

321. Tamaño de los radios medios de la aleta dorsal (n): (0) similares a los demás radios o más cortos que los anteriores y por lo general tan largos o un poco más largos que los posteriores; (1) más largos que los anteriores y posteriores.

En este carácter es considerado inaplicable para las especies que presentan casos similares al descripto en el estado 1, pero que están asociados al dimorfismo sexual de los machos adultos, codificado en otros caracteres en el apartado de dimorfismo sexual (caracteres 435 y 436 ).

322. Longitud relativa de los radios anteriores de la aleta dorsal (MI10: 271): (0) no alcanzan al extremo de los radios posteriores con la aleta dorsal plegada; (1) alcanzan al extremo de los radios posteriores con la aleta dorsal plegada.

323. Número de radios dorsales soportados por el último pterigióforo (MI10: 272): (0) uno; (1) dos adnatos.

324. Miorrabdos dorsales (MI10: 273): (0) ausentes; (1) presentes.

325. Posición de los epineurales más anteriores (MI10: 274): (0) laterales a la cuarta o quinta vértebra; (1) alcanzan el cráneo.

- Pterigióforos dorsales:

326. Espina predorsal formada por el primer pterigióforo de la aleta dorsal (MI10: 275): (0) ausente; (1) presente. 
327. Número de pterigióforos dorsales (MI10: 276): (0) nueve; (1) diez o más.

328. Número de pterigióforos dorsales (MI10: 277): (0) diez o menos; (1) once o más.

329. Número de pterigióforos dorsales (MI10: 278): (0) once o menos; (1) doce o más.

- Supraneurales:

330. Supraneurales (n): (0) presentes; (1) ausentes.

El carácter describe la pérdida de los supraneurales, observada en Scopaeocharax rhinodus (Fig. 1b), Tyttocharax sp. y Xenurobrycon macropus. La presencia de supraneurales es común en Characidae (Fig. 1a)

331. Supraneural anterior a la espina neural de la cuarta vértebra (MI10: 279): (0) ausente o reducido; (1) presente, alargado verticalmente.

332. Número de supraneurales (MI10: 280): (0) cuatro o menos; (1) cinco o más.

333. Número de supraneurales (FE07: 110; FE11: 46): (0) cinco o menos; (1) seis o más.

334. Número de supraneurales (FE07: 110; FE11: 46): (0) seis o menos; (1) siete o más.

335. Número de supraneurales (MI10: 281): (0) siete o menos; (1) ocho o más.

336. Número de supraneurales (n): (0) diez o menos; (1) once o más.

337. Número de supraneurales (n): (0) doce o menos; (1) trece o más.

338. Láminas óseas asociadas a los supraneurales (MI10: 282): (0) ausentes o reducidas;

(1) presentes, más anchas que el eje principal del supraneural.

339. Posición del supraneural más posterior (MI10: 283): (0) situado a dos o menos vértebras en frente del primer pterigióforo dorsal; (1) situado a más de dos vértebras en frente del primer pterigióforo dorsal.

\section{Pterigióforos y aleta anal}

- Aleta anal:

340. Posición de la aleta anal (MI10: 284): (0) posterior en vertical que pasa por el radio de la aleta dorsal más posterior; (1) extendida ventralmente a la aleta dorsal.

341. Posición del origen de la aleta anal (BE08: 68; FE11: 45): (0) posterior a la base del radio de la aleta dorsal más posterior; (1) en la vertical o anterior a la base del radio de la aleta dorsal más posterior.

En este carácter, se describe la posición del origen de la aleta anal con respecto a la línea vertical que pasa por el borde posterior del último radio de la aleta dorsal; el estado 0 incluye a las especies donde siempre el origen anal es posterior al radio dorsal más posterior y el estado 1 incluye a las especies en que el origen anal está en la vertical o anterior a este punto. El carácter 341 es diferente al 340 (Mirande, 2010: 
carácter 284) en su definición y su codificación (especialmente en las especies con condiciones intermedias en estos caracteres, por ejemplo Argopleura magdalenensis).

342. Número de radios no ramificados en la aleta anal (MI10: 285): (0) tres o menos; (1) cuatro o más.

343. Número de radios anales ramificados (MI10: 286): (0) diez o menos; (1) once o más.

344. Número de radios anales ramificados (MI10: 287): (0) 17 o menos; (1) 18 o más.

345. Número de radios anales ramificados (MI10: 288): (0) 24 o menos; (1) 25 o más.

346. Número de radios anales ramificados (MI10: 289): (0) 34 o menos; (1) 35 o más.

347. Radios articulando con el pterigióforo anal más posterior (MI10: 291): (0) dos; (1) uno.

- Pterigióforos anales:

348. Escotadura anterior en el primer pterigióforo proximal de la aleta anal (MI10: 292): (0) ausente; (1) presente.

349. Número de pterigióforos anales anteriores a la primera espina hemal (MI10: 293): (0) tres o menos; (1) cuatro o más.

350. Radiales anales proximales y medios (MI10: 294): (0) fusionados en los cinco anteriores pterigióforos; (1) fusionados en la mayoría de los pterigióforos; (2) radiales medios ausentes o completamente fusionados con los proximales.

351. Láminas laterales en los pterigióforos anales anteriores (MI10: 295): (0) ausentes; (1) presentes.

\section{Esqueleto caudal}

- Epurales:

352. Número de epurales (MI10: 296): (0) uno; (1) dos o tres.

353. Número de epurales (MI10: 297): (0) uno o dos; (1) tres.

- Hipurales:

354. Fusión del segundo hipural al centro vertebral compuesto (MI10: 298): (0) ausente; (1) presente.

355. Fusión entre el primer y segundo hipurales (MI10: 299): (0) ausente; (1) presente.

356. Borde posterior del segundo hipural (n, Fig. 5): (0) aproximadamente tan alto como la distancia vertical entre las bases de los radios caudales 11 y 12; (1) aproximadamente tan alto como la distancia vertical entre las bases de los radios caudales 11 a 13.

357. Borde posterior del tercer hipural (MI10: 300): (0) tan alto o más bajo que el borde posterior del cuarto hipural; (1) más alto que el borde posterior del cuarto hipural.

- Radio principales: 
358. Posición de la base del radio 12 de la aleta caudal (n, Fig. 5b: estado 1): (0) extendida sobre la porción posterior del primer hipural o sobre un espacio angosto formado entre el primer y segundo hipurales; (1) extendida sobre la porción posterior del segundo hueso hipural.

- Radios procurrentes:

359. Número de radios procurrentes ventrales de la aleta caudal (MI10: 302): (0) once o menos; (1) doce o más.

360. Tercer radio procurrente ventral de la aleta caudal (n): (0) no segmentado (1) segmentado.

361. Número de segmentos del tercer radio procurrente ventral (n): (0) tres o menos; (1) cuatro o más.

362. Elementos óseos accesorios de la aleta caudal (o "stays" según Zanata \& Vari, 2005; MI10: 304): (0) ausentes; (1) presentes.

- Uroneurales:

363. Radios procurrentes ventrales anteriores de la aleta caudal (MI10: 305): (0) pareados, solo fusionados en su porción distal; (1) fusionados en huesos mediales laminares.

364. Uroneurales (MI10: 306): (0) ausentes o un par; (1) dos pares.

\section{Escamas}

- Morfología:

365. Escamas (MI10: 317): (0) cicloides; (1) ctenoides, (2) espinoides; (2) crenadas.

366. Borde anterior de las escamas (MI10: 318): (0) uniformemente curvo o poco ondulado; (1) con ondulaciones conspicuas.

367. Circuli en el campo posterior de las escamas (MI10: 319): (0) presentes; (1) ausentes.

368. Radii en las escamas (MI10: 320): (0) ausentes, o en número muy reducido; (1) presentes y numerosos en la mayoría de las escamas.

369. Radii dirigidos hacia el campo anterior de las escamas (MI10: 321): (0) presentes; (1) solo como un surco longitudinal sin bordes definidos; (2) ausentes.

370. Radii en las escamas (MI10: 322): (0) no convergen hacia el foco; (1) convergen hacia el foco.

371. Surcos semicirculares sobre el campo posterior de las escamas (MI10: 323): (0) ausentes; (1) presentes.

- Distribución de las escamas:

372. Escamas cubriendo la espina supraoccipital (MI10: 324): (0) ausentes; (1) presentes, cubriéndola completamente. 
373. Escamas medias predorsales (MI10: 325): (0) cubren toda la zona predorsal; (1) deja un área desnuda anterior a la aleta dorsal.

374. Sierras ventrales (MI10: 326): (0) ausentes; (1) presentes.

375. Escamas que cubren la base de la aleta anal (MI10: 327): (0) en una o dos hileras; (1) varias hileras de escamas, que cubren al menos el tercio basal de los radios anales.

376. Escamas que cubren los lóbulos de la aleta caudal (MI10: 328): (0) cubren solo su base; (1) cubren un tercio de su longitud.

\section{Musculatura y ligamentos}

- Musculatura craneal:

377. Forma e inserción del ligamento primordial (VH01: 8; ME13: 373): aplanado e insertado sobre el proceso ascendente de la maxila; (1) redondeado sagitalmente e insertado sobre la mitad distal de la lámina maxilar.

378. Ligamento entre la premaxila y la maxila (VH01: 10; ME13: 376): (0) débil, con la premaxila apenas bifurcada en su zona de anclaje; (1) fuerte, con la premaxila profundamente bifurcada en su zona de anclaje.

379. Ligamento entre la premaxila y el extremo distal del proceso ascendente de la maxila (VH01: 11; ME13: 377): ausente; (1) presente.

380. Ligamento entre la premaxila y la porción media del proceso ascendente de la maxila (VH01: 12; ME13: 378): ausente; (1) presente.

381. Tendón accesorio del adductor mandibulae (MI10: 329): (0) ausente; (1) presente.

382. Posición longitudinal de la inserción del tendón accesorio del adductor mandibulae (MI10: 330): (0) en la línea vertical que pasa por la mitad posterior del cartílago de Meckel; (1) en la línea vertical que pasa en la mitad del cartílago de Meckel o anterior a este punto.

383. Posición longitudinal de la inserción del tendón accesorio del adductor mandibulae (m, MI10: 331): (0) ventral al cartílago de Meckel; (1) anterior al cartílago de Meckel; (2) en un proceso medial del dentario.

384. Inserción posterior de la sección rictalis $\left(=\mathrm{A}_{1}\right)$ del adductor mandibulae (MI10: 332): (0) principalmente sobre la rama vertical del preopérculo; (1) principalmente sobre la rama horizontal del preopérculo.

385. Sitios de inserción posterior del tendón facial de la sección rictalis $\left(=\mathrm{A}_{1}\right)$ del adductor mandibulae (MI10: 333): (0) en el cuadrado, cerca de su punto de articulación con el preopérculo; (1) en el preopérculo, posterior al cuadrado. 
386. Inserción anterior de la sección rictalis $\left(=\mathrm{A}_{1}\right)$ del adductor mandibulae (MI10: 334):

(0) en la maxila; (1) en el proceso coronoideo de la mandíbula.

387. Contacto entre el borde dorsal del adductor mandibulae y el borde ventral del dilatator operculi (MI10: 335): (0) ausente; (1) presente.

388. Extensión anterior del adductor arcus palatini (MI10: 336): (0) cubre conspicuamente más de la mitad de la superficie dorsal del mesopterigoides; (1) cubre hasta la mitad de la superficie dorsal del mesopterigoides.

389. Porción posterior del levator arcus palatini (MI10: 337): (0) bordeada lateralmente por el adductor mandibulae y medialmente por el adductor arcus palatini; (1) limitada lateral y medialmente por las secciones stego-malaris $\left(=\mathrm{A}_{2}\right)$ y stegalis $\left(=\mathrm{A}_{3}\right)$ del adductor mandibulae.

En los caracteres 381 al 389 se usó la nomenclatura miológica propuesta por Datovo \& Vari (2013): el tendón del adductor mandibulae, como fue llamado por Mirande (2010: carácter 329), se nombró como tendón accesorio y las secciones del adductor mandibulae fueron usadas con nombres en vez de símbolos alfanuméricos.

390. Origen del dilatator operculi (MI10: 338): (0) anterior a la vertical que pasa por el borde posterior del ojo; (1) completamente posterior a la vertical que pasa por el borde posterior del ojo.

- Postcráneo:

391. Pseudotímpano limitado por la primera costilla, el lateralis superficialis, la segunda costilla, el obliquus inferioris y el obliquus superioris (MI10: 339): (0) ausente; (1) presente.

392. Inserción anterior de la aponeurosis pterótica (MI10: 340): (0) en la espina pterótica o en la superficie lateral del canal semicircular horizontal; (1) en un lóbulo del pterótico situado dorsalmente al canal semicircular; (2) sobre el pterótico o esfenótico, distintamente dorsal al canal semicircular horizontal.

- Musculatura caudal:

393. Inserción posterior del flexor dorsalis superior en los radios de la aleta caudal (n): (0) a través de una fibra tendinosa simple; (1) a través de dos o más fibras tendinosas.

El flexor dorsalis superior se origina de la modificación o unión de algunas fibras del flexor dorsalis con algunas fibras de la porción posterior del supracarinalis posterior. Este último músculo se extiende posterodorsalmente a lo largo del pedúnculo caudal y por lo general alcanza la porción distal de las espinas neurales posteriores y parte de los radios procurrentes dorsales (Winterbottom, 1974). El flexor dorsalis superior se 
extiende desde la zona posterior del supracarinalis posterior o desde un punto en el área entre las porciones distales de las tres espinas neurales posteriores, hasta la superficie del primer radio caudal principal. El flexor dorsalis superior es visible posterolateralmente y aunque unas pocas fibras de su porción ventral pueden estar asociadas con fibras del flexor dorsalis, se pudieron codificar todas las especies examinadas sin problema (véase otros detalles en Weitzman \& Fink, 1985: figs. 48-49; Winterbottom, 1974: fig. 50). En la mayoría de las especies analizadas, incluyendo algunas de Gephyrocharax, se encontró el estado 0 del carácter 393. En contraste, un grupo reducido de especies de Gephyrocharax y del grupo externo fueron codificadas con el estado 1 (Fig. 6).

394. Inserción posterior de la fibra tendinosa más ventral de la musculatura hypaxialis en los radios de la aleta caudal (n): (0) en el radio 19; (1) en el radio 18.

En este carácter, se describe la variación observada en el punto de inserción terminal de la fibra tendinosa más ventral de la musculatura hypaxialis. En casi todas las especies analizadas, incluyendo las de Gephyrocharax, se encontró el estado 0 (Figs. 6 y 9). En muy pocas especies se encontró el estado 1 (e. g. Argopleura magdalenensis). Y solo en Astyanax asuncionensis, Xenurobrycon macropus, Pseudocorynopoma doriae y Tyttocharax sp., se encontraron ambos estados y fueron codificadas polimórficas.

395. Inserción posterior de la fibra tendinosa más ventral de la musculatura hypaxialis en el radio 19 de la aleta caudal (n): (0) en la superficie lateral o ventral; (1) en la superficie dorsal.

En este carácter, se describe la variación observada en la zona del radio caudal 19 en la que se inserta posteriormente la fibra tendinosa mencionada en el carácter anterior. En casi todas las especies de Gephyrocharax, Corynopoma riisei y Pterobrycon myrnae, entre otras, se encontró el estado 0 (Figs. 6 y 9). En la gran mayoría de las especies del grupo externo, se encontró el estado 1. Cuando esta fibra tendinosa se inserta en la superficie ventral del radio 18 de la aleta caudal, se codificó inaplicable.

396. Número de fibras tendinosas ventrales de los hypaxialis que se insertan posteriormente en los radios 18 y 19 de la aleta caudal (n): (0) una o dos; (1) tres o más. En este carácter, se excluyen de los conteos las fibras modificadas que forman parte del tendón común, descripto por Weitzman y Fink (1985: figs. 48-49), que se observa casi siempre entre los hypaxialis y el lateralis superficialis. En las especies de Chrysobrycon, por ejemplo, se encontró que la fibra insertada en el radio caudal 18 forma una estructura tendinosa laminar y fina, que, aunque parece muy ramificada, en 
su porción terminal se converge en un mismo punto. Las especies de Chrysobrycon y casos con esta misma condición fueron codificadas con el estado 0. La mayoría de las especies analizadas (incluyendo las de Gephyrocharax) presentaron tres o más fibras tendinosas, estado 1, y en todos los casos estas fibras fueron fácilmente identificables.

397. Segunda fibra tendinosa del hypochordal longitudinalis (n, Fig. 6: estado 0): (0) insertada posteriormente en el primer radio de la aleta caudal; (1) insertada posteriormente en el segundo radio de la aleta caudal.

398. Número de fibras tendinosas del hypochordal longitudinalis que se insertan posteriormente en los radios de la aleta caudal (n): (0) cuatro o más; (1) tres o menos.

399. Número de fibras tendinosas del hypochordal longitudinalis que se insertan posteriormente en los radios de la aleta caudal (n): (0) cinco o menos; (1) seis o más.

Los caracteres 397 a 399 muestran una serie de variaciones en las fibras tendinosas del hypochordal longitudinalis que se insertan posteriormente en los radios caudales. Este músculo fue descripto comparativamente por Winterbottom (1974) para diversos grupos de peces teleósteos. El hypochordal longitudinalis es fino, laminar, posicionado medialmente con respecto a los músculos epaxialis e hypaxialis, con su porción ventral ubicada en posición medial al flexor ventralis y su porción dorsal lateralmente al flexor dorsalis. En las especies estudiadas, se encontró que la inserción terminal de este músculo se da a través de diferentes ramificaciones tendinosas que se insertan posteriormente en los radios caudales. En el carácter 397, se describe la posición de la segunda fibra tendinosa (en sentido dorsoventral), donde el estado 0 se observó en la mayoría de las especies analizadas (incluye las de Gephyrocharax), mientras que el estado 1 se observó en pocas especies (e. g. Xenurobrycon macropus). Los caracteres 398 y 399 describen los intervalos observados en el conteo de estas ramificaciones tendinosas. La mayoría de las especies analizadas, incluyendo las de Gephyrocharax, presentan cuatro o cinco ramificaciones tendinosas, mientras que en algunas especies como Corynopoma riisei, Scopaeocharax rhinodus y Xenurobrycon macropus entre otras, se encontró como máximo tres ramificaciones tendinosas (398: estado 1). En pocas especies analizadas externas a Stevardiinae (e. g. Aphyocharax dentatus, Oligosarcus jenynsii y Prionobrama paraguayensis), se encontraron seis o más ramificaciones tendinosas (399: estado 1).

\section{Morfología externa, coloración y caracteres varios}

- Coloración:

400. Mancha humeral (BE08: 111; CA11: 373): (0) ausente; (1) presente. 
La presencia o ausencia de mancha humeral varía entre las especies de Gephyrocharax. Por esta razón y con el propósito de conocer su comportamiento filogenético se incluyó este carácter, mientras que se recodificó el carácter 401.

401. Mancha humeral (m, MI10: 341): (0) verticalmente alargada; (1) horizontal u ovoide. 402. Segunda mancha humeral (MI10: 342): (0) ausente o difusa; (1) presente como una barra vertical.

403. Mancha oscura conspicua en la aleta dorsal (MI10: 343): (0) ausente; (1) presente.

404. Intensa pigmentación negra o marrón oscura concentrada sobre los primeros cinco radios anteriores de la aleta dorsal (n): (0) ausente; (1) presente. (G. melanocheir)

En este carácter, se describe la presencia de un patrón de pigmentación que Eigenmann (1912: 25) reportó para Gephyrocharax melanocheir (otros detalles en Vanegas-Ríos et al., 2013: fig. 7). Esta pigmentación se usó en revisiones subsiguientes de Myers (en Eigenmann y Myers, 1929) y Schultz (1944).

405. Línea horizontal de cromatóforos justo dorsal a la base de la aleta anal (MI10: 344): (0) ausente; (1) presente.

406. Color de los lóbulos de la aleta caudal (MI10: 345) (0) simétricamente hialinos, amarillentos, rojizos o violáceos; (1) el lóbulo ventral es rojizo o anaranjado, mientras que el dorsal es hialino; (2) el lóbulo ventral es negro y el dorsal hialino; (3) ambos lóbulos son marrones oscuros o negros; (4) pigmentación negra o marrón oscura desde la base a las porciones distales de los radios externos; (5) área blanquecina o desprovista de pigmentación desde la parte proximal de los radios hasta un tercio de su longitud.

En este carácter, se adicionaron dos estados (4 y 5) que describen dos tipos de pigmentación caudal, no incluidas por Mirande (2010). El estado 4 fue descripto en Meek \& Hildebrand (1913) para Gephyrocharax atracaudatus, mientras que el estado 5 fue descripto por Meek \& Hildebrand (1916) para G. intermedius.

407. Manchas difusas en los flancos (MI10: 346): (0) ausentes; (1) presentes, especialmente en ejemplares juveniles.

408. Pequeñas manchas sobre cada escama de los flancos (MI10: 347): (0) ausentes; (1) presentes.

409. Mancha oscura que cubre toda la altura del pedúnculo caudal (MI10: 348): (0) ausente; (1) presente.

- Caracteres varios:

410. Aleta adiposa (MI10: 356): (0) presente; (1) ausente. 
411. Surcos con neuromastos sobre la cabeza, justo arriba de los ojos (m, FE07: 20; FE11: 13: MT12: 50): (0) ausentes o poco desarrollados, (1) presentes, bien desarrollados. Ferreira et al. (2011) propusieron que los surcos con neuromastos sobre la cabeza podían organizarse a través de una serie multiestado que describe su grado de desarrollo. En este estudio, este carácter se reorganizó en una serie de transformación binaria, dado que la separación entre la ausencia de surcos y la condición de surcos poco desarrollados no puede ser establecida en todas las especies. Cuando no se pudo asignar algún estado por observarse una condición intermedia, se codificó como polimórfico. En Carlastyanax aurocaudatus, se observaron hendiduras sobre los frontales, pero sin neuromastos visibles, razón por la cual se le asignó el estado 0.

412. Longitud del pedúnculo caudal (n): (0) igual o más corto que su altura; (1) muy alargado, dos veces más largo que alto.

413. Papilas sobre la lengua (MI10: 357): (0) desalineadas; (1) alineadas.

414. Papila urogenital en hembras adultas ( $m$, MW09: 14): (0) no desarrollada externamente o reducida; (1) bien desarrollada externamente.

415. Forma de la papila urogenital (n): (0) triangular y en parte orientada en sentido posteroventral; (1) recta o redondeada, en general orientada en sentido ventral.

La papila urogenital desarrollada externamente fue encontrada previamente en las hembras de Lophiobrycon weitzmani Castro, Ribeiro, Benine \& Melo por Menezes \& Weitzman (2009). Hay casos en los que esta papila también se desarrolla externamente en ambos sexos, como en las especies de Monotocheirodon Eigenmann \& Pearson, donde a los machos le sirve como un órgano intromitente asociado al proceso de inseminación (Menezes et al., 2013). Después, esta papila fue descripta para hembras adultas de Gephyrocharax torresi (Vanegas-Ríos et al., 2013: figs. 1b y 7b). Menezes et al. (2013) sugirieron que esta papila en hembras puede constituir un órgano para el depósito de óvulos, fecundados o no, antes de su liberación. La papila se observó externamente, pero sería óptimo contar con investigación histológica y ontogenética para estudiar aspectos más específicos de su desarrollo y función en hembras. El carácter 414 se codificó únicamente para hembras adultas de cada una de las especies analizadas.

416. Unión ventral de las membranas branquiales (MI10: 349): (0) unidas anteriormente, pero no cubren al istmo; (1) unidas a lo largo de la longitud del istmo, pero no sujetadas a este; (2) unidas entre sí y con el istmo. 
417. Forma de las narinas (MI10: 351): (0) dos orificios del mismo lado, divididos por un pliegue de piel; (1) dos orificios completamente separados de cada lado.

418. Número de 2n cromosomas (MI10: 361): (0) 36 a 40; (1) 46 o más.

419. Número de 2n cromosomas (MI10: 362): (0) 48 o menos; (1) 50 o más.

420. Número de 2n cromosomas (MI10: 363): (0) 50 o menos; (1) 52 o más.

421. Número de 2n cromosomas (MI10: 364): (0) 52 o menos; (1) 54 o más.

422. Número de 2n cromosomas (MI10: 365): (0) 56 o menos; (1) 58 o más.

\section{Dimorfismo sexual en machos adultos}

- Sistema laterosensorial de la línea lateral:

423. Tubo terminal de la línea lateral en la aleta caudal rodeado por una expansión laminar (m, WM98: 6; FE11: 71) (Fig. 5a: estado 1): (0) ausente; (1) presente.

424. Posición del tubo terminal de la línea lateral de la aleta caudal (n): (0) recto; (1) inclinado posteroventralmente.

425. Posición del tubo terminal de la línea lateral y la escama-bolsillo (n): (0) separados; (1) solapados, la porción posterior del tubo terminal localizada sobre la región dorsal de esta escama.

En los caracteres 423 a 425 (Fig. 5), se describen una serie de variaciones observadas en el tubo terminal de la línea lateral. Solamente en dos machos adultos de Gephyrocharax melanocheir, se encontró incrustado en la porción dorsal de la escamabolsillo un tubo de canal muy pequeño. Este tubo no se observó en otros ejemplares de G. melanocheir, por tal motivo su presencia fue considerara anómala y no considerada en este trabajo. El estado 1 de los caracteres 424 y 425 se observó en G. major (Fig. $1 b)$.

- Suspensorio y aparato opercular:

426. Estructura filamentosa del opérculo, subopérculo y radio branquiostego más posterior proyectada posteriormente a la longitud media del cuerpo (n): (0) ausente; (1) presente. La modificación posterior del opérculo, subopérculo y el radio branquiostego más posterior no ha sido analizada en un estudio filogenético (carácter 426). Esta modificación, presente en Corynopoma riisei, no se consideró homóloga a la modificación en el aparato opercular que presentan algunas especies de Diapoma (carácter 202). Ambas modificaciones tienen patrones distintos de forma o tamaño, incluyen diferentes estructuras entre ambos géneros y en $C$. riisei solo se desarrolla en los machos, mientras que en las especies de Diapoma aparece en ambos sexos. Esto 
sugiere que ambos tipos de modificaciones pueden tener orígenes diferentes y son codificados separadamente.

- Esqueleto branquial y hioideo:

427. Filamentos branquiales del primer arco branquial unidos o modificados para formar una glándula branquial (MI10: 352): (0) ausente; (1) presente.

Gephyrocharax intermedius fue la única especie del género en la que no se observó glándula branquial consistentemente presente en los ejemplares examinados. La pérdida de glándula se observó en un $94 \%$ de los machos maduros, y aunque esto denota una tendencia a perder completamente la glándula, se codificó polimórfico para esta especie para reflejar su distribución de estados en la matriz de caracteres.

- Cintura y aleta pectoral:

428. Primer radio ramificado de la aleta pectoral forma una estructura distal muy ramificada en forma de abanico (n): (0) ausente; (1) presente.

429. Número de ramificaciones terminales diminutas que forman la estructura en abanico de la aleta pectoral (n): (0) menos de 60; (1) 60 o más.

Vanegas-Ríos et al. (2013: fig. 3) describieron una estructura muy ramificada en forma de abanico en la porción distal del primer radio ramificado de la aleta pectoral en Gephyrocharax melanocheir y G. torresi (carácter 428). Si bien tal estructura ya había sido mencionada por otros autores para G. melanocheir (e. g. Schultz, 1944), no había sido analizada en un estudio filogenético. Esta estructura puede variar interespecíficamente en un intervalo estable en su número de ramificaciones terminales (carácter 429). Esta estructura distal es independiente de la pigmentación que puede darse en esta región y que describe en el carácter 536.

- Cintura y aletas pélvicas:

430. Posición del extremo anterior del hueso pélvico con respecto a la posición de las costillas pleurales (m, WF85: 12, 41-42): (0) similar en ambos sexos o apenas más anterior en machos; (1) más anterior en machos que en hembras, en una distancia mayor a la presente entre las costillas 6 y 7 .

Este carácter complementa la variación propuesta por Weitzman \& Fink (1985), que fue discutida previamente para los caracteres sobre la porción anterior del hueso pélvico con respecto a la posición de las costilla pleurales (311-315).

431. Extremos proximales de los radios pélvicos mediales primero, segundo, y a veces tercero (WF85: 5; WM98: 13): (0) no ubicados anteriormente con respecto a los radios adyacentes; (1) ubicados anteriormente con respecto a los radios adyacentes. 
Este carácter ha sido considerado una sinapomorfía de Xenurobryconini por Weitzman \& Fink (1985: figs. 35-36).

432. Tamaño de los radios de la aleta pélvica (n): (0) similares entre sí o los externos ligeramente más alargados; (1) los del medio y especialmente los radios ramificados 5 a 7 más alargados que los restantes radios.

El estado 1 de este carácter solo ha sido encontrado en especies de Pterobrycon. Otras especies presentan variación en el tamaño de los radios de la aleta pélvica, pero no cómo la indicada.

433. Longitud relativa del primer radio de la aleta pélvica (MI10: 257): (0) no extendido más posterior al extremo distal de los demás radios; (1) extendido más posterior al extremo distal de los demás radios.

434. Porción distal del primer radio de la aleta pélvica (n): (0) no hipertrofiada, de aspecto similar a la de los restantes radios; (1) muy hipertrofiada, engrosada y algo curvada.

En este carácter, se describe una gran modificación que tiene la porción distal del primer radio de la aleta pélvica. Esta modificación se observó en los machos adultos de Gephyrocharax sinuensis. Si bien, el primer radio de esta especie también esta alargado como se describió en el carácter anterior, no todas las especies que tienen tal alargamiento (e. g. Odontostilbe spp.) presentan la modificación descripta para $G$. sinuensis. Por consiguiente, ambos caracteres son complementarios pero reflejan condiciones diferentes. Ninguna otra especie de Gephyrocharax posee tal modificación en este radio.

- Aleta dorsal:

435. Radios anteriores de la aleta dorsal (MI10: 268): (0) no alargados; (1) alargados, llegan posteriormente hasta la aleta adiposa.

Pterobrycon landoni se codificó polimórfico para este carácter.

436. Radios anteriores o medios de la aleta dorsal (n): (0) indistintamente alargados; (1) radios muy desarrollados, alcanzan o sobrepasan la región media del pedúnculo caudal. Este carácter complementa el intervalo de variación del carácter 435 (especies que presentan un alargamiento de los radios dorsales en los machos adultos). El estado 1 se observó en algunas especies (e. g. Pseudocorynopoma doriae y Corynopoma riisei). El alargamiento de la aleta dorsal de los machos adultos de estas dos especies es muy similar, aunque en $C$. riisei los radios medios son un poco más largos que los anteriores y viceversa en $P$. doriae. 
437. Radio simple más posterior de la aleta dorsal (MI10: 269): (0) aproximadamente tan largo como el radio ramificado más anterior; (1) más alargado que el resto de los radios y en forma de filamento.

438. Forma y longitud de los radios anteriores de la aleta anal (MI10: 290): (0) similares a los posteriores; (1) más largos y comprimidos lateralmente que los posteriores.

439. Forma vertical de la aleta anal (m, WM98: 46): (0) no expandida, por lo general los radios anales anteriores un poco más largos que los posteriores; (1) expandida, casi todos los radios anales muy alargados ventralmente.

Weitzman \& Menezes (1998) encontraron que la aleta anal expandida (carácter 439, estado 1) es homoplásica entre Pterobrycon y Chrysobrycon myersi, y esta variación es incluida en este análisis para retestear su homología. El estado 1 se observó en Pterobrycon, Corynopoma y C. myersi. Además, este estado solo se codificó en aquellas especies cuyos machos adultos tienen una aleta anal sexualmente dimórfica. Por este motivo, especies como Markiana geayi, M. nigripinnis o Gymnocorymbus ternetzi fueron codificadas con el estado 0 . Las especies codificadas con el estado 1 del carácter anterior fueron codificadas inaplicables aquí y viceversa, para evitar ruido entre las optimizaciones de ambos caracteres. Si bien ambos estados descriptos en los dos caracteres son diferentes, el origen y función de estos tipos de modificaciones no está totalmente claro en todas las especies involucradas. Se ha planteado que en Pterobrycon o Corynopoma estas aletas anales modificadas pueden ser adaptaciones funcionales durante el cortejo (Weitzman \& Fink, 1985).

440. Contorno ventral de la aleta anal (n): (0) no convexo en la porción anterior de la aleta; (1) convexo desde la porción anterior de la aleta hasta la mitad o tres cuartos de su longitud, los radios de este intervalo un poco más largos que el resto.

En los machos adultos de casi todas las especies de Gephyrocharax, el contorno ventral de la aleta anal es moderadamente convexo (estado 1). Este aspecto convexo no es causado por el desarrollo de lóbulos especiales o expansiones de los radios que producen un contorno más sinusoidal (e. g. Pterobrycon, Burns \& Weitzman, 2005: figs. 16-17), sino por un leve y gradual alargamiento de los radios. Otras especies relacionadas con la aleta anal modificada en los machos adultos son: Chrysobrycon myersi, Corynopoma riisei, Pseudocorynopoma doriae, Pterobrycon landoni y $P$. myrnae (Weitzman \& Menezes, 1998: fig. 9; Burns \& Weitzman, 2005: figs. 16 y 18; Zarske, 2010: figs. 26-29). Estas especies fueron codificas con el estado 0 porque no presentan la misma condición observada en las especies de Gephyrocharax. En el caso 
particular de Chrysobrycon myersi y Corynopoma y Pterobrycon, la expansión y desarrollo dorsoventral de la aleta anal se codificó en el carácter anterior. En la gran mayoría de los carácidos la aleta anal no es sexualmente dimórfica en este aspecto y conserva una forma recta o cóncava en ambos sexos. Gephyrocharax martae se codificó inaplicable para este carácter porque no se conoce la forma de aleta anal de las hembras y los primeros radios anteriores del único macho adulto conocido son tan alargados que no describen ningún contorno regular.

441. Tamaño de los radios posteriores de la aleta anal (n): (0) tan largos como los restantes o ligeramente más cortos; (1) los tres o cuatro radios posteriores son más alargados que los radios contiguos, alcanzando los radios ventrales procurrentes de la aleta caudal.

Las especies de Pterobrycon fueron codificadas polimórficas debido a que presentan una condición intermedia, el último radio de la aleta anal es ligeramente más largo que el resto, y no el conjunto de dos o más radios como se describe en el estado 1.

- Esqueleto caudal:

442. Fusión entre el parhipural y el hipural uno (WF85: 1; WM98: 12): (0) ausente; (1) presente.

La fusión entre el parhipural y el primer hipural fue propuesta por Weitzman \& Fink (1985: 13) como “...fused each other...”, después, Weitzman \& Menezes (1998) lo redefinieron como “...either adpressed to each other with a narrow joint line, or fused to each other...”. Se prefirió usar el sentido original del carácter según Weitzman \& Fink (1985) y solo codificar en el estado 1, cuando estos huesos están completamente fusionados, es decir, no hay una línea estrecha entre ellos. Machos adultos de especies con estos huesos muy cercanos entre sí, con una casi indistinguible línea de separación, fueron codificados como casos intermedios.

Radios principales:

443. Mitades distales de los radios 7 a 10 de la aleta caudal (WF85: 29; WM98: 29, FE11: 69): (0) rectas, no curvadas ventralmente; (1) curvadas ventralmente.

444. Radios 11 al 14 de la aleta caudal (WF85: 30; WM98: 30: FE11: 66): (0) no estrechos distalmente y algunas veces acortados; (1) estrechos distalmente y algunas veces acortados.

445. Radios 1 a 8 y 16 a 19 más el primer radio procurrente ventral de la aleta caudal (WF85: 31; WM98: 31, FE11: 67): (0) nunca expandidos; (1) expandidos, con la 
expansión más marcada cerca de los márgenes dorsal y especialmente ventral de esta aleta.

446. Porción proximal de los radios 10 y 11 de la aleta caudal arqueada dorsalmente, con el radio 11 más curvado que el radio 10 (m, WF85: 27): (0) ausente; (1) presente.

Los caracteres 443 y 446 (estado 1) solo fueron observados en Xenurobrycon, Scopaeocharax y Tyttocharax (Weitzman \& Fink, 1985: figs. 11-14, 46 y 47).

447. Radios 10 y 11 de la aleta caudal (m, WF85: 55; WM98: 43): (0) no hipertrofiados o, si están hipertrofiados, no asociados a ligamentos; (1) hipertrofiados distalmente en el sitio de inserción proximal del ligamento de la escama-bolsillo, especialmente en el radio 11 .

Weitzman \& Fink (1985: figs. 13, 14) definieron el estado 1 como una sinapomorfía de Scopaeocharax y Tyttocharax.

448. Radios de la aleta caudal con forma de pliegue ("pump") (WM98: 9): (0) ausente, radios 11 y 12 no forman esta estructura; (1) presente, al menos con los radios 11 y 12 recurvados o expandidos, formando esta estructura.

En este carácter, se codificó solamente la presencia o ausencia de esta estructura, nombrada "caudal-fin pump" (Weitzman \& Fink, 1985: fig. 19), en vez de mantener la serie de transformación multiestado propuesta por Weitzman \& Menezes (1998).

449. Forma de los radios 11 y 12 de la aleta caudal (n, Fig. 5): (0) curvados dorsalmente o rectos a lo largo de su longitud; (1) muy curvados ventralmente a lo largo de su longitud.

450. Distancia entre las bases de los radios medios de la aleta caudal (m, WF85: 2 y 56; WM98: 44; FE11: 68) (Fig. 5b: estado 0): (0) tan grande o más pequeña entre las bases de los radios 10 y 11 que entre las bases de los radios 11 y 12; (1) mayor entre las bases de los radios 10 y 11 que entre las bases de los radios 11 y 12 .

Este carácter se modificó principalmente en función de las bases de los radios, para evitar una asociación con otros caracteres usados en este listado y en el de Mirande (2010), quien relaciona las distancias de los radios con respecto al tercer hipural.

451. Distancia entre las bases de los radios medios de la aleta caudal (n, Fig. 5): (0) ligeramente menor o casi tan grande entre los radios 12 y 13 que entre los radios 11 y 12; (1) dos veces más grande o mayor entre los radios 12 y 13 que entre los radios 11 y 12. 
452. Posición relativa de la base del radio 13 de la aleta caudal (n, Fig. 5): (0) se extiende sobre la porción posterior o posterodorsal del primer hipural; (1) se extiende sobre la porción posteroventral del segundo hipural.

453. Posición relativa de la base del radio 10 de la aleta caudal (n, Fig. 5b): (0) se extiende sobre la porción posteroventral del tercer hipural o inmediatamente ventral a este punto; (1) se extiende sobre un punto medio entre el segundo y tercer hipurales.

La posición de los radios de la aleta caudal parece no estar asociada con la forma de los hipurales o su desarrollo. Observaciones en la musculatura caudal, mostraron que el desarrollo diferencial de ciertos paquetes de fibras interradialis y los flexores dorsalis y ventralis puede alterar moderadamente la posición de inserción proximal de los radios de la aleta caudal. Sin embargo, esta posible asociación no se encontró en todos los casos.

\section{$\underline{\text { Radios procurrentes: }}$}

454. Radios procurrentes ventrales (MI10: 301): (0) finos; (1) laminares.

455. Desarrollo de los radios procurrentes ventrales de la aleta caudal (MI10: 303): (0) no proyectados a través de la musculatura y la piel del pedúnculo caudal; (1) proyectados ventralmente a través de la musculatura y la piel del pedúnculo.

456. Segundo, tercero y ocasionalmente cuarto radios procurrentes ventrales de la aleta caudal (m, EI12: Pág. 23; FE11: 72): (0) rectos, similares a los radios caudales pero de menor longitud en sentido anteroposterior, no asociados entre sí; (1) curvados, aplanados, de similar longitud y asociados entre sí formando una o dos estructuras en forma de pinza.

457. Radios procurrentes ventrales de la aleta caudal modificados formando estructuras en forma de pinza (n, Figs. 7a: estado 1): (0) una sola pinza, constituida principalmente por el segundo y tercer radio; (1) dos pinzas, la primera formada por el segundo y tercer radio y la segunda formada por el tercero y el cuarto.

En el carácter 456 (Figs. 5 y 7), se describe una modificación en los radios procurrentes ventrales de los machos adultos de Gephyrocharax, descripta inicialmente por Eigenmann (1912) con el nombre de "spur". Este término fue subsiguientemente utilizado por otros autores como Myers (en Eigenmann \& Myers, 1929) y Schultz (1944). Eigenmann (1914: 34) también utilizó el nombre de "lower caudal fulcra" en sentido similar a "spur". Hasta ese momento el término "spur" era utilizado sin una definición anatómica detallada, o al menos no reflejaba la complejidad de los radios procurrentes ventrales de Gephyrocharax. Después, Bussing (1974) usó el término 
"spur”, en su descripción de Pterobrycon myrnae, como “...Several lower procurrent rays are separate from the main fin and form a spur as in Gephyrocharax and other glandulocaudine genera...". Dado que este término "spur" ha sido usado en sentidos muy amplios y no tan similares, se consideró necesario redefinirlo en los últimos dos caracteres (456 y 457) que siguen la propuesta descripta como "claw-shape structure" por Vanegas-Ríos et al. (2013). El estado 1 del carácter 456 (Figs. 5 y 7a vs. 7c) se refiere estrictamente a la modificación que asocia el segundo, tercero e incluso cuarto radios procurrentes ventrales, los cuales, pueden tener variados grados de desarrollo y forma. Si bien estos radios suelen separarse del primer radio procurrente, tal separación no está perfectamente asociada con la modificación de tales radios procurrentes (otros Stevardiinae pueden presentarla sin tener un "spur", por ejemplo Pterobrycon myrnae). Por tal motivo, la separación y la modificación son consideradas en caracteres independientes. En el carácter 457, se discrimina la variación entre los radios que se modifican conjuntamente en forma de pinza.

458. Estructura en forma de pinza constituida por los radios procurrentes ventrales segundo y tercero (n, Figs. 5 y 9a): (0) radios muy curvados dorsal y ventralmente, respectivamente; (1) radios rectos o muy poco curvados a lo largo de su longitud.

Este carácter solo es aplicable para las especies que presentan estos radios modificados en una o dos estructura en forma de pinzas.

459. Estructura en forma de pinza constituida por los radios procurrentes ventrales segundo y tercero (n, Fig. 5): (0) radios separados entre sí por un espacio moderado en la mayoría de su longitud, nunca fusionados; (1) radios muy cercanos entre sí casi en toda su longitud, con frecuencia fusionados distalmente.

Este carácter solo es aplicable a las especies que presentan estos radios modificados en una o dos estructuras en forma de pinzas.

460. Hemiradii de la porción posterior del tercer radio procurrente ventral (n): (0) poco expandidos lateralmente o igualmente desarrollados lateral y sagitalmente en toda su longitud; (1) muy expandidos lateralmente, en especial con respecto a la porción anterior.

El estado 1 del carácter 460 (Fig. 5a) está condicionado a la presencia de radios procurrentes ventrales modificados en una o dos pinzas, pero es variable dentro de las especies con esta condición. Por tal motivo, ambas condiciones fueron codificadas separadas. En la mayoría de las especies de Gephyrocharax, se encuentra el estado 0 (Fig. 5b) 
461. Separación entre las mitades posteriores del primer y segundo radios procurrentes ventrales (n): (0) separados por una espacio estrecho, menor al grosor del primer radio procurrente ventral; (1) separados por un espacio igual o mayor al grosor del primer radio procurrente ventral.

Este carácter resume la variación observada por Eigenmann (1912) y Bussing (1974), quienes notaron que ciertos radios procurrentes ventrales (en este caso el segundo y tercero) están separados del resto de los radios (Fig. 5b). Este carácter es inaplicable para aquellas especies con el segundo radio procurrente ventral muy expandido sagitalmente en su porción posterior (carácter 463, estado 1).

462. Concavidad en la zona ventral del primer radio procurrente ventral (n, Figs. 5, 7a, c): (0) ausente; (1) presente.

463. Asociación entre el primer y segundo radio procurrente ventral (n): (0) débil, la concavidad del primero y la expansión posterior del segundo poco desarrolladas, separadas entre sí; (1) fuerte, la concavidad del primero y la expansión posterior del segundo muy desarrolladas, cercanas entre sí.

Los estados 1 de los caracteres 462 y 463 (Fig. 5a) están presentes en dos grupos diferentes de especies. El primer grupo desarrolla estructuras en forma de pinza en los radios procurrentes ventrales, mientras que el segundo presenta una fuerte separación entre el primer y segundo radios procurrentes ventrales en los machos adultos (características independientes entre sí); el segundo grupo incluye a la especies del primer grupo. El carácter 462 se consideró aplicable a las especies que tienen una separación mayor de los radios procurrentes ventrales, la cual, parece más asociada (aunque no de manera exacta) con la presencia de estructuras en forma de pinza. El carácter 463 solo es aplicable a las especies con la concavidad descripta en el carácter 462.

464. Longitud del primer y segundo radios procurrentes ventrales (n, Fig. 5): (0) el segundo tiene más de la mitad de la longitud del primero; (1) el segundo tiene la mitad o menos de la longitud del primero.

El estado 1 del carácter 464 aplica únicamente para las especies con radios procurrentes ventrales modificados en una o dos pinzas. La presencia de estas pinzas condiciona la variación de la longitud del primer y segundo radios procurrentes, pero no hay una correlación perfecta entre ambos caracteres. 
465. Longitud del tercer radio procurrente ventral (n, Fig. 5): (0) no alcanza la región media del primer radio procurrente ventral; (1) alcanza o sobrepasa la región media del primer radio procurrente ventral.

466. Número de segmentos del segundo radio procurrente ventral (n): (0) cuatro o más; (1) uno o tres.

467. Número de segmentos del segundo radio procurrente ventral (n): (0) siete o más; (1) seis o menos.

En los caracteres 465 al 467, se describe una serie de variaciones que no están asociadas con las estructuras en forma de pinzas u otras modificaciones en los radios procurrentes ya descriptas previamente. En la mayoría de las especies analizadas, las variaciones son más pronunciadas en los machos adultos que en las hembras y por este motivo se codificaron por separado.

468. Porción distal del cuarto radio procurrente ventral (n): (0) no comprimida sagitalmente ni curvada (1) comprimida sagitalmente y un poco curvada.

El estado 1 del carácter (Fig. 5a) no está completamente asociado con la modificación en forma de pinza de los radios procurrentes ventrales en los machos adultos. La expansión sagital de la porción distal del cuarto radio procurrente puede estar muy desarrollada (e. g. G. atracaudatus) o moderadamente desarrollada (e. g. G. caucanus o G. martae), pero estas variaciones son difíciles de cuantificar de forma discreta, y por tal motivo no fueron consideradas en este estudio. El estado 0 fue observado en pocas especies de Gephyrocharax, G. chocoensis y G. major (Fig. 5b). En especies donde la mayoría de los radios caudales están muy expandidos sagitalmente, como Tyttocharax sp., se codificó el estado 0 debido a que fueron consideradas condiciones diferentes.

469. Uno o dos pliegues laterales de tejido conectivo hipertrofiado desde y entre los radios del lóbulo ventral de la aleta caudal (n): (0) ausentes; (1) presentes.

En el estado 1, se describe una condición solamente observada en Landonia latidens. Esta especie presenta uno o dos pliegues laterales semejantes a bolsillos, que se proyectan en las superficies lateral y ventral desde y entre los radios caudales (Weitzman \& Menezes, 1998: 181, Landonia). Aunque estos pliegues parecen un bolsillo y están en el lóbulo ventral de la aleta caudal, no son considerados homólogos al resto de los bolsillos glandulares formados por escamas (véase carácter 491).

470. Tejido glandular de apariencia granular en la aleta caudal (MW09: 2; MI10: 353): (0) ausente; (1) presente. 
Como no se usaron técnicas histológicas para asignar los estados en el carácter 470, la codificación del tejido glandular en las especies analizadas está basada en lo reportado en la literatura (Bussing, 1974; Atkins \& Fink, 1979; Weitzman \& Fink, 1985; Weitzman \& Menezes, 1998; Weitzman et al., 2005; Menezes \& Weitzman, 2009, 2011; Ferreira et al., 2011). Las especies con o sin tejido glandular mencionadas en la literatura dentro de un género o subfamilia (no se discriminó la presencia vs. la ausencia del tejido para cada especie en la codificación de la respectiva matriz) o aquellas donde no se encontró tejido glandular se codificaron polimórficas. Se tomó como criterio complementario para codificar la presencia del tejido glandular en alguna especie, que ésta tuviera tejido de aspecto morfológicamente similar al tejido glandular de Corynopoma riisei [(Atkins \& Fink, 1979), (e. g. en Gephyrocharax)]. Cuando ninguno de estos criterios pudo ser aplicado o existió ambigüedad para codificar una especie, se prefirió asignar una entrada faltante en la matriz. Aunque el estudio de Ferreira et al. (2011) aportó nuevos datos histológicos de varias especies aquí analizadas, estos fueron tomados con precaución porque se encontraron varias inconsistencias de los estados de los caracteres listados con su respectiva codificación en la matriz de caracteres.

471. Tejido glandular compuesto por células de alarma modificadas ("club cells") (MW09: 4): (0) ausente; (1) presente.

472. Tejido glandular caudal compuesto por células mucosas modificadas (MW09: 5; MI10: 355): (0) ausente; (1) presente.

En los caracteres 471 y 472, la codificación del tipo de tejido glandular en las especies analizadas está basada en la literatura (Atkins \& Fink, 1979; Weitzman \& Fink, 1985; Weitzman \& Menezes, 1998; Weitzman et al., 2005; Menezes \& Weitzman, 2009, 2011; Ferreira et al., 2011). Las especies sin reportes histológicos sobre el tipo de células modificadas y codificadas por Menezes \& Weitzman (2009) dentro de su taxón Stevardiinae fueron asignadas polimórficas para el respectivo tipo de células, debido a la falta de información en muchas especies y que aparentemente este tipo de células solo puede ser observado en los machos activos (Ferreira et al., 2011). La presencia de tejido glandular y los tipos de células glandulares fueron asumidos independientemente en la codificación, porque los aspectos de su desarrollo son poco conocidos en los machos activos de muchas especies. Estos dos caracteres y el carácter sobre presencia de tejido glandular fueron incluidos en este estudio para propósitos de discusión con la literatura tradicional (e. g. Weitzman \& Menezes, 1998), aunque por su gran cantidad 
de entradas faltantes deben ser interpretados cuidadosamente en los resultados de la hipótesis final.

- Ganchos óseos en las aletas:

473. Ganchos óseos en las aletas (MI10: 307): (0) ausentes; (1) presentes en machos adultos.

474. Ganchos óseos en las aletas pectorales (MI10: 310): (0) ausentes; (1) presentes.

475. Ganchos óseos en la aleta dorsal (MI10: 311): (0) ausentes; (1) presentes.

476. Ganchos óseos en las aletas pélvicas (MI10: 309): (0) ausentes; (1) presentes.

477. Ganchos óseos en la base de los radios pélvicos (MI10: 313): (0) en número reducido comparado con la porción segmentada de los radios; (1) tan numerosos como en la porción segmentada de los radios.

478. Ganchos óseos en el último radio pélvico (MI10: 314): (0) en número reducido; (1) tan numerosos como en otros radios.

En el estado 0 de los caracteres 477 y 478, no se codificó la ausencia según Mirande (2010), para evitar codificar dos veces la pérdida de ganchos en la aleta pélvica (476).

479. Ganchos óseos en el primer radio pélvico (MI10: 315): (0) ausentes; (1) presentes.

480. Ganchos óseos en la aleta anal (MI10: 308): (0) ausentes; (1) presentes.

481. Posición de los ganchos óseos de la aleta anal (MI10: 316): (0) pareados y ordenados en sentido lateral o posterolateral; (1) posicionados medialmente y orientados en sentido posterior; (2) dispuestos asimétricamente.

482. Ganchos óseos en la aleta caudal (MI10: 312): (0) ausentes; (1) presentes.

483. Distribución de ganchos óseos en los radios principales de la aleta caudal (n): (0) presentes en la mitad o más de los radios; (1) presentes en menos de la mitad de los radios.

484. Posición de los ganchos óseos en los radios principales de la aleta caudal (n): (0) en los radios del lóbulo dorsal; (1) en los radios del lóbulo ventral.

485. Posición de los ganchos óseos en los radios principales de la aleta caudal (n): (0) en uno o casi todos los radios entre el 1 y 12; (1) en uno o casi todos los radios entre el 13 y 19.

486. Posición de los ganchos óseos en los radios principales de la aleta caudal (n): (0) en uno o casi todos los radios entre 1 y 13; (1) en uno o casi todos los radios entre 14 y 19. En los caracteres 483-486, se codificó la variabilidad observada en la distribución y posición de los ganchos óseos de la aleta caudal. En Stevardiinae, la mayoría de las especies carecen de estos ganchos óseos. Sin embargo, algunas especies de 
Bryconamericus y Hemibrycon y muchas especies de los géneros que presentan escamación hipertrofiada en aleta caudal de los machos adultos (e.g. Gephyrocharax) tienen ganchos óseos en la aleta dorsal. Aunque los estados definidos en los caracteres 485 y 486 tienen intervalos incluyentes entre sí, la variación observada en la mayoría de las especies analizadas no fue polimórfica. Además, estos intervalos permitieron incluir la variabilidad de varias especies de Characidae y Stevardiinae que tienen condiciones atípicas con pocos ganchos óseos en la aleta caudal (e. g. Brittanichthys axelrodi Géry o Mimagoniates rheocharis), los cuales podrían ser interpretados como posibles autapomorfías y ser codificados como tal por separado. En vez de esto, se prefirió formar agrupamientos con los estados definidos que incluyan estas especies atípicas en grupos de especies con ganchos óseos distribuidos de manera más generalizada.

\section{- Escamación corporal y caudal:}

487. Escamas modificadas que se ubican cerca de la región humeral del cuerpo (n): (0) ausentes; (1) con una o dos escamas de base ancha y expandidas en su porción distal.

La presencia de una o dos escamas hipertrofiadas que se localizan dorsales a la línea lateral, cerca de la región humeral, fueron usadas por Bussing (1974: fig. 4) para diferenciar el género Pterobrycon de otros géneros emparentados. Estas escamas solo se encontraron en P. landoni y P. myrnae.

488. Escamación hipertrofiada en el lóbulo dorsal de la aleta caudal (m, WM98: 4; MW09: 3): (0) ausente; (1) presente.

Los Glandulocaudinae sensu Menezes \& Weitzman (2009) fueron separados de los Stevardiinae sensu Menezes \& Weitzman (2009) por la presencia de un conjunto de escamas modificadas en el lóbulo dorsal de la aleta caudal (carácter 488: estado 1), las cuales han sido ampliamente detalladas en la literatura (Weitzman \& Fink, 1985: fig. 19; Menezes \& Weitzman, 2009: figs. 15, 24, 32, 38, 48, 58, 67, 68 y 75). Menezes \& Weitzman (2009) definieron a Stevardiinae, en parte, por la presencia de una escamación hipertrofiada en el lóbulo ventral de la aleta caudal, la cual también ha sido extensamente documentada (Weitzman \& Fink, 1985: figs. 8-17; Weitzman \& Menezes, 1998: figs. 3-7 y 10-16). Weitzman et al. (2005) y Weitzman \& Menezes (2009) propusieron que la escamación hipertrofiada de la aleta caudal es independiente en cada lóbulo; este criterio es compartido en este estudio y así se codificó. Ambos tipos de escamación están asociados con la formación de tejido glandular y, adicionalmente para el caso de este Stevardiinae, con un bolsillo. Sin embargo, la 
presencia de tejido glandular no parece exactamente asociada a estos tipos de escamación. Mirande (2010: carácter 354) incluyó solamente una de estas dos condiciones en su matriz (carácter 6 de Menezes \& Weitzman, 2009), la que define Stevardiinae sensu Menezes \& Weitzman (2009). El carácter 488 se incluye para complementar la variación no analizada por Mirande (2010).

489. Escamas en la base del lóbulo dorsal de aleta caudal (MW09: 9): (0) no alargadas; (1) alargadas, su longitud mayor a dos veces la extensión de su altura.

Aunque el carácter se tomó como se describió en Menezes \& Weitzman (2009), solo se codificaron aplicables aquellas especies que presentan escamación hipertrofiada y modificada en el lóbulo dorsal de la aleta caudal de los machos adultos. Así se evita codificar dos veces la presencia de escamas modificadas en el lóbulo dorsal en los caracteres 488 y 489. Las escamas alargadas (489: estado 1) que presentan los miembros de Mimagoniates son, verdaderamente, un tipo de escamación hipertrofiada en el lóbulo dorsal. Por lo tanto, el término "escamación hipertrofiada en el lóbulo dorsal" no hace referencia exclusiva a las escamas alargadas de las especies de Mimagoniates, sino a todos los posibles tipos de escamación hipertrofiada en el lóbulo dorsal.

490. Escamación hipertrofiada en el lóbulo ventral de la aleta caudal (m, MW09: 6; MI10: 354): (0) ausente; (1) presente.

Menezes \& Weitzman (2009) y Mirande (2010) codificaron este carácter como un bolsillo glandular formado por escamas. En este estudio, el término "escamación hipertrofiada" es usado para todos los tipos de escamación caudal hipertrofiada y no exclusivamente para las que constituyen este tipo de bolsillo. En este estudio, no se han incorporado especies de Characidae que presenten otros tipos de escamación hipertrofiada no asociadas a un bolsillo.

491. Saco o bolsillo presumiblemente glandular, compuesto por escamas y con una abertura al exterior en el lóbulo ventral de la aleta caudal (m, WM98: 1; MW09: 6): (0) ausente; (1) presente.

La presencia de bolsillo glandular es uno de los caracteres más tradicionales en la taxonomía de los Glandulocaudinae sensu Weitzman \& Menezes (1998). Esta estructura ha sido muy bien documentada en diversos estudios filogenéticos y taxonómicos (Bölhke, 1958; Weitzman \& Fink, 1985; Weitzman \& Menezes, 1998; Weitzman et al., 2005; Menezes \& Weitzman, 2009; Ferreira et al., 2011). La presencia de tejido glandular (carácter 470) se ha asociado al desarrollo de un bolsillo de 
escamas, sin embargo, no en todas las especies con o sin este bolsillo se ha confirmado histológicamente la presencia o ausencia de tejido glandular (véase detalles en Weitzman et al., 2005; Menezes \& Weitzman, 2009; Ferreira et al., 2011). Dada esta falta de información, se prefirió mantener separados ambos caracteres. Por otro lado, no se pudo examinar un macho adulto de Phenacobrycon henni con la escamación caudal bien preservada. En la literatura (Roberts, 1973; Weitzman \& Fink, 1985; Weitzman \& Menezes, 1998; Weitzman et al., 2005), se describe que esta especie tiene tres escamas hipertrofiadas débilmente adheridas a los radios del lóbulo ventral de la aleta caudal. Weitzman et al. (2005) afirmaron que esta escamación hipertrofiada en $P$. henni podría ser intermedia entre las especies que tienen bolsillo y las especies de Knodus. En el único dibujo disponible del esqueleto y escamación caudal de un macho adulto de $P$. henni (Weitzman \& Fink, 1985: 20), no es posible estimar claramente si son una o tres escamas las que forman el bolsillo. Por estas incertidumbres, para esta especie los caracteres que se describen de aquí en adelante relacionados al bolsillo o a la escamabolsillo fueron codificados como entradas faltantes. En el caso de la presencia de bolsillo glandular (estado 1), esta especie se codificó polimórfica como consenso entre las incertidumbres mencionadas y la codificación de Weitzman \& Menezes (1998).

492. Margen del saco o bolsillo que forma una abertura al exterior en el lóbulo ventral de la aleta caudal (m, WM98: 8): (0) formado por una o dos escamas modificadas, con o sin radii hipertrofiados, donde la más posterior es denominada escama-bolsillo; (1) formado por tres o más escamas de tamaño semejante que no tienen radii hipertrofiados en tamaño o número.

Dentro de los tipos de escamación hipertrofiada en el lóbulo ventral de la aleta caudal, Weitzman et al. (1994: 51-52), Weitzman \& Menezes (1998: 188) y Weitzman et al. (2005: 345) sugirieron que la escama-bolsillo es homóloga, en todas las especies que presentan tal tipo de escama. Estos autores se basaron en la hipótesis de que todas las escamas-bolsillo se originan, durante el desarrollo, del mismo conjunto de escamas inmediatamente ventrales a las escamas de la línea lateral y a su gran relación con el tejido glandular y con el proceso reproductivo. Las observaciones realizadas apoyan esta idea. Se examinaron grandes series de ejemplares de diferentes tamaños en especies de Gephyrocharax (e. g. G. melanocheir, G. chocoensis, G. intermedius y G. valencia) y Corynopoma riisei donde se pudo observar que la escama-bolsillo siempre forma parte de las hileras de escamas inmediatamente ventrales a las escamas de la línea lateral, de las cuales siempre es la más posterior. En el estado 0 del carácter 492, 
se incluye a todas las especies que fueron tomadas por Weitzman \& Menezes (1998) con una única escama-bolsillo. Sin embargo, este estado se modificó para reflejar adecuadamente la condición de algunas especies con escama-bolsillo (e. g. Argopleura magdalenensis) que tienen una escama accesoria que contribuye a la formación del bolsillo. Poco se conoce sobre el desarrollo de estas escamas accesorias y su grado de homología entre las diferentes especies. Lo único observado en este estudio es que su presencia no está exactamente asociada con la presencia de escama-bolsillo. Por tal motivo, se codificó por separado en otro carácter para conocer su distribución en la filogenia (521).

493. Serie de escamas más posteriores en especies con bolsillo en el lóbulo ventral de la aleta caudal (n): (0) libres o en parte adheridas a los radios, sin pliegues laterales o espacios cóncavos entre sí; (1) fuertemente adheridas a los radios, sus bordes posteriores algo recurvados lateralmente y con espacios cóncavos entre sí.

Esta serie de escamas en los machos adultos es única en Diapoma. Menezes \& Weitzman (2011: figs. 13, 20, 30 y 36) presentaron varias ilustraciones de estas escamas para las especies de dicho género.

494. Número de escamas inmediatamente ventrales a las de la línea lateral, que se extienden posteriormente en la misma hilera, y se asocian a un saco o bolsillo (m, WM98: 18): (0) tres o menos; (1) cuatro o más.

495. Número de escamas inmediatamente ventrales a las de la línea lateral que se extienden posteriormente, en la misma hilera, y se asocian a un saco o bolsillo (m, WM98: 18): (0) seis o menos; (1) siete o más.

Weitzman \& Menezes (1998: 184) definieron una tribu llamada Diapomini apoyados en dos sinapomorfías, una de las cuales es la presencia de “... a multiple series of scales (at least three or more) immediately ventral to the lateral line series and extending posteriorly to the dorsal border of pouch opening...". El intervalo de escamas usado por estos autores fue separado en dos caracteres (494 y 495) que representan mejor el intervalo de variación. Las codificaciones fueron basadas tanto en observaciones personales como en registros e ilustraciones de Menezes et al. (2003: revisión de Planaltina), Menezes y Weitzman (2011: revisión de Diapoma). Estos caracteres fueron redefinidos para incluir las escamas que se distribuyen en sentido posteroventral desde la última escama de la línea lateral, ya sea con poro o sin poro, hasta la escama más posterior que pertenezca a la misma hilera. También, en el conteo descripto en 
ambos estados, se incluye la escama-bolsillo (si corresponde) y aquellas de la misma hilera que son complementarias a ésta.

496. Escamación en el lóbulo ventral de la aleta caudal en especies con bolsillo (m, WM98: 10: FE11: 7): (0) más compleja, desarrollada y modificada en machos que en hembras, tanto en patrón como en tamaño; (1) equivalente o aproximadamente de similar desarrollo en ambos sexos.

El estado 1 fue reportado por Menezes \& Weitzman (2011: 80) como una sinapomorfía de Planaltina, Acrobrycon y Diapoma. Una discusión sobre este carácter fue presentada por Weitzman \& Menezes (1998: 184-185). El carácter solo es aplicable para especies con escamación hipertrofiada en la aleta caudal formando un bolsillo.

497. Forma de la escama-bolsillo (n): (0) grande, no alargada posteriormente y sin pliegues horizontales; (1) pequeña, alargada posteriormente, curvada y horizontalmente plegada de modo tal que se forma un bolsillo lateralmente cóncavo.

Según Weitzman \& Menezes (1998) y Vanegas-Ríos et al. (2011, 2014) la escamabolsillo descripta en este carácter es diagnóstica para las especies de Chrysobrycon.

498. Lóbulos o expansiones posteriores en el borde posterior de la escama-bolsillo (m, WM98: 7): (0) ausentes o poco desarrollados; (1) presentes, bien desarrollados.

499. Número de lóbulos del borde posterior de la escama-bolsillo (m, WM98: 7): (0) uno; (1) dos o tres.

Los caracteres 498 y 499 (Fig. 7) reflejan una serie de transformación multiestado que fue usada por Weitzman \& Menezes (1998).

500. Lóbulo posterior de la escama-bolsillo (n): (0) no cubre el tercer radio procurrente ventral; (1) cubre el tercer radio procurrente ventral.

La mayoría de las escamas-bolsillo tienen algún tipo de lóbulo, pero en algunas especies de Gephyrocharax dicho lóbulo está dirigido posteroventralmente y puede tener diferentes longitudes (carácter 500: estado 1). Sin embargo, el desarrollo posterior del lóbulo es algo inestable interespecíficamente y está bastante asociado al tamaño del ejemplar, por lo cual no fue incluido en este estudio.

501. Tejido conectivo en la porción dorsal de la escama-bolsillo (n, Fig. 8a: estado 1): (0) ancla la escama hasta un punto sobre el radio 14 de la aleta caudal; (1) ancla la escama hasta un punto entre los radios 15 a 17 de la aleta caudal.

502. Número máximo de radii de la escama-bolsillo (m, WM98: 15) (Fig. 7): (0) 28 o menos (1) 29 o más. 
503. Número máximo de radii de la escama-bolsillo (m, WM98: 15) (Fig. 7): (0) menos de 40; (1) 40 o más.

504. Número máximo de radii de la escama-bolsillo (m, WM98: 15) (Fig. 7): (0) menos de 70; (1) 70 o más.

Weitzman \& Menezes (1998: carácter 15) usaron un solo intervalo de variación para la distribución del número de radii en la escama-bolsillo. Conteos propios con base en ejemplares e ilustraciones (Bussing, 1974; Weitzman \& Fink, 1985; Weitzman \& Menezes, 1998) demostraron que se puede evaluar el número de radii en tres caracteres diferentes (502-504), cuando se consideran ejemplares adultos.

505. Distribución de los radii de la escama-bolsillo (WM98: 50; FE11: 11): (0) extendidos en todo el borde posterior y parte del dorsal; (1) confinados principalmente a un borde posterior o posteroventral.

La presencia de radii en el borde posteroventral moderadamente cóncavo de la escamabolsillo (Fig. 7: estado 1) fue propuesto por Weitzman \& Menezes (1998) como una de las sinapomorfías de la tribu Corynopomini (= Stevardiini sensu Weitzman et al., 2005) y así fue usada en la matriz de caracteres presentada por estos autores, aunque en la definición de la tribu Corynopomini se reportó como sinapomorfía otra condición (Pág. 186): “...pouch scale having hypertrophied radii spread over the entire border of the pouch scale...".

506. Escama-bolsillo (n): (0) con circuli; (1) sin circuli o reducido a un par de líneas vestigiales.

507. Hendidura y proceso anteroventral de la escama-bolsillo (m, WF85: 57; WM98: 45): (0) ausentes o débilmente desarrollados; (1) presentes, bien definidos.

El estado 1 del carácter 507 se observó en Tyttocharax sp. y Scopaeocharax rhinodus. La hendidura y el proceso anteroventral están asociados y no fueron considerados como dos caracteres separadamente.

508. Hendidura en el borde dorsal de la escama-bolsillo (n): (0) ausente o poco definida; (1) presente, bien definida.

Algunas especies de Gephyrocharax presentan una hendidura que forma el sitio de inserción de la porción anteroventral de tejido conectivo que ancla la escama-bolsillo a los radios de la aleta caudal (estado 1). Como no se encontró una asociación exacta entre la presencia de esta hendidura y la del tejido, ambas se codificaron en caracteres separados. 
509. Margen de la escama-bolsillo con radii (n, Fig. 7: estado 1): (0) más extenso que el margen sin radii; (1) ligeramente más corto o igual que el margen sin radii.

Este carácter complementa independiente los caracteres sobre el número de radii de la escama bolsillo (502-504). La asociación entre el mayor número de radii y su extensión en la escama-bolsillo no es exacta y ambos estados fueron considerados separadamente.

510. Tamaño de la escama-bolsillo (m, WM98: 3: FE11: 3): (0) pequeña o moderadamente grande, su mayor altura es menor a la mitad de la longitud entre el complejo hipural y la punta posterior de los radios centrales de la aleta caudal; (1) muy grande, su mayor altura es la mitad o más de la longitud entre el complejo hipural y la punta posterior de los radios centrales de la aleta caudal.

Weitzman \& Menezes (1998: carácter 3) definieron en una serie multiestado a un carácter sobre los tipos de escama-bolsillo, sustentados en el tamaño relativo. Esta serie se dividió en dos estados en el presente carácter. Otros caracteres que tratan aspectos del tamaño relativo son listados a continuación (511-512).

511. Altura de la escama-bolsillo (n, Fig. 7: estado 0): (0) mayor que su longitud; (1) menor o aproximadamente igual que su longitud.

512. Extensión posterior de la escama-bolsillo (n, Fig. 7: estado 0): (0) corta, no se extiende más allá de la vertical a través del extremo distal del segundo radio procurrente ventral; (1) larga, se extiende más allá de la vertical a través del extremo distal del segundo radio procurrente ventral.

513. Posición del borde dorsal de la escama-bolsillo en relación a los radios de la aleta caudal (m, WM98: 51): (0) se ubica en un punto entre los radios 4 a 8; (1) se ubica en un punto entre los radios 8 a 15 .

514. Posición del borde dorsal de la escama-bolsillo en relación a los radios de la aleta caudal (m, WM98: 51): (0) se ubica en un punto entre los radios 4 a 12; (1) se ubica en un punto entre los radios 12 a 17.

Weitzman \& Menezes (1998) definieron la presencia de una escama-bolsillo entre el radio 12 de la aleta caudal y los radios procurrentes ventrales como una sinapomorfía de Corynopomini (= Stevardiini sensu Weitzman et al. 2005). Aunque estos autores utilizaron una serie de transformación de tres estados, se observó inconsistencia en los estados 1 y 2 que fueron descriptos de manera similar (Weitzman \& Menezes, 1998: 192). Esta serie se reorganizó en dos caracteres (Fig. 7: 513 y 514) con un intervalo que representa la variación observada. La observación de múltiples series de machos adultos de distintos miembros de Stevardiinae con escama-bolsillo, las ilustraciones de 
Bussing (1974), Weitzman \& Fink (1985) y Weitzman \& Menezes (1998) permitieron tomar esta decisión.

515. Posición del borde ventral de la escama-bolsillo relativa a la de los radios de la aleta caudal (n, Fig. 8a): (0) se ubica desde un punto sobre el radio 14 hasta un punto entre los radios 15 y 16; (1) se ubica desde un punto sobre el radio 16 hasta un punto sobre los radios ventrales procurrentes posteriores.

516. Posición del borde ventral de la escama-bolsillo relativa a la de los radios de la aleta caudal (n, Fig. 8a): (0) se ubica desde un punto entre los radios 14 a 19; (1) se ubica desde un punto entre el radio $19 \mathrm{y}$ el primer radio procurrente ventral hasta un punto sobre los otros radios procurrentes ventrales.

517. Posición del borde ventral de la escama-bolsillo relativa a la de los radios de la aleta caudal (n, Fig. 8a): (0) se ubica desde un punto sobre el radio 14 hasta un punto sobre el primer radio procurrente ventral; (1) se ubica desde un punto entre el primer y segundo radio procurrente ventral hasta un punto sobre el sexto y séptimo radio procurrente ventral.

518. Margen posterior de la escama-bolsillo (n): (0) predominantemente recto o convexo; (1) cóncavo en gran parte de su longitud.

La presencia de esta concavidad en el borde posterior de la escama-bolsillo (estado 1), no está exactamente asociada con la distribución de radii (carácter 505), por tal motivo estos caracteres fueron codificados separadamente.

519. Hilera vertical de escamas más posteriores del lóbulo ventral de la aleta caudal (n, Fig. 8a): (0) no yuxtapuesta a la escama-bolsillo; (1) yuxtapuesta a la escama-bolsillo.

520. Número de escamas en la hilera vertical más posterior yuxtapuesta a la escamabolsillo (n, Vanegas-Ríos et al., 2013: fig. 4: estado 1): (0) tres o menos; (1) cuatro o más.

521. Una o varias escamas accesorias a la escama-bolsillo (m, WF85: 3): (0) ausentes; (1) presentes.

522. Escama accesoria independiente, algo curvada, alargada y situada ventralmente a la escama-bolsillo (n): (0) ausente; (1) presente.

523. Escama accesoria pequeña situada medial a la escama-bolsillo (n): (0) ausente; (1) presente.

En los caracteres 521 al 523, se describe la presencia de una o más escamas accesorias a la escama-bolsillo. Escama accesoria se define como (521: estado 1) una escama complementaria, desalineada de la hilera vertical de escamas yuxtapuestas a la escama- 
bolsillo (e. g. Gephyrocharax major), con forma distinta a las escamas circundantes, superpuesta o muy conectada a la escama-bolsillo (e. g. Argopleura magdalenensis) y que contribuye en algún grado en la formación de la abertura del bolsillo (Weitzman \& Fink, 1985: figs. 22-25). Dos tipos de escamas accesorias se describen en los caracteres 522 y 523: una alargada y curvada, presente en Gephyrocharax major (522: estado 1) y otra ubicada completamente medial a la escama-bolsillo, presente en las especies de Chrysobrycon (523: estado 1). En Pseudocorynopoma doriae, se encontraron dos escamas ventrales algo alargadas, pero en diferente posición con respecto a la zona ventral de la escama-bolsillo y no es posible homologarlas con alguna de las escamas accesorias mencionadas.

- Musculatura caudal:

524. Distribución de los paquetes de fibras interradialis (m, WM98: 17): (0) desarrollados en similar proporción hacia ambos lóbulos de la aleta caudal; (1) modificados, más desarrollados en alguna región o lóbulo de la aleta caudal.

Los músculos interradialis son muy parecidos entre los diferentes tipos de peces teleósteos (Winterbottom, 1974). Weitzman \& Fink (1985: figs. 44-47) describen un patrón completamente diferente entre machos y hembras en ciertas especies de Xenurobryconini. Además de ese estudio, no se conocen otros reportes en Characidae sobre este tipo de modificaciones en los interradialis asociados al dimorfismo sexual. En este carácter y varios que se listan abajo (525-529 y 533), se describen un conjunto de condiciones sobre los músculos interradialis de los machos adultos. El estado 1 del carácter 524 se consideró solo en las especies en las que los interradialis están organizados diferente en los machos respecto de las hembras (Fig. 8); no solo se tuvo en cuenta el desarrollo lateral de los paquetes de fibras, sino también la organización del patrón general de fibras entre los lóbulos (Fig. 10). El carácter 524 describe parte del estado 2 del carácter 17 de Weitzman \& Menezes (1998). En Gephyrocharax chocoensis, se observaron los interradialis sexualmente dimórficos en unos cuantos ejemplares con tallas > $40 \mathrm{~mm} \operatorname{LE}($ e. g. AMNH 5330), pero en otros ejemplares maduros de tallas ligeramente menores o alrededor de los $40 \mathrm{~mm}$ LE (e. $g$. IMCN 4830) el dimorfismo sexual es muy leve o poco evidente. No obstante, esta especie se codificó para el estado mencionado con base en el ejemplar de mayor talla. En Corynopoma riisei, los interradialis fueron sexualmente dimórficos solo en los machos activos o completamente desarrollados. 
525. Longitud de los interradialis modificados en la aleta caudal (m, WM98: 17) (Figs. 8a y 10b): (0) alcanzan un punto más posterior en el lóbulo dorsal que en el ventral; (1) alcanzan posteriormente un mismo punto o son apenas más largos en el lóbulo ventral que en el dorsal.

Weitzman \& Fink (1985) fueron los primeros en usar caracteres sobre los interradialis en una filogenia de Xenurobryconini. Luego, Weitzman \& Menezes (1998) definieron un carácter multiestado, organizado en una serie de dos caracteres binarios. El carácter 525 solo aplica a las especies con interradialis sexualmente dimórficos (524, estado 1), además incluye la variación asociada únicamente a la longitud relativa de los paquetes de fibras, la cual no está exactamente asociada al carácter anterior.

526. Paquetes de fibras interradialis modificadas más alargadas en los radios caudales del lóbulo ventral, especialmente entre los radios 12 a 16 (n, Figs. 8a y 10b): (0) ausentes; (1) presentes.

Este carácter solo aplica a las especies con interradialis sexualmente dimórficos.

527. Posición relativa de la escama-bolsillo y los interradialis (n): (0) las fibras musculares no sobrepasan el borde posterodorsal de la escama; (1) las fibras musculares sobrepasan el borde posterodorsal de la escama.

En el estado 1 (Fig. 8a) de este carácter las fibras interradialis siempre fueron visibles lateralmente (la escamación no los cubre). Aunque dos paquetes de fibras entre los radios 11 a 13 están ubicadas apenas anteriores a la porción posterior de la escamabolsillo en Pseudocorynopoma doriae, la proyección posterior de estos interradialis es muy breve. De hecho la misma, está cubierta posteriormente por tejido conectivo que ancla parte de la escama a los radios y no es visible lateralmente. Por tales razones, se codificó en esta especie como intermedio.

528. Grupos de fibras interradialis que sobrepasan el borde posterodorsal de la escamabolsillo (n): (0) correspondientes al lóbulo ventral; (1) correspondientes al lóbulo dorsal.

529. Número de interradialis en el lóbulo ventral de la aleta caudal que se insertan posteriormente al borde posterior de la escama-bolsillo (n): (0) dos o menos; (1) tres o más.

Los caracteres 527 al 529 forman una serie multiestado aditiva organizada separadamente en varios caracteres binarios. 
530. Anclaje entre la/s escama/s hipertrofiada/s en forma de bolsillo en los radios de la aleta caudal (m, WF85: 4; WM98: 14): (0) principalmente a través de tejido conectivo; (1) principalmente a través de fibras interradialis o una porción de ligamento.

531. Tejido conectivo en los radios de la aleta caudal de especies con escama/s hipertrofiada/s en forma de bolsillo (m, WF85: 4; WM98: 14): (0) ausente o relativamente débil y no organizado en un ligamento; (1) organizado en un ligamento.

532. Ligamento que conecta la escama-bolsillo a los radios 10 y/o 11 de la aleta caudal (m, WF85: 4; WM98: 14): (0) fuerte y no dividido; (1) débil y dividido.

533. Interradialis de la región central de la aleta caudal en especies con escamación hipertrofiada en forma de bolsillo (m, WF85: 35 y 36): (0) no organizados en secciones hipertrofiadas; (1) organizados en dos secciones hipertrofiadas $a$ y $b$.

Weitzman \& Fink (1985) establecieron la presencia de tejido conectivo denso organizado en un ligamento asociado a la escamación hipertrofiada en forma de bolsillo y a los radios de la aleta caudal como sinapomorfía de Xenurobryconini. Weitzman \& Menezes (1998) trataron este mismo carácter en una serie multiestado, la cual se reorganizó en los últimos cuatro caracteres para separar los tipos de anclaje que presentan las especies con escama/s hipertrofiada/s en forma bolsillo en los radios de la aleta caudal (tejido conectivo vs. músculo). Todas las especies con escamación hipertrofiada en forma de bolsillo, ya sea con una o más escamas modificadas, desarrollan tejido conectivo que refuerza el anclaje de esta/s escama/s a los radios caudales, mientras que solo un grupo reducido de especies presenta adicionalmente un ligamento o porciones interradialis hipertrofiadas involucradas con este anclaje, aportando algún tipo de movilidad. Se prefirió codificar los caracteres 530, 531 y 533 para las especies con bolsillo glandular en vez de las especies con escama-bolsillo, con base en las observaciones anteriores y la hipótesis de que el origen anatómico y el desarrollo del bolsillo glandular, ya sea formado por una o más escamas, parece estar íntimamente relacionado al tipo de anclaje (Weitzman \& Menezes, 1998; Ferreira et al. 2011). No se encontró una asociación exacta entre el ligamento y los interradialis que anclan la escama-bolsillo a los radios de la aleta caudal y por esto fueron codificados separadamente. En ciertos miembros de Xenurobryconini (sensu Weitzman \& Fink, 1985), los interradialis se hipertrofian y forman dos secciones ( $a$ y $b$ ) que tienen mayor desarrollo en la región central de la aleta caudal y están asociadas con el anclaje de la escama-bolsillo a los radios de la aleta caudal (véase Weitzman \& Menezes, 1998: carácter 17 , estado 2). 
534. Desarrollo de los interradialis entre los radios 12 y 13 de la aleta caudal (n, Fig. 810): (0) poco desarrollados en sentido posteroventral, sin una separación o divergencia notable entre los radios; (1) muy desarrollados en sentido posteroventral, con una muy fuerte divergencia o separación entre los radios.

El carácter 534 se codificó polimórfico en Gephyrocharax chocoensis y las especies de Pterobrycon debido a que en los machos adultos examinados de mayor tamaño los radios están separados (en G. chocoensis esto se observó variable), pero el músculo tiene desarrollo moderado lateralmente (en comparación con las demás especies de Gephyrocharax). En Pterobrycon landoni, se observó una fuerte separación entre los radios caudales 12 y 13, pero no se pudo inspeccionar el músculo interradialis y por eso se codificó polimórfico. En Corynopoma riisei, no se observó una fuerte separación entre los radios caudales 12 y 13 (estado 0) y, además, el paquete interradialis entre estos radios no está más desarrollado que los paquetes de fibras de los radios contiguos.

535. Sección más posterior de la musculatura hypaxialis y epaxialis relativa al flexor ventralis (n, Figs. 9 y 10): (0) bien desarrollada, cubre lateralmente al flexor ventralis; (1) reducida, no cubre la región posterior del flexor ventralis.

La reducción o casi pérdida de esta sección de los hypaxialis y epaxialis se correlaciona con el desarrollo lateral de la porción posterior del flexor ventralis (Fig. 9: estado 1), por tal motivo fueron codificadas en el mismo carácter. Aunque esta porción del flexor ventralis puede tener desarrollo variado, este es difícil de cuantificar y no se codificó en este estudio. En las hembras, la sección de los hypaxialis y epaxialis es algo reducida, pero solamente en los machos adultos es notable la condición descripta. Incluso en los machos adultos, esta reducción muscular deja un espacio que puede ser tan amplio o mayor al grosor del radio caudal 19. No se encontró correlación entre la presencia de escamación hipertrofiada, el tejido glandular y otros caracteres relacionados de la aleta caudal con la modificación de estos músculos, lo que justificó su codificación separada en este carácter.

- Coloración:

536. Porción distal del primer radio ramificado de la aleta pectoral (n): (0); no pigmentado, sin cromatóforos formando una mancha conspicua; (1) pigmentado, usualmente con una mancha difusa oscura o unos cuantos cromatóforos marrones oscuros o negros dispersos alrededor de sus ramificaciones.

La presencia de la pigmentación sobre el primer radio ramificado de la aleta pectoral en los machos de Gephyrocharax melanocheir fue reportada por Eigenmann (1912). Este 
carácter fue usado en las claves taxonómicas para identificar esta especie de las demás especies de Gephyrocharax por Myers (en Eigenmann \& Myers, 1929) y Schultz (1944). Recientemente, Vanegas-Ríos et al. (2013: fig. 7) describieron una especie, $G$. torresi, que también presenta tal pigmentación. Se observó que el estado 1 de este carácter también está presente en G. martae y Pseudocorynopoma doriae.

537. Densa pigmentación negra o marrón oscura alrededor del origen de la aleta pélvica (n): (0) ausente, (1) presente.

538. Pigmentación alrededor de la aleta pélvica: (0) más concentrada ventralmente, anterior y alrededor del origen de la aleta; (1) más concentrada lateral y ventralmente desde el origen de la aleta anal, atravesando el área pélvica y alcanzando un punto medio debajo de la aleta pectoral.

La pigmentación en el área pélvica (537) fue mencionada para los machos de $G$. caucanus en la descripción de Schultz (1944) y luego encontrada para G. sinuensis por Dahl (en Dahl \& Medem, 1964). Esta pigmentación puede separarse en dos tipos, de acuerdo con su desarrollo en el área pélvica (538). En algunos ejemplares machos adultos de G. valencia, se observó más concentrada y definida a la pigmentación ventral en el área pélvica, pero la diferencia con la hembras es muy leve. Por esta razón se codificó polimórfico a esta especie en este carácter.

- Reproducción:

539. Inseminación (MI10: 358): (0) ausente; (1) presente.

540. Tipo de espermatozoide (MI10: 359): (0) con núcleo redondeado o levemente alargado; (1) con núcleo muy alargado.

541. Área para el depósito de esperma en el testículo (MI10: 360): (0) ausente o pequeña; (1) presente, tan amplia como el área espermatogénica.

542. Espermatozeugmata (FE11: 35): (0) ausente; (1) presente.

\section{Resultados filogenéticos}

Se obtuvo el árbol de consenso estricto bajo pesos implicados extendidos (Goloboff, 2013), el cual es usado como la hipótesis filogenética final, a partir de un intervalo de ocho valores de K (un árbol encontrado por cada concavidad). Este intervalo más estable se encontró entre las $6^{\mathrm{a}}$ y $13^{\mathrm{a}}$ concavidades $(8,85-17,18)$, acorde a los valores del coeficiente de similitud y las distancias SPR descriptas en Material y Métodos (Tabla 2). Los primeros seis de estos árboles (con valores de $\mathrm{K}$ entre 8,85-13,95) fueron los más estables en las medidas mencionadas y compartieron el mismo número de pasos (3663). Los restantes dos árboles (con valores de $\mathrm{K}$ de 15,45 y 17,18) fueron ligeramente 
diferentes en el número de pasos (3662 y 3659) y sobre todo en los valores de las distancias SPR respecto a los del primer intervalo (Tabla 2). A pesar de estas ligeras diferencias en las topologías entre los árboles, el árbol de consenso estricto presentó pocas politomías (Figs. 11-14). La subfamilia Stevardiinae se halló más relacionada con el clado de Astyanacinus + Astyanax + Hyphessobrycon anisitsi + Markiana + Psellogrammus que con los clados compuestos por géneros de Characinae, Cheirodontinae, Aphyocharacinae o Aphyoditeinae. Por otro lado, Gephyrocharax resultó monofilético y claramente anidado dentro de la familia Characidae, subfamilia Stevardiinae.

Se calculó un árbol de consenso estricto a partir de 15000 árboles más parsimoniosos obtenidos (con 3598 pasos) en el análisis bajo pesos iguales. Este árbol de consenso, en comparación con el obtenido bajo pesos implicados, fue menos informativo en las relaciones resueltas entre los taxones estudiados, en especial en los clados afuera de Stevardiinae. Además, tiene muchas agrupaciones filogenéticas diferentes dentro de los principales clados concordantes (Figs. 15-17). Esto es algo esperable por las diferencias metodológicas propias de cada esquema de pesado usadas. La distancia SPR ("sprdiff") entre el árbol de consenso bajo pesos iguales y el árbol de consenso bajo pesos implicados extendidos fue de 0,8326 , con 36 movimientos de SPR necesarios para convertir el primer árbol en el segundo. Como se explicó en la metodología, el árbol de consenso estricto bajo pesos implicados extendidos es la hipótesis filogenética final de este estudio. Los resultados de pesos iguales y pesos implicados mostraron grandes coincidencias en los géneros que componen varios clados importantes para la presente investigación (Fig. 17): 1) el clado Stevardiinae (pesos iguales: nodo 261; pesos implicados extendidos: nodo $293)$; 2) el clado que agrupa casi todos los géneros stevardinos, excepto Landonia, Hemibrycon, Phenacobrycon y algunos Bryconamericus (pesos iguales: nodo 259; pesos implicados: nodo 290); 3) el clado Diapoma (pesos iguales: nodo 342; pesos implicados: nodo 398); 4) el clado Argopleura + Scopaeocharax + Tyttocharax + Xenurobrycon (pesos iguales: nodo 346; pesos implicados: nodo 403); 5) el clado Chrysobrycon (pesos iguales: nodo 352; pesos implicados: nodo 410); 6) el clado Pterobrycon + Corynopoma + Gephyrocharax (pesos iguales: nodo 354; pesos implicados extendidos = nodo 416); 7) el clado Corynopoma + Gephyrocharax (pesos iguales: nodo 353; pesos implicados extendidos = nodo 415); y 8) el clado Gephyrocharax (pesos iguales: nodo 361; pesos implicados extendidos $=$ nodo 423). Estas coincidencias encontradas en ambos esquemas de pesado, sugieren que los clados concordantes podrían ser independientes del método de 
pesado bajo parsimonia y algunas sinapomorfías implícitas en estos clados están poco influenciadas por la homoplasia relativa de los mismos.

\section{Clados principales y sinapomorfías}

En el apéndice II, se presenta un listado completo de las autapomorfías y sinapomorfías de todos los nodos obtenidos en el árbol de consenso estricto bajo pesos implicados extendidos. Las sinapomorfías de los principales clados que incluyen a Gephyrocharax o están muy relacionados con este género se presentan en detalle a continuación. Las autapomorfías de las especies de Gephyrocharax y géneros hermanos se listan después del apartado mencionado. Como Stevardiinae es el grupo monofilético de mayor interés para clasificar a Gephyrocharax, éste se tomó como punto de inicio para describir los clados mencionados. Se listan las convergencias y reversiones para cada una de las sinapomorfías y autapomorfías de los clados de interés, pero restringidas al contexto de Stevardiinae (únicamente para esta subfamilia se presentan aquellos cambios dados en otras partes del árbol de consenso estricto). Las autapomorfías solo se muestran para Gephyrocharax y sus géneros hermanos. Las medidas de estabilidad y apoyo son mostradas entre paréntesis (separadas por una barra) después del número de cada nodo en el siguiente orden: valores GC o diferencias de frecuencias por grupos (estabilidad), frecuencias absolutas por grupos y valores de GC (apoyo). Estas medidas fueron calculadas con $\mathrm{K}=12,66$ que corresponde al décimo valor explorado. Se encontró una gran estabilidad en la mayoría de los clados estudiados, por ejemplo Gephyrocharax, expresada en los valores altos de GC (cercanos o iguales a 100).

Nodo 293 (80/2/14): Stevardiinae

Géneros Acrobrycon, Argopleura, Aulixidens Böhlke, Attonitus Vari \& Ortega, Bryconadenos Weitzman, Menezes, Evers \& Burns, Bryconamericus, Carlastyanax, Chrysobrycon, Corynopoma, Creagrutus, Cyanocharax Malabarba \& Weitzman, Diapoma, Gephyrocharax, Hemibrycon, Knodus, Landonia, Microgenys, Mimagoniates, Nantis Mirande, Aguilera \& Azpelicueta, nuevo género, Odontostoechus Gomes, Phenacobrycon, Piabarchus Myers, Piabina, Pseudocorynopoma, Pterobrycon, Scopaeocharax, Tyttocharax y Xenurobrycon.

Weitzman et al. (2005) y Menezes \& Weitzman (2009) incluyeron en Stevardiinae seis tribus (Diapomini, Landonini, Hysteronotini, Phenacobryconini, Stevardiini y Xenurobryconini) basados sobre todo en su peculiar escamación hipertrofiada en el lóbulo 
ventral de los machos adultos. Esta composición de Stevardiinae no fue aceptada por Mirande $(2009,2010)$, quien redefinió a la subfamilia como un grupo más grande compuesto por los géneros del clado A de Malabarba \& Weitzman (2003). Sin embargo, Mirande (2010) no analizó gran parte de los géneros de las tribus de Menezes \& Weitzman (2009) y las relaciones de estos permanecieron tentativas en esta subfamilia. Ferreira et al. (2011) reanalizaron las relaciones filogenéticas entre la gran mayoría de los géneros originalmente posicionados en Stevardiinae (excepto los miembros de Glandulocaudini), y aunque no obtuvieron la monofilia de las tribus inicialmente propuestas en Stevardiinae sensu Weitzman \& Menezes 1998 y Weitzman et al. 2005, no cambiaron la propuesta clasificatoria para estos grupos. Oliveira et al. (2011) mantuvieron gran parte de la propuesta de Stevardiinae de Mirande (2010) pero incluyeron en ésta a Bryconamericus emperador y Markiana nigripinnis. Mirande et al. (2013) reanalizaron la filogenia de Stevardiinae con énfasis en Carlastyanax y Creagrutus y mantuvieron la definición de Mirande (2010). El clado Bryconamericus scleroparius (con B. emperador), que también fue encontrado por Mirande (2010) pero separado de Stevardiinae, debe ser reconocido en esta subfamilia como lo propuso Oliveira et al. (2011). La posición de M. nigripinnis , que formó un clado con $M$. geayi, aún no se obtiene en Stevardiinae con los caracteres morfológicos analizados, pero en este estudio el género tiene una posición más cercana a Stevardiinae que cualquier otra hipótesis morfológica previa (e. g. Mirande, 2010). La adición de caracteres espermáticos podría contribuir a que el género Markiana Eigenmann se clasifique en Stevardiinae con datos morfológicos (Baicere-Silva et al., 2011b). Además, la filogenia obtenida demuestra que el esquema tribal de Menezes \& Weitzman (2009) no es completamente monofilético y coherente con el esquema jerárquico de la presente hipótesis (e. g. véase posición de los géneros Landonia y Phenacobrycon). En este estudio, Stevardiinae se define por cuatro caracteres que, si bien fueron analizados previamente por Mirande (2010) y Mirande et al. (2013), no fueron obtenidos como sinapomorfías de Stevardiinae en dichos estudios. Una de las sinapomorfías obtenidas, cuatro dientes premaxilares en la hilera interna, ya había sido propuesta por Malabarba \& Weitzman (2003) para definir su clado A (= Stevardiinae de Mirande, 2010). En este sentido, el nodo 293 (Stevardiinae) concuerda más con la hipótesis de Malabarba \& Weitzman (2003) que con las hipótesis de Mirande (2010) y Mirande et al. (2013). La distinta interpretación de los caracteres en los diferentes estudios filogenéticos puede deberse al hecho de que se ha aumentado el número de caracteres y taxones terminales analizados en los distintos análisis llevados a cabo. La especie Cyanogaster noctivaga fue 
propuesta tentativamente como un miembro de Stevardiinae por Mattox et al. (2013), pero en la presente hipótesis filogenética esta especie no está incluida en Stevardiinae y se relaciona más con otras especies como Nematobrycon lacortei y $N$. palmeri. Los géneros Corynopoma, Gephyrocharax y Pterobrycon se confirman por primera vez como miembros de Stevardiinae (sensu Mirande, 2010), con datos morfológicos.

1. Borde dorsal de los etmoides laterales (17): dirigidos en sentido oblicuo en vista dorsal, convergen en un ángulo orientado anteriormente $(0 \rightarrow 1$, ci $=14$, ri $=93)$. Convergente en Astyanacinus moorii, los nodos 245, 248 y 251. Revertido en el nodo 372.

2. Desarrollo ventral del tercer infraorbital (73): alcanza hasta la rama horizontal del preopérculo $(1 \rightarrow 0, \mathrm{ci}=3, \mathrm{ri}=68)$. Convergente en Agoniates anchovia, Brycon pesu Müller \& Troschel, Moenkhausia sanctaefilomenae, Roeboexodon guyanensis Puyo, Stichonodon insignis y los nodos 243, 349, 358, 360, 362 y 382. Revertido Aphyodite grammica, Aulixidens lindeae, Bryconamericus rubropictus, Carlastyanax aurocaudatus, Creagrutus meridionalis, C. taphorni, Nantis indefessus, Thoracocharax stellatus y los nodos 231, 323 y 394.

3. Número de dientes en la hilera interna de la premaxila (155): cuatro o menos $(1 \rightarrow 0$, ci =6, ri =75). Revertido en Grundulus cochae y los nodos 367, 400 y 414.

Convergente en Probolodus heterostomus Eigenmann y los nodos 331, 362 y 385.

4. Posición del tercer postcleitro (294): alcanza o sobrepasa la mitad ventral del segundo postcleitro $(0 \rightarrow 1, \mathrm{ci}=4, \mathrm{ri}=35)$. Convergente en Aphyocharax nattereri, Astyanax chico Cheirodon interruptus, Tetragonopterus argenteus y el nodo 363. Revertido en Bryconamericus rubropictus, Diapoma speculiferum, Nantis indefessus, nuevo género, Parecbasis cyclolepis y el nodo 252.

\section{Nodo 292 (80/19/3):}

Géneros Acrobrycon, Argopleura, Aulixidens, Attonitus, Bryconadenos, Bryconamericus, Carlastyanax, Chrysobrycon, Corynopoma, Creagrutus, Cyanocharax, Diapoma, Gephyrocharax, Hemibrycon, Knodus, Landonia, Microgenys, Mimagoniates, Nantis, nuevo género, Odontostoechus, Phenacobrycon, Piabarchus, Piabina,

Pseudocorynopoma, Pterobrycon, Scopaeocharax, Tyttocharax y Xenurobrycon. Excepto B. emperador y B. scleroparius.

La posición filogenética de Landonia y Phenacobrycon en el esquema de tribus de 
Weitzman \& Menezes (1998) y Menezes \& Weitzman (2009) no es apoyada por la presente hipótesis que es producto de la matriz de caracteres con mayor información morfológica y mayor número de taxones terminales de Stevardiinae analizados hasta el momento. Aunque estos géneros fueron considerados en Glandulocaudinae sensu Weitzman \& Menezes (1998) y a su vez se propusieron como más relacionados con géneros como Diapoma o Gephyrocharax, ambos tienen una posición distante de estos géneros en la hipótesis filogenética obtenida. Se propone por primera vez en un estudio filogenético que Landonia y Phenacobrycon son grupos hermanos.

1. Longitud de la espina supraoccipital (61): extendida solo hasta el límite anterior del complejo neural $(0 \rightarrow 1$, ci $=4, \mathrm{ri}=71)$. Revertido en Parecbasis cyclolepis, Argopleura magdalenensis, Bryconamericus yokiae, Carlastyanax aurocaudatus y Creagrutus meridionalis.

2. Articulación entre el primer y segundo infraorbitales (71): inclinada en sentido anteroventral $(0 \rightarrow 1, \mathrm{ci}=11, \mathrm{ri}=84)$. Revertido en Acrobrycon ipanquianus y Knodus pectinatus.

3. Túbulos para el paso de vasos sanguíneos sobre la porción laminar de la maxila (115): un túbulo simple, convergente al borde dorsal de la maxila $(1 \rightarrow 0$, ci $=29$, ri $=87)$.

4. Lámina ósea entre el primer y segundo basibranquiales (215): ausente $(1 \rightarrow 0$, ci $=3$, ri = 33). Convergente en Gephyrocharax melanocheir y el nodo 407. Revertido en Bryconamericus plutarcoi, Microgenys minuta y Piabina argentea.

5. Posición del extremo anterior del hueso pélvico (312): posterior a la sexta costilla $(0 \rightarrow$ 1, ci $=5$, ri $=51$ ). Convergente en Gephyrocharax martae. Revertido en Carlastyanax aurocaudatus.

6. Número de radios articulados con el primer pterigióforo dorsal (317): dos $(1 \rightarrow 0$, ci $=$ 6 , ri $=80)$.

7. Número de radios ramificados en la aleta dorsal (320): ocho o menos $(1 \rightarrow 0$, ci $=8$, ri =64). Revertido en Pseudocorynopoma doriae.

8. Posición longitudinal de inserción del tendón accesorio del adductor mandibulae (382): en la línea vertical que pasa en la mitad del cartílago de Meckel o anterior a este punto (0 $\rightarrow 1, \mathrm{ci}=5, \mathrm{ri}=69)$. Convergente en Diapoma pyrrhopteryx, Mimagoniates inequalis y el nuevo género. Revertido en Attonitus ephimeros, Cyanocharax alburnus, Nantis indefessus y los nodos 342 y 369.

Nodo 402 (100/77/74): 
Géneros Landonia y Phenacobrycon.

Roberts (1973) consideró que Landonia y Phenacobrycon podían estar muy relacionados filogenéticamente, pero no encontró evidencia para demostrarlo. Ferreira et al. (2011) hallaron a Landonia más relacionado con Glandulocauda, pero no analizaron a Phenacobrycon.

1. Extremo anterior de la premaxila (120): al nivel de la mitad superior de la órbita $(0 \rightarrow$ 1, ci $=5$, ri = 61). Convergente en Hemibrycon surinamensis y los nodos 407 y 411 .

2. Ubicación del coronomeckeliano (131): principalmente lateral al cartílago de Meckel (1 $\rightarrow 0$, ci $=4$, ri = 69). Convergente en Chrysobrycon sp. nov. A, Creagrutus peruanus, Corynopoma riisei, Diapoma terofali y Knodus pectinatus.

3. Extensión posterior del proceso ventral del cuadrado (181): no alcanza la línea vertical que pasa por el borde posterior del simpléctico $(0 \rightarrow 1$, ci $=3$, ri $=65)$. Convergente en Cyanocharax alburnus, Mimagoniates inequalis y el nodo 294. Revertido en Chrysobrycon yoliae.

4. Número de rastrillos branquiales en el primer hipobranquial y ceratobranquial (228): 16 o más $(1 \rightarrow 0$, ci $=6$, ri $=44)$.

5. Mancha humeral (400): ausente $(1 \rightarrow 0, \mathrm{ci}=4, \mathrm{ri}=74)$. Convergente en Bryconadenos tanaothoros, Gephyrocharax martae y el nodo 424. Revertido en el nodo 423.

6. Inseminación (539): presente $(0 \rightarrow 1$, ci $=33$, ri $=92)$. Convergente en el nodo 288 .

7. Área para el depósito de esperma en el testículo (541): presente, tan amplia como el área espermatogénica $(0 \rightarrow 1$, ci $=33$, ri $=86)$.

\section{Nodo $291(80 / 15 / 7)$ :}

Géneros Acrobrycon, Argopleura, Aulixidens, Attonitus, Bryconadenos, Bryconamericus, Carlastyanax, Chrysobrycon, Corynopoma, Creagrutus, Cyanocharax, Diapoma, Gephyrocharax, Hemibrycon, Knodus, Microgenys, Mimagoniates, Nantis, nuevo género, Odontostoechus, Piabarchus, Piabina, Pseudocorynopoma, Pterobrycon, Scopaeocharax, Tyttocharax y Xenurobrycon. Excepto Bryconamericus emperador y B. scleroparius.

Este nodo se corresponde con el nodo Stevardiinae definido por Mirande (2010: nodo 243) y Mirande et al. (2013: nodo 238), pero en este caso se sustenta en un mayor número de sinapomorfías. Como se mencionó arriba, Stevardiinae se asignó al nodo 293. 
1. Confluencia de las láminas ventrales divergentes del mesetmoides con el septo nasal del mesetmoides (33): confluyen en la terminación posterior del septo nasal $(0 \rightarrow 1, \mathrm{ci}=6$, ri =53). Convergente en Creagrutus cracentis. Revertido en Aulixidens eugeniae, Knodus breviceps, K. pectinatus, nuevo género, Odontostoechus lethostigmus y el nodo 411. Algunos árboles: revertido en el nodo 390.

2. Rama epifisaria del tubo supraorbital (96): ausente $(0 \rightarrow 1$, ci $=20$, ri $=92)$. Revertido en Microgenys minuta y los nodos 390 y 403.

3. Poro supraorbitario localizado sobre la base de la barra epifisaria, cercano a ésta o en punto entre ésta y el poro frontoetmoidal (100): presente $(0 \rightarrow 1$, ci $=20$, ri $=92)$. Revertido en el nodo 403.

4. Número de dientes maxilares (164): cuatro o más $(0 \rightarrow 1$, ci $=3$, ri $=65)$. Convergente en Gephyrocharax martae. Revertido en Argopleura magdalenensis, Chrysobrycon sp. nov. A, Microgenys minuta y el nodo 301.

5. Borde posterior del cleitro (271): con una concavidad ventral al primer postcleitro $(0 \rightarrow$ 1, ci $=5$, ri $=80)$. Revertido en Carlastyanax aurocaudatus.

6. Número de pterigióforos dorsales (327): nueve $(1 \rightarrow 0$, ci $=8$, ri = 86). Revertido en Chrysobrycon myersi y Mimagoniates rheocharis.

\section{Nodo $290(80 / 5 / 17)$ :}

Géneros Acrobrycon, Argopleura, Aulixidens, Attonitus, Bryconadenos, Bryconamericus,

Carlastyanax, Chrysobrycon, Corynopoma, Creagrutus, Cyanocharax, Diapoma, Gephyrocharax, Knodus, Microgenys, Mimagoniates, Nantis, nuevo género, Odontostoechus, Piabarchus, Piabina, Pseudocorynopoma, Pterobrycon, Scopaeocharax, Tyttocharax y Xenurobrycon. Excepto B. emperador, B. scleroparius y B. yokiae.

La composición de este nodo es apenas similar a la obtenida por Mirande (2010) para el nodo 242 y algo más coincidente a la obtenida por Mirande et al. (2013) en el nodo 236 de su filogenia. En la hipótesis filogenética obtenida, este nodo se divide en dos grandes grupos (nodos 289 y 303), mientras que Mirande (2010) obtuvo a Cyanocharax alburnus más un clado divido en dos grandes clados y Mirande et al. (2013) obtuvieron a Bryconamericus mennii más, al menos, tres grandes clados anidados. La composición de estos clados es parecida pero las relaciones entre estos son diferentes y difícilmente comparables, en gran parte por la cantidad de taxones terminales de Stevardiinae 
analizados y los caracteres morfológicos codificados. De cualquier manera, hay una tendencia, desde el estudio de Mirande (2010) y a medida que se fueron estudiando más los stevardinos, a que las hipótesis filogenéticas morfológicas muestren menos clados pectinados y grupos más definidos.

1. Pequeño foramen cerca del borde posterior del pterosfenoides (52): presente, atravesado por una rama del nervio supraorbital $(0 \rightarrow 1$, ci $=20$, ri $=90)$. Revertido en Chrysobrycon yoliae, Chrysobrycon sp. nov. A y el nodo 367.

2. Longitud relativa del palatino (204): distintamente mayor que la mitad de la longitud del ectopterigoides $(0 \rightarrow 1$, ci $=4$, ri $=68)$. Convergente en Scopaeocharax rhinodus. Revertido en Bryconamericus plutarcoi y Knodus pectinatus. Algunos árboles: revertido en el nodo 390.

3. Forma del tercer postcleitro (295): fino, sin láminas asociadas $(1 \rightarrow 0, \mathrm{ci}=7, \mathrm{ri}=83)$. Revertido en Knodus pectinatus.

4. Número de radios anales ramificados (345): 24 o menos $(1 \rightarrow 0$, ci $=4$, ri $=68)$. Convergente en el nuevo género. Revertido en los nodos 370 y 408.

\section{Nodo 303 (23/0/50):}

Géneros Aulixidens, Bryconamericus, Carlastyanax, Creagrutus, Cyanocharax $(C$. alburnus), Knodus y Piabina. Excepto B. emperador, B. scleroparius, B. yokiae y K. pectinatus.

Este nodo está compuesto por los Creagrutus, Knodus, algunos géneros monotípicos y varias especies de Bryconamericus y se corresponde en parte con las especies obtenidas en los nodos 272 y 353 de Mirande et al. (2013). Parte de la relaciones internas de este nodo, en especial las de Creagrutus, fueron discutidas en detalle por Mirande et al. (2013). Los géneros Bryconamericus y Knodus no se obtuvieron monofiléticos en las hipótesis filogenéticas recientes (Javonillo et al., 2010; Mirande, 2010; Oliveira et al., 2011; Mirande et al., 2013) y tampoco fueron encontrados así en el presente análisis. Es claro que estos géneros deben ser mejor estudiados y su sistemática es una de las problemáticas más importantes para solucionar dentro de Stevardiinae. Es muy posible que Bryconamericus y Knodus incluyan especies o grupos monofiléticos internos que 
correspondan a otros géneros o incluso a géneros no descriptos. Por ejemplo, RománValencia \& Vanegas-Ríos (2009) propusieron la monofilia de un grupo de especies de Bryconamericus del sureste de América Central, pero no definieron la situación de este clado con respecto a todo el género. Cabe resaltar que la monofilia de este grupo coincide, en parte, con el clado Bryconamericus scleroparius de las hipótesis filogenéticas previas (Mirande, 2010; Mirande et al. 2013) y los resultados obtenidos en el cladograma de consenso. Sin embargo, las especies analizadas de Bryconamericus están divididas, en al menos, seis diferentes posiciones en la hipótesis filogenética obtenida y aún no se recuperan especies en un mismo clado con B. exodon, su especie tipo. Esto sugiere que este grupo de especies estudiado por Román-Valencia \& Vanegas-Ríos (2009) pueda ser un género diferente a Bryconamericus o algún género en sinonimia dentro de este $(e . g$. Eretmobrycon Fink).

1. Posición del extremo anterior del hueso pélvico (313): posterior a la séptima costilla (0 $\rightarrow 1, \mathrm{ci}=6$, ri $=43$ ). Convergente en Microgenys minuta y los nodos 296 y 400 . Revertido en Carlastyanax aurocaudatus y el nodo 300.

2. Ganchos óseos en el último radio pélvico en machos adultos (478): en número reducido $(1 \rightarrow 0, \mathrm{ci}=6, \mathrm{ri}=63)$. Convergente en Argopleura magdalenensis Piabarchus analis y el nodo 421. Revertido en Aulixidens eugeniae, Creagrutus gephyrus, C. taphorni, Knodus meridae y Piabina argentea

\section{Nodo 289 (23/0/51):}

Géneros Acrobrycon, Argopleura, Attonitus, Bryconadenos, Bryconamericus (B. cf. iheringii, B. cf. rubropictus, B. rubropictus y B. thomasi), Chrysobrycon, Corynopoma, Cyanocharax (C. obi), Diapoma, Gephyrocharax, Knodus (K. pectinatus), Microgenys, Mimagoniates, Nantis, nuevo género, Odontostoechus, Piabarchus, Pseudocorynopoma, Pterobrycon, Scopaeocharax, Tyttocharax y Xenurobrycon.

Este nodo está apoyado por una sola sinapomorfía y tiene una composición parecida al nodo 239 de Mirande (2010) y nodo 233 de Mirande et al. (2013).

1. Posición de la abertura sobre el neurocráneo que comunica con el tubo laterosensorial del sexto infraorbital (87): en el frontal $(0 \rightarrow 1$, ci $=9$, ri $=60)$. Revertido en el nodo 369. 


\section{Nodo 312 (38/18/9):}

Géneros Bryconamericus (B. cf. iheringii, B. cf. rubropictus, B. rubropictus y B. thomasi), Knodus (K. pectinatus), Nantis y Odontostoechus.

Este nodo es parecido al nodo 257 de Mirande et al. (2013) y difiere sobre todo en la posición filogenética de Attonitus.

1. Extensión anterior del nasal (37): no alcanza el proceso lateral del mesetmoides $(1 \rightarrow 0$, $\mathrm{ci}=25, \mathrm{ri}=90)$.

2. Extensión anterior del nasal (38): no cubre casi todo el proceso lateral del mesetmoides $(1 \rightarrow 0, \mathrm{ci}=14, \mathrm{ri}=85)$. Convergente en Attonitus ephimeros y el nodo 295 .

3. Longitud de la rama ascendente de la premaxila (122): alcanza solo el extremo anterior de los nasales $(0 \rightarrow 1$, ci $=6$, ri $=75)$. Convergente en los nodos 286, 295 y 408 .

4. Porción anterior, cartilaginosa, del simpléctico (199): alcanza o sobrepasa el borde anterior de la fenestra metapterigoidea $(0 \rightarrow 1$, ci $=6$, ri $=21)$. Convergente en Bryconamericus plutarcoi, Creagrutus atrisignum, Knodus heteresthes y Piabina argentea. Revertido en Bryconamericus rubropictus.

5. Hileras de rastrillos branquiales en el primer ceratobranquial (225): dos (0 $\rightarrow 1$, ci $=5$, ri $=52$ ). Convergente en Attonitus ephimeros, Phenacobrycon henni y los nodos 299 y 408. Revertido en Knodus sp. y el nodo 294.

6. Posición del origen de la aleta anal (341): posterior a la base del radio de la aleta dorsal más posterior $(1 \rightarrow 0, \mathrm{ci}=4, \mathrm{ri}=55)$. Convergente en Bryconamericus mennii, $B$. thomasi y los nodos 297 y 388.

Algunos árboles:

1. Número de radios anales ramificados (344): 17 o menos $(1 \rightarrow 0$, ci $=8$, ri $=72)$. Convergente en Knodus meridae, Pterobrycon landoni y los nodos 388 y 408. Algunos árboles: convergente en el nodo 287.

\section{Nodo $288(23 / 0 / 51)$ :}

Géneros Acrobrycon, Argopleura, Attonitus, Bryconadenos, Chrysobrycon, Corynopoma, Cyanocharax (C. obi), Diapoma, Gephyrocharax, Knodus (K. pectinatus), Microgenys, Mimagoniates, nuevo género, Piabarchus, Pseudocorynopoma, Pterobrycon, Scopaeocharax, Tyttocharax y Xenurobrycon. 
La composición de este nodo es bastante parecida al nodo 233 de Mirande et al. (2013), con diferencias en las posiciones de los géneros Attonitus, Aulixidens y Microgenys.

1. Inseminación (539): presente $(0 \rightarrow 1, \mathrm{ci}=33$, ri $=92)$. Convergente en el nodo 402. Algunos árboles:

1. Proceso horizontal del ánguloarticular (127): ampliamente cubierto por el dentario, que alcanza el borde posterior del cartílago de Meckel $(0 \rightarrow 1$, ci $=6$, ri $=71)$. Convergente en Gephyrocharax major, el nuevo género y los nodos 302, 407 y 410. Revertido en Attonitus ephimeros.

2. Lámina ósea entre el segundo y tercer basibranquiales (217): ausente $(1 \rightarrow 0$, ci $=4$, ri $=$ 39). Convergente en Chrysobrycon sp. nov. A, Knodus heteresthes y el nodo 389. Revertido en Microgenys minuta y el nodo 395. Algunos árboles: revertido en el nodo 369.

\section{Nodo 287 (66/0/51):}

Géneros Attonitus, Knodus (K. pectinatus) y Microgenys.

La relaciones filogenéticas cercanas entre Attonitus ephimeros, Knodus pectinatus y Microgenys minuta no habían sido propuestas en estudios previos (e. g. Mirande et al. 2013). Knodus pectinatus fue asignado originalmente a Bryconamericus (Lima et al., 2003) y después ubicado por Weitzman et al. (2005) en Knodus. Esta especie fue analizada por Mirande et al. (2013) por su gran afinidad morfológica con Carlastyanax. En este estudio, Attonitus se relacionó con Nantis, mientras que Microgenys fue el grupo hermano de Piabina + Carlastyanax + Creagrutus. Es posible que Knodus pectinatus no sea un Knodus en sentido estricto, pero aún hay varios géneros y especies que no han sido analizadas y su codificación robustecería cualquier tipo de cambio taxonómico.

1. Rinosfenoides (55): ausente $(1 \rightarrow 0$, ci = 4, ri = 61). Convergente en Bryconamericus plutarcoi, Carlastyanax aurocaudatus, Gephyrocharax valencia, Nantis indefessus y el nodo 393.

2. Borde ventral del proceso horizontal del ánguloarticular (128): angulado en sentido posteroventral con respecto al tubo laterosensorial del dentario, en vista medial $(1 \rightarrow 0$, ci $=8$, ri $=75$ ). Convergente en Carlastyanax aurocaudatus, Nantis indefessus y los nodos 287 y 408.

Algunos árboles: 
1. Número de radios anales ramificados (344): 17 o menos $(1 \rightarrow 0$, ci = 8, ri = 72). Convergente en Knodus meridae, Pterobrycon landoni y los nodos 388 y 408. Algunos árboles: convergente en el nodo 312.

\section{Nodo $286(33 / 3 / 48)$ :}

Géneros Attonitus y Microgenys.

Este es el primer estudio que propone un clado compuesto por Attonitus y Microgenys. Ambos géneros son muy particulares entre los miembros del nodo 289 y se caracterizan por su largo pedúnculo caudal y hocico en posición ventral. Estos dos géneros son morfológicamente muy afines a Monotocheirodon Eigenmann \& Pearson, Bryconacidnus Myers, Ceratobranchia Eigenmann, Rhinopetitia Géry y Othonocheirodus, los cuales forman un grupo de géneros tentativamente propuesto como monofilético por NettoFerreira et al. (2014). Análisis filogenéticos enfocados en estos géneros contribuirán a la resolución de este posible clado y a establecer la posición filogenética de Knodus pectinatus.

1. Longitud de la maxila relativa al dentario (117): la maxila no alcanza al borde posterior del cartílago de Meckel $(0 \rightarrow 1$, ci $=11$, ri = 69). Convergente en Aulixidens eugeniae, Creagrutus atrisignum y el nodo 408.

2. Longitud de la rama ascendente de la premaxila (122): alcanza solo el extremo anterior de los nasales $(0 \rightarrow 1$, ci $=6$, ri $=75)$. Convergente en los nodos 295, 312 y 408 .

3. Número máximo de cúspides de la hilera interna de dientes de la premaxila (149): tres o menos $(1 \rightarrow 0$, ci $=9$, ri =67). Convergente en Nantis indefessus, Piabarchus analis y los nodos 367 y 390 .

4. Número máximo de cúspides de la hilera interna de dientes de la premaxila (150): cuatro o menos $(1 \rightarrow 0$, ci $=8$, ri $=65)$. Convergente en Nantis indefessus, Piabarchus analis y los nodos 367 y 390 .

5. Longitud del pedúnculo caudal (412): muy alargado, dos veces más largo que alto $(0 \rightarrow$ 1 , ci $=25$, ri $=57$ ). Convergente en Corynopoma riisei, Pterobrycon landoni y el nodo 388.

Algunos árboles:

1. Dentículos en los rastrillos branquiales (234): ausentes $(0 \rightarrow 1$, ci $=6$, ri $=58)$. Convergente en Gephyrocharax venezuelae y los nodos 294 y 403 . Revertido en 
Creagrutus gephyrus. Algunos árboles: convergente en Bryconadenos tanaothoros y Piabina argentea.

\section{Nodo 370 (47/0/22):}

Géneros Acrobrycon, Argopleura, Chrysobrycon, Corynopoma, Cyanocharax (C. obi), Diapoma, Gephyrocharax, Mimagoniates, nuevo género, Piabarchus, Pseudocorynopoma, Pterobrycon, Scopaeocharax, Tyttocharax y Xenurobrycon.

La composición de este nodo se corresponde en parte con el nodo 232 de Mirande et al. (2013), con diferencias en la cantidad de especies terminales.

1. Posición del supraneural más posterior (339): situado a más de dos vértebras en frente del primer pterigióforo dorsal $(0 \rightarrow 1, \mathrm{ci}=9$, ri $=60)$. Convergente en los nodos 405, 409 y 416. Revertido en Diapoma terofali y Mimagoniates rheocharis.

2. Posición de la aleta anal (340): extendida ventralmente a la aleta dorsal $(0 \rightarrow 1$, ci $=8$, ri $=73$ ). Convergente en Bryconamericus plutarcoi. Revertido en Acrobrycon ipanquianus y Argopleura magdalenensis.

3. Número de radios anales ramificados (345): 25 o más $(0 \rightarrow 1$, ci $=4$, ri $=68)$. Revertido en el nuevo género y los nodos 290 y 408.

4. Filamentos branquiales del primer arco branquial unidos o modificados para formar una glándula branquial (427): ausente $(1 \rightarrow 0$, ci $=8$, ri $=75)$. Convergente en Bryconamericus cf. rubropictus, B. rubropictus, Knodus meridae, Nantis indefessus y Pseudocorynopoma doriae. Revertido en el nodo 405.

Algunos árboles:

1. Número de radios pélvicos ramificados (304): seis o menos $(1 \rightarrow 0$, ci $=3$, ri $=43)$. Convergente en Carlastyanax aurocaudatus, Cyanocharax alburnus y el nodo 407. Revertido en el nodo 406. Algunos árboles: convergente en Knodus pectinatus.

\section{Nodo $369(80 / 2 / 20)$ :}

Géneros Acrobrycon, Argopleura, Chrysobrycon, Corynopoma, Cyanocharax (C. obi), Diapoma, Gephyrocharax, Mimagoniates, nuevo género, Pseudocorynopoma, Pterobrycon, Scopaeocharax, Tyttocharax y Xenurobrycon.

Este nodo se compone, en parte, de las mismas especies del nodo 232 de Mirande et al. 
(2013). Cyanocharax obi se encontró como el grupo hermano de todos los demás stevardinos con escamación hipertrofiada en la aleta caudal, también conocidos como glandulocaudinos (sensu Weitzman \& Menezes, 1998, sin Landonia y Phenacobrycon), en este estudio y en el de Mirande et al. (2013). Cyanocharax no se consideró monofilético en todos los estudios filogenéticos llevados a cabo con caracteres morfológicos y moleculares en los últimos tiempos (Javonillo et al., 2010; Oliveira et al. 2011; Casciotta et al., 2012; Mirande et al. 2013). Dentro de estos estudios, el principal problema de la monofilia de este género ha sido su estrecha relación con Diapoma. Sin embargo, la anatomía de estos géneros es muy diferente en términos del dimorfismo sexual de los machos adultos (Menezes \& Weitzman, 2011). Entonces, hasta no tener analizadas todas las especies de Cyanocharax (o su mayoría) es prematuro interpretar su sistemática.

1. Posición de la abertura sobre el neurocráneo que comunica con el tubo laterosensorial del sexto infraorbital (87): entre el frontal y el pterótico $(1 \rightarrow 0$, ci $=9$, ri $=60)$. Revertido en el nodo 289. Algunos árboles: convergente en Creagrutus meridionalis.

2. Continuidad de la línea lateral (107): interrumpida $(0 \rightarrow 1$, ci $=5$, ri $=67)$. Convergente en Pterobrycon landoni y el nodo 408. Revertido en el nodo 406.

3. Tubo terminal de la línea lateral sobre las membranas de la aleta caudal (108): ausente $(1 \rightarrow 0$, ci $=5$, ri = 73). Convergente en Carlastyanax aurocaudatus, Gephyrocharax valencia, Nantis indefessus y el nodo 427.

4. Porción posterior del coracoides (278): alcanza o sobrepasa el borde posterior del cleitro $(0 \rightarrow 1$, ci $=8$, ri $=69)$. Convergente en el nodo 411 . Revertido en el nodo 406.

5. Primer postcleitro (288): ausente $(0 \rightarrow 1, \mathrm{ci}=13$, ri $=53)$. Convergente en los nodos 394 y 408. Revertido en el nodo 406.

6. Posición longitudinal de inserción del tendón accesorio del adductor mandibulae (382): en la línea vertical que pasa por la mitad posterior del cartílago de Meckel $(1 \rightarrow 0, \mathrm{ci}=5$, ri =69). Convergente en Attonitus ephimeros, Cyanocharax alburnus, Nantis indefessus y el nodo 342. Revertido en Diapoma pyrrhopteryx, Mimagoniates inequalis, el nuevo género y el nodo 292 .

Algunos árboles:

1. Lámina ósea entre el segundo y tercer basibranquiales (217): presente $(0 \rightarrow 1$, ci $=4$, ri = 39). Convergente en Microgenys minuta y el nodo 395. Revertido en Chrysobrycon sp. nov. A, Knodus heteresthes y el nodo 389. Algunos árboles: revertido en el nodo 288. 


\section{Nodo 368 (52/0/63): \\ Géneros Acrobrycon, Argopleura, Chrysobrycon, Corynopoma, Diapoma, Gephyrocharax, Mimagoniates, nuevo género, Pseudocorynopoma, Pterobrycon, Scopaeocharax, Tyttocharax y Xenurobrycon.}

Este nodo incluye parcialmente a los miembros de la tradicional subfamilia Glandulocaudinae sensu Weitzman \& Menezes (1998) con excepción de Landonia y Phenacobrycon. Sin embargo, esta subfamilia no es monofilética según estudios morfológicos (Weitzman et al., 2005; Menezes \& Weitzman, 2009) y moleculares posteriores (Javonillo et al., 2010) y a los resultados del presente análisis. De hecho, el esquema de tribus de Weitzman \& Menezes (1998), que en su momento fue clave para el estudio de estos géneros glandulocaudinos y stevardinos, no se ajusta a los resultados del obtenidos aquí. No es posible mantener estas tribus como fueron definidas originalmente por varias razones: 1) no todas son monofiléticas (e. g. Diapomini); 2) la jerarquía del árbol no muestra un patrón de organización tribal coherente que pueda ser, a su vez, aplicado a otros clados dentro de Stevardiinae (si Corynopoma, Gephyrocharax y Pterobrycon son Stevardiini, entonces Carlastyanax, Creagrutus y Piabina serían “Creagrutini”); 3) las relaciones filogenéticas internas de muchos stevardinos pueden estar sujetas a cambios futuros por la adición o reorganización de géneros problemáticos $(e . g$. Bryconamericus, Cyanocharax y Knodus); y 4) las filogenias moleculares tampoco sustentan estas tribus en su totalidad (e. g. Javonillo et al., 2010). En este estudio, las tribus de Weitzman \& Menezes (1998) y Weitzman et al. (2005) que resultaron monofiléticas son referidas como clados, acompañados del nombre del género con mayor antigüedad en el respectivo nodo para mantener cierta relación con dicha propuesta tribal y asociarla en futuras discusiones. El nodo 368 se corresponde en composición con el nodo 237 de Mirande (2010), el nodo 1 de Ferreira et al. (2011: excepto por Landonia) y el nodo 230 de Mirande et al. (2013). De todas maneras, este clado es considerado tentativo dado que aún falta codificar en la matriz de caracteres a Hysteronotus, Glandulocauda, Lepidocharax Ferreira, Menezes \& Quagio-Grassiotto, Lophiobrycon y Planaltina. Según Zarske (2010) la morfología de los machos del género Trochilocharax Zarske es muy afín con ciertos glandulocaudinos (sensu Weitzman \& Menezes, 1998) por lo tanto este género podría ser un miembro tentativo de este nodo, pero aún no hay evidencia filogenética que lo sustente. 
1. Hileras de rastrillos branquiales en el segundo ceratobranquial (226): uno $(1 \rightarrow 0$, ci $=$ 4, ri =64). Revertido en Creagrutus cracentis, C. maracaiboensis, Diapoma terofali y los nodos 299 y 403.

2. Número de supraneurales (334): ocho o más $(0 \rightarrow 1$, ci $=9$, ri $=80)$. Convergente en Bryconamericus plutarcoi. Revertido en el nuevo género.

3. Tejido glandular de apariencia granular en la aleta caudal de los machos adultos (470): presente $(0 \rightarrow 1$, ci $=33$, ri $=92)$.

\section{Nodo 367 (100/99/99): clado Mimagoniates}

\section{M. inequalis y $M$. rheocharis}

Este nodo no solo representa a la monofilia de Mimagoniates, sino posiblemente al clado 2 de Weitzman \& Menezes (1998) o al clado Glandulocaudini de Menezes \& Weitzman (2009). El nodo 367 se corresponde en parte con el clado Mimagoniates de Javonillo et al. (2010) y el nodo 84 de Oliveira et al. (2011). La adición de los géneros Glandulocauda y Lophiobrycon esclarecerá la resolución de este posible clado y la mejor optimización de las 17 sinapomorfías propuestas. En todo caso, Mimagoniates es apoyado como un género válido y monofilético (Menezes \& Weitzman, 2009).

1. Articulación sincondral entre el etmoides lateral y el borde anterodorsal del orbitosfenoides (42): presente $(1 \rightarrow 0$, ci $=10$, ri $=61)$. Convergente en Gephyrocharax sinuensis, G. valencia, G. venezuelae, Knodus pectinatus y el nodo 393.

2. Pequeño foramen cerca del borde posterior del pterosfenoides (52): ausente, o no atravesado por nervios $(1 \rightarrow 0, \mathrm{ci}=20, \mathrm{ri}=90)$. Convergente en Chrysobrycon yoliae y Chrysobrycon sp. nov. A. Revertido en el nodo 290.

3. Lámina posterior del supraoccipital, debajo de la espina (62): sin una fenestra $(1 \rightarrow 0$, ci $=9$, ri $=80)$. Convergente en Carlastyanax aurocaudatus, Cyanocharax alburnus, Hemibrycon surinamensis y Nantis indefessus.

4. Rama posteromedial o parietal del canal sensorial supraorbital en el frontal (94): ausente $(0 \rightarrow 1$, ci $=10$, ri $=36)$. Convergente en el nodo 408 .

5. Tubo laterosensorial del hueso postemporal (103): ausente $(1 \rightarrow 0$, ci $=11$, ri $=11)$. Convergente en Cyanocharax alburnus y Knodus heteresthes.

6. Altura del proceso dorsolateral del ánguloarticular (130): casi igual a la altura de la región posterior del proceso horizontal $(0 \rightarrow 1$, ci $=25$, ri $=67)$. Convergente en los nodos 
397 y 410.

7. Número máximo de cúspides de la hilera interna de dientes de la premaxila (149): tres o menos $(1 \rightarrow 0$, ci $=9$, ri =67). Convergente en Nantis indefessus, Piabarchus analis y los nodos 286 y 390 .

8. Número máximo de cúspides de la hilera interna de dientes de la premaxila (150): cuatro o menos $(1 \rightarrow 0$, ci $=8, \mathrm{ri}=65)$. Convergente en Nantis indefessus, Piabarchus analis y los nodos 286 y 390.

9. Número de dientes en la hilera interna de la premaxila (155): cinco o más $(0 \rightarrow 1$, ci $=$ 6, ri = 75). Revertido en los nodos 293,400 y 414.

10. Longitud del segundo diente del dentario (176): su cúspide central alcanza o sobrepasa la punta dorsal del primer y tercer diente o al menos la del primero $(1 \rightarrow 0, \mathrm{ci}=8, \mathrm{ri}=42)$. Convergente en Aulixidens eugeniae, Bryconamericus cf. rubropictus y Microgenys minuta.

11. Lámina dorsal ósea sobre el cuarto basibranquial (218): ausente $(0 \rightarrow 1$, ci $=4$, ri $=$ 57). Convergente en Carlastyanax aurocaudatus, Creagrutus gephyrus, C. taphorni, Knodus heteresthes, Knodus sp., Piabarchus analis y el nodo 407.

12. Proceso anteroventral del postemporal (298): reducido, no osificado o ausente $(0 \rightarrow 1$, ci $=9$, ri = 23). Convergente en Carlastyanax aurocaudatus, Diapoma speculiferum, Knodus heteresthes y Nantis indefessus.

13. Longitud relativa de los radios anteriores de la aleta dorsal (322): no alcanzan al extremo de los radios posteriores con la aleta dorsal plegada $(1 \rightarrow 0, \mathrm{ci}=17$, $\mathrm{ri}=35)$.

14. Radios de la aleta caudal con forma de pliegue en machos adultos (448): presente, al menos con los radios 11 y 12 recurvados o expandidos, formando esta estructura $(0 \rightarrow 1$, $\mathrm{ci}=100, \mathrm{ri}=100)$.

15. Posición relativa de la base del radio 10 de la aleta caudal en machos adultos (453): se extiende sobre un punto medio entre el segundo y tercer hipurales $(0 \rightarrow 1$, ci $=100$, ri $=$ 100).

16. Tejido glandular compuesto por células de alarma modificadas en machos adultos (471): presente $(0 \rightarrow 1$, ci $=100, \mathrm{ri}=100)$.

17. Escamación hipertrofiada en el lóbulo dorsal de la aleta caudal en machos adultos (488): presente $(0 \rightarrow 1, \mathrm{ci}=100, \mathrm{ri}=100)$.

\section{Nodo 399 (61/0/63):}

Géneros Acrobrycon, Argopleura, Chrysobrycon, Corynopoma, Diapoma, 
Gephyrocharax, nuevo género, Pseudocorynopoma, Pterobrycon, Scopaeocharax, Tyttocharax y Xenurobrycon.

Este nodo tiene una composición afín al clado 3 de Weitzman \& Menezes (1998: excepto Phenacobrycon) y se apoya por sinapomorfías asociadas al dimorfismo sexual de los machos adultos. También el nodo es muy afín al clado 3 de Ferreira et al. (2011), pero no tienen las mismas sinapomorfías (no asociadas al dimorfismo sexual); dos de estas fueron codificadas en este estudio (205 y 305) y no mostraron relación directa con el nodo. Los géneros Hysteronotus y Lepidocharax, no analizados en el presente estudio, podrían posicionarse en el nodo 399, al menos tentativamente, con base en los resultados obtenidos y los de Ferreira et al. (2011). En contraste, este nodo no se obtuvo en las filogenias moleculares de Javonillo et al. (2010) y Oliveira et al. (2011), en especial por la diferente posición de Diapoma, Pseudocorynopoma, Planaltina, Tyttocharax y Xenurobrycon según sea el caso. Esto sugiere que la filogenia de los géneros en el nodo 399 debe ser mejor estudiada en el futuro.

1. Escamación hipertrofiada en el lóbulo ventral de la aleta caudal en machos adultos (490): presente $(0 \rightarrow 1, \mathrm{ci}=50, \mathrm{ri}=97)$. Convergente en Phenacobrycon henni.

2. Saco o bolsillo presumiblemente glandular, compuesto por escamas y con una abertura al exterior en el lóbulo ventral de la aleta caudal en machos adulto (491): presente $(0 \rightarrow 1$, $\mathrm{ci}=100, \mathrm{ri}=100)$.

Nodo 398 (100/58/52): clado Diapoma

D. speculiferum, D. pyrrhopteryx y D. terofali

Este nodo representa la monofilia de Diapoma, género que fue revisado en detalle por Menezes \& Weitzman (2011). Las filogenias morfológicas han sido muy positivas al demostrar el estado monofilético al nivel de género (Weitzman \& Menezes, 1998; Ferreira et al., 2011), pero los datos moleculares no (Javonillo et al., 2010). Aunque el estudio de Casciotta et al. (2012) apoyado en caracteres moleculares, muestra a Diapoma monofilético, este cae dentro del clado de los Cyanocharax, lo que indica que la filogenia de ambos géneros necesita ser estudiada en profundidad para entender la razón de tal resultado. Ferreira et al. (2011) encontraron ocho sinapomorfías para el clado Diapoma, de las cuales tres fueron codificadas en este estudio, pero no fueron obtenidas como 
sinapomorfías para este género y las cinco restantes corresponden a caracteres sobre la biología de los espermatozoides. El género Diapoma se diferencia de sus congéneres stevardinos más afines filogenéticamente por la morfología de la escamación del lóbulo ventral de la aleta caudal de los machos adultos (Menezes \& Weitzman, 2011), mientras que Cyanocharax se distingue por una combinación de caracteres donde ninguno es único para el género (Malabarba \& Weitzman, 2003). Esto y los resultados filogenéticos mencionados sugieren que la sistemática de Cyanocharax es posiblemente más compleja y difícil de sostener con morfología de lo que se creía, sobre todo en comparación con la sistemática de Diapoma, la cual parece mejor apoyada. En el árbol de consenso estricto bajo pesos iguales, el clado Diapoma se apoya en tres sinapomorfías asociadas al dimorfismo sexual de los machos adultos (caracteres 470: $0 \rightarrow 1$; 490: $0 \rightarrow 1$; y 491: $1 \rightarrow$ $0)$.

1. Extensión posterior del proceso ventral del cuadrado (181): no alcanza la línea vertical que pasa por el borde posterior del simpléctico $(0 \rightarrow 1$, ci $=3$, ri $=65)$. Convergente en Cyanocharax alburnus, Mimagoniates inequalis y los nodos 294 y 402. Revertido en Chrysobrycon yoliae.

2. Ganchos óseos en la base de los radios pélvicos en machos adultos (477): en número reducido comparado con la porción segmentada de los radios $(1 \rightarrow 0, \mathrm{ci}=5$, ri $=46)$. Convergente en Bryconamericus agna, Creagrutus atrisignum, Gephyrocharax caucanus, G. torresi y Piabarchus analis.

\section{Nodo 397 (100/88/84):}

Diapoma speculiferum y D. pyrrhopteryx

Este es el primer estudio filogenético que analiza la posición filogenética de tres especies de Diapoma y en particular de D. pyrrhopteryx. Esta relación entre D. speculiferum y $D$. pyrrhopteryx es considerada tentativa hasta analizar todas las especies del género.

1. Longitud del borde lateral del hueso parietal (49): más larga que la longitud de su borde medial $(0 \rightarrow 1$, ci $=14, \mathrm{ri}=75)$. Convergente en el nodo 411 .

2. Altura del proceso dorsolateral del ánguloarticular (130): casi igual a la altura de la región posterior del proceso horizontal $(0 \rightarrow 1, \mathrm{ci}=25, \mathrm{ri}=67)$. Convergente en los nodos 367 y 410. 
3. Opérculo y subopérculo (202): no modificados o extendidos posteriormente $(0 \rightarrow 1$, ci $=100, \mathrm{ri}=100)$.

4. Posición del borde ventral del postemporal (299): anterior al borde lateral de epioccipital $(1 \rightarrow 0, \mathrm{ci}=5, \mathrm{ri}=31)$. Convergente en Bryconamericus exodon, Creagrutus anary Knodus pectinatus, el nuevo género y el nodo 298. Revertido en B. agna

\section{Nodo 406 (57/0/49):}

Géneros Acrobrycon, Argopleura, Chrysobrycon, Corynopoma, Gephyrocharax, nuevo género, Pseudocorynopoma, Pterobrycon, Scopaeocharax, Tyttocharax y Xenurobrycon.

Este nodo es parecido al clado 9 de Ferreira et al. (2011), pero ambos tienen diferentes géneros analizados. La monofilia de la tribu Diapomini tal y como fue definida por Weitzman \& Menezes (1998) no se obtuvo en este estudio. Aunque Planaltina no se analizó aquí, los géneros Acrobrycon y Diapoma cayeron distantes en la hipótesis filogenética obtenida. Ferreira et al. (2011) tampoco encontraron evidencia en la morfología para agrupar a Acrobrycon, Diapoma y Planaltina en un mismo clado. Si bien Menezes \& Weitzman (2011) sugieren mantener esta tribu, ningún estudio filogenético (tampoco con datos moleculares) demuestra que el clado Diapomini original de Weitzman \& Menezes (1998) deba ser conservado. Menezes \& Weitzman (2011) usaron dos caracteres para sostener la validez de Diapomini; ambos fueron analizados en este estudio (494 a 496) pero no agruparon a los miembros analizados de esta tribu.

1. Continuidad de la línea lateral (107): completa $(1 \rightarrow 0$, ci $=5$, ri =67). Convergente en el nodo 406. Revertido en Pterobrycon landoni y el nodo 408.

2. Porción posterior del coracoides (278): no alcanza el borde posterior del cleitro $(1 \rightarrow 0$, ci $=8$, ri =69). Convergente en el nodo 406. Revertido en los nodos 369 y 411.

3. Primer postcleitro (288): presente $(1 \rightarrow 0$, ci $=13$, ri $=53)$. Revertido en el nodo 369, 394 y 408.

4. Número de radios pélvicos ramificados (304): siete o más $(0 \rightarrow 1$, ci $=3$, ri $=43)$. Revertido en Carlastyanax aurocaudatus, Cyanocharax alburnus y el nodo 407. Algunos árboles: revertido en Knodus pectinatus y el nodo 370.

5. Ganchos óseos en la aleta caudal de machos adultos (482): presentes $(0 \rightarrow 1$, ci $=8$, ri $=$ 59). Convergente en Mimagoniates rheocharis. Revertido en Argopleura magdalenensis y Gephyrocharax martae. 


\section{Nodo 405 (61/1/48):}

Géneros Acrobrycon, Argopleura, Chrysobrycon, Corynopoma, Gephyrocharax, Pseudocorynopoma, Pterobrycon, Scopaeocharax, Tyttocharax y Xenurobrycon.

Acrobrycon se obtuvo como el grupo hermano de los restantes stevardinos con una escama-bolsillo en los machos adultos, lo cual coincide con el resultado de Ferreira et al. (2011).

1. Número de vértebras anteriores al pterigióforo más anterior de la aleta dorsal (265): 14 o más $(0 \rightarrow 1$, ci $=13$, ri $=77)$. Convergente en el nodo 405. Revertido en Argopleura magdalenensis y Tyttocharax sp.

2. Posición del supraneural más posterior (339): situado a dos o menos vértebras en frente del primer pterigióforo dorsal $(1 \rightarrow 0, \mathrm{ci}=9, \mathrm{ri}=60)$. Convergente en Diapoma terofali y Mimagoniates rheocharis. Revertido en los nodos 370, 409 y 416.

3. Número de segmentos del tercer radio procurrente ventral (361): cuatro o más $(0 \rightarrow 1$, ci $=6$, ri = 27). Revertido en Bryconamericus emperador, B. thomasi, Cyanocharax alburnus, Knodus meridae y el nodo 414.

4. Filamentos branquiales del primer arco branquial unidos o modificados para formar una glándula branquial en machos adultos (427): presente $(0 \rightarrow 1$, ci $=8$, ri $=75)$. Revertido en Bryconamericus cf. rubropictus y B. rubropictus, Knodus meridae, Nantis indefessus, Pseudocorynopoma doriae y el nodo 370.

5. Número de escamas inmediatamente ventrales a las de la línea lateral que se extienden posteriormente, en la misma hilera, y se asocian a un saco o bolsillo en machos adultos (495): seis o menos $(1 \rightarrow 0, \mathrm{ci}=100, \mathrm{ri}=100)$.

6. Distribución de los paquetes de fibras interradialis en machos adultos (524): modificados, más desarrollados en alguna región o lóbulo de la aleta caudal $(0 \rightarrow 1$, ci $=$ $100, \mathrm{ri}=100)$.

\section{Nodo 404 (61/2/47):}

Géneros Argopleura, Chrysobrycon, Corynopoma, Gephyrocharax, Pseudocorynopoma, Pterobrycon, Scopaeocharax, Tyttocharax y Xenurobrycon.

Este nodo coincide en gran parte con el clado 11 de Ferreira et al. (2011), pero las 
relaciones filogenéticas internas entre ambos son diferentes. Estos autores propusieron dos caracteres sobre los espermatozoides (forma de la mitocondria y la posición del centriolo) que apoyaron este clado. El nodo 404 corresponde a los stevardinos que tienen una escama-bolsillo en los machos adultos. En los estudios moleculares recientes, no se obtuvo la monofilia de este grupo (Javonillo et al. 2010; Oliveira et al., 2011) pero en un estudio molecular de Stevardiinae en proceso de publicación este grupo tiene resultados más parecidos a los aquí obtenidos (Dahiana K. Arcila-Mesa, comun. pers.).

1. Tamaño del segundo postcleitro (293): pequeño, casi completamente solapado por el cleitro $(0 \rightarrow 1$, ci $=33$, ri $=91)$.

2. Margen del saco o bolsillo que forma una abertura al exterior sobre el lóbulo ventral de la aleta caudal en machos adultos (492): formado por una o dos escamas modificadas, con o sin radii hipertrofiados, donde la más posterior es denominada escama-bolsillo $(1 \rightarrow 0$, $\mathrm{ci}=100, \mathrm{ri}=100)$.

3. Escamación en el lóbulo ventral de la aleta caudal en especies con bolsillo en machos adultos (496): más compleja, desarrollada y modificada en machos que en hembras, tanto en patrón como en tamaño $(1 \rightarrow 0$, ci $=100$, ri $=100)$.

\section{Nodo 403 (100/19/4): clado Argopleura}

Géneros Argopleura, Scopaeocharax, Tyttocharax y Xenurobrycon.

Este nodo coincide con los miembros tradicionalmente agrupados en Xenurobryconini por Weitzman \& Fink (1985). Aunque los géneros Iotabrycon y Ptychocharax no fueron analizados, es muy probable que estos correspondan a este clado debido a que este grupo está bien definido por su peculiar anatomía en la región caudal de los machos adultos. Weitzman \& Menezes (1998) adicionaron a Chrysobrycon en Xenurobryconini, pero esta decisión fue apoyada en una sola sinapomorfía (una escama-bolsillo con o sin radii hipertrofiados). Ferreira et al. (2011) no analizaron a Chrysobrycon en su filogenia morfológica, pero sí obtuvieron un clado correspondiente a los Xenurobryconini. Oliveira et al. (2011) también obtuvieron un clado afín a esta tribu representado por Tyttocharax y Xenurobrycon. En este estudio, los resultados filogenéticos muestran que las tribus de Weitzman \& Menezes (1998) no deberían usarse, y aunque Xenurobryconini es un grupo claramente monofilético excluyendo a Chrysobrycon, no hay un razonamiento lógico que 
implique mantener esta tribu sin considerar la creación de otras tribus acorde al sistema jerárquico de la hipótesis filogenética obtenida. Las relaciones filogenéticas internas de Stevardiinae en muchos grupos están parcialmente entendidas o son inestables y es mejor ser cauteloso antes de usar agrupamientos tribales que pueden ser solo temporarios.

1. Rama epifisaria del tubo supraorbital (96): presente $(1 \rightarrow 0$, ci $=20$, ri $=92)$. Convergente en Microgenys minuta y los nodos 291 y 390. Revertido en el nodo 296.

2. Poro frontoetmoidal del tubo sensorial supraorbital (99): localizado aproximadamente a media distancia entre la articulación del frontal con el etmoides lateral y la barra epifisaria $(1 \rightarrow 0, \mathrm{ci}=5, \mathrm{ri}=50)$. Convergente en Microgenys minuta .

3. Poro supraorbitario localizado sobre la base de la barra epifisaria, cercano a ésta o en punto entre ésta y el poro frontoetmoidal (100): ausente $(1 \rightarrow 0$, ci $=20$, ri $=92)$. Revertido en el nodo 291.

4. Hileras de rastrillos branquiales en el segundo ceratobranquial (226): dos ( $0 \rightarrow 1$, ci $=4$, ri $=64)$. Convergente en Creagrutus cracentis, C. maracaiboensis, Diapoma terofali y el nodo 299. Revertido en el 368.

5. Dentículos en los rastrillos branquiales (234): ausentes $(0 \rightarrow 1$, ci $=6$, ri $=58)$. Convergente en Gephyrocharax venezuelae y el nodo 294. Revertido en Creagrutus gephyrus. Algunos árboles: convergente en Bryconadenos tanaothoros, Piabina argentea y el nodo 286.

6. Extremos proximales de los radios pélvicos mediales primero, segundo, y a veces tercero en machos adultos (431): ubicados anteriormente con respecto a los radios adyacentes $(0 \rightarrow 1$, ci $=100$, ri $=100)$.

7. Fusión entre el parhipural y el hipural uno en machos adultos (442): presente $(0 \rightarrow 1$, ci $=100, \mathrm{ri}=100)$.

8. Anclaje entre la/s escama/s hipertrofiada/s en forma de bolsillo en los radios de la aleta caudal en machos adultos (530): principalmente a través de fibras interradialis o una porción de ligamento $(0 \rightarrow 1$, ci $=100, \mathrm{ri}=100)$.

9. Tejido conectivo sobre los radios de la aleta caudal de especies con escama/s hipertrofiada/s en forma de bolsillo en machos adultos (531): organizado en un ligamento $(0 \rightarrow 1, \mathrm{ci}=100, \mathrm{ri}=100)$.

\section{Nodo 408 (100/100/100):}

Géneros Scopaeocharax, Tyttocharax y Xenurobrycon. 
Este nodo se corresponde en composición con aquellos obtenidos en las filogenias de Weitzman \& Fink (1985), Weitzman \& Menezes (1998) y Ferreira et al. (2011), pero no coincide con las relaciones filogenéticas internas obtenidas en los primeros dos estudios.

1. Intercalar (19): ausente $(0 \rightarrow 1, \mathrm{ci}=50, \mathrm{ri}=67)$.

2. Zona anterior de la fontanela anterior (24): delimitada por el contacto anterior entre los frontales $(0 \rightarrow 1$, ci $=4$, ri $=44)$. Convergente en Bryconamericus scleroparius y Carlastyanax aurocaudatus. Revertido en B. agna y Gephyrocharax sinuensis Algunos árboles: convergente en Bryconadenos tanaothoros y Knodus pectinatus.

3. Forma de la espina del mesetmoides (29): relativamente corta, con las premaxilas articulando entre sí anterior al mesetmoides $(0 \rightarrow 1$, ci $=20, \mathrm{ri}=78)$.

4. Región posterior de la espina del mesetmoides tan ancha como los procesos laterales del mesetmoides (30): $(0 \rightarrow 1$, ci $=33, \mathrm{ri}=60)$. Convergente en el nuevo género.

5. Láminas ventrales divergentes del mesetmoides (32): ausentes $(1 \rightarrow 0, \mathrm{ci}=33$, ri $=90)$.

6. Rama posteromedial o parietal del canal sensorial supraorbital en el frontal (94): ausente $(0 \rightarrow 1, \mathrm{ci}=10, \mathrm{ri}=36)$. Convergente en el nodo 367 .

7. Continuidad de la línea lateral (107): interrumpida $(0 \rightarrow 1$, ci $=5$, ri $=67)$. Convergente en Pterobrycon landoni y el nodo 369. Revertido en el nodo 406.

8. Borde ventral de la zona dentada de la maxila (112): fuertemente cóncavo $(0 \rightarrow 1$, ci $=$ 33, ri $=75)$. Convergente en el nodo 395.

9. Longitud de la maxila relativa al dentario (117): la maxila no alcanza al borde posterior del cartílago de Meckel $(0 \rightarrow 1$, ci = 11, ri = 69). Convergente en Aulixidens eugeniae, Creagrutus atrisignum y el nodo 286.

10. Longitud de la rama ascendente de la premaxila (122): alcanza solo el extremo anterior de los nasales $(0 \rightarrow 1$, ci $=6$, ri $=75)$.

11. Alineamiento de la rama ascendente de la premaxila (123): desplazada medialmente respecto a los nasales $(0 \rightarrow 1, \mathrm{ci}=33, \mathrm{ri}=78)$.

12. Borde ventral del proceso horizontal del ánguloarticular (128): angulado en sentido posteroventral con respecto al tubo laterosensorial del dentario, en vista medial $(1 \rightarrow 0$, ci $=8$, ri $=85$ ). Convergente en Carlastyanax aurocaudatus, Nantis indefessus y el nodo 287.

13. Morfología de la premaxila, maxila y dentario (139): todos los dientes cónicos, caniniformes o mamiliformes $(1 \rightarrow 0$, ci $=13$, ri $=61)$. 
14. Número de cúspides de los dientes maxilares anteriores (166): una, dientes cónicos (1 $\rightarrow 0, \mathrm{ci}=8, \mathrm{ri}=60)$.

15. Foramen en la zona posterior del metapterigoides (198): en forma de un arco incompleto, limitado posteriormente por el hiomandibular $(1 \rightarrow 2$, ci $=25$, ri $=84)$. Convergente en Mimagoniates inequalis y el nodo 315.

16. Hileras de rastrillos branquiales en el primer ceratobranquial (225): dos ( $0 \rightarrow 1$, ci $=5$, ri = 52). Convergente en Attonitus ephimeros, Phenacobrycon henni y los nodos 299 y 312. Revertido en Knodus sp. y el nodo 294.

17. Vértebras transicionales con canal hemal (262): ausentes $(0 \rightarrow 1$, ci $=4$, ri $=49)$. Convergente en Bryconamericus rubropictus y Creagrutus maracaiboensis.

18. Primer postcleitro (288): ausente $(0 \rightarrow 1$, ci $=13$, ri $=53)$. Convergente en los nodos 369 y 394. Revertido en el nodo 406.

19. Número de radios ramificados de la aleta dorsal (319): siete o menos $(1 \rightarrow 0$, ci $=100$, $\mathrm{ri}=100)$.

20. Supraneurales (330): ausentes $(0 \rightarrow 1$, ci $=100, \mathrm{ri}=100)$.

21. Número de radios anales ramificados (344): 17 o menos $(1 \rightarrow 0, \mathrm{ci}=8$, ri $=72)$. Convergente en Knodus meridae, Pterobrycon landoni y el nodo 388. Algunos árboles: convergente en los nodos 287 y 312.

22. Número de radios anales ramificados (345): 24 o menos $(1 \rightarrow 0, \mathrm{ci}=4$, ri $=68)$. Convergente en el nuevo género y el nodo 290. Revertido en el nodo 370.

23. Tercer radio procurrente ventral de la aleta caudal (360): no segmentado $(1 \rightarrow 0$, ci $=$ 5, ri =49). Convergente en Chrysobrycon hesperus, Cyanocharax obi y el nodo 421.

24. Inserción posterior de la sección rictalis $\left(=\mathrm{A}_{1}\right)$ del adductor mandibulae (384): principalmente sobre la rama horizontal del preopérculo $(0 \rightarrow 1, \mathrm{ci}=9$, ri $=47)$.

25. Número de fibras tendinosas del hypochordal longitudinalis que se insertan posteriormente sobre los radios de la aleta caudal (398): tres o menos $(0 \rightarrow 1$, ci $=25$, ri $=$ 40). Convergente en Corynopoma riisei.

26. Posición del extremo anterior del hueso pélvico con respecto a la posición de las costillas pleurales (430): más anterior en machos que en hembras, en una distancia mayor a la presente entre las costillas 6 y $7(0 \rightarrow 1$, ci $=5$, ri $=67)$. Convergente en Chrysobrycon sp. nov. A.

27. Mitades distales de los radios 7 a 10 de la aleta caudal en machos adultos (443): curvadas ventralmente $(0 \rightarrow 1, \mathrm{ci}=100, \mathrm{ri}=100)$.

28. Radios 11 al 14 de la aleta caudal en machos adultos (444): estrechos distalmente y 
algunas veces acortados $(0) \rightarrow(1)(\mathrm{ci}=100, \mathrm{ri}=100)$.

29. Radios 1 a 8 y 16 a 19 más el primer radio procurrente ventral de la aleta caudal en machos adultos (445): expandidos, con la expansión más marcada cerca de los márgenes dorsal y especialmente ventral de esta aleta $(0) \rightarrow(1)(\mathrm{ci}=100, \mathrm{ri}=100)$.

30. Porción proximal de los radios 10 y 11 de la aleta caudal arqueada dorsalmente, con el radio 11 más curvado que el radio 10 en machos adultos (446): presente $(0 \rightarrow 1$, ci $=100$, $\mathrm{ri}=100)$.

31. Radios 10 y 11 de la aleta caudal en machos adultos (447): hipertrofiados distalmente en el sitio de inserción proximal del ligamento de la escama-bolsillo, especialmente en el radio $11(0 \rightarrow 1, \mathrm{ci}=100, \mathrm{ri}=100)$.

32. Número máximo de radii de la escama-bolsillo en machos adultos (504): 70 o más (0 $\rightarrow 1$, ci $=50$, ri $=67)$. Convergente en Pterobrycon myrnae.

33. Tamaño de la escama-bolsillo de los machos adultos (510): muy grande, su mayor altura es la mitad o más de la longitud entre el complejo hipural y la punta posterior de los radios centrales de la aleta caudal $(0 \rightarrow 1, \mathrm{ci}=50, \mathrm{ri}=88)$. Convergente en el nodo 415 .

34. Posición del borde dorsal de la escama-bolsillo en relación a los radios de la aleta caudal en machos adultos (513): se ubica en un punto entre los radios 4 a 8 ( $1 \rightarrow 0$, ci $=$ 100 , ri $=100)$.

35. Interradialis de la región central de la aleta caudal en especies con escamación hipertrofiada en forma de bolsillo en los machos adultos (533): organizados en dos secciones hipertrofiadas $a$ y $b(0 \rightarrow 1, \mathrm{ci}=100, \mathrm{ri}=100)$.

\section{Nodo 407 (100/75/67):}

\section{Géneros Tyttocharax y Xenurobrycon.}

El clado compuesto por Tyttocharax y Xenurobrycon ha sido obtenido en estudios filogénicos con datos morfológicos y moleculares (Ferreira et. al. 2011; Oliveira et al., 2011). Por el contrario, este resultado no coincide con las hipótesis filogenéticas tradicionales de Weitzman \& Fink (1985) y Weitzman \& Menezes (1998). En la presente investigación, se codificaron casi todos los caracteres analizados por estos autores, por lo que se considera que las relaciones obtenidas de estos géneros y sus grupos cercanos están sustentados en toda la evidencia morfológica disponible. El clado Scopaeocharax + Tyttocharax + Xenurobrycon se ha encontrado muy estable en los estudios filogenéticos (Weitzman \& Fink, 1985; Weitzman \& Menezes, 1998; Ferreira et. al., 2011) y es poco 
probable que los géneros Iotabrycon y Ptychocharax, no analizados en este estudio, rompan la monofilia de este grupo para relacionarse más con Tyttocharax o Xenurobrycon.

1. Puente epioccipital sobre la fosa postemporal (4): ausente $(1 \rightarrow 0, \mathrm{ci}=33$, ri $=33)$.

2. Longitud del tubo laterosensorial del dentario (89): reducido o ausente $(0 \rightarrow 1$, ci $=10$, ri $=10)$. Convergente en Carlastyanax aurocaudatus.

3. Extremo anterior de la premaxila (120): al nivel de la mitad superior de la órbita $(0 \rightarrow$ 1, ci $=5$, ri =61). Convergente en Hemibrycon surinamensis, nodos 402 y 411.

4. Proceso horizontal del ánguloarticular (127): ampliamente cubierto por el dentario, que alcanza el borde posterior del cartílago de Meckel $(0 \rightarrow 1$, ci $=6$, ri $=71)$. Algunos árboles: Convergente en Gephyrocharax major, el nuevo género, y los nodos 302 y 410. Revertido en Attonitus ephimeros. Algunos árboles: convergente el nodo 288,

5. Lámina ósea entre el primer y segundo basibranquiales (215): ausente $(1 \rightarrow 0$, ci $=3$, ri = 33). Convergente en Gephyrocharax melanocheir y el nodo 292. Revertido en Bryconamericus plutarcoi, Microgenys minuta y Piabina argentea.

6. Lámina dorsal ósea sobre el cuarto basibranquial (218): ausente $(0 \rightarrow 1$, ci $=4$, ri $=57)$. Convergente en Carlastyanax aurocaudatus, Creagrutus gephyrus, C. taphorni, Knodus heteresthes, Knodus sp., Piabarchus analis y el nodo 367.

7. Extraescapular (297): ausente o reducido a una rama de canal laterosensorial que usualmente comunica con el pterótico $(0 \rightarrow 1$, ci $=25$, ri $=25)$. Convergente en Mimagoniates inequalis.

8. Número de radios pélvicos ramificados (304): seis o menos $(1 \rightarrow 0$, ci $=3$, ri $=43)$. Convergente en Carlastyanax aurocaudatus y Cyanocharax alburnus. Revertido en el nodo 406. Algunos árboles: convergente en Knodus pectinatus y el nodo 370.

9. Tamaño de los radios medios de la aleta dorsal (321): más largos que los anteriores y posteriores $(0 \rightarrow 1$, ci $=13$, ri $=73)$. Convergente en el nodo 411 .

\section{Nodo 411 (61/52/33):}

Géneros Chrysobrycon, Corynopoma, Gephyrocharax, Pseudocorynopoma, Pterobrycon.

Este es el primer estudio filogenético que propone a Chrysobrycon como grupo hermano de los restantes stevardinos, conocidos por sus complejos comportamientos de cortejo, modificaciones anatómicas y pigmentaciones asociadas al dimorfismo sexual de los machos adultos. Chrysobrycon se elimina del clado de los Xenurobryconini (sensu 
Weitzman \& Menezes (1998) o el nodo 403 del presente análisis.

1. Confluencia de las láminas ventrales divergentes del mesetmoides con el septo nasal del mesetmoides (33): ausente o confluyen cerca de la articulación terminal del septo nasal del mesetmoides $(1 \rightarrow 0$, ci $=6$, ri $=53)$. Convergente en Aulixidens eugeniae, Knodus breviceps, K. pectinatus, el nuevo género y Odontostoechus lethostigmus. Revertido en Creagrutus cracentis y el nodo 291. Algunos árboles: convergente en el nodo 390.

2. Longitud del borde lateral del hueso parietal (49): más larga que la longitud de su borde medial $(0 \rightarrow 1$, ci $=14, \mathrm{ri}=75)$. Convergente en el nodo 397 .

3. Extremo anterior de la premaxila (120): al nivel de la mitad superior de la órbita $(0 \rightarrow$ 1, ci = 5, ri =61). Convergente en Hemibrycon surinamensis y los nodos 420 y 407.

4. Forma de la expansión anterior del basihial (224): expandida, el borde anterior tiene dos tercios de su longitud $(0 \rightarrow 1$, ci $=8$, ri $=39)$. Convergente en Aulixidens eugeniae, Mimagoniates inequalis y el nuevo género. Revertido Chrysobrycon sp. nov. A y nodo 311.

5. Porción anterior del cleitro (275): alcanza el borde posterior del metapterigoides.

$(0 \rightarrow 1, \mathrm{ci}=11, \mathrm{ri}=65)$. Convergente en Carlastyanax aurocaudatus, Knodus breviceps y Piabarchus analis.

6. Porción posterior del coracoides (278): alcanza o sobrepasa el borde posterior del cleitro $(0 \rightarrow 1$, ci $=8$, ri $=69)$. Convergente en el nodo 369. Revertido en el nodo 406.

7. Tamaño de los radios medios de la aleta dorsal (321): más largos que los anteriores y posteriores $(0 \rightarrow 1, \mathrm{ci}=13$, ri $=73)$.

8. Radiales anales proximales y medios (350): fusionados en la mayoría de los pterigióforos $(0 \rightarrow 1$, ci $=13$, ri $=58)$.

9. Surcos con neuromastos sobre la cabeza, justo arriba de los ojos (411): presentes, bien desarrollados $(0 \rightarrow 1$, ci $=100$, ri $=100)$.

\section{Nodo 410 (100/94/92): clado Chrysobrycon}

C. eliasi, C. hesperus, C. myersi, C. yoliae y Chrysobrycon sp. nov. A.

Este es el primer estudio filogenético que apoya la monofilia de Chrysobrycon con 11 sinapomorfías. Además, se encontraron caracteres distintivos para el género que no habían sido mencionados en su diagnosis original (Weitzman \& Menezes, 1998). La sistemática de Chrysobrycon fue estudiada por Weitzman \& Menezes (1998) y actualmente es objeto 
de revisión (Vanegas-Ríos et al., 2011, 2014). No existen hipótesis filogenéticas que permitan comparar las relaciones filogenéticas de las especies de Chrysobrycon y por tal motivo no se realizan discusiones al respecto. En el árbol de consenso estricto bajo pesos iguales, el clado Chrysobrycon se apoya en trece sinapomorfías en su mayoría no asociadas al dimorfismo sexual de los machos adultos (caracteres $23: 0 \rightarrow 1$; 48: $0 \rightarrow 1$; $55: 1 \rightarrow 0 ; 130: 0 \rightarrow 1 ; 350: 0 \rightarrow 1 ; 356: 0 \rightarrow 1 ; 358: 0 \rightarrow 1 ; 395: 0 \rightarrow 1 ; 400: 0 \rightarrow 1$; 497: $0 \rightarrow 1 ; 502: 0 \rightarrow 1 ; 523: 0 \rightarrow 1 ;$ y 527: $1 \rightarrow 0)$.

1. Fontanela anterior o frontal (23): totalmente cerrada por los frontales $(0 \rightarrow 1$, ci $=10$, ri =47). Convergente en Gephyrocharax major y G. martae.

2. Nasal en vista dorsal (41): en forma de media luna, muy cóncavo, arqueado en un ángulo igual o menor a $135^{\circ}(0 \rightarrow 1, \mathrm{ci}=13, \mathrm{ri}=13)$. Convergente en Aulixidens eugeniae y Gephyrocharax major.

3. Fontanela posterior o parietal (48): ausente o reducida en adultos $(0 \rightarrow 1$, ci $=13$, ri $=$ $50)$.

4. Proceso horizontal del ánguloarticular (127): ampliamente cubierto por el dentario, que alcanza el borde posterior del cartílago de Meckel $(0 \rightarrow 1$, ci $=6$, ri $=71)$. Convergente en Gephyrocharax major, el nuevo género y los nodos 302 y 407. Revertido en Attonitus ephimeros. Algunos árboles: Convergente en el nodo 288.

5. Altura del proceso dorsolateral del ánguloarticular (130): casi igual a la altura de la región posterior del proceso horizontal $(0 \rightarrow 1, \mathrm{ci}=25, \mathrm{ri}=67)$. Convergente en los nodos 367 y 397.

6. Borde posterior del segundo hueso hipural (356): aproximadamente tan alto como la distancia vertical entre las bases de los radios caudales 11 a $13(0 \rightarrow 1$, ci $=5$, ri $=20)$. Convergente en Argopleura magdalenensis, Bryconamericus plutarcoi, B. rubropictus, B. scleroparius y Gephyrocharax major.

7. Posición de la base del radio 12 de la aleta caudal (358): extendida sobre la porción posterior del segundo hipural $(0 \rightarrow 1$, ci $=6$, ri $=21)$. Convergente en Acrobrycon ipanquianus, Attonitus ephimeros, Bryconamericus plutarcoi y Gephyrocharax major Algunos árboles: convergente en el nodo 389.

8. Forma de la escama-bolsillo de los machos adultos (497): pequeña, alargada posteriormente, curvada y horizontalmente plegada de modo tal que se forma un bolsillo lateralmente cóncavo $(0 \rightarrow 1$, ci $=100, \mathrm{ri}=100)$.

9. Número máximo de radii de la escama-bolsillo en machos adultos (502): 28 o menos (1 
$\rightarrow 0$, ci $=25$, ri $=63$ ). Convergente en Corynopoma riisei y el nodo 419. Revertido en Chrysobrycon hesperus.

10. Escama accesoria pequeña situada medial a la escama-bolsillo en machos adultos (523): presente $(0 \rightarrow 1$, ci $=100$, ri $=100)$.

11. Posición relativa de la escama-bolsillo y los interradialis en machos adultos (527): las fibras musculares no sobrepasan el borde posterodorsal de la escama $(1 \rightarrow 0$, ci $=33$, ri $=$ 80). Convergente en el nodo 423. Revertido en el nodo 425.

\section{Nodo 409 (100/40/5):}

Chrysobrycon eliasi, C. hesperus, C. yoliae y Chrysobrycon sp. nov. A.

1. Extremo dorsal del tubo sensorial del preopérculo y suprapreopérculo (92): solapa el proceso anterodorsal del opérculo $(0 \rightarrow 1$, ci $=7$ ri $=43)$. Convergente en Creagrutus cracentis. Revertido en Chrysobrycon yoliae.

2. Número de vértebras anteriores al pterigióforo más anterior de la aleta dorsal (266): 18 o más $(0 \rightarrow 1$, ci $=20, \mathrm{ri}=69)$.

3. Número de supraneurales (336): once o más $(0 \rightarrow 1$, ci $=33$, ri $=67)$.

4. Posición del supraneural más posterior (339): situado a más de dos vértebras en frente del primer pterigióforo dorsal $(0 \rightarrow 1$, ci $=9$, ri $=60)$. Convergente en el nodo $370 \mathrm{y}$ el nodo 416. Revertido en Diapoma terofali, Mimagoniates rheocharis y el nodo 405.

5. Longitud del tercer radio procurrente ventral en machos adultos (465): alcanza o sobrepasa la región media del primer radio procurrente ventral $(0 \rightarrow 1$, ci $=10$, ri $=44)$. Convergente en Cyanocharax obi y el nodo 423. Revertido en Gephyrocharax martae.

6. Ganchos óseos en el primer radio pélvico de machos adultos (479): presentes $(0 \rightarrow 1$, ci = 7, ri = 30). Convergente en Aulixidens eugeniae, Bryconamericus cf. iheringii, Diapoma pyrrhopteryx, Gephyrocharax chocoensis, Mimagoniates inequalis y Xenurobrycon macropus.

\section{Nodo 412 (100/17/6):}

Chrysobrycon eliasi, $C$. hesperus y $C$. yoliae.

1. Longitud relativa de la espina del pterótico (54): extendida posteriormente más allá de la zona de anclaje del ligamento procedente del hiomandibular $(1 \rightarrow 0, \mathrm{ci}=25, \mathrm{ri}=92)$. Convergente en Pseudocorynopoma doriae. 
2. Número total de vértebras (260): 41 o más $(0 \rightarrow 1$, ci $=8$, ri $=48)$.

\section{Nodo 413 (100/29/10):}

Chrysobrycon eliasi y C. yoliae.

1. Extensión de la implantación dentaria a lo largo de la maxila (165): extendida sobre casi toda la lámina maxilar $(0 \rightarrow 1, \mathrm{ci}=5, \mathrm{ri}=61)$. Convergente en Chrysobrycon myersi, el nuevo género y el nodo 392.

2. Número de segmentos del segundo radio procurrente ventral de machos adultos (466): uno o tres $(0 \rightarrow 1$, ci $=14$, ri $=45)$. Convergente en Diapoma terofali, Gephyrocharax major y Xenurobrycon macropus.

\section{Nodo 414 (61/23/14):}

Géneros Corynopoma, Gephyrocharax, Pseudocorynopoma y Pterobrycon.

En el estudio filogenético de Weitzman \& Menezes (1998), las relaciones entre estos géneros (también considerados dentro de Hysteronotini e Stevardiini) constituyó una politomía. Javonillo et al. (2010), con datos moleculares, obtuvieron que Pseudocorynopoma es el género hermano de los restantes miembros de su clado A (similar a la definición de Stevardiinae usada aquí y al clado A de Malabarba \& Weitzman, 2003). Ferreira et al. (2011) encontraron que los géneros Hysteronotus y Pseudocorynopoma estaban más relacionados con el clado Scopaeocharax + Tyttocharax + Xenurobrycon que con Gephyrocharax en su filogenia morfológica. Oliveira et al. (2011) no resolvieron esta cuestión en su filogenia molecular. Es muy posible que el género Hysteronotus corresponda al nodo 414 por su gran afinidad morfológica y relación filogenética cercana a Pseudocorynopoma. Por lo tanto, las relaciones filogenéticas a este nivel pueden estar sujetas a una ligera modificación con la inclusión de este género.

1. Número de dientes en la hilera interna de la premaxila (155): cinco o más $(0 \rightarrow 1$, ci $=$ 6, ri = 75). Convergente en los nodos 367 y 400. Revertido en el nodo 293.

2. Número de segmentos del tercer radio procurrente ventral (361): tres o menos $(1 \rightarrow 0$, ci $=6$, ri = 27). Convergente en Bryconamericus emperador, B. thomasi, Cyanocharax alburnus y Knodus meridae. Revertido en el nodo 361.

3. Altura de la escama-bolsillo en machos adultos (511): mayor que su longitud ( $\rightarrow 0$, ci 
$=50, \mathrm{ri}=86)$. Convergente en Tyttocharax sp.

4. Posición del borde ventral de la escama-bolsillo relativa a la de los radios de la aleta caudal en machos adultos (516): se ubica desde un punto entre el radio 19 y el primer radio procurrente ventral hasta un punto sobre los otros radios procurrentes ventrales $(0 \rightarrow$ 1 , ci $=100$, ri $=100)$.

\section{Nodo 416 (100/44/13): clado Corynopoma}

Géneros Corynopoma, Gephyrocharax y Pterobrycon.

Weitzman \& Menezes (1998) fueron los primeros en proponer un clado entre estos tres géneros al que nombraron Corynopomini (= Stevardiini). Estos autores definieron este clado con dos sinapomorfías asociadas al dimorfismo sexual de los machos adultos, las cuales fueron incluidas y reorganizadas en este estudio en varios caracteres (caracteres 505 y 513 a 514). En la hipótesis filogenética obtenida, el número de sinapomorfías para este clado se aumentó a siete, lo que demuestra que gran parte de su anatomía interna había sido poco estudiada. Por las razones mencionadas antes, la tribu Stevardiini no se usa y se le asignó el nombre informal de clado Corynopoma. En el árbol de consenso estricto bajo pesos iguales, el clado Corynopoma está apoyado por ocho sinapomorfías en su mayoría asociadas al dimorfismo sexual de los machos adultos (caracteres 164: $1 \rightarrow 0$; 339: $0 \rightarrow 1$; $461: 0 \rightarrow 1 ; 500: 0 \rightarrow 1 ; 505: 0 \rightarrow 1 ; 517: 0 \rightarrow 1 ; 518: 0 \rightarrow 1 ;$ y 521: $1 \rightarrow 0)$.

1. Posición del supraneural más posterior (339): situado a más de dos vértebras en frente del primer pterigióforo dorsal $(0 \rightarrow 1$, ci $=9$, ri $=60)$. Convergente en los nodos 370 y 409. Revertido en Diapoma terofali, Mimagoniates rheocharis y el nodo 405.

2. Separación entre las mitades posteriores del primer y segundo radios procurrentes ventrales en machos adultos (461): separados por un espacio igual o mayor al grosor del primer radio procurrente ventral $(0 \rightarrow 1, \mathrm{ci}=100, \mathrm{ri}=100)$.

3. Lóbulo posterior de la escama-bolsillo en machos adultos (500): cubre el tercer radio procurrente ventral $(0 \rightarrow 1$, ci $=100, \mathrm{ri}=100)$.

4. Distribución de los radii de la escama-bolsillo en machos adultos (505): confinados principalmente a un borde posterior o posteroventral $(0 \rightarrow 1$, ci $=50$, ri $=90)$. Revertido en Gephyrocharax major.

5. Posición del borde ventral de la escama-bolsillo relativa a la de los radios de la aleta caudal en machos adultos (517): se ubica desde un punto entre el primer y segundo radio 
procurrente ventral hasta un punto sobre el sexto y séptimo radio procurrente ventral $(0 \rightarrow$ $1, \mathrm{ci}=100, \mathrm{ri}=100)$.

6. Margen posterior de la escama-bolsillo en machos adultos (518): cóncavo en gran parte de su longitud $(0 \rightarrow 1$, ci $=100, \mathrm{ri}=100)$.

7. Una o varias escamas accesorias a la escama-bolsillo en machos adultos (521): ausentes $(1 \rightarrow 0$, ci $=50, \mathrm{ri}=90)$.

Nodo 417 (100/84/80): clado Pterobrycon

P. landoni y P. myrnae.

La monofilia de Pterobrycon no había sido sustentada en ningún estudio filogenético previo. Si bien la diagnosis de Pterobrycon incluye características ausentes en otros stevardinos (Bussing, 1974), éstas no se habían analizado formalmente en un análisis cladístico.

1. Posición del extremo anterior del hueso pélvico (311): anterior a la quinta costilla $(1 \rightarrow$ 0, ci = 20, ri = 33). Convergente en Chrysobrycon yoliae.

2. Tamaño de los radios de la aleta pélvica de machos adultos (432): los del medio y especialmente los radios ramificados 5 a 7 más alargados que los restantes radios $(0 \rightarrow 1$, $\mathrm{ci}=100, \mathrm{ri}=100)$.

3. Escamas modificadas que se ubican cerca de la región humeral del cuerpo en los machos adultos (487): con una o dos escamas de base ancha y expandidas en su porción distal $(0 \rightarrow 1$, ci $=100$, ri $=100)$.

Nodo 415 (100/24/7):

Géneros Corynopoma y Gephyrocharax.

Javonillo et al. (2010) y Oliveira et al. (2011) obtuvieron en un mismo a Corynopoma y Gephyrocharax, pero no incluyeron a Pterobrycon en sus análisis; Weitzman \& Menezes (1998) propusieron a Corynopoma y Pterobrycon como géneros hermanos con base en un solo carácter (analizado en este estudio: carácter 439). Dado que la presente contribución tiene la matriz de caracteres morfológicos más extensa en términos de taxones terminales y caracteres codificados, la relación filogenética obtenida entre Corynopoma + Gephyrocharax con Pterobrycon como su grupo hermano se considera la hipótesis más 
robusta para estos géneros. En el árbol de consenso estricto bajo pesos iguales, el clado Corynopoma + Gephyrocharax está apoyado por cuatro sinapomorfías asociadas al dimorfismo sexual de los machos adultos (caracteres $456: 0 \rightarrow 1 ; 462: 0 \rightarrow 1 ; 510: 0 \rightarrow 1$; y $535: 0 \rightarrow 1)$.

1. Segundo, tercero y ocasionalmente cuarto radios procurrentes ventrales de la aleta caudal en machos adultos (456): curvados, aplanados, de similar longitud y asociados entre sí formando una o dos estructuras en forma de pinza $(0 \rightarrow 1$, ci $=100$, ri $=100)$.

2. Tamaño de la escama-bolsillo de los machos adultos (510): muy grande, su mayor altura es la mitad o más de la longitud entre el complejo hipural y la punta posterior de los radios centrales de la aleta caudal $(0 \rightarrow 1, \mathrm{ci}=50, \mathrm{ri}=88)$. Convergente en el nodo 408 .

\section{Nodo 423 (100/30/1): clado Gephyrocharax}

G. atracaudatus, G. caucanus, G. chocoensis, G. intermedius, G. major, G. martae, G. melanocheir, G. sinuensis, G. torresi, G. valencia y G. venezuelae.

Este es el primer estudio filogenético que propone la monofilia de un clado compuesto por todas las especies de Gephyrocharax. Bonilla-Rivero \& López-Rojas (2013) presentaron un árbol de distancias genéticas con tres especies de Gephyrocharax y con Corynopoma como grupo externo. Estos autores encontraron que las tres especies de Gephyrocharax se relacionaban más entre sí que con Corynopoma, lo que de alguna manera era congruente con la monofilia del género. Ninguna de las sinapomorfías obtenida para el clado Gephyrocharax coincidió con los caracteres propuestos en la diagnosis original del género (Eigenmann, 1912; Myers en Eigenmann \& Myers, 1929). Sin embargo, algunos de esos caracteres discriminatorios se usan igualmente para ayudar en su identificación taxonómica. Gephyrocharax major resultó como las especie hermana del resto de las especies del género y con mayor cantidad de autapomorfías (18), lo cual indica que ésta es la más divergente morfológicamente dentro del mismo. Gephyrocharax se redefine basado en cinco sinapomorfías, de las cuales el carácter 440 no tiene homoplasia. No se conocen estudios previos que permitan hacer comparaciones de la gran mayoría de las relaciones filogenéticas internas obtenidas en Gephyrocharax, por lo varios nodos de aquí en adelante no se comentan. En el árbol de consenso estricto bajo pesos iguales, el clado Gephyrocharax está apoyado por cuatro sinapomorfías en su mayoría asociadas al dimorfismo sexual de los machos adultos (caracteres $266: 0 \rightarrow 1$; 468: $0 \rightarrow 1$; 520: $0 \rightarrow 1$; 
534: $0 \rightarrow 1$ ). Se encontró estabilidad absoluta (100) del clado Gephyrocharax en las 21 concavidades exploradas.

1. Mancha humeral (400): presente $(0 \rightarrow 1$, ci $=4$, ri =74). Revertido en Bryconadenos tanaothoros, Gephyrocharax martae y en los nodos 402 y 424.

2. Contorno ventral de la aleta anal en machos adultos (440): convexo desde la porción anterior hasta la mitad o tres cuartos de su longitud, los radios de este intervalo un poco más largos que el resto $(0 \rightarrow 1, \mathrm{ci}=100, \mathrm{ri}=100)$.

3. Longitud del tercer radio procurrente ventral en machos adultos (465): alcanza o sobrepasa la región media del primer radio procurrente ventral $(0 \rightarrow 1$, ci $=10, \mathrm{ri}=44)$. Convergente en Cyanocharax obi y el nodo 409. Revertido en Gephyrocharax martae.

4. Longitud de los interradialis modificados en la aleta caudal de los machos adultos (525): alcanzan posteriormente un mismo punto o son apenas más largos en el lóbulo ventral que en el dorsal $(0 \rightarrow 1$, ci $=25, \mathrm{ri}=63)$. Convergente en Pseudocorynopoma doriae. Revertido en Gephyrocharax atracaudatus y G. martae.

5. Posición relativa de la escama-bolsillo y los interradialis en los machos adultos (527): las fibras musculares no sobrepasan el borde posterodorsal de la escama $(1 \rightarrow 0, \mathrm{ci}=33$, ri $=80$ ). Convergente en el nodo 410. Revertido en el nodo 425.

\section{Nodo 422 (90/44/30):}

Gephyrocharax atracaudatus, G. caucanus, G. chocoensis, G. intermedius, G. martae, G. melanocheir, G. sinuensis, G. torresi, G. valencia y G. venezuelae.

1. Lóbulos o expansiones posteriores en el borde posterior de la escama-bolsillo en machos adultos (498): presentes, bien desarrollados $(0 \rightarrow 1$, ci $=25$, ri $=67)$. Convergente en Pseudocorynopoma doriae y Pterobrycon myrnae. Revertido en el nodo 418.

\section{Nodo $421(90 / 22 / 4)$ :}

Gephyrocharax atracaudatus, G. caucanus, G. intermedius, G. martae, G. melanocheir, G. sinuensis, G. torresi, G. valencia y G. venezuelae.

1. Tercer radio procurrente ventral de la aleta caudal (360): no segmentado $(1 \rightarrow 0, \mathrm{ci}=5$, ri $=49$ ). Convergente en Chrysobrycon hesperus, Cyanocharax obi y el nodo 408.

2. Ganchos óseos en el último radio pélvico en machos adultos (478): en número reducido 
$(1 \rightarrow 0, \mathrm{ci}=6, \mathrm{ri}=63)$. Convergente en Argopleura magdalenensis, Piabarchus analis y el nodo 303. Revertido en Aulixidens eugeniae, Creagrutus gephyrus, C. gephyrus, Knodus meridae y Piabina argentea.

3. Sección más posterior de la musculatura hypaxialis y epaxialis relativa al flexor ventralis en machos adultos (535): reducida, no cubre la región posterior del flexor ventralis $(0 \rightarrow 1, \mathrm{ci}=50, \mathrm{ri}=88)$. Convergente en Corynopoma riisei.

\section{Nodo 420 (66/0/13):}

Gephyrocharax atracaudatus, G. caucanus, G. intermedius, G. martae, G. melanocheir, G. sinuensis, G. torresi y G. valencia.

1. Porción distal del cuarto radio procurrente ventral en machos adultos (468): comprimida sagitalmente y un poco curvada $(0 \rightarrow 1$, ci $=100$, ri $=100)$.

\section{Nodo 419 (90/6/4):}

Gephyrocharax atracaudatus, G. caucanus, G. intermedius y G. valencia.

1. Forma de los dientes de la hilera interna de la premaxila (154): con cúspides alineadas, en series rectas y $\sin$ concavidad anterior $(0 \rightarrow 1$, ci $=7$, ri $=55)$. Convergente en Aulixidens eugeniae, Diapoma pyrrhopteryx, Gephyrocharax chocoensis, Mimagoniates inequalis y Odontostoechus lethostigmus.

2. Número máximo de radii de la escama-bolsillo en machos adultos (502): 28 o menos (1 $\rightarrow 0$, ci $=25$, ri $=63$ ). Convergente en Corynopoma riisei y el nodo 410 . Revertido en Chrysobrycon hesperus.

Nodo 424 (100/30/20):

Gephyrocharax caucanus y G. valencia.

Bonilla-Rivero \& López-Rojas (2013) encontraron que Gephyrocharax valencia era la especie hermana de un clado entre G. venezuelae y una especie del género aparentemente no descripta en su árbol filogenético de distancias genéticas. Sin embargo, estos autores solo incluyeron dos especies válidas del género y usaron un solo grupo externo (su objetivo era filogeográfico más que filogenético) y por tal razón sus resultados están limitados a ese pequeño contexto. En el árbol de consenso estricto bajo pesos iguales, este 
clado está apoyado por tres sinapomorfías en su mayoría asociadas al dimorfismo sexual de los machos adultos (caracteres 154: $0 \rightarrow 1$; 501: $0 \rightarrow 1$; y 502: $1 \rightarrow 0$ ).

1. Mancha humeral (400): ausente $(1 \rightarrow 0, \mathrm{ci}=4, \mathrm{ri}=74)$. Convergente en Bryconadenos tanaothoros, Gephyrocharax martae y el nodo 402. Revertido en el nodo 423.

2. Tejido conectivo en la porción dorsal de la escama-bolsillo en machos adultos (501): ancla la escama hasta un punto entre los radios 15 a 17 de la aleta caudal $(0 \rightarrow 1$, ci $=50$, ri =67). Convergente en el nodo 427.

\section{Nodo 418 (100/92/91):}

Gephyrocharax atracaudatus y G. intermedius.

En el árbol de consenso estricto bajo pesos iguales este clado se apoya por cuatro sinapomorfías en su mayoría asociadas al dimorfismo sexual de los machos adultos (caracteres 393: $1 \rightarrow 0 ; 460: 0 \rightarrow 1 ; 464: 0 \rightarrow 1 ;$ y 465: $1 \rightarrow 0$ ).

1. Estructura en forma de pinza constituida por los radios procurrentes ventrales segundo y tercero en machos adultos (458): radios rectos o muy poco curvados a lo largo de su longitud $(0 \rightarrow 1, \mathrm{ci}=50, \mathrm{ri}=50)$. Convergente en Gephyrocharax major.

2. Hemiradii de la porción posterior del tercer radio procurrente ventral en machos adultos (460): muy expandidos lateralmente, en especial con respecto a la porción anterior $(0 \rightarrow 1$, $\mathrm{ci}=100, \mathrm{ri}=100)$.

3. Asociación entre el primer y segundo radio procurrente ventral en machos adultos (463): fuerte, la concavidad del primero y la expansión posterior del segundo muy desarrolladas, cercanas entre sí $(0 \rightarrow 1$, ci $=100$, ri $=100)$.

4. Longitud del primer y segundo radios procurrentes ventrales en machos adultos (464): el segundo tiene la mitad o menos de la longitud del primero $(0 \rightarrow 1, \mathrm{ci}=100$, ri $=100)$.

5. Lóbulos o expansiones posteriores en el borde posterior de la escama-bolsillo en machos adultos (498): ausentes o poco desarrollados $(1 \rightarrow 0$, ci $=25$, ri $=67)$. Revertido en Pseudocorynopoma doriae, Pterobrycon myrnae y el nodo 422.

6. Extensión posterior de la escama-bolsillo en machos adultos (512): larga, se extiende más allá de la vertical a través del extremo distal del segundo radio procurrente ventral (0 $\rightarrow 1$, ci $=17$, ri $=29)$. Convergente en Gephyrocharax chocoensis, G. sinuensis y Pterobrycon landoni. 


\section{Nodo 426 (90/1/12):}

Gephyrocharax martae, G. melanocheir, G. sinuensis y G. torresi.

1. Papila urogenital en hembras adultas (414): bien desarrollada externamente $(0 \rightarrow 1$, ci $=$ $50, \mathrm{ri}=67)$.

\section{Nodo $425(90 / 17 / 3)$ :}

Gephyrocharax martae, G. melanocheir y G. torresi.

1. Posición relativa de la escama-bolsillo y los interradialis en machos adultos (527): las fibras musculares sobrepasan el borde posterodorsal de la escama $(0 \rightarrow 1$, ci $=33$, ri $=80)$. Revertido en los nodos 410 y 423.

2. Porción distal del primer radio ramificado de la aleta pectoral en machos adultos (536): pigmentado, usualmente con una mancha difusa oscura o unos cuantos cromatóforos marrones oscuros o negros dispersos alrededor de sus ramificaciones $(0 \rightarrow 1$, $\mathrm{ci}=50$, ri $=$ 67). Convergente en Pseudocorynopoma doriae.

\section{Nodo 427 (100/100/100):}

Gephyrocharax melanocheir y G. torresi.

En el árbol de consenso estricto bajo pesos iguales este clado está apoyado por ocho sinapomorfías en su mayoría asociadas al dimorfismo sexual de los machos adultos (caracteres 108: $1 \rightarrow 0 ; 414: 0 \rightarrow 1 ; 428: 0 \rightarrow 1 ; 474: 0 \rightarrow 1 ; 501: 0 \rightarrow 1 ; 526: 0 \rightarrow 1$; $527: 0 \rightarrow 1 ;$ y $536: 0 \rightarrow 1)$.

1. Tubo terminal de la línea lateral sobre las membranas de la aleta caudal (108): ausente $(1 \rightarrow 0$, ci $=5$, ri = 73). Convergente en Carlastyanax aurocaudatus, Gephyrocharax valencia, Nantis indefessus y el nodo 369.

2. Primer radio ramificado de la aleta pectoral forma una estructura distal muy ramificada en forma de abanico en machos adultos (428): presente $(0 \rightarrow 1$, ci $=100$, ri $=100)$.

3. Ganchos óseos en las aletas pectorales de machos adultos (474): presentes $(0 \rightarrow 1$, ci $=$ 9 , ri $=38)$. Convergente en los nodos 313, 315 y 343. 
4. Tejido conectivo en la porción dorsal de la escama-bolsillo en machos adultos (501): ancla la escama hasta un punto entre los radios 15 a 17 de la aleta caudal $(0 \rightarrow 1$, ci $=50$, ri $=67)$. Convergente en el nodo 424.

5. Paquetes de fibras interradialis modificadas más alargadas en los radios caudales del lóbulo ventral, especialmente entre los radios 12 a 16 en los machos adultos (526): presente $(0 \rightarrow 1, \mathrm{ci}=25, \mathrm{ri}=25)$. Convergente en Gephyrocharax intermedius, G. major y Pseudocorynopoma doriae.

\section{Autapomorfías}

\section{Corynopoma riisei}

1. Ubicación del coronomeckeliano (131): principalmente lateral al cartílago de Meckel (1 $\rightarrow 0$, ci $=4$, ri $=69$ ). Convergente en Chrysobrycon sp. nov. A, Creagrutus peruanus, Diapoma terofali y Knodus pectinatus y el nodo 402.

2. Expansión posterior abrupta en el interopérculo (194): presente $(0 \rightarrow 1$, ci $=11$, ri $=$ 38). Convergente en Tyttocharax sp.

3. Dientes en el tercer faringobranquial (239): ausentes $(0 \rightarrow 1$, ci $=9$, ri $=50)$. Convergente en Chrysobrycon myersi y C. eliasi.

4. Radiales anales proximales y medios (350): fusionados en los cinco anteriores pterigióforos $(1 \rightarrow 0$, ci $=13$, ri $=58)$. Convergente en Chrysobrycon sp. nov. A. Revertido en el nodo 411.

5. Número de fibras tendinosas del hypochordal longitudinalis que se insertan posteriormente sobre los radios de la aleta caudal (398): tres o menos $(0 \rightarrow 1$, ci $=25$, ri $=$ 40). Convergente en el nodo 408.

6. Aleta adiposa (410): ausente $(0 \rightarrow 1, \mathrm{ci}=17, \mathrm{ri}=55)$.

7. Longitud del pedúnculo caudal (412): muy alargado, dos veces más largo que alto $(0 \rightarrow$ 1, ci = 25, ri = 57). Convergente en Pterobrycon landoni y los nodos 286 y 388.

8. Estructura filamentosa del opérculo, subopérculo y radio branquiostego más posterior proyectada posteriormente a la longitud media del cuerpo en machos adultos (426): presente $(0 \rightarrow 1, \mathrm{ci}=0, \mathrm{ri}=0)$.

9. Radios anteriores de la aleta dorsal en machos adultos (435): alargados, llegan posteriormente hasta la aleta adiposa $(0 \rightarrow 1$, ci $=33$, ri $=0)$. Convergente en Pseudocorynopoma doriae.

10. Radios anteriores o medios de la aleta dorsal (436): radios muy desarrollados, alcanzan o sobrepasan la región media del pedúnculo caudal $(0 \rightarrow 1$, ci $=33$, ri $=0)$. Convergente en Pseudocorynopoma doriae. 
11. Tamaño de los radios posteriores de la aleta anal en machos adultos (441): los tres o cuatro radios posteriores son más alargados que los radios contiguos, alcanzando los radios ventrales procurrentes de la aleta caudal $(0 \rightarrow 1$, ci $=33$, ri $=0)$. Convergente en Tyttocharax sp.

12. Número máximo de radii de la escama-bolsillo en machos adultos (502): 28 o menos $(1 \rightarrow 0, \mathrm{ci}=25, \mathrm{ri}=53)$. Convergente en los nodos 410 y 419. Revertido en Chrysobrycon hesperus.

13. Número de interradialis en el lóbulo ventral de la aleta caudal que se insertan posteriormente al borde posterior de la escama-bolsillo en machos adultos (529): tres o más $(0 \rightarrow 1$, ci $=50$, ri $=0)$. Convergente en Gephyrocharax melanocheir.

14. Sección más posterior de la musculatura hypaxialis y epaxialis relativa al flexor ventralis en machos adultos (535): reducida, no cubre la región posterior del flexor ventralis $(0 \rightarrow 1$, ci $=50, \mathrm{ri}=88)$. Convergente en el nodo 421 .

\section{Gephyrocharax atracaudatus}

1. Longitud de los interradialis modificados en la aleta caudal (525): alcanzan un punto más posterior en el lóbulo dorsal que en el ventral $(1 \rightarrow 0, \mathrm{ci}=25$, ri $=63)$. Convergente en Gephyrocharax martae. Revertido en Pseudocorynopoma doriae y el nodo 423.

\section{Gephyrocharax caucanus}

1. Ganchos óseos en la base de los radios pélvicos de los machos adultos (477): en número reducido comparado con la porción segmentada de los radios $(1 \rightarrow 0, \mathrm{ci}=25$, ri $=63$, ci $=$ 5, ri =46). Convergente en Bryconamericus agna, Creagrutus atrisignum, Gephyrocharax torresi, Piabarchus analis y el nodo 398.

\section{Gephyrocharax chocoensis}

1. Forma de los dientes de la hilera interna de la premaxila (154): con cúspides alineadas, en series rectas y $\sin$ concavidad anterior $(0 \rightarrow 1$, ci $=7$, ri $=55)$. Convergente en Aulixidens eugeniae, Diapoma pyrrhopteryx, Mimagoniates inequalis y Odontostoechus lethostigmus y el nodo 419.

2. Número de segmentos del segundo radio procurrente ventral en machos adultos (467): siete o más $(1 \rightarrow 0, \mathrm{ci}=5, \mathrm{ri}=22)$. Convergente en Acrobrycon ipanquianus, Argopleura magdalenensis, Bryconamericus agna, Chrysobrycon myersi, $C$. hesperus. Revertido en $B$. cf. iheringii y el nodo 298. 
3. Ganchos óseos en el primer radio pélvico de los machos adultos (479): presentes $(0 \rightarrow$ 1, ci $=7$, ri = 30). Convergente en Aulixidens eugeniae, Bryconamericus cf. iheringii, Diapoma pyrrhopteryx, Mimagoniates inequalis, Xenurobrycon macropus y el nodo 409.

4. Extensión posterior de la escama-bolsillo en machos adultos (512): larga, se extiende más allá de la vertical a través del extremo distal del segundo radio procurrente ventral (0 $\rightarrow 1, \mathrm{ci}=17, \mathrm{ri}=29)$. Convergente en Gephyrocharax sinuensis, Pterobrycon landoni y el nodo 418.

\section{Gephyrocharax intermedius}

1. Paquetes de fibras interradialis modificadas más alargadas en los radios caudales del lóbulo ventral, especialmente entre los radios 12 a 16 (526): presente $(0 \rightarrow 1$, ci $=25$, ri $=$ 25). Convergente en Gephyrocharax major, Pseudocorynopoma doriae y el nodo 427.

\section{Gephyrocharax major}

1. Fontanela anterior o frontal (23): totalmente cerrada por los frontales $(0 \rightarrow 1$, ci $=10$, ri =47). Convergente en Gephyrocharax major y el nodo 410 .

2. Nasal en vista dorsal (41): en forma de media luna, muy cóncavo, arqueado en un ángulo igual o menor a $135^{\circ}(0 \rightarrow 1$, ci $=13$, ri $=13)$. Convergente en Aulixidens eugeniae y el nodo 410.

3. Proceso horizontal del ánguloarticular (127): ampliamente cubierto por el dentario, que alcanza el borde posterior del cartílago de $\operatorname{Meckel}(0 \rightarrow 1$, ci $=6$, ri $=71)$. Convergente en el nuevo género y los nodos 302, 407 y 410. Revertido en Attonitus ephimeros. Algunos árboles: Convergente en el nodo 288.

4. Borde posterior del segundo hipural (356): aproximadamente tan alto como la distancia vertical entre las bases de los radios caudales 11 a $13(0 \rightarrow 1$, ci $=5$, ri $=20)$. Convergente en Argopleura magdalenensis, Bryconamericus plutarcoi, B. rubropictus, B. scleroparius y el nodo 410.

5. Posición de la base del radio 12 de la aleta caudal (358): extendida sobre la porción posterior del segundo hipural $(0 \rightarrow 1$, ci $=6$, ri $=21)$. Convergente en Acrobrycon ipanquianus, Attonitus ephimeros, Bryconamericus plutarcoi y el nodo 410. Algunos árboles: convergente en el nodo 389.

6. Posición del tubo terminal de la línea lateral de la aleta caudal en machos adultos (424): inclinado posteroventralmente $(0 \rightarrow 1, \mathrm{ci}=0, \mathrm{ri}=0)$.

7. Posición del tubo terminal de la línea lateral y la escama-bolsillo en machos adultos (425): solapados, la porción posterior del tubo terminal localizada sobre la región dorsal de esta escama $(0 \rightarrow 1$, ci $=0$, ri $=0)$. 
8. Forma de los radios 11 y 12 de la aleta caudal en machos adultos (449): muy curvados ventralmente a lo largo de su longitud $(0 \rightarrow 1, \mathrm{ci}=0, \mathrm{ri}=0)$.

9. Distancia entre las bases de los radios medios de la aleta caudal en machos adultos (450): tan grande o más pequeña entre las bases de los radios 10 y 11 que entre las bases de los radios 11 y $12(1 \rightarrow 0, \mathrm{ci}=25, \mathrm{ri}=0)$. Convergente en el nuevo género.

10. Distancia entre las bases de los radios medios de la aleta caudal en machos adultos (451): dos veces más grande o mayor entre los radios 12 y 13 que entre los radios 11 y 12 $(0 \rightarrow 1, \mathrm{ci}=0, \mathrm{ri}=0)$.

11. Estructura en forma de pinza constituida por los radios procurrentes ventrales segundo y tercero en machos adultos (458): radios rectos o muy poco curvados a lo largo de su longitud $(0 \rightarrow 1, \mathrm{ci}=50, \mathrm{ri}=50)$. Convergente en el nodo 418

12. Estructura en forma de pinza constituida por los radios procurrentes ventrales segundo y tercero en machos adultos (459): radios muy cercanos entre sí casi en toda su longitud, con frecuencia fusionados distalmente $(0 \rightarrow 1, \mathrm{ci}=0, \mathrm{ri}=0)$.

13. Número de segmentos del segundo radio procurrente ventral en machos adultos (466): uno o tres $(0 \rightarrow 1$, ci $=14$, ri $=45)$. Convergente en Diapoma terofali, Xenurobrycon macropus y el nodo 413 .

14. Distribución de los radii de la escama-bolsillo en machos adultos (505): extendidos en todo el borde posterior y parte del dorsal $(1 \rightarrow 0, \mathrm{ci}=50$, ri $=90)$. Revertido en el nodo 416.

15. Escama-bolsillo en machos adultos (506): con circuli $(1 \rightarrow 0$, ci $=33$, ri $=0)$. Convergente en Chrysobrycon hesperus.

16. Hendidura en el borde dorsal de la escama-bolsillo en machos adultos (508): presente, bien definida $(0 \rightarrow 1$, ci $=0$, ri $=0)$.

17. Una o varias escamas accesorias a la escama-bolsillo en machos adultos (521): presentes $(0 \rightarrow 1$, ci $=50$, ri $=90)$. Revertido en el nodo 416 .

18. Paquetes de fibras interradialis modificadas más alargadas en los radios caudales del lóbulo ventral, especialmente entre los radios 12 a 16 (526): presente $(0 \rightarrow 1$, ci $=25$, ri $=$ 25). Convergente en Gephyrocharax intermedius, Pseudocorynopoma doriae y el nodo 427.

\section{Gephyrocharax martae}

1. Fontanela anterior o frontal (23): totalmente cerrada por los frontales $(0 \rightarrow 1$, ci $=23$, ri =47). Convergente en Gephyrocharax major y el nodo 410 . 
2. Número de dientes maxilares (164): cuatro o más $(0 \rightarrow 1$, ci $=3$, ri $=65)$. Convergente en el nodo 291. Revertido en Argopleura magdalenensis, Chrysobrycon sp. nov. A, Microgenys minuta y el nodo 301.

3. Posición del extremo anterior del hueso pélvico (312): posterior a la sexta costilla $(0 \rightarrow$ 1, ci $=5$, ri $=51$ ). Convergente en el nodo 292. Revertido en Carlastyanax aurocaudatus. Mancha humeral (400): ausente $(1 \rightarrow 0, \mathrm{ci}=4, \mathrm{ri}=74)$. Convergente en Bryconadenos tanaothoros y los nodos 402 y 424 . Revertido en el nodo 423.

4. Longitud del tercer radio procurrente ventral en machos adultos (465): no alcanza la región media del primer radio procurrente ventral $(1 \rightarrow 0$, ci $=10$, ri $=44)$. Revertido en Cyanocharax obi y los nodos 409 y 423.

5. Ganchos óseos en la aleta caudal de los machos adultos (482): ausentes ( $1 \rightarrow 0$, ci $=8$, ri = 59). Convergente en Argopleura magdalenensis. Revertido en Mimagoniates rheocharis y el nodo 406.

6. Longitud de los interradialis modificados en la aleta caudal en machos adultos (525): alcanzan un punto más posterior en el lóbulo dorsal que en el ventral $(1 \rightarrow 0$, ci $=25$, ri $=$ 63). Convergente en Gephyrocharax atracaudatus. Revertido en Pseudocorynopoma doriae.

\section{Gephyrocharax melanocheir}

1. Lámina ósea entre el primer y segundo basibranquiales (215): ausente $(1 \rightarrow 0$, ci $=3$, ri = 33). Convergente en los nodos 292 y 407. Revertido en Bryconamericus plutarcoi, Microgenys minuta y Piabina argéntea.

2. Intensa pigmentación negra o marrón oscura concentrada sobre los primeros cinco radios anteriores de la aleta dorsal (404): presente $(0 \rightarrow 1$, ci $=0, \mathrm{ri}=0)$.

3. Número de interradialis en el lóbulo ventral de la aleta caudal que se insertan posteriormente al borde posterior de la escama-bolsillo en machos adultos (529): tres o más $(0 \rightarrow 1$, ci $=50, \mathrm{ri}=0)$. Convergente en Corynopoma riisei.

\section{Gephyrocharax sinuensis}

1. Zona anterior de la fontanela anterior (24): delimitada por el mesetmoides $(1 \rightarrow 0$, ci $=$ 3, ri = 44). Convergente en Bryconamericus agna. Revertido en B. scleroparius y Carlastyanax aurocaudatus. Algunos árboles: revertido en Bryconadenos tanaothoros y Knodus pectinatus. 
2. Articulación sincondral entre el etmoides lateral y el borde anterodorsal del orbitosfenoides (42): presente $(1 \rightarrow 0$, ci $=10$, ri $=61)$. Convergente en Gephyrocharax valencia, G. venezuelae, Knodus pectinatus y los nodos 367 y 393.

3. Longitud relativa del primer radio de la aleta pélvica en machos adultos (433): extendido más posterior al extremo distal de los demás radios $(0 \rightarrow 1$, ci $=33$, ri $=60)$.

4. Porción distal del primer radio de la aleta pélvica en machos adultos (434): muy hipertrofiada, engrosada y algo curvada $(0 \rightarrow 1$, ci $=0$, ri $=0)$.

5. Número máximo de radii de la escama-bolsillo en machos adultos (503): 40 o más (0 $\rightarrow 1, \mathrm{ci}=25, \mathrm{ri}=50)$.

6. Extensión posterior de la escama-bolsillo en machos adultos (512): larga, se extiende más allá de la vertical a través del extremo distal del segundo radio procurrente ventral $(0$ $\rightarrow 1, \mathrm{ci}=17, \mathrm{ri}=29$ ).

7. Densa pigmentación negra o marrón oscura alrededor del origen de la aleta pélvica en machos adultos (537): presente $(0 \rightarrow 1$, ci $=50, \mathrm{ri}=0)$.

\section{Gephyrocharax torresi}

1. Ganchos óseos en la base de los radios pélvicos en machos adultos (477): en número reducido comparado con la porción segmentada de los radios $(1 \rightarrow 0, \mathrm{ci}=5$, ri $=46)$. Convergente en Bryconamericus agna, Creagrutus atrisignum, Gephyrocharax caucanus, Piabarchus analis y el nodo 398.

\section{Gephyrocharax valencia}

1. Articulación sincondral entre el etmoides lateral y el borde anterodorsal del orbitosfenoides (42): presente $(1 \rightarrow 0$, ci $=10$, ri $=61)$. Convergente en Gephyrocharax sinuensis, G. venezuelae, Knodus pectinatus y los nodos 367 у 393.

2. Rinosfenoides (55): ausente $(1 \rightarrow 0, \mathrm{ci}=4, \mathrm{ri}=61)$. Convergente en Bryconamericus plutarcoi, Carlastyanax aurocaudatus, Nantis indefessus y los nodos 287 y 393.

3. Tubo terminal de la línea lateral sobre las membranas de la aleta caudal (108): ausente $(1 \rightarrow 0, \mathrm{ci}=5, \mathrm{ri}=73)$. Convergente en Carlastyanax aurocaudatus, Nantis indefessus y los nodos 369 y 427.

\section{Gephyrocharax venezuelae}

1. Articulación sincondral entre el etmoides lateral y el borde anterodorsal del orbitosfenoides (42): presente $(1 \rightarrow 0$, ci = 10, ri =61). Convergente en Gephyrocharax sinuensis, G. valencia, Knodus pectinatus y los nodos 367 у 393. 
2. Cartílagos anteriores al basihial (221): dos bloques bien desarrollados $(0 \rightarrow 1$, ci $=3$, ri = 19). Convergente en Attonitus ephimeros, Attonitus ephimeros, Bryconamericus plutarcoi, Chrysobrycon sp. nov. A, Cyanocharax obi y Knodus meridae.

3. Dentículos en los rastrillos branquiales (234): ausentes $(0 \rightarrow 1$, ci $=6$, ri $=58)$. Convergente en los nodos 294 y 403. Revertido en Creagrutus gephyrus. Algunos árboles: convergente en Bryconadenos tanaothoros, Piabina argentea y el nodo 286.

\section{Pterobrycon landoni}

1. Continuidad de la línea lateral (107): interrumpida $(0 \rightarrow 1$, ci $=5$, ri $=67)$. Convergente en los nodos 369 y 408. Revertido en el nodo 406.

2. Número de radios anales ramificados (344): 17 o menos $(1 \rightarrow 0$, ci $=8$, ri $=72)$. Convergente en Knodus meridae y los nodos 388 y 408. Algunos árboles: convergente en los nodos 287 y 312 .

3. Longitud del pedúnculo caudal (412): muy alargado, dos veces más largo que alto $(0 \rightarrow$ 1, ci $=25$, ri $=57$ ). Convergente en Corynopoma riisei y los nodos 286 y 388.

4. Extensión posterior de la escama-bolsillo en machos adultos (512): larga, se extiende más allá de la vertical a través del extremo distal del segundo radio procurrente ventral $(0$ $\rightarrow 1, \mathrm{ci}=17, \mathrm{ri}=29)$. Convergente en Gephyrocharax chocoensis, G. sinuensis y el nodo 418.

\section{Pterobrycon myrnae}

1. Extensión anterior del eje principal del hueso pélvico (308): proyectado anterior a las láminas medial y lateral del hueso pélvico $(0 \rightarrow 1$, ci $=14$, ri $=33)$.

2. Lóbulos o expansiones posteriores en el borde posterior de la escama-bolsillo en machos adultos (498): presentes, bien desarrollados $(0 \rightarrow 1$, ci $=25$, ri $=67)$. Convergente en Pseudocorynopoma doriae. Revertido en los nodos 418 y 422.

3. Número máximo de radii de la escama-bolsillo en machos adultos (504): 70 o más (0 $\rightarrow 1, \mathrm{ci}=50, \mathrm{ri}=67)$. Convergente en el nodo 408 .

4. Posición del borde dorsal de la escama-bolsillo en relación a los radios de la aleta caudal en machos adultos (514): se ubica en un punto entre los radios 12 a $17(0 \rightarrow 1$, ci $=$ 25, ri $=0$ ). Convergente en Chrysobrycon myersi.

\section{Material comparativo examinado}

Acestrocephalus sardina, MCP 17072, 2 d\&t, 56,6-63,0 mm. Brasil, Amazonas, cuenca alta del río Negro, cerca de la desembocadura del río Marauiá. Acestrorhynchus pantaneiro, CI-FML 3870, 1 d\&t, 127,8 mm. Argentina, Corrientes, Guayquiraró, río Corriente. Acrobrycon ipanquianus, CI-FML 3890, 7, 48,8-58,1 mm LE (4 d\&t 49,0-54,7 
mm LE), Argentina, Tucumán, Monteros, Capitán Cáceres, río Mandolo. Agoniates anchovia, MHNG 2388-93, 1 d\&t, 158,5 mm LE, Brasil, cuenca río Negro, Lago Tupé. Apareiodon affinis, CI-FML 3862, 1 d\&t, 88,0 mm LE, Argentina, Entre Ríos, río Uruguay. Aphyocharacidium bolivianum, MCP 37960, 3 d\&t, 23,1-26,3 mm LE, Brasil, Acre, Sena Madureira, cuenca río Purús, Igarapé Taquari entre los ríos Atimani Sena Madureira. Aphyocharax anisitsi, CAS 59697*, holotipo Aphyocharax anisitsi Eigenmann \& Kennedy, 1903, 29,3 mm LE (R), Paraguay, Laguna Pasito en Asunción. CI-FML 2951, 1 d\&t, 30,3 mm LE, Argentina, Salta, Cañada El Hogar, río Pilcomayo. Aphyocharax dentatus, CAS 59697*, holotipo Aphyocharax dentatus Eigenmann \& Kennedy, 1903, 52,2 mm LE (R), Paraguay, Laguna Pasito en Asunción. CI-FML 3035, 2 d\&t, 51,0-53,2 mm LE, Argentina, Salta, Cañada El Hogar, Misión La Paz, río Pilcomayo. CI-FML 5410, 3, 62,3-70,6 mm LE. Aphyocharax nattereri, Argentina, Corrientes, Ituizangó, Corrientes, río Paraná. CI-FML 3876, 8, 17,0-27,5 mm LE (2 d\&t 19,6-21,7 mm LE), Argentina, Formosa, El Bagual, río Bermejo. Aphyodite grammica, MHNG 2172-89, 2 d\&t, 21,522,5 mm LE, Brasil, Atauia, cuenca río Negro. Argopleura magdalenensis, Colombia: CIFML 5016, 2, 49,4-52,5 mm LE (1 d\&t 49,4 mm LE), Quindío, Quimbaya, Alejandría, río La Vieja. CI-FML 5879, 2, 36,3-41,0 mm LE (1 d\&t 41,0 mm LE), Colombia, Tolima, sistema río Magdalena, quebrada Tuluní. Astyanacinus moorii, MCP 15572, 3, 63,1-68,8 mm LE (1 d\&t, 63,1 mm LE), Brasil, Mato Grosso, Cáceres, cuenca río Paraguay. Astyanax asuncionensis, Paraguay: CAS 38988*, 3 sintipos Astyanax bimaculatus paraguayensis Eigenmann, 1921, 54,2-71,7 mm LE (3R), cuenca río Paraná, río Paraguay. CI-FML 3910, 2 d\&t, 46,0-46,3 mm LE, Alto Paraguay, Bahía Negra, río Paraguay. Astyanax cf. eigenmanniorum 1, CI-FML 3914, 2 d\&t, 45,5-47,5 mm LE. Argentina, Santiago del Estero, Los Quiroga, río Dulce. Astyanax chico, CI-FML 3913, 2 d\&t, 60,275,2 mm LE, Argentina, Salta, cuenca del río Bermejo, quebrada El Oculto. Astyanax latens, CI-FML 3327, 2 d\&t, 40,6-44,0 mm LE, Argentina, Salta, Orán, El Oculto, quebrada El Oculto. Astyanax parís, CI-FML 3919, 2 d\&t, 45,7-48,6 mm. Argentina, Misiones, San Pedro, Parque Provincial Piñalito, quebrada Piñalito. Astyanax troya, CIFML 3920, 2 d\&t, 74,7-80,9 mm LE, Argentina, Misiones, Aristóbulo del Valle arroyo Cuñá-Pirú. Attonitus ephimeros, CI-FML 3895, 3, 45,0-51,4 mm LE (1 d\&t 51,4 mm LE), Perú, Cuzco, río Coribeni, cercanias de Kiteni. Aulixidens eugeniae, Venezuela: ANSP 134797, 2 d\&t, 39,7-41,7 mm LE, playa Matepalma, río Orinoco. ANSP 150127, 2, 34,835,2 mm LE, río Orinoco, en la playa Matepalma, abajo de Yapacama. CAS 16940*, holotipo Aulixidens eugeniae Böhlke, 1952, 36,1 mm LE (R), Amazonas, cuenca río 
Orinoco, río Casiquiare, desembocadura del río Curamuni. FMNH 103417*, 1, 38,6 mm LE, río Orinoco, playa sobre el río Cuao. Axelrodia lindeae, MCP 37314, 4 d\&t, 18,7-23,8 mm LE, Brasil, Acre, cuenca del río Purus, Igarapé Marizinho BR 364, drenaje río Antimari. Bramocharax bransfordii, MHNG 2120-078. 086. 088, 2 d\&t, 59,0-66,5 mm LE, Nicaragua, Lago Managua, Momotobo. Brycon meeki, CAS 13467*, sintipo de Brycon meeki Eigenmann \& Hildebrand, 1918, 220,0 mm LE (R), Colombia, Nariño, cuenca río Patía, Barbacoas, cerca a la desembocadura del río Telembi. Bryconadenos tanaothoros, MCP 30516, 5 d\&t, 16,0-32,1 mm LE, Brasil, Mato Grosso, Cláudia, Corrego Tatú, MT 423 a 14 km al oeste de Cláudia. Bryconamericus agna, CI-FML 3896, 2 d\&t, 42,1- 48,9 mm LE, Argentina, Misiones, Aristóbulo del Valle, Cuñá-Pirú. Bryconamericus cf. iheringii, CI-FML 6107, 1 d\&t, 62,4 mm LE, Argentina, Buenos Aires, Coronel Vidal, arroyo $10 \mathrm{~km}$ del puente. Bryconamericus cf. rubropictus, CI-FML 3902, 83, 24,8-47,3 mm LE (2 d\&t 34,3-47,3 mm LE), Argentina, Catamarca, tributario al río Santa María, Fuerte Quemado. Bryconamericus emperador, Colombia: CI-FML 4011, 4, 27,0-39,8 mm LE (1 d\&t 39,8 mm LE), Chocó, río Chintado, tributario del río Atrato. CI-FML 4012， 2， 54,6-83,0 mm LE, Ladrilleros-Buenaventura, Bahía Málaga. Bryconamericus exodon, CI-FML 3897, 11, 24,1-43,9 mm LE (2 d\&t 39,0-41,1 mm LE), Paraguay, Alto Paraguay, Bahía Negra, río Paraguay. Bryconamericus mennii, CI-FML 3900, 21, 31,8-43,8 mm LE (2 d\&t 39,5-41,4 mm LE), Argentina, Misiones, Aristóbulo del Valle, Cuñá Pirú. Bryconamericus plutarcoi, CAR 267, 3, 39,1-50,9 mm LE (1 d\&t 50,9 mm LE), Colombia, Santander, Sinacota, sistema del río Suárez, Puente de la quebrada Santa Rosa. Bryconamericus rubropictus, CI-FML 3901, 5, 49,1-56,4 mm LE (1 d\&t 49,1 mm LE), Argentina, Salta, Cachi, río Calchaquí. Bryconamericus scleroparius, ANSP 163169, 5, 32,8-75,0 mm LE (2 d\&t 58,0-65,3 mm LE), Costa Rica, Limón, río sobre la carretera entre Sixaola y Limón, 7 km NE desde Bribri. Bryconamericus thomasi, CI-FML 3348, 131, 18,1-51,6 mm LE (3 d\&t 49,1-51,0 mm LE), Argentina, Salta, Orán, El Oculto, río Blanco. Bryconamericus yokiae, MBUCV 12505, 3, 42,9-58,4 mm LE (2 d\&t 42,9-44,7 mm LE), Venezuela, Sucre, quebrada Manacel, Golfo de Paría, cerca de Yoko. Bryconexodon juruenae, MCP 30657, 1 d\&t, 67,3 mm LE, Brasil, Mato Grosso, Porto dos Gaúchos, cuenca del río Tapajós, Igarapé Ribeirão Preto, MT-338, cerca de 26

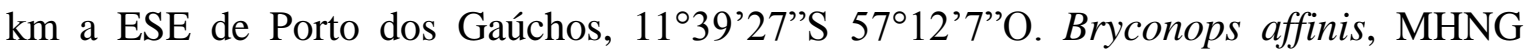
2184-28, 2 d\&t, 29,0-32,0 mm LE, Guayana Francesa, Balatée crick, cuenca río Maroni. Bryconops melanurus, MCP 15807, 3 d\&t, 41,2-83,4 mm LE, Brasil, Mato Grosso, Barra do Bugres, arroyo cruzando la carrera Tangara da Sierra, $13 \mathrm{~km}$ al $\mathrm{S}$ de Nova Limpia, 
afluente del río Paraguai. Carlana eigenmanni, LACM 9230-020, 2 d\&t, 45,2-57,6 mm LE, Costa Rica, Heredia, río Puerto Viejo. Carlastyanax aurocaudatus, CI-FML 5015, 15 , 31,3-48,1 mm LE (2 d\&t 39,4-40,1 mm LE), Colombia, alto Cauca, cuenca del río La Vieja, quebrada La Siria. Chalceus macrolepidotus, MHNG 2189-13, 2 d\&t, 64,0-67,0 mm LE, Guyana Francesa, Litany Maripasoula en su confluencia con le Tampoe, alto río Maroni. Charax stenopterus, CI-FML 3878, 1 d\&t, 39,2 mm LE, Argentina, Corrientes, Guayquiraró, río Corriente. Cheirodon interruptus, Argentina: CI-FML 3825, 2 d\&t, 32,933,4 mm LE, Santiago del Estero, río Hondo, río Hondo dam. CI-FML 6106, 1 t\&m, 39,6 mm LE, Argentina, Entre Ríos, arroyo Ubajay en los Manantiales dentro de la estancia Los Monigotes (31 $\left.48,94^{\prime} \mathrm{S}-58^{\circ} 12,41^{\prime} \mathrm{W}\right)$. Chrysobrycon eliasi, véase material d\&t, tipos y no tipos examinados en Vanegas-Ríos et al. (2011). Chrysobrycon hesperus, Colombia: ICNMHN 11002, 1, 39,38 mm LE, Putumayo, Orito, quebrada La Guara, cuenca río Putumayo, aproximadamente $0^{\circ} 36^{\prime} 00^{\prime} \mathrm{N}$ 7652’15,00”O 344 m s.n.m. Ecuador: ANSP 75912, 1 paratipo, 77,4 mm LE, alto río Villano cerca de Villano, cuenca alta río Napo, $1^{\circ} 30^{\prime} \mathrm{S} 77^{\circ} 28^{\prime} \mathrm{O}$. ANSP 79513, 1 paratipo, 67,4 mm LE, alto río Villano, cerca de Villano, cuenca alta río Napo, $1^{\circ} 30^{\prime} \mathrm{S} 7^{\circ} 28^{\prime} \mathrm{O}$. ANSP 75914, 1 paratipo, 63,2 mm LE, río Suno cerca de la desembocadura, tributario alto río Napo, $0^{\circ} 42^{\prime} \mathrm{S} 77^{\circ} 8^{\prime} \mathrm{O}$ 300-320 m s.n.m. ANSP 79159, 2 paratipos, 60,3-76,0 mm LE, río Pucuno, a tributario de río Suno, cuenca alta río Napo, aproximadamente 350 m s.n.m. USNM 164042, 1 paratipo, 70,5 mm LE, Napo-Pastaza, río Villano, alto Curaray, cerca de Villano, $1^{\circ} 30^{\prime} \mathrm{S} 77^{\circ} 28^{\prime} \mathrm{O}$, aproximadamente 375 m s.n.m. USNM 164056, holotipo Hysteronotus hesperus Böhlke, 1958, 72,3 mm LE (R), Napo-Pastaza, río Pucuno, tributario de río Suno, Pucuno, entrada de Suno, $0^{\circ} 46^{\prime} \mathrm{S} 77^{\circ} 12^{\prime} \mathrm{O}$, aproximadamente 300-350 m s.n.m. USNM 175124, 1 paratipo, 59,1 mm LE (R), Napo-Pastaza, río Pucuno, tributario de río Suno, Pucuno, dentro de Suno, $3^{\circ} 46^{\prime} \mathrm{S} 17^{\circ} 12^{\prime} \mathrm{O}$. Perú, MUSM 26607, 2, 59,9-66,1 mm LE, Loreto, cuenca alta del río Amazonas, Andoas, cuenca del río Corrientes, quebrada Caballo, 2³3’41,17” S 76²13'45,32’O 209 m s.n.m. MUSM 26617, 2, 298-33,1 mm LE, Loreto, cuenca alta del río Amazonas, río Corrientes, drenaje fluyendo hacia la quebrada Huayuri, 2³5’51,05”S 76²13'53,31'” 208 m s.n.m. MUSM 28640, 2, 25,5-27,0 mm LE, quebrada Forestal, río Corrientes basin, $2^{\circ} 19^{\prime} 13,79^{\prime \prime} \mathrm{S} 76^{\circ} 10^{\prime} 30,55^{\prime}$ 'O 215 m s.n.m. MUSM 28665, 3, 36,2-54,6 mm LE (1 d\&t 54,6 mm LE), Loreto, cuenca alta del río Amazonas, Andoas, cuenca del río Corrientes, quebrada Forestal, 2²1'27,71”S 769'25,34”O 237 m s.n.m. MUSM 28682, 3, 41,6-46,1 mm LE, Loreto, cuenca alta del río Amazonas, Andoas, quebrada San Carlos, fluyendo hacia el río Manchari, 2²4’34,59”S 766’35,69”O 196 m s.n.m. MUSM 
32124, 1, 27,1 mm LE, Loreto, cuenca alta del río Amazonas, Andoas, cuenca río Corrientes, río Platanoyacu, 38'26,54”S 7545’8,65”O 153 m s.n.m. MUSM 33159, 2, 29,3-43,9 mm LE, Loreto, cuenca alta del río Amazonas, Andoas, río Pastaza, quebrada Carmen, 2²2’43,85’S 769'44,12”O 216 m s.n.m. Chrysobrycon myersi, Perú: ANSP 112325, 2 paratipos, 30,1-46,1 mm LE, Huánuco, pequeña quebrada al noreste saliendo de Tournavista, tributario de río Pachitea. ANSP 112326, 3 paratipos, 28,3-32,0 mm LE, Huánuco, pequeña quebrada al noreste saliendo de Tournavista, tributario del río Pachitea. LACM 37720-004, 3, 34,3-63,8 mm LE, Pasco, Valle Iscozacin, Pan de Azúcar, quebrada cerca de 100 yardas arriba de la entrada del río Iscozacin. MUSM 12040, 1, 29,7 mm LE, Cusco, La Convención, Echarate, cuenca del río Urubamba, río Picha, Cocha Kamariampiveni, aproximadamente $11^{\circ} 36^{\prime} 00^{\prime}$ 'S 7305'00”O 380 m s.n.m. MUSM 18908, 2, 42,4-48,6 mm LE, Pasco, Oxapampa. Puerto Bermúdez, cuenca río Pachitea, quebrada Atas, aproximadamente $10^{\circ} 17^{\prime} 47^{\prime \prime}$ ' 7456'11,04”O 259 m s.n.m. MUSM 36068, 1, 31,6 mm LE, Curso, La Convención, Echarate, río cuenca río Urubamba, sistema río Parotori, río Poyiriari, $12^{\circ} 10^{\prime} 43,96^{\prime} \mathrm{S} 73^{\circ} 5^{\prime} 6,15^{\prime}$ 'O 544 m. s.n.m. MUSM 36084, 3, 37,1-58,7 mm LE, Cusco, La Convención, Echarate, cuenca río Urubamba, sistema río Parotori, río Poyiriari, $12^{\circ} 10^{\prime} 44,61^{\prime \prime S} 73^{\circ} 5^{\prime} 18,18$ ”O 585 m s.n.m. MUSM 36109, 2, 32,8-36,3 mm LE, Cusco, La Convención, Echarate, río Urubamba, río Parotori, río Poyiriari, quebrada Piriabindeni, $12^{\circ} 1^{\prime} 13,05^{\prime}$ 'S 730'23,59”O 585 m s.n.m. MUSM 36125, 3, 29,2-38,6 mm LE, Cusco, La Convención, Echarate, río Parotori, quebrada Piriabindeni, 12¹'19,29”S 734'14,66”O 545 m s.n.m. MUSM 37889, 2, 45,1-51,0 mm LE, Junín, Satipo, Mashira,

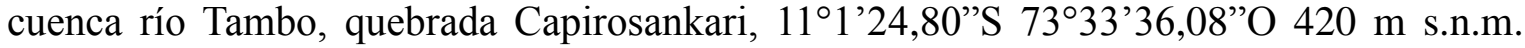
MUSM 37933, 3, 58,0-60,8 mm LE, Cusco, La Convención, Echarate, Kinterani, quebrada Naca-naca, $11^{\circ} 28^{\prime} 9,49^{\prime}$ 'S 73¹8'1,97’O 420 m s.n.m. MUSM 38671, 3, 50,960,7 mm LE (1 d\&t 58,6 mm LE), Junín, Satipo, cuenca río Tambo, quebrada Pukakunga, 73²8’2,19”O 11²4’37,27’'S, 587 m s.n.m. USNM 203697, holotipo Hysteronotus myersi Weitzman \& Thomerson, 1970, 46,5 mm LE, Huánuco, pequeña quebrada tributario directo del río Pachitea (en sí tributario del río Ucayali) al noreste de Tournavista. USNM 203698, 6 paratipos, 24,9- 31,3 mm LE (1R 31,3 mm LE), colectados con holotipo. Chrysobrycon yoliae, véase material d\&t y tipos examinados en Vanegas-Ríos et al. (2014). Chrysobrycon sp. nov. A, MPUJ sin catalogar, 19, 26,5-33,6 mm LE (2 d\&t, 30,431,3 mm LE), Colombia, Meta, caño Cunumia. Corynopoma riisei, MBUCV 285, 3, 27,435,4 mm LE (2 d\&t 27,4-34,1 mm LE), Venezuela, Carabobo, Hacienda Monte Sacro. UF 33410, 31, 32,0-41,5 (2 d\&t 33,2-37,3 mm LE), Colombia, Meta, cuenca río Meta, río 
Guacavía ENE de Villavicencio, aproximadamente 4²17'24,24"N 73³0'51,06"O 449 m s.n.m. USNM 310578*, 2, 23,2-31,9 mm LE (2R), Trinidad \& Tobago, Isla de Trinidad, Piarco. Creagrutus anary, CI-FML 3905, 1 d\&t, 47,1 mm LE, Perú, Loreto, Maynas, río Napo, cerca del pueblo de Mazan. Creagrutus atrisignum, Brasil, Goiás: CAS 41339*, holotipo Creagrutus atrisignum Myers, 1927, 44,6 mm LE, cuenca río Tocantins, río Maranhao en el río Tocantins. MCP 15929, 6 d\&t, LE no tomada, Niquelândia, Ribeirão do Engenho, en la carretera entre Niquelandia y Codemin, a $29 \mathrm{~km}$ al sur de Codemin. Creagrutus taphorni, MHNG 2183-34, 2, d\&t, 49,0-51,3 mm LE, Venezuela, Carabobo 5 km N de Guacara, río Vigirima. Cyanocharax alburnus, CI-FML 3906, 2, 37,5-46,4 mm LE; MCP 7054, 9, 30,6-57,1 mm LE, Brasil, Rio Grande do Sul, Porto Alegre, Praia das Pombas. Cyanocharax obi, CI-FML 3892, 3 d\&t, 31,2-57,3 mm LE, Argentina, Misiones, Aristóbulo del Valle, arroyo Moreno. Deuterodon iguape, MHNG 2183-6, 2 d\&t, 52,052,5 mm LE, Brasil, São Paulo, cuenca del río Iguapé da Ribeira. Deuterodon langei, MCP 12158, 1 d\&t, 80,8 mm LE, Brasil, Paraná, Morretes, río São João. Diapoma pyrrhopteryx, MLP sin catalogar, $1 \mathrm{d \& t}$, 49,5 mm LE, Argentina, Misiones, cuenca del río Uruguay, arroyo Toro, afluente del río Pepirí Guazú. Diapoma speculiferum, Brasil, Rio Grande do Sul, Barra do Ribeiro: CI-FML 3891, 1 d\&t, 33,1 mm LE, BR-116 km 56, Açude dos García. MCP 7979, 4, 31,3-43,3, drenaje Guaiba, acude dos Garcia, junto a la carretera BR-116, KM 56. Diapoma terofali, CI-FML 6101, 1 d\&t, 35,7 mm LE, Argentina, Entre Ríos, Concepción del Uruguay, arroyo el Sauce. Exodon paradoxus, MHNG 2188-47, 2 d\&t, 37,0-40,0 mm LE, Brasil, Ilha do Bananal, río Araguaia. Galeocharax humeralis, CI-FML 3951, 1 d\&t, 94,6 mm LE, Argentina, Salta, Rivadavia, La Unión, Pozo de los Yacarés, río Bermejo. Genycharax tarpon, Colombia: IMCN 4833, 2, 85,0-92,3 mm LE (1 d\&t 85,0 mm LE), Yocotó, Alto Cauca, río Media Canoa. USNM 79207, 1 paratipo (R), 108,9 mm LE, Cartago. Grundulus cochae, ANSP 134934, 4 d\&t, 35,8-47,1 mm LE, Colombia, norte de Bogotá, en el Puente de Suba. Gymnocharacinus bergii, CI-FML 3922, 2 d\&t, 39,0-43,8 mm LE, Argentina, río Negro, arroyo Valcheta. Gymnocorymbus ternetzi, CI-FML 3826, 2 d\&t, 33,7-35,6 mm LE, Paraguay, alto río Paraguay, Fortín Patria, río Negro. Hemibrycon dariensis, ANSP 104426, 2 d\&t, 36,643,4 mm LE, Panamá, Coclé, quebrada del río Coclé cerca 5 millas al $\mathrm{N}$ de Penonomé sobre la carretera a La Pintada. Hemibrycon surinamensis, MHNG 2182-63, 1 d\&t, 48,0 mm LE, Guayana Francesa, quebrada Balatée, río Comté. Hemigrammus erythrozonus, CI-FML 3827, 2 d\&t, 25,5-26,9 mm LE, especímenes de acuario. Hemigrammus ulreyi, CI-FML 3925, 1 d\&t, 31,5 mm LE, Misiones, río Paraná en Nemesio Parma. 
Heterocharax macrolepis, MCP 11457, 2 d\&t, 33,4-34,0 mm LE, Brasil, Amazonas, Boa Vista, cuenca alta del río Negro, confluencia el río Negro con el río Urubaxi. Hollandichthys multifasciatus, MHNG 2173-91, 2, 46,0-52,0 mm LE, Brasil, Paranagua. Hoplocharax goethei, Brasil, Amazonas: CAS 56478*, holotipo Hoplocharax goethei Géry, 1966, 27,8 mm LE (R), Igarape do Mai Joana, Igarape do Mai Joana en el río Negro en Manaos. MCP 11456, 2 d\&t, 21,0-25,0 mm LE, Boa Vista, cuenca alta del río Negro, confluencia el río Negro con el río Urubaxi. Hyphessobrycon anisitsi, CI-FML 3926, 2 d\&t, 30,3-34,7 mm LE, Argentina, Santa Fe, Helvecia. Hyphessobrycon bifasciatus, CIFML 3927, 2 d\&t, 28,8-36,0 mm LE, especímenes de acuario. Hyphessobrycon luetkenii, CI-FML 3931, 2 d\&t, 25,6-30,4 mm LE, Argentina, Santa Fe, San José del Rincón. Hyphessobrycon meridionalis, CI-FML 3931, 2 d\&t, 25,6-30,4 mm LE, Argentina, Santa Fe, San José del Rincón. Hyphessobrycon pulchripinnis, CI-FML 3932, 2 d\&t, 28,4-33,2 mm LE, especímenes de acuario. Inpaichthys kerri, CI-FML 3934, 3 d\&t, 25,4-26,9 mm LE, especímenes de acuario. Knodus breviceps, MHNG 2184-97, 2 d\&t, 43,5-47,0 mm LE, Perú, cuenca río Amazonas, cerca de Iquitos. Knodus gamma, ANSP 130512, 2 d\&t, 35,3-42,8 mm LE, Ecuador, Napo, Santa Cecilia, río Aguarico. Knodus heteresthes, MHNG 2184-051, 3 d\&t, 25,9-32,8 mm LE, Guyana Francesa, Gaa Kaba, Maroni. Knodus meridae, MCP 44038, 2 d\&t, LE no medida, Venezuela, Amazonas, Culebra, cerca Puerto Ayacucho. USNM 221933, 4 d\&t, 39,7-58,1 mm LE, Venezuela, Maracaibo, río Motatán, 4 km arriba Motatán. Knodus sp., MBUCV 24827, 3, 42,8-45,3 mm LE (2 d\&t 42,8-44,3 mm LE), Venezuela, Bolívar, río Caura, el playón debajo del Salto Para. Landonia latidens, Ecuador, Los Ríos: CAS 55297*, holotipo Landonia latidens Eigenmann \& Henn, 1914, 42,0 mm LE (R), cuenca río Guayas, río Vinces en Vinces. MEPN RBS89-12, 57, 20,0-39,4 mm LE, río Vinces, $5 \mathrm{~km}$ agua arriba de la ciudad de Vinces. Leporinus striatus, CI-FML 3864, $1 \mathrm{~d} \& \mathrm{t}, 81,4 \mathrm{~mm}$ LE, Paraguay, alto río Paraguay, Bahía Negra, río Paraguay. Lonchogenys ilisha, CAS 61719*, holotipo Lonchogenys ilisha Myers, 1927, 47,9 mm LE (R), Brasil, Amazonas, cuenca río Amazonas, río Negro, Cucui, banco de arena sobre el lado colombiano. MCP 11460, 2 d\&t, 39,3-45,0 mm LE, Brasil, Amazonas, Anavilhanas, bajo río Negro, río Negro en Anavilhanas. Markiana geayi, MBUCV 11032, 3, 35,2-40,6 mm LE (2 d\&t 35,2-40,3 mm LE), Venezuela, Apure, El Negro, carretera San Fernando, Caramacate. Markiana nigripinnis, CI-FML 3936, 2 d\&t, 75,3-78,6 mm LE, Paraguay, alto Paraguay, Parque Nacional Defensores del Chaco. Microgenys minuta, CI-FML 5021, 2, 24,7-31,4 (1 d\&t 31,4 mm LE), Colombia, Quindío, Quimbaya, Alejandría, río La Vieja. 
Microschemobrycon casiquiare, ANSP 159704, 2 d\&t, 260-26,4 mm LE, Venezuela, Amazonas, río Sipapo, a lo largo de las playas de arena y roca cerca de 1 a 4 km arriba de Pendare. CAS 17497*, holotipo Microschemobrycon casiquiare Böhlke, 1953, 27,7 mm LE (R), Brasil, Amazonas, cuenca río Amazonas, río Negro, Bucury. Mimagoniates inequalis, material citado en Azpelicueta \& Koerber (2012), 1 d\&t, 27,1 mm LE). Mimagoniates rheocharis, MCP 29273, 3 d\&t, 38,6-53,1 mm LE, Brasil, Santa Catarina, Praia Grande, cuenca río Mampituba, arroyo Molha Coco en Vila Rosa. Moenkhausia cf. intermedia, CI-FML 3417, 4 d\&t, 31,5-35,4 mm LE, Argentina, Salta, Orán, El Oculto, arroyo El Oculto. Moenkhausia dichroura, CI-FML 3938, 2 d\&t, 45,3-47,2 mm LE, Paraguay, Alto Paraguay, Bahía Negra, río Paraguay. Moenkhausia sanctaefilomenae, CIFML 3939, 4 d\&t, 28,3-31,8 mm LE, Paraguay, alto Paraguay, Fortín Patria, río Negro. Nantis indefessus, Argentina: CI-FML 3940, 1 d\&t, 41,6 mm LE, Salta, Orán, Estancia Anta Muerta, río Pescado. CI-FML 3941, 1 d\&t, 35,2 mm LE, Jujuy, Pozo de los Sauces, entre Purmamarca y Tilcara, río Grande. Nematobrycon lacortei, CI-FML 6102, 1 d\&t, 32,9 mm LE, Colombia, Valle del Cauca, Buenaventura, bajo San Juan, bajo Calima, pequeña quebrada a 300-500 $\mathrm{m}$ del pueblo. Nematobrycon palmeri, MHNG 2182-86, 2 d\&t, 25,0-30,2 mm LE, Colombia, especímenes de acuario. Nematocharax venustus, MCP 17987, 3 d\&t, 34,3-42,4 mm LE, Brasil, Bahía, Buerarema, cuenca río Pratas en São Jose. Nuevo género, MUSM 26709, 3, 27,1-30,8 (1 d\&t 30,8 mm LE), Perú, alto río Amazonas. Odontostilbe microcephala, Argentina, Salta, Orán: CI-FML 3408, 2 d\&t, 41,9-44,1 mm LE, Argentina, Salta, Orán, río Santa Muerta, tributario del río Blanco. CI-FML 3886, 43, 31,2-53,6 mm LE (2 d\&t 42,2-50,1 mm LE), Argentina, Salta, Orán, Finca Anta Muerta, río Pescado. Odontostilbe paraguayensis, CI-FML 3885, 117, 21,6-31,7 mm LE (2 d\&t 29,4-31,2 mm LE), Paraguay, Alto Paraguay, Bahía Negra, río Paraguay. Odontostilbe pequira, CI-FML 3887, 2 d\&t, 34,4-37,8 mm LE, Argentina, Salta, La Unión, Pozo de los Yacarés. Odontostilbe pulchra, MBUCV 33839, 3, 28,0-35,8 mm LE (1 d\&t 33,9 mm LE), Venezuela, Bolívar, río Yahumo, afluente del río Carapo. Odontostoechus lethostigmus, MCP 10776, 1 d\&t, 61,3 mm LE, Brasil, Rio Grande do Sul, Maquiné, cuenca río Maquiné en Maquiné, cuenca río Tramandaí. Oligosarcus bolivianus, CI-FML 3366, 1 d\&t, 83,4 mm LE, Argentina, Salta, Orán, El Oculto, arroyo El Oculto. Oligosarcus cf. jenynsii, CI-FML 3771, 1 d\&t, 68,8 mm LE, Argentina, Santiago del Estero, río Hondo. Paragoniates alburnus, MHNG 2188-67, 1 d\&t, 50,0 mm LE, Brasil, Ilha do Careiro cerca Manaos. Parecbasis cyclolepis, MHNG 2228, 2 d\&t, 60,0-61,5 mm LE, Bolivia, Cochabamba, río Chapare. Phenacobrycon henni, Ecuador, Los Ríos: MCZ 
48660, 11, 22,1-29,6 mm LE (1 d\&t 29,8 mm LE), río Vinces en Vinces. MCZ 48661, 3 d\&t, 25,6-27,7 mm LE, Ecuador, río Nuevo donde fluye sobre el lado izquierdo del río Vinces en Vinces. Phenacogaster tegatus, CI-FML 3880, 1 d\&t, 35,3 mm LE, Argentina, Misiones, Capital, Nemesio Parma. Phenagoniates macrolepis, ANSP 134909, 2 d\&t, 25,8-34,8 mm LE, Venezuela, tributario del río Motatán $30 \mathrm{~km}$ al $\mathrm{N}$ de Trujillo. Piabarchus analis, MCP 15571, 3 d\&t, LE no medida, Brasil, Mato Grosso, Cáceres, arroyo cerca carretera Barra do Bugres. Piabina argentea, ANSP 171965, 3, 38,8-44,2 mm LE; CI-FML 3907, 1 d\&t 41, 2 mm LE, Brasil, Minas Gerais, Riacho dos Poções, tributario del río Coxá-río Carinhanha. CI-FML 5899, 18, 32,8-68,3 mm LE, Brasil, Paraíso do Norte, Ribeirão 19, afluente río Juai, 2315'57"N 52³2'38"O. Piabucus menalostomus, CI-FML 3894, 2 d\&t, 67,0-86,8 $\mathrm{mm}$ LE, especímenes de acuario. Prionobrama paraguayensis, CI-FML 3877, 1 d\&t, 35,9 mm. Paraguay, Alto Paraguay,

Bahía Negra, río Paraguay. Prodontocharax melanotus, CAS 59793*, lectotipo Prodontocharax melanotus Pearson, 1924 designado por Böhlke, 1953, 42,2 mm LE (R), Bolivia, La Paz, cuenca río Amazonas, Tumupasa, 30 millas al noroeste de Rurrenabaque. CI-FML 3888, 1 d\&t, 32,9 mm LE; ANSP 143528, 3, 26,1-31,2 mm LE Perú, Madre de Dios, alto río Madre de Dios en Shintuya. Psellogrammus kennedyi, CIFML 3946, 4 d\&t, 36,3-40,3 mm LE, Paraguay, Alto Paraguay, Fortín Patria, río Negro. Pseudochalceus kyburzi, USNM 324462, 2 d\&t, 36,8-45,3 mm LE, especímenes de acuario. Pseudocorynopoma doriae, Argentina: material citado en Mirande et al. (2013), 4, 35,2-55,4 mm LE (2 d\&t 51,0-55,4 mm LE). CI-FML 3893, $1 \mathrm{~d} \& \mathrm{t}, 57,5 \mathrm{~mm}$ LE, sin datos. Pterobrycon landoni, Colombia, Chocó: FMNH 56250*, holotipo Pterobrycon landoni Eigenmann, 1913, 20,98 mm LE (R), tributario del río Atrato cerca a Boca de Raspadura. FMNH 56606*, holotipo Microbrycon minutus Eigenmann \& Wilson, en Eigenmann, Henn \& Wilson, 1914, 22,9 mm LE (R), río Truandó, tributario del río Atrato. USNM 367131*, 4, 15,8-20,0 mm LE (4R), Colombia, especímenes de acuario. Pterobrycon myrnae, Costa Rica, Punta Arenas: ANSP 164243, 20, 20,6-29,2 mm LE (2 d\&t 29,1-29,2 mm LE), charco Culvert en la carretera Interamericana cerca $20 \mathrm{~km} \mathrm{~S}$ de Palmar Norte. LACM 33861-001, 10 paratipos, 24,2-34,7 mm LE (2 d\&t, 30,6-32,9 mm LE), quebrada Banegas (10 m) 0,8 km corriente arriba desde la carretera Pacífico número 3 al SO de Rinco. Rhaphiodon vulpinus, CI-FML 3871, 1 d\&t, 193,8 mm LE, Argentina, Corrientes, Guayquiraró, río Corriente. Rhoadsia altipinna, MHNG 2173-31, 2 d\&t, 59,073,5 mm LE, Perú, El Caucho, río Faical en el río Zarumilla. Roeboexodon geryi, MHNG 2188,14, 1 d\&t, 37,0-41,0 mm LE, Surinam, Desiongkondre y Pokigron, río Surinam. 
Roeboides descalvadensis, CI-FML 3859, 2 d\&t, 61,4-63,1 mm LE, Argentina, Salta, La Unión, Pozo de los Yacarés. Salminus brasiliensis, CI-FML 3784, 1 d\&t, 131,4 mm LE, Argentina, Santiago del Estero, cuenca río Salí, río Hondo dam. Scopaeocharax rhinodus, MUSM 8441, 4 25,7-29,0 mm LE (2 d\&t 25,7-28,0 mm LE), Perú, San Martín, Tarapoto, Morales, San Antonio, río Cumbaza. Serrapinus calliurus, CI-FML 3889, 38, 18-8-23,5 mm LE (3 d\&t 23,1-23,2 mm LE), Argentina, Salta, La Unión, Puesto de la Viuda, cuenca río Bermejo. Sistomus tetrazona, CI-FML 3860, 2, 22,8-26,2 mm LE (1 d\&t 26,2 mm LE), especímenes de acuario. Stethaprion erythrops, MHNG 2187-33, 2 d\&t, 43,0-44,5 mm LE, Perú, Yarina Cocha cerca Pucallpa, río Ucayali. Stichonodon insignis, MHNG 2173-85, 1 d\&t, 54,5 mm LE, Brasil, Solimões, Muddy Iguarape. Tetragonopterus argenteus, CI-FML 3883, 1 d\&t 62,2 mm LE, Paraguay, Alto Paraguay, Bahía Negra, río Paraguay. Thayeria boehlkei, CI-FML 3947, 2 d\&t, 25,2-26,6 mm LE, especímenes de acuario. CAS-SU 49907*, holotipo Thayeria boehlkei Weitzman, 1957, 29,0 mm LE (R), espécimen de acuario. Thoracocharax stellatus, CI-FML 3869, 2 d\&t 43,7-45,2 mm LE, Paraguay, Alto Paraguay, Bahía Negra, río Paraguay. Triportheus pantanensis, CI-FML 3948, 1 d\&t, 82,1 mm LE, Paraguay, Alto Paraguay, Fortín Patria, río Negro. Tyttocharax sp., MUSM 36130, 5, 17,5-20,6 mm LE (2 d\&t 17,5-19,9 mm LE), Perú, Cuzco, La Convención, Echarate, cuenca río Urubamba, río Parotori, quebrada Piriabindeni. Xenagoniates bondi, Venezuela: CAS 36486*, holotipo Xenagoniates bondi Myers, 1942, Monagas, río Amana $6 \mathrm{~km}$ al este de Santa Bárbara, $35 \mathrm{~km}$ al oeste de Maturim, 48,2 mm LE (R), MHNG 2366-27, 1 d\&t, 44,5 mm LE, Portuguesa, río Apuré. Xenurobrycon macropus, MUSM 16974, 5, 11,6-12,6 mm LE (2 d\&t 12,3-12,5 mm LE), Brasil, Aquidauana, río Taboco.

\section{Revisión taxonómica}

\section{Gephyrocharax Eigenmann, 1912}

Gephyrocharax Eigenmann, 1912: 23 (especie tipo: Gephyrocharax chocoensis Eigenmann, 1912 por designación original). Eigenmann, 1914: 41 (lista, clave especies, ubicación sistemática en Glandulocaudinae). Meek \& Hildebrand, 1916: 268 y 277 (clave géneros, diagnosis). Eigenmann, 1920a: 11 (ubicación sistemática en Glandulocaudinae). Eigenmann, 1922: 100 y 155-156 (clave género, lista 
especies, ubicación sistemática en Glandulocaudinae). Eigenmann, 1927: 395 (ubicación sistemática probable en Corynopominae) Eigenmann \& Myers, 1929: 463, 464 y 467 (clave género, ubicación sistemática en Glandulocaudinae). Myers en Eigenmann \& Myers, 1929: 477-484 (diagnosis, revisión de género y especies). Hildebrand, 1938: 252 (diagnosis, revisión especies Panamá). Fowler, 1940: 71 (ubicación sistemática en Glandulocaudinae). Schultz, 1944: 246 y 322-326 (complementa la diagnosis, clave de especies, revisión de especies de Venezuela). Fowler, 1954: 341 (ubicación sistemática en Stevardiidae, Stevardiinae). Miles, 1947: 155-157 (ubicación sistemática en Glandulocaudinae, clave de especies Magdalena). Géry, 1966: 216, 218, 227 y 233-235 (ubicación sistemática en Tetragonopterinae, Glandulocaudini en clave). Dahl, 1971: 133-135 (ubicación sistemática en Glandulocaudinae, clave de especies, lista de especies CaucaMagdalena). Miles, 1973: 52-53 (ubicación sistemática en Glandulocaudinae). Géry, 1977: 351, 354 y 358 (ubicación sistemática en Glandulocaudinae, Glandulocaudini, clave de género, y distribución errónea en Costa Rica). Weitzman \& Fink, 1985: 1, 2, 24, 28-29, 51, 54, 96 y 103-104, fig. 17 (ubicación sistemática en Glandulocaudinae, comentarios taxonómicos, comparaciones con miembros de Xenurobryconinae, material examinado). Weitzman, Menezes \& Weitzman 1988: 384 y 394 (ubicación sistemática aparente en Corynopomini como "other tribes de glandulocaudines"). Menezes \& Weitzman, 1990: 381, fig. 1 (ubicación sistemática en filogenia como "other tribes de glandulocaudines"). Ortí \& Meyer, 1997: 92, fig. 11 (relaciones filogenéticas, ubicación sistemática en Glandulocaudinae). Weitzman \& Menezes, 1998: 172-174 y 186-188 tablas 1-3, fig. 1 (clasificación, relaciones filogenéticas, ubicación sistemática en Glandulocaudinae, Corynopomini, comentarios morfológicos). Castro, Ribeiro, Benine \& Melo, 2003: 17, fig. 8 (ubicación sistemática en Glandulocaudinae, Corynopomini). Malabarba \& Weitzman, 2003: 84, 86 y 87, fig. 11 (ubicación sistemática en "clado A", Glandulocaudinae, Corynopomini). Weitzman, 2003 (revisión catálogo), Calcagnotto, Schaefer \& DeSalle, 2005: 142 y 145, fig. 6 (relaciones filogenéticas, ubicación sistemática en Characidae y Glandulocaudinae). Weitzman, Menezes, Evers \& Burns, 2005: 331, 344-345, fig. 11 (comentarios taxonómicos, reubicación sistemática en "clado A", Stevardiinae [nueva definición], Corynopomini). Menezes \& Weitzman, 2009: 298-299 y 302, figs. 1-2 (relaciones filogenéticas, ubicación sistemática en "clado A", 
Stevardiinae, Stevardiini). Mirande, 2009: 8 (ubicación sistemática tentativa en Stevardiinae). Javonillo, Malabarba, Weitzman \& Burns, 2010: 500, 508-509, tabla 1, figs. 4-6 (relaciones filogenéticas, ubicación sistemática en "clado A" o Stevardiinae, Corynopomini). Mirande, 2010: 533-540 (ubicación sistemática tentativa en Stevardiinae). Oliveira, Avelino, Abe, Mariguela, Benine, Ortí, Vari \& Castro, 2011: 16, fig. 12 (relaciones filogenéticas, ubicación sistemática en Stevardiinae, en un mismo clado con Corynopoma). Tagliacollo, Souza-Lima, Benine \& Oliveira, 2012: 302, fig. 2 (filogenia combinada, ubicación sistemática en Stevardiinae). Bonilla-Rivero \& López-Rojas, 2013: 487-495, figs. 1-3 (filogeografía de especies de Venezuela). Género: masculino.

Corynopomops Fowler, 1943: 6, fig. 4 (especie tipo: Corynopomops opisthopterus Fowler, 1943 por designación original). Género: masculino.

Diagnosis. Gephyrocharax puede distinguirse por la mancha humeral presente, el contorno ventral de la aleta anal de los machos adultos es convexo desde su porción anterior hasta la mitad o tres cuartos de su longitud (los radios son un poco más largos en este intervalo que en otras porciones de la aleta), el tercer radio procurrente ventral de los machos adultos alcanza o sobrepasa la región media del primer radio procurrente ventral, los interradialis modificados en la aleta caudal de los machos adultos alcanzan posteriormente un mismo punto o son apenas más largos en el lóbulo ventral que en el dorsal y las fibras musculares de los interradialis no sobrepasan el borde posterodorsal de la escama-bolsillo en los machos adultos.

Aunque estos caracteres son las sinapomorfías obtenidas en el análisis filogenético bajo pesos implicados extendidos, no todos son compartidos perfectamente por todas las especies de Gephyrocharax (véase reversiones Nodo 423). Las especies tienen como mínimo una sinapomorfía de las cuatro usadas en la diagnosis (excepto G. martae). La forma de la aleta anal de los machos adultos es la que mejor agrupa a las especies de Gephyrocharax, excepto por G. martae, especie cuya aleta anal tiene una forma diferente; razón por la cual se codificó inaplicable para este carácter en el análisis filogenético. Gephyrocharax martae tiene una moderada cantidad de entradas faltantes en la matriz de datos, pero comparte posición y sinapomorfías con otros congéneres en los clados internos del nodo 423, lo que refuerza su posición dentro del clado Gephyrocharax al menos indirectamente. De cualquier manera, G. martae es morfológicamente más afín con Gephyrocharax que cualquier género cercano (Corynopoma o Pterobrycon), como lo 
demostraron los árboles de consenso de ambos análisis filogenéticos bajo diferentes esquemas de pesado.

Caracteres discriminatorios adicionales. Gephyrocharax se diferencia de los demás géneros de Characiformes y Characidae por los radios procurrentes ventrales segundo y tercero de la aleta caudal de los machos adultos, los cuales están modificados en una única estructura tipo pinza ( $v s$. tal estructura no desarrollada y si desarrollada involucra dos pinzas formadas por los radios segundo al cuarto). Gephyrocharax difiere de Corynopoma por el tamaño del pedúnculo caudal que es casi tan alto como largo ( $v s$. alargado, dos veces más largo que alto), la presencia de aleta adiposa excepto en G. torresi (vs. ausencia de tal aleta) y la ausencia de una estructura filamentosa formada por la proyección posterior del opérculo, subopérculo y radio branquiostego más posterior de los machos adultos ( $v s$. tal estructura presente) y difiere de Pterobrycon por carecer de escamas hipertrofiadas cerca de la región humeral del cuerpo de los machos adultos, las cuales son anchas y expandidas en su porción distal ( $v s$. escamas parecidas al resto). Además, Gephyrocharax se distingue de una gran cantidad de miembros de Characidae (e. g. géneros de Acestrorhynchinae, Agoniatinae, Bryconinae, Bryconops, Cynodontinae, Iguanodectinae y Salmininae) por la ausencia de hueso supraorbital ( $v s$. presencia de tal hueso). Además de los grupos carácidos antes listados, el género difiere de otro gran grupo de peces [los géneros de Aphyocharacinae (excepto Prionobrama Fowler, Phenagoniates Eigenmann \& Wilson y Xenagoniates Myers), Aphyoditeinae, Characinae, Cheirodontinae, Gymnocharacinae, Rhoadsiinae, Tetragonopterinae y géneros Astyanax, Bramocharax, algunos Bryconamericus (B. emperador y B. scleroparius), Landonia, Oligosarcus Günther, Phenacobrycon y Pseudochalceus] por la presencia de nueve pterigióforos proximales en la aleta dorsal (vs. diez o más). Gephyrocharax también se distingue de otros géneros y algunas subfamilias afuera de Stevardiinae [como Carlana Strand, Grundulus Valenciennes, Paracheirodon Géry, Probolodus Eigenmann, en parte Oligosarcus y Characinae, Aphyocharacinae (excepto Paragoniates), Aphyoditeinae, Cheirodontinae] y dentro de esta (como Aulixidens, Odontostoechus, algunos Mimagoniates, Scopaeocharax, Tyttocharax y Xenurobrycon) por la presencia de dos hileras de dientes premaxilares ( $v s$. una hilera o un parche complejo de dientes). El género se diferencia de la gran mayoría de los géneros stevardinos (excepto algunas especies de Cyanocharax, Chrysobrycon, Corynopoma, Glandulocauda, algunas especies de Hemibrycon, Hysteronotus, Iotabrycon, Landonia, Lepidocharax, Lophiobrycon, Mimagoniates, Phenacobrycon, Pseudocorynopoma, Pterobrycon, Ptychocharax, 
Scopaeocharax, Tyttocharax y Xenurobrycon) por el extremo anterior de la premaxila ubicado al nivel de la mitad superior de la órbita ( $v s$. al nivel de la mitad inferior). Gephyrocharax también se distingue de un gran grupo de géneros de Stevardiinae (excepto Argopleura, Chrysobrycon, Hysteronotus, Iotabrycon, Pseudocorynopoma, Pterobrycon, Ptychocharax, Scopaeocharax, Tyttocharax y Xenurobrycon) por la presencia de una escama-bolsillo en el lóbulo ventral de la aleta caudal en los machos adultos ( $v s$. ausencia de tal escama modificada).

Morfometría asociada al dimorfismo sexual. En todas las especies de Gephyrocharax, ciertos datos morfométricos presentaron una tendencia gradual a desarrollar un marcado dimorfismo sexual con el aumento de las tallas de los ejemplares. Esta tendencia no se encontró muy informativa para discriminar entre las distintas especies del género, razón por la cual los resultados de las comparaciones pareadas entre éstas no se presentan. Sin embargo, se encontró un patrón común generalizado para Gephyrocharax que agrupa las tendencias individuales de cada una de sus especies y a su vez describe el comportamiento de las medidas entre machos y hembras. Gráficos de regresión por sexo y que agrupan a todas las especies fueron construidos en función de la longitud estándar (Fig. 18). Las hembras de las especies de Gephyrocharax presentaron valores un poco más altos que los machos en las longitudes del hocico-origen aleta pélvica, hocico-origen aleta anal y la distancia aleta pectoral-aleta pélvica. En contraste, los machos de las especies de Gephyrocharax presentaron valores un poco más altos que las hembras en la longitud de la aleta pélvica, altura del pedúnculo caudal y longitud del pedúnculo caudal. Los puntos (correspondientes a ejemplares) poco ajustados a las rectas de regresión por sexos indican una más alta variación interespecífica (Fig. 18). Estos desajustes se explican también por las diferentes longitudes estándar de las especies, por ejemplo G. major tiene tallas un poco más grandes $(22,8-64,4 \mathrm{~mm}$, media $=41,5 \mathrm{~mm})$, mientras que $G$. venezuelae tiene tallas ligeramente más pequeñas (18,0-41,1 mm, media 29,1 mm).

Distribución. Las especies de Gephyrocharax se encuentran en sistemas de ríos cis y transandinos, desde el sureste de América Central en drenajes costeros del Golfo de Chiriquí en Panamá, a lo largo de ríos y quebradas de las vertientes Pacífico y Caribe hasta el Darién al oeste del Canal de Panamá y en el río Palenque, Archipiélago de las Perlas; en las cuencas de los ríos Atrato, San Juan, León, Ranchería, Cauca-Magdalena, sistema del Lago de Maracaibo, variados drenajes costeros del Caribe de América del Sur y la cuenca del río Orinoco en Colombia y Venezuela; los ríos Moriquite y Moruga en la 
isla de Trinidad y las cuencas de los ríos Nanay, Ucayali, Yuruá, Orton, Beni y Mamoré en Bolivia y Perú (Fig. 19-21).

\section{Clave taxonómica de las especies de Gephyrocharax}

1a. Distancia hocico-origen aleta pectoral 20,7 \% LE; cinco dientes maxilares; el radio simple más posterior de la aleta anal del macho adulto más expandido sagitalmente que el radio contiguo posterior; la longitud de la aleta anal en el macho adulto 61,6 \% LE; los siete radios ramificados más anteriores de la aleta anal del macho adulto se proyectan posteriormente más allá de la mitad de la longitud de la aleta; presencia de un lóbulo posteroventral de la escama-bolsillo del macho adulto donde convergen una gran cantidad de los radii de la escama; ganchos óseos ausentes en los radios de la aleta caudal en el macho adulto

G. martae

1b. Distancia hocico-origen aleta pectoral 22,8-31,1 \% LE; sin dientes maxilares o con uno a cuatro (raramente cinco, $\mathrm{n}=2$ ); el radio simple más posterior de la aleta anal de los machos adultos casi tan expandido como el radio contiguo posterior; la longitud de la aleta anal en machos adultos 13,2-25,2 \% LE; los siete radios ramificados más anteriores de la aleta anal del macho adulto no se proyectan más allá de la mitad de la longitud de la aleta; la ausencia de un lóbulo posteroventral de la escama-bolsillo en machos adultos o, si presente, los radii no convergen en dicho lóbulo; ganchos óseos presentes en los radios de la aleta caudal en machos adultos.

2a. Los radios 11 y 12 de la aleta caudal muy curvados ventralmente a lo largo de su longitud en machos adultos, el nasal en vista dorsal con su borde lateral muy cóncavo, arqueado en un ángulo igual o menor a $135^{\circ}$; los radii de la escama-bolsillo se distribuyen a lo largo del borde dorsal y posterior en machos adultos; primer y segundo radios procurrentes ventrales de la aleta caudal de los machos adultos muy cercanos entre sí o fusionados distalmente; escama-bolsillo de los machos adultos con una escama accesoria en su porción posteroventral.

G. major

2b. Los radios 11 y 12 de la aleta caudal rectos a lo largo de su longitud en machos adultos; el nasal en vista dorsal con su borde lateral recto a lo largo de toda su longitud o ligeramente cóncavo, arqueado en un ángulo mayor a $135^{\circ}$; los radii de la escama-bolsillo se distribuyen únicamente en el borde posterior; primer y segundo radios procurrentes ventrales de la aleta caudal de los machos adultos separados entre sí y no fusionados distalmente; escama-bolsillo de los machos adultos sin escamas accesorias en su porción 
posteroventral....

3a. El primer radio de la aleta pélvica hipertrofiado o curvado distalmente en los machos adultos.

G. sinuensis

3b. El primer radio de la aleta pélvica no hipertrofiado o curvado distalmente en los machos adultos....

4a. Tubo terminal de la línea lateral presente entre los radios caudales 10 y $11 \ldots \ldots \ldots \ldots . . .5$

4b. Tubo terminal de la línea lateral ausente entre los radios caudales 10 y $11 \ldots \ldots \ldots \ldots . . .9$

5a. Machos adultos sin un lóbulo o proceso en el margen posterior de la escama-bolsillo que se dirige hacia los radios procurrentes ventrales de la aleta caudal.

6

5b. Machos adultos con un lóbulo o proceso en el margen posterior de la escama-bolsillo que se dirige hacia los radios procurrentes ventrales de la aleta caudal

6a. Los radios procurrentes dorsales y ventrales y los radios principales 1 a 6 y 14 a 19 de la aleta caudal con densa pigmentación marrón oscura o negra; machos adultos con glándula branquial.

G. atracaudatus

6b. Los radios de la aleta caudal sin densa pigmentación marrón oscura o negra; machos adultos casi siempre sin glándula branquial (raramente presente en 5 de 87 ejemplares examinados)....

G. intermedius

7a. Mancha peduncular extendida más allá de la mitad de la longitud de los radios medios de la aleta caudal; dentículos ausentes sobre los rastrillos branquiales; dientes de la hilera interna premaxilar con cúspides que forman un arco anteriormente cóncavo.

G. venezuelae

7b. Mancha peduncular difusa o alcanzado solo la mitad de la longitud de los radios medios de la aleta caudal; dentículos presentes sobre los rastrillos branquiales; dientes de la hilera interna premaxilar con cúspides alineadas.

8a. Con 41-42 vértebras; machos adultos con densa pigmentación negra o marrón oscura alrededor del origen de la aleta pélvica; ancho mínimo interorbital 27,1-33,7 \% LE; la mancha peduncular difusa o no alcanzando la mitad de la longitud de los radios medios de la aleta caudal.

G. caucanus

8b. Con 39-40 vértebras, machos adultos sin densa pigmentación negra o marrón oscura alrededor del origen de la aleta pélvica; ancho mínimo interorbital 35,3-43,7 \% LE; la mancha peduncular bien desarrollada, más concentrada en los radios medios de la aleta caudal que en el pedúnculo caudal y alcanzando la mitad de la longitud de los radios medios caudales.

G. chocoensis

9a. Sin mancha humeral; músculos interradialis cortos, no sobrepasan el borde 
posterodorsal de la escama-bolsillo de los machos adultos; primer radio ramificado de la aleta pectoral de los machos adultos moderadamente ramificado (nunca constituye una estructura en forma de abanico), sin ganchos óseos y sin una pigmentación marrón oscura o negra

G. valencia

9b. Con mancha humeral; músculos interradialis largos, sobrepasan el borde posterodorsal de la escama-bolsillo de los machos adultos; primer radio ramificado de la aleta pectoral de los machos adultos muy ramificado distalmente en forma de abanico, con ganchos óseos diminutos y con una pigmentación marrón oscura o negra

10a. Con 38-39 vértebras; longitud del hocico 22,1-28,6 \% LC; la escama-bolsillo de los machos adultos alcanza dorsalmente el radio 10 o el área entre los radios caudales 9 y 10; con 28-54 ramificaciones terminales diminutas del radio ramificado lateral de la aleta pectoral en los machos adultos; la extensión de la pigmentación lineal en la región media lateral del cuerpo que alcanza un punto medio del pedúnculo caudal en machos; tres o más paquetes interradialis en el lóbulo ventral de la aleta caudal que se insertan posteriormente más allá del borde posterior de la escama-bolsillo en machos adultos; cuarto infraorbital presente; aleta adiposa presente; adultos con fontanela anterior bien desarrollada o, si los frontales se contactan, no la reducen demasiado

G. melanocheir

10b. Con 40-41 vértebras; longitud del hocico 28,3-31,8 \% LC; la escama-bolsillo de los machos adultos alcanza dorsalmente el radio 11 o el área entre los radios caudales 11 y 12; con 60-88 ramificaciones terminales diminutas del radio ramificado lateral de la aleta pectoral en los machos adultos; la extensión de la pigmentación lineal en la región media lateral del cuerpo que alcanza la base de los radios de la aleta caudal en machos; uno o dos paquetes interradialis en el lóbulo ventral de la aleta caudal que se insertan posteriormente más allá del borde posterior de la escama-bolsillo en machos adultos; cuatro infraorbital frecuentemente ausente o fusionado (más del $60 \%$ de los ejemplares examinados); aleta adiposa por lo general ausente (más del $80 \%$ de los ejemplares examinados) o vestigial; adultos con fontanela anterior reducida o no desarrollada debido al extenso contacto de los frontales anteriormente G. torresi 


\section{Descripciones de las especies}

\section{Gephyrocharax atracaudatus (Meek \& Hildebrand, 1912) \\ Figs. 14, 17, 19 y 22-25, Tablas 1 y 3}

Deuterodon atracaudata Meek \& Hildebrand, 1912: 68 (descripción original sobre un ejemplar, designación material tipo, paratipos no mencionados, holotipo FMNH 7573, localidad tipo: Panamá, Zona del Canal, río Frijoles).

Gephyrocharax atracaudatus Eigenmann, 1914: 41 (nueva combinación género, clave, orth. mut. "atricaudata"). Meek \& Hildebrand, 1916: 226, 229, 231-232 y 277-278 (orth. mut. "atricaudata", clave, datos morfológicos). Eigenmann, 1920b: 15 (lista de peces este de Panamá, orth. mut. "atricaudata"). Eigenmann, 1922: 156 (cita en catálogo y orth. mut. “atricaudata”). Breder, 1925: 144 (río Tapia, Panamá). Breder, 1927: 125 y 144-145, 148-151, 158, 163, 168 (variación de la coloración en juveniles, registros de distribución, clave, orth. mut. "atricaudata" o “atricuadata”). Myers en Eigenmann \& Myers, 1929: 477 y 482-483, lámina 63 fig. 4 (clave, redescripción). Schultz, 1944: 322 (clave). Hildebrand, 1938: 252253 (orth. mut. "atricaudata", lista de caracteres diagnósticos, nuevos datos de distribución). Miller, 1966: 137 (lista de especies primarias). Weitzman \& Fink, 1985: 18, 24, 29 y 96 fig. 17 (orth. mut. “atricaudata" o “atricaudatus", ilustración esqueleto caudal macho, comentarios morfología machos, citado en material examinado). Burns, Weitzman \& Menezes, 1995: 133-138, figs. 1-3 (espermatozoide, inseminación, orth. mut. “atricaudatus"). Bushmann, Burns \& Weitzman, 2002: 189 (glándula branquial). Weitzman, 2003: 224 (cita en catálogo, orth. mut "atracaudata"). Burns \& Weitzman, 2005: 121, fig. 14 (comentarios dimorfismo sexual). Burns, Quagio-Grassiotto, Jamieson, 2009: 329-330, fig. 11.29 (detalles espermatozoides, orth. mut. "atricaudatus"). Ferreira, Menezes \& Quagio-Grassiotto, 2011: 283 y 290 (relaciones filogenéticas, material examinado, orth. mut. "atracaudata"). Oliveira, Abelino, Abe, Mariguela, Benine, Ortí, Vari \& Castro et al., 2011: 16, fig. 12 (relaciones filogenéticas). Tagliacollo, Souza-Lima, Benine \& Oliveira, 2012: 302, fig. 2 (filogenia combinada, ubicación sistemática en Stevardiinae). Bonilla-Rivero \& López-Rojas, 2013: 489, fig. 1 (mapa). Vanegas-Ríos, Azpelicueta, Mirande, Gonzáles, 2013: 281 (material examinado). 
Diagnosis. Gephyrocharax atracaudatus se diferencia de todos sus congéneres por la presencia de pigmentación marrón oscura o negra muy intensa sobre los radios procurrentes dorsales y ventrales y sobre los radios caudales principales 1 a 6 y 14 a 19 (vs. tales radios hialinos, gris claro o amarillentos, nunca intensamente pigmentados de ese color) y (excepto G. intermedius) por el primer radio procurrente ventral muy cóncavo y asociado a una fuerte expansión sagital de la porción posterior del segundo radio procurrente ventral de la aleta caudal en machos adultos ( $v s$. primer radio recto o un poco cóncavo y débilmente asociado a una expansión sagital moderada del segundo radio procurrente ventral). La especie también difiere de sus congéneres (excepto $G$. intermedius y G. major) por carecer de un lóbulo en el margen posterior de la escamabolsillo de los machos adultos (vs. lóbulo presente en tal margen). Gephyrocharax atracaudatus se distingue de G. melanocheir, G. torresi y G. valencia por la presencia del tubo terminal de la línea lateral entre los radios caudales 10 y 11 ( $v s$. ausencia de este tubo). La especie también se diferencia de G. caucanus, G. melanocheir, G. sinuensis, G. valencia y G. venezuelae por la fontanela anterior completamente ocluida por el contacto de los frontales ( $v s$. bien desarrollada o reducida a una pequeña abertura por el contacto anterior de los frontales). Además, G. atracaudatus se distingue de G. chocoensis, G. martae, G. sinuensis y G. torresi por el número de radii en la escama-bolsillo de machos adultos 11-20 (vs. 21-43). La especie se distingue de G. martae, G. melanocheir y G. torresi por la longitud de la glándula branquial en los machos 0,5-3,4 \% LE (vs. 6,0-11,4 $\%$ LE). Gephyrocharax atracaudatus también difiere de G. martae por la distancia hocicoorigen aleta pectoral 23,0-30,1\% LE (vs. 20,7 \% LE) y de G. caucanus por el número de escamas con poros en la línea lateral 36-41 (vs. 42-47), el número de radios ramificados de la aleta anal 24-29 (vs. 29-36) y el número de vértebras 37-39 (vs. 41-42). La especie difiere de G. intermedius por caracteres adicionales descriptos en la diagnosis de esta especie. Véase también la lista de autapomorfías mencionadas para G. atracaudatus.

Descripción. Datos morfométricos en la tabla 3. Macho de mayor tamaño con 48,8 mm LE y hembra de mayor tamaño con 46,2 mm LE. Cuerpo lateralmente comprimido, con altura máxima en la vertical que pasa anterior o por el origen de la aleta pélvica. Perfil dorsal de la cabeza un poco convexo desde el borde del labio superior hasta el extremo posterior del proceso ascendente de la premaxila y recto desde este punto hasta la espina supraoccipital. Perfil dorsal del cuerpo recto o algo convexo desde la región posterior de la 
espina supraoccipital hasta el origen de la aleta dorsal, desciende en sentido posteroventral a lo largo de la base de la aleta dorsal y continúa recto desde el radio dorsal más posterior hasta el pedúnculo caudal (Fig. 22). Perfil ventral del cuerpo convexo desde la punta del hocico hasta un punto situado debajo de la mitad posterior de la aleta pectoral, continúa un poco convexo desde este punto hasta el origen de la aleta anal y asciende posterodorsalmente recto o a veces un poco cóncavo desde el origen anal hasta el inicio del pedúnculo caudal. Fontanela anterior ausente o reducida a una abertura estrecha anterior a la barra epifisaria. Narina anterior redondeada y separada por un pliegue de piel de la narina posterior de mayor tamaño. Hendidura extendida desde un punto medio entre el poro posterior del nasal y las narinas hasta la región posterior de los frontales, con al menos tres hileras de neuromastos. Hendidura más pequeña con pocos neuromastos sobre la región entre las narinas y los huesos nasales.

Aleta dorsal con ii,7 (10), 8* (65) o 9 (1) radios y 9* pterigióforos proximales. Origen de la aleta dorsal en la vertical que pasa por la base de los radios 5 a 10 de la aleta anal. Aleta adiposa presente, su origen al nivel de las bases de los últimos dos o tres radios posteriores de la aleta anal o por un punto posterior al origen de radio anal más posterior. Aleta anal con iv (15), v* (60), vi (1) o vii (1),24 (2), 25* (18), 26 (25), 27 (21), 28 (10) o 29 (1) radios (un ejemplar malformado con v,23 radios no incluido en los conteos) y $26^{*}$ 28 pterigióforos proximales. Origen de la aleta anal más cerca del origen de la unión hipural que de la punta del hocico. Aleta pectoral con i,8 (2), 9 (45), 10 (20) o 11* (4) radios. Aleta pectoral larga, alcanza entre un tercio y un medio de la longitud de la aleta pélvica. Aleta pélvica con i,6* (12) o 7 (59) radios. Origen de la aleta pélvica localizado en la vertical que pasa por las escamas 8 a 10 de la línea lateral y apenas anterior a la mitad del cuerpo. Aleta caudal bilobulada, con 10/9 radios principales en todos los ejemplares.

Hocico superior, con la mandíbula inferior apenas anterior a la punta de la mandíbula superior. Premaxila con dos hileras de dientes; hilera externa con 2 (1), 3 (13), 4* (50), 5 (6) o 6 (1) dientes por lo general tricúspides y raras veces bicúspides. Hilera interna con 4 (58) o $5^{*}$ (13) dientes; el sinfisial tetracúspide y los restantes dientes pentacúspides. Maxila con 1* (38), 2 (28), 3 (4) o 4 (1) dientes; pocas veces bicúspides, por lo general tricúspides a pentacúspides (Figs. 23a-24). Maxila larga, alcanza posteriormente el tercio anterior del ojo. Dentario con 10 (8), 11 (9), 12 (13), 13* (10), 14 (7), 15 (4), 16 (3) o 18 (1) dientes; los tres más anteriores grandes y pentacúspides, seguidos por uno de tamaño mediano casi siempre pentacúspide y 6 (10), 7 (9), 8 (13), $9^{*}$ 
(10), 10 (7), 11 (4), 12 (3) o 14 (1) dientes más pequeños cónicos, tricúspides o tetracúspides que poco a poco disminuyen en tamaño en sentido anteroposterior a lo largo del borde dorsal del dentario, el diente posterior al de tamaño mediano de mayor tamaño y número de cúspides (Fig. 23b).

Escamas cicloides, con pocos a numerosos radii a lo largo del campo posterior. Línea lateral completa (un ejemplar sin poros). Escamas con poros 36 (1), 37* (6), 38 (10), 39 (25), 40 (11) o 41 (3). Tubo terminal de la línea lateral presente. Escamas predorsales 17 (5), 18 (17), 19* (25), 20 (8) o 21 (2). Hileras de escamas entre la aleta dorsal y la línea lateral 6* (46) o 7 (11). Escamas entre la línea lateral y la aleta anal 5* (46) o 6 (11). Escamas entre la línea lateral y la aleta pélvica 4 (5) o 5* (52). Escamas circumpedunculares 14 (3), 15 (17), 16 (34) o 17 (1), escamas perdidas en el holotipo. Una hilera de escamas dispuestas a lo largo de la base de la aleta anal de 12 (1), 13 (4), 14 (5), 15 (5), 16 (2), 17 (5), 18 (3), 19 (1), 20 (22) o 21 (1) escamas. Número total de vértebras $37(3), 38^{*}(4)$ o $39(3), 15^{*}(5)$ o 16 (5) precaudales y 21 (1), 22 (3), 23* (6) caudales (ocho ejemplares radiografiados y dos ejemplares $\mathrm{d} \& \mathrm{t}$ ). Rastrillos branquiales del primer arco branquial 5 (1), 6 (47) o $7^{*}(17)$ sobre la porción dorsal y 11 (13) o 12* (51) sobre la porción ventral.

Coloración en alcohol. Cuerpo de color amarillento pálido o marrón oscuro, más oscuro a lo largo de la línea media dorsal y un poco más claro en la zona ventral. Cromatóforos marrones diminutos cubren el cuerpo, en menor proporción en las regiones lateral y ventral del abdomen y región ventral del pedúnculo caudal. Línea lateral negra extendida desde la región posterior de la mancha humeral hasta la región central o posterior del pedúnculo caudal. Cromatóforos marrones oscuros distribuidos a lo largo de los mioseptos entre la línea lateral y la porción superior de la aleta anal. Mancha humeral marrón oscura o negra, verticalmente alargada. Mancha marrón oscura grande en el pedúnculo caudal, en especial sobre su porción posterior y ligeramente extendida hasta la base de los radios medios de la aleta caudal y los músculos interradialis. Aleta dorsal gris clara, pero algo oscurecida por la presencia de cromatóforos marrones oscuros concentrados en los bordes de los radios y las membranas. Aleta anal gris clara, apenas oscurecida por la presencia de cromatóforos marrones oscuros y negros situados sobre las membranas. Aleta caudal bicoloreada, con los radios medios grises claros o amarillos tenue y provistos de pocos cromatóforos marrones oscuros o negros entre sus membranas y con los radios procurrentes dorsales y ventrales más los radios caudales 1 a 6 y 14 a 19 muy pigmentados con cromatóforos marrones oscuros o negros. Aletas pectoral y pélvica grises claras, con 
cromatóforos marrones oscuros o negros dispersos en los radios. Cabeza más oscura dorsal que ventralmente. Opérculo e infraorbitales con unos pocos cromatóforos marrones distribuidos sobre sus superficies. Premaxila, porción anterior de la maxila, dentario y labios con cromatóforos marrones oscuros muy concentrados. Variaciones en la coloración entre machos y hembras se describen en el dimorfismo sexual.

Dimorfismo sexual. Ejemplares machos, con ganchos óseos en los radios de las aletas anal, caudal y pélvica. Aleta caudal con ganchos cortos, finos y orientados en sentido anterodorsal, en especial sobre las porciones ramificadas dorsales de los radios 13 a 17 (Fig. 25a). Todos los radios de la aleta pélvica con ganchos finos con frecuencia pareados o solo uno por segmento (aunque en las bases de los radios por lo general no pareados y numerosos), sobre todo orientados en sentido anterolateral o anteroventral a lo largo de la porción ramificada de cada radio; a veces reducidos en número en el primer y último radios. Aleta anal con ganchos finos, de base ancha, pareados por segmento y orientados en sentido anterodorsal o anterolateral en los radios; con dos a 32 pares de ganchos localizados en el radio simple más posterior y los primeros diez radios ramificados anteriores (ganchos comparativamente de mayor tamaño en los radios medios de este intervalo). En los machos adultos, el radio simple más posterior y los primeros 14 a 17 radios ramificados de la aleta anal son similares en longitud entre sí y un poco más largos que el resto (aleta de aspecto convexo), mientras que en las hembras los radios disminuyen poco a poco en longitud en sentido anteroposterior (aleta de aspecto recto). Los machos adultos tienen con frecuencia el borde basal de la aleta anal cóncavo en la región media, mientras que las hembras lo tienen recto. Hembras adultas no tienen papila urogenital externamente (Fig. 22).

En los machos la pigmentación de aleta caudal bicolor es apenas diferente de las hembras, debido a que los radios procurrentes segundo y tercero están poco pigmentados. Cromatóforos de la aleta anal un poco más concentrados sobre aquellos radios con ganchos óseos en machos. Machos maduros con una escama modificada para formar un bolsillo en el lóbulo ventral de la aleta caudal y con el segundo y tercer radios procurrentes ventrales modificados en forma de una estructura tipo pinza, ventral al radio principal 19. Tejido de apariencia glandular en poca cantidad, localizado en su mayoría sobre los radios de la aleta caudal y medial a la escama-bolsillo. Estructura tipo pinza osificada de manera incompleta en su porción distal y alcanza la mitad de la longitud del primer radio procurrente ventral (Fig. 25a). Primer radio procurrente ventral con una fuerte concavidad en su porción ventral. Segundo radio procurrente ventral un poco más 
largo que el tercero y muy expandido en el plano sagital, más notable en su porción posterior. Porción posterior del tercer radio procurrente ventral muy desarrollada lateralmente. Escama-bolsillo hipertrofiada, con 11 o 20 radii que por lo general se localizan entre los radios 16 o 17 y el segundo radio procurrente ventral de la aleta caudal. Escama-bolsillo sin lóbulo posteroventral (Figs. 25a, b). Superficie dorsal de la escamabolsillo anclada a través de un tejido blando o conectivo a los radios de la aleta caudal 11 a 14. Borde posterior de la escama-bolsillo localizado entre el radio 14 de la aleta caudal y el segundo radio procurrente ventral. Cuatro escamas en serie vertical, justo debajo de la escama más posterior de la línea lateral, sobre la porción posterior de la escama-bolsillo. La primera escama dorsal de esta serie vertical con su borde dorsal un poco ondulado y en algunos ejemplares con pequeños procesos mediales orientados hacia el borde dorsal de la escama-bolsillo. Borde anterodorsal de la escama-bolsillo por lo general con una pequeña hendidura. Las hembras con una escama grande con 14 (1), 18 (1) o 21 (1) radii.

Machos maduros con glándula branquial corta, casi siempre desarrollada en ejemplares con ganchos óseos en al menos la aleta caudal, pero poco desarrollada en dos ejemplares machos 36,5 mm LE y 44,1 mm LE. Glándula branquial formada por 2 (1), 3 (1), 4 (3), 5 (1), 6 (3), 9 (1), u 11 (1) filamentos branquiales modificados de la porción ventral del primer arco branquial funcional. Número total de filamentos branquiales en la porción ventral 23 (1), 24 (1), 25 (4), 25 (5), 26 (1), 27 (1) o 28 (1). Longitud de la glándula branquial 0,5-3,4\% LE (media $=1,7 \%$ LE).

Distribución. Se encuentra en varios drenajes en el Canal de Panamá y al este del mismo sobre las vertientes Pacífico, Caribe y el Archipiélago Las Perlas en Panamá (Fig. 19).

Notas ecológicas. Kramer (1978) presentó datos sobre la biología reproductiva en poblaciones dentro del sistema del Canal de Panamá; Kramer \& Bryant (1995a, b) datos sobre dieta en poblaciones de la cuenca del río Chagres en Panamá y Zaret \& Rand (1971) datos sobre competencia ecológica de la especie.

Comentarios. El epíteto especifico atracaudata es un sustantivo en aposición, proviene de las palabras atra (latín = oscuro) y cauda (latín = cola de un animal), las cuales denotan la coloración oscura de la aleta caudal. De acuerdo con el ICZN (1999: artículo 31.2 y 34.2), su terminación debe concordar en género gramatical con el nombre del género (tanto Deuterodon como Gephyrocharax son masculinos), por tal razón la grafía correcta es atracaudatus. El holotipo de G. atracaudatus corresponde a una hembra, casi sin escamas sobre el cuerpo y con su coloración perdida o difusa (excepto la coloración bicolor de la aleta caudal), pero con sus aletas y dientes en buena condición. La 
descripción original se hizo sobre este ejemplar, pero Meek \& Hildebrand (1912) no incluyeron diagnosis ni una figura de la especie. Luego, Meek \& Hildebrand (1916) redescribieron la especie con mayor detalle morfológico. Meek \& Hildebrand (1916), Myers (en Eigenmann \& Myers, 1929) y Hildebrand (1938) han usado la pigmentación bicolor de la aleta caudal para distinguir a G. atracaudatus de G. intermedius o G. whaleri y tal carácter ha sido usado hasta la fecha. La presente redescripción adiciona varios caracteres diagnósticos para la especie y apoya la hipótesis inicial sugerida por el carácter de pigmentación mencionado.

Gephyrocharax atracaudatus se confirma por primera vez para el río Palenque, Archipiélago de las Perlas, en la costa del Pacífico de Panamá (STRI 1161) y por lo tanto esta es la segunda especie del género registrada en sistemas hidrográficos insulares (véase G. valencia, Vanegas-Ríos \& Phillip, 2013).

Material examinado. Panamá: AMNH 11233, 4, 24,5-28,3 mm LE, Tapia, río Tapia, aproximadamente $9^{\circ} 5^{\prime} 50,50 " \mathrm{~N} 79^{\circ} 24^{\prime} 52,82^{\prime \prime O} 60$ m s.n.m., 1 Feb. 1924, C. M. Breder. AMNH 11488, 2, 24,8-25,1 mm LE, Darién, boca del río Metiti en río Chucunaque, aproximadamente $8^{\circ} 31^{\prime} 28,41^{\prime \prime N} 77^{\circ} 53{ }^{\prime} 57,15^{\prime \prime O} 34$ m s.n.m., 31 Mar. 1924, C. M. Breder. AMNH 11518, 5, 23,2-28,5 mm LE, Darién, boca del río Membrillo en río Chucunaque, aproximadamente $8^{\circ} 35^{\prime} 25,19^{\prime \prime N} 77^{\circ} 54^{\prime} 57,73$ "O 39 m s.n.m., 1 Abr. 1924, C. M. Breder. AMNH 37808, 20, 29,1-38,2 mm LE, Zona del Canal, quebrada Juan Grande cerca a Gamboa, aproximadamente $9^{\circ} 7^{\prime} 0,00^{\prime \prime N} 79^{\circ} 42^{\prime} 0,00^{\prime \prime O} 39$ m. a. n. m., 4 Ene. 1978, P. C. Rosen et al. AUM 32108, 10, 30,4-45,6 mm LE, Colón, Vertiente Caribe, sistema río Chagres, río Frijoles, carretera Pipeline a 4,6 km, 99'8,35"N 79²44'5,28"O 68 m s.n.m., 8 Ene. 2001, J. W. Armbruster, J. D., D. C. Evans, T. P. Werneke \& R. G. Pera. AUM 31666 , 8, 22,6-39,4 mm LE, Vertiente Pacífico, sistema río Chepo (Bayano), río Cañita, $27 \mathrm{~km}$ ENE Chepo sobre la carretera Pan Americana, 9¹3'7,72"N 7850'41,09"O 38 m s.n.m., 7 Ene. 2001, J. W. Armbruster, J. D. Evans, D. C. Werneke \& T. P. Pera. FMNH 7573, holotipo Deuterodon atracaudatus Meek \& Hildebrand, 1912, 39,7 mm LE (R), hembra, Frijoles, Zona del Canal, río Frijoles, aproximadamente 99'8,35"N 79²4'5,28"O $68 \mathrm{~m}$ s.n.m., 13 Feb. 1911, S. E. Meek \& S. F. Hildebrand. INHS 68120, 19, 24,0-42,8 mm LE, Colón, sistema río Chagres, río Frijoles (d), Parque Nacional Soberanía, aproximadamente 94'27,47"N 79³9'35,31"O 90 m. a. n. m., Mar-Abr. 1979, J. R. Karr \& Angermeier. LACM 56197-005, 4, 19,6-32,1 mm LE, rio Cardenas, en el puente y arriba del Fuerte Clayton, 90'18,72"N 79³4'12,00"O 26 m. a. n. m., 18 Jul. 2003, M. Hardman, R. Belancus \& G. Reina. MCZ 32827*, 2, 21,2-24,1 mm LE (2R), Darién, río Jesusito, 
aproximadamente $7^{\circ} 59^{\prime} 28,82^{\prime \prime N} 78^{\circ} 17^{\prime 26,17 " O, ~} 49$ m s.n.m., Mar. 1922, T. Barbour \& W. S. Brooks. MCZ 32828*, 1, 42,2 mm LE (R), Darién, río Esnape, posible tributario del río Taimati, aproximadamente $8^{\circ} 9^{\prime} 0,00^{\prime \prime} \mathrm{N} 78^{\circ} 13^{\prime} 59,79 " \mathrm{O}, 14$ m s.n.m., 1922, T. Barbour \& W. S. Brooks. MCZ 57071*, 1, 34,4 mm LE (R), en Culvert $11 \mathrm{~km}$ del puente de Bayano en la carretera Panamericana, pequeña quebrada seca, aproximadamente $9^{\circ} 9^{\prime} 21,88^{\prime \prime} \mathrm{N}$ 7841'47,50"O, 86 m s.n.m., 31 Mar. 1978. MCZ 57072*, 1, 38,0 mm LE (R), drenaje Bayano, tributario del río Cañita, pequeño tributario del cauce principal del lado izquierdo cerca de $0,75 \mathrm{~km}$ río arriba del puente sobre la carretera Panamericana cerca del campamento y cuarteles de construcción, aproximadamente $9^{\circ} 12^{\prime} 36,80^{\prime \prime} \mathrm{N} 78^{\circ} 50 ' 55,96^{\prime \prime} \mathrm{O}$ 35 m s.n.m., 1 Abr. 1978, W. L. Fink \& K. E. Hartel. MCZ 57070*, 1, 29,6 mm LE (R), drenaje Bayano, una pequeña quebrada cerca de $3 \mathrm{~km}$ al oeste de el Llano sobre la carretera entre el Chepo y el Llano, aproximadamente 9¹3'9,54"N 7859'56,05"O 29 m s.n.m., 22 Mar. 1978, W. L. Fink \& K. E. Hartel. MCZ 57073*, 1, 30,4 mm LE (R), posible río Parti (sistema Bayano), salida carretera Panamericana cerca de $30 \mathrm{~km}$ este del puente Bayano, aproximadamente $9^{\circ} 3^{\prime} 16,16^{\prime \prime N} 78^{\circ} 39^{\prime} 19,81^{\prime \prime O} 107$ m s.n.m., 31 Mar. 1978, W. L. Fink \& K. E. Harstel. STRI 1161, 1, 35,7 mm LE, Archipiélago de las Perlas, río Palenque, 8²0'27"N 7855'36"O 23 m s.n.m., 12 Mar. 1994, sin datos. STRI 1168, 2 , 37,7-37,8 mm LE, Darién, cuenca del río Tuira, río Yape, 806'8,41"N 77³31'9,82"O 126 m s.n.m., 25 Mar. 1995, sin datos. STRI 1174, 2, 28,9-29,0 mm LE, Darién, sistema del río Tuira, río Membrillo a 1,5 horas arriba del Sinai, $8^{\circ} 37^{\prime} 33$ "N 77²49'01"O $41 \mathrm{~m}$ a. n. m, sin datos. STRI 1178, 2, 37,7-39,6 mm LE, cuenca del río Chagres, Cerro Azul, río Indio, 9¹1'5,61"N 79²6'6,08"O 482 m a. n m., 22 Ene. 1998, sin datos. STRI 1185, 2, 38,841,2 mm LE, cuenca del río Bayano, río Mamoni, 9¹2'59"N 7904'59"O 43 m s.n.m., 4 Jul. 1999, sin datos. STRI 1190, 2, 40,3-41,2 mm LE, cuenca del río Bayano, quebrada en río Aguas Claras, 9¹6'25,7"N 7840'52,8"O 104 m. a. n. m., 17 Feb. 2000, sin datos. STRI 7228, 2 (d\&t), 43,5-44,1 mm LE, Colon, río Chagres, 9²1'36,3"N 79²19'20,1"O 328 m. a. n. m., 1 Mar. 2002, sin datos. USNM 226469, 2, 40,0-43,0 mm LE, Zona del Canal, cuenca del río Chagres, quebrada Juan Grande Pipelina Road aproximadamente 97'42,62"N 7942'55,06"O 66 m a. n. m, 25 Jun. 1979, D. Kramer. USNM 226470, 7 (d\&t), 28,4-48,8 mm LE, Zona del Canal, cuenca del río Chagres, quebrada Juan Grande Pipelina Road aproximadamente 9²'42,62"N 7942'55,06"O 66 m a. n. m, 25 Jun. 1979, D. Kramer. USNM 236086*, 1 (d\&t), 47,4 mm LE, quebrada por la carretera, 8 millas al norte de Cerro Azul, 9¹1'60,00"N 79²6'60,00"O, 397 m a. n. m, 27 Ago. 1962, H. Ldetin \& W. Kosan. 


\section{Gephyrocharax caucanus Eigenmann, 1912}

Figs. 4b, 14, 17,19, 24 y 26-28, Tablas 1 y 4

Gephyrocharax caucanus Eigenmann, 1912: 24 (descripción original, designación material tipo, holotipo FMNH 56012 [antes CM 4802], localidad tipo: Cartago). Eigenmann, 1914: 41 (lista y clave). Eigenmann, 1920c: 32 (lista de peces cuenca río Magdalena). Eigenmann, 1922: 155 (cita en catálogo). Myers en Eigenmann \& Myers, 1929: 477 y 481-482, lámina 63, fig. 2 y lámina 88 figs. 4 y 5 (clave, redescripción). Schultz, 1944: 323 (clave). Miles, 1947: 156, fig. 107 (lista de peces río Magdalena y clave). Dahl, 1971: 134 (clave). Géry 1977: 351-352, foto (coloración en vida). Miles, 1973: 52-53, fig. 31 (comentarios taxonómicos). Mojica, 1999: 557 (lista de peces de Colombia, compilación de datos). Weitzman, 2003: 224 (cita en catálogo). Maldonado-Ocampo, Ortega-Lara, Usma, Galvis, Villa-Navarro, Vásquez, Prada-Pedreros \& Ardila, 2005: 89, fig. 92 (lista de peces andinos de Colombia, datos ecológicos y morfológicos). Ortega-Lara, Usma, Bonilla \& Santos, 2006: 47 (lista cuenca alta río Cauca). Maldonado-Ocampo, Vari \& Usma, 2008: 180 (lista de peces de Colombia). Arai, 2011: 82: (cromosomas: 2n = 52). Álvarez-León, Orozco-Rey, Páramo-Fonseca \& Restrepo-Santamaría, 2013: 101 (lista de peces vivientes y fósiles de Colombia). Bonilla-Rivero \& LópezRojas, 2013: 489, fig. 1 (mapa). Vanegas-Ríos, Azpelicueta, Mirande \& Gonzales, 2013: 282 (material examinado).

Diagnosis. Gephyrocharax caucanus se diferencia de sus congéneres (excepto $G$. sinuensis y G. valencia) por la densa pigmentación negra o marrón oscura alrededor del origen de la aleta pélvica en machos adultos (vs. tal área desprovista de pigmentación o solo con cromatóforos dispersos) y (excepto G. chocoensis, G. martae y G. valencia) por la ausencia de mancha humeral (vs. presencia de tal mancha). La especie difiere de $G$. sinuensis y G. valencia por el tipo de pigmentación alrededor de la aleta pélvica, la cual está muy concentrada lateral y ventralmente desde el origen de la aleta anal, atraviesa el área pélvica y alcanza un punto medio debajo de la aleta pectoral ( $v s$. tal pigmentación más concentrada ventralmente, anterior y alrededor del origen de dicha aleta). Gephyrocharax caucanus también difiere de G. sinuensis por el número de radios ramificados de la aleta anal 29-36 (vs. 22-28), la longitud de la aleta pélvica en los machos 
12,2-16,1 \% LE (vs. 17,1-26,8 \% LE), la longitud de la aleta anal en los machos 13,2-17,8 \% LE (vs. 17,6-22,4 \% LE), el extremo anterior del hueso pélvico situado posterior a la sexta costilla pleural ( $v s$. situado anterior a la sexta costilla pleural) y por la ausencia de papila urogenital externa en las hembras adultas ( $v s$. bien desarrollada externamente). Gephyrocharax caucanus se distingue de G. melanocheir, G. torresi y G. valencia por la presencia del tubo terminal de la línea lateral entre los radios caudales 10 y 11 (vs. ausencia de este tubo). Además, la especie también difiere de G. torresi y G. valencia por la presencia de rinosfenoides (vs. ausencia de tal hueso) y de G. chocoensis, $G$. intermedius, G. martae, G. melanocheir, G. torresi y G. venezuelae por el ancho mínimo interorbital 27,1-33,7 \% LC (34,0-43,7 \% LC). La especie se distingue de G. martae por el número de radios ramificados de la aleta anal 29-36 (vs. 28), el número de escamas con poros en la línea lateral 42-47 (vs. 40), distancia hocico-origen aleta pectoral 22,8-27,9 \% LE ( $v s .20,7 \%$ LE), la longitud de la aleta dorsal 14,7-20,6 \% LE ( $v s .22,6 \%$ LE), la longitud de la base de la aleta dorsal 7,3-9,9 \% LE ( vs. 12,8 \% LE), la longitud de la aleta anal 13,2-19,2 \% LE (61,6 \% LE) y la longitud de la mandíbula superior 37,5-42,8 \% LC (46,2 \% LC). Gephyrocharax caucanus también difiere de G. intermedius por la altura del cuerpo en el origen del aleta dorsal 20,5-28,3 \% LE ( $v s .28,4-38,0 \%$ LE) y el número de vértebras 41-42 (vs. 37-39). Caracteres adicionales que distinguen a G. caucanus de G. atracaudatus fueron mencionados en la diagnosis de esta última. Véase también la lista de autapomorfías mencionada para G. caucanus.

Descripción. Datos morfométricos en la tabla 4. Macho de mayor tamaño con 44,8 mm LE, hembra de mayor tamaño con 50,2 mm LE. Cuerpo lateralmente comprimido, con altura máxima sobre la vertical que pasa por un punto en el origen de la aleta anal o un punto entre este origen y el origen de la aleta pélvica. Perfil dorsal de la cabeza recto desde el borde del labio superior hasta la espina supraoccipital. Perfil dorsal del cuerpo recto o un poco convexo desde la región posterior de la espina supraoccipital hasta el origen de la aleta dorsal, desciende en sentido posteroventral a lo largo de la base de la aleta dorsal y continúa recto desde el radio dorsal más posterior hasta el pedúnculo caudal (Fig. 26). Perfil ventral del cuerpo convexo desde la punta del hocico hasta el origen de la aleta pélvica, continúa recto o un poco convexo entre los orígenes de las aletas pélvica y anal y asciende posterodorsalmente recto o a veces curvado desde el origen anal hasta el inicio del pedúnculo caudal. Fontanela anterior casi siempre reducida a una abertura estrecha anterior a la barra epifisaria y un poco más desarrollada en uno o dos ejemplares 
adultos (aunque los frontales contactan entre sí). Narina anterior redondeada y separada por un pliegue de piel de la narina posterior de mayor tamaño. Hendidura extendida desde un punto medio entre el poro posterior del nasal y las narinas hasta la región posterior de los frontales, con al menos tres hileras de neuromastos. Hendidura más pequeña con pocos neuromastos sobre la región entre las narinas y los huesos nasales.

Aleta dorsal con ii,7 (1) u 8* (59) radios y 9* pterigióforos proximales. Origen de la aleta dorsal en la vertical que pasa por la base de los radios 9 a 14 de la aleta anal. Aleta adiposa presente, su origen al nivel de las bases de los últimos dos o tres radios posteriores de la aleta anal. Aleta anal con iii (1), iv* (33), v (26) o vi (1),29 (1), 30 (4), 31 (10), 32 (13), 33 (16), 34* (12), 35 (4) o 36 (1) radios (Figs. 24b) y 32-35* pterigióforos proximales. Origen de la aleta anal más cerca del origen de la unión hipural que de la punta del hocico. Aleta pectoral con i,8 (7), 9 (45) o 10* (7) radios. Aleta pectoral larga, alcanza entre un cuarto y un medio de la longitud de la aleta pélvica. Aleta pélvica con i,6 radios en todos los ejemplares examinados (un ejemplar atípico con i,9). Origen de la aleta pélvica localizado en la vertical que pasa por las escamas 9 a 10 de la línea lateral y apenas anterior a la mitad del cuerpo. Aleta caudal bilobulada con 10/9 radios principales en todos los ejemplares.

Hocico superior, con la mandíbula inferior anterior a la punta de la mandíbula superior. Premaxila con dos hileras de dientes; hilera externa con 2 (3), 3* (50) o 4 (6) dientes, por lo general tricúspides y raras veces bicúspides. Hilera interna con $4 *$ (58) o 5 (4) dientes; el sinfisial tricúspide a tetracúspide, los demás tricúspides a pentacúspides y a veces el más posterior cónico. Maxila sin dientes* (5), con 1 (53) o 2 (1) dientes cónicos, bicúspides o tricúspides en todos los ejemplares (Fig. 27a). Maxila larga, alcanza posteriormente el tercio anterior del ojo. Dentario con 8 (1), 9 (1), 10 (18), 11 (8), 12 (3), 13 (6) o 14 (1) dientes; los tres anteriores grandes y pentacúspides, seguidos por uno de tamaño mediano por lo general tricúspide y rara vez tetracúspide y 4 (1), 5 (1), 6 (18), 7 (8), 8 (3), 9 (6) o 10 (1) dientes más pequeños cónicos, raras veces bicúspides o tricúspides, con tamaños aproximadamente similares entre sí, pero poco a poco disminuyen en tamaño en sentido anteroposterior a lo largo del borde dorsal del dentario (Fig. 27b).

Escamas cicloides, con pocos o numerosos radii a lo largo del campo posterior. Línea lateral completa. Escamas con poros 42 (7), 43* (28), 44 (15), 45 (8), 46 (2) o 47 (1). Tubo terminal de la línea lateral presente. Escamas predorsales 20 (5), 21* (19), 22 (29) o 23 (8). Hileras de escamas entre la aleta dorsal y la línea lateral 4 (1), 5* (49) o 6 
(9). Hileras de escamas entre la línea lateral y la aleta anal 4 (6), $5^{*}(52)$ o 6 (1). Hileras de escamas entre la línea lateral y la aleta pélvica 3 (1), 4* (52) o 5 (6). Escamas circumpedunculares $12(3), 13(24), 14 *(22)$ o 15 (1). Con poca frecuencia una y casi siempre dos hileras de escamas dispuestas a lo largo de la base de la aleta anal; la hilera principal ventral compuesta por 8 (1), 14 (1), 15 (3), 16 (2), 17 (12), 18 (7), 19 (3), 20 (4) o 21 (2) escamas. Número total de vértebras 41 (3) o 42* (7), 16* (10) precaudales y 25 (3) o 26* (7) caudales (seis ejemplares radiografiados y cuatro ejemplares d\&t). Rastrillos branquiales del primer arco branquial 6 (14) o $7 *$ (35) sobre la porción dorsal y 12 (15), 13 (27), 14* (6) o 15 (1) sobre la porción ventral.

Coloración en alcohol. Cuerpo amarillento pálido, más oscuro en la línea media dorsal y un poco más claro en la zona ventral e incluso en algunos ejemplares (e. g. IMCN 4834) la zona lateral del abdomen es más clara y con iridiscencia plateada. Cromatóforos marrones oscuros y/o negros diminutos cubren el cuerpo, en menor proporción en las regiones lateral y ventral del abdomen y región ventral del pedúnculo caudal. Banda lateral negra, marrón oscura o plateada extendida desde un punto dorsal al nivel del origen de la aleta pélvica o incluso la región humeral hasta el pedúnculo caudal. Cromatóforos marrones oscuros, algo dispersos, distribuidos a lo largo de los mioseptos entre la línea lateral y la porción superior de la aleta anal. Mancha humeral ausente o no diferenciada de la banda lateral de cromatóforos. Mancha difusa en el pedúnculo caudal, con similar coloración a la banda lateral de cromatóforos, por lo general no diferenciada de esta banda y extendida hasta los músculos interradialis. Aleta dorsal gris clara, con cromatóforos marrones oscuros o negros poco concentrados a lo largo de los radios y las membranas. Aleta anal gris clara, con cromatóforos marrones oscuros o negros poco concentrados a lo largo de los radios y/o las membranas. Aleta caudal gris clara, con cromatóforos marrones oscuros o negros poco concentrados a lo largo de los radios. Aletas pectoral y pélvica grises claras, con cromatóforos marrones oscuros o negros poco concentrados en los radios y/o las membranas. Cabeza más oscura dorsal que ventralmente, algunos ejemplares con una fuerte pigmentación negra en su región posterodorsal (e. g. IMCN 4834). Cromatóforos ausentes o reducidos en número sobre el opérculo y los infraorbitales. Premaxila, porción anterior de la maxila, dentario y labios con cromatóforos marrones oscuros o negros muy concentrados. Variaciones en la coloración entre machos y hembras se describen en el dimorfismo sexual.

Coloración en vivo. Tomada sobre los ejemplares IMCN 4834. Cuerpo con el perfil dorsal dorado y amarillento. Banda lateral plateada desde la región posterior del opérculo 
hasta el pedúnculo caudal. Regiones lateroventral y dorsolateral a la banda lateral con una tonalidad brillante plateada y amarillenta, respectivamente. Mancha humeral ausente o difusa (pocos cromatóforos verdosos muy dispersos). Mancha del pedúnculo caudal ausente o muy poco diferenciada de la banda lateral de cromatóforos. Aleta dorsal hialina, con una pequeña pigmentación naranja en las puntas de sus radios. Aleta adiposa rojiza o naranjada. Aleta anal hialina, algunos ejemplares con pintas rojas o negras en los primeros radios anales. Aleta caudal en su mayoría hialina, pero amarillenta en la base y anaranjada o grisácea en los lóbulos. Aleta adiposa rojiza o naranjada. Aletas pectoral y pélvica hialinas, pero la primera con una leve pigmentación naranja en las puntas de sus radios. Cabeza amarillenta dorsalmente, con algunas iridiscencias metálicas verdosas. Premaxila, porción anterior de la maxila, dentario y labios (en especial la mandíbula inferior) con una pigmentación negra muy fuerte y cierta iridiscencia dorada. Variaciones de coloración entre machos y hembras se describen en el dimorfismo sexual.

Dimorfismo sexual. Ejemplares machos con ganchos óseos en los radios de las aletas anal, caudal y pélvica. Aleta caudal con ganchos cortos, finos y orientados en sentido anterodorsal, en especial sobre las porciones ramificadas dorsales de los radios 15 a 18 (Fig. 28a). Todos los radios de la aleta pélvica, excepto el primero y último radios, con ganchos finos pareados o uno por segmento (aunque en las bases de los radios por lo general no pareados y numerosos) y sobre todo orientados en sentido anterolateral o anteroventral a lo largo de la porción ramificada de cada radio. Aleta anal con ganchos finos, de base ancha, pareados por segmento y orientados en sentido anterodorsal o anterolateral sobre los radios; con uno a 18 pares de ganchos localizados sobre el radio simple más posterior y los primeros nueve radios ramificados anteriores (ganchos comparativamente más largos en los radios medios de este intervalo). En los machos adultos, los radios medios de la aleta anal son un poco más largos que el resto (aleta de aspecto convexo), mientras que en las hembras los radios anales disminuyen en longitud poco a poco en sentido anteroposterior (aleta de aspecto recto o algo cóncavo). Los machos adultos con frecuencia tienen el borde basal de la aleta anal un poco cóncavo o algo curvado, mientras que las hembras lo tienen recto. Hembras adultas no tienen papila urogenital externamente.

La región posterior de la banda lateral y/o la difusa mancha del pedúnculo de los machos (en vida y en ejemplares en alcohol), a diferencia de las hembras, es dispersa y más clara en la porción inferior del pedúnculo caudal. Los machos maduros en vida y en alcohol difieren de las hembras por una pigmentación negra (permanece este color en los 
ejemplares en alcohol), rojiza o rojiza oscura alrededor de las zonas anterior y posterior al origen de la aleta pélvica y en especial sobre la zona ventral del poro urogenital (no se observó esta mancha en dos ejemplares machos maduros y excepcionalmente se observó en un ejemplar hembra una pigmentación parecida a la de los machos) (Fig. 26b). Machos maduros con una escama modificada para formar un bolsillo sobre el lóbulo ventral de la aleta caudal y con el segundo y tercer radios procurrentes ventrales modificados en forma de una estructura tipo pinza, ventral al radio principal 19. Tejido de apariencia glandular en poca cantidad, localizado en su mayoría sobre los radios de la aleta caudal y medial a la escama-bolsillo. Estructura tipo pinza osificada de manera incompleta en su porción distal y alcanza la mitad de la longitud del primer radio procurrente ventral (Fig. 28a). Primer radio procurrente ventral con una moderada concavidad en su porción ventral. Segundo radio procurrente ventral un poco más largo que el tercero y poco expandido en el plano sagital, más notable en su porción posterior. Porción posterior del tercer radio procurrente poco desarrollada lateralmente. Escama-bolsillo hipertrofiada, con 20 a 27 radii que por lo general se localizan entre los radios 15 o 16 y el tercer radio procurrente ventral de la aleta caudal. Escama-bolsillo con un lóbulo posteroventral extendido a lo largo del tercer radio procurrente ventral (Figs. 28a, b). Superficie dorsal de la escama-bolsillo anclada a través de un tejido blando o conectivo a los radios de la aleta caudal 11 o 12 a 15 . Borde posterior de la escama-bolsillo localizado entre los radios 14 o 15 de la aleta caudal y el tercer radio procurrente ventral. Cuatro escamas en serie vertical, justo debajo de la escama más posterior de la línea lateral, sobre la porción posterior de la escama-bolsillo. Borde dorsal de la escama-bolsillo por lo general con una pequeña hendidura. Las hembras con una escama grande con 15 (1), 16 (1), 17 (2), 18 (1), 19 (1), 20 (1), 22 (1) o 27 (1) radii.

Machos maduros con glándula branquial corta. Glándula branquial formada por 8 (1), 9 (3), 10 (6), 11 (5), 12 (5) o 15 filamentos branquiales modificados de la porción ventral del primer arco branquial funcional. Número total de filamentos branquiales en la porción ventral 17 (1), 18 (1), 19 (1), 20 (4), 21 (6), 22 (5), 23 (1), 24 (1) o 26 (1). Longitud de la glándula branquial 2,7-5,4 \% LE (media = 4,1 \% LE).

Distribución. Se encuentra en diferentes localidades dentro del sistema del alto río Cauca, cuenca del río Magdalena en Colombia (Fig. 19).

Comentarios. Parte de la localidad tipo G. caucanus se asignó revisando la información dada por Eigenmann (1912: 7-8) en sus itinerarios de expedición en el Valle del Cauca. En la descripción de Eigenmann (1912) no fue especificada la localidad precisa donde se 
pescaron los ejemplares usados para validar la especie. Eigenmann (1912: 9) informó las coordenadas geográficas de su viaje de campo en la ciudad de Cartago, sin embargo, no se pudo encontrar ningún dato concluyente para atribuir una localidad a un río o quebrada. La conclusión obtenida indica que la localidad tipo de la especie esta en algún punto dentro del sistema del alto río Cauca, en los alrededores de Cartago. Los ejemplares IMCN 4296, 4302 y 4323 fueron identificados como Gephyrocharax caucanus, pero los datos de localidad de estos corresponden con la cuenca del río Calima, vertiente Pacífico en Colombia. Los resultados de la presente revisión sugieren que estos registros son incorrectos y se cree que la especie fue introducida artificialmente por el hombre en el Lago Calima (Armando Ortega-Lara, comun. pers.). Los registros de estos ejemplares no se incluyeron en la presente revisión, pero se adicionaron sus datos morfológicos para incrementar la variación.

En una hembra de G. caucanus con 48,5 mm LE (MCZ 35872), se observó la papilla urogenital muy desarrollada sobre la región urogenital, pero muy poco proyectada externamente al tejido circundante del poro urogenital, y por esta razón se consideró como no externamente desarrollada.

Material examinado. Colombia: CAS 44275 (antes IU 12668a-j), 10 paratipos, 44,550,0 $\mathrm{mm}$ LE, [Valle del Cauca, río La Vieja, aproximadamente 445'12,00"N 7552'30,00"O 993 m s.n.m.], cuenca del río Magdalena, cuenca del río Cauca, Cartago en río Viejo, a seis millas desde el río Cauca, 22 a 23 Feb. 1912, C. H. Eigenmann. CAS 44276* (antes IU 12669a-e), 1 paratipo, 50,2 mm LE, [Valle del Cauca, aproximadamente $4^{\circ} 18^{\prime} 44,73^{\prime \prime N} 76^{\circ} 3^{\prime} 17,55^{\prime \prime O} 959$ m s.n.m.], cuenca del río Magdalena, río La Paila en río Cauca, La Paila a 31,25 millas arriba del río desde Cartago, 22 a 23 Feb. 1912, C. H. Eigenmann. CZUT-IC 1118, 4 de 10, 33,10-39,68 mm LE, Cauca, cuenca río Cauca, quebrada Silletero antes de Santander de Quilichao, aproximadamente $3^{\circ} 5^{\prime} 27,85^{\prime \prime N}$ 76²8'15,29"O 992 m. a. n. m., 10 Feb. 2004, A. Ortega-Lara. FMNH 56012* (antes CM 4803a-j en parte), holotipo Gephyrocharax caucanus Eigenmann, 1912, 64,4 mm LE (R), hembra, [Valle del Cauca, sistema alto río Cauca, aproximadamente $4^{\circ} 45^{\prime} 12,00^{\prime \prime} \mathrm{N}$ 7552'30,00"O 993 m s.n.m.] Cartago, 22 a 23 Feb. 1912, C. H. Eigenmann. IAvH-P 3701, 4, Cauca, quebrada Silletero puente sobre vía Cali-Santander de Quilichao, aproximadamente $3^{\circ} 5^{\prime} 12,97 " \mathrm{~N} 76^{\circ} 28^{\prime} 20,71$ "O 992 m s.n.m., 10 Feb. 2004, A. OrtegaLara. IMCN 111, 4, 20,8-38,2 mm LE, Cauca, Timba, alto río Cauca, Parte media Zangón bagazal, aproximadamente $3^{\circ} 6^{\prime 25,00 " N ~ 76^{\circ} 32 ' 27,00 " O} 977$ m s.n.m., 16 Ene. 1998, P. Lehmann \& C. Román-Valencia. IMCN 2260, 19, 18,77-40,66 mm LE (2 d\&t 40,7-34,2 
mm LE), Cauca, quebrada Silletero antes de Santander de Quilichao, aproximadamente 35'8,91"N 76²8'21,39"O 992 m s.n.m., 10 Feb. 2004, A. Ortega-Lara. IMCN 3084, 10, 32,05-39,83 mm LE (2 d\&t 34,0-40,0 mm LE), Valle del Cauca, Jamundí, sistema río Cauca, río Jamundí, aproximadamente $3^{\circ} 16^{\prime} 57,38^{\prime \prime N ~ 76 ³ 2 ' 20,90 " O ~} 969$ m. a. n. m., 25 Jul. 1999, G. E. Murillo, A. Ortega-Lara \& M. C. Pimienta. IMCN 3183, 4, 34,6-41,8 mm LE, Risaralda, La Virginia, río Cauca, aproximadamente 453'22,68"N 7552'41,67"O 901 m s.n.m., 5 Jun. 1999, G. E. Murillo, A. Ortega-Lara \& M. C. Pimienta. IMCN 3407, 3, 37,9-41,1 mm LE, Risaralda, La Virginia, río Cauca antes de la confluencia con río Risaralda, aproximadamente 453'29,99"N 7553'22,76"O 896 m s.n.m., 26 Feb. 2005, A. Ortega-Lara. IMCN 4296, 3, 16,4-18,4 mm LE, Valle del Cauca, Calima, Darién, Lago Calima en el muro de la represa (ejemplares introducidos artificialmente), 6 Ene. 2009, W. Aguar. IMCN 4302, 1, 39,0 mm LE, Valle del Cauca, Calima, Darién, Lago Calima en el muro de la represa (ejemplares introducidos artificialmente), 29 Dic. 2008, W. Aguar \& P. Bonilla. IMCN 4323, 1, 37,6 mm LE, Valle del Cauca, Calima, Darién, Lago Calima en el muro de la represa (ejemplares introducidos artificialmente), 26 Mar. 2009, W. Aguar \& P Bonilla. IMCN 4834, 9, 23,0-41,9 mm LE, Cauca, alto río Cauca, quebrada Silleteros en la carretera a Santander de Quilichao y a $200 \mathrm{~m}$ del club los Andes, aproximadamente 34'50,31"N 76²8'31,21"O 992 m s.n.m., 31 Ene. 2012, J. A. Vanegas-Ríos, G. C. Sánchez \& A. Ortega-Lara. MCZ 35811*, 1, 44,8 mm LE (R), Valle del Cauca, cuenca del río Cauca, río La Paila, aproximadamente 4²19'15,30"N 76³'48,92"O 960 m s.n.m., Oct. 1042, C. Miles. MCZ 35872*, 1, 48,5 mm LE (R), Valle del Cauca, tributario alto río Cauca, 4 Mar. 1943, C. Miles. USNM 81921 (posiblemente CM 4809a-j en parte), 3 paratipos, 42,6-49,1 mm LE, [Valle del Cauca, sistema alto río Cauca, Cartago, aproximadamente $4^{\circ} 45^{\prime} 12,00^{\prime \prime} \mathrm{N} 75^{\circ} 52^{\prime} 30,00 " \mathrm{O} 993$ m s.n.m.] Carbago, 22 a 23 Feb. 1912, C. H. Eigenmann. 
Gephyrocharax chocoensis Eigenmann, 1912: 23-24 (designación como tipo del género, descripción original, designación material tipo, holotipo FMNH 56016 [CM 4806], localidad tipo: Istmina). Eigenmann, 1914: 41 (lista y clave). Meek \& Hildebrand, 1916: 289 (comparación con G. intermedius). Eigenmann, 1922: 155 (cita en catálogo, orth. mut. "chocöensis”). Pearson, 1924: 46 (distribución incorrecta para el río Beni, orth. mut. “chocöensis"). Myers en Eigenmann \& Myers, 1929: 477479, lámina 53, fig. 1 y lámina 97 fig. 3 (clave, redescripción). Schultz, 1944: 323 (clave). Fowler, 1945: 6 (error de distribución Honda, Magdalena). Weitzman \& Fink, 1985: 103 (material examinado). Román-Valencia, 1990: 206, (lista de peces del río Atrato). Román-Valencia \& Acero, 1992: 122, tabla 5 (río Sucio y río León, Antioquia, Colombia, erróneamente identificado como Gephyrocharax cf. sinuensis). Burns, Weitzman \& Menezes, 1995: 133-135 (espermatozoide, inseminación). Mojica, 1999: 557 (lista de peces de Colombia, compilación de datos). Bushmann, Burns \& Weitzman, 2002: 189 (glándula branquial). Weitzman, 2003: 224 (cita en catálogo). Mojica, Usma \& Galvis, 2004: (lista de peces del Chocó, cita río Baudó sin material examinado). Maldonado-Ocampo, Ortega-Lara, Usma, Galvis, Villa-Navarro, Vásquez, Prada-Pedreros, Jaramillo \& Ardila, 2005: (lista de peces andinos de Colombia). Maldonado-Ocampo, Villa-Navarro, OrtegaLara, Prada-Pedreros, Jaramillo, Claro, Usma, Rivas, Chaverra, Cuesta \& GarcíaMelo, 2006: 149 (lista de peces cuenca río Atrato). Maldonado-Ocampo, Vari \& Usma, 2008: 180 (lista de peces de Colombia). Maldonado-Ocampo, Usma, VillaNavarro, Ortega-Lara, Prada-Pedreros, Jaramillo, Claro, Arango, Rivas \& Sánchez, 2012: 28 y 145-146, (lista de peces Chocó, foto coloración en vivo, cita río Baudó sin material examinado). Álvarez-León, Orozco-Rey, Páramo-Fonseca \& RestrepoSantamaría, 2013: 101 (lista de peces vivientes y fósiles de Colombia). BonillaRivero \& López-Rojas, 2013: 489, fig. 1 (mapa). Vanegas-Ríos, Azpelicueta, Mirande \& Gonzales, 2013: 282 (material examinado).

Diagnosis. Gephyrocharax chocoensis difiere de sus congéneres (excepto G. major) por presentar la sección más posterior de la musculatura hypaxialis y epaxialis bien desarrollada y extendida lateralmente sobre el flexor ventralis en machos adultos ( $v s$. esta sección reducida, no cubre completamente la región posterior del flexor ventralis) y (excepto G. major y G. valencia) por la porción distal del cuarto radio procurrente ventral de la aleta caudal no comprimida sagitalmente ni curvada en machos adultos ( $v s$. tal 
porción muy comprimida sagitalmente y un poco curvada). Gephyrocharax chocoensis también se diferencia de todos sus congéneres (excepto $G$. sinuensis, $G$. martae y $G$. venezuelae) por la posición y extensión de la mancha peduncular, la cual está más concentrada sobre los radios medios de la aleta caudal que sobre el pedúnculo caudal y alcanza la mitad de la longitud de los radios medios caudales (vs. tal mancha más concentrada sobre el pedúnculo caudal que sobre los radios caudales y sin alcanzar la mitad de la longitud de éstos) y el borde dorsal de la escama-bolsillo en machos adultos que supera dorsalmente al radio 12 de la aleta caudal ( $v s$. este borde es ventral al radio 12 de la aleta caudal). Gephyrocharax chocoensis se distingue de G. atracaudatus, G. intermedius y G. major por presentar un lóbulo sobre el margen posterior de la escamabolsillo de los machos adultos (vs. tal lóbulo ausente). Además, la especie difiere de $G$. major por carecer de escamas accesorias a la escama-bolsillo en machos adultos ( $v s$. tales escamas presentes) y poseer el segundo y tercer radios procurrentes ventrales muy curvados dorsal y ventralmente en machos adultos (vs. tales radios rectos). Gephyrocharax chocoensis difiere de G. melanocheir, G. torresi y G. valencia por la presencia del tubo terminal de la línea lateral entre los radios caudales 10 y 11 (vs. este tubo ausente). Gephyrocharax chocoensis difiere de G. caucanus, G. sinuensis y G. valencia (variable) por carecer de pigmentación negra o marrón oscura alrededor de la aleta pélvica ( $v s$. tal pigmentación presente) y se distingue de G. martae por la distancia hocico-origen aleta pectoral 24,5-28,6 \% LE ( $v s .20,7 \%$ LE). Caracteres adicionales que distinguen a $G$. chocoensis de $G$. atracaudatus y $G$. caucanus fueron mencionados en las diagnosis respectivas de estas especies. Véase también la lista de autapomorfías descriptas para $G$. chocoensis.

Descripción. Datos morfométricos en la tabla 5. Macho de mayor tamaño con 52,1 mm LE, hembra de mayor tamaño con 52,1 mm LE. Cuerpo lateralmente comprimido, con altura máxima sobre la vertical que pasa por un punto medio entre los orígenes de las aletas anal y pélvica o apenas anterior al origen de la aleta anal. Perfil dorsal de la cabeza un poco convexo desde el borde del labio superior hasta la espina supraoccipital. Perfil dorsal del cuerpo convexo desde la porción posterior de la espina supraoccipital hasta el origen de la aleta dorsal, desciende en sentido posteroventral a lo largo de la base de la aleta dorsal y continúa recto desde el radio dorsal más posterior hasta el pedúnculo caudal (Fig. 29). Perfil ventral del cuerpo convexo desde la punta del hocico hasta la vertical que pasa por la mitad de la longitud de la aleta pectoral, sigue recto o algo cóncavo desde este 
punto hasta el origen de la aleta anal y asciende posterodorsalmente recto desde el origen anal hasta el inicio del pedúnculo caudal. Fontanela anterior ausente o reducida a una abertura estrecha anterior a la barra epifisaria. Narina anterior redondeada y separada por un pliegue de piel de la narina posterior de mayor tamaño. Hendidura extendida desde un punto medio entre el poro posterior del nasal y las narinas hasta la región posterior de los frontales, con al menos tres hileras de neuromastos. Hendidura más pequeña con pocos neuromastos sobre la región entre las narinas y los huesos nasales.

Aleta dorsal con ii,7 (2), 8* (86) o 9 (1) radios y 9* pterigióforos proximales. Origen de la aleta dorsal en la vertical que pasa por la base de los radios 6 a 10 de la aleta anal. Aleta adiposa presente, su origen al nivel de la base del radio más posterior de la aleta anal. Aleta anal con iv* (39), v (49) o vi (6),24 (1), 25 (6), 26 (17), 27 (28), 28* (15), 29 (16), 30 (6) o 31 (1), radios y 27-31 pterigióforos proximales. Origen de la aleta anal más cerca del origen de la unión hipural que de la punta del hocico. Aleta pectoral con i,8 (1), 9 (45), 10* (40) o 11 (1) radios. Aleta pectoral larga, alcanza entre un cuarto y un medio de la longitud de la aleta pélvica. Aleta pélvica con i,6 (7) o 7* (81) radios (un ejemplar atípico con 8 radios ramificados) (Fig. 24c). Origen de la aleta pélvica localizado en la vertical que pasa por las escamas 10 a 11 de la línea lateral y anterior a la mitad del cuerpo. Aleta caudal bilobulada con 10/9 radios principales.

Hocico superior, con la mandíbula inferior apenas anterior a la punta de la mandíbula superior. Premaxila con dos hileras de dientes; hilera externa con 2 (2), 3 (18), 4* (65) o 5 (2) dientes; por lo general tricúspides y pocas veces bicúspides o cónicos. Hilera interna con 4 (70) o $5^{*}$ (19) dientes; el sinfisial tetracúspide, los demás pentacúspides y raras veces tetracúspides. Maxila sin dientes (1) o con $1^{*}$ (74) o 2 (14) dientes tricúspides a pentacúspides (ejemplares de mayor tamaño por lo general con el mayor número de cúspides) (Fig. 27c). Maxila larga, alcanza posteriormente el tercio anterior del ojo. Dentario con 9 (1), 10 (2), 11 (15), 12 (27), 13 (26), 14 (4), 15 (1), 16 (1) o 17 (1) dientes; los tres más anteriores grandes y tetracúspides a pentacúspides, seguidos por uno de tamaño mediano tricúspide a pentacúspide y 5 (1), 6 (1), 7 (15), 8 (27), 9 (26), 10 (4), 11 (1), 12 (1) o 13 (1) dientes más pequeños cónicos a tricúspides que poco a poco disminuyen en tamaño en sentido anteroposterior a lo largo del borde dorsal del dentario (Fig. 27d).

Escamas cicloides, con numerosos radii a lo largo del campo posterior. Línea lateral completa. Escamas con poros 37 (1), 38 (22), 39 (18), 40 (23), 41* (19), 42 (5) o 43 (1). Tubo terminal de la línea lateral presente. Escamas predorsales 17 (22), 18 (27), 19 
(28), 20* (12) o 21 (1). Hileras de escamas entre la aleta dorsal y la línea lateral 5 (31) o 6* (59). Hileras de escamas entre la línea lateral y la aleta anal 4 (58) o 5* (32). Hileras de escamas entre la línea lateral y la aleta pélvica 3 (2), 4 (78) o $5^{*}$ (10). Escamas circumpedunculares 13 (24), 14* (56) o 15 (6). Una hilera de escamas dispuestas a lo largo de la base de la aleta anal (un ejemplar con dos hileras) de 11 (2), 12 (4), 13 (5), 14 (9), 15 (15), 16 (12), 17 (15), 18 (3), 19 (5), 21 (1) o 22(1) escamas. Número total de vértebras 39 (3) o 40* (6), 16 (9) precaudales y 23 (3) o 24* (6) caudales (cuatro ejemplares radiografiados y seis ejemplares $\mathrm{d} \& \mathrm{t}$ ). Rastrillos branquiales del primer arco branquial 5* (8), 6 (57) o 7 (6) sobre la porción dorsal y 11* (37), 12 (33) o 13 (2) sobre la porción ventral.

Coloración en alcohol. Cuerpo amarillento pálido, más oscuro en la línea media dorsal y un poco más claro en la zona ventral. Cromatóforos marrones oscuros o negros diminutos cubren la superficie del cuerpo, excepto la región lateral del abdominal y las regiones ventrales preanal y del pedúnculo caudal. Línea lateral marrón oscura o a veces una banda plateada (e. g. IMCN 4830) extendida desde un punto al nivel del origen de la aleta pélvica o incluso la región humeral hasta el pedúnculo caudal. Cromatóforos marrones oscuros distribuidos sobre los mioseptos entre la línea lateral y la porción superior de la aleta anal. Mancha humeral ausente (poblaciones de la cuenca del río San Juan), verticalmente alargada o difusa (poblaciones de la cuencas de los ríos Atrato y León). Mancha caudal marrón oscura o negra, algo ovoide, longitudinalmente alargada y extendida desde la región posterior del pedúnculo caudal, cubre los músculos interradialis hasta la mitad de la longitud de los radios medios de la aleta caudal. Aleta dorsal gris clara o amarilla tenue, con cromatóforos marrones oscuros o negros apenas concentrados a lo largo de los radios y las membranas. Aleta anal gris clara, con cromatóforos marrones oscuros o negros distribuidos en gran manera sobre las membranas. Aleta caudal gris clara, con cromatóforos marrones oscuros o negros en su mayoría concentrados a lo largo de los radios. Aletas pectoral y pélvica grises claras, sin cromatóforos o solo con unos pocos distribuidos en especial sobre los radios. Cabeza más oscura dorsal que ventralmente. Opérculo e infraorbitales con unos pocos cromatóforos marrones o negros. Premaxila, porción anterior de la maxila, dentario y labios con cromatóforos marrones oscuros o negros muy poco concentrados. No se observó variación en coloración entre machos y hembras.

Coloración en vivo. Tomada sobre los ejemplares IMCN 4830. Cuerpo con perfil dorsal dorado o algo amarillento, con una tenue línea de cromatóforos negros en la zona 
predorsal. Banda lateral plateada o blanquecina desde la región posterior del opérculo hasta el pedúnculo caudal. Región ventral a la banda lateral con iridiscencia verdosa o blanquecina. Mancha humeral ausente o no diferenciada de la banda lateral de cromatóforos. Mancha caudal negra y extendida desde la región posterior del pedúnculo caudal (más oscura en este punto) hasta la mitad de los radios medios de la aleta caudal. Aleta dorsal y anal amarillentas o rojizas. Aleta caudal amarillenta, especialmente sobre la base de sus lóbulos, grisácea en los extremos. Aleta adiposa rojiza. Aleas pectoral y pélvica hialinas. Cabeza dorada dorsalmente, con cromatóforos negros concentrados en la región frontoparietal. Premaxila, porción anterior de la maxila, dentario y labios con una moderada pigmentación negra, especialmente en el labio inferior y con cierta iridiscencia dorada en la mandíbula superior. Variaciones de coloración entre machos y hembras se describen en el dimorfismo sexual.

Dimorfismo sexual. Ejemplares machos con ganchos óseos en los radios de las aletas anal, caudal y pélvica. Aleta caudal con ganchos cortos, finos y orientados en sentido anterodorsal, en especial sobre las porciones ramificadas dorsales de los radios 14 a 18 (Fig. 28c). Todos los radios de la aleta pélvica (pocas veces sin ganchos óseos en el primer radio) con ganchos finos pareados o solo uno por segmento (aunque en las bases de los radios por lo general no pareados y numerosos) y en especial orientados en sentido anteroventral a lo largo de cada radio. Aleta anal con ganchos finos, de base ancha, pareados por segmento y situados en sentido anterodorsal o anterolateral sobre los radios; con tres a 24 pares de ganchos localizados sobre el radio simple más posterior y los primeros diez radios ramificados anteriores (los ganchos son más largos en los radios medios de este intervalo; un ejemplar con un par de ganchos diminutos sobre el radio de la aleta anal más posterior). Los machos adultos tienen con frecuencia el borde basal de la aleta anal algo convexo en su porción anterior, mientras que las hembras lo tienen recto. Aleta anal con forma un poco convexa en los machos adultos, mientras que es recta o un poco cóncava en las hembras. Hembras adultas no tienen papila urogenital externamente.

Los machos con las aletas dorsal y anal rojizas en vida, mientras que las hembras con estas aletas amarillentas y grisáceas. Machos maduros con una escama modificada para formar un bolsillo sobre el lóbulo ventral de la aleta caudal y con el segundo y tercer radios procurrentes ventrales modificados en forma de una estructura tipo pinza, ventral al radio principal 19. Tejido de apariencia glandular en poca cantidad, localizado en su mayoría sobre los radios de la aleta caudal y medial a la escama-bolsillo. Estructura tipo pinza osificada de manera incompleta en su porción distal y alcanza la mitad de la 
longitud del primer radio procurrente ventral (Fig. 28c). Primer radio procurrente ventral con una moderada o muy desarrollada concavidad en su porción ventral. Segundo radio procurrente ventral un poco más largo que el tercero y muy expandido en el plano sagital, más notable en su porción posterior. Porción posterior del tercer radio procurrente poco desarrollada lateralmente. Escama-bolsillo hipertrofiada, con 22 a 39 radii que por lo general se localizan entre el radio 16 y el tercer procurrente ventral de la aleta caudal. Escama-bolsillo con un lóbulo posteroventral extendido a lo largo del tercer radio procurrente ventral (Figs. 28c, d). Superficie dorsal de la escama-bolsillo anclada a través de un tejido blando o conectivo a los radios de la aleta caudal 11 o 12 a 14 . Borde posterior de la escama-bolsillo localizado entre los radios 14 o 15 y el tercer radio procurrente ventral de la aleta caudal. Cuatro escamas en serie vertical, justo debajo de la escama más posterior de la línea lateral, sobre la porción posterior de la escama-bolsillo. Borde dorsal de la escama-bolsillo sin hendiduras. Las hembras con una escama grande con 19 (1), 23 (1), 21 (1), 22 (1), 24 (1), 26 (1), 29 (2) o 34 (1) radii.

Machos maduros con glándula branquial corta. Glándula branquial formada por 2 (1), 7 (3), 8 (4), 9 (3), 10 (8), 11 (7) o 12 (4) filamentos branquiales modificados de la porción ventral del primer arco branquial funcional. Número total de filamentos branquiales en la porción ventral 21 (1), 22 (1), 23 (1), 24 (1), 25 (3), 26 (5), 27 (5), 28 (6), 29 (4), 30 (1) o 31 (2). Longitud de la glándula branquial 2,5-4,0 \% LE (media = 3,2 $\%$ LE).

Distribución. Se encuentra en diferentes localidades pertenecientes a las cuencas de los ríos Atrato, León y San Juan, en Colombia (Fig. 19).

Comentarios. Parte de la localidad tipo de G. chocoensis se infirió a partir de los itinerarios de Eigenmann (1912: 7-8) durante su expedición en el Chocó. Eigenmann (1912) no especificó la quebrada o el río donde se pescaron los ejemplares usados para validar la especie. Sin embargo, en el itinerario se menciona que Eigenmann pescó de noche en Istmina y después partió hacia el norte hasta llegar a Tambo, ya en aguas del río Atrato. Es posible concluir que la pesca en Istmina fue en algún lugar dentro del sistema del río San Juan o en el mismo río por su cercanía con Istmina, pero la localidad exacta no se puede estimar. Gephyrocharax chocoensis presenta variación geográfica poblacional en la presencia/ausencia de mancha humeral. Las poblaciones de las cuencas de los ríos Atrato y León presentan una mancha humeral bastante definida, mientras que las poblaciones de la cuenca del río San Juan (e. g. el holotipo) no presentan tal mancha. Esta variación en la mancha humeral es considerada poblacional y no es suficiente para 
confirmar dos especies, porque toda la información merística y morfométrica está, en gran parte, superpuesta entre ambos morfotipos. Un ACP de las medidas entre los dos morfotipos confirmó que no existen diferencias representativas o agrupamientos que permitan separarlos a lo largo de las distintas componentes obtenidas (Fig. 30). Además, se compararon todos los caracteres usados en la matriz de caracteres del análisis filogenético para cada uno de estos morfotipos y no se encontraron diferencias anatómicas robustas para considerarlos dos especies diferentes. La variación de la mancha humeral es considerada poblacional dentro de esta especie y única en el género.

Material examinado. Colombia: AMNH 5330, 4, 39,6-45,1 mm LE, Chocó, río San Juan, Istmina, aproximadamente $5^{\circ} 9^{\prime} 17,26^{\prime \prime} \mathrm{N} 76^{\circ} 41^{\prime} 0,21^{\prime \prime} O 52$ m. a. n. m., 1913, C. E. Wilson. STRI 1309, 1, 35,1 mm LE, Chocó, cuenca del río Atrato, quebrada desconocida, 5³7'8"N 76²4'11"O 43 m. a. n. m., 27 Mar. 1994, sin datos. CAR 320, 6, 35,5-40,6 mm LE (2 d\&t 38,5-40,6 mm LE), Chocó, río Cabi, afluente río Atrato, aproximadamente 5 40'0,15"N 76³7'58,39"O 46 m s.n.m., 6 Ene. 2003, C. A. Ardila-Rodríguez. CAS 44278, 9 paratipos (antes IU 12671a-j en parte), 42,6-52,1 mm LE, Chocó, cuenta del río San Juan, Alto río San Juan, Istmina, aproximadamente 59'24,24"N 76²40'51,00"O 50 m s.n.m., 18 al 20 Mar. 1912, C. H. Eigenmann. CI-FML 6103, 5, 27,9-34,1 mm LE (2 d\&t 29,9-34,1 mm LE), Antioquia, Carepa, Finca Corpoica, sistema del río León, quebrada pequeña junto a cultivo de plátano, aproximadamente $7^{\circ} 45^{\prime} 45,15^{\prime \prime} \mathrm{N} 76^{\circ} 39^{\prime} 15,60 " \mathrm{O} 35 \mathrm{~m}$ s.n.m., 11 Nov. 2011, G. A. Ballen. CI-FML 6104, 3, 31,2-39,5 mm LE, Antioquia, Carepa, Finca Corpoica, sistema del río León, quebrada pequeña de aguas lentas, aproximadamente $7^{\circ} 45^{\prime} 30,61$ "N 76³8'35,83"O 35 m s.n.m., 11 Nov. 2011, G. A. Ballen. FMNH 56016* (antes CM 4806), holotipo Gephyrocharax chocoensis Eigenmann, 1912, 52,9 mm LE (R), macho, [Chocó, cuenca del río San Juan, aproximadamente 59'12,79"N 76² 41'13,61"O 50 m s.n.m.] Istmina, 18 al 20 Mar. 1912, C. H. Eigenmann. IAvH-P 2228, 4, 28,5-39,7 mm LE, Chocó, Unguía, cuenca del río Atrato, quebrada Ipeti, 8²'29,1"N 775'51"O, 31 m s.n.m., 2 Dic. 2009. J. A. Maldonado-Ocampo et al. IAvH-P 7233, 29, 22,8-43,2 mm LE, Chocó, Riosucio, cuenca del río Atrato, quebrada Tendal, vereda Sautata Parque Natural Nacional Katios, $7^{\circ} 51^{\prime} 0,1^{\prime \prime} \mathrm{N} 77^{\circ} 8^{\prime} 44,5^{\prime \prime O} 36$ m s.n.m., 20 Jul. 2009, J. A. Maldonado-Ocampo et al. ICNMHN 1615, 47, 12,5-42,2 mm LE, Chocó, Quibdó, cuenca del río Atrato, bocas río Quito, aproximadamente 541'4,77"N 76²0'1,46"O 36 m s.n.m., 1 May. 1988, C. Román-Valencia \& E. Puentes. ICNMHN 2218, 3, 29,2-36,90 mm LE, Chocó, cuenca del río Atrato, quebradas en la vía QuibdóIstmina, aproximadamente $5^{\circ} 31^{\prime} 50,49 " \mathrm{~N} 76^{\circ} 40^{\prime} 1,46 " \mathrm{O} 66$ m s.n.m., 1 Mar. 1994, G. 
Galvis \& M. Camargo. ICNMHN 2265, 1, 41,5 mm LE, Chocó, cuenca del río San Juan, Prdeundó, drenaje desconocido, aproximadamente $5^{\circ} 11^{\prime} 36,02 " \mathrm{~N} 76^{\circ} 36^{\prime} 51,08^{\prime \prime O} 85 \mathrm{~m}$ s.n.m., 1 Mar. 1995, G. Galvis \& M. Camargo. ICNMHN 2953, 4, 37,7-39,6 mm LE, Chocó, Lloró, río Atrato $2 \mathrm{~km}$ arriba de la desembocadura del Capa, aproximadamente 5³2'28,67"N 76²9'34,44"O 68 m s.n.m., 1 Mar. 1988, G. Galvis \& Est. de Biol. ICNMHN 3098, 1, 32,0 mm LE, Antioquia, sistema río León, río Porroso en vía MedellínUrabá, aproximadamente 7²5'47,14"N 76³3'29,92"O 49 m s.n.m., 12 Dic. 1990, C. Román-Valencia \& L. Suarez. ICNMHN 3378, 10, 38,0-42,4 mm LE, Chocó, Lloró, La Vuelta, cuenca del río Atrato, quebrada afluente margen derecha 3ra. vuelta, aproximadamente $5^{\circ} 28^{\prime} 4,37^{\prime \prime N} 76^{\circ} 32^{\prime} 1,14 " O \quad 86$ m s.n.m., 1 Mar 1988, P. Cala \& Est. Biol. ICNMHN 3395, 11, 33,8-40,0 mm LE, Chocó, Quibdó, cuenca del río Atrato, sistema río Samurindo, quebrada Carmelita, carretera Yutó-Quibdo km 15, aproximadamente $5^{\circ} 34^{\prime} 49,50^{\prime \prime} \mathrm{N} 76^{\circ} 37^{\prime} 35,28^{\prime \prime O} 82$ m s.n.m., 1 Mar. 1988, P. Cala \& Est. Biol. IMCN 4830, 12, 29,9-42,6 mm LE (2 d\&t 38,9-39,4 mm LE, 2 t\&m 32,4-40,1 mm LE), Valle del Cauca, Calima, cuenca baja del río San Juan, quebrada La Brea en la parte baja del río Calima, aproximadamente 359'59,89"N 7659'0,13"O 28 m s.n.m., 28 Ene. 2012, J. A. Vanegas-Ríos, G. C. Sánchez \& A. Ortega-Lara. MCZ 30956*, 1, 49,4 mm LE (R), Chocó, Cuenca río San Juan, Istmina, aproximadamente $5^{\circ} 10^{\prime} 60,00^{\prime \prime} \mathrm{N} 76^{\circ} 39^{\prime} 0,00^{\prime \prime} \mathrm{O}$ 71 m s.n.m., fecha ausente, C. C. Wilson. NRM 23834, 4, 22,8-30,3 mm LE, Chocó, cuenca del río Atrato, quebrada atravesada por la carretera Tutunendo-San Francisco de Ichó, a 1 km de San Francisco de Ichó, 545'N 76³2'O aproximadamente 90 m s.n.m., 2 Feb. 1989, S. O. Kullander, S. O. \& A. M. C. Silfvergrip. NRM 23835, 30, 20,4-33,5 mm LE, Chocó, cuenca del río Atrato, quebrada atravesada por la carretera Tutunendo-San Francisco de Ichó, a 1,5 km de San Francisco de Ichó, 547'N 76³2'O aproximadamente 59 m s.n.m., 2 Feb. 1989, S. O. Kullander, S. O. \& A. M. C. Silfvergrip. NRM 23836, 25, 33,4-43,5 mm LE, Chocó, cuenca del río Atrato, quebrada Taridó en el cruce de la carretera Panamericana, $5^{\circ} 28^{\prime} \mathrm{N} 76^{\circ} 44^{\prime} \mathrm{O}$ aproximadamente 43 m s.n.m., 7 Feb. 1989, S. O. Kullander, S. O. \& A. M. C. Silfvergrip. NRM 23837, 7, 27,84-37,38 mm LE, Chocó, cuenca del río San Juan, río Condoto, banco en playa derecha abajo del puente a Condoto, $5^{\circ} 6^{\prime} \mathrm{N} 76^{\circ} 40^{\prime} \mathrm{O}$ aproximadamente 58 m s.n.m., 5 Feb. 1989, S. O. Kullander, S. O. \& A. M. C. Silfvergrip. USNM 76973 (posiblemente IU 12671a-j en parte), 12 paratipos, 29,3-47,6 mm LE, [Chocó, cuenca del río San Juan, aproximadamente 59'12,79"N 7641'13,61"O 50 m s.n.m.] Istmina, 18 a 20 Mar. 1912, C. H. Eigenmann. USNM 79208 (posiblemente CM 4807a-j en parte) 2 paratipos, 46,2-48,1 mm LE (2R), [Chocó, cuenca del río San 
Juan, aproximadamente $5^{\circ} 9^{\prime} 12,79^{\prime \prime} \mathrm{N} 76^{\circ} 41^{\prime} 13,61$ "O 50 m s.n.m.] Istmina, 18 a 20 Mar. 1912, C. H. Eigenmann.

\section{Gephyrocharax intermedius Meek \& Hildebrand, 1916}

Figs. 2b, 5a, 14, 17, 19, 23-25, 31 y 32, Tablas 1 y 6

Gephyrocharax intermedius Meek \& Hildebrand, 1916: 221, 224, 277-279 (descripción original, designación material tipo, paratipos no mencionados, holotipo FMNH 8945, localidad tipo: Panamá, río Chame). Eigenmann, 1920b: 15 (cita en lista). Eigenmann, 1922: 156 (cita en catálogo). Myers en Eigenmann \& Myers, 1929: 477 y 483 (redescripción sin figuras). Hildebrand, 1938: 253-254 (datos localidad tipo y morfología). Schultz, 1944: 323 (clave). Dahl en Dahl \& Medem, 1964: 65 (similitud con G. sinuensis). Bussing, 1966: 215 (quebradas río Grande de Térraba, Costa Rica, error de identificación, corresponde a P. myrnae). Miller, 1966: 137 (lista de especies primarias, cita errónea para Costa Rica). Bussing, 1974: 139-140 (comparación P. myrnae). Weitzman \& Fink, 1985: 103 (material examinado, comentarios localidad tipo). Vari \& Howe, 1991: 21 (comentarios material tipo). Burns, Weitzman \& Menezes, 1995: 133-135 (espermatozoide, inseminación). Weitzman, 2003: 224 (cita en catálogo). Burns, Quagio-Grassiotto, Jamieson, 2009: 329 (detalles espermatozoides). Bonilla-Rivero \& López-Rojas, 2013: 489, fig. 1 (mapa). Vanegas-Ríos, Azpelicueta, Mirande, Gonzales, 2013: 282 (material examinado).

Gephyrocharax whaleri Hildebrand, 1938: 231, 252, 254-256, fig. 2 (descripción original, designación material tipo, paratipos mencionados sin número de catálogo, holotipo USNM 106513, localidad tipo: Panamá, Vertiente Pacifico, río Chame o varias pequeñas quebradas cercanas que cruzan la carretera Nacional entre Campana y La Venta). Schultz, 1944: 323 (clave). Miller, 1966: 137 (lista de especies primarias).

Weitzman \& Fink, 1985: 103 (material examinado, comentarios localidad tipo). Vari \& Howe, 1991: 22 (comentarios localidad tipo y paratipos). Weitzman, 2003: 225 (cita en catálogo). Bonilla-Rivero \& López-Rojas, 2013: 489, fig. 1 (mapa). Vanegas-Ríos, Azpelicueta, Mirande, Gonzales, 2013: 283 (material examinado). (Nueva sinonimia) 
Diagnosis. Gephyrocharax intermedius se diferencia de todos sus congéneres por tener despigmentado o apenas blanquecino el primer tercio vertical de los radios externos de la aleta caudal ( $v s$. tal tercio muy pigmentado o apenas oscurecido por cromatóforos marrones oscuros o negros), por la pérdida de glándula branquial (en 82 ejemplares de 87 examinados), ya sea por carecer de células columnares glandulares o por no tener fusionados los filamentos branquiales ( $v s$. presencia de glándula branquial) y (excepto $G$. atracaudatus) por el primer radio procurrente ventral muy cóncavo y asociado a una fuerte expansión sagital de la porción posterior del segundo radio procurrente ventral de la aleta caudal en los machos adultos ( $v s$. primer radio recto o un poco cóncavo y débilmente asociado a una expansión sagital moderada del segundo radio procurrente ventral). La especie también difiere de sus congéneres (excepto $G$. atracaudatus y $G$. major) por carecer de un lóbulo sobre el margen posterior de la escama-bolsillo de los machos adultos (vs. lóbulo presente en tal margen). Gephyrocharax intermedius se distingue de $G$. melanocheir, G. torresi y G. valencia por la presencia del tubo terminal de la línea lateral sobre los radios caudales 10 y 11 ( $v s$. ausencia de este tubo). Además, Gephyrocharax intermedius se diferencia de G. martae por la distancia hocico-origen aleta pectoral 25,431,3\% LE (vs. 20,7 \% LE) y de G. caucanus por el número de escamas con poros en la línea lateral 36-41 (vs. 42-47), el número de radios ramificados de la aleta anal 24-29 (vs. 29-36) y el número de vértebras 37-39 (vs. 41-42). Caracteres adicionales que distinguen a G. intermedius de G. atracaudatus, G. caucanus y G. chocoensis fueron mencionados en las diagnosis respectivas de estas especies. Véase también la lista de autapomorfías mencionadas para G. intermedius.

Descripción. Datos morfométricos en la tabla 6. Macho de mayor tamaño con 61,1 mm LE y hembra de mayor tamaño con 56,4 mm LE. Cuerpo lateralmente comprimido, con altura máxima en un punto anterior o en el origen de la aleta pélvica. Perfil dorsal de la cabeza apenas convexo desde el borde del labio superior hasta el extremo posterior del proceso ascendente de la premaxila y recto o un poco convexo desde este punto hasta la espina supraoccipital. Perfil dorsal del cuerpo un poco convexo desde la región posterior de la espina supraoccipital hasta el origen de la aleta dorsal, desciende en sentido posteroventral a lo largo de la base de la aleta dorsal y continúa recto desde el radio dorsal más posterior hasta el pedúnculo caudal (Fig. 31). Perfil ventral del cuerpo convexo desde la punta del hocico hasta un punto situado por debajo de la mitad posterior de la aleta pectoral, continúa algo convexo desde este punto hasta el origen de la aleta anal y asciende 
posterodorsalmente recto a veces un poco cóncavo desde el origen anal hasta el inicio del pedúnculo caudal. Fontanela anterior variable intraespecíficamente en adultos (no se observó algún patrón poblacional consistente); ausente por el contacto de los frontales, reducida a una abertura anterior a la barra epifisaria y completamente desarrollada (limitada por el mesetmoides en su zona anterior). Narina anterior redondeada y separada por un pliegue de piel de la narina posterior de mayor tamaño. Hendidura extendida desde un punto medio entre el poro posterior del nasal y las narinas hasta la región posterior de los frontales, con al menos tres hileras de neuromastos. Hendidura más pequeña con pocos neuromastos sobre la región entre las narinas y los huesos nasales.

Aleta dorsal con ii,7 (17) o $8^{*}(185)$ radios y $9 *$ pterigióforos proximales. Origen de la aleta dorsal en la vertical que pasa por la base de los radios 5 a 11 de la aleta anal. Aleta adiposa presente en casi todos los ejemplares (ausente en dos), localizada en la vertical que pasa por la base del radio más posterior de la aleta anal o por un punto posterior a este. Aleta anal con iv* (126), $\mathrm{v}^{* *}(77)$ o vi (3),24 (12), 25* (27), 26* (55), 27 (73), 28** (29), 29 (6) o 30 (3) radios y $27 *-29 * *$ pterigióforos proximales. Origen de la aleta anal más cerca del origen de la unión hipural que de la punta del hocico. Aleta pectoral con i,8 (6), 9* (120), 10 (68) o 11 (11) radios. Aleta pectoral larga, alcanza entre un sexto y tres cuartos de la longitud de la aleta pélvica. Aleta pélvica con i,6 (4) o 7* (197) radios (un ejemplar atípico con 8 radios ramificados). Origen de la aleta pélvica localizado en la vertical que pasa por las escamas 8 a 10 de la línea lateral y apenas anterior a la mitad del cuerpo. Aleta caudal bilobulada, con 10/9 radios principales en todos los ejemplares.

Hocico superior, con la mandíbula inferior apenas anterior a la punta de la mandíbula superior. Premaxila con dos hileras de dientes; hilera externa con 2 (2), 3 (54), $4^{*}(124), 5^{* *}(20)$ o 6 (2) dientes por lo general tricúspides y pocas veces bicúspides o tetracúspides. Hilera interna con 4 (43), 5* (157) o 6 (2) dientes; el sinfisial tetracúspide y los restantes dientes pentacúspides (el más posterior rara vez bicúspide a tetracúspide). Maxila con $1^{*}(30), 2$ (78), 3 (76), 4 (15) o 5 (2) dientes; pocas veces cónicos o bicúspides, en general tricúspides a pentacúspides y con el diente más dorsal con frecuencia con mayor número de cúspides (Fig. 23c). Maxila larga, alcanza posteriormente el tercio anterior del ojo. Dentario con 9 (7), 10 (24), 11 (34), 12 (55), 13** (47), 14 (15), 15 (12) o 16 (2) dientes; los tres más anteriores grandes y pentacúspides, seguidos por uno de tamaño mediano por lo general tetracúspide o pentacúspide y 5 (7), 6 (24), 7 (34), 8 (55), 9** (47), 10 (15), 11 (12) o 12 (2) dientes más pequeños cónicos, bicúspides o 
tricúspides que poco a poco disminuyen en tamaño en sentido anteroposterior a lo largo del borde dorsal del dentario, pero el diente posterior al de tamaño mediano de mayor tamaño y número de cúspides (Fig. 23d).

Escamas cicloides, con pocos a numerosos radii a lo largo del campo posterior. Línea lateral completa. Escamas con poros 36 (2), 37* (23), 38 (41), 39 (51), 40* (58), 41 (20) o 42 (8) (Fig. 24d). Tubo terminal de la línea lateral presente. Escamas predorsales 16 (1), 17 (78), 18** (75), 19 (35), 20* (20), 21 (2) o 22 (1). Hileras de escamas entre la aleta dorsal y la línea lateral $5(1), 6^{*}(145)$ o $7 * *$ (56). Escamas entre la línea lateral y la aleta anal 4 (1), 5* (191) o 6 (12). Escamas entre la línea lateral y la aleta pélvica 4 (12), 5* (191) o 6 (1). Escamas circumpedunculares 15 (90), 16* (87) o 17 (15). Una o dos hileras de escamas dispuestas a lo largo de la base de la aleta anal (la hilera dorsal solo superpuesta en parte); la hilera principal ventral compuesta por 11 (1), 12 (1), 13 (3), 14 (11), 15** (32), 16 (16), 17 (42), 18 (17), 19 (18), 20 (10), 21 (3), 22 (2), o 23 (1) escamas. Número total de vértebras 37 (3), 38* (11) o 39 (3), 15* (10) o 16 (4) precaudales y $22(7), 23 *$ (6) o 24 (1) caudales (seis ejemplares radiografiados, ocho ejemplares d\&t y tres ejemplares diseccionados). Rastrillos branquiales del primer arco branquial 5* (18), 6 (134) o $7^{* *}(36)$ sobre la porción dorsal y 10 (3), 11* (94), 12* (79), $13 * *$ (10) o 14 (1) sobre la porción ventral.

Coloración en alcohol. Cuerpo de color amarillento pálido o marrón oscuro, más oscuro a lo largo de la línea media dorsal y un poco más claro en la zona ventral. Cromatóforos marrones o marrones oscuros diminutos cubren el cuerpo, en menor proporción en las regiones lateral y ventral del abdomen y región ventral del pedúnculo caudal. Línea lateral negra extendida desde la región posterior de la mancha humeral hasta la región central o posterior del pedúnculo caudal. Cromatóforos marrones oscuros distribuidos a lo largo de los mioseptos entre la línea lateral y la porción superior de la aleta anal. Mancha humeral marrón oscura o negra, verticalmente alargada. Mancha marrón oscura o negra, muy concentrada verticalmente en su región posterior, casi cubre toda la altura del pedúnculo caudal en sentido dorsoventral y extendida de la región central del pedúnculo caudal hasta la base de los radios medios de la aleta caudal y los músculos interradialis. Aleta dorsal gris clara, apenas oscurecida por la presencia de cromatóforos marrones oscuros concentrados sobre los bordes de los radios y las membranas. Aleta anal gris clara, apenas oscurecida por la presencia de cromatóforos marrones oscuros y negros situados en su mayoría sobre las membranas. Aleta caudal gris clara de fondo, en dos tonalidades, el primer tercio despigmentado verticalmente o apenas blanquecino (posterior a la mancha 
peduncular), especialmente en los radios caudales externos, y la restante porción posterior de la aleta algo oscurecida por la presencia de cromatóforos marrones oscuros o negros distribuidos sobre las membranas y los radios. Aletas pectoral y pélvica grises claras, con cromatóforos marrones oscuros o negros dispersos sobre los radios. Cabeza más oscura dorsal que ventralmente. Opérculo e infraorbitales con unos pocos cromatóforos marrones o marrones oscuros distribuidos sobre sus superficies. Premaxila, porción anterior de la maxila, dentario y labios con cromatóforos marrones oscuros muy concentrados. Variaciones en la coloración entre machos y hembras se describen en el dimorfismo sexual.

Dimorfismo sexual. Ejemplares machos con ganchos óseos en los radios de las aletas anal, caudal, pélvica y excepcionalmente en la dorsal. Aleta caudal con ganchos cortos, finos y orientados en sentido anterodorsal, en especial sobre las porciones ramificadas dorsales de los radios 15 a 17 y muy rara vez en el 13 (Fig. 25c). Todos los radios de la aleta pélvica, excepto el último radio proximal, con ganchos finos pareados o solo uno por segmento (aunque en las bases de los radios por lo general no pareados y numerosos) y orientados en sentido anteroventral a lo largo de casi toda la longitud de cada radio, pero reducidos en número o a veces ausentes sobre el primer radio. Aleta anal con ganchos finos, de base ancha, pareados por segmento y orientados en sentido anterodorsal o anterolateral en los radios; con dos a 38 pares de ganchos localizados sobre el radio simple más posterior y los primeros diez radios ramificados anteriores (ganchos comparativamente de mayor tamaño en los radios medios de este intervalo). Aleta dorsal con dos a cinco pares de ganchos diminutos orientados en sentido anterolateral sobre el borde ventral de la rama posterior de los dos radios ramificados más anteriores (observado en un único ejemplar, STRI 1205). En los machos adultos, los radios posteriores al radio simple más posterior y anteriores a los últimos cinco o seis radios anales son parecidos en longitud entre sí y un poco más largos que el resto (aleta de aspecto convexo), mientras que en las hembras los radios disminuyen poco a poco en longitud en sentido anteroposterior (aleta de aspecto recto o algo cóncavo). Los machos adultos con frecuencia tienen el borde basal de la aleta anal cóncavo en la región media, mientras que las hembras lo tienen recto. Hembras adultas no tienen papila urogenital externamente.

En los machos la pigmentación de aleta caudal es apenas diferente de las hembras, debido a que el área cubierta por la escama-bolsillo por lo general esta menos pigmentada. Cromatóforos de la aleta anal un poco más concentrados sobre aquellos radios con ganchos óseos en machos. Machos maduros con una escama modificada para formar un 
bolsillo sobre el lóbulo ventral de la aleta caudal y con el segundo y tercer radios procurrentes ventrales modificados en forma de una estructura tipo pinza, ventral al radio principal 19. Tejido de apariencia glandular en poca cantidad, localizado en su mayoría sobre los radios de la aleta caudal y medial a la escama-bolsillo. Estructura tipo pinza osificada de manera incompleta en su porción distal y alcanza la mitad de la longitud del primer radio procurrente ventral (Fig. 25c). Primer radio procurrente ventral con una fuerte concavidad en su porción ventral. Segundo radio procurrente ventral un poco más largo que el tercero y muy expandido en el plano sagital, más notable en su porción posterior. Porción posterior del tercer radio procurrente ventral muy desarrollada lateralmente. Escama-bolsillo hipertrofiada, con 11 a 23 radii que por lo general se localizan entre el radio 16 y el segundo radio procurrente ventral de la aleta caudal. Escama-bolsillo sin lóbulo posteroventral (Figs. 25c, d). Superficie dorsal de la escamabolsillo anclada a través de un tejido blando o conectivo a los radios de la aleta caudal 10 o 11 a 14. Borde posterior de la escama-bolsillo localizado entre el radio 16 de la aleta caudal y el segundo radio procurrente ventral o un punto entre este y el tercer radio procurrente ventral. Cuatro escamas en serie vertical, justo debajo de la escama más posterior de la línea lateral, sobre la porción posterior de la escama-bolsillo. La primera escama dorsal de esta serie vertical pocas veces con pequeños procesos mediales en su borde dorsal. Borde anterodorsal de la escama-bolsillo por lo general con una pequeña o moderada hendidura. Las hembras con una escama grande con 17 (3), 18 (2) 19 (2), 20 (8), 21 (8) 22 (8), 23 (5), 24 (1), 25 (3), 26 (3) radii.

Machos maduros en general no desarrollan glándula branquial (82) visible por la fusión de filamentos, solo cinco individuos tiene una glándula reducida a los 2 (1), 5 (2), 6 (1) o 7 (1) primeros filamentos branquiales modificados de la porción ventral del primer arco branquial funcional. Número total de filamentos branquiales en la porción ventral 24 (1), 25 (2) o 27 (1). Longitud de la glándula branquial 0,7-2,8 \% LE (media = 1,7 \% LE). El procesamiento histológico del arco branquial de tres machos maduros corroboró la ausencia de células columnares glandulares y por lo tanto la ausencia de glándula branquial.

Distribución. Se encuentra a lo largo de variados drenajes costeros entre el oeste del Canal de Panamá y el Golfo de Chiriquí, principalmente sobre la vertiente del Pacífico en las provincias de Coclé, Herrera, Los Santos, Veraguas y Chiriquí y en el río Coclé del Norte de la vertiente Caribe (Fig. 19). 
Comentarios. Meek \& Hildebrand (1916) no especificaron en la descripción original de G. intermedius los número de catálogo de los ejemplares paratipos (solo citaron el holotipo), pero es claro que la descripción fue llevada a cado sobre más ejemplares (64 según estos autores). En el caso de G. whaleri, Hildebrand (1938) mencionó que la descripción fue sustentada en 50 ejemplares paratipos, pero no mencionó sus números de catálogo. El artículo 72.4.5 del ICZN (1999) afirma que cuando un autor designa un tipo, los restantes ejemplares usados en la descripción son consecuentemente paratipos. Por tal motivo, los ejemplares paratipos examinados de ambas siguen los catálogos de tipos revisados del FMNH (Ibarra \& Stewart, 1987) y USNM (Vari \& Howe, 1991). La fecha de captura de la serie tipo de G. intermedius no fue aclarada en la descripción original (Meek $\&$ Hildebrand, 1916) y tampoco aparece en algunos de los datos de los ejemplares tipos examinados. No obstante, Meek \& Hildebrand (1916: 217) anotaron que las expediciones fueron realizadas en dos períodos, enero a mayo de 1911 y enero a marzo de 1912. Luego, Hildebrand (1938: 254), uno de los colectores de la serie tipo de G. intermedius, afirmó que ejemplares de G. intermedius fueron recolectados en 1911. De acuerdo con esto, se propone que la fecha de colecta para los frascos sin fecha especificada debería ser el período entre enero a mayo de 1911. Si bien la localidad tipo de Gephyrocharax intermedius (río Chame) fue establecida por Meek \& Hildebrand (1916), la localidad tipo de G. whaleri no lo fue. Hildebrand (1938) afirmó, dentro de la descripción de G. whaleri, que el 10 de marzo de 1937 mientras recorría la carretera de Balboa hacia La Venta en Panamá se hicieron varias paradas para pescar en media docena o más de pequeños drenajes costeros que atraviesan la carretera entre Campana y La Venta. Sin embargo, los ejemplares capturados no fueron debidamente separados y aquellos usados en la serie tipo de G. whaleri no pudieron ser atribuidos a ningún drenaje en particular. Por esto, Hildebrand (1938: 279) sugirió que la localidad tipo de la especie podría ser el río Chame o drenajes cercanos (esta localidad fue usada para el holotipo y paratipos respectivos); prácticamente la misma localidad tipo de $G$. intermedius o muy cercana geográficamente.

Gephyrocharax whaleri es sinónimo junior de G. intermedius de acuerdo con los resultados de varias comparaciones morfológicas llevadas a cabo. Hildebrand (1938: 256) diferenció a G. whaleri de G. intermedius por el hocico más vertical (vs. menos vertical), el labio inferior del hocico más desarrollado y alineado con el perfil dorsal de la cabeza (vs. menos desarrollado y no alineado con este perfil) y la aleta dorsal más larga (alcanza o sobrepasa el origen la aleta adiposa vs. no lo alcanza). Los primeros dos caracteres fueron muy variables entre los ejemplares examinados, ya sea de otras poblaciones o los de la 
serie tipo de ambas especies. El tercer carácter fue observado un poco más estable, aunque no exactamente ajustado a las observaciones de Hildebrand (1938) respecto de la serie tipo de ambas especies. De hecho, la longitud de la aleta dorsal respecto del origen de la aleta adiposa fue observado muy variable y sin ningún patrón entre las demás poblaciones de la costa Pacífica y hacia el oeste de Panamá. La merística y la morfometría comparadas entre los ejemplares tipo de ambas especies están superpuestas y no son informativas. Un ACP de los datos morfométricos para comparar los ejemplares tipo de ambas especies confirmó que estos son parecidos entre sí y no forman grupos separados (Figs. 32a, b). Además, se compararon todos los caracteres usados en la matriz de caracteres del análisis filogenético para ejemplares atribuibles a ambas especies y no se encontraron diferencias anatómicas robustas para considerarlas diferentes. Tampoco se encontraron diferencias en la anatomía esquelética en las radiografías de los holotipos de G. intermedius y G. whaleri. Acorde al principio de prioridad para sinonimias el nombre válido de la especie es G. intermedius (artículos 23.1 y 23.3 del ICZN, 1999).

Por otro lado, se realizó un análisis de la variación morfométrica de los principales grupos formados por proximidad geográfica: Chame (cuenca del río Chame más drenajes cercanos, Golfo de Panamá), Santa María (cuenca de los ríos Santa María y La Villa más drenajes cercanos, Golfo de Panamá), San Pablo (río San Pablo más drenajes cercanos, Golfo de Montijo), Chiriquí (cuenca del río Chiriquí más drenajes cercanos, Golfo de Chiriquí) y Coclé del Norte (cuenca del río Coclé del Norte, Golfo de los Mosquitos). Este análisis mostró que tales agrupaciones no se separan morfométricamente, identificó una gran similitud en las medidas entre los ejemplares examinados y describió una amplia distribución y superposición de los ejemplares de grupo Chame con el resto, a lo largo de las CP2 y CP3 (Figs. 32c, d). También, se compararon todos los caracteres codificados en la matriz de caracteres del análisis filogenético para diferentes poblaciones aisladas geográficamente (río Chame, STRI 1209; río Chiriquí, ANSP 99885; y río Santa María, STRI 1205) y no se encontraron diferencias. Se concluye que G. intermedius es una especie ampliamente distribuida por los drenajes costeros del Pacífico y Caribe de Panamá.

Gephyrocharax intermedius puede distinguirse de $G$. atracaudatus por no tener glándula branquial, ya sea porque no hay fusión de filamentos (en el $94 \%$ los machos adultos examinados) o por carecer de células columnares glandulares. En el $6 \%$ de los machos examinados de G. intermedius, se observó una glándula pequeña o incipiente formada por la fusión de varios filamentos branquiales. A pesar de esta pequeña variación, 
la perdida de glándula branquial es un carácter útil para diferenciar a $G$. intermedius de $G$. atracaudatus, debido a que los resultados sugieren que dicha pérdida tiende a generalizarse en la especie.

Material examinado. Panamá: ANSP 99885, 10, 34,4-39,1 mm LE (2 d\&t 37,4-35,63 mm LE), Chiriquí, río Esti cerca 1 milla al norte de Gualaca, aproximadamente $8^{\circ} 32^{\prime} 51,28 " N 2^{\circ} 17 ' 59,84 " O 128$ m s.n.m., 16 Dic. 1961, H. G. Ldetin \& E. L Tyson. ANSP 99856 (antes USNM 233631), 10, 30,9-38,2 mm LE, Coclé, quebrada cerca de 3 millas de río Hato en el puente sobre la carretera Interamericana, aproximadamente $8^{\circ} 23^{\prime} 17,65^{\prime N}$ 80¹2'51,69"O 30 m s.n.m., 14 Oct. 1961, H. G Ldetin \& E. T. Tyson. ANSP 104176 (antes USNM 249234), 10, 19,3-25,4 mm LE, Los Santos, río Tonosi en el puente cerca del centro entre el Llano de Piedra y la llanura de Tonosi, aproximadamente 7²6'59,89"N 80³1'1,67"O 49 m s.n.m., Mar. 1963, H. G. Ldetin \& W. Kosan. ANSP 104236, 10, 21,7-33,0 mm LE, río Cotón, en el Puente sobre la carretera Interamericana cerca de 5 millas al oeste de San Carlos, aproximadamente $8^{\circ} 26^{\prime} 52,41^{\prime \prime} \mathrm{N} 80^{\circ} 1^{\prime} 31,38^{\prime \prime} \mathrm{O} 38$ m s.n.m., 11 Mar. 1962, H. G. Ldetin \& E. Heslop. ANSP 104254, 8, 30,7-38,4 mm LE, Los Santos, río Estibana en el Puente un poco antes de entrar a Macaracas, aproximadamente $7^{\circ} 44^{\prime} 48,25^{\prime \prime N} 80^{\circ} 31^{\prime} 53,08$ "O 72 m s.n.m., 30 Sep. 1961, H. G. Ldetin \& E. L. Tyson. ANSP 104434, 20, 22,7-39,0 mm LE (2 t\&m 35,4-36,6 mm LE), Veraguas, quebrada en el Puente a 12 millas oeste de Santiago sobre la carretera Soná, aproximadamente $8^{\circ} 3^{\prime} 22,19 " \mathrm{~N} 81^{\circ} 6^{\prime} 34,40 " \mathrm{O} 34$ m s.n.m., 28 Ene. 1962, H. G Ldetin, E. L Tyson \& R. W. Yerger. AUM 28580, 39, 18,5-39,0 mm LE, Veraguas, sistema Bahía de Parita, tributario del río Santa María, 4 km desde San Francisco sobre la carretera San Francisco a Santiago, aproximadamente $8^{\circ} 10^{\prime} 54,59^{\prime \prime} \mathrm{N} 80^{\circ} 57^{\prime} 5,46 " \mathrm{O} 62$ m s.n.m., 28 Feb. 1975, R. O. Smitherman \& E. L. Díaz. AUM 31533, 12, 21,7-34,6 mm LE, Coclé, Bahía de Parita, río Antón, carretera Pan Americana justo al este de Antón, aproximadamente

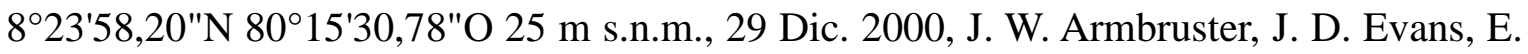
E. Bermigham, R. G. Gonzales, D. C. Werneke \& T. P. Pera. AUM 31677, 15, 32,5-39,1 mm LE, Chiriquí, cuenca río Chiriquí-Guayabal, quebrada Grande cerca de 9,5 mi NE de David sobre la carretera de las Lomas a Dolega, $8^{\circ} 28^{\prime} 0,62^{\prime \prime} \mathrm{N} 82^{\circ} 22^{\prime} 32,71$ "O 70 m s.n.m., 6 Ene. 2001, J. A. Armbruster, J. D. Evans, D. C. Werneke, T. P. Pera \& R. G. González. AUM 31712, 37, 15,0-41,1 mm LE, Herrera, cuenca río La Villa, río Pesé, $2 \mathrm{~km}$ al sur de Pesé, 753'46,00"N 80³6'0,99"O 61 m a. n. m, 1 Ene. 2001, J. W. Armbruster, J. D. Evans, T. P. Pera \& D. C. Werneke. AUM 32124, 17, 15,8-34,7 mm LE, Herrera, Bahía de Parita, río Parita 5,5 Km NNW Pesé. 754'35,06"N 80³8'57,24"W 63 m s.n.m., 1 Ene. 
2001, J. W. Armbruster, J. D. Evans, T. P. Pera \& D. C. Werneke. CAS 44280, 2 paratipos, 31,7-30,7 mm LE, [aproximadamente 8³4'24,59"N 7953'14,83"O 15 m s.n.m.], río Chame, [Ene. a Mar. 1911], S. Meek \& S. F. Hildebrand. FMNH 8945*, holotipo Gephyrocharax intermedius Meek \& Hildebrand, 1916, 57,6 mm LE (R), macho, [aproximadamente $8^{\circ} 34^{\prime} 24,59^{\prime \prime N} 79^{\circ} 53^{\prime} 14,83 " O 15$ m s.n.m.], río Chame, [Ene. a Mar. 1911], S. Meek \& S. F. Hildebrand. FMNH 12511*, 1 paratipo, 41,9 mm LE, [aproximadamente $8^{\circ} 34^{\prime} 24,59^{\prime \prime} \mathrm{N} 79^{\circ} 53^{\prime} 14,83^{\prime \prime O} 15$ m s.n.m.], río Chame, [Ene. a Mar. 1911], S. Meek \& S. F. Hildebrand. FMNH 12512*, 1 paratipo, 39,1 mm LE, [aproximadamente $8^{\circ} 34^{\prime} 24,59^{\prime \prime} \mathrm{N} 79^{\circ} 53^{\prime} 14,83^{\prime \prime} \mathrm{O} 15$ m s.n.m.], río Chame, [Ene. a Mar. 1911], S. Meek \& S. F. Hildebrand. FMNH 36760*, 1 paratipo, 61,1 mm LE, [aproximadamente entre $8^{\circ} 43^{\prime} 29,20^{\prime \prime} \mathrm{N} 79^{\circ} 53^{\prime} 8,29 " \mathrm{O} 139$ m s.n.m. y $8^{\circ} 27^{\prime} 43,85^{\prime \prime} \mathrm{N}$ 7958'33,37"O 43 m a. n. m], río Chame o varias pequeñas quebradas cercanas que cruzan la carretera Nacional entre Campana y La Venta, [10 Mar. 1937], S. F. Hildebrand. FMNH $36761^{*}, 1$ paratipo, 56,4 mm LE, [aproximadamente entre $8^{\circ} 43^{\prime} 29,20^{\prime \prime} \mathrm{N} 79^{\circ} 53^{\prime} 8,29^{\prime \prime} \mathrm{O}$ 139 m s.n.m. y $8^{\circ} 27^{\prime} 43,85^{\prime \prime N} 79^{\circ} 58^{\prime} 33,37^{\prime \prime O} 43$ m a. n. m], río Chame o varias pequeñas quebradas cercanas que cruzan la carretera Nacional entre Campana y La Venta, [10 Mar. 1937], S. F. Hildebrand. INHS 53206, 6, 14,5-26,8 mm LE, Coclé, río Coclé del Sur, 1 km al sur de La Pintada, 8³4'03"N 80²5'58"O aproximadamente 58 m s.n.m., 11 Sep. 1999, L. M. Page \& S. M Phelps. INHS 53216, 10, 35,5-40,3 mm LE, Chiriquí, río Chiriquí, 3 km E Guayaba, 8²6'13"N 82¹9'08"O aproximadamente 32 m s.n.m., 9 Sep. 1999, L. M. Page \& S. M. Phelps. LACM 56203-003, 2, 24,9-25,0 mm LE, Coclé, río Grande en la carretera 1 sobre el puente y arriba $20 \mathrm{~km}$ suroeste de Penonomé, 8²5'0"N 80³0'0"O aproximadamente 18 m s.n.m., 23 Jul. 2003, M. Hardman, G. Reina \& R. Belancus. LACM 56202-004, 2, 24,7-28,9 mm LE, Coclé, río Chorrera, sobre la carretera 1 en el puente, aproximadamente $8 \mathrm{~km}$ SSE de Penonomé, 8²6'29,00"N 80¹8'57,00"O $31 \mathrm{~m}$ s.n.m., 23 Jul. 2003, M. Hardman, G. Reina \& R. Belancus. STRI 1199, 1, 38,8 mm LE, Veraguas, río San Pablo, 8¹1'59"N 81¹5'2"O aproximadamente 56 m s.n.m., 19 Ago. 1993, sin datos. STRI 1200, 1, 36,0 mm LE, Herrera, río La Villa, 754'5"N 80³1'24"O aproximadamente 23 m s.n.m., 23 Dic. 1993, sin datos. STRI 1205, 2 d\&t, 41,1-41,2 mm LE, Veraguas, cuenca río Santa María, río Las Lajas, 8²1'10"N 8047'57"O aproximadamente 225 m a.n.m. STRI 1208, 2, río Chiriquí, quebrada en nueva carretera en Gualaca, 8³6'30,6"N 82¹7'51,1"O aproximadamente 266 m s.n.m., 25 Feb. 1998, sin datos. STRI 1209, 2 (d\&t), 40,8-42,6 mm LE, río Chame, 8³9'10,0"N 7957'71,3”O 207 aproximadamente m s.n.m., 1 Ene. 1998, sin datos. STRI 5944, 2, 43,0-43,3 mm LE, 
Coclé, sistema río Coclé del Norte, río Toabre, quebrada Tortuguita, quebrada Los

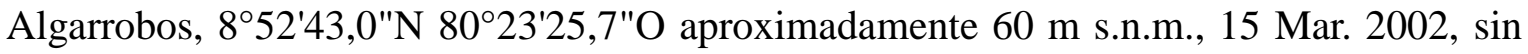
datos. STRI 5945, 2, 44,0-44,1 mm LE, Coclé, cuenca río Coclé del Norte, río Moreno, $8^{\circ} 46^{\prime} 00^{\prime} \mathrm{N} 80^{\circ} 32^{\prime} 10,1$ ' $\mathrm{O}$ aproximadamente 106 m s.n.m., 3 Oct. 2002, sin datos. STRI 7654, 2, 34,0-36,5 mm LE, río Chiriquí, quebrada Grande, 8²7'52"N 82²2'36,7"O aproximadamente 71 m s.n.m., 6 Ene. 2001, sin datos. UF 27525, 72, 20,0-36,2 mm LE, en el segundo puente sobre la carretera Panamericana al $\mathrm{N}$ de la carretera a El Valle, muy cerca de la cuenca del río Chame, aproximadamente 8³3'49,37"N 7953'35,13"O $30 \mathrm{~m}$ s.n.m., 24 Abr. 1965, F. W. Brockmann et al. USNM 78556, 26 paratipos, 23,8-36,5 mm LE (2R 34,4-36,5 mm LE), [aproximadamente 8³4'24,59"N 7953'14,83"O 15 m s.n.m.], río Chame, 14 Feb. 1912, S. Meek \& S. F. Hildebrand. USNM 106513, holotipo Gephyrocharax whaleri Hildebrand, 1938, 39,4 mm LE (R), macho, [aproximadamente entre $8^{\circ} 43^{\prime} 29,20^{\prime \prime} \mathrm{N} 79^{\circ} 53^{\prime} 8,29^{\prime \prime O} 139$ m s.n.m. y 8²7'43,85"N 7958'33,37"O 43 m a. n. $\mathrm{m}]$, río Chame o varias pequeñas quebradas cercanas que cruzan la carretera Nacional entre Campana y La Venta, 10 Mar. 1937, S. Hildebrand. USNM 109276, 39 paratipos, 19,0-47,9 mm LE, [aproximadamente entre 843'2920"N 7953'829"O 139 m s.n.m. y $8^{\circ} 27^{\prime} 43,85^{\prime \prime} \mathrm{N} 79^{\circ} 58^{\prime} 33,37^{\prime \prime O} 43 \mathrm{~m}$ a. n. m], río Chame o varias pequeñas quebradas cercanas que cruzan la carretera Nacional entre Campana y La Venta, 10 Mar. 1937, S. Hildebrand. USNM 235926 (antes USNM 109276), 2 paratipos, 37,2-40,1 mm LE (2R), [aproximadamente entre $8^{\circ} 43^{\prime} 29,20^{\prime \prime} \mathrm{N} \quad 79^{\circ} 53^{\prime} 8,29^{\prime \prime O} 139$ m s.n.m. y $8^{\circ} 27^{\prime} 43,85^{\prime \prime} \mathrm{N}$ 7958'33,37"O 43 m a. n. m], río Chame o varias pequeñas quebradas cercanas que cruzan la carretera Nacional entre Campana y La Venta, 10 Mar. 1937, S. Hildebrand. USNM 236104, 5 (d\&t), 32,2-36,9 mm LE, Los Santos, cuenca río La Villa, río Tebario, cerca de 3 millas al O de Llano de Piedra, aproximadamente 740'7,11"N 80³4'41,67"O 115 m s.n.m., 30 Sep. 1961, H. Ldetin \& E. Tyson.

\section{Gephyrocharax major Myers, 1929}

Figs. 5b-6, 14, 17, 21, 24 y 33-35, Tablas 1 y 7

Gephyrocharax major Myers en Eigenmann \& Myers, 1929: 477 y 479-480 (clave, descripción original, designación material tipo, nueve sintipos "cotipos" CAS 
44286 [IU 17290], localidad tipo: río Popoi, Alto Beni). Pearson, 1924: 46 (material examinado mal identificado como G. chocoensis). Schultz, 1944: 323 (clave). Böhlke, 1958: 51 (comentario similitud con G. chaparae). Weitzman \& Fink, 1985: 103 (material examinado). Weitzman, 2003: 224 (cita en catálogo). Carvalho, Flores, Espino, Trevejo, Ortega, Jerep, Reis \& Albert, 2012: 975 y 993, tabla 2, figura apéndice (río Las Piedras, cuenca río Madre de Dios, Perú). Ortega, Hidalgo, Trevejo, Correa, Cortijo, Meza \& Espino, 2012: 36 (lista de peces de Perú). Bonilla-Rivero \& López-Rojas, 2013: 489, fig. 1 (mapa). Vanegas-Ríos, Azpelicueta, Mirande \& Gonzales, 2013: 282 (material examinado).

Gephyrocharax chaparae Fowler, 1940: 70-72, fig. 25-27 (descripción original, designación material tipo, holotipo ANSP 68967, localidad tipo: río Chapare, Todos Santos). Schultz, 1944: 322 (clave, orth. mut. "chaporae”). Chernoff, Machado-Allison, Willink, Sarmiento, Barrera, Menezes \& Ortega, 2000: 274 y 279, tabla 1 (lista de peces Amazonia Boliviana, error grafía "chapare"). Weitzman, 2003: 224 (cita en catálogo). Bonilla-Rivero \& López-Rojas, 2013: 489, fig. 1 (mapa). Vanegas-Ríos, Azpelicueta, Mirande \& Gonzales, 2013: 282 (material examinado). (Nueva sinonimia).

Corynopomops opisthopterus Fowler, 1943: 6-7, fig. 4 (descripción original sobre un ejemplar, designación material tipo, holotipo ANSP 69195, localidad tipo: Bolivia, Todos Santos). Böhlke, 1958: 40, 42-43 y 50-51, tabla 1 (revisión, nueva sinonimia con G. chaparae). Weitzman \& Fink, 1985: 2 (igual conclusión y sinonimia que Böhlke, 1958). Weitzman, 2003: 224 (sinonimia de G. chaparae en catálogo). Vanegas-Ríos, Azpelicueta, Mirande \& Gonzales, 2013: 282 (citado como sinónimo de G. chaparae, material examinado). (Nueva sinonimia).

Diagnosis. Gephyrocharax major se distingue de sus congéneres por los radios 11 y 12 de la aleta caudal muy curvados ventralmente a lo largo de su longitud en machos adultos ( $v s$. rectos a lo largo de su longitud), el nasal en vista dorsal con su borde lateral muy cóncavo, arqueado en un ángulo igual o menor a $135^{\circ}(\mathrm{vs}$. recto a lo largo de toda su longitud o apenas cóncavo, arqueado en un ángulo menor a $135^{\circ}$ ), por los radii de la escama-bolsillo que se distribuyen a lo largo del borde dorsal y posterior en los machos adultos ( $v s$. distribuido únicamente sobre el borde posterior) y (excepto G. chocoensis) por una moderada separación entre los radios 12 y 13 de la aleta caudal en los machos adultos, no causada por el desarrollo posteroventral de los interradialis (vs. una muy fuerte separación 
o divergencia entre estos radios, acompañada por un fuerte desarrollo posteroventral de los interradialis). La especie también difiere de sus congéneres por la base del radio 12 de la aleta caudal que se extiende sobre la porción posterior del segundo hueso hipural, excepto en G. intermedius y en G. martae ( $v s$. tal base extendida sobre la porción posterior del primer hueso hipural o sobre un espacio angosto formado entre el primer y segundo hipurales). La especie se distingue de G. martae por la distancia hocico-origen aleta pectoral 24,3-29,9 \% LE ( $v s .20,7 \%$ LE). Gephyrocharax major difiere de $G$. melanocheir, G. torresi y G. valencia por la presencia del tubo terminal de la línea lateral entre los radios caudales 10 y 11 (vs. ausencia de este tubo). Gephyrocharax major también se diferencia de G. atracaudatus, G. caucanus, G. chocoensis, G. intermedius y G. valencia por dos fibras tendinosas que se insertan posteriormente desde el flexor dorsalis superior hacia los radios de la aleta caudal ( $v s$. una sola fibra tendinosa insertada posteriormente). Caracteres adicionales que distinguen a G. major de G. atracaudatus, $G$. caucanus, G. chocoensis y $G$. intermedius fueron mencionados en las diagnosis respectivas de estas especies. Véase también la lista de autapomorfías mencionadas para G. major.

Descripción. Datos morfométricos en la tabla 7. Macho de mayor tamaño con 60,0 mm LE, hembra de mayor tamaño con 64,4 mm LE. Cuerpo lateralmente comprimido, con altura máxima en un punto entre los orígenes de las aletas anal y pélvica. Perfil dorsal de la cabeza apenas convexo desde el borde del labio superior hasta el extremo distal del proceso ascendente de la premaxila y recto desde este punto hasta la espina supraoccipital. Perfil dorsal del cuerpo un poco convexo desde la porción posterior de la espina supraoccipital hasta el origen de la aleta dorsal, desciende en sentido posteroventral a lo largo de la base de la aleta dorsal y continúa recto desde el radio dorsal más posterior hasta el pedúnculo caudal (Fig. 33). Perfil ventral del cuerpo convexo desde la punta del hocico hasta el origen de la aleta pélvica, apenas convexo desde este punto hasta el origen de la aleta anal y asciende posterodorsalmente recto desde el origen anal hasta el inicio del pedúnculo caudal. Fontanela anterior ausente (con frecuencia en ejemplares adultos los frontales se contactan posterior a la barra epifisaria) o reducida a una abertura muy pequeña anterior a la barra epifisaria. Narina anterior redondeada y separada por un pliegue de piel de la narina posterior de mayor tamaño. Hendidura extendida desde un punto medio entre el poro posterior del nasal y las narinas hasta la región posterior de los 
frontales, con al menos tres hileras de neuromastos. Hendidura más pequeña con pocos neuromastos sobre la región entre las narinas y los huesos nasales.

Aleta dorsal con ii,7 (6), 8* (199) o 9 (3) radios y $8^{*}$ o $9 * * / * * *$ pterigióforos proximales. Origen de la aleta dorsal en la vertical que pasa por la base de los radios 5 a 11 de la aleta anal. Aleta adiposa presente, su origen al nivel de un punto medio entre las bases de los últimos dos radios posteriores de la aleta anal. Aleta anal con iv (12), $\mathrm{v}^{*} / * *$ (160) o vi (35),26 (1), 27 (1), 28 (2), 29 (31), 30** (46), 31 (50), 32* (43), 33 (23), 34 (6) o 35 (4) radios y 29-34 pterigióforos proximales (holotipo ANSP 69195 con vi,12 radios, malformado y no incluido en las comparaciones). Origen de la aleta anal más cerca del origen de la unión hipural que de la punta del hocico. Aleta pectoral con i,9 (12), 10*/*** (97), 11** (86) o 12 (10) radios. Aleta pectoral larga, alcanza entre un cuarto y tres cuartos de la longitud de la aleta pélvica. Aleta pélvica con i,6 (205) radios en todos los ejemplares examinados. Origen de la aleta pélvica localizado en la vertical que pasa por las escamas 8 a 11 de la línea lateral y anterior a la mitad del cuerpo. Aleta caudal bilobulada con 10/9 radios principales.

Hocico superior, con la mandíbula inferior apenas anterior a la punta de la mandíbula superior. Premaxila con dos hileras de dientes; hilera externa con 2 (1), $3 * * *$ (49), 4*/** (135) o 5 (21) dientes; por lo general tricúspides y pocas veces bicúspides o cónicos. Hilera interna con 4* (194) o 5 (15) dientes; el sinfisial tetracúspide, los demás pentacúspides y raras veces tetracúspides. Maxila sin dientes (1) o con $1 *$ (85), 2 (111) o 3 (10) dientes tricúspides, tetracúspides o pentacúspides (ejemplares de mayor tamaño por lo general con mayor número de cúspides y con el diente más dorsal muy ancho) (Fig. 34a). Maxila larga, alcanza posteriormente el tercio anterior del ojo. Dentario con 9 (1), 10 (11), $11 * * *(32), 12(28), 13 * / * *(37), 14(14), 15$ (9), 16 (3) o 17 (1) dientes; los tres más anteriores grandes y pentacúspides, seguidos por uno de tamaño mediano tricúspide a pentacúspide y 5 (1), 6 (11), 7*** (32), 8 (28), 9*/** (37), 10 (14), 11 (9), 12 (3) o 13 (1) dientes más pequeños cónicos a tricúspides que poco a poco disminuyen en tamaño en sentido anteroposterior a lo largo del borde dorsal del dentario (Fig. 34b).

Escamas cicloides, con numerosos radii a lo largo del campo posterior. Línea lateral completa. Escamas con poros 40 (3), 41 (17), 42** (33), 43* (55), 44 (65), 45 (21), 46 (9), 47 (2), 48 (1) (holotipo ANSP 69195 con escamas perdidas, posiblemente 38). Tubo terminal de la línea lateral presente. Escamas predorsales 17 (23), 18** (54), 19 (64), 20* (40), $21 * * *(19)$ o 22 (3). Hileras de escamas entre la aleta dorsal y la línea lateral 6 (102) o $7 *(104)$. Hileras de escamas entre la línea lateral y la aleta anal $5 * * / * * *$ 
(111) o 6* (96). Hileras de escamas entre la línea lateral y la aleta pélvica 4 (18), $5^{* * *}$ (164) o $6 * / * *(62)$. Escamas circumpedunculares 14 (10), 15 (35), 16*/** (83), 17*** (45) o 18 (9). Una o dos hileras de escamas dispuestas a lo largo del $80 \%$ o casi toda la longitud de la base de la aleta anal (perdidas en holotipos ANSP 68967 y 69195 y lectotipo CAS 44286) de 14 (1), 15 (2), 17 (2), 18 (1), 20 (3), 21 (2), 23(60), 24 (9), 25 (5), 26 (15), 27 (19), 28 (12), 29 (11), 30 (6), 31 (5) o 32 (5) escamas. Número total de vértebras 39 (7), $40 * / * *(13), 41$ (7) o 42 (1), 16 (7), 17*/** (21) o 18 (1) precaudales y 22 (4), 23** (13), 24 (8) o 25 (2) caudales; holotipo ANSP 69195 malformado con 34, 23 у 17 respectivamente (17 ejemplares radiografiados y 14 ejemplares d\&t). Rastrillos branquiales del primer arco branquial $6(11), 7 *(98)$ o 8 (18) sobre la porción dorsal y 11 (2), 12 (55), 13* (63) o 14 (6) sobre la porción ventral.

Coloración en alcohol. Cuerpo amarillento pálido o marrón claro tenue, más oscuro en la línea media dorsal y un poco más claro en la zona ventral. Cromatóforos marrones, marrones oscuros o negros diminutos cubren la superficie del cuerpo, excepto, o en menor cantidad, sobre la región lateral abdominal y las regiones ventrales preanal y del pedúnculo caudal. Línea lateral marrón oscura o negra o en general una banda lateral plateada extendida desde la región posterior a la mancha humeral y un punto dorsal al origen de la aleta pélvica hasta el pedúnculo caudal. Cromatóforos marrones oscuros o negros distribuidos sobre los mioseptos entre la línea lateral y la porción superior de la aleta anal. Mancha humeral marrón, marrón oscura o negra verticalmente alargada (en algunos ejemplares de forma irregular). Mancha caudal marrón oscura o negra, algo ovoide, longitudinalmente alargada y extendida desde la región posterior del pedúnculo caudal, cubre los interradialis, hasta la base de los radios medios de la aleta caudal. Aleta dorsal gris clara o amarilla tenue, con cromatóforos marrones oscuros o negros distribuidos a lo largo de los bordes de los radios y las membranas. Aleta anal gris clara, con cromatóforos marrones oscuros o negros distribuidos en su mayoría sobre las membranas y a veces muy agrupados en las bases de estas. Aleta caudal gris clara, un poco oscurecida por la presencia de cromatóforos marrones oscuros o negros en su mayoría distribuidos a lo largo de los radios y en mayor cantidad sobre los radios medios caudales. Aletas pectoral y pélvica grises claras o a veces amarillas tenue, sin cromatóforos o solo unos pocos distribuidos en especial sobre los radios. Cabeza más oscura dorsal que ventralmente. Opérculo e infraorbitales con unos pocos cromatóforos marrones o negros. Premaxila, porción anterior de la maxila, dentario y labios con cromatóforos marrones oscuros o negros poco concentrados y algunas veces dispersos. 
Variaciones en la coloración entre machos y hembras se describen en el dimorfismo sexual.

Dimorfismo sexual. Ejemplares machos con ganchos óseos en los radios de las aletas anal, caudal y pélvica. Aleta caudal con ganchos cortos, finos y orientados en sentido anterodorsal, en especial sobre las porciones ramificadas dorsales de los radios 13 a 16 . Todos los radios de la aleta pélvica, excepto el último radio proximal, con uno o dos ganchos finos por segmento (casi nunca pareados), un poco más numerosos en las bases, orientados en sentido anteroventral y localizados en casi toda la longitud y sobre el costado medial de los radios y/o sus ramificaciones. Aleta anal con ganchos finos, de base ancha, pareados por segmento y situados en sentido anterodorsal o anterolateral en los radios; con tres a 17 pares de ganchos localizados sobre el radio simple más posterior y los primeros ocho radios ramificados anteriores (los ganchos son más largos en los radios centrales y posteriores de este intervalo). Los machos adultos tienen con frecuencia el borde basal de la aleta anal un poco cóncavo en su porción central o algo curvado, mientras que las hembras lo tienen recto. Aleta anal con forma un poco convexa en los machos adultos (a veces el radio simple más posterior y los primeros 15 o 17 radios ramificados similares en longitud entre sí y un poco más largos que el resto), mientras que es recta o un poco cóncava en las hembras. Hembras adultas no tienen papila urogenital externamente.

Los machos adultos algunas veces con cromatóforos más numerosos y concentrados en las membranas de los radios de la aleta anal y en las porciones de los radios de la aleta caudal mediales a la escama-bolsillo. Machos maduros con los radios 11 y 12 de la aleta caudal muy curvados a lo largo de toda su longitud, mientras que estos radios son rectos a lo largo de su longitud en las hembras. Machos maduros con una escama modificada para formar un bolsillo sobre el lóbulo ventral de la aleta caudal y con el segundo y tercer radios procurrentes ventrales modificados en forma de una estructura tipo pinza, ventral al radio principal 19. Tejido de apariencia glandular en poca cantidad o a veces muy poco desarrollado, localizado en su mayoría sobre los radios de la aleta caudal y medial a la escama-bolsillo. Estructura tipo pinza osificada en su porción distal, algunas veces el segundo radio procurrente ventral termina en una pequeña pieza de cartílago, y alcanza la mitad de la longitud del primer radio procurrente ventral (Fig. 24c). El segundo y tercer radios procurrentes ventrales rectos o un poco convexos, separados entre sí por un estrecha línea y fusionados en su porción posterior y distal en machos adultos de mayor tamaño. Primer radio procurrente ventral recto o un poco convexo en su 
porción ventral. Segundo radio procurrente ventral un poco más largo que el tercero o de similar longitud, un poco más expandido sagitalmente que el tercer radio procurrente ventral. Segundo y tercer radios procurrentes ventrales desarrollados sagital y lateralmente en igual proporción con respecto a los demás radios caudales. Escama-bolsillo hipertrofiada, con 15 a 38 radii distribuidos a lo largo de su borde dorsal y posteroventral y localizados entre el radio 10 o 11 a un punto sobre el primer y segundo radio procurrente ventral de la aleta caudal (Figs. 24c, d). Escama-bolsillo sin lóbulo posteroventral extendido a lo largo del tercer radio procurrente ventral. Superficie dorsal de la escamabolsillo anclada a través de un tejido blando o conectivo a los radios de la aleta caudal 10 o 11 a 13. Borde posterior de la escama-bolsillo localizado entre los radios 10 o 11 y el tercer radio procurrente ventral de la aleta caudal (casi nunca el borde dorsal del cuarto). Cinco o seis escamas en serie vertical, justo debajo de la escama más posterior de la línea lateral, sobre la porción posterior de la escama-bolsillo. Borde posterodorsal de la escamabolsillo con una hendidura moderada o bien desarrollada (solo en machos completamente maduros) que en parte permite el anclaje de tejido blando o conectivo. Porción ventral de la escama-bolsillo con dos escamas accesorias (una relativamente pequeña y otra de mayor tamaño muy alargada longitudinalmente), yuxtapuestas, independientes entre sí y en parte involucradas con la abertura del bolsillo. Escama accesoria de mayor tamaño (posterior con respecto a la otra accesoria) forma la región posteroventral del bolsillo y se extiende posterolateralmente sobre el segundo y tercer radios procurrentes ventrales. Las hembras con una escama grande con 18 (1), 19 (1), 20 (2), 22 (2), 23 (1), 25 (3), 26 (1), 29 (1), 35 (1) o 37 (1) radii.

Machos maduros con glándula branquial corta. Glándula branquial formada por 3 (1), 4 (2), 5 (2), 6 (5), 7 (6), 8 (8), 9 (23), 11 (6), 11 (11), 12 (6), 13 (1) o 14 (1) filamentos branquiales modificados de la porción ventral del primer arco branquial funcional. Número total de filamentos branquiales en la porción ventral 21 (3), 24 (1), 25 (7), 26 (2), 27 (9), 28 (9), 29 (18), 30 (13), 31 (7) o 32 (7). Longitud de la glándula branquial 1,7-4,6 $\% \mathrm{LE}($ media $=3,0 \% \mathrm{LE})$.

Distribución. Se encuentran diferentes poblaciones en las cuencas de los ríos Yuruá, Nanay, Madre de Dios, Beni y Mamoré en la cuenca del río Amazonas de Bolivia y Perú (Fig. 21).

Comentarios. Los ejemplares de la serie tipo G. chaparae y G. major tuvieron morfología muy similar en las variadas comparaciones anatómicas llevadas a cabo. Durante la revisión de la serie tipo de G. chaparae se encontró que la serie de 11 paratipos designada 
por Fowler (1940: ANSP 68968 a 68978) estaba mezclada en el mismo frasco con 14 ejemplares topotipos (ANSP 69161, no mencionados en la descripción original) recolectados por las mismas personas en la misma expedición (8 de agosto de 1937). Estos ejemplares no pudieron separarse morfológicamente, fueron identificados como ejemplares de la misma especie y son analizados como tal. Fowler (1940) diferenció a $G$. chaparae de G. major por la mayor proporción de la longitud de la cabeza en la LE (3 con 4/5-4 vs. 4,2-4,4) y el menor número de escamas en la línea lateral (36-38 vs. 40-44). Después de examinar la serie tipo de ambas especies, se concluyó lo contrario, $G$. chaparae (ANSP 68967, ANSP 68969-68978 y 69161) y G. major (CAS 44286 y 236011) son completamente indistinguibles por estos caracteres (3,9-4,5 vs. 4,1-4,6 longitud cabeza en LE y 41-45 vs. 41-45 escamas). Además, no se encontraron datos merísticos o morfométricos útiles para separar estas dos especies; después de comparar la anatomía esquelética de los ejemplares tipos se obtuvo la misma conclusión. Un ACP de los datos morfométricos para comparar los ejemplares de la serie tipo de ambas especies confirmó que estos son parecidos entre sí y no forman grupos separados (Figs. 35a, b). Además, se compararon todos los caracteres usados en la matriz de caracteres del análisis filogenético para ejemplares afines geográficamente con las localidades tipo de ambas especies $(G$. major, cuenca del río Beni y G. chaparae, cuenca del río Chaparae) y no se encontraron diferencias morfológicas robustas para confirmar dos especies separadas. Estos resultados sostienen la hipótesis de que G. chaparae es un sinónimo junior de G. major, donde el último corresponde al nombre válido por principio de prioridad en sinonimias (artículos 23.1 y 23.3 del ICZN, 1999). El holotipo de Corynopomops opisthopterus fue considerado un sinónimo junior de G. chaparae por Böhlke (1958); esta decisión fue mantenida por Weitzman \& Fink (1985) y Vanegas-Ríos et al. (2013). Aunque este holotipo no fue incluido en el ACP a causa de su irregular forma, posiblemente malformado, después de compararlo con los ejemplares examinados de G. major y/o G. chaparae se obtuvo la misma conclusión, pero asignándose a $C$. opisthopterus como sinónimo de G. major en vez de G. chaparae para actuar en correspondencia con la sinonimia antes mencionada.

Un ACP de los datos morfométricos de varios grupos de ejemplares de G. major organizados por grandes cuencas hidrográficas (ríos Acre, Beni, Madre de Dios, Mamoré, Nanay, Tahuamanu, Ucayali y Yuruá) mostró que no existen diferencias para separarlos (Figs. 35c, d). Este resultado coincidió con la gran superposición encontrada en los datos merísticos y la coloración del cuerpo para cada grupo. De hecho, se compararon ejemplares d\&t de varias cuencas hidrográficas (río Beni, UMSS 10015; río Chapare, UF 
38194 y UMSS 2833; río Orton, MUSM 8518 y 21519 cuenca del río Ucayali, MUSM 18906 y 26100) a través de los caracteres de la matriz del análisis filogenético y nuevamente no se encontraron diferencias anatómicas robustas para apoyar la hipótesis de que algún grupo correspondiese con una nueva especie. Por lo tanto, se concluye que $G$. major es una especie ampliamente distribuida en la cuenca del río Amazonas; los ejemplares de las cuencas de los ríos Yuruá y Nanay se consideran nuevos registros geográficos de esta especie, donde el último corresponde al registro latitudinal del género más norteño y cercano al paralelo del Ecuador en la cuenca del río Amazonas.

En este estudio se designó un lectotipo (mantiene el número CAS 44286) de los respectivos sintipos de Gephyrocharax major, mientras los restantes ejemplares de la serie de sintipos son designados como paralectotipos (CAS 236011). Myers en Eigenmann \& Myers (1929) cuando describió a G. major referenció el lote IU 17291 (= actual CAS 44286) como cotipos (= sintipos, artículo 73.2 y 73.2.1 del ICZN, 1999); ningún otro grupo de ejemplares fue indicado como parte de la serie tipo. De acuerdo con la recomendación 16E del ICZN (1999) un tipo debería ser mejor que un grupo de sintipos (= cotipos). Myers en Eigenmann \& Myers (1929) tampoco presentó una figura o fotografía de la especie o de algún ejemplar atribuible como "tipo". Como no se encontró evidencia de ningún “tipo” en la descripción de Myers en Eigenmann \& Myers (1929) que pudiese tomar el lugar de lectotipo, el ejemplar designado es un macho en buen estado de preservación que porta la información morfológica característica del género y la especie.

Material examinado. Bolivia: ANSP 68967, holotipo Gephyrocharax chaparae Fowler, 1940, 32,8 mm LE (R), hembra, [Cochabamba, aproximadamente 16²7'59,99"S 65'59,99"O 215 m s.n.m.], Todos Santos, río Chapare, 8 Ago. 1937, M. A. Carriker \& G. Howes. ANSP 68968 a 68978 y 69161 (ejemplares no separables), 25 paratipos (11 ejemplares paratipos mezclados con 14 topotipos), 24,5-44,7 mm LE (3R 30,2-44,7 mm LE), [Cochabamba, aproximadamente 1647'59,99"S 65²'59,99"O 215 m s.n.m.] Todos Santos, río Chapare, 8 Ago. 1937, M. A. Carriker \& G. Howes. ANSP 69195, holotipo Corynopomops opisthopterus Fowler, 1943, 30,9 mm LE (R), [Cochabamba, aproximadamente $16^{\circ} 47^{\prime} 59,99^{\prime S}$ 65'59,99"O 215 m s.n.m.], Todos Santos, río Chapare, 8 Ago. 1937, M. A. Carriker \& G. Howes. AUM 23725, 1, 25,3 mm LE, Beni, cuenca río Amazonas, cuenca río Madeira, tributario del río Beni casi $15 \mathrm{~km} \mathrm{~S}$ Rurrenabaque, aproximadamente $14^{\circ} 33^{\prime} 38,14^{\prime \prime S} 67^{\circ} 29^{\prime} 43,28^{\prime \prime O} 232$ m s.n.m., 14 Ene. 1982, C. K. Swing \& M. Lutz. CAS 44286 (antes sintipos), lectotipo Gephyrocharax major por presente designación, 40,6 mm LE (R), macho, [La Paz, cerca a Popoy, aproximadamente 
$15^{\circ} 37^{\prime} 0,12^{\prime \prime} \mathrm{S} 67^{\circ} 17^{\prime} 60,00 " \mathrm{O} 532$ m s.n.m.] cuenca alta río Beni, río Popoi [o río Popoy], Sep. 1921, N. E. Pearson. CAS 78813, Beni, cuenca río Amazonas, río Beni, Rurrenabaque, aproximadamente 14²6'29,65"S 67³1'54,64"O 333 m s.n.m., Sep. 1921, N. E. Pearson. CAS 236011 (antes CAS 44286 sintipos), 8 paralectotipos Gephyrocharax major por presente designación, 35,4-55,8 mm LE (8R), mismos datos del lectotipo. UF 30697, 54, 23,1-28,4 mm LE, Sara, Santa Cruz, pequeños arroyos y charcos $3 \mathrm{~km} \mathrm{~S}$ de Santa Rosa, aproximadamente 176'51,42"S 63³5'52,76"O 262 m s.n.m., 27 Feb. 1969, R. E. Woodruff. UF 38194, 7, 41,4-46,8 mm LE (2 d\&t 45,4-46,5 mm LE), Cochabamba, Chapare, quebrada $7 \mathrm{~km} \mathrm{NW}$ de Villa Tunari, aproximadamente 16 $566^{\prime} 51,34^{\prime \prime S}$ 65²2'19,07"O 268 m s.n.m., 9 Dic. 1982, F. G. Thompson. UF 82024, 6, 25,1-40,1 mm LE, Beni, Yacuma, arroyo Seco, tributario río Matos $29 \mathrm{~km} \mathrm{E,} 12 \mathrm{~km} \mathrm{~S} \mathrm{San} \mathrm{Borja,}$ 14 ${ }^{\circ} 58^{\prime} 60,00 " S$ 66²6'0,00"O 202 m s.n.m., 3 Sep. 1986, J. L. Tello. UF 82333, 29, 18,531,6 mm LE, Santa Cruz, Andrés Ibáñez, cuenca del río Piray, río Jorge $12 \mathrm{~km} \mathrm{O}$ de Warnes, $1^{\circ} 27^{\prime} 27,73^{\prime \prime S} 63^{\circ} 13^{\prime} 13,79 " O 327$ m s.n.m. 8 Oct. 1986, F. G. Thompson. UMSS 1163, 1, 22,8 mm LE, Cochabamba, cuenca del río Mamoré, Isiboro, Chipiriri, río Colonia Santa Rosa, $16^{\circ} 50^{\prime} 42,85^{\prime \prime S} 65^{\circ} 23^{\prime} 44,33^{\prime \prime O}$ aproximadamente 243 m a. n. m, 6 Jun. 2004, J. Zubieta, R. Bigorne \& N. Moya. UMSS 1894, 1, 35,1 mm LE, cuenca del río Mamoré, Isiboro, Chipiriri, río Santa Fé, 16²4'10,81"S 18'30,46"O 225 m s.n.m., 16 May. 2006, J. Zubieta, R. Bigorne \& N. Moya. UMSS 2833, 25, 33,2-50,9 mm LE (2 d\&t 43,7-50,2 mm LE), Cochabamba, cuenca del río Mamoré, Isiboro, Chipiriri, río Senda Bayer, $16^{\circ} 53 ' 5,15^{\prime S}$ 65²3'3,53"O aproximadamente 254 m s.n.m., 17 May. 2006, J. Zubieta, R. Bigorne \& N. Moya. UMSS 2868, 6, 40,2-45,3 mm LE, cuenca del río Mamoré, Isiboro, Chipiriri, río Villa Samual San Juan, 16²5'56,51"S 65²0'44,03"O aproximadamente 249 m s.n.m., 18 May. 2006, J. Zubieta, R. Bigorne \& N. Moya. UMSS 3468, 15, 34,8-50,5 $\mathrm{mm}$ LE, Isiboro, cuenca del río Mamoré, cuenca río Chipiriri, río Senda Bayer, $16^{\circ} 52^{\prime} 0,04 " \mathrm{~S} 65^{\circ} 23 ' 26,46 " \mathrm{O} 245$ m s.n.m., 9 Jul. 2006, J. Zubieta, N. Moya \& B. De Merona. UMSS 3818, 10, 31,0-50,8 mm LE, cuenca del río Mamoré, Isiboro, Chipiriri, río Colonia Senda Bayer, 1651'4,95"S 65²1'40,63"O aproximadamente 240 m s.n.m., 26 Oct. 2004, J. Zubieta, C. Ibáñez \& R. Bigorne. UMSS 3997, 1, 38,1 mm LE, cuenca del río Mamoré, Isiboro, Chipiriri, río de Villa General Barrientos, 16²49'38,90"S 65²2'2,73"O aproximadamente 232 m s.n.m., 2 Ago. 2004, J. Zubieta, R. Bigorne \& N. Moya. UMSS 4386, 4, 27,5-32,3 mm LE, Madeira, cuenca del río Mamoré, Ichilo Arroyo 15 de Junio, Puerto Cochabamba, 16²51'57,30"S 65²'55,21"O aproximadamente $229 \mathrm{~m}$ s.n.m., 10 Jul. 2003, F. Carvajal, M. Maldonado \& L. Córdova. UMSS 4449, 5, 30,6-35,7 
mm LE, Madeira, cuenca del río Mamoré, Ichilo, arroyo Sin Nombre, 1652'44,45"S 65²7'50,89"O aproximadamente 271 m s.n.m., 26 Jun. 2003, F. Carvajal, L. Córdova \& E. De La Barra. UMSS 4673, 5, 35,1-51,0 mm LE, cuenca río Mamoré, Isiboro, Chipiriri, río de Villa 14 de Septiembre, 1650'26,33"S 65²0'41,77"O aproximadamente $234 \mathrm{~m}$ s.n.m., 6 Oct. 2004, J. Zubieta, C. Ibáñez \& R. Bigorne. UMSS 4765, 6, 21,2-26,3 mm LE, cuenca del río Mamoré, Isiboro, Chipiriri, río Chipiriri, $16^{\circ} 53^{\prime} 40,61^{\prime \prime S} 65^{\circ} 23^{\prime} 4,45^{\prime \prime O}$ aproximadamente 263 m s.n.m., 4 Jun. 2004, J. Zubieta, R. Bigorne \& N. Moya. UMSS 4787, 1, 41,8 mm LE, cuenca del río Mamoré, Isiboro, Chipiriri, Río Colonia Santa Fé, 16 52'12,89"S 65¹9'59,31"O aproximadamente 243 m s.n.m., 8 Jun. 2004, J. Zubieta, R. Bigorne \& N. Moya. UMSS 5260, 5, 39,7-49,0 mm LE, cuenca del río Mamoré, Isiboro, Chipiriri, río de Villa 14 de Septiembre, 16 50 '25,52"S 65¹6'32,95"O aproximadamente 226 m s.n.m., 7 Oct. 2004, J. Zubieta, C. Ibáñez \& R. Bigorne. UMSS 5289, 12, 34,9-47,1 mm LE ( 2 t\&m 43,6-44,9 mm LE), cuenca del río Mamoré, Isiboro, Chipiriri, río Colonia San Carlos, 1650'40,21"S1650'40,21"S aproximadamente 232 m s.n.m., 5 Ago. 2005, J. Zubieta, C. Ibáñez \& R. Bigorne. UMSS 5428, 3, 39,1-53,3 mm LE, cuenca del río Mamoré, Isiboro, Chipiriri, río Porvenir, 16²9'58,04"S 65¹8'37,67"O 234 m s.n.m., 5 Oct. 2004, J. Zubieta, R. Bigorne \& N. Moya. UMSS 6685, 2, 45,1-45,7 mm LE, Madeira, cuenca río Mamoré, Ichilo, río Fabopal, 1658'39,06"S 65¹3'40,03"O aproximadamente 248 m s.n.m., 9 Nov. 2002, F. Carvajal, L. Córdova \& De La Barra. UMSS 9708, 3, 35,539,5 mm LE, La Paz-Beni, Amazonas, Madeira, Beni, Alto Beni, Mapuri Chuqui, $15^{\circ} 32^{\prime} 0,42^{\prime \prime} \mathrm{S} 67^{\circ} 23^{\prime} 10,53 " \mathrm{O}$ aproximadamente 406 m s.n.m., 6 Nov. 2009, J. Zubieta, E. De la Barra \& Calamani. UMSS 10015, 5, 31,8-42,0 mm LE (2 d\&t 32,7-41,2 mm LE), La Paz-Beni, Amazonas, Madeira, Beni, Alto Beni, arroyo Tacuaral, Tohomonoco, 15²7'16,68"S 67²6'54,48"O aproximadamente 396 m s.n.m., 4 Nov. 2009, J. Zubieta, E. De la Barra \& Calamani. Perú: ANSP 142379, 3, 26,3-27,5 mm LE, Madre de Dios, Parque Nacional Manu, río Manu muy cerca a Cosha Cashu, 1159’30”S 71¹4'O aproximadamente 392 m s.n.m., 9 Ago. 1977, R. Horwitz. ANSP 142385, Cuzco/Madre de Dios, desembocadura del río Carbón, abajo de Atalaya sobre la carretera norte-sur y arriba y abajo de Ford, $12^{\circ} 53$ 'S $71^{\circ} 20^{\prime} \mathrm{O}$ aproximadamente 634 m s.n.m., 15 Jul. 1977, R. Horwitz. MUSM 171, 3, 47,0-64,4 mm LE, Ucayali, Coronel Portillo, Pucallpa, Ivita, cuenca río Ucayali, Neshuya, quebrada Lechería, aproximadamente 8²3'50,68"S 750'45,08"O 176 m s.n.m., 30 Jun. 1981, H. Ortega. MUSM 1929, 4, 37,5-54,7 mm LE, Madre de Dios, Parque Nacional Manu, Manu, Pakitza, quebrada Picaflor, aproximadamente $12^{\circ} 16^{\prime} \mathrm{S} 70^{\circ} 51^{\prime} \mathrm{O} 299$ m s.n.m., 3 Jul. 93, H. Ortega \& F. Chang. 
MUSM 3774, 1, 58,2 mm LE, Madre de Dios, Parque Nacional Manu, Manu, Pakitza,

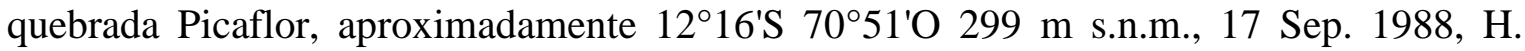
Ortega et al. MUSM 3829, 1, 55,3 mm LE, Parque Nacional Manu, Manu, Pakitza, quebrada Picaflor, aproximadamente $12^{\circ} 16^{\prime}$ S 7051'O 299 m s.n.m., 13 Sep. 1988, H. Ortega et al. MUSM 3840, 3, 44,7-50,9 mm LE, Madre de Dios, río Alto Madre de Dios, Manu, quebrada Salvación, aproximadamente 1252'36,04"S 71²21'30,28"O 497 m s.n.m., 5 Sep. 1988, H. Ortega et al. MUSM 4557, 4, 31,4-62,7 mm LE, Madre de Dios, Manu,

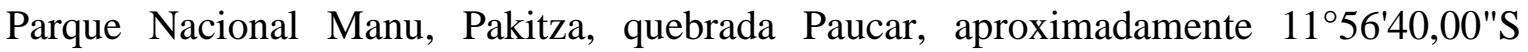
71²16'59,00"O 351 m s.n.m., 23 Jun. 1993, F. Chang. MUSM 4975, 3, 39,7-47,3 mm LE, Madre de Dios, Manu, Parque Nacional Manu, Pakitza, quebrada Martin Pescador, aproximadamente $11^{\circ} 56^{\prime} 40,00^{\prime \prime S ~} 71^{\circ} 16^{\prime} 59,00 " O \quad 351$ m s.n.m., 25 Jun. 1993, H. Ortega \& F. Chang. MUSM 8518, 7, 35,5-49,4 mm LE (1 d\&t 49,4 mm LE), Madre de Dios, Manu, Parque Nacional Manu, Pakitza, quebrada Martin Pescador, $11^{\circ} 566^{\prime} 40,00^{\prime S} \mathrm{~S} 71^{\circ} 166^{\prime} 59,00$ "O 351 m s.n.m., 14 Oct. 1991, H. Ortega \& E. Guevara. MUSM 9078, 1, 53,4 mm LE, Madre de Dios, Tambopata, SNPH, Pv. Enahuipe, río Palma Real, 12³2'3,21"S 6851'34,29"O 206 m s.n.m., 29 Jul. 1995, H. Ortega \& E. Castro. MUSM 12946, 2, 59,860,0 mm LE, Puno, Sandia, ZRTC, río Candamo, Cabeceras, quebrada Agua negra, aproximadamente $13^{\circ} 23^{\prime} 34,25^{\prime \prime S} 69^{\circ} 59^{\prime} 6,64 " O 433$ m s.n.m., 7 Dic. 1996, F. Chang \& G. Carreño. MUSM 13354, 6, 27,8-39,1 mm LE, Loreto, Maynas, Santa María de Nanay, río Nanay, aproximadamente $3^{\circ} 48^{\prime} 54,83^{\prime \prime S ~ 7323 ' 26,70 " O ~} 92$ m s.n.m., 26 Feb. 1998, E. Castro. MUSM 13390, 2, 49,4-53,7 mm LE, Cuzco, La Convención, Echarate, Sejakiato, río Camisea, quebrada Sejakiato, aproximadamente $11^{\circ} 42^{\prime} 52,58^{\prime \prime S} 72^{\circ} 55^{\prime} 42,66^{\prime \prime O} 409 \mathrm{~m}$ s.n.m., 07 Oct. 1997, M. Hidalgo. MUSM 14913, 38, 26,4-3,0 mm LE, Madre de Dios, Tahuamanu, río Tahuamanu, quebrada Nohage (Nohaya), aproximadamente 11²4'29,55"S 69³1'28,27"O 271 m s.n.m., May. 1999, J. Maco. MUSM 15744, 10, 32,049,3 mm LE, Madre de Dios, Parque Nacional Manu, Pakitza, río Manu, aproximadamente $12^{\circ} 15^{\prime} 53,48 " \mathrm{~S}$ 7051'9,89"O 307 m s.n.m., 10 Jun. 1993, H. Ortega. MUSM 15884, 3, 43,6-51,1 mm LE, Loreto, Ucayali, cuenca río Pisqui, Rashaya A, caño Vibora, aproximadamente $7^{\circ} 41^{\prime} 56,85^{\prime S}$ 75²'49,33"O 148 m s.n.m., 17. May. 1997, M. Hidalgo. MUSM 17729, 2, 55,3-57,0 mm LE, Ucayali, Coronel Portillo, cuenca del río Shesha, quebrada Paujil, $8^{\circ} 03^{\prime} 52^{\prime \prime S} 73^{\circ} 53^{\prime} 33,6^{\prime \prime O} 231$ m s.n.m., 18. Ene. 2001, M. Hidalgo. MUSM 17860, 1, 51,0 mm LE, Ucayali, Coronel Portillo, río Shesha, $8^{\circ} 05^{\prime} 46,4$ "S 7351'36,4"O 230 m s.n.m., 1 Abr. 2001, M. Hidalgo. MUSM 18906, 15, 35,9-47,2 mm LE (38,0-47,2 mm LE), Pasco, Oxapampa, Puerto Bermúdez, quebrada 
Atas, $10^{\circ} 21^{\prime} 5,4^{\prime \prime S} 74^{\circ} 58 ' 50,1^{\prime \prime O} 268$ m s.n.m., 09 Jul. 2001, Grupo EarthWatch. MUSM 18969, 6, 29,9-33,1 mm LE, Pasco, Oxapampa, Puerto Bermúdez, río Chivis, aproximadamente $10^{\circ} 17^{\prime} 46,68^{\prime \prime S} 74^{\circ} 56^{\prime} 2,44^{\prime \prime O} 243$ m s.n.m., 05 Jul. 2001, Grupo EarthWatch 1. MUSM 19304, 20, 31,2-49,7 mm LE, Pasco, Oxapampa, Puerto Bermúdez, quebrada Km 18, 10²0'12,6"S 7459'16,5"O 258 m s.n.m., 9 Jul. 2001 H. Ortega et al. MUSM 19380, 21, 28,0-37,6 mm LE, Huánuco, Pachitea, Puerto Inca, río Pintoyacu,

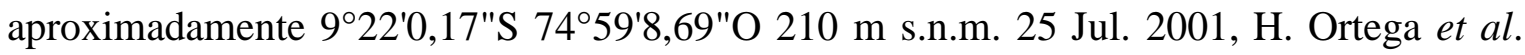
MUSM 19782, 8, 14,8-33,9 mm LE, Pasco, Oxapampa, Puerto Bermúdez, río Anacayali, aproximadamente $10^{\circ} 11^{\prime} 33,08^{\prime \prime S} 74^{\circ} 52^{\prime} 26,59^{\prime \prime O} 246$ m s.n.m., 7 Jul. 2001, EarthWatch. MUSM 20919, Madre de Dios, Tahuamanu, Iberia, quebrada María Cristina, 11²4’37,10S 69²8’24,97’O 167 m s.n.m., 7 Ago. 2003, EarthWatch. MUSM 20960, 6, 42,1-50,0 mm LE, Cuzco, La Convención, cuenca del río bajo Urubamba, Miaria, quebrada Charapa, $11^{\circ} 17^{\prime} 49,75^{\prime}$ 'S 72॰59’44,61”O 365 m s.n.m., 8 Sep. 2003, H. Ortega et al. MUSM 21338, 4, 43,6-47,1 mm LE, Madre de Dios, Tahuamanu, cuenca río Yaverija, quebrada Primavera, 110’34,87"S 69³3’25,67’O 273 m s.n.m., 12 Ago. 2003, H. Ortega et al. MUSM 21519, 45, 29,5-46,9 mm LE (3 d\&t 39,8-46,1 mm LE), Madre de Dios, Tahuamanu, cuenca río Tahuamanu, sistema río Acre, río Noaya, 11’40,11"S 69³4’27,33”O 289 m s.n.m., 11 Ago. 2003, H. Ortega et al. MUSM 22391, 6, 21,4-50,8 mm LE, Cuzco, La Convención, Miaria, cuenca río Bajo Urubamba, aproximadamente $11^{\circ} 18^{\prime} 17,36^{\prime \prime S} 72^{\circ} 59^{\prime} 34,03 " O 288$ m s.n.m., 5 Jun. 2003, H. Ortega et al. MUSM 23977, 7, 43,7-60,5 mm LE, Madre de Dios, Manu, cuenca río Los Amigos, río Los Amiguillos, quebrada sin nombre, $12^{\circ} 25^{\prime} 12,55^{\prime \prime S} 70^{\circ} 17^{\prime} 40,56 " O 267$ m s.n.m., 16 Jun. 2004, M. Hidalgo et al. MUSM 23978, 1, 39,0 mm LE, Madre de Dios, Manu, cuenca río Los Amigos, río Los Amiguillos, quebrada sin nombre, 12²5'12,55"S 70²1740,56"O $267 \mathrm{~m}$ s.n.m., 16 Jun. 2005, M. Hidalgo et al. MUSM 24397, 1, 55,1 mm LE, Madre de Dios, Manu, cuenca río Los Amigos, río Los Amiguillos, 12²5'23,90"S 70¹7'30,02"O $261 \mathrm{~m}$ s.n.m., 18 Jul. 2004, M. Hidalgo et al. MUSM 25423, 3, 47,6-56,5 mm LE, Madre de Dios, Tambopata, Mazuko, cuenca río Inambari, quebrada Isarael a izquierda río Inambari, 13ํ'40,01"S 70²4'37,17"O 330 m s.n.m., 5 Ago. 2004, H. Ortega et al. MUSM 25497, 2, 48,8-50,6 mm LE, Madre de Dios, Tambopata, Mazuko, Coricancha, cuenca río Inambari, quebrada Sachabacay, 136'22,90”S 70²4'45,27’O 331 m s.n.m., 5 Ago. 2004, H. Ortega et al. MUSM 26100, 10, 37,4-42,5 mm LE (2 d\&t 41,1-41,5 mm LE), Cuzco, La Convención, Echarate, cuenca río Bajo Urubamba, CCNN Miaria, quebrada Shimbillo, $11^{\circ} 21^{\prime} 47,36$ ”'S 730'3,99”O 308 m s.n.m., 12 Oct. 2005, H. Ortega et al. MUSM 26763, 
3, 51,0-61,5 mm LE, Cuzco, Quispicanchi, Camanti, cuenca río Araza, San Lorenzo, río Araza, $13^{\circ} 12^{\prime} 51,44^{\prime S}$ 70³2'57,12"O 405 m s.n.m., 24 Oct. 2005, M. Hidalgo. MUSM 27505, 7, 24,0-63,3 mm LE, Ucayali, Atalaya, Raimondi, cuenca río Yuruá, río Breu, quebrada 30 minutos aguas debajo de CCNN Paucar, 9³0'5,73"S 72²1'16,73"O $405 \mathrm{~m}$ s.n.m., 22 Mar. 2006, B. Rengifo \& V. Chipollini. MUSM 27641, 2, 28,2-32,9 mm LE, Ucayali, Atalaya, Raimondi, cuenca río Yuruá, río Breu, cocha 2 frente a CCNN Yacobina, 9³1'6,02"S 72²0’70,28"O 400 m s.n.m., 28 Mar. 2006, B. Rengifo \& V. Chipollini. MUSM 28073, 2, 12,6-33,6, Huánuco, cuenca río Pachitea, Honorio, caño Inturuya $8^{\circ} 45^{\prime} 54,06 " \mathrm{~S} 74^{\circ} 31^{\prime} 38,38^{\prime \prime O} 166$ m s.n.m., 05 Jul. 2005, V. Palacios \& M. Rojas. MUSM 28278, 5, 37,4-47,6 mm LE, Huánuco, Puerto Inca, cuenca río Pachitea, río Zungaruyacu, quebrada Huacana, 9²8'31,43"S 75²14'41,94"O 258 m s.n.m., 11 Jul. 2005, V. Palacios \& M. Rojas. MUSM 28286, 23, 26,1-35,1 mm LE, Huánuco, Puerto Inca, cuenca río Pachitea, río Zungaruyacu, quebrada Huacana, 9²8'31,43"S 75²14'41,94"O 258 m s.n.m., 11 Jul. 2006, V. Palacios \& M. Rojas. MUSM 28471, 11, 32,4-43,1 mm LE, Cuzco, La Convención, Echarate, cuenca río Urubamba, CCNN Miaria, quebrada Shimbillo, $11^{\circ} 21^{\prime} 4,42^{\prime \prime} S 73^{\circ} 0^{\prime} 25,99^{\prime \prime O} 307$ m s.n.m., 25 Ago. 2004, H. Ortega. MUSM 29663, 11, 20,6-28,3 mm LE, Pasco, Oxapampa, Puerto Bermúdez, Ciudad Constitución, cuenca río Palcazu, quebrada $4 \mathrm{~m}$ del río Palcazu, 952'13,85”S 7503'53,9”O $252 \mathrm{~m}$ a. n. m, 8 May. 2001, H. Ortega \& B. Rengifo. MUSM 31414, 127, 17,5-31,3 mm LE, Ucayali, Atalaya, Sepahua, cuenca río Bajo Urubamba, río Mishahua, $11^{\circ} 12^{\prime} 56,79^{\prime \prime}$ S 7258'2,06”O 285 m s.n.m., 9 Ago. 2004, H. Ortega et al. MUSM 33566, 1, 53,4 mm LE, Ucayali, Coronel Portillo, Abujao, cuenca río Ucayali, quebrada sin nombre, 8³9’13,99’S $73^{\circ} 21^{\prime} 16,63$ ”O aproximadamente 273 m s.n.m., 4 Oct. 2008, F. Cari \& I. Gamboa. MUSM 33567, 11, 32,0-53,5 mm LE, Ucayali, Coronel Portillo, Abujao, cuenca río

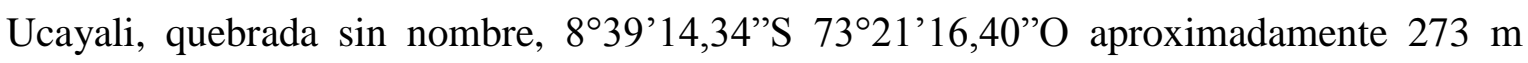
s.n.m., 04 Dic. 2009, F. Cari \& I. Gamboa. MUSM 33593, 10, 34,8-46,3 mm LE, Ucayali, Coronel Portillo, Abujao, cuenca río Ucayali, quebrada Shansho, 8³4’16,99”S 73³1'2,13”'O 238 m s.n.m., 30 Oct. 2008, F. Cari \& I. Gamboa. MUSM 35517, 82, 20,936,6 mm LE, Ucayali, Atalaya, Sepahua, quebrada Ocote, tributario río Mishahua, cerca de la boca del río Mishahua, 11¹3'8,48”S 7258'3,79”O 279 m s.n.m., 21 Jul. 2009, H. Ortega et al. MUSM 35620, 49, 24,5-40,1 mm LE, Cuzco, La Convención, río Urubamba, quebrada Chimbillo, entre Sepahua y río Pakiria, 11²1'44,65”S 730’7,54”O $264 \mathrm{~m}$ s.n.m., 23 Jul. 2009, H. Ortega et al. MUSM 42090, 1, Madre de Dios. Parque Nacional Manu, Manu, Pakitza, quebrada Picaflor, aproximadamente 12¹6'S 7051'O $299 \mathrm{~m}$ 
s.n.m., 20 Oct. 1991, H. Ortega. ROM 83457, 1, 41,1 mm LE, Madre de Dios, Manu, quebrada Salvación, en su confluencia con el alto río Madre de Dios, 1252'60,00"S $71^{\circ} 12^{\prime} 0,00^{\prime \prime} \mathrm{O}^{\circ}$ aproximadamente 712 m s.n.m., 5 Sep. 1989, H. Ortega. ROM 83577, 2, 29,6-35,3 mm LE, Madre de Dios, Pakitza, Parque Nacional Manu, Manu, quebrada Aquajal, $11^{\circ} 49^{\prime} 60,00^{\prime S} 71^{\circ} 21^{\prime} 0,00^{\prime \prime} \mathrm{O}^{\circ}$ aproximadamente 394 m s.n.m., 11 Sep. 1989, H. Ortega \& R. Bouchard.

\section{Gephyrocharax martae Dahl, 1943}

Figs. 14, 17, 19, 24 y 36-38, Tablas 1 y 8

Gephyrocharax martae Dahl, 1943: 218-220, fig. inferior x2 (descripción original sobre un ejemplar, material tipo no especificado directamente, holotipo MZLU L939/3703, localidad tipo: Colombia, departamento Bolívar, municipio de Ayapel, cuenca Magdalena, río Batatal afluente del río San Jorge, altitud aproximada 800 m, similitud con Pseudocorynopoma). Dahl, 1971: 134-135 (lista, clave, datos distribución, figura sin leyenda, orth. mut. “marthae”). Mojica, 1999: 557 (lista de peces Colombia, compilación de datos). Weitzman, 2003: 224 (cita catálogo). Maldonado-Ocampo, Vari \& Usma, 2008: 181 (lista de peces Colombia). ÁlvarezLeón, Orozco-Rey, Páramo-Fonseca \& Restrepo-Santamaría, 2013: 101 (lista de peces vivientes y fósiles de Colombia). Bonilla-Rivero \& López-Rojas, 2013: 489, fig. 1 (mapa, orth. mut. "marthae"). Vanegas-Ríos, Azpelicueta, Mirande \& Gonzales, 2013: 282 (material examinado, acrónimo holotipo ZMUL).

Diagnosis. Gephyrocharax martae difiere de sus congéneres por la distancia hocicoorigen aleta pectoral 20,7 \% LE ( $v s .22,8-31,1 \%$ LE), el radio simple más posterior de la aleta anal del macho adulto más expandido sagitalmente que el radio contiguo posterior (vs. tal radio casi tan expandido como el radio contiguo posterior), la longitud de este radio simple 61,6 \% LE ( $v s .13,2-25,2 \%$ LE), los siete radios ramificados más anteriores de la aleta anal del macho adulto se proyectan posteriormente más allá de la mitad de la longitud de la aleta (vs. tales radios no se proyectan más allá de la mitad de la longitud de la aleta), la presencia de un lóbulo o proceso sobre el margen posterior de la escamabolsillo del macho adulto donde convergen una gran cantidad de los radii de la escama (tal lóbulo ausente o si presente, los radii no convergen sobre este), la ausencia ganchos óseos en los radios de la aleta caudal en el macho adulto ( $v s$. ganchos óseos desarrollados) y 
(excepto G. intermedius y G. atracaudatus) cinco dientes maxilares (vs. cero a tres). La especie también se distingue de sus congéneres, excepto G. melanocheir y G. torresi, por tener una pequeña área sobre el último tercio distal del primer radio ramificado de la aleta pectoral del macho adulto apenas pigmentado por cromatóforos marrones oscuros ( $v s$. tal pigmentación ausente). Gephyrocharax martae difiere de G. melanocheir, G. torresi y G. valencia por la presencia del tubo terminal de la línea lateral entre los radios caudales $10 \mathrm{y}$ 11 (vs. ausencia de este tubo). Gephyrocharax martae también se distingue de $G$. atracaudatus, G. caucanus, G. chocoensis, G. intermedius, G. major y G. venezuelae por la longitud de la glándula branquial del macho adulto 6,4 \% LE ( $v s$. 0,5-5,4 \% LE). Caracteres adicionales que distinguen a $G$. martae de G. atracaudatus, G. caucanus, $G$. chocoensis, G. intermedius y G. major fueron mencionados en las diagnosis respectivas de estas especies. Véase también la lista de autapomorfías mencionadas para G. martae.

Descripción. Basada en el ejemplar holotipo. Datos morfométricos en la tabla 8. Macho con 34,5 mm LE. Cuerpo lateralmente comprimido, con altura máxima sobre la vertical que pasa por el origen de aleta pélvica. Perfil dorsal de la cabeza un poco convexo desde el borde del labio superior hasta el extremo distal del proceso ascendente de la premaxila, continúa recto desde este punto hasta la espina supraoccipital. Perfil dorsal del cuerpo algo convexo desde la porción posterior de la espina supraoccipital hasta el origen de la aleta dorsal, desciende en sentido posteroventral a lo largo de la base de la aleta dorsal y continúa recto desde el radio dorsal más posterior hasta el pedúnculo caudal (Fig. 36a). Perfil ventral del cuerpo convexo desde la punta del hocico hasta la vertical que pasa por el origen de la aleta pectoral, sigue apenas cóncavo entre los orígenes de las aletas pectoral y pélvica y asciende posterodorsalmente recto desde ese punto hasta el inicio pedúnculo caudal. Fontanela anterior reducida a un diminuta abertura anterior a la barra epifisaria. Narina anterior redondeada y separada por un pliegue de piel de la posterior de mayor tamaño. Hendiduras con neuromastos sobre la cabeza presentes, pero muy pobremente preservadas.

Aleta dorsal con ii, 8 radios y 9 pterigióforos proximales. Origen de la aleta dorsal en la vertical que pasa por la base del quinto radio anal. Aleta adiposa presente, su origen al nivel del radio más posterior de la aleta anal. Aleta anal con v,28 radios y 32 pterigióforos proximales. Origen de la aleta anal más cerca de la unión hipural que de la punta del hocico. Aleta pectoral con i,10 radios. Aleta pectoral larga, alcanza un cuarto de la longitud de la aleta pélvica. Aleta pélvica con i,6 radios. Origen de la aleta pélvica 
localizado en la vertical que pasa por la escama 10 de la línea lateral y anterior a la mitad del cuerpo. Aleta caudal bilobulada con 10/9 radios principales.

Hocico superior, con la mandíbula inferior apenas anterior a la punta de la mandíbula superior. Premaxila con dos hileras de dientes; hilera externa con 3 dientes tricúspides. Hilera interna con 4 dientes; el sinfisial tetracúspide, los demás pentacúspides a hexacúspides. Maxila con 5 dientes, el más dorsal pentacúspide, los tres ventrales tricúspides y el más ventral cónico. Maxila larga, alcanza posteriormente el tercio anterior del ojo (Fig. 37a). Dentario con 12 dientes; los tres más anteriores grandes y pentacúspides, seguidos por uno de tamaño mediano pentacúspide y 9 dientes más pequeños cónicos o tricúspides (el diente más anterior de esta serie en general con mayor número de cúspides) que poco a poco disminuyen en tamaño en sentido anteroposterior a lo largo del borde dorsal del dentario (Fig. 37b).

Escamas cicloides, con varios radii a lo largo del campo posterior. Línea lateral completa. Tubo terminal de la línea lateral presente. Escamas con poros 40. Escamas predorsales 20. Hileras de escamas entre la aleta dorsal y la línea lateral 6. Hileras de escamas entre la línea lateral y la aleta anal 5. Hileras de escamas entre la línea lateral y la aleta pélvica 4. Escamas circumpedunculares 14. Una hilera de tres escamas muy grandes, distribuidas a lo largo de la base de la aleta anal. Número total de vértebras 39, 15 precaudales y 23 caudales. Rastrillos branquiales sobre la porción dorsal y ventral del primer arco branquial deteriorados.

Coloración en alcohol. Cuerpo marrón pálido, un poco más oscuro en la línea media dorsal y apenas más claro en la zona ventral. La región predorsal pigmentada por diminutos cromatóforos marrones oscuros. Cromatóforos marrones diminutos y dispersos cubren el cuerpo, excepto las regiones lateral y ventral del abdomen y la región ventral del pedúnculo caudal. Línea lateral negra extendida desde un punto dorsal al origen de la aleta pélvica hasta el pedúnculo caudal. Cromatóforos marrones oscuros distribuidos sobre los mioseptos entre la línea lateral y la porción dorsal de la aleta anal. Mancha humeral ausente o no diferenciada de la banda lateral de cromatóforos. Mancha caudal difusa, con cromatóforos marrones oscuros, extendida desde la región posterior del pedúnculo caudal, sobre los interradialis y alcanza la mitad de la longitud de los radios medios de la aleta caudal. Aleta dorsal gris claro y amarilla tenue, con unos pocos cromatóforos marrones dispersos sobre las membranas. Aleta anal gris clara y amarilla tenue, con cromatóforos marrones localizados sobre las membranas. Aleta caudal gris clara, con cromatóforos marrones oscuros o negros poco concentrados a lo largo de los radios. Aletas pectoral y 
pélvica grises claras, con pocos cromatóforos marrones dispersos sobre las membranas. Aleta pectoral con una pigmentación difusa formada por cromatóforos marrones oscuros sobre una pequeña área del último tercio distal del primero radio ramificado. Cabeza más oscura dorsal que ventralmente. Opérculo e infraorbitales desprovistos de cromatóforos. Premaxila, porción anterior de la maxila, dentario y labios sin cromatóforos, con pigmentación difusa.

Dimorfismo sexual. Se describen los caracteres sexualmente dimórficos basado en el único macho conocido para comparar con machos de otras especies. Macho con ganchos óseos en los radios de las aletas anal y pélvica. Radios de la aleta pélvica con ganchos cortos, pareados o solo uno por segmento y orientados en sentido anteroventral a lo largo de casi toda la longitud de los radios (el primer radio está roto). Aleta anal con ganchos finos, de base ancha, pareados por segmento y orientados en sentido anterolateral en los radios; con cuatro a once pares de ganchos ubicados sobre la porción segmentada del radio simple más posterior y los primeros cinco radios ramificados anteriores. Radios simples y primeros siete radios ramificados anteriores de la aleta anal comprimidos en el plano sagital y muy desarrollados; el radio simple más posterior es alargado y alcanza la aleta caudal (Fig. 36b), mientras que los restantes siete radios ramificados tienen menor longitud gradualmente, pero sobrepasan la región posterior de la aleta anal. Macho con una escama modificada para formar un bolsillo sobre el lóbulo ventral de la aleta caudal y con el segundo y tercer radios procurrentes ventrales modificados en forma de una estructura tipo pinza, ventral al radio principal 19. Tejido de apariencia glandular no visible. Estructura tipo pinza alcanza la mitad de la longitud del primer radio procurrente ventral (Fig. 38a, b). Primer radio procurrente ventral con una moderada concavidad en su porción ventral. Segundo radio procurrente ventral un poco más largo que el tercero y un poco expandido en el plano sagital, más notable en su porción posterior. Porción posterior del tercer radio procurrente poco desarrollada lateralmente. Escama-bolsillo hipertrofiada con 37 radii que se localizan entre el radio 16 y el tercer radio procurrente ventral. Escama-bolsillo con un lóbulo posteroventral puntiagudo, surcado por radii, extendido desde el tercer radio procurrente ventral hasta un punto entre el primero y segundo radios procurrentes ventrales (Fig. 38a). Superficie dorsal de la escama-bolsillo anclada a través de un tejido blando o conectivo a los radios de la aleta caudal 11 a 14. Borde posterior de la escama-bolsillo localizado entre el radio 14 y el tercer radio procurrente ventral de la aleta caudal. Cuatro escamas en serie vertical, justo debajo de la escama más posterior de 
la línea lateral, sobre la porción posterior de la escama-bolsillo. Borde dorsal de la escama-bolsillo sin hendiduras.

Macho con una glándula branquial mediana, pero pobremente preservada. Longitud de la glándula branquial 6,4\% LE*. Filamentos branquiales sobre los arcos branquiales deteriorados.

Distribución. Conocida solo de su localidad tipo en la cuenca alta del río San Jorge en Colombia (Fig. 19).

Comentarios. Holotipo macho en mal estado, deshidratado y muy descolorido. El radio simple más posterior de la aleta anal, parte de los lóbulos de la aleta caudal y el opérculo del lado izquierdo están rotos (partes desprendidas disponibles), por esto fueron arreglados cuidadosamente para las fotos y/o dibujos realizados. La musculatura y gran parte del tejido blando del cuerpo y la cabeza en mal estado de preservación. El cuerpo está algo doblado lateralmente; la dentición en buen estado. Se tomaron todos los caracteres posibles sin causar más deterioro sobre el ejemplar.

Con respecto a la localidad tipo de la especie, Dahl (1943) reportó “...Rio Batatal, tributary to Rio San Jorge, Magdalena system. Municipio de Ayapel, department de Bolivar, Republic de Colombia. Altitude approx. 800 m...”. En la distribución geográfica y política de Colombia (véase http://www.bolivar.gov.co) antes de 1951, el departamento de Bolívar incluía a lo que hoy se conoce como departamentos de Sucre y Córdoba y el Ayapel era considerado un municipio de mayor extensión (respecto del presente). Actualmente, el río Batatal (también llamado río Uré) pertenece a los límites geopolíticos del municipio de Montelíbano (cercano a Ayapel) y fluye por el Cerro Matoso, a lo largo del corrimiento de Uré hasta la Serranía de Ayapel. Además, la cuenca del río San Jorge solo alcanza su parte alta (cercano a los 800 m. s. n. m.) en el departamento de Córdoba. Por lo tanto, la localidad tipo debería estar ubicada en el corregimiento de Uré, municipio de Montelíbano, al sureste del departamento de Córdoba, justo en el límite con Antioquia. El único dato curioso informado por Dahl (1943) es la altitud, 800 m, la cual indicaría que las capturas de la especie fueron hechas en la parte alta del río. Las coordenadas geográficas calculadas para la localidad tipo fueron inferidas aproximadamente en $800 \mathrm{~m}$ siguiendo el mapa del río, para propósitos ilustrativos, porque no existen registros conocidos de los puntos de muestreo de Dahl (1943) y es incierto el lugar exacto de la captura de la especie. La etiqueta que acompaña al holotipo indica que la fecha de recolección fue febrero de 1939 (dato no informado en la descripción original). 
Los intentos de recolectar nuevos ejemplares de Gephyrocharax martae en las localidades visitadas de la cuenca media-baja del río San Jorge no fueron exitosos (solamente se capturaron ejemplares de G. melanocheir en algunos puntos del bajo río San Jorge). Se trato de alcanzar la parte alta del río San Jorge, cerca a Montelíbano, pero la zona no se pudo visitar por motivos de seguridad. Dahl (1971) comentó que la especie es abundante y restringida a unos pocos tributarios del río San Jorge (donde también cita a $G$. melanocheir). Además, Dahl (1971) en su clave para identificar las especies de Gephyrocharax informa un intervalo de 45 a 47 escamas en la línea lateral, lo que indica que este autor pudo tener más de un ejemplar disponible. Infortunadamente, estos ejemplares no están referidos a ninguna colección científica, posiblemente estén perdidos, por lo que los únicos datos morfológicos que se conocen sobre la especie son los del holotipo.

Material examinado. Colombia: MZLU L939/3703, holotipo Gephyrocharax martae Dahl, 1943, 34,51 mm LE (R), [Córdoba, Montelíbano, Uré, aproximadamente 7²3'10,42"N 76²'57,78"O 800 m s.n.m.] Bolívar, Ayapel, cuenca del río Magdalena, río Batatal [o río Uré], afluente del río San Jorge, altitud aproximada 800 m, Feb. 1939, G. Dahl.

\section{Gephyrocharax melanocheir Eigenmann, 1912}

Figs. 8, 9, 14, 17, 19, 24 y 39-41, Tablas 1 y 8

Gephyrocharax melanocheir Eigenmann, 1912: 24-25 (descripción original, designación material tipo, holotipo FMNH 56049 [CM 4840], localidad tipo: quebrada Bernal). Eigenmann, 1914: 41 (lista y clave). Eigenmann, 1920c: 32 (lista de peces cuenca Magdalena). Myers en Eigenmann \& Myers, 1929: 477 y 480-481, lámina 63, fig. 3 (redescripción sin figuras). Schultz, 1944: 322 (clave). Fowler, 1943: 243 (Acequia, Aracataca, Magdalena, Colombia, sin material examinado). Fowler, 1945: 5 (cita Honda, Magdalena, Colombia). Miles, 1947: 156, fig. 106 (lista de peces río Magdalena y clave). Bussing \& Roberts, 1971: 179-180 (comentarios morfología machos). Dahl, 1971: 133-134 (clave, datos distribución). Bussing, 1974: 136 (comentarios morfológicos machos). Mojica, 1999: 557 (lista de peces Colombia, compilación de datos). Bushmann, Burns \& Weitzman, 2002: 189 (glándula branquial). Weitzman, 2003: 225 (cita en catálogo). Burns \& Weitzman, 2005: 122 y 127 (morfología macho, inseminación). Maldonado-Ocampo, Ortega- 
Lara, Usma, Galvis, Villa-Navarro, Vásquez, Prada-Pedreros \& Ardila, 2005: 90 fig. 93 (lista de peces andinos de Colombia, datos ecológicos y morfológicos). Mojica, Castellanos, Sánchez-Duarte \& Díaz, 2006a: 135 (lista de peces río Ranchería). Mojica, Galvis, Sánchez-Duarte, Castellanos \& Villa-Navarro, 2006b: (lista de peces valle medio Magdalena). Villa-Navarro, Zuñiga-Upegui, CastroRoa, García-Melo, García-Melo \& Herrada-Yara, 2006: 10: (lista de peces alto río Magdalena). Maldonado-Ocampo, Vari \& Usma, 2008: 181 (lista de peces Colombia). Álvarez-León, Orozco-Rey, Páramo-Fonseca \& Restrepo-Santamaría, 2013: 101 (lista de peces vivientes y fósiles de Colombia). Bonilla-Rivero \& López-Rojas, 2013: 489, fig. 1 (mapa). Vanegas-Ríos, Azpelicueta, Mirande, Gonzales, 2013: 282-283, fig. 7 (comparación G. torresi, material examinado).

Diagnosis. Gephyrocharax melanocheir se diferencia de sus congéneres por la presencia de una intensa pigmentación negra en la base de los cinco radios más anteriores de la aleta dorsal (vs. la ausencia de esta pigmentación) y (excepto G. torresi) la forma del primer radio ramificado de la aleta pectoral de los machos adultos, el cual tiene un patrón de ramificación distal muy desarrollado en forma de abanico ( $v s$. patrón de ramificación poco desarrollado, no constituye una estructura en forma de abanico) que a su vez tiene ganchos óseos diminutos ( $v s$. no presenta ganchos óseos). La especie también difiere de sus congéneres (excepto G. torresi, G. sinuensis y G. valencia) por la ausencia del tubo terminal de la línea lateral entre los radios caudales 10 y 11 (vs. presencia de este tubo) y (excepto G. martae y G. torresi) la pigmentación marrón oscura o negra sobre el último tercio distal del primer radio ramificado de la aleta pectoral en los machos adultos. Gephyrocharax melanocheir se distingue de G. atracaudatus, G. caucanus, G. chocoensis, G. intermedius, G. major y G. venezuelae por la longitud de la glándula branquial de los machos adultos 7,0-11,4 \% LE ( $v$. 0,5-5,4 \% LE). La especie se distingue de $G$. atracaudatus, G. caucanus, G. chocoensis, G. intermedius, G. major y G. venezuelae por la papila urogenital desarrollada externamente en las hembras adultas (vs. tal papila no desarrollada externamente). Gephyrocharax melanocheir se diferencia de G. caucanus, G. chocoensis, G. sinuensis y G. torresi por la presencia de una lámina ósea entre el primer y segundo basibranquiales. Además, la especie se distingue de G. torresi por la longitud del hocico 22,1-28,6 \% LC (vs. 28,3-31,8 \% LC), el número de vertebras 38-39 (vs. 40-41), el margen posterior del mesetmoides cóncavo en su región central ( $v s$. recto en esta región), la escama-bolsillo de los machos adultos la cual alcanza dorsalmente el radio 10 o el área 
entre los radios caudales 9 y 10 ( $v s$. alcanza dorsalmente el radio 11 o el área entre los radios caudales 11 y 12), el número de ramificaciones terminales diminutas del primer radio ramificado de la aleta pectoral en los machos adultos 28-54 (vs. 60-88), la extensión de la pigmentación lineal en la región media lateral del cuerpo que alcanza un punto medio del pedúnculo caudal en los machos ( $v s$. alcanza la base de los radios de la aleta caudal) y la presencia de tres o más paquetes interradialis sobre el lóbulo ventral de la aleta caudal que se insertan posteriormente más allá del borde posterior de la escamabolsillo en los machos adultos ( $v s$. uno o dos). Caracteres adicionales que distinguen a $G$. melanocheir de G. atracaudatus, G. caucanus, G. chocoensis, G. intermedius, G. major y G. martae fueron mencionados en las diagnosis respectivas de estas especies. Véase también la lista de autapomorfías mencionadas para G. melanocheir.

Descripción. Datos morfométricos en la tabla 8. Macho de mayor tamaño con 39,3 mm LE, hembra de mayor tamaño con 41,9 mm LE. Cuerpo lateralmente comprimido, con altura máxima en un punto entre los orígenes de las aletas anal y pélvica. Perfil dorsal de la cabeza apenas convexo desde el borde del labio superior hasta la punta de la espina supraoccipital. Perfil del cuerpo recto o un poco convexo desde la porción posterior de la espina supraoccipital hasta el origen de la aleta dorsal, desciende en sentido posteroventral a lo largo de la base de la aleta dorsal y continúa recto desde el radio dorsal más posterior hasta el pedúnculo caudal (Fig. 39). Perfil ventral del cuerpo convexo desde la punta del hocico hasta el origen de la aleta pélvica, recto desde este punto hasta el origen de la aleta anal y asciende posterodorsalmente recto o un poco convexo desde ese punto hasta el inicio del pedúnculo caudal. Fontanela anterior casi siempre bien desarrollada, pocas veces reducida en tamaño. Narina anterior redondeada y separada por un pliegue de piel de la narina posterior de mayor tamaño. Hendidura extendida desde un punto medio entre el poro posterior del nasal y las narinas hasta la región posterior de los frontales, con al menos tres hileras de neuromastos. Hendidura más pequeña con pocos neuromastos sobre la región entre las narinas y los huesos nasales.

Aleta dorsal con ii,7 (4), 8 (81) o 9 (1) radios y 9 pterigióforos proximales. Origen de la aleta dorsal en la vertical que pasa por la base de los radios 4 a 9 de la aleta anal. Aleta adiposa presente, su origen al nivel de las bases de los últimos dos radios posteriores de la aleta anal. Aleta anal con iii (1), iv (52), v (37) o vi (1),24 (2), 25 (12), 26 (22), 27 (28), 28 (14) o 29 (12) radios (un ejemplar atípico con 32 radios ramificados no utilizado en los análisis) y 26-30 pterigióforos proximales. Origen de la aleta anal más cerca del 
origen de la unión hipural que de la punta del hocico. Aleta pectoral con i,8 (1), 9 (49), 10 (32) o 11 (6) radios. Aleta pectoral larga, alcanza entre un quinto y toda la longitud de la aleta pélvica. Aleta pélvica con i,6 (78) o 7 (4) radios (un ejemplar atípico con 5 radios ramificados). Origen de la aleta pélvica localizado en la vertical que pasa por las escamas 8 a 9 de la línea lateral y apenas anterior a la mitad del cuerpo. Aleta caudal bilobulada con 10/9 radios principales.

Hocico superior, con la mandíbula inferior anterior a la punta de la mandíbula superior. Premaxila con dos hileras de dientes; hilera externa con 2 (5), 3 (19), 4 (57) o 5 (2) dientes en general tricúspides y pocas veces bicúspides o tetracúspides. Hilera interna con 4 (24), 5 (58) o 6 (1) dientes; el sinfisial tricúspide o tetracúspide y los restantes dientes pentacúspides o hexacúspides. Maxila sin dientes (2) o con un 1 (73), 2 (6) o 3 (2) dientes bicúspides a pentacúspides (el más dorsal en general con mayor número de cúspides) (Fig. 40a). Maxila larga, alcanza posteriormente el tercio anterior del ojo. Dentario con 7 (1), 8 (1), 9 (7), 10 (3), 11 (11), 12 (17), 13 (15), 14 (7) o 15 (1) dientes; los tres más anteriores grandes y pentacúspides, seguidos por uno de tamaño mediano tricúspide, tetracúspide o pentacúspide y 4 (1), 5 (1), 6 (7), 7 (3), 8 (11), 9 (17), 10 (15), 11 (7) o 12 (1) dientes más pequeños, por lo general cónicos a tricúspides, que disminuyen poco a poco en tamaño en sentido anteroposterior a lo largo del borde dorsal del dentario (Fig. 40b).

Escamas cicloides, con varios radii a lo largo del campo posterior. Línea lateral completa. Tubo terminal de la línea lateral ausente. Escamas con poros 37 (7), 38 (17), 39 (32), 40 (21), 41 (8), 42 (5) o 43 (1). Escamas predorsales 17 (15), 18 (51), 19 (18) o 20 (4). Hileras de escamas entre la aleta dorsal y la línea lateral 5 (31), 6 (56) o 7 (1). Hileras de escamas entre la línea lateral y la aleta anal 4 (16) 5 (71) o 6 (1). Hileras de escamas entre la línea lateral y la aleta pélvica 3 (2), 4 (43) o 5 (39). Escamas circumpedunculares 14 (53), 15 (29) o 16 (2). Una hilera de escamas dispuestas a lo largo de la base de la aleta anal de 11 (6), 12 (7), 13 (6), 14 (8), 15 (13), 16 (14), 17 (6), 18 (7), 19 (1), 20 (1), 21 (1) o 23 (2) escamas. Número total de vértebras 38 (3) o 39 (8), 15 precaudales (9) y 23 (2) o 24 (7) caudales (cinco ejemplares radiografiados y seis ejemplares d\&t). Rastrillos branquiales del primer arco branquial 5(4), 6 (37) o 7 (11) sobre la porción dorsal y 11 (15), 12 (35) o 13 (3) sobre la porción ventral.

Coloración en alcohol. Cuerpo amarillento pálido o marrón claro, más oscuro en la línea media dorsal y un poco más claro en la zona ventral. Cromatóforos marrones o negros cubren el cuerpo, en menor cantidad en la región lateral del abdomen. Línea o banda 
lateral negra o plateada (e. g. CZUT-IC 7883) extendida desde la vertical que pasa por el origen de la aleta pélvica hasta la región central o posterior del pedúnculo caudal. Cromatóforos marrones oscuros o negros distribuidos a lo largo de los mioseptos entre la línea lateral y la porción superior de la aleta anal. Mancha humeral marrón, verticalmente alargada. Mancha caudal marrón o marrón oscura, longitudinalmente alargada, extendida desde la región central del pedúnculo caudal hasta los radios de la aleta caudal. Aleta dorsal gris clara, con unos cuantos cromatóforos negros o marrones oscuros distribuidos sobre los radios y las membranas y con una intensa pigmentación negra sobre la base de los primeros cinco radios anteriores. Aleta anal gris clara con cromatóforos marrones o negros distribuidos en su mayoría sobre las membranas. Aleta caudal gris clara, con unos cuantos cromatóforos marrones o negros distribuidos sobre los radios y las membranas. Aletas pectoral y pélvica grises claras, con muy pocos cromatóforos negros o marrones dispersos sobre los radios. Cabeza usualmente más oscura en el dorso. Opérculo e infraorbitales con unos pocos cromatóforos marrones distribuidos sobre sus superficies. Premaxila, porción anterior de la maxila, dentario y labios con cromatóforos marrones oscuros o negros muy concentrados. Variaciones de coloración entre machos y hembras se describen en el dimorfismo sexual.

Coloración en vivo. Tomada sobre los ejemplares CZUT-IC 7890. Cuerpo con perfil dorsal verdoso metálico. Banda lateral plateada o blanquecina desde la región posterior de la mancha humeral hasta el pedúnculo caudal. Región ventral a la banda lateral blanquecina. Mancha humeral negra, débil y verticalmente alargada. Mancha negra o del mismo color de la banda lateral sobre pedúnculo caudal y los radios de la aleta caudal. Aleta dorsal hialina, con algunas porciones de iridiscencia verdosa o amarillenta y con una intensa pigmentación negra sobre la base de sus primeros cinco radios más anteriores. Aleta anal grisácea y algo hialina, con las puntas de sus radios negras difusas. Aleta caudal hialina en las puntas, amarillenta y algo verdosa en la base de sus lóbulos. Aleta adiposa anaranjada. Aleta pectoral grisácea. Aleta pélvica hialina y algo grisácea en su porción anterior. Cabeza anaranjada dorsalmente, dorada y verdosa en la región frontoparietal y cerca del área entre el nasal y el mesetmoides. Ojo con la pupila rojiza dorsalmente. Premaxila, porción anterior de la maxila, dentario y labios con una intensa pigmentación negra, especialmente en el labio inferior. Variaciones de coloración entre machos y hembras se describen en el dimorfismo sexual.

Dimorfismo sexual. Ejemplares machos con ganchos óseos en los radios de las aletas anal, caudal, pectoral y pélvica. Aleta caudal con ganchos cortos, finos y orientados en 
sentido anterodorsal sobre las porciones no ramificadas y las ramificaciones dorsales de los radios 14 a 18 (Fig. 41a). Todos los radios de la aleta pélvica con ganchos finos, pareados o solo uno por segmento (aunque en las bases de los radios por lo general no pareados y numerosos) y orientados en sentido anteroventral a lo largo de casi toda la longitud de cada radio (excepto el primer radio que tiene un gancho). Aleta pectoral con unos pocos ganchos diminutos dispersos sobre la porción distal del primer radio ramificado. Aleta anal con ganchos finos, de base ancha, pareados por segmento y orientados en sentido anterolateral en los radios; con uno a 17 pares de ganchos localizados sobre el radio simple más posterior y los primeros diez radios ramificados anteriores (ganchos comparativamente más largos en los radios medios de este intervalo). En los machos adultos, el radio simple más posterior y los primeros 18 radios ramificados de la aleta anal disminuyen poco a poco en longitud (aleta de aspecto convexo), mientras que en las hembras el radio simple más posterior y los primeros tres radios ramificados más largos que el resto (aleta de aspecto recto o apenas cóncavo). Los machos adultos con frecuencia tienen el borde basal de la aleta anal apenas convexo en su porción anterior o todo el borde algo curvado, mientras que las hembras lo tienen recto. Hembras adultas con una papila urogenital grande, externa, cónica y sobre todo orientada en sentido ventral, o pocas veces, posteroventral.

Machos vivos con una pigmentación negra, pocas veces blanquecina e incluso anaranjada o rojiza sobre las porciones distales del primer y segundo radios de la aleta pectoral (esta pigmentación permanece marrón, negra o blanquecina en ejemplares en alcohol) (Fig. 39). Solo las hembras tienen una suave tonalidad anaranjada o amarillenta en las aletas dorsal y anal. En ejemplares vivos o en alcohol, la mancha del pedúnculo caudal es más intensa en los radios medios de la aleta caudal en las hembras que en los machos (incluso la región ventral de la mancha). En los machos, la mitad posterior del primer radio ramificado de la aleta pectoral más grueso, dividido en dos ramas iguales que individualmente se dividen en dos ramas más pequeñas, las cuales vuelven a dividirse en nueve a doce ramas que a su vez se dividen hasta formar una estructura distal con 28 (1), 30 (1), 32 (1), 38 (1), 40 (1), 42 (2), 46 (1), 48 (1), 50 (2), 53 (2) o 54 (1) ramas diminutas. En las hembras con frecuencia, este radio pectoral se divide en dos ramas principales, cada una se divide en tres o cuatro pares de ramas, las cuales en general se dividen una vez más (algunas veces el radio se ramifica en igual manera que los restantes radios ramificados).

Machos maduros con una escama modificada para formar un bolsillo sobre el lóbulo ventral de la aleta caudal y con el segundo y tercer radios procurrentes ventrales 
modificados en forma de una estructura tipo pinza, ventral al radio principal 19. Tejido de apariencia glandular localizado sobre los radios de la aleta caudal y medial a la escamabolsillo. Estructura tipo pinza osificada de manera incompleta en su porción distal y alcanza la mitad de la longitud del primer radio procurrente ventral (Fig. 41a). Primer radio procurrente ventral con una moderada concavidad en su porción ventral. Segundo radio procurrente ventral un poco más largo que el tercero y con su porción posterior apenas expandida sagitalmente. Porción posterior del tercer radio procurrente ventral poco desarrollada lateralmente. Escama-bolsillo hipertrofiada, con 16 o 38 radii localizados entre los radios 16 a 18 y el tercer radio procurrente ventral de la aleta caudal. Escamabolsillo con un lóbulo posteroventral extendido hasta la mitad o en toda la longitud (poblaciones de la cuenca del río San Jorge) del tercer radio procurrente ventral (Figs. 41a, b). Superficie dorsal de la escama-bolsillo anclada a través de un tejido blando o conectivo a los radios de la aleta caudal 10 o 11 a 15 a 17. Borde posterior de la escama-bolsillo localizado entre los radios 15 o 16 de la aleta caudal y el tercer radio procurrente ventral. Cuatro o cinco escamas en serie vertical, justo debajo de la escama más posterior de la línea lateral, sobre la porción posterior de la escama-bolsillo. Borde dorsal de la escamabolsillo con un tubo de canal muy pequeño en dos machos adultos. Pocas veces con una serie de procesos espinosos diminutos que forman un parche sobre la porción dorsal de la escama-bolsillo. Las hembras con una escama grande con 20 (1), 21 (5), 23 (1), 24 (1) o 25 (1) radii.

Machos maduros con glándula branquial larga. Glándula branquial formada por 9 (1), 15 (1), 19 (4), 20 (2), 21 (5), 22 (7), 23 (3), 24 (5), 25 (1) o 26 (1) filamentos branquiales modificados de la porción ventral del primer arco branquial funcional. Número total de filamentos branquiales en la porción ventral 20 (1), 22 (1), 24 (7), 25 (4), 26 (6), 27 (5), 28 (4), 29 (1) o 30 (1). Longitud de la glándula branquial 7,0-11,4 \% LE (media $=9,8 \%$ LE).

Distribución. Se encuentra en diferentes localidades a lo largo del sistema de los ríos Magdalena, San Jorge, Ranchería y vertiente Caribe en Colombia (Fig. 19).

Comentarios. Durante el transcurso de la presente investigación el holotipo (FMNH 56049) de G. melanocheir no pudo ser examinado por varias razones. El holotipo fue prestado en la época de los 80s a Stanley H. Weitzman (Weitzman \& Fink, 1985: material examinado) y desde ese momento permaneció bajo su cuidado y estudio hasta el presente. Al retirarse S. Weitzman este holotipo y una considerable cantidad de ejemplares prestados comenzó a ser ordenado para su retorno a las instituciones de origen. El actual 
personal de la división de peces (especialmente Richard Vari, Lisa Palmer y Jeff Clayton) me informó se había devuelto gran parte de este material. En una visita al Museum Center Support en 2013, no encontré ningún ejemplar atribuible al holotipo de G. melanocheir (tampoco hay fotos disponibles en la colección de USNM). Por el momento el holotipo de esta especie está perdido o mezclado en algún frasco, pero todavía hay material por devolver y es posible que el holotipo pueda ser recuperado en este proceso. Por lo tanto, en la presente investigación se prefirió no designar un neotipo. Richard P. Vari (Department Chairman, Vertebrates, USNM) acordó con esta decisión a la espera de un tiempo prudencial.

Taphorn \& Lilyestrom (1984), Bonilla-Rivero \& López-Rojas (2001) y BonillaRivero et al. (2002) registraron a Gephyrocharax melanocheir para la cuenca del Lago de Maracaibo y río Meachiche (vertiente Caribe) en Venezuela, respectivamente. En este estudio, no se pudieron revisar ejemplares de la cuenca del Lago de Maracaibo atribuibles a G. melanocheir y ni reidentificar algún ejemplar usado por Taphorn \& Lilyestrom (1984). Recientemente, Bonilla-Rivero \& López-Rojas (2013) encontraron algunas diferencias morfológicas (no especificadas) entre los ejemplares provenientes de la vertiente Caribe que ellos identificaron como G. melanocheir en estudios previos (BonillaRivero \& López-Rojas, 2001; Bonilla-Rivero et al., 2002) vs. la descripción original de $G$. melanocheir (tampoco citan ejemplares verdaderos de G. melanocheir en su material examinado) y concluyeron que estos ejemplares podrían corresponder a una nueva especie. Cinco ejemplares no muy bien preservados del Caribe de Venezuela (UF 23806) fueron identificados previamente como G. melanocheir (Vanegas-Ríos et al. 2013) con base en la pigmentación marrón oscura sobre la base de los primeros cinco radios anteriores de la aleta dorsal. Estos fueron reexaminados después de los hallazgos de Bonilla-Rivero \& López-Rojas (2013), pero dado su estado de preservación, no es posible encontrar todos los caracteres diagnósticos de G. melanocheir o suficiente información morfológica para describirlo como una nueva especie. Por estas razones, se prefirió no incluir a estos ejemplares UF en la presente investigación. Los registros mencionados de G. melanocheir para el Caribe de Venezuela podrían ser incorrectos o necesitarían ser confirmados con estudios subsecuentes. El único registro confirmado de G. melanocheir más al noreste en la vertiente Caribe, se encuentra en la cuenca del río Ranchería en Colombia.

Material examinado. Colombia: CAR 73, 6, 31,0-36,7 mm LE (2 t\&m, 32,8-35,4 mm LE), Atlántico, Ponedera, cuenca río Magdalena, quebrada Grande, aproximadamente 
$10^{\circ} 39^{\prime} 0,95^{\prime N} 7^{\circ} 45^{\prime} 47,88^{\prime \prime O} 16$ m s.n.m., 19 Mar. 2001, C. A. Ardila-Rodríguez. CAS 44292 (antes IU 12696a-f), 1 paratipo, 33,4 mm LE (R), quebrada Bernal cerca a Honda, aproximadamente $5^{\circ} 12^{\prime} 14,89^{\prime \prime} \mathrm{N} 74^{\circ} 45^{\prime} 44,32^{\prime \prime O} 455$ m s.n.m., 28 Ene. 1912, C. H. Eigenmann. CAS 44293 (antes IU 12697a-c), 1 paratipo, 35,4 mm LE (R), Soplaviento, pueblo sobre el dique de Cartagena, entre Cartagena y Calamar, aproximadamente $10^{\circ} 19^{\prime} 60,00^{\prime \prime N} 75^{\circ} 6^{\prime} 0,00 " O 2$ m s.n.m., 11-13 Ene. 1912, C. H. Eigenmann. CZUT-IC 196, 3, 35,6-37,3 mm LE (2 d\&t 35,6-36,0 mm LE), Tolima, Coello, quebrada Gualanday en inspección de Policía de Gualanday, aproximadamente $4^{\circ} 16^{\prime} 49,54$ "N 75²1'58,85"O 4763 m s.n.m., 28 Mar. 2003, Grupo Investigación en Zoología. CZUT-IC 615, 15, 19,6$36,3 \mathrm{~mm}$ LE, Tolima, Coello, quebrada Potrerilla, aproximadamente $4^{\circ} 16{ }^{\prime} 57,90 " \mathrm{~N}$ 75²'53,80"O 463 m s.n.m., 20 Sep. 2003, Grupo Investigación Zoología. ANSP 139153, 10 de 20, 23,6-30,5 mm LE, Magdalena, quebrada de Aguja, $40 \mathrm{~km}$ al sureste de Santa Marta, aproximadamente $10^{\circ} 58^{\prime} 22,18^{\prime \prime} \mathrm{N} 74^{\circ} 15^{\prime} 10,00^{\prime \prime O} 2$ m s.n.m., 4 Dic. 1976, F. W. Saul. CIUA 250, 4 de 7, 31,2-35,0 mm LE, Caldas-Antioquia, cuenca río Magdalena, río La Miel, aproximadamente $5^{\circ} 46^{\prime} 47,39^{\prime \prime} \mathrm{N} 74^{\circ} 41^{\prime 2} 2,97 " \mathrm{O} 154$ m s.n.m., 2 abr. 2005, sin dato. CIUA 1060, 15 de 33, 25,9-37,8 mm LE (2 d\&t 34,2-36,7 mm LE), Caldas, cuenca río Magdalena quebrada Casanguilas, tributario del río Guarinó, aproximadamente 5¹8'36,69"N 7453'28,42"O 513 m s.n.m., 10 Ene. 2007, sin dato. CZUT-IC 933, 8, 31,334,8 mm LE, Tolima, sistema río Tetuán, río Peralonso, aproximadamente 352'12,40"N 75¹6'7,59"O 377 m s.n.m., 5 Oct. 2003, L. García. CZUT-IC 1878, 1, 34,3 mm LE, Tolima, río Alvarado, en el puente, aproximadamente 4³1'3,04"N 7459'5,03"O $517 \mathrm{~m}$ s.n.m., 6 May. 2005, Grupo Investigación Zoología. CZUT-IC 2164, 3, 22,1-22,3 mm LE, La Guajira, vereda Reposo, río Aguja, aproximadamente 1057'34,00"N 74²10'26,00"O 27 m s.n.m., 2 Jul. 2005, CZUT-IC 2175, 4, 12,4-22,8 mm LE, César, río César, vereda Puente Canoas, aproximadamente $9^{\circ} 38^{\prime} 54,20 " \mathrm{~N}$ 7338'47,83"O 39 m s.n.m., 2 Jul. 2005, sin datos. CZUT-IC 2187, 1, 33,4 mm LE, Norte de Santander, río San Alberto, aproximadamente $7^{\circ} 45^{\prime} 20,82^{\prime \prime} \mathrm{N} 73^{\circ} 23^{\prime} 18,37 " \mathrm{O} 120$ m s.n.m., 4 Jul. 2005, L García et al. CZUT-IC 2209, 2, 11,7-16,6 mm LE, Santander, vereda Villa Eva, río Lebrija vía San Alberto, aproximadamente $7^{\circ} 35^{\prime} 11,50^{\prime \prime} \mathrm{N}$ 73³3'50,43"O 77 m s.n.m., 4 Jul. 2005, L. García et al. CZUT-IC 2327, 2 de 27, 39,3-41,9 mm LE, Tolima, quebrada La Joya, vereda Chorrillo, aproximadamente 450'19,95"N 7446'37,87"O 265 m s.n.m., 30 Sep. 2006, L. García. CZUT-IC 2626, 10, Tolima, Ibagué, vereda Chucuní, río Totaré, quebrada Manjarres, aproximadamente $4^{\circ} 29^{\prime} 08^{\prime \prime} \mathrm{N} 75^{\circ} 04^{\prime} 35^{\prime \prime O} 734 \mathrm{~m}$ a. n. m, 17 Feb. 2007, Y. Lorzano \& L. García. CZUT-IC 2990, 2, 25,9-36,2 mm LE, Huila, vereda Letían, sistema 
Yaguará, quebrada La Boa, aproximadamente 2³9'32,58"N 75³0'57,27"O 570 m a. n. m, 27 Sep. 2007, L García et al. CZUT-IC 5757, 1, 33,0 mm LE, Cundinamarca, sistema río Negro, quebrada La Morena, aproximadamente 5²2'0,01"N 74³3'25,02"O 366 m s.n.m., 3 Jul. 2011, L. J. García. CZUT-IC 5858, Huila, alto río Magdalena, quebrada Yaguilga, $2^{\circ} 13 ' 25,00 " \mathrm{~N} 75^{\circ} 44^{\prime} 11,98^{\prime \prime} \mathrm{O} 876 \mathrm{~m}$ a. n. m, sin datos. CZUT-IC 6139, 3, 35,4-39, 2 mm LE, Huila, Garzón, alto río Magdalena, quebrada Guandinosa, 2²3'40,00"N 75³2'47,00"O 830 m s.n.m., 6 Oct. 2011, L. G. Melo \& J. Enrique. CZUT-IC 7883, 14, 23,7-31,0 mm LE, Sucre, El Pital, cuenca río San Jorge, caño Caracolí, aproximadamente 8³4'4948"N 75¹1'1399"O 21 m s.n.m., 8 Feb. 2012, Vanegas-Ríos \& J. Peña. CZUT-IC 7890, 6, 28,8-31,4 mm LE (2 d\&t 29,3-31,4 mm LE), Sucre, Buenavista, cuenca río San Jorge, caño San Vicente afluente río Montegrande, aproximadamente 8³9'24,60"N 75²15'0,59"O, 8 Feb. 2013, J. A. Vanegas-Ríos \& J. Peña. CZUT-IC 7896, 3, 28,3-31,0 mm LE, Sucre, Buenavista, cuenca río San Jorge, caño Montegrande afluente río san Jorge, aproximadamente $8^{\circ} 39^{\prime} 8,86 " \mathrm{~N} 75^{\circ} 12^{\prime} 19,86^{\prime \prime O} 30 \mathrm{~m}$ s.n.m., 9 Feb. 2012, J. A. Vanegas-Ríos \& J. Peña. CZUT-IC 7997, 7, 27,7-33,8 mm LE, Sucre, San Marcos, caños río San Jorge $200 \mathrm{~m}$ del puente, aproximadamente $8^{\circ} 38^{\prime} 48,63^{\prime \prime} \mathrm{N} 75^{\circ} 5^{\prime} 59,1$ 1"O 19 m s.n.m., 9 Feb. 2012, J. A. Vanegas-Ríos. FMNH 69554, 3 paratipos (3R), 32,50-41,3 mm LE, quebrada Bernal cerca a Honda, aproximadamente 5¹2'14,89"N 7445'44,32"O 455 m s.n.m., 28 Ene. 1912, C. H. Eigenmann. IAvH-P 1, 1-35, 18,8-34,7 mm LE, La Guajira, cuenca río Ranchería, arroyo Tabaco, $11^{\circ} 9^{\prime} 0^{\prime \prime} \mathrm{N} 72^{\circ} 34^{\prime} 0^{\prime \prime} \mathrm{O}$ aproximadamente $81 \mathrm{~m}$ s.n.m., 27 Ago. 1985, MB/GSR. IAvH-P 10378, 2, 34,3-39,1 mm LE, Antioquia, Puerto Triunfo, cuenca río Magdalena, quebrada La Isla, 5 53'0"N 7444'49"O aproximadamente $252 \mathrm{~m}$ s.n.m., 16 Sep. 2010, U. Jaramillo et al. IAvH-P 10379, 2, 26,9-29,6 mm LE, Antioquia, Puerto Triunfo, cuenca río Magdalena, quebrada Dos quebradas, 554'13,1"N 74²4'30,2"O aproximadamente 249 m s.n.m., 13 Sep. 2010, U. Jaramillo et al. ICNMHN 3182, 31, 22,1-34,9 mm LE, Boyacá, Puerto Romero, aproximadamente 550'2,05"N 74²0'23,04"O 244 m s.n.m., 1 Abr. 1994, G. Galvis \& Estudiantes de Biología. ICNMHN 5299, 8, 22,5-37,5 mm LE, Boyacá, Puerto Boyacá, Serranías Las Quinchas, cuenca río Magdalena, quebrada La Colorada, aproximadamente 549'45,08"N 74²0'54,96"O $244 \mathrm{~m}$ a. n. m, 3 Mar. 200, J. I Mojica, A. Polanco \& C. Castellanos. ICNMHN 6459, 70, 15,639,4 mm LE, Boyacá, Puerto Boyacá, Serranías Las Quinchas, cuenca río Magdalena, quebrada La Colorada, aproximadamente 549'45,08"N 74²0'54,96"O 244 m a. n. m, 1 Abr. 2001, J. I. Mojica \& C. A. Chipamocha. ICNMHN 6472, 16, 23,0-37,8 mm LE, Boyacá, Puerto Boyacá, Serranía de las Quinchas, quebrada la Fiebre, aproximadamente 
555'59,88"N 74²1'59,86"O 204 m s.n.m., 1 Abr. 2001, J. I. Mojica \& C. A. Chipamocha. ICNMHN 9657, 188, 26,7-37,2 mm LE, La Guajira, Distracción, Chorreras, El Cerrado, río Ranchería, aproximadamente $10^{\circ} 54^{\prime} 46,18^{\prime \prime N} 72^{\circ} 53^{\prime} 39,95^{\prime \prime O} 213$ m s.n.m., 2 May. 2004, C. Castellanos. ICNMHN 11045, 1, 37,5 mm LE, Caldas, La Dorada, cuenca río Magdalena, puente Victoria en vía a Mariquita, quebrada Bocarná en confluencia con río Guarinó, aproximadamente 5¹7'35,63"N 7452'37,81"O 434 m s.n.m., 27 Dic. 2004, P. Sánchez \& C. Castellanos. ICNMHN 11527, 1, 37,1 mm LE, Caldas, La Dorada, cuenca río Magdalena, puente Victoria en vía a Mariquita, quebrada Bocarná en confluencia con río Guarinó, aproximadamente $5^{\circ} 16 ' 45,73 " \mathrm{~N}$ 7452'46,23"O 428 m s.n.m., 18 Mar. 2005, P. Sánchez \& C. Castellanos. ICNMHN 11762, 5, 22,0-36,2 mm LE, Caldas, La Dorada, Victoria, finca Villa del Río, río Guarinó, quebrada Canguillas, aproximadamente 5¹8'50,62"N 7453'53,98"O 513 m s.n.m., 17 Abr. 2005, P. Sánchez. ICNMHN 13551, 3, 29,9-36,2 mm LE, Caldas, La Dorada, Victoria, Bocatoma, acueducto La Dorada, río Guarinó, aproximadamente 5¹8'37,58"N 7454'45,11"O 618 m s.n.m., 21 Jul. 2005, G. Mora \& H. Benítez. ICNMHN 15897, 1, 33,7 mm LE, Caldas, Norcasia en el primer viaducto de fuga de la represa río La Miel, aproximadamente $5^{\circ} 33$ '35,74"N 74'53'26,23"O 444 m s.n.m., 18 Feb. 2006, P. Sánchez \& L. Mesa. ICNMHN 16095, 1, 33,0 mm LE, Caldas, Norcasia, túnel de fuga represa río La Miel, aproximadamente 5³3'35,74"N 7453'26,23"O 444 m s.n.m., 26 Mar. 2006, P. Sánchez \& L. Mesa. ICNMHN 16198, 2, 31,7-36,9 mm LE, Caldas, La Dorada, vereda La Habana, finca la Palmera, río La Miel, aproximadamente 5³8'30,67"N 74²7'5,01"O 190 m s.n.m., 26 Mar. 2006, L. Mesa \& P. Sánchez. ICNMHN 16296, 6, 32,5-37,4 mm LE, Caldas, La Dorada, vereda La Habana, finca la Palmera, aproximadamente $5^{\circ} 38^{\prime} 30,67^{\prime \prime N} 74^{\circ} 47^{\prime} 5,01^{\prime \prime O} 190$ m s.n.m., 30 Abr. 2006, P. Sánchez. ICNMHN 17777, 7, 31,8-33,5 mm LE, Santander, El Carmen de Chucuri, vereda El Topón, cuenca río La Colorada, río Topón canal principal del río, 645'45"N 73³4'56"O 276 m s.n.m., 18 Mar. 2011, J. I. Mojica, G. A. Ballen \& estudiantes de Biología. ICNMHN 17790, 12, 33,8-39,4 mm LE, Santander, El Carmen de Chucuri, vereda El Topón, cuenca río La Colorada, río Topon en el puente, 643'16"N 73³2'49"O 348 m s.n.m., 16 Mar. 2011, J. I. Mojica, G. A. Ballen \& estudiantes de Biología. ICNMHN 17817, 2, 30,7-31,4 mm LE, Santander, El Carmen de Chucuri, vereda El Topon, cuenca río La Colorada, río Topón canal principal del río, 645'45"N 73³4'56"O 276 m s.n.m., 20 Mar. 2011, J. I. Mojica, G. A. Ballen \& estudiantes de Biología. ICNMHN 17826, 24, 20,6-38,1 mm LE, Santander, El Carmen de Chucuri, vereda El Topón, cuenca río La Colorada, río Topón, pequeño tributario, 645'46"N 
73³4'57"O 265 m s.n.m., 22 Mar. 2011, J. I. Mojica, G. A. Ballen \& estudiantes de Biología. IMCN 3425, 5, 23,3-29,1 mm LE, Tolima, Honda, cuenca del río Magdalena, quebrada Bernal, aproximadamente $5^{\circ} 12^{\prime} 19,73^{\prime \prime N} 74^{\circ} 45^{\prime} 46,09^{\prime \prime O} 284 \mathrm{~m}$ a. n. m, 17 Oct. 2004, L. M. García \& C. Ardila Rodríguez. IMCN 3458, 4, 34,64-36,25 mm LE, Tolima, Coello, cuenca del río Magdalena, estación de Policía de Gualanday, quebrada Gualanday, aproximadamente $4^{\circ} 18^{\prime} 17,50 " \mathrm{~N} 75^{\circ} 2^{\prime} 0,01^{\prime \prime} \mathrm{O} 561 \mathrm{~m}$ s.n.m., 28 Mar. 2003, Grupo Investigación Zoología. USNM 79209 (antes posiblemente CM 4840a-f en parte), 2 paratipos, 31,9-35,2 mm LE (2R), quebrada Bernal cerca a Honda, aproximadamente $5^{\circ} 12^{\prime} 14,89^{\prime \prime} \mathrm{N} 74^{\circ} 45^{\prime} 44,32^{\prime \prime O} 455$ m s.n.m., 28 Ene. 1912, C. H. Eigenmann.

\section{Gephyrocharax sinuensis Dahl, 1964}

Figs. 14, 17, 19, 24, 37-38 y 41-42, Tablas 1 y 9

Gephyrocharax sinuensis Dahl en Dahl \& Medem, 1964: 64-66, figura sin referencia (descripción original, designación material tipo sin números de catálogo, holotipo ICNMHN perdido, localidad tipo: de Esmeraldas, Alto Sinú). Dahl, 1971: 134-135 (clave, datos distribución, figura sin leyenda). Mojica, 1999: 557 (lista de peces Colombia, compilación de datos). Weitzman, 2003: 225 (cita en catálogo). Maldonado-Ocampo, Vari \& Usma, 2008: 180 (lista de peces Colombia). ÁlvarezLeón, Orozco-Rey, Páramo-Fonseca \& Restrepo-Santamaría, 2013: 101 (lista de peces vivientes y fósiles de Colombia). Bonilla-Rivero \& López-Rojas, 2013: 489, fig. 1 (mapa). Vanegas-Ríos, Azpelicueta, Mirande, Gonzales, 2013: 283 (material examinado).

Diagnosis. Gephyrocharax sinuensis se distingue de sus congéneres por el primer radio de la aleta pélvica que está hipertrofiado o curvado distalmente en los machos adultos ( $v s$. este radio similar a los demás radios y recto en toda su longitud) y (excepto G. caucanus y G. valencia con variabilidad intraespecífica) por una densa pigmentación negra o marrón oscura alrededor del origen de la aleta pélvica en machos adultos. Además, G. sinuensis difiere de $G$. caucanus, G. intermedius, G. martae, G. valencia y $G$. venezuelae por la longitud de la aleta pélvica en los machos 17,1-26,8 \% LE (vs. 12,2-17,5). La especie se diferencia de G. caucanus, G. valencia y $G$. martae por la presencia de mancha humeral (vs. esta mancha ausente) y de G. melanocheir y G. torresi por la ausencia de ganchos óseos en la aleta pectoral de los machos adultos ( $v s$. tales radios presentes). 
Gephyrocharax sinuensis difiere de G. torresi y G. valencia por la presencia de rinosfenoides (vs. ausencia de este hueso) y de G. atracaudatus, G. caucanus, $G$. chocoensis, G. intermedius, G. major y G. venezuelae por la papila urogenital desarrollada externamente en las hembras adultas ( $v s$. tal papila no desarrollada externamente). La especie también se distingue de G. melanocheir, G. torresi, G. valencia y G. venezuelae por la escama-bolsillo de machos adultos que se extiende posteriormente más allá de la vertical a través del extremo distal del segundo radio procurrente ventral de la aleta caudal (vs. tal escama no se extiende más allá de esta vertical). Caracteres adicionales que distinguen a G. sinuensis de G. atracaudatus, G. caucanus, G. chocoensis, G. intermedius, G. major, G. martae y G. melanocheir fueron mencionados en las diagnosis respectivas de estas especies. Véase también la lista de autapomorfías mencionadas para G. sinuensis.

Descripción. Datos morfométricos en la tabla 9. Macho de mayor tamaño con 35,1 mm LE, hembra de mayor tamaño con 40,8 mm LE. Cuerpo lateralmente comprimido, con altura máxima sobre la vertical que pasa por un punto entre los orígenes de las aletas pélvica y anal. Perfil dorsal de la cabeza un poco convexo desde el borde del labio superior hasta la espina supraoccipital. Perfil dorsal del cuerpo un poco convexo desde la porción posterior de la espina supraoccipital hasta el origen de la aleta dorsal, desciende en sentido posteroventral a lo largo de la base de la aleta dorsal y continúa recto desde el radio dorsal más posterior hasta el pedúnculo caudal (Fig. 42). Perfil ventral del cuerpo convexo desde la punta del hocico hasta el origen de la aleta pélvica, recto desde este punto hasta el origen de la aleta anal y asciende posterodorsalmente recto desde el origen anal hasta el inicio del pedúnculo caudal. Fontanela anterior presente o a veces reducida a una abertura estrecha o de tamaño mediano anterior a la barra epifisaria. Narina anterior redondeada y separada por un pliegue de piel de la narina posterior de mayor tamaño. Hendidura extendida desde un punto medio entre el poro posterior del nasal y las narinas hasta la región posterior de los frontales, con al menos tres hileras de neuromastos. Hendidura más pequeña con pocos neuromastos sobre la región entre las narinas y los huesos nasales.

Aleta dorsal con ii, $8 *(55)$ o 9 (2) radios y 9* pterigióforos proximales. Origen de la aleta dorsal en la vertical a través de los radios anales 6 a 11. Aleta adiposa presente, su origen al nivel de la base del radio más posterior de la aleta anal. Aleta anal con iii (1), iv (39) o $\mathrm{v}^{*}(17), 22$ (1), 24 (4), 25 (9), 26 (18), 27 (15) o 28* (8) y 26-30 pterigióforos proximales. Origen de la aleta anal más cerca del origen de la unión hipural que de la 
punta del hocico. Aleta pectoral con i,8 (11), 9* (32) o 10 (13) radios. Aleta pectoral larga, alcanza entre un cuarto y un medio de la longitud de la aleta pélvica. Aleta pélvica con i,6 (56) o i,7 (1). Origen de la aleta pélvica localizado en la vertical que pasa por las escamas 8 a 10 de la línea lateral y anterior a la mitad del cuerpo. Aleta caudal bilobulada con 10/9 radios principales.

Hocico superior, con la mandíbula inferior anterior a la punta de la mandíbula superior. Premaxila con dos hileras de dientes; hilera externa con 1 (1), 2 (4), 3 (10), $4^{*}$ (36) o 5 (5) dientes, por lo general tricúspides. Hilera interna con 4 (35), 5* (21) o 6 (1) dientes; el sinfisial y los demás dientes tricúspides a pentacúspides. Maxila sin dientes (2) o con $1^{*}(45)$ a 2 (9) dientes tricúspides a pentacúspides, por lo general tetracúspides, en todos los ejemplares, excepto en uno sin dientes (Fig. 37c). Maxila larga, alcanza posteriormente el tercio anterior del ojo. Dentario con 9 (1), 10 (4), 11 (16), 12 (17), 13 (6), 14* (6) o 15 (2) dientes; los tres más anteriores grandes y tetracúspides o pentacúspides, seguidos por uno de tamaño mediano pentacúspide y 5 (1), 6 (1), 7 (16), 8 (17), 9 (6), 10* (6) o 11 (2) dientes más pequeños cónicos a tricúspides que poco a poco disminuyen en tamaño en sentido anteroposterior a lo largo del borde dorsal del dentario (Fig. 37d).

Escamas cicloides, con numerosos radii a lo largo del campo posterior. Línea lateral completa. Tubo terminal de la línea lateral presente, rara vez ausente (dos ejemplares machos). Escamas con poros 37 (1), 38 (10), 39 (10), 40 (20), 41 (9), 42* (5) o 43 (1). Escamas predorsales 16 (1), 17 (12), 18* (11), 19 (16), 20 (11) o 21 (5). Hileras de escamas entre la aleta dorsal y la línea lateral $5^{*}(15)$ o 6 (39). Hileras de escamas entre la línea lateral y la aleta anal $4^{*}(19)$ o 5 (37). Hileras de escamas entre la línea lateral y la aleta pélvica 3 (3), 4* (32) o 5 (21). Escamas circumpedunculares 14* (18), 15 (30) o 16 (4). Una hilera de escamas dispuestas a lo largo de la base de la aleta anal de 11 (7), 12 (1), 13 (3), 14* (12), 15 (9), 16 (9), 17 (4), 18 (1) o 19 (1) escamas. Número total de vértebras 39 (2) o $41^{*}(1), 16^{*}$ (3) precaudales y 23 o 25* (1) caudales (un ejemplar radiografiado y dos ejemplares $\mathrm{d} \& \mathrm{t}$ ). Rastrillos branquiales del primer arco branquial $5 *$ (3), 6 (36), 7 (9) o 8 (1) sobre la porción dorsal y 11* (19), 12 (27) o 13 (3) sobre porción ventral.

Coloración en alcohol. Cuerpo amarillento pálido, más oscuro en la línea media dorsal y un poco más claro en la zona ventral. Cromatóforos marrones o negros diminutos cubren la superficie del cuerpo, pero ausentes o en menor cantidad sobre las regiones lateral y ventral del abdomen y la región ventral del pedúnculo caudal. Línea lateral negra 
extendida desde la vertical que pasa por un punto medio entre los orígenes de las aletas pélvica y anal hasta la región posterior del pedúnculo caudal. Cromatóforos marrones oscuros distribuidos sobre los mioseptos entre la línea lateral y la porción superior de la aleta anal. Mancha humeral marrón oscura y verticalmente alargada. Mancha caudal marrón oscura, longitudinalmente alargada y extendida desde la región media del pedúnculo caudal, cubre los interradialis, hasta la mitad de la longitud de los radios medios de la aleta caudal. Aleta dorsal gris clara, con cromatóforos marrones oscuros o negros un poco o muy concentrados a lo largo de los radios y las membranas. Aleta anal gris clara, con cromatóforos marrones oscuros o negros más concentrados sobre las membranas que los radios. Aleta caudal gris clara, con cromatóforos marrones oscuros o negros poco concentrados sobre las membranas y los radios. Aletas pectoral y pélvica grises claras, con cromatóforos marrones oscuros o negros distribuidos en su mayoría sobre los radios. Cabeza más oscura dorsal que ventralmente. Opérculo e infraorbitales con cromatóforos marrones o negros, más concentrados en el primero y los bordes infraorbitales que rodean al ojo. Premaxila, porción anterior de la maxila, dentario y labios con cromatóforos marrones oscuros o negros muy concentrados. Variaciones en la coloración entre machos y hembras se describen en el dimorfismo sexual.

Dimorfismo sexual. Ejemplares machos con ganchos óseos en los radios de las aletas anal, caudal y pélvica. Aleta caudal con ganchos cortos, finos y orientados en sentido anterodorsal, en especial sobre las mitades posteriores de los radios 13 a 18 (Fig. 38c). Todos los radios de la aleta pélvica, excepto el primer y último radios, con ganchos finos pareados o solo uno por segmento (aunque en las bases de los radios por lo general no pareados y numerosos) y orientados en sentido anteroventral en casi toda la longitud de cada radio. Aleta anal con ganchos finos, de base ancha, pareados por segmento y orientados en sentido anterolateral en los radios; con dos a 19 pares de ganchos localizados sobre el radio simple más posterior y los primeros ocho radios ramificados anteriores (los ganchos son más largos en los radios medios de este intervalo). Los machos adultos con frecuencia tienen el borde basal de la aleta anal un poco convexo en su porción anterior o algo curvado, mientras que las hembras lo tienen recto. Aleta anal convexa en su región media en los machos adultos, mientras que es recta o cóncava en las hembras. Aleta pélvica de los machos maduros, a diferencia de las hembras, con el primer radio hipertrofiado y pocas veces con el primero y último radios ramificados un poco más largos que el resto de los radios. Los machos maduros tienen el primer radio notablemente más largo y un poco más engrosado que el resto de los radios, con su porción distal algo 
curvada o a veces un poco ensanchada (Fig. 42), mientras que las hembras tienen este radio un poco más ancho y largo que el resto de los radios. Hembras adultas presentan papila urogenital externamente desarrollada, orientada ventralmente (Fig. 42).

Los machos adultos presentan una pigmentación marrón oscura extendida desde el poro urogenital hasta un punto medio debajo de la aleta pectoral, pero más intensa alrededor y anterior al origen de la aleta pélvica. Machos maduros con una escama modificada para formar un bolsillo sobre el lóbulo ventral de la aleta caudal y con el segundo y tercer radios procurrentes ventrales modificados en forma de una estructura tipo pinza, ventral al radio principal 19. Tejido de apariencia glandular localizado en poca cantidad y en su mayoría sobre los radios de la aleta caudal y medial a la escama-bolsillo. Estructura tipo pinza osificada de manera incompleta en su porción distal y alcanza la mitad de la longitud del primer radio procurrente ventral (Fig. 38c). Primer radio procurrente ventral con una moderada concavidad en su porción ventral. Segundo radio procurrente ventral un poco más largo que el tercero y apenas expandido en el plano sagital, más notable en su porción posterior. Porción posterior del tercer radio procurrente ventral poco desarrollada lateralmente. Escama-bolsillo hipertrofiada, con 21 a 43 radii que por lo general se localizan entre el radio $16 \mathrm{y}$ el tercer procurrente ventral de la aleta caudal. Escama-bolsillo con un lóbulo posteroventral extendido a lo largo del tercer radio procurrente ventral (Figs. 38c, d). Superficie dorsal de la escama-bolsillo anclada a través de un tejido blando o conectivo a los radios de la aleta caudal 11 a 14. Borde posterior de la escama-bolsillo localizado entre el radio $14 \mathrm{y}$ el tercer radio procurrente ventral de la aleta caudal. Cuatro escamas en serie vertical, justo debajo de la escama más posterior de la línea lateral, sobre la porción posterior de la escama-bolsillo. Borde dorsal de la escama-bolsillo apenas convexo. Las hembras con una escama grande con 21 (2), 22 (1), 23 (3) o 26 (1) radii.

Machos maduros con una glándula branquial mediana. Glándula branquial formada por 7 (1), 10 (2), 11 (2), 12 (3), 13 (4), 14 (1), 15* (2), 16 (2) o 17 (1) filamentos branquiales modificados de la porción ventral del primer arco branquial funcional. Número total de filamentos branquiales en la porción ventral 21 (1), 22 (1), 23 (1), 24* (6), 25 (2), 26 (5) o 27 (1). Longitud de la glándula branquial 3,0-7,5 \% LE (media = 6,0 $\%$ LE), 6,9\% LE*.

Distribución. Se distribuye en varias localidades de la cuenca del río Sinú en Colombia (Fig. 19). 
Comentarios. El holotipo de $G$. sinuensis actualmente ICNMHN (no mencionado su número de catálogo en la descripción original) está perdido. Cala (1987: 79) informó que después del retiro de George Dahl como encargado de la colección del ICN en 1961, se trasladó al INDERENA (= CVM, Cartagena) donde se mantuvieron los tipos de muchas de sus especies descriptas para Colombia hasta 1967. Después, Cala (1987) trasladó al ICN los tipos de Dahl depositados en el INDERENA que pudo recuperar. Cala (1987) también confirmó la pérdida y destrucción de varios tipos descriptos por Dahl. El actual curador del ICNMHN, José Iván Mojica, no citó más el holotipo de G. sinuensis en el listado de los tipos de la colección (Mojica \& Castellanos, 2007). Posteriores autores reconocieron la pérdida del holotipo (Maldonado-Ocampo et al., 2008). En las visitas realizadas al ICNMHN en los últimos dos años, no se encontró el holotipo y el personal de colección corroboró que el holotipo permanece perdido o destruido. Dada está pérdida del holotipo se designó un neotipo en concordancia con el artículo 75.3.4 del ICZN (1999). El neotipo (ICNMHN 18999) es un ejemplar macho adulto proveniente de la serie de 78 paratipos contados para la especie (ICNMHN 749), lo que satisface la recomendación 75A del ICZN (1999). Se prefirió un macho en vez de una hembra, porque el primero tiene un gran número de caracteres informativos para la especie y el género. El estado de los paratipos es bastante bueno en aletas, dentición y fijación, pero la coloración está muy perdida. Detalles ecológicos sobre la especie son mencionados por Dahl (1971). Este material pudo ser examinado en el National Museum de Natural History, Smithsonian Institution, donde permanece hasta la fecha, porque fue prestado desde 1984 al Stanley H. Weitzman.

Material examinado. Colombia, Córdoba, cuenca río Sinú: CAR 403, 7, 30,5-36,0 mm LE (2 d\&t 35,1-35,9 mm LE), Tierra Alta, quebrada La Oscura, afluente del río Tai, aproximadamente $8^{\circ} 0^{\prime} 15,97 " \mathrm{~N} 76^{\circ} 7^{\prime} 27,44^{\prime \prime} \mathrm{O} 86$ m s.n.m., 15 May. 2008, C. A. ArdilaRodríguez. CAR 446, 5, 28,2-34,0 mm LE, Tierra Alta, río Tigre arriba de la quebrada El Carmen, aproximadamente $8^{\circ} 15^{\prime} 2,90 " \mathrm{~N} 75^{\circ} 58^{\prime} 9,79^{\prime \prime O} 36$ m s.n.m., 2 Jun. 2009, C. A. Ardila-Rodríguez. ICNMHN 749, 78 paratipos, 16,1-40,8 mm LE, recolectados con el neotipo. Dahl. ICNMHN 6843, 10, 30,7-39,6 mm LE, río Sinú, aproximadamente $7^{\circ} 48^{\prime} 27,83^{\prime \prime N} 76^{\circ} 19^{\prime} 52,52 " \mathrm{O} 253 \mathrm{~m}$ s.n.m. (coordenadas supuestas para mapa), 1999, M. Lundberg. ICNMHN 6915, 13, 24,0-34,2 mm LE, río Sinú, aproximadamente $7^{\circ} 48^{\prime} 27,83^{\prime \prime N ~ 76} 19 ' 52,52 " O 253$ m s.n.m. (coordenadas supuestas para mapa), 1999, M. Lundberg. ICNMHN 18999 (antes ICNMHN 749), neotipo Gephyrocharax sinuensis por presente designación, 32,1 mm LE (R), macho, [aproximadamente 749'17,73"N 
76²17'32,05"O 196 m s.n.m.], alto río Sinú (Sinú entre el río Manso y Chobogadó en descripción original), Dic. 1950, G. Dahl. NRM 36890, 2, 32,9-34,1 mm LE, Tierra Alta, quebrada sin nombre desembocando cerca de $3 \mathrm{~km}$ corriente abajo de la represa hidroeléctrica de Urrá, aproximadamente 8²'59,07"N 76²10'13,62"O 68 m a n. m., 1997, A. Anka et al. NRM 16275, 2, 30,4-33,1 mm LE, Tierra Alta, río Manso, afluente río Sinú, aproximadamente 7³9'53,06"N 769'43,64"O 182 m s.n.m., posiblemente 1975, G. Roldan. NRM 39614, 11, 20,2-32,5 mm LE, Tierra Alta, quebrada sin nombre desembocando cerca de $3 \mathrm{~km}$ corriente abajo de la represa hidroeléctrica de Urrá, aproximadamente $8^{\circ} 3^{\prime} 4,98^{\prime \prime} \mathrm{N} 76^{\circ} 10^{\prime} 3,64 " O 67$ m s.n.m., Jul. a Dic. 1996, A. Anka.

\section{Gephyrocharax torresi Vanegas-Ríos, Azpelicueta, Mirande \& Gonzales, 2013}

Figs. 14, 17, 19, 24, 40-41 y 43, Tablas 1 y 10

Gephyrocharax torresi Vanegas-Ríos, Azpelicueta, Mirande \& Gonzales, 2013: 276-280, figs. 1-6 (descripción original, designación material, holotipo UIST 1767, localidad tipo: Colombia, Santander, El Carmen, cuenca río Magdalena, cuenca río La Colorada, sistema río Cascajales, cuenca río Sucio, Caño Volador, 6³9’56,44”N 73³4’47,36”'O, aproximadamente 338 m s.n.m.)

Diagnosis. Gephyrocharax torresi se distingue de sus congéneres (excepto $G$. melanocheir) por la aleta adiposa ausente o vestigial ( $v s$. esta aleta bien desarrollada) y la forma del primer radio ramificado de la aleta pectoral de los machos adultos, el cual tiene un patrón de ramificación muy desarrollado distalmente en forma de abanico (vs. patrón de ramificación poco desarrollado, no constituye una estructura en forma de abanico) que a su vez tiene ganchos óseos diminutos (vs. no presenta ganchos óseos). La especie también difiere de sus congéneres (excepto G. melanocheir, G. sinuensis y G. valencia) por la ausencia del tubo terminal de la línea lateral entre los radios caudales 10 y 11 ( $v s$. presencia de este tubo) y (excepto G. martae y G. melanocheir) la pigmentación marrón oscura o negra sobre el último tercio distal del primer radio ramificado de la aleta pectoral en los machos adultos. Gephyrocharax torresi se distingue de G. atracaudatus, $G$. caucanus, G. chocoensis, G. intermedius, G. major y G. venezuelae por la presencia de papila urogenital desarrollada externamente en las hembras adultas (vs. papila no desarrollada externamente). La especie también difiere de G. caucanus, G. melanocheir y G. valencia por la reducción o completa pérdida en adultos de la fontanela anterior debido 
al extenso contacto anterior de los frontales ( $v s$. esta fontanela bien desarrollada o si los frontales contactándose, no la reducen). Gephyrocharax torresi se distingue de $G$. atracaudatus, G. caucanus, G. chocoensis, G. intermedius, G. major y G. venezuelae por la longitud de la glándula branquial de los machos adultos 6,0-10,3 \% LE (vs. 0,5-5,4 \% LE). Caracteres adicionales que distinguen a G. torresi de G. atracaudatus, G. caucanus, G. chocoensis, G. intermedius, G. major, G. martae, G. melanocheir y G. sinuensis fueron mencionados en las diagnosis respectivas de estas especies. Véase también la lista de autapomorfías mencionadas para G. torresi.

Descripción. Datos morfométricos en la tabla 10. Macho de mayor tamaño con 37,3 mm LE y hembra de mayor tamaño con 42,0 mm LE. Cuerpo lateralmente comprimido, con altura máxima en el origen de la aleta pélvica. Perfil dorsal de la cabeza un poco convexo desde el borde del labio superior hasta la punta de la espina supraoccipital. Perfil dorsal del cuerpo recto desde la región posterior de la espina supraoccipital hasta el origen de la aleta dorsal, desciende en sentido posteroventral a lo largo de la base de la aleta dorsal y continúa recto desde el radio dorsal más posterior hasta el pedúnculo caudal (Fig. 43). Perfil ventral del cuerpo convexo desde la punta del hocico hasta el origen de la aleta pectoral, continúa un poco convexo hasta un punto situado entre los orígenes de las aletas pectoral y pélvica y asciende posterodorsalmente recto desde este punto hasta el inicio del pedúnculo caudal. Fontanela anterior ausente o reducida a una abertura estrecha anterior a la barra epifisaria. Narina anterior redondeada y separada por un pliegue de piel de la narina posterior de mayor tamaño. Hendidura extendida desde un punto medio entre el poro posterior del nasal y las narinas hasta la región posterior de los frontales, con al menos tres hileras de neuromastos. Hendidura más pequeña con pocos neuromastos sobre la región entre las narinas y los huesos nasales.

Aleta dorsal con ii, $7 *(14)$ o 8 (23) radios y 9 pterigióforos proximales. Origen de la aleta dorsal en la vertical que pasa por la base de los radios 5 a 8 de la aleta anal. Aleta adiposa reducida en tamaño (6) o ausente* (31), y cuando presente, localizada en la vertical que pasa entre las bases de los últimos 4 o 5 radios posteriores de la aleta anal. Aleta anal con iv* (30) o v (7),26 (1), 27 (4), 28 (9), 29* o 30 (9) radios y 29-30 pterigióforos proximales. Origen de la aleta anal más cerca del origen de la unión hipural que de la punta del hocico. Aleta pectoral con i,8 (5), 9 (25), 10* (6) o 11(1) radios. Aleta pectoral larga, alcanza entre un tercio y casi toda la longitud de la aleta pélvica. Aleta pélvica con i,6* (37) radios. Origen de la aleta pélvica localizado en la vertical que pasa 
por las escamas 9 a 10 de la línea lateral y apenas anterior a la mitad del cuerpo. Aleta caudal bilobulada, con 10/9 radios principales en todos los ejemplares.

Hocico superior, con la mandíbula inferior apenas anterior a la punta de la mandíbula superior. Premaxila con dos hileras de dientes; hilera externa con $3 *$ (30) o 4 (7) dientes por lo general tricúspides y pocas veces bicúspides. Hilera interna con $4 *$ (33) o 5 (4) dientes; el sinfisial tetracúspide y los restantes dientes pentacúspides. Maxila con 1 (23), 2 (12) o 3* (1) dientes tricúspides o tetracúspides (Fig. 40c). Maxila larga, alcanza posteriormente el tercio anterior del ojo. Dentario con 9 (1), 10 (1), 11 (7), 12 (8), 13* (7) o 14 (2) dientes; los tres más anteriores grandes y pentacúspides, seguidos por uno de tamaño mediano casi siempre tricúspide y 5 (1), 6 (1), 7 (7), 8 (8), 9* (7) o 10 (2) dientes más pequeños tricúspides o cónicos, con tamaños aproximadamente similares entre sí, pero disminuyen poco a poco en tamaño en sentido anteroposterior a lo largo del borde dorsal del dentario (Fig. 40d).

Escamas cicloides, con varios radii a lo largo del campo posterior. Línea lateral completa. Tubo terminal de la línea lateral ausente. Escamas con poros 40 (1), 41 (10), 42 (15), 43* (10) o 44 (1), un ejemplar con varias escamas sin poros y línea lateral interrumpida. Escamas predorsales 18* (9), 19 (20), 20 (5) o 21 (3). Hileras de escamas entre la aleta dorsal y la línea lateral 5 (3) o $6^{*}$ (34). Escamas entre la línea lateral y la aleta anal 4 (13) o 5* (24). Escamas entre la línea lateral y la aleta pélvica 4* (11) o 5 (26). Escamas circumpedunculares 14 (16), 15* (18) o 16 (3). Una hilera de escamas dispuestas a lo largo de la base de la aleta anal de 14 (3), 15 (3), 16 (8), 17* (5), 18 (3), 19 (3), 20 (8), 21 (1) o 22 (3) escamas. Número total de vértebras 40-41 (dos ejemplares d\&t), 16 precaudales y 24 o 25 caudales. Rastrillos branquiales del primer arco branquial 5(1) o $6^{*}$ (21) sobre la porción dorsal y 11 (1), 12 (18) o 13* (3) sobre la porción ventral.

Coloración en alcohol. Cuerpo de color amarillento pálido, más oscuro a lo largo de la línea media dorsal y un poco más claro en la zona ventral. Cromatóforos marrones diminutos cubren completamente el cuerpo. Línea lateral negra extendida desde la región posterior de la mancha humeral hasta la región central o posterior del pedúnculo caudal. Cromatóforos marrones oscuros distribuidos a lo largo de los mioseptos entre la línea lateral y la porción superior de la aleta anal. Mancha humeral marrón y verticalmente alargada. Mancha caudal marrón oscura, alargada longitudinalmente, extendida desde la región central del pedúnculo caudal, cubre los interradialis, hasta la base de los radios de la aleta caudal. Aleta dorsal gris clara, pero oscurecida por la presencia de cromatóforos marrones oscuros concentrados sobre los radios y las membranas. Aleta anal gris clara y 
algo oscurecida por la presencia de cromatóforos marrones oscuros y negros situados sobre las membranas. Aleta caudal gris clara, con unos pocos cromatóforos marrones oscuros o negros distribuidos sobre los radios y las membranas. Aletas pectoral y pélvica grises claras, con cromatóforos negros dispersos sobre los radios. Cabeza más oscura dorsal que ventralmente. Opérculo e infraorbitales con unos pocos cromatóforos marrones distribuidos sobre sus superficies. Premaxila, porción anterior de la maxila, dentario y labios con cromatóforos marrones oscuros muy concentrados. Variaciones de coloración entre machos y hembras se describen en el dimorfismo sexual.

Dimorfismo sexual. Ejemplares machos con ganchos óseos en los radios de las aletas anal, caudal, pectoral y pélvica. Aleta caudal con ganchos cortos, finos y orientados en sentido anterodorsal sobre las porciones no ramificadas y las ramificaciones dorsales de los radios 14 a 18 (Fig. 41c). Todos los radios de la aleta pélvica con ganchos finos, pareados o solo uno por segmento (aunque en las bases de los radios por lo general no pareados y numerosos) y orientados en sentido anterolateral a lo largo de casi toda la longitud de cada radio (excepto el primer radio que tiene dos ganchos). Aleta pectoral con unos pocos ganchos diminutos dispersos sobre la porción distal del primer radio ramificado. Aleta anal con ganchos finos, de base ancha, pareados por segmento y anterodorsalmente situados en los radios; con tres a quince pares de ganchos localizados sobre el radio simple más posterior y los primeros siete radios ramificados anteriores (ganchos comparativamente más largos en los radios medios de este intervalo). En los machos adultos, el radio simple más posterior y los primeros 18 radios ramificados de la aleta anal disminuyen poco a poco en longitud (aleta de aspecto convexo), mientras que en las hembras el radio simple más posterior y los primeros tres radios ramificados son más largos que el resto (aleta de aspecto recto o un poco cóncavo). Los machos adultos con frecuencia tienen el borde basal de la aleta anal un poco convexo en su porción anterior o todo el borde algo curvado, mientras que las hembras lo tienen recto. Hembras adultas con una papila urogenital externa, grande, cónica y por lo general orientada en sentido posteroventral (Fig. 43).

La mancha caudal de los machos solo alcanza la base de los radios de la aleta caudal, mientras que en las hembras, esta mancha se extiende hasta la mitad de la longitud de los radios medios caudales. En los machos, esta mancha bordea dorsalmente la escamabolsillo y deja un área no pigmentada en la porción inferior del pedúnculo caudal, mientras que en las hembras esta mancha está bien desarrollada en el pedúnculo caudal. Cromatóforos de la aleta anal sobre la porción anterior y distal, en general más 
concentrados en los machos que en las hembras. La línea lateral negra de los machos bordea dorsalmente la mancha caudal, mientras que en las hembras esta línea finaliza sobre las porciones anterior o dorsal. Los machos difieren de las hembras por la presencia de una mancha difusa o unos pocos cromatóforos marrones oscuros sobre la porción distal del primer radio ramificado de la aleta pectoral y rara vez sobre el radio continuo proximal. Porción distal del primer radio ramificado de la aleta pectoral modificado en ambos sexos; la ramificación es más compleja en los machos que en las hembras. En los machos, la mitad posterior del primer radio ramificado de la aleta pectoral hipertrofiado como en $G$. melanocheir, pero tal modificación algo diferente. Este radio dividido en dos ramas iguales que individualmente se dividen en tres ramas más pequeñas, las cuales se dividen en seis ramas que continúan la división hasta formar una estructura distal con 60 (1), 61 (2), 62 (2), 64 (1), 70 (3), 72* (1), 78 (1) o 88 (1) ramas diminutas (Vanegas-Ríos et al., 2013: fig. 3). En las hembras, este radio pectoral se divide en dos ramas principales, cuya rama más externa se divide en cuatro ramas más cortas y cuya rama más interna se divide en tres ramas más cortas; cada una de estas siete ramas por lo general se divide una vez más.

Machos maduros con una escama modificada para formar un bolsillo sobre el lóbulo ventral de la aleta caudal y con el segundo y tercer radios procurrentes ventrales modificados en forma de una estructura tipo pinza, ventral al radio principal 19. Tejido de apariencia glandular localizado sobre los radios de la aleta caudal y medial a la escamabolsillo. Estructura tipo pinza osificada de manera incompleta en su porción distal y alcanza la mitad de la longitud del primer radio procurrente ventral (Fig. 41c). Primer radio procurrente ventral con una moderada concavidad en su porción ventral. Segundo radio procurrente ventral un poco más largo que el tercero y con su porción posterior apenas expandida sagitalmente. Porción posterior del tercer radio procurrente ventral poco desarrollada lateralmente. Escama-bolsillo hipertrofiada, con 26 o 30 radii localizados entre los radios 16 o 17 a 18 y el tercer radio procurrente ventral de la aleta caudal. Escama-bolsillo con un lóbulo posteroventral extendido a lo largo del tercer radio procurrente ventral (Figs. 41c, d). Superficie dorsal de la escama-bolsillo anclada a través de un tejido blando o conectivo a los radios de la aleta caudal 9 o 10 a 15 a 16 . Borde posterior de la escama-bolsillo localizado entre el radio 15 de la aleta caudal y el tercer radio procurrente ventral. Cuatro o cinco escamas en serie vertical, justo debajo de la escama más posterior de la línea lateral, sobre la porción posterior de la escama-bolsillo. Con una escama mediana ondulada entre estas escamas y la escama-bolsillo. Una serie de 
procesos espinosos diminutos forman un parche sobre la porción dorsal de la escamabolsillo. Las hembras con una escama grande con 20 (1), 21 (3), 22 (2), 24 (2), 26 (2), 27 (1), 28 (2) o 29 (3) radii.

Machos maduros con glándula branquial larga (dos machos juveniles no fueron analizados por la glándula poco desarrollada). Glándula branquial formada por 11 (1), 12 (1), 14 (1), 20 (2), 21 (3), 22* (3), 23 (3) o 24 (2) filamentos branquiales modificados de la porción ventral del primer arco branquial funcional. Número total de filamentos branquiales en la porción ventral 23 (2), 24 (1), 25 (3), 26 (2), 27 (2), 28 (2), 29 (2) o 30* (2). Longitud de la glándula branquial 6,0-10,3 \% LE (media = 8,6 \% LE), 8,7 \% LE*.

Distribución. Se encuentra en dos localidades de la cuenca del río Sucio, sistema del río Cascajales, cuenca del río La Colorada, cuenca del río Magdalena, Colombia (Fig. 19).

Comentarios. Se identificaron como G. melanocheir varios ejemplares del río Topón en Santander, Colombia (ICNMHN, 17777, 17790, 17817 y 17826) los cuales no fueron previamente analizados por Vanegas-Ríos et al. (2013) en sus comparaciones entre G. melanocheir y $G$. torresi y corresponden a un punto geográfico intermedio entre las distribuciones de ambas especies. Los ejemplares d\&t de G. torresi presentaron el cuarto infraorbital ausente o fusionado y después de examinar la serie completa de los tipos, se encontró que más del $60 \%$ de los ejemplares pierde este infraorbital. Esta pérdida del infraorbital también se observó en casi todos los ejemplares de tallas mayores, lo que sugiere una posible variación ontogenética. Este carácter se codificó polimórfico en el análisis filogenético y no se usó en la diagnosis de G. melanocheir vs. G. torresi porque sería necesario contar con un mayor número de ejemplares de G. torresi para determinar si este carácter es bimodal o la pérdida del infraorbital es una característica más estable en la especie. Sin embargo, tanto la pérdida del cuarto infraorbital como la de la aleta adiposa fueron incluidas en la clave taxonómica, porque pueden ser útiles para la discriminación de esta especie.

Material examinado. UIST 1767, holotipo Gephyrocharax torresi Vanegas-Ríos, Azpelicueta, Mirande \& Gonzales, 2013, 36,7 mm LE, macho, Colombia, Santander, El Carmen, cuenca del río Magdalena, cuenca del río La Colorada, sistema río Cascajales, cuenca del río Sucio, Caño Volador, 6³9'56,44"N 73³4'47,36"O, aproximadamente 338 m s.n.m., 17 Dic. 2009, M. Torres-Mejía. Paratipos: todos de Colombia, Santander: MLP 10518, 1 macho (d\&t), 34,7 mm LE, CI-FML 6105, 2, 34,0-36,0 mm LE y UIST 1751, 19 , 26,3-37,3 mm LE (1 d\&t 36,0 mm LE), El Carmen, cuenca del río Magdalena, cuenca del río La Colorada, sistema del río Cascajales, río Sucio bajo el puente hacia la Vereda 
Islandia, 641'14,6"N 73³5'15,10"O, aproximadamente 280 m s.n.m., 16 Dic. 2009, M. Torres. MLP 10519, 2, 35,1-39,0 mm LE; UIST 1766, 12, 32,0-42,0 mm LE, recolectados con el holotipo.

\section{Gephyrocharax valencia Eigenmann, 1920a}

Figs. 14, 17, 20, 24 y 44-47, Tablas 1 y 11

Gephyrocharax valencia Eigenmann, 1920a: 11-12 (descripción original, designación material tipo, holotipo CAS 44297 [IU 15131], localidad tipo: Maracay, Lago de Valencia, cerca del muelle de la fábrica de papel. Myers en Eigenmann \& Myers, 1929: 477 y 484 (clave, redescripción sin figuras). Schultz, 1944: 323-324, tabla 20 (clave, datos de distribución, comparación con G. venezuelae). Géry, 1977: 352, foto (coloración en vida, orth. mut. "valenciae"). Weitzman \& Fink, 1985: 104 (material examinado). Bonilla \& López, 1995: 33-45 (análisis morfológico y genético). Burns, Weitzman \& Menezes, 1995: 133-135 (espermatozoide, inseminación). Machado-Allison, Chernoff, Royero-León, Mago-Leccia, Velázquez, Lasso, López-Rojas, Bonilla-Rivero, Provenzano \& Silvera, 2000: 16 (río Cuyuní, cuenca río Esequibo, Venezuela). Bonilla-Rivero \& López-Rojas, 2001: 1-10 (comparación morfológica y genética). Taphorn, 2003: 61, 141-142, figs. 42 y 133-134 (clave, datos morfológicos y ecológicos). Weitzman, 2003: 225 (cita en catálogo). Lasso, Lew, Taphorn, DoNascimiento, Lasso-Alcalá, Provenzano \& Machado-Allison, 2004: 152 (lista de peces Venezuela). RodríguezOlarte, Coronel, Taphorn \& Amaro, 2007: 2 (río Tocuyo, Caribe, Venezuela). Maldonado-Ocampo, Vari \& Usma, 2008: 181 (lista de peces Colombia). Arai, 2011: 82: (cromosomas: $2 \mathrm{n}=52$ ). Bonilla-Rivero \& López-Rojas, 2013: 487-495, tablas 1-4, figs. 1-3 (estudio filogeográfico comparado). Vanegas-Ríos, Azpelicueta, Mirande \& Gonzales, 2013: 283 (material examinado). Phillip, Taphorn, Holm, Gilliam, Lamphere \& López-Fernández, 2013: 9, 16 y 28, tabla 1, fig. 38 (lista de peces Trinidad \& Tobago, clave). Vanegas-Ríos \& Phillip, 2013: 1329-1334, tabla 1, figs. 1 y 2 (ríos Moriquite y Moruga, costa sur isla de Trinidad, Trinidad \& Tobago, datos morfológicos y ecológicos).

Diagnosis. Gephyrocharax valencia se diferencia de sus congéneres (excepto $G$. caucanus, G. chocoensis y G. martae) por la ausencia de mancha humeral (vs. presencia 
de esta mancha) y (excepto G. melanocheir, G. sinuensis y G. torresi) la ausencia del tubo terminal de la línea lateral entre los radios caudales 10 y 11 ( $v s$. presencia de este tubo). La especie también difiere de G. atracaudatus, G. caucanus, G. chocoensis, G. intermedius, G. sinuensis y $G$. venezuelae por la ausencia de rinosfenoides (vs. presencia de este hueso). Además, G. valencia se distingue de G. caucanus, G. chocoensis, G. sinuensis, G. torresi y G. venezuelae por la ausencia de lámina ósea entre el primero y segundo basibranquiales (vs. presencia de esta lámina). La especie difiere de G. chocoensis, G. martae, G. sinuensis y $G$. torresi por el mayor número de radii de la escama-bolsillo en los machos adultos 13-21 (vs. 21-30). Gephyrocharax valencia también se distingue de G. venezuelae por la porción anterior (cartilaginosa) del simpléctico que no alcanza el borde anterior de la fenestra metapterigoidea ( $v s$. esta porción alcanza o sobrepasa el borde anterior de tal fenestra). Caracteres adicionales que distinguen a $G$. valencia de $G$. atracaudatus, G. caucanus, G. chocoensis, G. intermedius, G. major, G. martae, G. melanocheir, G. sinuensis y G. torresi fueron mencionados en las diagnosis respectivas de estas especies. Véase también la lista de autapomorfías mencionadas para G. valencia.

Descripción. Datos morfométricos en la tabla 11. Macho de mayor tamaño con 34,1 mm LE, hembra de mayor tamaño con 39,8 mm LE. Cuerpo lateralmente comprimido, con altura máxima en el origen de la aleta pélvica o por un punto entre este y el origen de la aleta anal. Perfil dorsal de la cabeza recto desde la punta del hocico hasta la espina supraoccipital. Perfil dorsal del cuerpo un poco convexo desde la porción posterior de la espina supraoccipital hasta el origen de la aleta dorsal, desciende en sentido posteroventral a lo largo de la base de la aleta dorsal y continúa recto desde el radio dorsal más posterior hasta el pedúnculo caudal (Fig. 44). Perfil ventral del cuerpo convexo desde la punta del hocico hasta el origen de la aleta pélvica, continúa algo convexo desde este punto hasta el origen de la aleta anal y asciende posterodorsalmente recto o a veces apenas curvado desde el origen anal hasta el inicio del pedúnculo caudal. Fontanela anterior desarrollada, raras veces reducida por el contacto anterior de los frontales. Narina anterior redondeada y separada por un pliegue de piel de la narina posterior de mayor tamaño. Hendidura extendida desde un punto medio entre el poro posterior del nasal y las narinas hasta la región posterior de los frontales, con al menos tres hileras de neuromastos. Hendidura más pequeña con pocos neuromastos sobre la región entre las narinas y los huesos nasales.

Aleta dorsal con ii,7 (6), 8* (285) o 9 (1) radios y $9 *$ pterigióforos proximales. Origen de la aleta dorsal en la vertical a través de los radios anales 6 a 12. Aleta adiposa 
presente (ausente en dos ejemplares), su origen al nivel de las bases de los dos radios más posteriores de la aleta anal. Aleta anal con iv (246) o v* (47), 23 (2), 24 (2), 25 (2), 26 (20), $27 *$ (81), 28 (80), 29 (78), 30 (22) o 31 (5) radios y 26-31 pterigióforos proximales. Origen de la aleta anal más cerca de la unión hipural que de la punta del hocico. Aleta pectoral con i,8 (20), 9* (210) o 10 (55) radios. Aleta pectoral larga, alcanza entre un séptimo y un medio de la longitud de la aleta pélvica. Aleta pélvica con i,6* (281) o 7 (3) radios. Origen de la aleta pélvica localizado en la vertical que pasa por las escamas 7 a 10 de la línea lateral y anterior a la mitad del cuerpo. Aleta caudal bilobulada con 10/9 radios principales.

Hocico superior, por lo general con la mandíbula inferior un poco anterior a la punta de la mandíbula superior. Premaxila con dos hileras de dientes; hilera externa con 2 (9), 3* (89), 4 (184) o 5 (3) dientes tricúspides, algunas veces cónicos o bicúspides. Hilera interna con 4 (30), 5* (248) o 6 (8) dientes; el sinfisial tetracúspide (rara vez pentacúspide) y los demás tricúspides a pentacúspides, muchas veces el diente más posterior con menor número de cúspides o cónico. Maxila sin dientes (7) o con $1^{*}(268)$ o 2 (11) dientes en general cónicos a tricúspides (pocas veces tetracúspides o pentacúspides) (Fig. 45a). Maxila larga, alcanza posteriormente el tercio anterior del ojo. Dentario con 8 (5), 9 (18), 10 (41), 11 (86), 12 (48), 13* (21), 14 (10), 15 (2) o 16 (1); los tres más anteriores grandes y pentacúspides (algunas veces el más anterior tetracúspide), seguidos por uno de tamaño mediano tricúspide a pentacúspide y 4 (5), 5 (18), 6 (41), 7 (86), 8 (48), 9* (21), 10 (10), 11 (2) o 12 (1) dientes más pequeños cónicos a tricúspides que poco a poco disminuyen en tamaño en sentido anteroposterior a lo largo del borde dorsal del dentario (Fig. 45b).

Escamas cicloides, con numerosos radii a lo largo del campo posterior. Línea lateral completa. Tubo terminal de la línea lateral presente. Escamas con poros 36 (2), 37 (12), 38 (45), 39* (77), 40 (68), 41 (61), 42 (18), 43 (4) o 44 (1). Escamas predorsales 17* (43), 18 (87), 19 (84), 20 (54) o 21 (4). Hileras de escamas entre la aleta dorsal y la línea lateral 5 (34), 6* (250) o 7 (3). Hileras de escamas entre la línea lateral y la aleta anal 4 (31), 5 (250) o 6* (6). Hileras de escamas entre la línea lateral y la aleta pélvica 4 (152) o 5* (129). Escamas circumpedunculares 13 (21), 14 (164), 15 (48) o 16* (15). Una hilera de escamas dispuestas a lo largo de la base de la aleta anal de 10 (2), 11 (6), 12 (23), 13 (32), 14* (52), 15 (38), 16 (18), 17 (20), 18 (9), 19 (2) o 20 (1) escamas. Número total de vértebras 38* (3), 39 (7), 40 (5) o 41 (1), 15* (12) o 16 (4) precaudales y 23* (3), 24 (8) o 25 (3) caudales (seis radiografiados y diez ejemplares $d \& t$ ). Rastrillos branquiales del 
primer arco branquial 6 (171) o 7* (64) sobre la porción dorsal y 10 (2), 11* (139), 12 (92) o 13 (1) sobre porción ventral.

Coloración en alcohol. Cuerpo amarillento claro o marrón oscuro, más oscuro en la línea media dorsal y un poco más claro en la zona ventral. Cromatóforos marrones o negros diminutos cubren la superficie del cuerpo, pero a veces ausentes o en menor cantidad sobre la región lateral del abdomen y la región ventral del pedúnculo caudal. Línea lateral negra o marrón oscura (o con frecuencia una banda lateral plateada) extendida hacia atrás desde un punto sobre el último tercio de la aleta pectoral o el origen de la aleta pélvica, dorsal a la línea lateral, hasta la región posterior del pedúnculo caudal. Cromatóforos marrones oscuros dispersos sobre los mioseptos entre la línea lateral y la porción superior de la aleta anal. Mancha humeral ausente o no diferenciada de la banda lateral de cromatóforos. Mancha caudal marrón, marrón oscura o rara vez negra, alargada en sentido longitudinal y extendida desde región media y posterior del pedúnculo caudal, cubre en parte a los interradialis, hasta la base de los radios medio caudales. Aleta dorsal gris clara o amarilla tenue, con cromatóforos marrones oscuros o negros un poco concentrados a lo largo de las membranas y los bordes de los radios. Aleta anal gris clara, con cromatóforos marrones oscuros en especial concentrados sobre las membranas. Aleta caudal gris clara o amarilla tenue, con cromatóforos marrones oscuros o negros distribuidos sobre las membranas y los bordes de los radios (a veces estos cromatóforos un poco más numerosos en los radios medios caudales). Aletas pectoral y pélvica grises claras, con algunos cromatóforos marrones oscuros distribuidos en especial sobre las membranas. Cabeza más oscura dorsal que ventralmente. Opérculo e infraorbitales con pocos cromatóforos marrones oscuros o negros. Premaxila, porción anterior de la maxila, dentario y labios con cromatóforos marrones oscuros o negros un poco concentrados. Variaciones en la coloración entre machos y hembras se describen en el dimorfismo sexual.

Dimorfismo sexual. Ejemplares machos con ganchos óseos en los radios de las aletas anal, caudal y pélvica. Aleta caudal con ganchos cortos, finos y orientados en sentido anterodorsal, en especial sobre las porciones ramificadas dorsales de los 14 a 17 (Fig. 46a). Todos los radios de la aleta pélvica, excepto el primer radio, con ganchos finos pareados o solo uno por segmento (aunque en las bases de los radios casi siempre no pareados y numerosos) y orientados en sentido anteroventral en casi toda la longitud de cada radio (a veces ausentes o en menor cantidad en el último radio proximal). Aleta anal con ganchos finos, de base ancha, pareados por segmento y anterolateralmente orientados en los radios; con uno a quince pares de ganchos localizados sobre el radio simple más 
posterior y los primeros siete radios ramificados anteriores (los ganchos son más largos en los radios medios o posteriores de este intervalo). Los machos adultos casi siempre con el borde basal de la aleta anal curvado o cóncavo en el centro, mientras que las hembras lo tienen recto. Aleta anal un poco convexa en su región media en los machos adultos (el radio simple más posterior y los primeros 15 a 17 radios ramificados parecidos en longitud entre sí y más largos que el resto), mientras que es recta o apenas cóncava en las hembras. Hembras adultas con frecuencia tienen externamente una pequeña papila urogenital externa orientada ventralmente.

Los machos adultos presentan un suave parche de cromatóforos marrones oscuros o negros extendidos desde la región anterior del poro urogenital hasta la región anterior al origen de la aleta pélvica. En cambio, las hembras a veces carecen de estos cromatóforos en parche o si los presentan, su concentración sobre tal región es menor. Machos maduros con una escama modificada para formar un bolsillo sobre el lóbulo ventral de la aleta caudal y con el segundo y tercer radios procurrentes ventrales modificados en forma de una estructura tipo pinza, ventral al radio principal 19. Tejido de apariencia glandular en muy poca cantidad, localizado en especial sobre los radios de la aleta caudal y medial a la escama-bolsillo. Estructura tipo pinza en parte osificada en su zona distal y alcanza la mitad de la longitud del primer radio procurrente ventral (Fig. 46a). Primer radio procurrente ventral con una concavidad en su porción ventral. Segundo radio procurrente ventral un poco más largo que el tercero y expandido en el plano sagital, más notable en su porción posterior. Porción posterior del tercer radio procurrente ventral poco desarrollada en sentido lateral. Escama-bolsillo hipertrofiada, con 13 a 21 radii que por lo general se localizan entre el radio 17,18 o 19 y el tercer radio procurrente ventral de la aleta caudal. Escama-bolsillo con un lóbulo posteroventral de variada longitud y extendido a lo largo del tercer radio procurrente ventral (Figs. 46a, b). Superficie dorsal de la escama-bolsillo anclada a través de un tejido blando o conectivo a los radios de la aleta caudal 10 o 11 a 15 o 16. Borde posterior de la escama-bolsillo localizado entre los radios 15 o 16 y el tercer radio procurrente ventral de la aleta caudal. Cuatro escamas en serie vertical, justo debajo de la escama más posterior de la línea lateral, sobre la porción posterior de la escamabolsillo. Borde dorsal de la escama-bolsillo recto, a veces un poco cóncavo. Las hembras con una escama grande con 12 (1), 14 (2), 15 (4), 16 (2), 17 (2), 18 (3), 19 (1) o 20 (1) radii.

Machos maduros con una glándula branquial mediana (holotipo con filamentos branquiales deteriorados). Glándula branquial formada por 7 (1), 8 (2), 9 (4), 11 (8), 12 
(4), 13 (5), 14 (8), 15 (14), 16 (4), 17 (4), 18 (4) o 22 (2), filamentos branquiales modificados de la porción ventral del primer arco branquial funcional. Número total de filamentos branquiales en la porción ventral 20 (3), 21 (4), 22 (7), 23 (14), 24 (13), 25 (6), 26 (2), 28 (1) o 30 (1). Longitud de la glándula branquial 3,5-9,2 \% LE (media = 6,2 \% LE).

Distribución. Se encuentra en diferentes localidades a lo largo de la cuenca del río Orinoco, vertiente Caribe y región costera de la isla de Trinidad, en Colombia, Venezuela y Trinidad \& Tobago (Fig. 20). Otros registros son presentados en Bonilla-Rivero \& López-Rojas (2001) y Bonilla-Rivero \& López-Rojas (2013).

Notas ecológicas. Bonilla \& López (1995) presentaron datos sobre el hábitat de dos poblaciones, Lago de Valencia y cuenca el río Tuy en Venezuela; Vanegas-Ríos \& Phillip (2013) datos de hábitat en poblaciones de Trinidad; Winemiller (1989) datos sobre la presencia de protuberancias dermales en el labio inferior asociadas a la condiciones del hábitat en individuos de la cuenca del río Apure de Venezuela y Winemiller (1992) datos ecomorfológicos.

Comentarios. Inicialmente, Bonilla \& López (1995) estudiaron dos poblacionales aisladas geográficamente de G. valencia (cuenca del Lago de Valencia y cuenca del río Tuy) y no encontraron divergencia morfológica representativa en la morfometría de ambas poblaciones. Bonilla-Rivero \& López (2001) describieron una gran superposición en los datos morfométricos de varias poblaciones de G. valencia y G. venezuelae. Luego, Bonilla-Rivero et al. (2002) encontraron cierta separación en los datos morfométricos entre poblaciones de G. valencia y $G$. venezuelae, en un estudio similar al anterior pero con menor número de ejemplares. Bonilla-Rivero \& López (2013) nuevamente analizaron la problemática poblacional de G. valencia en contraste con otros Gephyrocharax de Venezuelae, pero enfocados en la variabilidad genética. Esta vez, estos autores encontraron una estructura poblacional mejor definida en G. valencia comparativamente con G. venezuelae, a través de una aproximación de distancias genéticas (Bonilla-Rivero \& López, 2013: fig. 2) y a su vez explicaron históricamente las razones de las posibles divergencias geográficas de los linajes de interés, a lo largo del movimiento del curso del río Orinoco en el tiempo.

Varios grupos de ejemplares de G. valencia organizados por grandes cuencas y/o proximidad geográfica (Apuré, cuenca del río Apuré; Caribe, algunos drenajes costeros de la vertiente Caribe; Cuyuní, cuenca del río Cuyuní; Delta, drenajes afines al delta del río Orinoco; Meta; cuenca del río Meta; Trinidad; cuenca de los ríos Moruga-Moriquite en la 
isla de Trinidad; Uyaré-Orocopiche, drenajes cercanos entre los río Uyaré y Orocopiche; y Valencia, cuenca del Lago de Valencia) fueron estudiados a través de un ACP de los datos morfométricos. El ACP no mostró diferencias notables entre los diferentes grupos analizados y la variabilidad está en general superpuesta a lo largo de las CP2 y CP3 (Fig. 47). Sin embargo, una población de la cuenca del río Apure (UF 80511) se encontró mejor definida en las componentes obtenidas y con menor superposición con los restantes grupos. Esta población aparece, casi por completo, distribuida a lo largo de las CP2 entre las coordenadas $-0,3$ y $-0,1$ y en la región superior de la CP3 entre las coordenadas $-0,05$ y 0,10 (véase símbolos grupo "Apure" en esos intervalos). En la CP2, donde la nube de grupos se dispersa de manera más notable, las variables con mayor aporte fueron la longitud del pedúnculo caudal $(-0,83)$ y la longitud del hocico $(0,43)$, lo que sugiere que gran parte de la estructura dada para los distintos grupos poblacionales está influenciada por la variabilidad intraespecífica e intergrupal de estas medidas. Basado en los datos de coloración, restantes datos de morfometría y merística, esta población UF 80511 pertenece a $G$. valencia y su ligera divergencia en esta componente es considerada variación geográfica dentro de la especie.

Material examinado. Colombia: ANSP 133981, 10, 29,4-34,4 mm LE (2 d\&t 29,9-33,0 mm LE), Meta, cuenca río Meta, quebrada la Venturosa, entre La Balsa y Puerto López, 45'N 7258'O aproximadamente, 186 m s.n.m., 21 Mar. 1975, J. E. Bölhke, W.G. Saúl \& L. Fuiman. ANSP 139816, 8, 17,7-18,7 mm LE, Meta, cuenca río Meta, Lago Mozambique (Rancho Mozambique), en la línea costera sobre el lado norte del lago, 358'N 734'W 206 m s.n.m., 23 May. 1969, J. E. Böhlke et al. CZUT-IC 5346, 10, 23,530,2 mm LE, Casanare, Paz de Ariporo, río Chire Viejo, 601'20,0”N 71²3’4,5’O $150 \mathrm{~m}$ s.n.m. IAvH-P 4972, 10, 22,1-28,6 mm LE, Meta, Puerto López, cuenca río Meta, río Negrito, 47'0”N 7257'0”'O 172 m s.n.m., 13 Ene. 1988, Castro \& Arboleda. NRM 23841, 6, 20,0-25,7 mm LE, Meta, río Negro, casi 2 km S del pueblo Rincón de Pompeya, aproximadamente $4^{\circ} 1^{\prime} 36,01^{\prime \prime N} 73^{\circ} 21^{\prime} 48,99 " O 256$ m s.n.m., 27 Dic. 1987, A. M. C. Silfvergrip. UF 23824, 7, 17,0-32,3 mm LE, Meta, cuenca ríos Meta-Guatiquía, caño Negros casi 18,7 km sobre la carretera desde Villavicencio a Puerto Porfía, aproximadamente $4^{\circ} 6^{\prime} 57,30^{\prime \prime} \mathrm{N} 73^{\circ} 23^{\prime} 17,67^{\prime \prime O} 275$ m s.n.m., 13 Ene. 1973, H. T. Boschung et al. UF 33410, 2, 30,6-34,4 mm LE, Meta, cuenca río Meta, río Guacavía ENE de Villavicencio, aproximadamente $4^{\circ} 17^{\prime} 24,24 " \mathrm{~N} 73^{\circ} 30^{\prime} 51,06 " \mathrm{O} 449$ m s.n.m., 3 Ene. 1973, J. D. Williams. UF 80967, 5, 26,7-30,4 mm LE, Meta, cuenca río Meta, pequeña quebrada casi $70 \mathrm{~km}$ E de Villavicencio sobre la carretera a Puerto López, 
aproximadamente $4^{\circ} 4^{\prime} 24,81^{\prime \prime N 72}{ }^{\circ} 59^{\prime} 16,55^{\prime \prime O} 185$ m s.n.m., 30 Dic. 1972, J. D. Williams et al. UF 80968, 11, 26,2-30,8 mm LE, Meta, cuenca río Meta, pequeña quebrada casi 70 $\mathrm{km}$ E de Villavicencio sobre la carretera a Puerto López, aproximadamente 44'24,81"N7259'16,55"O 185 m s.n.m., 30 Dic. 1972, J. D. Williams et al. Venezuela: AMNH 77783, 4, 22,7-26,6 mm LE, Guárico, cuenca río Orinoco, caño al oeste de la carretera desde Calabozo a San Fernando cerca 35 km al sur de Fundo Masaguaral (caño falcón), aproximadamente $8^{\circ} 14^{\prime} \mathrm{N} 67^{\circ} 35^{\prime} \mathrm{O} 55 \mathrm{~m}$ s.n.m., 20 Ene. 1983, R. P. Vari et al. AMNH 217653, 2, 24,6-25,8 mm LE, Delta Amacuro, río Orinoco, corriente principal de la costa norte de la isla Tres Canos, 129,7 millas náuticas, aproximadamente $8^{\circ} 39,6^{\prime} \mathrm{N}$ 6159’O 8 m s.n.m., 13 Nov. 1979, D. J. Stewart \& Otillo. ANSP 133986, 25, 21,6-37,0 mm LE, Carabobo, río Vigirima (tributario río Guácara), cerca 10 km NNW de Guácara, donde la "dirt road" se une a la carretera no pavimentada, aproximadamente $10^{\circ} 24^{\prime} \mathrm{N}$ 6755'O 253 m s.n.m., 30 Nov. 1966, N. R. Foster et al. ANSP 134185, 20, 21,9-28,1 mm LE, Guárico, tributario del río Guárico, $3 \mathrm{~km} \mathrm{~S}$ de Calabozo sobre la carretera federal No. 2, aproximadamente $8^{\circ} 51^{\prime} \mathrm{N} 67^{\circ} 28^{\prime} \mathrm{O} 88$ m s.n.m., 26 Nov. 1966, N. R. Foster. ANSP 134924, 2 (d\&t), 24,5-32,7 mm LE, Carabobo, tributario Lago de Valencia, caño Cambur $11 \mathrm{~km} \mathrm{~S}$ El Valencia, aproximadamente $10^{\circ} 5^{\prime} 44,56^{\prime \prime} \mathrm{N} 67^{\circ} 52^{\prime} 49,25^{\prime \prime O} 425$ m s.n.m., 13 Ene. 1938. ANSP 159869, 25, 21,9-32,7 mm LE (t\&m 30,4-32,7 mm LE), Bolívar, caño en puente de concreto cerca Hacienda Fundo Malama (Sr. Biales), casi 11 km N Sipao, aproximadamente $7^{\circ} 33^{\prime} \mathrm{N} 65^{\circ} 23^{\prime}$ O 53 m s.n.m., 19 Nov. 1985, W. S. \& R. Royero. ANSP 159881, 50, 22,1-32,5 mm LE, Bolívar, río y área inundada $15 \mathrm{~km} \mathrm{~N}$ de Maniapure sobre la ruta Caicara-Puerto Ayacucho, 655'27,87"N 66³3'32,44"O 72 m s.n.m., 16. Nov. 1985, B. Chernoff, W. Saul, H. López, R. Royero, O. Brull \& L. Aguana. ANSP 161047, 15, 19,3-28,7 mm LE, Bolívar, río Agua Blanca, desde 100 a $600 \mathrm{~m}$ abajo del puente cruzando la carretera Caicara-Bolívar, aproximadamente 750’ $\mathrm{N} 63^{\circ} 51^{\prime} 18^{\prime}$ 'O 71 m s.n.m., 21 Nov. 1985, B. Chernoff et al. ANSP 165291, 7, 20,0-26,3 mm LE, Apure, tributario río Arauca, caño el Yagua, aproximadamente 7³0'0”'N 68²0'0”O 74 m s.n.m., 5 Nov. 1989, S. Schaefer, W. G. Saul, F. Provenzano \& O. Castillo. ANSP 168015, 10, 22,9-27,0 mm LE, Bolívar, cuenca Yuruari-Cuyuní, río Miamo, sobre la carretera Guasipati-El Miamo casi 20 km SO El Miamo, aproximadamente 7³8'0”N 6150’0”O 212 m s.n.m., 24 Ene. 1991, Schaefer, W. G. Saul \& F. Provenzano. AUM 5307, 104, 15,3-29,2 mm LE, Portuguesa, cuenca río Portuguesa, caño Igues, carretera Guanare-Guanarito en el km 60, 849'39,00"N 69²0'42,00"O aproximadamente 110 m s.n.m., 17 Dic. 1999, J. W. Armbruster, M. Hardman, J. D. Evans \& J. A. Thomas. AUM 22776, 21, 21,2-30,5 mm 
LE, Portuguesa, cuenca río Apure, río Portuguesa, en el puente de la carretera 5, 94'54,48"N 6940'53,72"O aproximadamente 147 m a. n. m, 31 Dic. 1999 a 1 Ene. 2000, J. W. Armbruster, M. Harman, J. D. Evans \& J. A. Thomas. CAS 44294 (antes IU 15129), 99 paratipos, 27,4-38,2 $\mathrm{mm}$ LE, [Carabobo, aproximadamente 10 ${ }^{\circ} 9^{\prime} 58,21 " \mathrm{~N}$ 67²3'50,85"O 410 m s.n.m.] cuenca Lago de Valencia, Isla del Burro, 11 Jul. 1918, A. S. Pearse. CAS 44295, 1, 30,4 mm LE, Aragua, Maracay, río Bue, 19 Jul. 1918, A. S. Pearse. CAS 44297, holotipo Gephyrocharax valencia Eigenmann, 1920, 27,5 mm LE (R), macho, Aragua, Maracay, Lago de Valencia, cerca del muelle de la fábrica de papel [aproximadamente $10^{\circ} 13^{\prime} 0,85^{\prime \prime} \mathrm{N} 67^{\circ} 37^{\prime} 11,82^{\prime \prime O} 448$ m s.n.m.], 1 a 31 Jul. 1918, A. S. Pearse. INHS 27775, 20, 24,4-30,6 mm LE, Barinas, cuenca río Apure, caño Curito en la carretera $5,7^{\circ} 58,41^{\prime} \mathrm{N}, 71^{\circ} 0,5^{\prime} \mathrm{O}$ aproximadamente $202 \mathrm{~m}$ s.n.m., 7 Ene. 1992, L. M. Page et al. INHS 28356, 20, 22,8-32,3 mm LE, Apure, cuenca río Apure, río Orichuna, aproximadamente $7^{\circ} 8^{\prime} 40,32^{\prime \prime} \mathrm{N} 70^{\circ} 2^{\prime} 54,16 " \mathrm{O} 107$ m s.n.m., $62 \mathrm{Km}$ E Elorza sobre carretera hacia La Victoria en el Charal, 5 Ene. 1992, L. M Page et al. INHS 28368, 20, 17,2-25,7 mm LE, Barinas, cuenca río Apure, caño $7^{\circ} 16,26^{\prime} \mathrm{N} 71^{\circ} 5,20^{\prime} \mathrm{O}$ aproximadamente 114 m s.n.m., 6 Ene. 1992, L. M Page et al. INHS 29877, 16, 24,2-32,6 mm LE, Barinas, cuenca río Apure, tributario del río Suripa, Yaure sobre carretera 5, 36 km NE de La Pedrera, caño Yaure, $7^{\circ} 42,05^{\prime} \mathrm{N} 71^{\circ} 17,77^{\prime} \mathrm{O}$ aproximadamente $174 \mathrm{~m}$ s.n.m., 25 Ene. 1993, L. M Page, S. Hundorf \& J. L Crane. INHS 31385, 20, 20,2-28,0 mm LE, Aragua, cuenca río Apure, río Guárico, Barbacoas, 9²8'44"N 6659'03"O aproximadamente 170 m s.n.m., 5 Ene. 1994, L. M Page et al. INHS 31627, 15, 20,7-30,5 mm LE, Bolívar, cuenca río Cuyuní, tributario río Yuruari, $3 \mathrm{~km} \mathrm{O}$ Guasipati vía La Pastora, 7²8' $17^{\prime \prime} \mathrm{N} 61^{\circ} 55^{\prime} 01$ "O aproximadamente $176 \mathrm{~m}$ a. n. m, 10 Ene. 1994, L. M Page et al. INHS 31720, 16, 23,0-29,2 mm LE, Bolívar, INHS 31720, Bolívar, El Miamo, cuenca río Yuruari, río Guanare, aproximadamente 7³8'13,32"N 6146’41,97"O $207 \mathrm{~m}$ s.n.m., 11 Ene. 1994, L. M Page et al. INHS 34668, 14, 18,8-28,2 mm LE, Barinas, cuenca ríos Apure-Masparro, río Caipe, 2 millas E La Luz, aproximadamente $8^{\circ} 24^{\prime} 31^{\prime \prime} \mathrm{N}$ 6948'19"O aproximadamente 119 m s.n.m., 26 Ene. 1995, L. M Page et al. INHS 60438, 8, 28,2-39,8 mm LE, Carabobo, sistema Lago de Valencia, caño La Cumara, $3 \mathrm{~km} \mathrm{~N}$ de San Diego, $10^{\circ} 16,55^{\prime} \mathrm{N} 67^{\circ} 56,21^{\prime} \mathrm{O}$ aproximadamente 492 m s.n.m., 26 Dic. 1990, L. M Page et al. INHS 69242, 20, 26,3-33,4 mm LE, Bolívar, cuenca río Orinoco, río Pao, caño El Rodeo, carretera 19 cruzando cerca a El Báquiro, aproximadamente 7³0'42,26"N 64³3'23,85"O 80 m s.n.m., 25 Ene. 1986, L. M Page et al. INHS 69285, 20, 21,8-32,6 mm LE, Bolívar, cuenca río Uyare-Orinoco, río Suapire, carretera 19 puente $29 \mathrm{~km}$ E del 
río Cuchivero, aproximadamente 7²9'51,95"N 65³9'38,22"O 72 m s.n.m., 25 Ene. 1986, L. M Page et al. LACM 43138-017, 150, 20,4-30,1 mm LE, Delta Amaruco, río Orinoco, pequeño caño, caño Araguao, 112 millas náuticas corriente arriba desde el mar de Buoy,

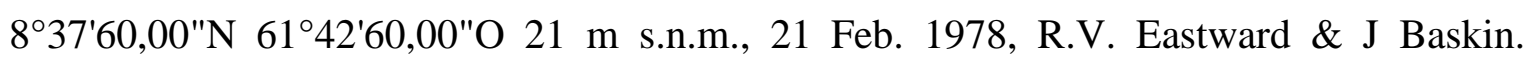
LACM 43354-029, 80, 16,0-26,8 mm LE, Bolívar, cuenca río Orinoco, río Orocopiche, casi $15 \mathrm{~km}$ desde la desembocadura en el río Orinoco, corriente abajo desde el puente de la carretera 19, $8^{\circ} 2^{\prime} 60,00^{\prime \prime} \mathrm{N} 63^{\circ} 40^{\prime} 0,00^{\prime \prime} \mathrm{O} 27$ m s.n.m., 3 Nov. 1979, Mago, L. et al. LACM 43355-008, 8, 16,4-21,5 mm LE, cuenca río Orinoco, río Orocopiche, casi 15 km desde la desembocadura en el río Orinoco, corriente abajo desde el puente de la carretera 19, $8^{\circ} 2^{\prime} 60,00 " N$ 6340'0,00"O 27 m s.n.m., 3 Nov. 1974, D. Stewart. MBUCV 3675, 5, 26,2-39,1 mm LE (2 d\&t 27,5-33,9 mm LE), Miranda, río Tuy, pozo aislado del curso principal cerca de Ocumare del Tuy, aproximadamente 107'53,34"N 6646'46,31"O 174 m s.n.m., 23 Abr. 1966, Campos \& Aguirre. MBUCV 8400, 5, 23,1-27,2 mm LE, Portuguesa, río Ospino, aproximadamente 9²'55,73"N 69²15'51,76"O 115 m s.n.m., 27 Oct. 1974, A. Machado-Allison et al. MBUCV 15414, 5, 27,0-31,3 mm LE, Anzoátegui, río Neverí, $100 \mathrm{~m}$ río arriba del puente San Diego, aproximadamente 105'55,44"N 64³4'3,86"O 37 m s.n.m., 18 Jul. 1986, J. G. Lundberg \& F. Mago-Leccia. MBUCV 21163, 5, 27,7-32,0 mm LE, Barinas, río Anaro, cerca 10 minutos de la boca del Suripá, aproximadamente $7^{\circ} 49^{\prime} 4,51$ "N 70¹7'57,38"O 110 m s.n.m., 10 Ene. 1991. A. MachadoAllison et al. MBUCV 21928, 5, 24,5-26,9 mm LE, Guárico, río Orituco, préstamo en carretera vía Píritu, aproximadamente $8^{\circ} 48^{\prime 2} 24,50 " N$ 67²2'37,54"O 81 m s.n.m., 29 Nov. 1991, F. Provenzano et al. MBUCV 35336, 5, 25,8-28,8 mm LE, Bolívar, río Guaigura, afluente río Aro, aproximadamente 7³6'15,87"N 64³'36,07"O 86 m s.n.m., 15 Feb. 2008. F. Provenzano et al. MCZ 59390*, 1 (R), 26,8 mm LE, Portuguesa, cuenca río Apure, caño Maraca en el Puente sobre la carretera desde Guanare a Guanarito, aproximadamente $8^{\circ} 56^{\prime} 28,84^{\prime \prime} \mathrm{N} 69^{\circ} 35^{\prime} 12,47^{\prime \prime O} 115$ m s.n.m., sin fecha, D. C. Taphorn et al. MCZ 59642*, 1 (R), 26,0 mm LE, Delta Amaruco, río Orinoco en bahía costera, $8^{\circ} 33^{\prime} 60,00 " \mathrm{~N} 62^{\circ} 16^{\prime} 0,00^{\prime \prime O} 11$ m s.n.m., sin fecha, R. V. Eastward. MCZ 93507*, 1 (R), 29,8 mm LE, Guárico, localidad desconocida, 856'16,56"N 67²5'38,90"O 86 m s.n.m., sin fecha, T. J. Zaret et al. UF 80511, 45, 18,4-36,2 mm LE, Guárico, caño E de Calabozo pozos aislados, 13 Abr. 1984, D. C. Taphorn et al. USNM 257494, 2 (d\&t), 31,0-32,0 mm LE, Guárico, río Guárico, $6 \mathrm{~km}$ SE de Calabozo, aproximadamente 844'58,41"N 67²5'37,11"O 76 m s.n.m., 13 Feb. 1912, F. Bond. Trinidad \& Tobago: ROM 87531, 40, 21,3-26,9 mm LE, Antillas, Isla de Trinidad, río Moriquite, 107'0,08"N 
61ํำ'34,01"O 16 m s.n.m., 19 Abr. 2010, D. Bloom \& E. Holm. ROM 88770, 30, 19,028,3 mm LE, Antillas, Isla de Trinidad, Victoria, río Moruga, reserva Mayaro, $10^{\circ} 7^{\prime} 2,42^{\prime \prime N} 61^{\circ} 12^{\prime} 14,58^{\prime \prime O} 21$ m s.n.m., 19 Abr. 2010, E. Holm, D. Taphorn, D. T. Phillip \& H. López-Fernández. USNM 349208*, 2 (R), 24,8-28,3 mm LE, Antillas, Isla de Trinidad, Moruga, río Moriquite, pueblo Basse Terre, $10^{\circ} 07,904^{\prime} \mathrm{N}$ 61¹5,436’O aproximadamente 46 m s.n.m., 4 Feb. 1998, D. A. T. Phillip. UWIZM 2010-14-253, 5, 23,1-29,9 mm LE (2 d\&t 25,2-28,0 $\mathrm{mm}$ LE), río Moriquite, aproximadamente 106’51,54’N 61¹7’39,78’’ 24 m s.n.m., 24 Sep. 1997, D. A. T. Phillip.

\section{Gephyrocharax venezuelae Schultz, 1944}

Figs. 14, 17, 20, 24, 45-46 y 48, Tablas 1 y 12

Gephyrocharax venezuelae Schultz, 1944: 323-326, tabla 20, fig. 44 (clave, descripción original, designación material tipo, holotipo USNM 121369, localidad tipo: Venezuela, río San Juan en el puente al sur de Mene Grande, sistema del Motatán). Taphorn \& Lilyestrom, 1984: 13 (clave). Weitzman \& Fink, 1985: 29 y 104 (comentarios morfología machos, material examinado). Burns, Weitzman \& Menezes, 1995: 133-135 (espermatozoide, inseminación). Bonilla-Rivero \& López-Rojas, 1997: 45-49 (descripción dimorfismo sexual). Bonilla-Rivero \& López-Rojas, 2001: 1-10 (comparación morfológica y genética). Bushmann, Burns \& Weitzman, 2002: 189 (glándula branquial). Weitzman, 2003: 225 (cita en catálogo). Lasso, Lew, Taphorn, DoNascimiento, Lasso-Alcalá, Provenzano \& Machado-Allison, 2004: 152 (lista de peces Venezuela). Rodríguez-Olarte, Coronel, Taphorn \& Amaro, 2007: 2 (río Tocuyo, Caribe, Venezuela). Ortega-Lara, Lasso-Alcalá, Lasso, Pasquier, Bogotá-Gregory, 2012: (río Catatumbo, cuenca Lago Maracaibo, Colombia y Venezuela). Bonilla-Rivero \& López-Rojas, 2013: 487-495, tablas 1-4, figs. 1-3 (estudio filogeográfico comparado). Vanegas-Ríos, Azpelicueta, Mirande \& Gonzales, 2013: 283 (material examinado).

Diagnosis. Gephyrocharax venezuelae se diferencia de sus congéneres por la mancha del pedúnculo caudal que se extiende más allá de la mitad de la longitud de los radios medios caudales ( $v s$. esta mancha solo alcanza la mitad de la longitud de tales radios), la ausencia de dentículos en los rastrillos branquiales ( $v s$. presencia de estos dentículos) y (excepto $G$. chocoensis) el borde dorsal de la escama-bolsillo en machos adultos que supera 
dorsalmente al radio 12 de la aleta caudal ( $v s$. este borde es ventral al radio 12 de la aleta caudal). Además, $G$. venezuelae se distingue de $G$. atracaudatus, $G$. caucanus, $G$. chocoensis, G. intermedius y $G$. valencia por el flexor dorsalis superior que se inserta posteriormente a través de dos fibras tendinosas en los radios de la aleta caudal ( $v s$. este músculo insertado a través de una fibra tendinosa simple). La especie difiere de $G$. atracaudatus, G. melanocheir y G. valencia por la presencia de lámina ósea entre el primer y segundo basibranquiales (vs. ausencia de tal lámina). Gephyrocharax venezuelae también se distingue de G. caucanus, G. melanocheir, G. torresi y G. valencia por la escama-bolsillo de los machos adultos que está anclada a través de tejido conectivo hasta un punto sobre el radio 14 de la aleta caudal (vs. esta escama está anclada sobre un punto en el radio 13 o entre los radios 15 a 17). Caracteres adicionales que distinguen a $G$. venezuelae de G. atracaudatus, G. caucanus, G. chocoensis, G. intermedius, G. major, G. martae, G. melanocheir, G. sinuensis, G. torresi y G. valencia fueron mencionados en las diagnosis respectivas de estas especies. Véase también la lista de autapomorfías mencionadas para G. venezuelae.

Descripción. Datos morfométricos en la tabla 12. Macho de mayor tamaño con 39,7 mm LE, hembra de mayor tamaño con 41,4 mm LE. Cuerpo lateralmente comprimido, con altura máxima en un punto entre los orígenes de las aletas pélvica y anal. Perfil dorsal de la cabeza apenas convexo desde el borde del labio superior hasta el extremo posterior del proceso ascendente de la premaxila y recto desde este punto hasta la espina supraoccipital. Perfil dorsal del cuerpo recto o apenas convexo desde la porción posterior de la espina supraoccipital hasta el origen de la aleta dorsal, desciende en sentido posteroventral a lo largo de la base de la aleta dorsal y continúa recto desde el radio dorsal más posterior hasta el pedúnculo caudal (Fig. 48). Perfil ventral del cuerpo convexo desde la punta del hocico hasta el origen de la aleta pélvica, recto desde este punto hasta el origen de la aleta anal y asciende posterodorsalmente recto desde el origen anal hasta el inicio del pedúnculo caudal. Fontanela anterior casi siempre bien desarrollada, pero a veces reducida a una abertura estrecha o de tamaño mediano anterior a la barra epifisaria. Narina anterior redondeada y separada por un pliegue de piel de la narina posterior de mayor tamaño. Hendidura extendida desde un punto medio entre el poro posterior del nasal y las narinas hasta la región posterior de los frontales, con al menos tres hileras de neuromastos. Hendidura más pequeña con pocos neuromastos sobre la región entre las narinas y los huesos nasales. 
Aleta dorsal con ii,7 (4), 8* (58) o 9 (1) radios y 9* pterigióforos proximales. Origen de la aleta dorsal en la vertical a través de los radios anales 6 a 12. Aleta adiposa presente, su origen al nivel de la base del radio más posterior de la aleta anal o en un punto anterior a este. Aleta anal con iv (35), $\mathrm{v}^{*}(27)$ o vi (1),25 (3), 26 (6), 27* (17), 28 (24), 29 (8), 30 (4) o 31 (1) radios y 26-32 pterigióforos proximales. Origen de la aleta anal más cerca de la unión hipural que de la punta del hocico. Aleta pectoral con i,8 (17), 9* (38) o 10 (8) radios. Aleta pectoral larga, alcanza entre un cuarto y un medio de la longitud de la aleta pélvica. Aleta pélvica con i, 6* (57) radios (i,5 en un solo ejemplar). Origen de la aleta pélvica localizado en la vertical que pasa por las escamas 9 a 10 de la línea lateral y anterior a la mitad del cuerpo. Aleta caudal bilobulada con 10/9 radios principales.

Hocico superior, con la mandíbula inferior apenas anterior a la punta de la mandíbula superior. Premaxila con dos hileras de dientes; hilera externa con 2 (18), 3* (35) o 4 (4) dientes tricúspides, pocas veces bicúspides. Hilera interna con 4 (11), $5^{*}$ (46) o 6 (1) dientes; el sinfisial tricúspide a tetracúspide y los demás tetracúspides a hexacúspides. Maxila con $1 *(53)$ o 2 (4) dientes tricúspides a pentacúspides (pocas veces bicúspides) (Fig. 45c). Maxila larga, alcanza posteriormente el tercio anterior del ojo. Dentario con 9 (1), 10 (3), 11 (8), 12 (13), 13 (14), 14 (10), 15* (4) o 16 (1); los tres más anteriores grandes y pentacúspides, seguidos por uno de tamaño mediano tricúspide a pentacúspide y 5 (1), 6 (3), 7 (8), 8 (13), 9 (14), 10 (10), 11* (4) o 12 (1) dientes más pequeños cónicos a tricúspides que poco a poco disminuyen en tamaño en sentido anteroposterior a lo largo del borde dorsal del dentario (Fig. 45d).

Escamas cicloides, con numerosos radii a lo largo del campo posterior. Línea lateral completa. Tubo terminal de la línea lateral presente. Escamas con poros 36 (5), 37 (17), 38 (11), 39 (13), 40* (9) o 41 (2). Escamas predorsales 16 (1), 17 (23), 18 (19), 19 (6), 20 (3) o 21 (2). Hileras de escamas entre la aleta dorsal y la línea lateral 5 (28) o 6* (28). Hileras de escamas entre la línea lateral y la aleta anal 4 (23) o $5^{*}$ (33). Hileras de escamas entre la línea lateral y la aleta pélvica 3 (1), 4* (47) o 5 (4). Escamas circumpedunculares 13 (4), 14 (34) o 15* (14). Una hilera de escamas dispuestas a lo largo de la base de la aleta anal de 9 (1), 10 (1), 11 (2), 12 (2), 13 (1), 14 (4), 15 (9), 16 (6), 17 (3), 18 (1) o 19 (2) escamas. Número total de vértebras 38* (9), 39 (1) o 41 (1), $15^{*}$ (9) o 16 (2) precaudales y 22 (1), 23* (9) o 25 (1) caudales (seis radiografiados y cinco ejemplares d\&t). Rastrillos branquiales del primer arco branquial 6* (24), 7 (12) o 8 (1) sobre la porción dorsal y con 11* (15), 12 (20) o 13 (2) sobre la porción ventral. 
Coloración en alcohol. Cuerpo amarillento pálido o marrón claro, más oscuro en la línea media dorsal y un poco más claro en la zona ventral. Cromatóforos marrones o negros diminutos cubren la superficie del cuerpo, pero ausentes o en menor cantidad sobre las regiones lateral y ventral del abdomen y la región ventral del pedúnculo caudal. Línea lateral negra o marrón (algunas veces con cierta tonalidad plateada en forma de banda) extendida desde la región posterior de la mancha humeral hasta la región posterior del pedúnculo caudal. Cromatóforos marrones oscuros distribuidos sobre los mioseptos entre la línea lateral y la porción superior de la aleta anal. Mancha humeral marrón oscura o negra, verticalmente alargada. Mancha caudal marrón oscura o negra, longitudinalmente alargada y extendida desde la región media o posterior del pedúnculo caudal, cubre los interradialis, hasta el extremo distal de los radios medios de la aleta caudal. Aleta dorsal gris clara, con cromatóforos marrones oscuros o negros distribuidos a lo largo de las membranas y los radios. Aleta anal gris clara, con cromatóforos marrones oscuros en su mayoría concentrados sobre las membranas. Aleta caudal gris clara, con cromatóforos negros o marrones oscuros distribuidos sobre las membranas y los radios. Aletas pectoral y pélvica grises claras, con unos pocos cromatóforos marrones oscuros distribuidos en su mayoría sobre los radios. Cabeza más oscura dorsal que ventralmente. Opérculo e infraorbitales con cromatóforos marrones o negros, más concentrados en el primero y los bordes infraorbitales que rodean al ojo. Premaxila, porción anterior de la maxila, dentario y labios con cromatóforos marrones oscuros o negros un poco concentrados. No se observaron variaciones en la coloración entre machos y hembras.

Dimorfismo sexual. Ejemplares machos con ganchos óseos en los radios de las aletas anal, caudal y pélvica. Aleta caudal con ganchos cortos, finos y orientados en sentido anterodorsal, en especial sobre las porciones ramificadas dorsales de los 13 a 18. Todos los radios de la aleta pélvica, excepto el primer radio, con ganchos finos pareados o solo uno por segmento (aunque en las bases de los radios por lo general no pareados y numerosos) y orientados en sentido anteroventral en casi toda la longitud de cada radio (en menor cantidad en el último radio proximal). Aleta anal con ganchos finos, de base ancha, pareados por segmento y orientados en sentido anterolateral en los radios; con uno a quince pares de ganchos localizados sobre el radio simple más posterior y los primeros doce radios ramificados anteriores (los ganchos son más largos en los radios medios de este intervalo). Los machos adultos con frecuencia con el borde basal de la aleta anal un poco convexo en su porción anterior o algo curvado, mientras que las hembras lo tienen recto. Aleta anal con una forma un poco convexa en su región media en los machos 
adultos, mientras que es recta o algo cóncava en las hembras. Hembras adultas no tienen papila urogenital externamente (Fig. 48).

Los machos adultos en vida (se pierde en ejemplares en alcohol) tienen las aletas caudal y dorsal rojizas, mientras que en las hembras son amarillentas (Bonilla-Rivero \& López-Rojas, 1997). Machos maduros con una escama modificada para formar un bolsillo sobre el lóbulo ventral de la aleta caudal y con el segundo y tercer radios procurrentes ventrales modificados en forma de una estructura tipo pinza, ventral al radio principal 19. Tejido de apariencia glandular localizado en muy poca cantidad y en su mayoría sobre los radios de la aleta caudal y medial a la escama-bolsillo. Estructura tipo pinza en parte osificada en su porción distal y alcanza la mitad de la longitud del primer radio procurrente ventral (Fig. 46c). Primer radio procurrente ventral con una concavidad en su porción ventral. Segundo radio procurrente ventral un poco más largo que el tercero y muy expandido en el plano sagital, más notable en su porción posterior. Porción posterior del tercer radio procurrente ventral poco desarrollada lateralmente. Escama-bolsillo hipertrofiada, con 20 a 31 radii que por lo general se localizan entre el radio 15 y el tercer procurrente ventral de la aleta caudal. Escama-bolsillo con un lóbulo posteroventral extendido a lo largo del tercer radio procurrente ventral (Figs. 46c, d). Superficie dorsal de la escama-bolsillo anclada a través de un tejido blando o conectivo a los radios de la aleta caudal 11 o 12 a 14. Borde posterior de la escama-bolsillo localizado entre el radio 14 y el tercer radio procurrente ventral de la aleta caudal. Cuatro escamas en serie vertical, justo debajo de la escama más posterior de la línea lateral, sobre la porción posterior de la escama-bolsillo. Borde dorsal de la escama-bolsillo sin hendiduras. Las hembras con una escama grande con 16 (1), 17 (1), 15 (1), 21 (1) o 22 (1) radii.

Machos maduros con glándula branquial corta. Glándula branquial formada por 6 (2), 7 (5), 8* (3), 9 (11), 10 (1), 11 (2), 12 (1) o 14 (1) filamentos branquiales modificados de la porción ventral del primer arco branquial funcional. Número total de filamentos branquiales en la porción ventral 20 (1), 21 (1), 22 (6), 23 (6), 24 (2), 25* (3), 26 (4), 27 (1) o 29 (1). Longitud de la glándula branquial 2,7-4,8 \% LE (media = 3,5 \% LE), 3,6* \% LE.

Coloración en vivo. Consultar Bonilla-Rivero \& López-Rojas (1997) para detalles sobre variaciones en la coloración entre machos y hembras.

Distribución. Se encuentra en diferentes localidades del Golfo de Venezuela, cuenca del Lago de Maracaibo y vertiente Caribe de Colombia y Venezuela (Fig. 20). Registro adicional para el río Alpargatón en Venezuela por Bonilla-Rivero \& López-Rojas (1997). 
Comentarios. Bonilla-Rivero \& López-Rojas (2001), Bonilla-Rivero et al. (2002), Bonilla-Rivero \& López-Rojas (2013) indicaron que G. valencia y G. venezuelae son simpátricas en drenajes de la cuenca de los río Tocuyo y Urama, vertiente Caribe de Venezuela. El holotipo y los paratipos examinados de G. venezuelae están en buenas condiciones de preservación de escamas, radios y dentición, con algunos lotes paratipos con la coloración algo difusa por la preservación.

Material examinado. Colombia: IAvH-P 9788, 9, 32,1-41,4 mm LE, Norte de Santander, cuenca media del Catatumbo, río antes de El Aserrío al Divisó, aproximadamente $8^{\circ} 31^{\prime} 28,92^{\prime \prime N} 73^{\circ} 15^{\prime} 29,16 " O 410$ m s.n.m., 1 Feb. 2007, J A. Maldonado-Ocampo et al. ICNMHN 2401, 4, 22,6-30,7 mm LE, Norte de Santander, corregimiento La Garraba, río Brandy, afluente río Catatumbo, aproximadamente 858'12,13"N 7258'22,95"O $181 \mathrm{~m}$ s.n.m., Feb. 1995, M. Camargo \& J. I. Mojica. ICNMHN 17668, 2, 28,1-28,7 mm LE, Norte de Santander, Cúcuta, corregimiento Carmen de Tonchalá, predio Corponor, sistema Lago Maracaibo, cuenca río Zulia, aproximadamente 751'1,17"N 72³4'11,64"O 246 m s.n.m., 17 Dic. 2009, G. A. Ballen. Venezuela: MBUCV 23840, 3, 18,0-39,5 mm LE (1 d\&t 39,5 mm LE), Zulia, Hacienda el Totumo, Sierra de Perijá, sistema Lago Maracaibo, río Lajas, aproximadamente $10^{\circ} 33^{\prime} 27,93 " \mathrm{~N} 72^{\circ} 27^{\prime 2} 21,17^{\prime \prime O} 305$ m s.n.m., 8 Dic. 1982, sin datos. MBUCV 24079, 4, 21,4-27,3 mm LE, Venezuela, Falcón, Vertiente Caribe, vía carretera el Tocuyo de la Costa, río Tabaná, aproximadamente $11^{\circ} 0^{\prime} 7,56 " \mathrm{~N} 68^{\circ} 21$ '15,81"O 5 m s.n.m., 3 Oct. 1992, C. Marcano. MBUCV 24258, 5, 28,2-31,0 mm LE (1 d\&t 31,0 mm LE), Yaracuy, Vertiente Caribe, río Urama en puente carretera Morón-San Felipe, aproximadamente $10^{\circ} 27^{\prime} 24,04^{\prime \prime} \mathrm{N} 68^{\circ} 19^{\prime} 18,22^{\prime \prime O} 27$ m s.n.m., 27 abr. 1987, sin datos. UF 23804, 5, 19,3-30,2 mm LE, Mérida, sistema Lago de Maracaibo, río Onia al puente, Onia, aproximadamente $8^{\circ} 35^{\prime} 34,13^{\prime \prime N} 71^{\circ} 41^{\prime} 34,72^{\prime \prime O} 85$ m s.n.m., 16 Sep. 1974, D. C. Taphorn \& G. C. Lilyestrom. USNM 121359, 1 paratipo, 23,8 mm LE, [Zulia, aproximadamente $10^{\circ} 5^{\prime} 43,67^{\prime \prime N} 72^{\circ} 23^{\prime} 37,95^{\prime \prime O} 58$ m s.n.m.] cuenca Maracaibo, río Apón alrededor de $35 \mathrm{~km}$ al sur de Rosario 26 Feb. 1942, L. P. Schultz. USNM 121360, 1 paratipo, 21,6 $\mathrm{mm}$ LE, [Caribe, Golfo de Venezuela, Zulia, aproximadamente $11^{\circ} 18 ' 2,24 " N$ 7157'6,77"O 3 m s.n.m.] boca del Caño de Sagua, 35 km al norte de Sinamaica, 12 Mar. 1942, L. P. Schultz. USNM 121361, 24 paratipos (25 en descripción original), 22,2-36,3 mm LE, recolectados con el holotipo. USNM 121362, 11 paratipos, 22,2-34,9 mm LE, [Zulia, aproximadamente 10²7'37,67"N 72 16 '52,19"O 65 m s.n.m.] río Palmar cerca de Totuma alrededor $100 \mathrm{~km}$ al sureste de Maracaibo, 21 Feb. 1942, L. P. Schultz. USNM 121363, 10 paratipos (11 en descripción original, un ejemplar 
corresponde a otra especie), 20,2-32,2 mm LE, [Trujillo, 9²6'7,16"N 70³4'47,70"O 294 m s.n.m.] río Motatán, 4 km arriba de Motatán, 25 Mar. 1942, L. P. Schultz. USNM 121364, 43 paratipos (41 en descripción original), 20,4-34,4 mm LE, [Trujillo, 9²5'4,70"N 70³4'58,68"O 334 m s.n.m.] río Motatán en el puente a $22 \mathrm{~km}$ al norte de Motatán, 17 Mar. 1942, L. P. Schultz. USNM 121365, 22 paratipos, 22,9-32,0 mm LE, [Trujillo, aproximadamente $9^{\circ} 21^{\prime} 42,61^{\prime \prime N ~ 70 ³ 5 ' 47,61 " O ~} 366$ m s.n.m.] río Motatán 8 km debajo de Motatán, 24 Mar. 1942, L. P. Schultz. USNM 121366, 129 paratipos, 20,6-31,7 mm LE, [Zulia, aproximadamente 941'20,59"N 72²5'26,26"O 26 m s.n.m.] cuenca Maracaibo, río Negro debajo de la desembocadura del río Yasa, 2 Mar. 1942, L. P. Schultz. USNM 121367, 6 paratipos, 21,7-27,1 mm LE, [Zulia, aproximadamente 10²'123,63"N 72¹9'8,45"O 63 m s.n.m.] río San Juan 12 km al sur de Rosario, 26 Feb. 1942, L. P. Schultz. USNM 121368, 94, 19,-31,6 mm LE, [Zulia, aproximadamente 956'48,23"N 715'36,14"O 8 m s.n.m.] río Machango en el puente al sur de Lagunillas, 16 Mar. 1942, L. P. Schultz. USNM 121369, holotipo Gephyrocharax venezuelae Schultz, 1944, 32,0 mm LE (R), macho, [Trujillo, sistema Lago Maracaibo, aproximadamente $9^{\circ} 44 ' 46,82^{\prime \prime N}$ 7048'7,92"O 41 m s.n.m.] sistema Motatán, río San Juan en el puente al sur de Mene Grande, 20 Mar. 1942, L. P. Schultz. USNM 121533, 3 paratipos, 26,6-28,1 mm LE, [Zulia, aproximadamente 9 $46^{\prime} 4,55^{\prime \prime} \mathrm{N} 70^{\circ} 54^{\prime} 49,20 " \mathrm{O} 9$ m s.n.m.] río San Pedro en el puente al sur de Mene Grande, 20 Mar. 1942, L. P. Schultz. USNM 236087 (antes USNM 121366), 3 paratipos (d\&t), 28,7-32,7 mm LE, [Zulia, aproximadamente 9 $411^{\prime 20,59 " \mathrm{~N}}$ 72²5'26,26"O 26 m s.n.m.] cuenca Maracaibo, río Negro debajo de la desembocadura del río Yasa, 2 Mar. 1942, L. P. Schultz. MCZ 37269 (antes USNM 121366), 5 paratipos, 29,0-33,8 mm LE (5R), [Zulia, aproximadamente 941'20,59"N 72²5'26,26"O 26 m s.n.m., 75 km por la carretera al sur de Rosario] cuenca Maracaibo, río Negro debajo de la desembocadura del río Yasa, 2 Mar. 1942, L. P. Schultz. 


\section{Resumen taxonómico de los géneros hermanos}

\section{Corynopoma Gill, 1858}

Corynopoma Gill, 1858: 424-425 (especie tipo: Corynopoma riisei Gill, 1858 por designación subsecuente de Günther, 1864, clasificado en Stevardiinae). Günther, 1864: 278 y 287-288 (sinonimias, combinación nueva, clave género). Eigenmann, 1922: 100 y 155 (clave género, lista especies, ubicación sistemática). Eigenmann \& Myers, 1929: 467467-471 (clave géneros, ubicación sistemática, revisión género y especies). Myers, 1933: 11 (comentarios sinonimias). Gregory \& Conrad, 1938: 333 y 335, tabla 2 (ubicación sistemática en Characinidae, Characinae). Fowler, 1954: 341 (ubicación sistemática en Stevardiidae, Stevardiinae) Böhlke, 1958: 43 (clave géneros, ubicación sistemática). Géry, 1966: 218 (ubicación sistemática en Tetragonopterinae, Glandulocaudini o en Stevardiidi [= Glandulocaudinae auct.]). Géry, 1977: 354 y 358 (ubicación sistemática, tribu Glandulocaudini, clave géneros). Weitzman \& Fink, 1985: 2, 94-95, 102-103 y 113-115, fig. 16 (ubicación sistemática, comentarios prioridad de nombre, comentarios morfología machos, cortejo, material examinado). Weitzman, Menezes \& Weitzman 1988: 384 y 394 (en Corynopomini, en filogenia como "other tribes de glandulocaudines"). Menezes \& Weitzman, 1990: 381, fig. 1 (atribuido en filogenia como "other tribes de glandulocaudines"). Ortí \& Meyer, 1997: 92, fig. 11 (relaciones filogenéticas, en Glandulocaudinae grupo de hermano de Gephyrocharax). Weitzman \& Menezes, 1998: 172-174 y 186-188, tablas 1-3, fig. 1 (clasificación, relaciones filogenéticas, ubicación sistemática y Corynopomini, comentarios morfología). Castro, Ribeiro, Benine \& Melo, 2003: 17, fig. 8 (ubicación sistemática en Glandulocaudinae, Corynopomini). Weitzman, 2003: 223 (revisión catálogo). Mirande, 2009: 8, fig. 4 (relaciones filogenéticas tentativas, ubicación sistemática en Stevardiinae [nueva definición, similar al "clado A"]). Malabarba \& Weitzman, 2003: 86 y 87, fig. 11 (ubicación sistemática en "clado A” de Characidae, Glandulocaudinae, Corynopomini). Weitzman, Menezes, Evers \& Burns, 2005: 332, 336, 344-345, fig. 11 (comentarios taxonómicos, reubicación sistemática en "clado A", Stevardiinae [nueva definición], Corynopomini). Menezes \& Weitzman, 2009: 298-299 y 302, figs. 1-2 (relaciones filogenéticas, ubicación sistemática en 
"clado A", Glandulocaudinae, Stevardiinae, Stevardiini [= Corynopomini $]$ ). Mirande, 2009: 8 (atribuido a Stevardiinae [nueva definición, similar al "clado A”]). Javonillo, Malabarba, Weitzman \& Burns, 2010: 505-507 y 509, tabla 1, figs. 4-6 (relaciones filogenéticas, ubicación sistemática en "clado A", Stevardiinae, Corynopomini). Mirande, 2010: 533-540 (atribuido a Stevardiinae). Oliveira, Avelino, Abe, Mariguela, Benine, Ortí, Vari \& Castro, 2011: 16, fig. 12 (relaciones filogenéticas, ubicación sistemática en Stevardiinae). Tagliacollo, Souza-Lima, Benine \& Oliveira, 2012: 302, fig. 2 (filogenia combinada, ubicación sistemática en Stevardiinae). Bonilla-Rivero \& López-Rojas, 2013: 487-488, 490, 494, figs. 13 (como grupo externo en filogeografía de especies de Gephyrocharax, aproximación filogenética). Género: neutro.

Nematopoma Gill, 1858: 428-429 (especies tipo: Nematopoma searlesii Gill, 1858 designada por monotipia). Günther, 1864: 287 (nueva sinonimia con Corynopoma). Género: neutro.

Stevardia Gill, 1858: 422-423 (especie tipo: Stevardia albinnipis Gill, 1958 designada por monotipia). Günther, 1864: 287 (nueva sinonimia con Corynopoma). Eigenmann, 1914: 34, 37 (ubicación sistemática en Glandulocaudinae, clave géneros, lista). Eigenmann, 1922: 100 (clave). Géry, 1966: 218 (ubicación sistemática en Tetragonopterinae, Glandulocaudini o en Stevardiidi [= Glandulocaudinae auct.]). Género: femenino.

Diagnosis. Véase caracteres listados como autapomorfías para la especie y género en los resultados filogenéticos.

Descripción. Datos generales en Gill (1858), Eigenmann (1914), Eigenmann \& Myers (1929).

Distribución. Véase Weitzman \& Fink (1985), Weitzman (2003), Lasso et al. (2004) y Phillip et al. (2013).

Material examinado. Véase material comparativo grupos externos. 


\section{Corynopoma riisei Gill, 1958}

Figs. 7a-b ; 24 de Phillip et al. (2013) y 27 de Zarske (2010)

Stevardia albipinnis Gill, 1858: 425 (descripción original, material tipo no mencionado, localidad tipo: porciones al oeste de la isla de Trinidad, Antillas). Eigenmann, 1914: 37-38 (clave, lista).

Corynopoma riisei Gill, 1858: 426-427 (descripción original, material tipo no mencionado, localidad tipo: porciones al oeste de la isla de Trinidad, Antillas). Eigenmann \& Myers, 1929: 468 y 470-471 (clave y redescripción). Géry, 1977: 356-357, dos fotos (coloración en vida). Atkins \& Fink, 1979: 466-469, fig. 1 (descripción tejido glandular machos). Weitzman \& Fink, 1985: 7, 24, 29, 38, 51, 56 y 102-103, fig. 16 (comentarios morfología, datos de distribución en material examinado). Burns, Weitzman \& Menezes, 1995: 133-135 y 138, fig. 8 (espermatozoide, inseminación). Burns \& Weitzman, 1996: 628-633, figs. 1-4 (glándula branquial). Taphorn, 2003: 59 y 123 (clave, comentarios taxonómicos y morfológicos). Weitzman, 2003: 224 (cita catálogo). Lasso, Lew, Taphorn, DoNascimiento, Lasso-Alcalá, Provenzano \& Machado-Allison, 2004: 151 (lista de peces Venezuela). Burns \& Weitzman, 2005: 125 y 127, fig. 18 (comentarios biología reproductiva). Weitzman, Menezes, Evers \& Burns, 2005: 345 y 356 (comentarios morfología escamación caudal, material examinado). Pecio, Burns \& Weitzman, 2007: 457-470, fig. 4, 5, 7 y 9 (espermatogénesis comparada). Maldonado-Ocampo, Vari \& Usma, 2008: 180 (lista de peces Colombia). Burns, Quagio-Grassiotto, Jamieson, 2009: 328-329, fig. 11.27-28 (detalles espermatozoides). Javonillo, Malabarba, Weitzman \& Burns, 2010: 505-507, tabla 1, figs. 5 y 6 (relaciones filogenéticas). Ferreira, Menezes \& Quagio-Grassiotto, 2011: 290-292 (comentarios tejido glandular). Oliveira, Abelino, Abe, Mariguela, Benine, Ortí, Vari \& Castro et al., 2011: 16, fig. 12 (relaciones filogenéticas). Tagliacollo, Souza-Lima, Benine \& Oliveira, 2012: 302, fig. 2 (filogenia combinada, ubicación sistemática en Stevardiinae). Phillip, Taphorn, Holm, Gilliam, Lamphere \& López-Fernández, 2013: 9, 16, 27 y 41, tabla 1, fig. 24 (lista de peces Trinidad \& Tobago, clave).

Corynopoma veedonii Gill, 1858: 427-428 (descripción original, material tipo no mencionado, localidad tipo: porciones al oeste de la isla de Trinidad, Antillas). 
Nematopoma searlesii Gill, 1858: 429 (descripción original, material tipo no mencionado, localidad tipo: porciones al oeste de la isla de Trinidad, Antillas).

Stevardia aliata Eigenmann, 1914: 37-38 (descripción original, designación material tipo, holotipo FMNH 56400 [CM 5215], localidad tipo: río Negro en Villavicencio).

Diagnosis. La misma que para el género.

Descripción. Los mismos datos citados para el género.

Distribución. Los mismos registros citados para el género.

Material examinado. Véase material comparativo grupos externos.

\section{Pterobrycon Eigenmann, 1913}

Pterobrycon Eigenmann, 1913: 3 (especie tipo: Pterobrycon landoni Eigenmann, 1913 designada por monotipia, ubicación sistemática en Pterobryconinae). Eigenmann, 1914: 34 y 38 (ubicación sistemática en Glandulocaudinae, clave géneros, lista). Eigenmann, 1922: 100 y 155 (clave géneros, lista, ubicación sistemática en Glandulocaudinae). Eigenmann \& Myers, 1929: 467 y 472-473 (clave géneros, ubicación sistemática en Glandulocaudinae, revisión). Böhlke, 1958: 43 (clave géneros, ubicación sistemática en Glandulocaudinae). Géry, 1966: 216, 218 y 233 235 (ubicación sistemática en Tetragonopterinae, Glandulocaudini en clave o en Stevardiini [= Glandulocaudinae auct.], Microbrycon como sinónimo). Géry, 1977: 354 y 358 (ubicación sistemática en Glandulocaudinae, Glandulocaudini, clave géneros). Bussing, 1974: 136-137 (comentarios taxonómicos, diagnosis, ubicación sistemática en Glandulocaudinae). Weitzman \& Fink, 1985: 1-2, 29, 32, 36, 38, 51, 56, 95-96 y 107 (comentarios sinonimias, datos morfológicos, ubicación sistemática, material examinado). Weitzman, Menezes \& Weitzman 1988: 384 y 394 (ubicación sistemática aparente en Corynopomini, en filogenia como "other tribes de glandulocaudines"). Menezes \& Weitzman, 1990: 381, fig. 1 (en filogenia como "other tribes de glandulocaudines"). Weitzman \& Menezes, 1998: 172-74, 174 y 186-188, tablas 1-3, fig. 1 (clasificación, relaciones filogenéticas, ubicación sistemática en Glandulocaudinae, Corynopomini, comentarios morfología). Castro, Ribeiro, Benine \& Melo, 2003: 17, fig. 8 (ubicación sistemática en Glandulocaudinae, Corynopomini). Weitzman, 2003: 227 (cita 
catálogo). Weitzman, Menezes, Evers \& Burns, 2005: 344, fig. 11 (comentarios taxonómicos, reubicación sistemática en "clado A", Stevardiinae [nueva definición], Corynopomini). Menezes \& Weitzman, 2009: 298-299 y 302, figs. 1-2 (relaciones filogenéticas, ubicación sistemática en "clado A", Glandulocaudinae, Stevardiinae, Stevardiini [= Corynopomini]). Mirande, 2009: 8, fig. 4 (ubicación sistemática estimada en Stevardiinae [nueva definición, similar al "clado A"]). Mirande, 2010: 533-540 (ubicación sistemática estimada en Stevardiinae). Género: masculino.

Microbrycon Eigenmann \& Wilson, in Eigenmann, Henn \& Wilson, 1914: 3 (especie tipo: Microbrycon minutus Eigenmann \& Wilson, 1914 designada por monotipia). Eigenmann, 1922: 100 y 155 (clave, lista). Género: masculino.

Diagnosis. Véase caracteres listados como sinapomorfías para el género en los resultados filogenéticos. Caracteres distintivos pueden ser consultados en Bussing (1974).

Descripción. Datos en Eigenmann (1913), Eigenmann et al. (1914), Eigenmann \& Myers (1929) y Bussing (1974).

Distribución. Registros de Eigenmann \& Myers (1929), Bussing (1974) \& Weitzman (2003).

Material examinado. Véase material comparativo grupos externos.

\section{Pterobrycon landoni Eigenmann, 1913}

Fig. 28 de Zarske (2010), Tabla 1 de Bussing (1974)

Pterobrycon landoni Eigenmann, 1913: 3 (descripción original sobre un ejemplar, material tipo, holotipo FMNH 56260 [CM 5051], localidad tipo: Boca de Raspadura). Eigenmann, 1914: 38 (lista). Eigenmann, 1922: 100 y 155 (lista). Eigenmann \& Myers, 1929: 472 (comentarios taxonómicos, datos morfológicos, lista sinonimias). Böhlke, 1958: 43 (comentarios en clave). Géry, 1966: 227, 233235 (ubicación sistemática en Tetragonopterinae, Glandulocaudini en clave). Bussing, 1974: 146, tabla 1, figs. 3 y 5 (redescripción, comparación P. myrnae, atribuye localidad tipo: Departamento Chocó, tributario del río Atrato cerca a Boca de Raspadura). Bork, 2000a: 30-34, cuatro figuras (río Atrato). Bork, 2000b: 30, tres figuras (datos reproductivos). Bushmann, Burns \& Weitzman, 2002: 189 
(glándula branquial). Weitzman, 2003: 227 (lista catálogo). Burns \& Weitzman, 2005: 124 y 127, fig. 17 (inseminación).

Microbrycon minutus Eigenmann \& Wilson, en Eigenmann, Henn \& Wilson, 1914: 3-4 (descripción original sobre un ejemplar, material tipo, holotipo 56606 [CM 5422], localidad tipo: Truando). Eigenmann, 1922: 100 y 155 (lista). Eigenmann \& Myers, 1929: 472 (nueva sinonimia con P. landoni). Bussing, 1974: 137 y 146, tabla 1 (datos morfológicos, revisión sinonimias P. landoni, atribuye localidad holotipo como: Departamento Chocó, río Truandó, afluente del río Atrato). Weitzman, 2003: 227 (lista sinonimias catálogo).

Diagnosis. Consultar Eigenmann \& Myers (1929) y Bussing (1974). También véanse caracteres listados como autapomorfías en los resultados filogenéticos.

Descripción. Datos en Eigenmann (1913), Eigenmann et al. (1914), Eigenmann \& Myers (1929) y Bussing (1974).

Distribución. Registros en Eigenmann \& Myers (1929), Bussing (1974) \& Weitzman (2003).

Material examinado. Véase material comparativo grupos externos.

\section{Pterobrycon myrnae Bussing, 1974}

Figs. 3a y 7c-d; 1, 2, 4a y 5 de Bussing (1974) y 28 de Zarske (2010), Tabla 1 de Bussing (1974)

Pterobrycon myrnae Bussing, 1974: 138-159, figs. 1-4 y 6 (descripción original, designación material tipo, holotipo LACM 33857-1, localidad tipo: Costa Rica, Provincia Puntarenas, Osa Península, en quebrada Agua Buena, drenaje río Rincón, 2 km O de Rincón altitud 30 m). Burns, Weitzman \& Menezes, 1995: 133135 y 138, fig. 3 (espermatozoide, inseminación). Bussing, 2002: 75, 113-116, dos figuras, mapa 4 (clave, datos morfológicos y ecológicos). Bushmann, Burns \& Weitzman, 2002: 189 (glándula branquial). Angulo, Garita-Alvarado, Bussing \& López, 2013: 989 y 991 (lista de peces Costa Rica).

Pterobrycon sp. Bussing \& Roberts, 1971: 179-180 (datos reproductivos).

Diagnosis. Consultar Bussing (1974) y caracteres listados como autapomorfías para la especie en los resultados filogenéticos. 
Descripción. Datos detallados en Bussing (1974).

Distribución. Registros en Bussing (1974) \& Weitzman (2003).

Material examinado. Véase material comparativo grupos externos.

\section{DISCUSIÓN}

Se corrobora la monofilia de Stevardiinae en este estudio (Fig. 14), con la adición de Bryconamericus emperador y B. scleroparius, un resultado más coincidente con la clasificación propuesta por Oliveira et al. (2011) a partir de su filogenia molecular de Characidae. Si bien estas especies fueron consideradas afuera de Stevardiinae en filogenias morfológicas previas (Mirande, 2010; Mirande et al., 2011, 2013), la nueva información analizada aquí apoya su inclusión en esa subfamilia. En la filogenia de Stevardiinae obtenida, los géneros Landonia y Phenacobrycon quedaron en una posición filogenética distante de los demás géneros tradicionalmente clasificados como Glandulocaudinae por Weitzman \& Menezes (1998). Estos dos géneros han sido considerados por mucho tiempo (Weitzman \& Menezes, 1998; Weitzman et al., 2005; Ferreira et al., 2011) como tribus monotípicas separadas (Landonini y Phenacobryconini) dentro de Stevardiinae sensu Menezes \& Weitzman (2009). Además, se obtuvo a Landonia como el grupo hermano de Phenacobrycon, lo que también contradice los resultados de estudios anteriores (e. g. Weitzman \& Menezes, 1998). Como en este estudio se elaboró la hipótesis filogenética con mayor número de caracteres examinados que analiza ambos géneros (542 vs. 51 en Weitzman \& Menezes, 1998; 153 en Ferreira et al., 2011), los resultados obtenidos son considerados la estimación más robusta de la filogenia de Landonia o Phenacobrycon hasta el momento.

La posición filogenética de Markiana es un problema no resuelto en la filogenia de Stevardiinae. Este género se ha encontrado, con datos morfológicos, más relacionado con Astyanax que con los géneros de Stevardiinae (Mirande, 2010; Mirande et al., 2011, 2013). En contraste, Oliveira et al. (2011) ubicaron a este género en Stevardiinae con datos moleculares. Baicere-Silva et al. (2011b) encontraron evidencia en los espermatozoides de Markiana nigripinnis para relacionarlo tentativamente con los Stevardiinae. Las dos especies de Markiana fueron analizadas en este estudio, como grupos externos adicionales posiblemente stevardinos, pero ambas especies fueron encontradas más relacionadas con las especies de Astyanax. Si bien la hipótesis filogenética obtenida muestra que las especies de Astyanax forman gran parte del clado 
hermano de Stevardiinae, aún no hay coincidencia completa con las hipótesis de Oliveira et al. (2011) y Baicere-Silva et al. (2011b). La filogenia de Markiana es un interrogante abierto a discusión y merece abordarse en futuras contribuciones.

Se encontró la monofilia de varios géneros stevardinos, considerados muy cercanos filogenéticamente con Gephyrocharax; entre estos se destacan Chrysobrycon, Diapoma y Pterobrycon. La monofilia de Diapoma se ha puesto en duda en diversos estudios moleculares (Javonillo et al., 2010; Casciotta et al., 2012), principalmente porque sus especies se mezclan con especies de Cyanocharax en esas filogenias. Sin embargo, Diapoma ha sido defendido como válido por Menezes \& Weitzman (2011), basándose en observaciones morfológicas. En el caso de Chrysobrycon, sus especies no habían sido analizadas formalmente en un estudio filogenético y la monofilia aquí encontrada constituye la primera hipótesis filogenética para este género. Nuevas especies de Chrysobrycon han sido descritas en contribuciones recientes (Vanegas-Ríos et al., 2011; 2014), lo que muestra que su taxonomía alfa había sido poco estudiada desde su descripción original (Weitzman \& Menezes, 1998). La monofilia de Pterobrycon no ha sido cuestionada en ningún estudio y se corrobora en este trabajo, en gran parte por los caracteres usados en la diagnosis de Bussing (1974).

Corynopoma, Gephyrocharax y Pterobrycon han sido ubicados tradicionalmente en la tribu Stevardiini (= Corynopomini) por Weitzman \& Menezes (1998), una propuesta que ha sido mantenida en estudios posteriores (Weitzman et al., 2005; Menezes \& Weitzman, 2009; Mirande, 2010). La tribu Stevardiini de Weitzman \& Menezes (1998) no se reconoce como tribu, aunque aquí se encontró monofilética, porque se considera prematuro el uso de clasificaciones tribales dentro de Stevardiinae, cuando todavía no se tiene un conocimiento más detallado de los principales clados, con mejor apoyo, que alberga esta subfamilia. Además, puede ser arbitrario mantener tribus pequeñas (con uno a tres géneros) y parcialmente distantes en la hipótesis filogenética, conservando la propuesta de Weitzman \& Menezes (1998), cuando otros clados bien apoyados en Stevardiinae también cumplen este criterio (e. g. Carlastyanax + Creagrutus + Piabina) . Los géneros Gephyrocharax y Corynopoma se consideran géneros hermanos acorde a la hipótesis filogenética obtenida, lo cual contradice la filogenia de Weitzman \& Menezes (1998), que muestra a Pterobrycon como el grupo hermano de Corynopoma. En el presente estudio, se usaron casi todos los caracteres utilizados por estos autores en su filogenia y constituye la hipótesis filogenética más inclusiva de Stevardiinae realizada hasta el momento con caracteres morfológicos. Entonces, los resultados filogenéticos 
obtenidos para Gephyrocharax se consideran más robustos que aquellos propuestos por Weitzman \& Menezes (1998). Gephyrocharax se ubica dentro de la familia Characidae sensu Mirande (2010) y Oliveira et al. (2011) y dentro de la subfamilia Stevardiinae sensu Mirande (2010), Oliveira et al. (2011) y Mirande et al. (2013) acorde a los resultados de este trabajo, pero a su vez se descartan previas clasificaciones propuestas para el género al nivel de subfamilia (Weitzman \& Menezes, 1998; Weitzman et al., 2005; Menezes \& Weitzman, 2009)

Gephyrocharax se redefine filogenéticamente con base en cinco sinapomorfías, ninguna de las cuales había sido usada en su diagnosis original (Eigenmann, 1912). Eigenmann (1912) diferenció a Gephyrocharax de los demás Characidae por varios caracteres, pero el más relevante es la presencia de un "spur" en la aleta caudal de los machos adultos. Vanegas-Ríos et al. (2013) renombraron este "spur" como "claw-shape structure" haciendo énfasis en definir más adecuadamente dicha modificación en términos de los radios procurrentes ventrales de la aleta caudal. Esta definición utilizada por Vanegas-Ríos et al. (2013) fue usada aquí y nombrada como estructura tipo pinza. Sin embargo, la optimización del mismo no produjo una sinapomorfía para el género. Los machos adultos de Corynopoma (grupo hermano de Gephyrocharax) también presentan modificaciones en el segundo, tercero y cuarto radios procurrentes ventrales (como lo indicó Weitzman \& Fink, 1985), las cuales fueron interpretadas como estructuras en forma de pinza. Entonces, el tipo particular de pinza en los machos adultos de Gephyrocharax no constituye una de sus sinapomorfías porque el carácter cantidad de pinzas (carácter 457) no optimiza en la hipótesis filogenética donde Pterobrycon es el grupo hermano de Corynopoma + Gephyrocharax (la misma situación ocurriría si el carácter hubiese sido codificado en una serie multiestado). De cualquier manera, el tipo de pinzas es útil como un carácter único y discriminatorio para Gephyrocharax dentro de la familia Characidae. Una sinapomorfía encontrada para Gephyrocharax libre de convergencias o reversiones es la condición descripta en el estado 1 del carácter 404, la cual consiste, en una singular forma del contorno ventral de la aleta anal que presentan los machos adultos de las especies de Gephyrocharax. Este contorno se caracteriza por ser muy convexo anteriormente, seguido de una leve curvatura expresada en una disminución gradual de la longitud de los radios anales (Figs. 22, 26, 29, 31, 33, 39, 42, 43, 44 y 48). En cambio, el contorno ventral de la aleta anal de las hembras en todas las especies de Gephyrocharax es claramente recto o cóncavo. En los géneros hermanos de Gephyrocharax, Corynopoma y Pterobrycon, los machos adultos tienen una aleta anal completamente diferente a la 
encontrada en las especies de Gephyrocharax, por lo general está muy alargada en dirección ventral, ya sea con los radios centrales de la aleta más desarrollados que el resto o con todos los radios muy desarrollados simultáneamente (en comparación con las hembras). Si bien todos o la mayoría de los tipos de modificaciones de la aleta anal de los machos adultos encontrados en algunos géneros de Characidae (e. g., Pseudocorynopoma o Pterobrycon) podrían ser homologados en un carácter multiestado, una razón para no hacerlo, es que se desconocen los orígenes etológicos o funcionales de estas modificaciones en la gran mayoría de los casos. El hecho de que estos tipos de aletas estén presentes en los machos adultos, no es un criterio excluyente para asumir que todas las aletas anales son funcionalmente activas durante el cortejo. Además, también es difícil homologar los tipos de cortejo como caracteres separados con la escasa información que hay al respecto. Esta discusión también se había planteado, por ejemplo por Weitzman \& Menezes (1998), quienes codificaron la presencia de una aleta anal muy expandida en los machos adultos únicamente para Corynopoma y Pterobrycon en su análisis filogenético, excluyendo a Chrysobrycon myersi o Pseudocorynopoma doriae (ambos con condiciones intermedias), y justificados en el hecho de que la aleta anal de Corynopoma y Pterobrycon se asocia con un comportamiento de cortejo homólogo entre sí y no homólogo a los demás géneros con tales tipos de aletas anales. Si bien este criterio es posible, conlleva dos dificultades: no resuelve cómo codificar otros estados diferentes o intermedios presentes en otros géneros y asume, sin conocimiento de fondo, que los demás tipos de aletas anales en otros géneros están o no asociadas a cortejos diferentes. En consecuencia, resulta más cauteloso codificar las modificaciones más similares entre sí (véase listado de Mirande, 2010) y separarlas unas de otras, en vez de suponer cualquier otra hipótesis con poca justificación.

La biogeografía histórica de Gephyrocharax parece estar relacionada con los cambios ocasionados por el levantamiento de la cordillera de los Andes (proceso vicariante) en los cursos de los principales ríos de América del Sur (Atrato, Cauca, Magdalena, Orinoco y Amazonas) y por la formación del istmo de Panamá (proceso de dispersión) en el caso de los ríos en el suroeste de América Central (Hoorn, 1994, Albert et al., 2006; Román-Valencia \& Vanegas-Ríos, 2009). Las especies cis y transandinas de Gephyrocharax no formaron grupos separados entre sí (Fig. 14b). En vez de esto, las especies cisandinas se mezclaron con las especies transandinas en la filogenia obtenida. Por ejemplo, Gephyrocharax major (especie cisandinas) se relacionó con otras especies del género, mientras que Gephyrocharax caucanus (especie transandina) se relacionó 
filogenéticamente más cerca con G. valencia (especie cisandina) que con cualquier otra especie del género (e. g. las especies transandinas, G. melanocheir o G. sinuensis). Entonces, no se encuentra una asociación general entre la separación histórica de los ríos cis y transandinos y las relaciones filogenéticas de las especies de Gephyrocharax. Bonilla-Rivero \& López-Rojas (2013) propusieron un árbol de distancias genéticas donde G. venezuelae estaba más relacionado con una posible especie no descrita de Gephyrocharax que con G. valencia. Estos autores plantearon que el origen de las especies de Gephyrocharax en Venezuela estuvo determinado por los eventos geológicos que involucraron el cambio en el curso de la cuenca del río Orinoco durante el Neógeno (Díaz de Gamero, 1996). La diversificación histórica de Gephyrocharax es realmente compleja debido a su amplia distribución en el Neotrópico Americano. Sin embargo, no es objetivo de este estudio abordar la biogeografía histórica del género, una investigación que merece hacerse en un estudio más detallado en el futuro.

\section{CONCLUSIONES}

De acuerdo a los resultados de este estudio, las conclusiones principales son:

Análisis filogenético:

1) Se establecen 542 caracteres (casi todos morfológicos) informativos para estudios filogenéticos en la subfamilia Stevardiinae y para la filogenia de géneros con escamación hipertrofiada en la aleta caudal, como Gephyrocharax.

2) Se define la subfamilia Stevardiinae con cuatro sinapomorfías para incluir a las especies Bryconamericus emperador y B. scleroparius.

3) Se plantea que los géneros Landonia y Phenacobrycon son género hermanos y están distantemente relacionados de los demás géneros con modificaciones en la escamación hipertrofiada de la aleta caudal, inseminación o tejido glandular en los radios caudales de los machos adultos.

4) Se corrobora la monofilia de Carlastyanax + Creagrutus propuesta por Mirande et al. (2013).

5) Se propone que los géneros Bryconamericus, Cyanocharax y Knodus no forman grupos monofiléticos.

6) Se confirma la monofilia de los géneros Chrysobrycon, Diapoma y Pterobrycon, muy relacionados con Gephyrocharax.

7) Se ratifica el clado Pterobrycon + Corynopoma + Gephyrocharax propuesto por Weitzman \& Menezes (1998). 
8) Se propone a Corynopoma como el género hermano de Gephyrocharax.

9) Se corrobora la monofilia de Gephyrocharax con base en cinco sinapomorfías.

10) Se comprueba que las búsquedas filogenéticas bajo pesos iguales y pesos implicados son coincidentes para la monofilia de Stevardiinae y Gephyrocharax.

11) Se establece que los caracteres de la diagnosis original de Eigenmann (1912) no son informativos para apoyar la monofilia de Gephyrocharax.

12) Se demuestran dos clados dentro de Gephyrocharax: el primero compuesto por $G$. atracaudatus, G. caucanus, G. intermedius y G. valencia; y el segundo compuesto por G. sinuensis, G. martae, G. melanocheir y G. torresi.

13) Se plantea que la especie transandina Gephyrocharax caucanus está más relacionada filogenéticamente con la especie cisandina G. valencia.

\section{Revisión taxonómica:}

1) Se confirma que el género Corynopomops es un sinónimo del género Gephyrocharax.

2) Se conoce que el género Gephyrocharax se diferencia morfológicamente de los demás géneros stevardinos sin ninguna dificultad.

3) Se reafirma que el género Gephyrocharax está ampliamente distribuido en las principales cuencas hidrográficas cis y transandinas de la región Neotropical, desde el sureste de la baja América Central hasta la región noroeste de América de Sur.

4) Se validan 11 especies para el género Gephyrocharax.

5) Se comprueba que los datos morfométricos y merísticos tradicionales son poco informativos para diferenciar todas las especies de Gephyrocharax entre sí.

6) Se demuestra que la coloración del cuerpo, la osteología, la musculatura caudal y caracteres asociados al dimorfismo sexual de los machos adultos son muy informativos en las diagnosis de las especies de Gephyrocharax.

7) Se confirma a Gephyrocharax atracaudatus por primera vez para río Palenque, Archipiélago de las Perlas, Pacífico de Panamá.

8) Se establece que Gephyrocharax chocoensis alberga poblaciones con y sin mancha humeral.

9) Se propone a Gephyrocharax whaleri como sinónimo junior de G. intermedius.

10) Se descubre que Gephyrocharax intermedius es la única especie del género que no tiene glándula branquial o tiene una muy alta tendencia a perderla.

11) Se demuestra que Gephyrocharax intermedius está ampliamente distribuida en ríos y quebradas de la cuenca del Pacífico y Caribe al oeste del canal de Panamá en América Central. 
12) Se plantea que Corynopomops opisthopterus y Gephyrocharax chaparae son sinónimos de G. major.

13) Se confirma que Gephyrocharax major es la única especie del género distribuida ampliamente en la cuenca del río Amazonas.

14) Se designan lectotipo y paralectotipos para Gephyrocharax major.

15) Se confirma que Gephyrocharax martae, la especie menos conocida del género y descripta únicamente con el holotipo, está ubicada dentro del género y se redescribe en mayor detalle.

16) Se reconoce que Gephyrocharax melanocheir es una especie ampliamente distribuida en la cuenca del río Magdalena y en la vertiente Caribe en Colombia.

17) Se designa el neotipo de Gephyrocharax sinuensis.

18) Se proponen nuevos caracteres morfológicos para diferenciar a Gephyrocharax torresi de G. melanocheir.

19) Se confirma que Gephyrocharax valencia está ampliamente distribuida en la cuenca del río Orinoco y tiene varias poblaciones en las cuencas del Caribe, río Cuyuní y ríos Mesquite-Moruga en la isla de Trinidad.

\section{LITERATURA CITADA}

Aguilera, G. \& J. M. Mirande. 2005. A new species de Jenynsia (Cyprinodontiformes: Anablepidae) from northwestern Argentina and its phylogenetic relationships. Zootaxa, 1096: 29-39.

Albert, J. S., N. R. Lovejoy \& W. G. R. Crampton. 2006. Miocene tectonism and the separation of cis- and trans-Andean river basins: Evidence from neotropical fishes. Journal of South American Earth Sciences, 21: 14-27.

Álvarez-León, R., R. H. Orozco-Rey, M. E. Páramo-Fonseca \& D. Restrepo-Santamaría. 2013. Lista de los peces fósiles y actuales de Colombia: Nombres científicos válidos, distribución geográfica, diagnosis de referencia y nombres comunes e indígenas. Primera Edición. Eco Prints Diseño Gráfico y Audiovisual Ltda, Bogotá D. C., Colombia, 346 pp.

Angulo, A., C. A. Garita-Alvarado, W. A. Bussing \& M. I. López. 2013. Annotated checklist of the freshwater fishes of Continental and insular Costa Rica: additions and nomenclatural revisions. Check List, 8(5): 987-1019.

Arai, R. 2011. Fish karyotypes, a check list. Springer, Tokio, Japón, 347 pp. 
Arias, J. S. \& D. R. Miranda-Esquivel. 2004. Profile Parsimony (PP): an analysis under Implied Weights (IW). Cladistics, 20: 56-63.

Atkins, D. L. \& W. L. Fink. 1979. Morphology and histochemistry of the caudal gland of Corynopoma riisei Gill. Journal of Fish Biology, 14: 465-469.

Azpelicueta, M. M. \& S. Koerber. 2012. First record of Mimagoniates inequalis (Eigenmann, 1911) (Characiformes: Characidae) from Argentina. Check List 8(4): 784-786.

Baicere-Silva, C., K. M. Ferreira, L. R. Malabarba, R. C. Benine \& I. Quagio-Grassiotto. 2011a. Spermatic characteristics and sperm evolution on the subfamily Stevardiinae (Ostariophysi: Characiformes: Characidae). Neotropical Ichthyology, 9(2): 377-392.

Baicere-Silva, C., R. C. Benine \& I. Quagio-Grassiotto. 2011b. Markiana nigripinnis (Perugia, 1891) as a putative member of the subfamily Stevardiinae (Characiformes: Characidae): spermatic evidence. Neotropical Ichthyology, 9(2): 371-376.

Berra, T. M. 2001. Freshwater fish distribution. Academic Press, San Diego, 604 pp.

Bertaco, V. A. 2008. Taxonomy and phylogeny of the neotropical fish genus Hemibrycon Günther, 1864 (Ostariophysi: Characiformes: Characidae). Tesis Doctoral. Universidade Federal do Rio Grande do Sul, Porto Alegre, 296 pp.

Bertaco, V. A. \& L. R. Malabarba. 2010. A review of the Cis-Andean species of Hemibrycon Günther (Teleostei: Characiformes: Characidae: Stevardiinae), with description of two new species. Neotropical Ichthyology, 8(4): 737-770.

Betancur-R., R., R. E. Broughton, E. O. Wiley, K. Carpenter, J. A. López, C. Li, N. I. Holcroft, D. Arcila, M. Sanciangco, J. C. Cureton, F. Zhang, T. Buser, M. A. Campbe, J. A. Ballesteros, A. Roa-Varon, S. Willis, W. C. Borden, T. Rowley, P. C. Reneau, D. J. Hough, G. Lu, T. Grande, G. Arratia \& G. Ortí. 2013. The Tree of Life and a New Classification of Bony Fishes. PLoS Currents Tree of Life, 2013 Apr 18 [last modified: 2013 Apr 23]. Edición 1. doi: 10.1371/currents.tol.53ba26640df0ccaee75bb165c8c26288.

Böhlke, J. 1958. Studies on fishes of the family Characidae. No 14. A report on several extensive recent collections from Ecuador. Proceedings of the Academy of Natural Sciences of Philadelphia, 110: 1-121, láminas 1-7. 
Bonilla, A. L. \& H. López. 1995. A comparative morphological and genetic study of Gephyrocharax valencia (Characidae) in two isolated basins of Venezuela. Acta Biológica Venezuélica, 16(1): 33-45.

Bonilla-Rivero, A. L. \& H. López-Rojas. 1997. Sexual dimorphism in color pattern of Gephyrocharax venezuelae (Characidae: Glandulocaudinae) in Venezuela. Acta Biológica Venezuélica, 17(3): 45-29.

Bonilla-Rivero, A. L. \& H. López-Rojas. 2001. Diferenciación morfológica cuantitativa de las especies del género Gephyrocharax Eigenmann, 1912 (Pisces: Characidae: Glandulocaudinae) de Venezuela. Acta Biológica Venezuélica, 21(2): 1-10.

Bonilla-Rivero, A. L. \& H. López. 2013. On the origin and diversification of Venezuelan freshwater fishes: the genus Gephyrocharax (Ostariophysi: Characidae) a case study. Neotropical Ichthyology, 11(3): 487-496.

Bonilla-Rivero, A. L., H. López-Rojas \& A. Machado-Allison. 2002. Especiación vicariante en el género Gephyrocharax Eigenmann 1912 (Pisces: Characidae: Glandulocaudinae) de Venezuela. Interciencia, 27: 118-127.

Bork, D. 2000a. Der Fadenschuppensalmner Pterobrycon landoni galt bis jetzt als verschollen. Das Aquarium. 34 (377): 30-34.

Bork, D. 2000b. Der Fadenschuppensalmner, ein aktueller Nachtrag zur Fortpflanzung von Pterobrycon landoni. Das Aquarium. 34 (378): 30.

Brazeau, M. D. 2011. Problematic character coding methods in morphology and their effects. Biological Journal of the Linnean Society, 104: 489-498.

Breder, C. M. 1925. Notes on fishes from three Panama localities: Gatun spillway, Rio Tapia and Caledonia BA. Zoologica, 4(4): 137-158.

Breder, C. M. 1927. The fishes of the Rio Chucunaque drainage, eastern Panama. Bulletin of the American, Museum of Natural History, 57: 91-176.

Broughton, R. E. 2010. Phylogeny of teleosts based on mitochondrial genome sequences. Pp: 61-76. En: Nelson, J. S., H.-P. Schultze \& M. V. H. Wilson (Eds.), Origin and Phylogenetic Interrelationships of Teleosts. Verlag Dr. Friedrich Pfeil, München, $480 \mathrm{pp}$.

Buckup, P. A. 1998. Relationships of the Characidiinae and phylogeny of characiform fishes (Teleostei, Ostariophysi). Pp: 123-143. En: L. R. Malabarba, R. E. Reis, R. P. Vari, Z. M. S. de Lucena, C. A. Lucena (Eds.), Phylogeny and classification of neotropical fishes. EDIPUCRS, Porto Alegre, 603 pp. 
Burns J. R \& S. H. Weitzman. 1996. Novel gill-derived gland in the male swordtail characin, Corynopoma riisei (Teleostei: Characidae: Glandulocaudinae). Copeia, 1996:627-633.

Burns, J. R. \& S. H. Weitzman. 2005. Insemination in Ostariophysan fishes. Pp. 107-134. In: Grier H.J. \& M. C. Uribe (Eds.). Viviparous Fishes. New Life Publications, Homestead Florida.

Burns, J. R., I. Quagio-Grassiotto \& B. G. M. Jamieson. 2009. Ultrastructure of spermatozoa: Ostariophysi, Chapter 11. Pp: 287-338. En: B. G. M. Jamieson (Ed.), Reproductive biology and phylogeny of fishes (Agnatha and bony fishes): Phylogeny, reproductive system, viviparity, spermatozoa. Science Publisher, Enfield, NH, 788 pp.

Burns, J. R. \& S. H. Weitzman, H. J. Grier \& N. A. Menezes. 1995. Internal fertilization, testis and sperm morphology in glandulocaudine fishes (Teleostei: Characidae: Glandulocaudinae). Journal of Morphology, 224: 131-145.

Bushmann, P. J, J. R., Burns \& S. H. Weitzman. 2002. Gill-derived glands in glandulocaudine fishes (Teleostei: Characidae: Glandulocaudinae). Journal of Morphology, 253:187-195.

Bussing, W. A. 1966. New species and new records of Costa Rican freshwater fishes with a tentative list of species. Revista de Biología Tropical, 14(2): 205-249.

Bussing, W. A. 1974. Pterobrycon myrnae, a remarkable new glandulocaudine characid fish from Costa Rica. Revista de Biología Tropical, 22 (1): 135-159.

Bussing, W. A. 2002. Peces de las aguas continentales de Costa Rica. Segunda Edición, Editorial de la Universidad de Costa Rica, San José de Costa Rica, 504 pp.

Bussing, W. A. \& T. R. Roberts. 1971. Rediscovery of the Glandulocaudine fish Pterobrycon and hypothetical significance of its spectacular humeral scales (Pisces: Characidae). Copeia, 1971: 179-181.

Cala, P. 1987. La ictiología dulceacuícola de Colombia: una visión histórica y su estado actual. Revista de la Asociación Colombiana de Ciencias Exactas, Físicas y Naturales, 16: 69-84.

Calcagnotto, D., S. A. Schaefer \& R. DeSalle. 2005. Relationships among characiforms fishes inferred from analysis of nuclear and mitochondrial gene sequences. Molecular Phylogenetics and Evolution, 36: 135-153. 
Carvalho, F. R. 2011. Sistemática de Hyphessobrycon Durbin, 1908 (Ostariophysi: Characidae). Tesis Doctoral. Universidade Federal do Rio Grande do Sul, Porto Alegre, 365 pp.

Carvalho, T. P., J. A. Flores, J. Espino, G. Trevejo, H. Ortega, F. C. Jerep, R. E. Reis \& J. S. Albert. 2012. Fishes from the Las Piedras River, Madre de Dios basin, Peruvian Amazon. Check List, 8(5): 973-1019.

Casciotta, J., A. Almirón, L. Piálek \& O. Říčan. 2012. Cyanocharax obi, a new species (Characiformes: Characidae) and the first record of the genus from tributaries of the río Paraná basin, Argentina. Zootaxa, 3391: 39-51.

Castro, R. C., A. C. Ribeiro, R. C. Benine \& A. L. A. Melo. 2003. Lophiobrycon weitzmani, a new genus and species of glandulocaudine fish (Characiformes: Characidae) from the rio Grande drainage, alto rio Paraná system, southeastern Brazil. Neotropical Ichthyology, 1(1): 11-19.

Chernoff, B., A. Machado-Allison, P. Willink, J. Sarmiento, S. Barrera, N. A. Menezes \& H. Ortega. 2000. Fishes of three Bolivian rivers: diversity, distribution and conservation. Interciencia, 25(6): 273-283.

Chen, W-J., S. Lavoué \& R. L. Mayden. Evolutionary origin and early biogeography of Otophysan fishes (Ostariophysi: Teleostei). Evolution, 67(8): 2218-2239.

Cione, A. \& M. M. Azpelicueta. 2013. The first fossil species of Salminus, a conspicuous South American freshwater predatory fish (Teleostei, Characiformes), found in the Miocene of Argentina. Journal of Vertebrate Paleontology, 33: 1051-1060.

Dahdul, W. M. 2010. Review of the Phylogenetic Relationships and Fossil Record of Characiformes. Pp: 441-464. T. Grande, F. J. Poyato-Ariza \& R. Diogo. Gonorynchiformes and Ostariophysan relationships: a comprensive review. Science Publishers, Enfield, 587 pp.

Dahl, G. 1943. New or rare fishes of the family Characinidae from the Magdalena system. Kunglinga Fysiografiska Sällskapets I Lund Förhandlingar, 12 (18): 215-220.

Dahl, F. 1971. Los peces del Norte de Colombia. Ministerio de Agricultura, Instituto de desarrollo de los recursos naturales renovables, INDERENA, Bogotá, D. C. 391 pp.

Dahl, G. \& F. Medem. 1964. Informe sobre la fauna acuática del río Sinú. Corporación Autónoma Regional de los Valles del Magdalena y del Sinú-CVM-Depto. de Investigaciones Ictiológicas y Faunísticas, Bogotá, D. C., 109 p. 
Datovo, A. \& F. A. Bockmann. 2010. Dorsolateral head muscles of the catfish families Nematogenyidae and Trichomycteridae (Siluriformes: Loricarioidei): comparative anatomy and phylogenetic analysis. Neotropical Ichthyology, 8(2): 193-246.

Datovo, A. \& R. M. C. Castro. 2012. Anatomy and evolution of the mandibular, hyopalatine, and opercular muscles in characiform fishes (Teleostei: Ostariophysi). Zoology, 115: 84-116.

Datovo, A. \& R. P. Vari. 2013. The jaw adductor muscle complex in Teleostean fishes: Evolution, homologies and revised nomenclature (Osteichthyes: Actinopterygii). PLoS ONE, 8(4) e60846. doi:10.1371/journal.pone.0060846

Díaz de Gamero, M. L. 1996. The changing course of the Orinoco River during the Neogene: a review. Palaeogeography, Palaeoclimatology, Palaeoecology, 123: 385402 .

Dimmick, W. W. \& A. Larson. 1996. A molecular and morphological perspective on the phylogenetic relationships of the Otophysan fishes. Molecular Phylogenetic and Evolution, 6(1): 120-133.

Eigenmann, C. H. 1910. Catalogue and bibliography of the fresh water fishes of the Americas south of the tropic of Cancer. Contribution from the Zoological Laboratory of Indiana University. Pp. 375-511. En: W. B. Scott (Ed.), Reports of the Princeton Expedition to Patagonia, 1896-1899. J. Pierpont Morgan Publication Fund, volumen 3 (Parte IV), 511 pp.

Eigenmann, C. H. 1912. Some results from an ichthyological reconnaissance of Colombia,

South America. Part I. Indiana University Studies, 16 [sic no. 8]: 1-27.

Eigenmann, C. H. 1913. Some results from an ichthyological reconnaissance of Colombia, South America. Part II. Indiana University Studies, 18: 1-31.

Eigenmann, C. H. 1914. Some results from studies of South American fishes. II. The Glandulocaudinae (a new subfamily of Characid fishes with innate potentialities for sexual dimorphism). Indiana University Studies, 20: 31-42.

Eigenmann, C. H. 1915. The Cheirodontinae, a subfamily of minute characid fishes of South America. Memoirs of the Carnegie Museum, 7(1): 1-99. 17 láminas.

Eigenmann, C. H. 1917. American Characidae [Part I]. Memoirs of the Museum of Comparative Zoology, 43 (1): 1-102, 16 láminas.

Eigenmann, C. H. 1918. American Characidae [Part II]. Memoirs of the Museum of Comparative Zoology, 43(2): 103-208. 
Eigenmann, C. H. 1920a. The fishes of Lake Valencia, Caracas, and of the Rio Tuy at El Concejo, Venezuela. Indiana University Studies, 7(44): 1-13.

Eigenmann, C. H. 1920b. The fresh-water fishes of Panama east of longitude $80^{\circ} \mathrm{W}$. Contribution from the Zoological Laboratory of Indiana University, 175: 1-19.

Eigenmann, C. H. 1920c. The Magdalena basin and the horizontal and vertical distribution of its fishes. Contribution from the Zoological Laboratory of Indiana University, 177: 21-34.

Eigenmann, C. H. 1921. American Characidae [Part III]. Memoirs of the Museum of Comparative Zoology, 43(3): 209-310, 28 láminas.

Eigenmann, C. H. 1922. The fishes of the northwestern South American including Colombia, Panama and Pacific slopes of Ecuador and Peru, together with appendix upon the fishes of the Río Meta in Colombia. Memoires of the Carnegie Museum, 9(1): 1-346, 38 láminas.

Eigenmann, C. H. 1927. The American Characidae [Part 4]. Memoirs of the Museum of Comparative Zoology, 43 (4): 311-428, 24 láminas.

Eigenmann, C. H. \& G. S. Myers G. S. 1929. The American Characidae [Part 5]. Memoirs of the Museum of Comparative Zoology, 43 (5): 429-558, 11 láminas.

Eigenmann, C. H., A. Henn \& C. Wilson. 1914. New fishes from western Colombia, Ecuador, and Peru. Indiana University Studies, 19: 1-15.

Eschmeyer, W. N. 2014. Catalog of fishes: genera, species, references. Academy of Natural Sciences, California, Versión electrónica del 17 Mar. 2014. http://research.calacademy.org/research/ichthyology/catalog/fishcatmain.asp.

Eschmeyer, W. N. \& J. D. Fong. 2014. Catalog of fishes: species by family and subfamily. Academy of Natural Sciences, California. Versión electrónica del 1 Feb. 2014. http://research.calacademy.org/research/ichthyology/catalog/SpeciesByFamily.asp.

Farris, J. S. 1969. A successive approximations approach to character weighting. Systematic Zoology, 18: 374-385.

Farris, J. S. 1970. Methods for computer Wagner trees. Systematic Zoology, 19: 83-92.

Farris, J. S. 1983. The logical basis of phylogenetic analysis. Pp: 7-36. En: N. I. Platnick \& V. A. Funk (Eds.), Advances in Cladistics II. Columbia University Press, Nueva York, $593 \mathrm{pp}$.

Farris, J. S. 1989. The retention index and the rescaled consistency index. Cladistics, 5: 417-419. 
Ferreira, K. M. 2007. Análise filogenética e revisão taxonômica do gênero Knodus Eigenmann, 1911 (Characiformes: Characidae). Tesis Doctoral. Universidade de São Paulo, Ribeirão Preto, 549 pp.

Ferreira, K. M., N. A. Menezes \& I. Quagio-Grassiotto. 2011. A new genus and two new species of Stevardiinae (Characiformes: Characidae) with a hypothesis on their relationships based on morphological and histological data. Neotropical Ichthyology, 9(2): 281-298.

Fink, S. V. \& W. L. Fink. 1981. Interrelationships of the Ostariophysan fishes (Teleostei). Zoological Journal of the Linnean Society, 72(4): 297-353.

Fink, S. V. \& W. L. Fink. 1996. Interrelationships of the Ostariophysan fishes (Teleostei). Pp: 209-249. En: M. L. J. Stiassny, L. R. Parenti \& G. D. Johnson (Eds.), Interrelationships of Fishes. Academic Press, San Diego, 496 pp.

Fink, W. L. \& S. H. Weitzman. 1974. The so-called Cheirodontin fishes of Central America with descriptions of two new species (Pisces: Characidae) Smithsonian Contributions to Zoology, 172: 1-45.

Fowler, H. W. 1940. Zoological results of the second Bolivian expedition for the Academy of Natural Sciences of Philadelphia, 1936-1937. Part I: The Fishes. Proceedings of the Academy of Natural Sciences of Philadelphia, 92: 43-103.

Fowler, H. W. 1943. A collection of fresh-water fishes from Colombia, obtained chiefly by Brother Nicéforo Maria. Proceeding of the Academy of Natural Sciences of Philadelphia, 95: 223-226.

Fowler, H. W. 1945. Descriptions of two new fresh-water fishes from Colombia. Notulae Nature, The Academy of Natural Sciences of Philadelphia, 158: 1-11.

Fowler, H. W. 1954. Os peixes de água doce do Brasil. Arquivos de Zoologia do Estado de São Paulo, 9: 1-400.

Géry, J. 1964. Glandulocauda terofali sp. nov., un nouveau Poisson characoïde of la République Argentine, avec une note sur la "glande" caudale des Stevardiidi. Opuscula Zoologica, 78: 1-12.

Géry, J. 1966. A review of certain Tetragonopterinae (Characoidei), with the description of two new genera. Ichthyologica, The Aquarium Journal, 37: 211-236.

Géry, J. 1977. Characoids of the world. T. F. H. Publ. Neptune City, 672 pp.

Gill, T. N. 1858. Synopsis of the fresh water fishes of the western portion of the island of Trinidad, W. I. Annales of the Lyceum of Natural History, Nueva York, 6 (10-13): 363-430. 
Giribet, G. 2003. Stability on phylogenetic formulations and its relationship with nodal support. Systematic Biology, 52: 554-564.

Goloboff, P. A. 1993. Estimating character weights during tree search. Cladistics, 9: 83-91

Goloboff, P. A. 1995. Parsimony and weighting: a reply to Turner and Zandee. Cladistics, 11:91-114.

Goloboff, P. A. 1997. Selfweighted optimization: tree searches and character state reconstructions under implied transformation costs. Cladistics, 13: 225-245.

Goloboff, P. A. 1999. Analyzing large data sets in reasonable times: solutions for composite optima. Cladistics, 15: 415-428.

Goloboff, P. A. 2013. Extended implied weighting. Cladistics, 2013: 1-13

Goloboff, P. A. \& J. S. Farris. 2001. Methods for quick consensus estimation. Cladistics, 17: S26-S34.

Goloboff, P. A., J. S. Farris \& K. Nixon. 2008a. TNT, a free program for phylogenetic analysis. Cladistics, 24: 774-786.

Goloboff, P. A., J. M. Carpenter, J. S. Arias \& D. R. Miranda-Esquivel. 2008b. Weighting against homoplasy improves phylogenetic analysis of morphologic datasets. Cladistics, 24: 1-16.

Goloboff, P. A., J. S. Farris, M. Källersjö, B. Oxelman, M. J. Ramírez \& C. A. Szumik. 2003. Improvements to resampling measures of group support. Cladistics, 19: 324332.

Greenwood, P. H., D. E. Rosen, S. H. Weitzman \& G. S. Myers. 1966. Phyletic studies of teleostean fishes, with a provisional classification of living forms. Bulletin of the American Museum of Natural History, 131: 339-456.

Gregory, W. K. \& G. M. Conrad. 1938. The Phylogeny of the Characin Fishes. Zoologica (Nueva York), 23(17): 319-360.

Günther, A. 1864. Catalog of the Fishes in the Collection of the British Museum. Londres, Volumen 5, xii +455 pp.

Hammer, Ø., D. A. T. Harper \& P. D. Ryan. 2001. PAST: Paleontological Statistics Software Package for Education and Data Analysis. Palaeontologia Electronica, 4(1): 1-9. (http://palaeo-electronica.org/2001_1/past/issue1_01.htm)

Helfman, G. S., B. B. Collette, D. E. Facey \& B. W. Bowen. 2009. The diversity of fishes, Biology, Evolution, and Ecology. Segunda edición. Wiley-Blackwell, Wiley \& Sons, Publication, Chichester UK, 720 pp. 
Hennig, W. 1950. Grundzüge einer Theorie der phylogenetischen Systematik. Deutscher Zentralverlag, Berlín, 370 pp.

Hennig, W. 1966. Phylogenetic Systematics. University of Illinois, Urbana, Illinois, 263 pp.

Hildebrand, S. F. 1938. A new catalogue of the fresh-water fishes of Panama. Publication of Field Museum of Natural History, Zoological Series, 22(4): 217-359.

Hoorn, C. 1994. An environmental reconstruction of the palaeo-Amazon River system (Middle-Late Miocene, NW Amazonia). Palaeogeography, Palaeoclimatology, Palaeoecology, 112: 187-238.

Humphries, J. M., F. L. Bookstein, B. Chernoff, G. R. Smith R. L. Elder \& S. G. Poss. 1981. Multivariate discrimination by shape in relation to size. Systematic Zoology, 30(3): 291-308.

Ibarra, M. \& D. J. Stewart. 1987. Catalogue of Type Specimens of Recent Fishes in Field Museum of Natural History. Fieldiana Zoology, 35: 1-112.

ICZN [International Commission on Zoological Nomenclature]. 1999. International Code of Zoological Nomenclature. Cuarta Edición. Londres (International Trust for zoological Nomenclature), i-xxix, 1-306 pp.

Javonillo, R., J. R. Burns \& S. H. Weitzman. 2007. Reproductive morphology of Brittanichthys axelrodi (Teleostei: Characidae), a miniature inseminating fish from South America. Journal of Morphology, 268: 23-32.

Javonillo, R., J. R. Burns \& S. H. Weitzman. 2009. Sperm modifications related to insemination, with examples the Ostariophysi. Pp: 723-763. En: B. G. M. Jamieson (ed.), The Reproductive biology and phylogeny in fishes. Volumen I. Science Publishers, Enfield, NH, 788 pp.

Javonillo, R., L. R. Malabarba, S. H. Weitzman \& J. Burns. 2010. Relationships among major lineages of characid fishes (Teleostei: Ostariophysi: Characiformes), based on molecular sequence data. Molecular Phylogenetic and Evolution, 54: 498-511.

Klingenberg, C. P. 1996. Multivariate allometry. Pp: 23-49. En: L. F. Marcus, M. Corti, A. Loy, G. J. P. Naylor \& D. E. Slice (Eds.), Advances in Morphometrics. Plenium Press, Nueva York, 587 pp.

Kluge, A. \& J. S. Farris. 1969. Quantitative phyletics and the evolution of anurans. Systematic Zoology, 18:1-32.

Kramer, D. L. 1978. Reproductive Seasonality in the Fishes of a Tropical Stream. Ecology, 59(5): 976-985. 
Kramer, D. L. \& M. J. Bryant. 1995a. Intestine length in the fishes of a tropical stream: 1. Ontogenetic allometry. Environmental Biology of Fishes, 42: 115-127.

Kramer, D. L. \& M. J. Bryant. 1995b Intestine length in the fishes of a tropical stream: 2. Relationships to diet - the long and short of a convoluted issue. Environmental Biology of Fishes, 42: 129-141.

Lasso, C., Lew D., Taphorn D., DoNascimiento C., Lasso-Alcalá O., Provenzano F. \& A. Machado-Allison. 2004 (“2003”). Biodiversidad ictiológica continental de Venezuela. Parte I. Lista especies y distribución por cuencas. Memoria de la Fundación La Salle de Ciencias Naturales, 159-160: 105-195.

Lima, F. C. T., L. R., Malabarba, P. A., Buckup, J. F. P., Da Silva, R. P. Vari, A. Harold, R. A. Benine, O. Oyakawa, C. S. Pavanelli, N. E. Menezes, C. A. Lucena, C. S. L Malabarba, Z. M. S., Lucena, Z. M. S., R. Reis, F. Langeani, L. Cassati, V. A. Bertaco, C, Moreira \& P. F. Lucinda. 2003. Genera incertae sedis in Characidae. Pp: 106-169. En: Reis, R. E., S. O. Kullander \& C. J. Ferraris Jr (Eds.), Check list of the freshwater fishes of South and Central America. EDIPUCRS, Porto Alegre, 729 pp.

Lucena, C. A. S. 1993. Estudo filogenético da família Characidae com uma discussão dos grupos naturais propostos (Teleostei, Ostariophysi, Characiformes). Tesis Doctoral. Universidade de São Paulo, San Pablo, Brasil, 158 pp.

Machado-Allison, A., B. Chernoff, R. Royero-León, F. Mago-Leccia, J. Velázquez J., C. Lasso, H. López-Rojas, A. Bonilla-Rivero, F. Provenzano \& C. Silvera. 2000. Ictiofauna de la cuenca del río Cuyuní en Venezuela. Interciencia, 25(1): 13-21.

Mahnert, V. \& J. Géry. 1984. Poissons Characoïdes (Characoidea) du Paraguay I: Xenurobrycon macropus Myers et Miranda Ribeiro. Revue Suisse Zoologie, 91(2): 497-513.

Malabarba, M. C. S. L. 2004. Revision of the neotropical genus Triportheus Cope, 1872 (Characiformes: Characidae). Neotropical Ichthyology, 2(4): 167-204.

Malabarba, L. R. 1998. Monophyly of the Cheirodontinae, characters and major clades (Ostariophysi, Characidae). Pp: 193-234. En: L. R. Malabarba, R. E. Reis, R. P. Vari, Z. M. S. de Lucena, C. A. Lucena (Eds.), Phylogeny and classification of neotropical fishes. EDIPUCRS, Porto Alegre, 603 pp.

Malabarba, L. R. \& S. H. Weitzman. 2003. Description of new genus with six new species from southern Brazil, Uruguay and Argentina, with a discussion of a putative characid clade (Teleostei: Characiformes: Characidae). Comunicações do Museu de Ciências e Tecnologia da PUCRS, Série Zoologia, 16(1): 67-151. 
Malabarba, L. R., V. C. Bertaco, F. R. Carvalho \& T. Litz. 2012. Revalidation of the genus Ectrepopterus Fowler (Teleostei: Characiformes), with the redescription of its type species, E. uruguayensis. Zootaxa, 3204: 47-60.

Malabarba, L. R., R. E. Reis, R. P. Vari, Z. M. S. de Lucena \& C. A. Lucena (Eds.). 1998. Phylogeny and classification of neotropical fishes. EDIPUCRS, Porto Alegre, Brasil, $603 \mathrm{pp}$.

Maldonado-Ocampo, J. A., R. P. Vari \& J. S. Usma. 2008. Checklist of the freshwater fishes of Colombia. Biota Colombiana, 9(2): 143-237.

Maldonado-Ocampo, J., A., Ortega-Lara, J. S. Usma, G. Galvis, F. Villa-Navarro, L. Vasquez, S. Prada-Pedreros \& C. Ardila. 2005. Peces de los Andes de Colombia. Instituto de Investigaciones de Recursos Biológicos Alexander von Humboldt. Bogotá, D. C., 346 pp.

Maldonado-Ocampo, J. A., J. S. Usma, F. A. Villa-Navarro, A. Ortega-Lara, S. PradaPedreros, L. F. Jiménez, U. Jaramillo-Villa, A. Arango, T. S. Rivas \& G. C. Sánchez. 2012. Peces dulceacuícolas del Chocó biogeográfico. WWF Colombia, Unión Gráfica, Bogotá D. C., Colombia, 400 pp.

Maldonado-Ocampo, J. A., F. A. Villa-Navarro, A. Ortega-Lara, S. Prada-Pedreros, U. Jaramillo, A. Claro, J. S. Usma, T. S. Rivas, W. Chaverra, J. F. Cuesta \& J. E. García-Melo. 2006. Peces del río Atrato, zona hidrogeográfica del Caribe, Colombia. Biota Colombiana, 7(1): 143-154.

Mattox, G. M. T \& M. Toledo-Piza. 2012. Phylogenetic study of the Characinae (Teleostei: Characiformes: Characidae). Zoological Journal of the Linnean Society, $165,809-915$.

Mattox, G. M. T., R. Britz, M. Toledo-Piza \& M. M. F. Marinho. 2013. Cyanogaster noctivaga, a remarkable new genus and species of miniature fish from the Rio Negro, Amazon basin (Ostariophysi: Characidae). Ichthyological Exploration of Freshwaters, 23(4): 297-318.

Meek, S. E. \& S. F. Hildebrand. 1912. Descriptions of new fishes from Panama. Publication of Field Museum of Natural History, Zoological Series, 10(6): 67-68.

Meek, S. E. \& S. F. Hildebrand. 1916. The fishes of the fresh waters of Panama. Publication of Field Museum of Natural History, Zoological Series, 10(15): 219374.

Menezes, N. A. \& S. H. Weitzman. 1990. Two new species of Mimagoniates (Teleostei: Characidae: Glandulocaudinae), their phylogeny and biogeography and a key to the 
glandulocaudin fishes from Brazil and Uruguay. Proceeding of the Biological Society of Washington, 103(2): 380-426.

Menezes, N. A. \& S. H. Weitzman. 2009. Systematics of the neotropical fish subfamily Glandulocaudinae (Teleostei: Characiformes: Characidae). Neotropical Ichthyology, 7(3): 295-370.

Menezes, N. A. \& S. H. Weitzman. 2011. A systematic review of Diapoma (Teleostei: Characiformes: Characidae: Stevardiinae: Diapomini) with descriptions of two new species from southern Brazil. Papéis Avulsos de Zoologia, 51(2): 59-82.

Menezes, N. A., S. H. Weitzman \& J. R. Burns. 2003. A systematic review of Planaltina (Teleostei: Characidae: Glandulocaudinae: Diapomini) with a description of two new species from the upper rio Paraná, Brazil. Proceeding of the Biological Society of Washington, 116(3): 557-600.

Miles, C. W. 1947. Los peces del río Magdalena. Ministerio de La Economía Nacional, Sección de Piscicultura, Pesca y Caza. Editorial El grafico, Bogotá D. C., 214 pp.

Miles, C. W. 1973. Estudio económico y ecológico de los peces de agua dulce del valle del Cauca. Cespedesia, 2(5): 9-63.

Miller, R. R. 1966. Geographical distribution of Central American freshwater fishes. Copeia, 4: 773-802.

Mirande, J. M. 2008. Filogenia de la familia Characidae (Teleostei, Characiformes). Tesis Doctoral, Universidad Nacional de Tucumán, San Miguel de Tucumán, 520 pp.

Mirande, J. M. 2009. Weighted parsimony phylogeny of the family Characidae (Teleostei, Characiformes). Cladistics, 25: 574-613.

Mirande, J. M. 2010. Phylogeny of the family Characidae (Teleostei: Characiformes): from characters to taxonomy. Neotropical Ichthyology, (8)3: 385-568.

Mirande, J. M., G. Aguilera \& M. M. Azpelicueta. 2011. A threatened new species of Oligosarcus and its phylogenetic relationships, with comments on Astyanacinus (Teleostei: Characidae). Zootaxa, 2994: 1-20.

Mirande, J. M., F. C. Jerep \& J. A. Vanegas-Ríos. 2013. Phylogenetic relationships of the enigmatic Carlastyanax aurocaudatus (Eigenmann) with remarks on the phylogeny of the Stevardiinae (Teleostei: Characidae). Neotropical Ichthyology, 11(4): 747766.

Mojica, J. I. 1999. Lista preliminar de las especies de peces dulceacuícolas de Colombia. Revista de la Academia Colombiana de Ciencias Exactas, Físicas y Naturales, 23 (Suplemento especial): 547-565. 
Mojica, J. I. \& C. Castellanos. 2007. Colección de Ictiología. Pp: 75-88. En: G. AndradeC. \& J. D. Lynch (Eds.), Los tipos nomenclaturales depositados en la Colección Zoológica del Instituto de Ciencias Naturales. Biblioteca José Jerónimo Triana 16, Bogotá, D. C., 211 pp.

Mojica, J. I., S. Usma, G. Galvis. 2004. Peces dulceacuícolas del Choco Biogeográfico Catálogo. Pp: 725-744. En: O. Rangel (ed.). Colombia diversidad biótica IV: El Choco Biogeográfico / Costa Pacífica, Universidad Nacional de Colombia, Bogotá, D.C., 997 pp.

Mojica, J. I., C. Castellanos, P. Sánchez-Duarte \& C. Díaz. 2006a. Peces de la cuenca del río Ranchería, La Guajira, Colombia. Biota Colombiana, 7 (1): 129-142.

Mojica, J. I., G. Galvis, P. Sanchez-Duarte, C. Castellanos \& F. A. Villa-Navarro. 2006b. Peces del valle medio del río Magdalena, Colombia). Biota Colombiana, 7(1): 2328.

Myers, G. S. 1933. Stevardia albipinnis?. The Home Aquarium Bulletin, 3(4): 11.

Myers, G. S. \& J. E. Böhlke. 1956. The Xenurobryconini, a group of minute South American characid fishes with teeth outside the mouth. Stanford Ichthyological Bulletin, 7(2): 6-12.

Nakatani, M., M. Miya, K. Mabuchi, K. Saitoh \& M. Nishida. 2011. Evolutionary history of Otophysi (Teleostei), a major clade of the modern freshwater fishes: Pangean origin and Mesozoic radiation. BMC Evolutionary Biology, 11:177.

Nelson, G. J. 1969. Gill arches and the phylogeny of fishes with notes on the classification of the vertebrates. Bulletin of the American Museum of Natural History, 141 (4): 475-522.

Nelson, J. S. 2006. Fishes of the World. Cuarta Edición, John Wiley \& Sons, Inc, Nueva Jersey. $601 \mathrm{pp}$.

Nelson, K. 1964. Behavior and morphology in the Glandulocaudine fishes (Ostariophysi, Characidae). University of California Publications in Zoology, 75(2): 59-152.

Netto-Ferreira, A. L., L. O. Birindeli, L. M. de Sousa \& N. A. Menezes. 2014. A new species of Rhinopetitia Géry 1964 (Ostariophysi: Characiformes: Characidae) from the Rio Teles Pires, Rio Tapajós basin, Brazil. Journal of Fish Biology, 84: 15391550.

Netto-Ferreira, A. L., J. L. O. Birindeli, L. M. de Sousa, T. C. Mariguela \& C. Oliveira. 2013. A new miniature characid (Ostariophysi: Characiformes: Characidae), with 
phylogenetic position inferred from morphological and molecular data. PLoS ONE, 8: e52098. doi:10.1371/journal.pone.0052098.

Nixon, K. C. 1999. The parsimony ratchet, a new method for rapid parsimony analysis. Cladistics, 15: 407-414.

Nixon, K. C. \& J. M. Carpenter. 1993. On outgroups. Cladistics, 9: 413-426.

Oliveira, C., G. S. Avelino, K. T. Abe, T. C. Mariguela, R. C. Benine, G. Ortí, R. P. Vari \& R. M. C. Castro. 2011. Phylogenetic relationships within the speciose family Characidae (Teleostei: Ostariophysi: Characiformes) based on multilocus analysis and extensive ingroup sampling. BMC Evolutionary Biology, 11: 275.

Ortega, H., M. Hidalgo, G. Trevejo, E. Correa, A. M. Cortíjo, V. Meza \& J. Espino. 2012. Lista anotada de los peces de aguas continentales del Perú: estado actual del conocimiento, distribución, usos y aspectos de conservación. Ministerio del Ambiente, Dirección General de Diversidad Biológica, Museo de Historia Natural (UNMSM), Punto Gráfico y Grafía, Lima, Perú. 58 pp.

Ortega-Lara, A., O. M. Lasso-Alcalá, C. A. Lasso, G. A. Pasquier, J. D. Bogotá-Gregory. 2012. Peces de la cuenca del río Catatumbo, cuenca del Lago de Maracaibo, Colombia y Venezuela. Biota Colombiana, 13(1): 71-98.

Ortega-Lara A., J. S. Usma, P. A. Bonilla, N. L. Santos. 2006. Peces de la cuenca alta del río Cauca, Colombia. Biota Colombiana, 7(1): 39-54.

Ortí, G. \& A. Meyer. 1997. The radiation of Characiform fishes and the limits of resolution of mitochondrial ribosomal DNA sequences. Systematic Biology, 46(1): 75-100.

Patterson, C. 1975. The braincase of pholidophorid and leptolepid fishes with a review of the Actinopterygian braincase. Philosophical Transactions of the Royal Society B, 269: $275-579$.

Pearson, N. 1924. The fishes of the eastern slope of the Andes. I. The fishes of the rio Beni basin, Bolivia, collected by the mulford expedition. Indiana University Studies, 11(64): 1-59, 12 láminas.

Pecio, A., J. R. Burns \& S. H. Weitzman. 2005. Sperm and spermatozeugma ultrastructure in the inseminating Species Tyttocharax cochui, T. tambopatensis, and Scopaeocharax rhinodus (Pisces: Teleostei: Characidae: Glandulocaudinae: Xenurobryconini). Journal of Morphology, 263: 216-226.

Pecio, A., J. R. Burns \& S. H. Weitzman. 2007. Comparison of spermiogenesis in the externally fertilizing Hemigrammus erythrozonus and the inseminating Corynopoma 
riisei (Teleostei: Characiformes: Characidae). Neotropical Ichthyology, 5(4): 457470.

Phillip, D. A. T., Taphorn, D. C., Holm, E., Gilliam J. F., Lamphere B. A. \& H. LópezFernández. 2013. Annotated list and key to the stream fishes of Trinidad \& Tobago. Zootaxa, 3711: 1-64.

Prendini, L. 2000. Phylogeny and classification of the superfamily Scorpionoidea Latreille 1802 (Chelicerata, Scorpiones): An exemplar approach. Cladistics, 16: 1-78.

Ramírez, M. J. 2003. The spider subfamily Amaurobioidinae (Aranae, Anyphaenidae): a phylogenetic revision at the generic level. Bulletin of the American Museum of Natural History, 277: 1-262.

Reis, R. E., S. O., Kullander \& C. J. Ferraris Jr. 2003 (Eds.). Check list of the freshwater fishes of South and Central America. EDIPUCRS, Porto Alegre, Brasil, 729 pp.

Roberts, T. R. 1973. The Glandulocaudine characid fishes of the Guayas basin in western Ecuador. Bulletin of the Museum of Comparative Zoology, 144(8): 489-514.

Rodríguez-Olarte, D., Coronel J. L., Taphorn, D. C. \& A. Amaro. 2007 (“2006”). Los peces del río Tocuyo, vertiente Caribe, Venezuela: un análisis preliminar para su conservación. Memoria de la Fundación La Salle de Ciencias Naturales, 165: 45-72.

Rohlf, F. J. 2005. tpsDig, digitize landmarks and outlines, version 2.05. Department of Ecology and Evolution, State University of New York at Stony Brook.

Román-Valencia, C. 1990. Lista y distribución de peces en la cuenca media del río Atrato, Chocó, Colombia. Caldasia, 16(77): 201-208.

Román-Valencia, C. \& A. Acero. 1992. Notas sobre las comunidades de peces del norte de Antioquia (Colombia). Anuario Instituto Investigaciones Marinas Punta Betín, 21: 117-125.

Román-Valencia, C. \& Vanegas-Ríos, J. A. 2009. Análisis filogenético y biogeográfico de las especies del género Bryconamericus (Characiformes, Characidae) de la baja América Central. Caldasia, 31(2): 381-394.

Schultz, L. P. 1944. The fishes of the family Characinidae from Venezuela, with descriptions of seventeen new forms. Proceeding of the United States National Museum, 95 (3181): 235-367.

Strauss, R. E. 2010. Discriminating groups of organisms. Pp: 73-91. En: A. M. T. Elewa (Ed.), Morphometrics for Nonmorphometricians. Lecture notes in Earth Sciences 124, Springer-Verlag, Berlin, 367 pp. 
Strong, E. E. \& D. Lipscomb. 1999. Character coding and inapplicable data. Cladistics, 15: $363-371$

Swofford, D \& G. Olsen. 1990. Phylogeny reconstruction. Pp: 411-501. En: D. Hillis \& C. Moritz (eds.), Molecular Systematics. Sinauer Associates, Sunderland, Mass, 588 pp.

Tagliacollo, V. A., R. Souza-Lima, R. C. Benine \& C. Oliveira. 2012. Molecular phylogeny of Aphyocharacinae (Characiformes, Characidae) with morphological diagnoses for the subfamily and recognized genera. Molecular Phylogenetics and Evolution, 64: 297-307.

Taphorn, D. C. 2003. Manual de identificación y biología de los peces Characiformes de la cuenca del río Apure en Venezuela. Universidad Nacional Experimental de los Llanos Occidentales "Ezequiel Zamora" UNELLEZ, BioCentro, Guanare, Venezuela. $446 \mathrm{pp}$.

Taphorn, D. C. \& C. G. Lilyestrom. 1984. Claves para los peces de agua dulce de Venezuela. 1. Las familias de Venezuela. 2. Los géneros y especies de la cuenca del Lago de Maracaibo. Revista UNELLEZ de Ciencia y Tecnología, 2(2): 87-92

Taylor, W. R. \& G. C. Van Dyke. 1985. Revised procedures for staining and clearing small fishes and other vertebrates for bone and cartilage study. Cybium, 9: 107-119.

Uj, A. 1987. Les Cheirodontinae (Characidae, Ostariophysi) du Paraguay. Revue Suisse de Zoologie, 94(1): 129-175.

Uj, A. 1990. Etude comparative de l'osteologie cranienne des poissons de la familie des Characidae et son importance phylogenetique. Tesis Doctoral. Faculté des Sciences, Université de Genève, Suiza, 247 pp.

Valdez-Moreno, M. E. \& S. Contreras-Balderas. 2003. Skull osteology of the characid fish Astyanax mexicanus (Teleostei: Characidae). Proceedings of the Biological Society of Washington, 116: 341-355.

Vanegas-Ríos, J. A. \& D. A. T. Phillip. 2013. First record of Gephyrocharax valencia (Characiformes: Characidae: Stevardiinae) from the island of Trinidad, West Indies. Revista Mexicana de Biodiversidad, 84: 1329-1334.

Vanegas-Ríos, J. A., M. M. Azpelicueta \& H. Ortega. 2011. Chrysobrycon eliasi, new species of stevardiine fish (Characiformes: Characidae) from the río Madre de Dios and alto río Manuripe basins, Peru. Neotropical Ichthyology, 9(4): 731-740. 
Vanegas-Ríos, J. A., M. M. Azpelicueta \& H. Ortega. 2014. Chrysobrycon yoliae, a new species of stevardiin (Characiformes: Characidae) from the Ucayali basin, Peru. Neotropical Ichthyology, 12(2): 291-300.

Vanegas-Ríos, J. A., M. M. Azpelicueta, J. J. Mirande \& M. D. G. Gonzales. 2013. Gephyrocharax torresi (Characiformes: Characidae: Stevardiinae), a new species from the río Cascajales basin, río Magdalena system, Colombia. Neotropical Ichthyology, 11(2): 275-284.

Vari, R. P. \& A. S. Harold. 2001. Phylogenetic study of the neotropical fish Genera Creagrutus Günther and Piabina Reinhardt (Teleostei: Ostariophysi: Characiformes), with a revision of the Cis-Andean species. Smithsonian Contribution to Zoology, 613: 1-239.

Vari, R. P. \& J. C. Howe. 1991. Catalog of type specimens of recent fishes in the National Museum of Natural History, Smithsonian Institution, 1: Characiformes (Teleostei: Ostariophysi). Smithsonian Contribution to Zoology, 517: 1-52.

Vari, R. P. \& D. J. Siebert. 1990. A new, unusually sexually dimorphic species of Bryconamericus (Pisces: Ostariophysi: Characidae) from the Peruvian Amazon. Proceeding of the Biological Society of Washington, 103: 516-524.

Villa-Navarro, F. A., P. Zuñiga-Upegui, D. Castro-Roa, J. E. García-Melo, L. J. GarcíaMelo \& M. E. Herrada-Yara. 2006. Peces del alto Magdalena, cuenca del río Magdalena, Colombia. Biota Colombiana, 7(1): 3-22.

Weiss, F. L. R. Malabarba \& M. C. Malabarba. 2012. Phylogenetic relationships of Paleotetra, a new characiform fish (Ostariophysi) with two new species from the Eocene-Oligocene of south-eastern Brazil. Journal of Systematic Palaeontology, 10: 73-86.

Weitzman, S. H. 1962. The osteology of Brycon meeki, a generalized characid fish, with an osteological definition of the family. Stanford Ichthyological Bulletin, 8(1): 1-77.

Weitzman, S. H. 1964. Osteology and relationships of South American characid fishes of subfamilies Lebiasininae and Erythrininae with special reference to subtribe Nannostomina. Proceedings of the United States National Museum, 116(3499): 127169.

Weitzman, S. H. 2003. Subfamily Glandulocaudinae. Pp: 222-230. En: R. E. Reis, S. O., Kullander \& C. J. Ferraris Jr. (Eds.), Check list of the freshwater fishes of South and Central America. EDIPUCRS, Porto Alegre, 729 pp. 
Weitzman, S. H. \& W. L. Fink. 1983. Relationships of the neon tetras, a group of south American freshwater fishes (Teleostei, Characidae) with comments on the phylogeny of the new world Characiforms. Bulletin of the Museum of Comparative Zoology (Harvard University), 150(6): 339-395.

Weitzman, S. H. \& S. V. Fink. 1985. Xenurobryconin phylogeny and putative pheromone pumps in Glandulocaudine fishes (Teleostei: Characidae). Smithsonian Contribution to Zoology, 421: 1-121.

Weitzman, S. H. \& N. A. Menezes. 1998. Relationships of the tribes and genera of Glandulocaudinae (Ostariophysi: Characiformes: Characidae) with a description of a new genus, Chrysobrycon. Pp. 171-192. En: L. R. Malabarba, R. E. Reis, R. P. Vari, Z. M. S. de Lucena \& C. A. Lucena (Eds.), Phylogeny and Classification of neotropical Fishes. EDIPUCRS, Porto Alegre, 603 pp.

Weitzman, S. H. \& R. P. Vari. 1988. Miniaturization in South American freshwater fishes: an overview and discussion. Proceeding of the Biological Society of Washington, 101(2): 444-465.

Weitzman, S. H., N. A. Menezes \& M. J. Weitzman. 1988. Phylogenetic biogeography of the Glandulocaudini (Teleostei: Characiformes: Characidae) with comments on the distributions of other freshwater fishes in eastern and southeastern Brazil. Pp. 370427. En: Vanzolini, P. E. \& W. R. Heyer (Eds.), Proceedings of a workshop on neotropical distribution patterns. Academia Brasileira de Ciências, Rio de Janeiro, $488 \mathrm{pp}$.

Weitzman, S. H., S. V. Fink, A. Machado-Allison \& R. Royero. 1994. A new genus and species of Glandulocaudinae (Teleostei: Characidae) from southern Venezuela. Ichthyological Exploration of Freshwaters, 5(1): 45-64.

Weitzman, S. H., N. A. Menezes, H. G. Evers \& J. R. Burns. 2005. Putative relationships among inseminating and externally fertilizing characids, with a description of a new genus and species of Brazilian inseminating fish bearing an anal-fin gland in males (Characiformes: Characidae). Neotropical Ichthyology, 3: 329-360.

Wheeler, W. C. J. Gatesy \& R. DeSalle. 1995. Elision: a method for accommodating multiple molecular sequence alignments with alignment-ambiguous sites. Molecular Phylogenetics and Evolution, 4: 1-9.

Whiting, M. F., J. M., Carpenter, Q. D., Wheeler \& W. C Wheeler. 1997. The Strepsiptera problem: phylogeny of the holometabolous insect orders inferred from $18 \mathrm{~S}$ and $28 \mathrm{~S}$ ribosomal DNA sequences and morphology. Systematic Biology, 46: 1-68. 
Wiley, E. O. \& D. Johnson. 2010. A teleost classification based on monophyletic groups. Pp: 123-182 En: Nelson, J. S., H.-P. Schultze \& M. V. H. Wilson (Eds.), Origin and phylogenetic interrelationships of teleosts. Verlag Dr. Friedrich Pfeil, München, 480 pp.

Winemiller, K. O. 1989. Development of dermal lip protuberances for aquatic surface respiration in South American characid fishes. Copeia, 1989(2): 382-390.

Winemiller, K. O. 1992. Ecomorphology of freshwater fishes. National Geographic Research \& Exploration, 8(3): 308-327.

Winterbottom, R. 1974. A descriptive synonymy of the striated muscles of the Teleostei. Proceedings of the Academy of Natural Sciences of Philadelphia, 125: 225-317.

Zanata, A. M \& R. P. Vari. 2005. The family Alestidae (Ostariophysi, Characiformes): a phylogenetic analysis of a trans-Atlantic clade. Zoological Journal of the Linnean Society, 145: 1-144.

Zaret, T. M. \& A. S. Rand. 1971. Competition in Tropical Stream Fishes: Support for the Competitive Exclusion Principle. Ecology, 5(2): 336-342.

Zarske, A. 2010. Der Kolibrisalmler-Trochilocharax ornatus gen. et spec. nov.- ein neuer Salmler aus Peru (Telestei: Characiformes: Characidae). Vertebrete Zoology, 60: 7598. 